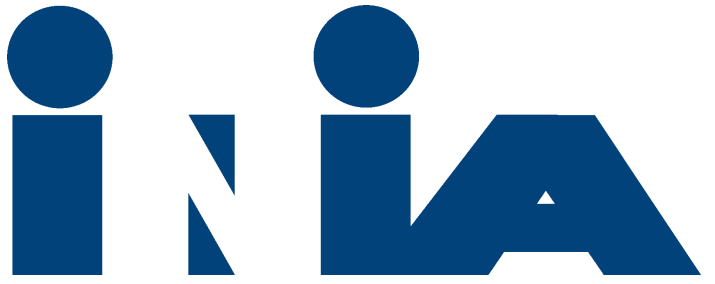

INSTITUTO NACIONAL DE INVESTIGACIÓN AGROPECUARIA

URUGUAY

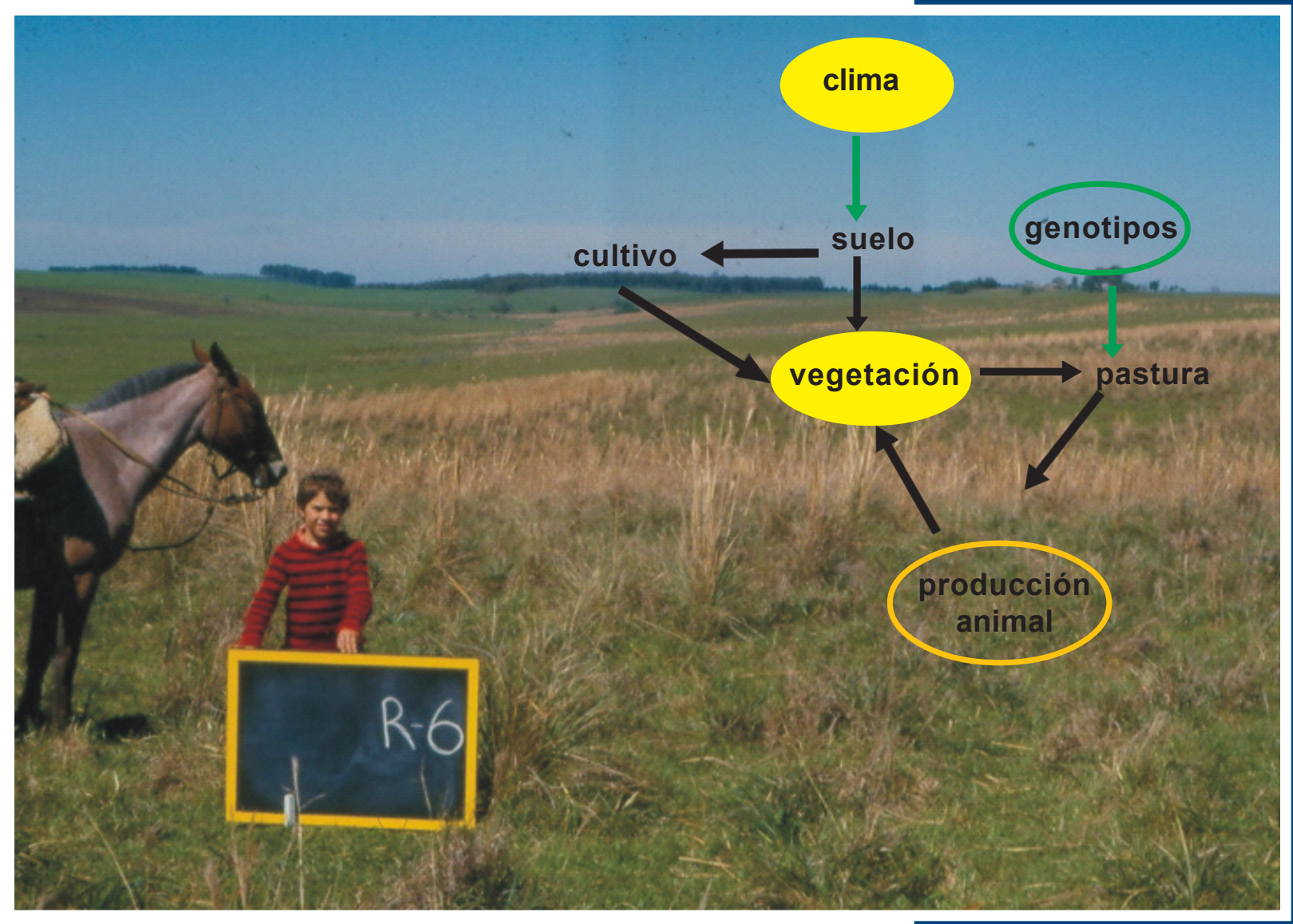

INTEGRACIÓN DE RESULTADOS PARA EL MANEJO DEL CAMPO NATURAL EN LA REGIÓN NORESTE

Diciembre, 2014

SERIE TÉCNICA

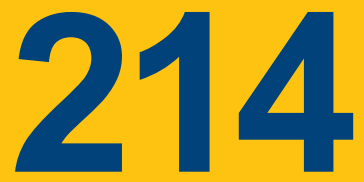

INIA 


\section{INTEGRACIÓN DE RESULTADOS PARA EL MANEJO DEL CAMPO NATURAL EN LA REGIÓN NORESTE}

Autores: Fernando Elcear Olmos López ${ }^{1}$

Martín Osorio Sosa Pintado²

Juan Manuel Soares de Lima Lapetina ${ }^{3}$ 
Título: INTEGRACIÓN DE RESULTADOS PARA EL MANEJO DEL CAMPO NATURAL EN LA REGIÓN NORESTE

Autores: Fernando Elcear Olmos López

Martín Osorio Sosa Pintado

Juan Manuel Soares de Lima Lapetina

Serie Técnica $N^{\circ} 214$

(C) 2014, INIA

Editado por la Unidad de Comunicación y Transferencia de Tecnología del INIA Andes 1365, Piso 12. Montevideo - Uruguay

http://www.inia.uy

Quedan reservados todos los derechos de la presente edición. Esta publicación no se podrá reproducir total o parcialmente sin expreso consentimiento del INIA. 


\section{I nstituto Nacional de I nvestigación Agropecuaria}

\section{Integración de la Junta Directiva}

Ing. Agr., MSc., PhD. Álvaro Roel - Presidente

D.M.T.V., PhD. J osé Luis Repetto - Vicepresidente
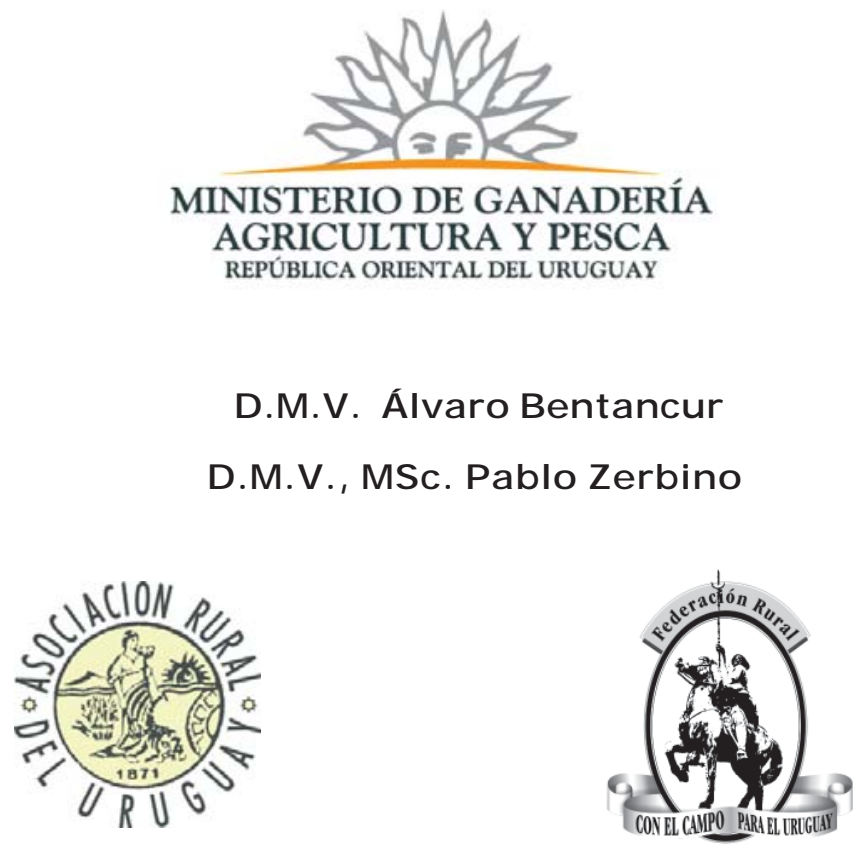

I ng. Agr. J oaquín Mangado

Ing. Agr. Pablo Gorriti
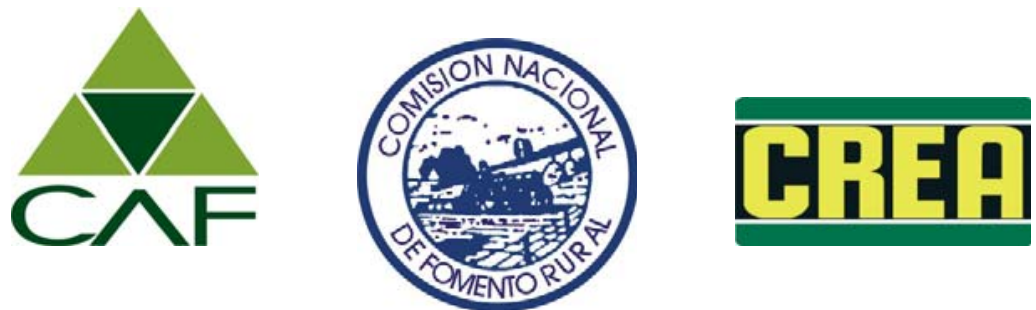



\section{CONTENIDO}

Página

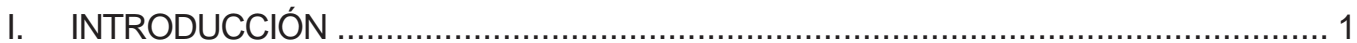

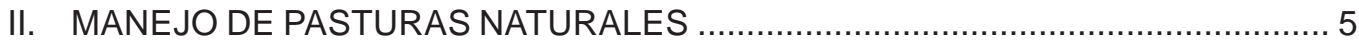

III. EL CLIMA Y SUS IMPACTOS. Sensibilidad de los ecosistemas naturales ..... 139

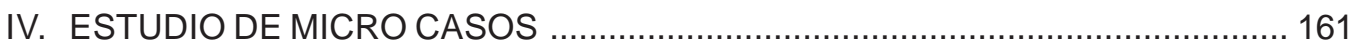

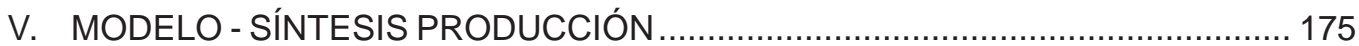

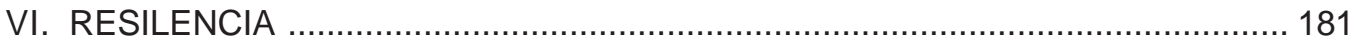

VII. VALORACIÓN - REANÁLISIS Y PERSPECTIVAS ........................................... 193

VIII. PROPUESTA DE USO Y CONSERVACIÓN. Propuesta metodológica para el uso y conservación de las pasturas naturales ............................................. 199

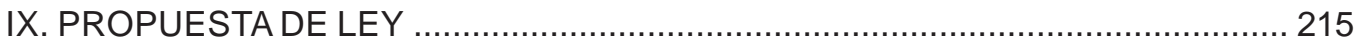

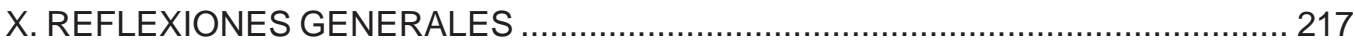




\title{
AGRADECIMENTOS
}

Estos trabajos reportados para la Región Noreste, fueron realizados gracias a la colaboración de muchas personas entre las que queremos destacar por el tiempo dedicado tanto al trabajo físico diario como la contribución a la discusión y elaboración de las propuestas y su seguimiento en el campo.

Ellas son en orden alfabético:

\author{
María Bemhaja \\ Elbio Berretta \\ Alfredo Castrillón \\ Enrique Castro \\ Pablo de Souza \\ J. Estevez \\ Tulia Fernández \\ Daniel Formoso \\ Olinto Gama \\ Juan Levratto \\ Pablo López \\ Guido Machado \\ Italo Malaquín \\ Julio Méndez \\ Quirino Mezquita \\ Carlos Picos \\ Carlos Pírez \\ Celerino Porcal \\ Lydia Reyles \\ Diego Rodríguez \\ Gustavo Rodríguez \\ Román Sención \\ Román Torres
}




\section{INTRODUCCIÓN}

Los sistemas de producción agropecuaria de la región noreste de Uruguay están intrínsicamente asociados a la utilización de los ecosistemas naturales. En estos ecosistemas la principal actividad productiva lo constituye la ganadería siendo las pasturas naturales uno de los principales recursos forrajeros utilizados. En el año 2000 el $55 \%$ de la superficie regional estaba ocupada por pasturas naturales y en el año 2011 las empresas ganaderas constituyeron el $81 \%$ del total de la superficie regional (Figura 1) (Censo General Agropecuario 2000, 2002; Censo General Agropecuario 2011, 2013).

De acuerdo a la estructura fundiaria tanto los registros del Censo 2000 como los del
Censo 2011 muestran una relativa concentración de la tierra donde prácticamente el $25 \%$ de los productores, con una superficie predial mayor a 500 hectáreas, dispone del $81 \%$ de la superficie productiva (Cuadros 1 y 2). Se constata por otra parte, una disminución importante del número de productores con superficie predial menor a 500 hectáreas, las cuales fueron 8.117 en el año 2000 y disminuyeron a 5.368 en el año 2011.

Esta estructura fundiaria seguramente condiciona, a lo hora de la toma de decisiones, los mecanismos operativos prediales, los procesos de inversión así como la eventual intensificación productiva en cada predio frente a la estructura familiar y la necesidad de ingresos.

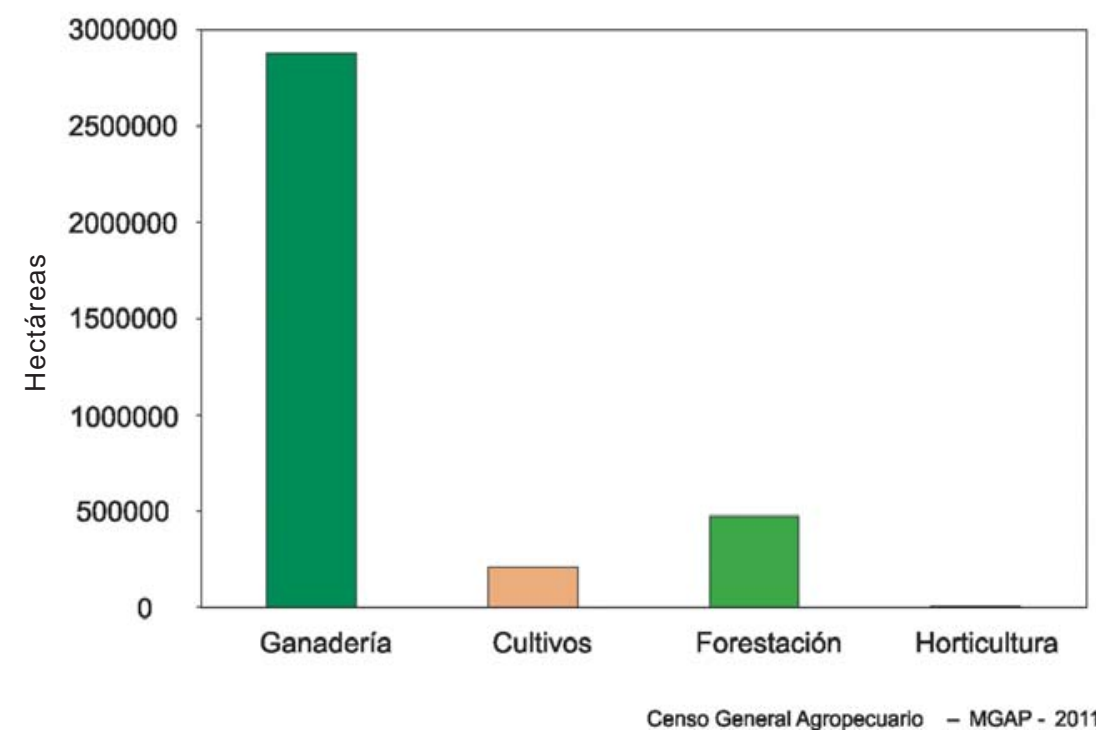

Figura 1. Superficie ocupada por los principales rubros de explotación en la región noreste, Cerro Largo, Tacuarembó y Rivera, según Censo General Agropecuario 2011. M.G.A.P.

Cuadro 1. Número de explotaciones y superficie según el tamaño de las explotaciones. En base a Censo General Agropecuario 2000 (2002).

\begin{tabular}{|l|c|c|c|}
\hline \multicolumn{1}{|c|}{$\mathbf{2 0 0 0}$} & Superficie (ha) & Número de explotaciones & Tamaño predial medio \\
\hline Total Regional & 3.698 .685 & 9.843 & 376 ha \\
\hline Predios $<500$ ha & 777.270 & 8.117 & 96 ha \\
\hline Predios $>500$ ha & 2.921 .685 & 1.726 & 1.692 ha \\
\hline
\end{tabular}


Cuadro 2. Número de explotaciones y superficie según el tamaño de las explotaciones. En base a Censo General Agropecuario 2011 (2013).

\begin{tabular}{|l|c|c|c|}
\hline \multicolumn{1}{|c|}{$\mathbf{2 0 1 1}$} & Superficie (ha) & Número de explotaciones & Tamaño predial medio \\
\hline Total Regional & 3.603 .665 & 7.157 & $504 \mathrm{ha}$ \\
\hline Predios $<500 \mathrm{ha}$ & 684.696 & 5.368 & $128 \mathrm{ha}$ \\
\hline Predios $>500 \mathrm{ha}$ & 2.918 .967 & 1.789 & $1.632 \mathrm{ha}$ \\
\hline
\end{tabular}

Sistema de Información Geográfica

D.G.R.N.R. PRENADER

U.P.C.T. OPYPA

Marzo 2002

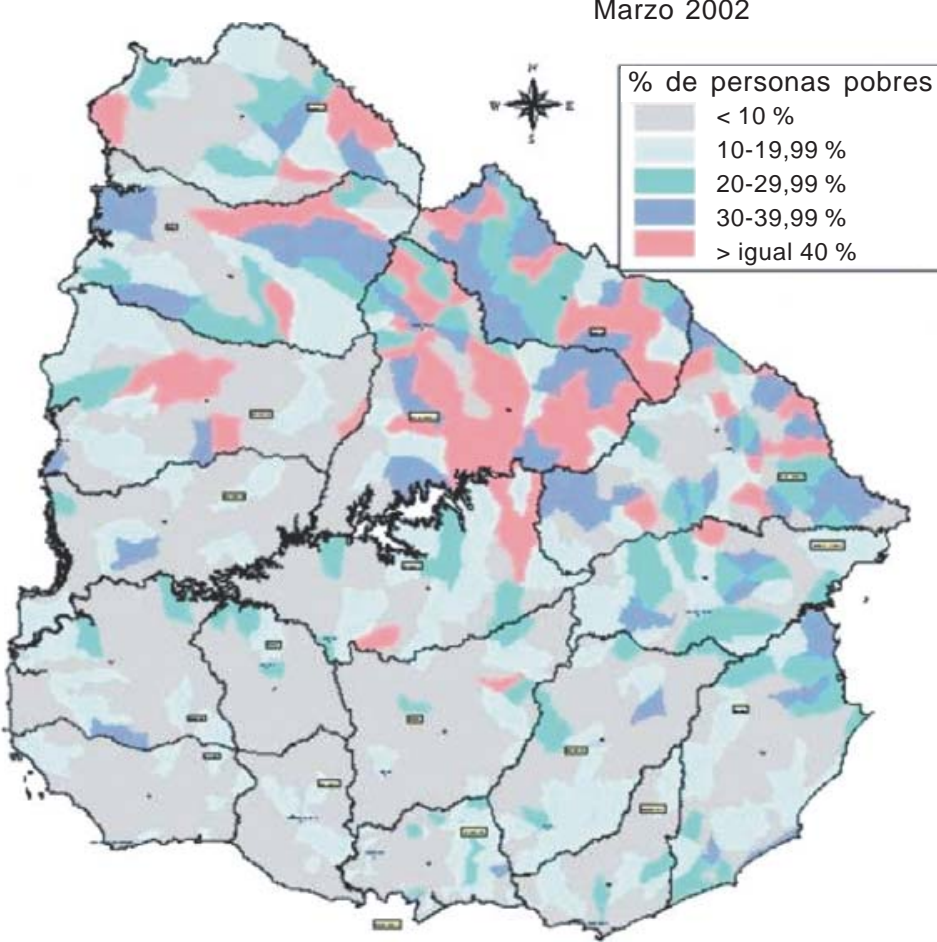

Figura 2. Proporción de personas por debajo de la línea de pobreza según el sector censal (Ministerio Ganadería Agricultura y Pesca, 2002).

Por otra parte, desde el punto de vista social, la misma región mostraba en el año 2002 los mayores índices de personas por debajo de la línea de pobreza en las zonas rurales (Figura 2).

Un modelo conceptual donde se insertan los diferentes sistemas productivos de la región en el ecosistema pastoril ha sido propuesto por Olmos (1990) (Figura 3). En ese modelo se describe el efecto general del clima que abarca todos los sistemas de producción, la eventual realización de cultivos, así como la interpretación de la presencia de la vegetación la cual constituye la base forrajera para la obtención de productos animales. Al mismo tiempo existe una retroalimentación hacia la vegetación según los impactos producidos en el sistema por la utilización animal del recurso. Según los componentes principales de la pastura (genotipos) en interacción con las variables climáticas, el suelo y el manejo determinarán los niveles de productividad del sistema. 


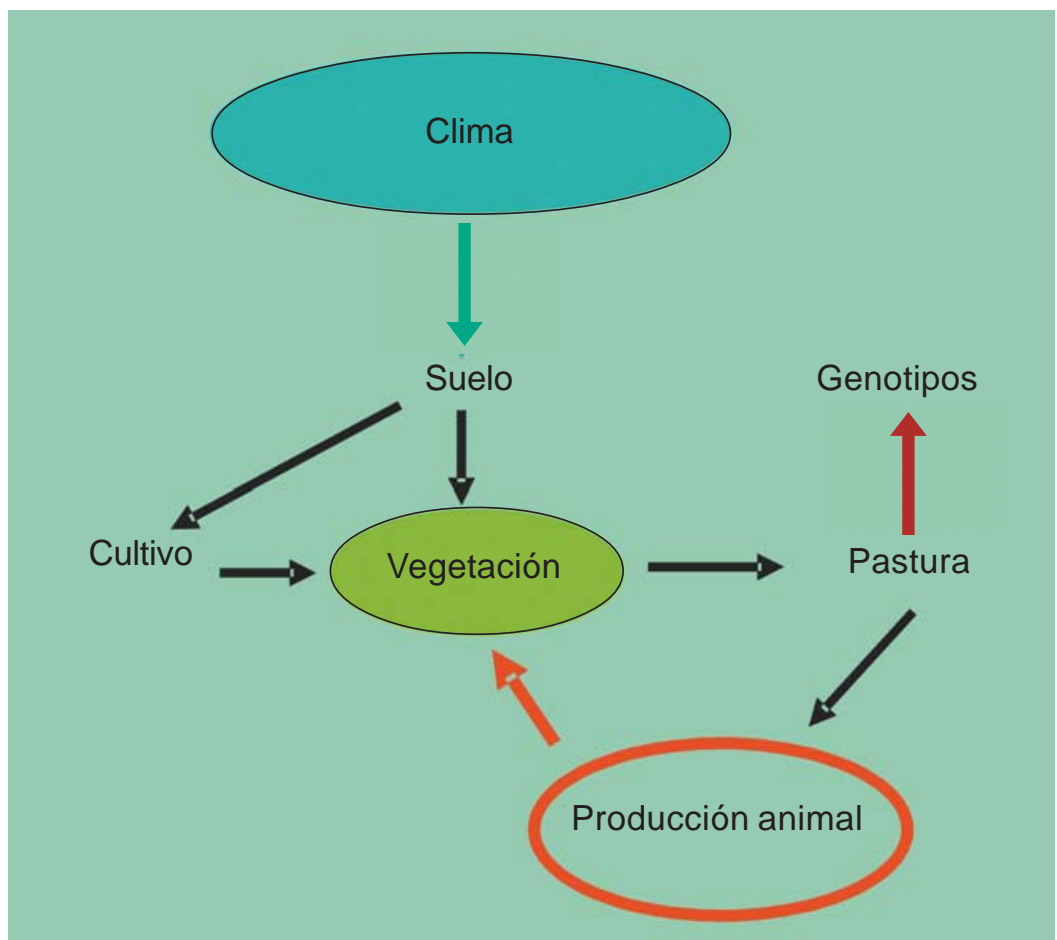

Figura 3. Modelo conceptual del ecosistema pastoril en la región noreste.

La importancia de describir el modelo y profundizar en el conocimiento de sus componentes, es que nos permite visualizar el diferente grado de información que disponemos en cada uno y así complementarlo con el modelo socio - económico que permita tomar decisiones respecto al desarrollo regional equilibrado.

En este trabajo se toman trabajos experimentales realizados en la región, fundamentalmente por la Estación Experimental del Norte (CIAAB, INIA-Tacuarembó), en el área de pasturas naturales integrándolos conceptualmente en el modelo propuesto. Los primeros trabajos reportados sobre pasturas naturales en la región fueron llevados adelante por Gallinal et al. (1938) y Rosengurtt (1943) en la región de Palleros en el departamento de Cerro Largo, dentro de una propuesta nacional de investigación de las pasturas naturales.

En la década de 1960 se realizaron esfuerzos por el establecimiento de pasturas mejoradas en las diferentes regiones del país, incluyendo la región noreste (Sociedad Mejoramiento de Praderas, 1960; Fillat et al., 1960; Allegri y Formoso, 1978) indicando estas evaluaciones que algunas especies de gramíneas nativas presentan un alto potencial de crecimiento invernal (Formoso y Allegri, 1984).

En este trabajo se reanalizan e integran resultados obtenidos en la región con pasturas naturales, considerando el tipo de suelo, el manejo de cada pastura, así como las variables climáticas. Luego se realiza un análisis de diferentes resultados integrados en un modelo matemático del sistema de producción ganadero (Soares de Lima, 2009) y se realizan consideraciones sobre la importancia de las pasturas naturales para la región así como la importancia de los recursos genéticos presentes en las mismas.

Finalmente se realizan consideraciones sobre la importancia de las pasturas naturales y la necesidad de aplicar una tecnología de uso y manejo que permita una mayor estabilidad productiva. 


\section{BIBLIOGRAFÍA}

ALLEGRI M.; F. FORMOSO. 1978. Región noreste. In: Avances en Pasturas IV. CIAAB. Miscelánea No. 18. pp.: 83-110.

CENSO GENERAL AGROPECUARIO. 2000. 2002. Ministerio de Ganadería, Agricultura y Pesca. DIEA Estadísticas Agropecuarias. Volumen 2. $121 \mathrm{p}$.

CENSO GENERAL AGROPECUARIO. 2011. 2013. Ministerio de Ganadería, Agricultura y Pesca. DIEA Estadísticas Agropecuarias.

FILLAT A.; NAVARRO, G.; MEDERO, B. 1960. Ensayo de incorporación de lotus corniculatus y trébol blanco en praderas naturales. In: Anuario de la Sociedad Mejoramiento de Praderas. Montevideo. Uruguay. No. IV. pp. 167-180.

FORMOSO F.; ALLEGRI, M. 1984. Estudio comparativo de gramíneas perennes invernales en suelos arenosos, pesados e hidromórficos. In: Gramíneas perennes en la región noreste. Miscelánea No. 56. pp. 1-18.
GALLINAL J. P.; BERGALLI, E.; CAMPAL, L.; ARAGONE,L.; ROSENGURTT, B. 1938. Estudios sobre Praderas Naturales del Uruguay. Primera Contribución. Imp. Germano Uruguaya. Montevideo. 208 p.

OLMOS F. 1990. Utilización de pasturas con animales: avances y propuestas. In: 2 do. Seminario Nacional de Campo Natural. Tacuarembó. Ed. Hemisferio Sur. pp. 279-290.

ROSENGURTT B. 1943. Estudios sobre Praderas Naturales del Uruguay. 3ra. C o n tribución. 281 p.

SOARES DE LIMA J. M. 2009. Modelo Bioeconómico para la Evaluación del Impacto de la Genética y Otras Variables sobre la Cadena Cárnica Vacuna en Uruguay. Tesis Doctoral. Universidad Politécnica de Valencia. España. 2009. 240 p.

SOCIEDAD MEJORAMIENTO DE PRADERAS. 1960. Informes. In: Anuario de la Sociedad Mejoramiento de Praderas. Montevideo. Uruguay. No. IV. pp.: 41-71. 


\section{MANEJO DE PASTURAS NATURALES}

\section{INTRODUCCIÓN}

La productividad de las pasturas naturales esta relacionada directamente con el tipo de suelo donde se desarrolla; en este sentido tanto el nivel de fertilidad como las relaciones hídricas de los suelos muestran un efecto marcado sobre la productividad (Allegri y Formoso, 1978; Castro, 1979; Formoso y Allegri, 1980; Formoso y Allegri, 1983). De las variaciones reportadas la más marcada es la referente a los valores de producción forrajera anual, en este sentido se han observado diferencias de cinco veces en los valores yendo desde $800 \mathrm{~kg} \mathrm{MS} \mathrm{ha}^{-1}$ en un suelo superficial de basalto hasta $4.000 \mathrm{~kg}$ MS ha-1 en suelos de alta fertilidad de la Unidad Fray Bentos o de la Unidad Fraile Muerto (Carámbula, 1978). Por otro lado se registraron diferencias muy marcadas en la distribución estacional de la producción de forraje como entre suelos arenosos y arcillosos o entre suelos arenosos y superficiales sobre basalto, los cuales, dependiendo del balance hídrico estival, pueden alcanzar en verano valores de $300 \mathrm{~kg} \mathrm{MS} \mathrm{ha-1} \mathrm{en} \mathrm{verano} \mathrm{a}$ 1.300 MS ha-1 en los suelos superficiales / arcillosos y los arenosos respectivamente. La producción de forraje en los suelos arenosos es básicamente una curva con un único pico productivo desde la primavera tardía hasta el verano, en cambio sobre los suelos arcillosos tenemos un doble pico en la curva de producción en otoño y en primavera.

Respecto a la composición botánica los principales registros presentados han sido los de Gallinal et al. (1938) y Rosengurtt (1943) en la región de Palleros en Cerro Largo y los de los campos experimentales sobre areniscas, en la Unidad Experimental La Magnolia, Tacuarembó (Castro, 1979).

Dada la descripción del campo natural y de la curva de producción y distribución de forraje estacional la investigación privilegió el análisis y estudio de la intensificación en pequeñas áreas dentro de los predios ganaderos donde se incluyó la utilización de especies fundamentalmente de clima templa- do como trébol blanco, lotus corniculatus, festuca, dactylis, raigras, trébol subterráneo entre otras, para tratar de cubrir los períodos donde las pasturas naturales no cubrieran las necesidades de los lanares y vacunos. En este sentido en la Jornada Agrícola Ganadera de Caraguatá se presentó la información actualizada para la región noreste sobre la productividad de las pasturas naturales y las posibilidades de intensificación (Olmos, 1983; Formoso y Allegri 1983; Pittaluga, 1983).

Desde el punto de vista de la utilización de las pasturas por animales en general la aproximación ha sido a través del enfoque de sistemas de producción donde se compararon diferentes alternativas evaluándose su productividad en términos de carne equivalente por hectárea (Pittaluga, 1983; Pittaluga et al., 1978). Olmos (1990 b), por su parte, analizando un modelo funcional del ecosistema discutió los avances y desafíos para la producción animal en la región, destacando la necesidad de una mejor comprensión del funcionamiento de los componentes del modelo así como de su variabilidad.

En este capítulo se presentan resultados de tres trabajos realizados en la región noreste: primero una caracterización regional de las pasturas naturales, en segundo lugar una comparación de la productividad en diferentes tipos de pasturas y finalmente se incluye el uso de animales para la caracterización de las pasturas y su productividad.

\section{CARACTERIZACIÓN DE LAS COMUNIDADES NATURALES}

En el año 1987 se realizó una serie de relevamientos fito ecológicos en la región noreste de Uruguay, abarcando un amplio rango de situaciones de uso y manejo de las pasturas naturales en los principales suelos: arenosos y arcillosos. De acuerdo a la metodología propuesta por el Centro de Estudios Fitosociológicos y Ecológicos (CEPE) (Godron et al., 1983), se confeccionaron tres 
formularios para la caracterización de las comunidades naturales: el área mínima fitosociológica, el relevamiento de las principales variables ambientales de cada sitio y la descripción de la vegetación mediante una transecta. El área mínima se caracterizó en 21 sitios registrando la aparición de cada nueva especie a partir de un cuadro de 1/64 de $\mathrm{m}^{2}$ y duplicando el área sucesivamente, hasta alcanzar los $32 \mathrm{~m}^{2}$. La composición botánica se registró en la zona media del área utilizada para la realización de la curva área - especie, utilizando una transecta de $10 \mathrm{~m}$ de longitud con registros cada $10 \mathrm{~cm}$., totalizando 100 observaciones en cada sitio.

En la Figura 1 se presenta los resultados para veintiuna determinaciones de la curva área - especie en pasturas naturales de la región noreste; si bien existe un rango relativamente amplio, a los $32 \mathrm{~m}^{2}$ se llega con la presencia de 56 especies en promedio, indicando la alta riqueza específica de las comunidades naturales. Al mismo tiempo se observa que la mayoría de las especies se encuentran presentes en los primeros $8 \mathrm{~m}^{2}$ de la serie.

Al realizar el análisis de cada transecta en relación al número total de especies registradas en cada área mínima, se observa un disminución prácticamente hasta la mi- tad del mismo, es decir, si en un área mínima aparecen 60 especies en $32 \mathrm{~m}^{2}$, en la transecta de 10 metros que la cruza aparecen 30 especies. En los 67 relevamientos realizados en la región noreste, el promedio de especies por transectas registrado fue de 28.

Desde el punto de vista de la contribución específica de cada especie en la comunidad, las mismas muestran una estructura muy consistente, indicando que hay pocas especies que presentan una importancia relativa mayor como son la $1^{\text {ra. }}, 2^{\text {da. }}$ y $3^{\text {ra. }}$ especies y en cambio hay muchas que con poca contribución al recubrimiento de la vegetación, como son la 4ta. a décima presencia (Figura 2). Se observa una mayor variación en la contribución de las primeras especies dependiendo de la historia de uso de cada comunidad; los menores valores corresponden a pasturas que han sido fuertemente intervenidas y los valores mayores corresponden a pasturas manejadas con pastoreos relativamente aliviados y con un manejo menos intensivo.

Estos resultados nos indican que existe un grupo de especies que contribuye mayoritariamente al recubrimiento de la vegetación, en la Figura 3 se aprecia que las primeras diez especies, ordenadas por su contribución acumulada de mayor a menor,

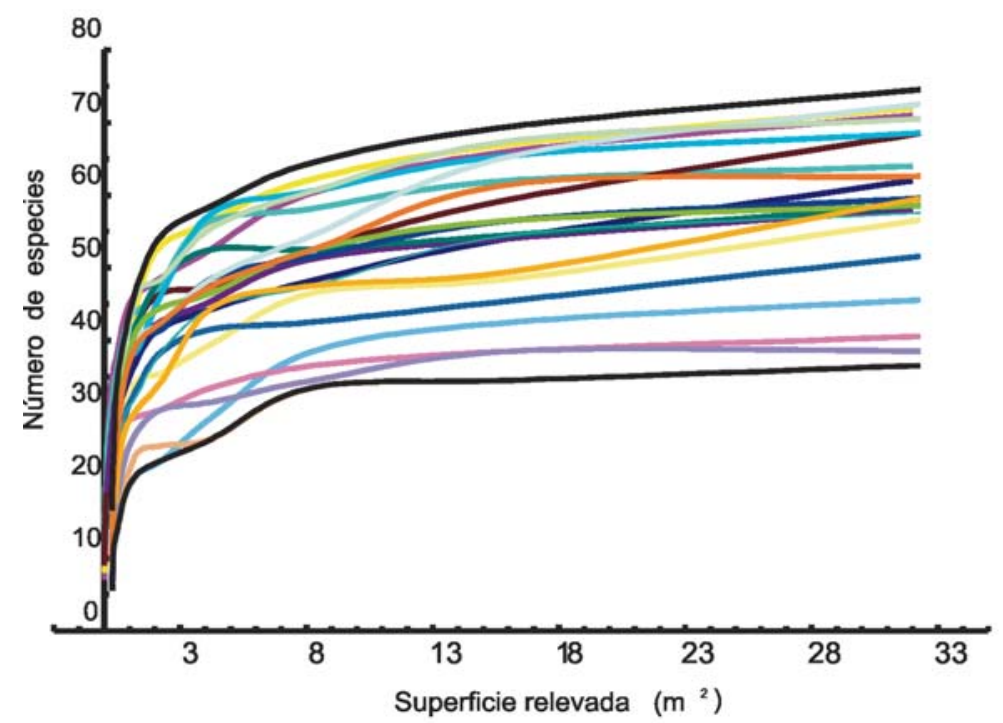

Figura 1. Curva área especie en la región noreste de Uruguay. Número de especies vegetales presentes en las pasturas naturales al incrementar el área relevadadesde 1/64 hasta $32 \mathrm{~m}^{2}$. 


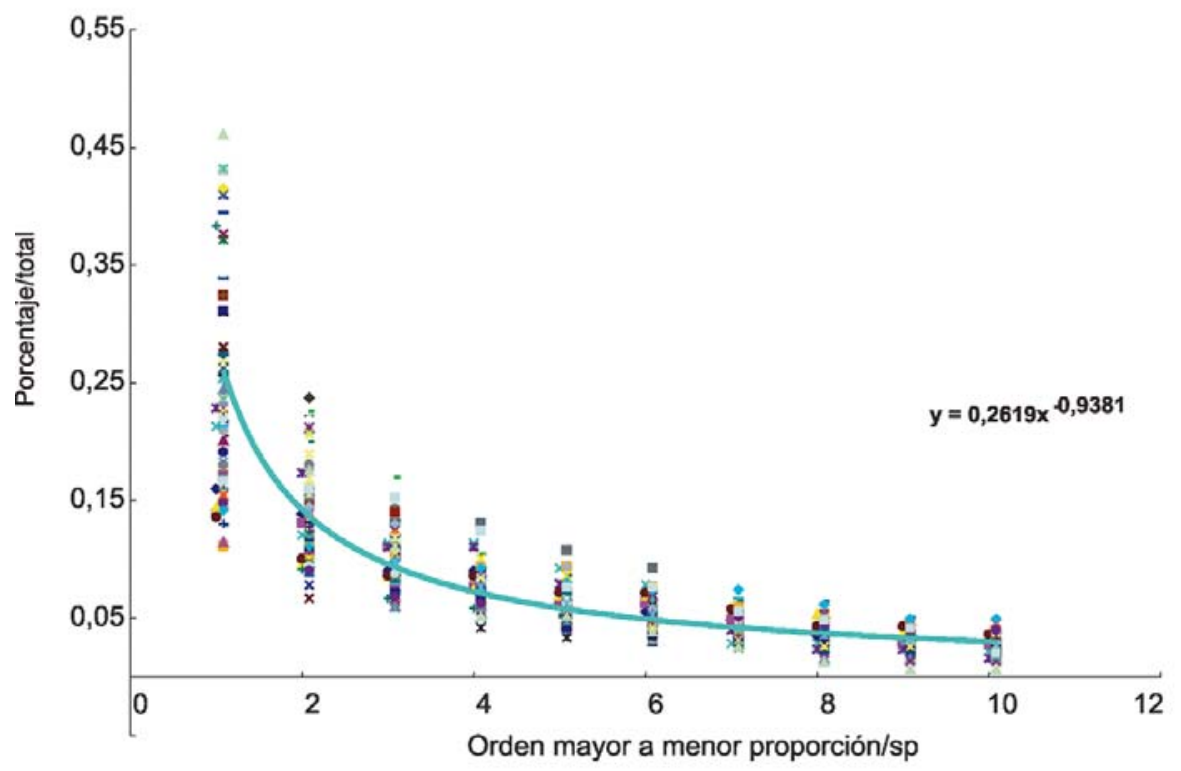

Figura 2. Contribución específica de las primeras diez especies, ordenadas de mayor a menor, registradas en la transecta de $10 \mathrm{~m}$ de largo.

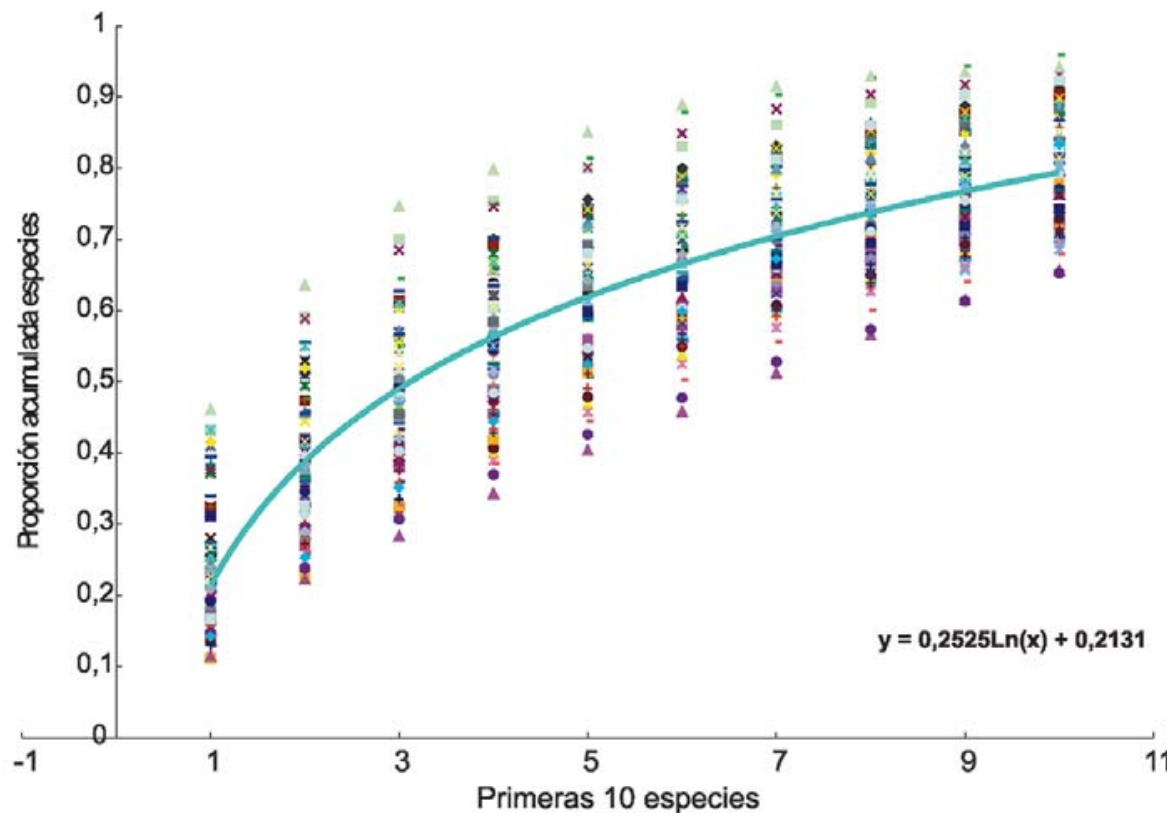

Figura 3. Contribución específica acumulada de las primeras diez especies registradas en la transecta de $10 \mathrm{~m}$ de largo.

determinan algo más del $70 \%$ de la composición de la vegetación.

Las primeras 10 especies de cada transecta, en base a registros de 21 sitios contribuyeron al $70-80 \%$ del recubrimiento de la vegetación. En forma resumida en la
Figura 4 se esquematiza la estructura básica de las comunidades de pasturas naturales.

En conclusión, al hacer el relevamiento de un sitio en una pastura natural esperamos encontrar en $32 \mathrm{~m}^{2}$ entre 55-60 especies y en una transecta que atraviese dicha 


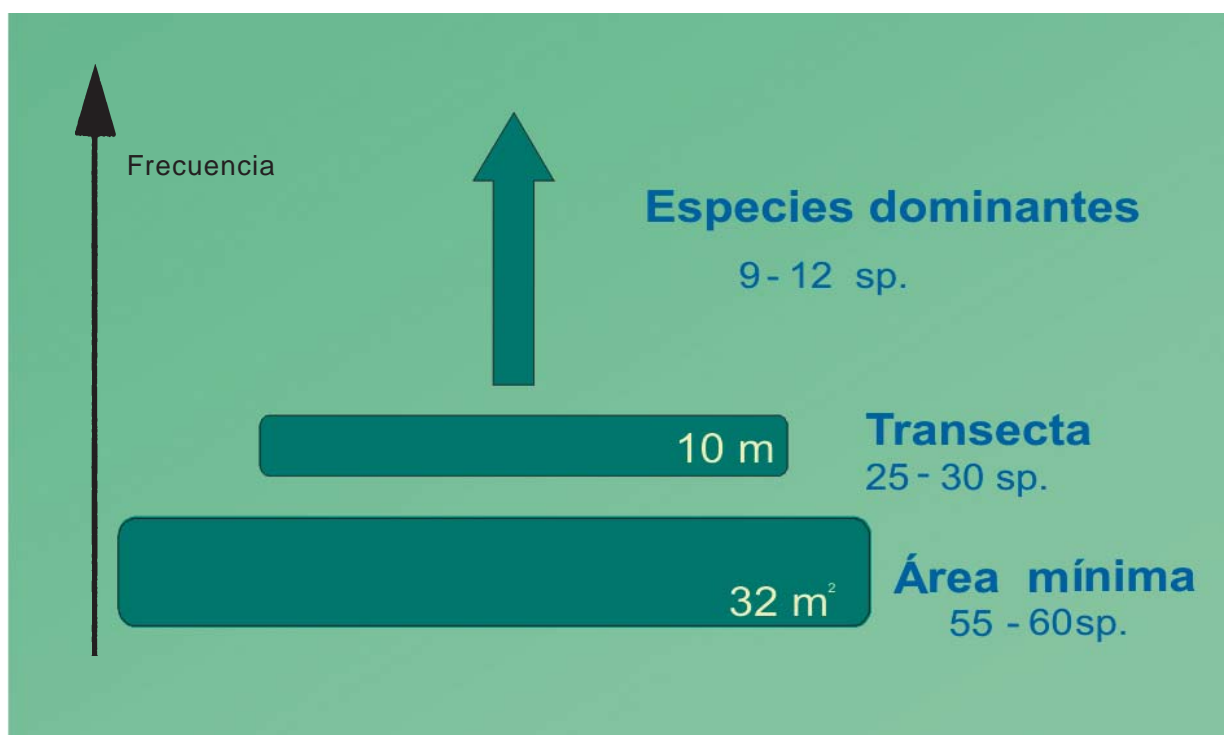

Figura 4. Estructura básica de pasturas naturales (comunidades) en la región noreste, relación entre la presencia y frecuencia de especies con la superficie.

área encontraremos la mitad de ese total de especies; en general el $30 \%$ de las especies de la transecta (9-12) presentan una mayor frecuencia, contribuyendo al $70 \%$ del recubrimiento de la vegetación.

\section{RELEVAMIENTOS REGIONALES}

En el año 1987 se realizaron 67 relevamientos fito ecológicos en la región noreste. El propósito básico fue explorar la diversidad de especies presentes en dos tipos de suelos predominantes en la región, arenosos $(n=27)$ y arcillosos $(n=40)$, los cuales comprenden diversas Unidades de Suelo (Altamirano et al., 1976) alcanzando un área de 1.500.000 hectáreas. Dentro de cada tipo de suelo se realizó la descripción de la composición botánica de las pasturas asociadas al sistema de producción del establecimiento y dentro de estos los diferentes manejos del pastoreo; para ello, en consulta con el productor, se identificaron dentro de cada predio tres tipos de situación: la mejor pastura (generalmente asociada a potreros de invernada), la peor pastura (generalmente asociada a piquetes más o menos grandes) y una situación intermedia. Asimismo en algunos casos se identificaron situaciones específicas como rastrojos de cultivos mayores a 10 años (campo bruto), mejoramientos de pasturas, potreros de pastoreo. La identificación primaria de los sitios en muchos casos se llevó adelante tanto con técnicos privados como del Ministerio de Ganadería Agricultura y Pesca o del Instituto Plan Agropecuario.

Estos relevamientos fueron planificados de acuerdo a la metodología propuesta por el Centro de Estudios Fitosociológicos y Ecológicos - Montpellier (Francia) y adaptada para nuestras condiciones (Godron et al., 1983), al mismo tiempo se confeccionó una planilla para el registro de la composición botánica en cada sitio. En cada uno de los 67 sitios relevados se procedió a la lectura de una transecta de 100 puntos donde se registraron las especies presentes. En cada sitio se procedió a la caracterización ambiental utilizando un escala para cada variable considerando: el grado de abertura de la vegetación, el tipo de formación, el grado de artificialización, el grado de exposición a la radiación solar, la topografía, la pendiente, la humedad aparente en la estación, la intensidad de la explotación, la utilización por animales, el tipo de explotación, la carga animal, el tipo de pastoreo y los períodos de alivio, la clasificación por uso de cada pastura, la cantidad de forraje disponible y con respecto al suelo, el $\mathrm{pH}$, el contenido de materia orgánica, el contenido de nutrientes ( $\mathrm{Ca}, \mathrm{Mg}, \mathrm{K}, \mathrm{Na}, \mathrm{Al}$ ) y la textura. 
En la Figura 5 se muestra, para los dos tipos de suelos, la contribución relativa de cada especie, tomando como referencia las especies que contribuyen al $70 \%$ del recubrimiento de la vegetación.

Las principales especies registradas en los dos tipos de suelo correspondieron para el caso de los suelos arenosos Andropogon lateralis, Paspalum nicorae, Paspalum pumilum, Arachis sp. y Coelorachis selloana, Stipa setigera, Paspalum dilatatum, Piptochaetium stipoides se registraron básicamente en los suelos arcillosos siendo las diferencias en la presencia de las especies estadísticamente diferentes $(P<0,01)$ y por otro las especies que se encuentran indistintamente en ambos suelos, por ejemplo Trifolium polymorphum y Chaptalia excapa (Olmos y Godron, 1990).

\section{Métodos multivariados}

En base a la contribución relativa de las primeras especies que contribuyen hasta el $70 \%$ del recubrimiento de la vegetación se efectuaron análisis de las comunidades por métodos multivariados.

En la Figura 6 se observa la distribución, considerando los dos primeros ejes del análisis de correspondencia (MVSP, 2004), de los sitios clasificados según el tipo de suelo y los componentes de las pasturas. Se destaca la separación entre los suelos con textura arcillosa (brunosoles y vertisoles) de los de texturas arenosas indicando que la composición botánica de los mismos corresponde a diferentes especies en cada caso corroborando lo presentado en la Figura 5. Al mismo tiempo se observa un pequeño grado de solapamiento así como una cierta dispersión de los sitios dentro de cada tipo de suelo, principalmente en el sentido del primer eje (abscisas), por ejemplo entre los sitios 34 y 36 para los suelos arenosos y los sitios 2 y 7 para los suelos arcillosos.

Estas diferencias se deben a la diferente composición botánica presente en cada relevamiento, asociada fundamentalmente a la historia de manejo de cada pastura. Al comparar los 67 sitios en base a la composición botánica el diferente grado de intervención por manejo de la pastura determina una dispersión y separación en el primer eje (abscisas) de la Figura 7 agrupando especies caracterizadas como más productivas y de crecimiento erecto (cespitosas) hacia la izquierda del mismo y las menos productivas, anuales, malezas, de crecimiento más postrado hacia la derecha del eje. Ejemplos de cespitosas agrupadas hacia la izquierda en el primer eje del análisis de correspondencia están Coelorachis selloana,

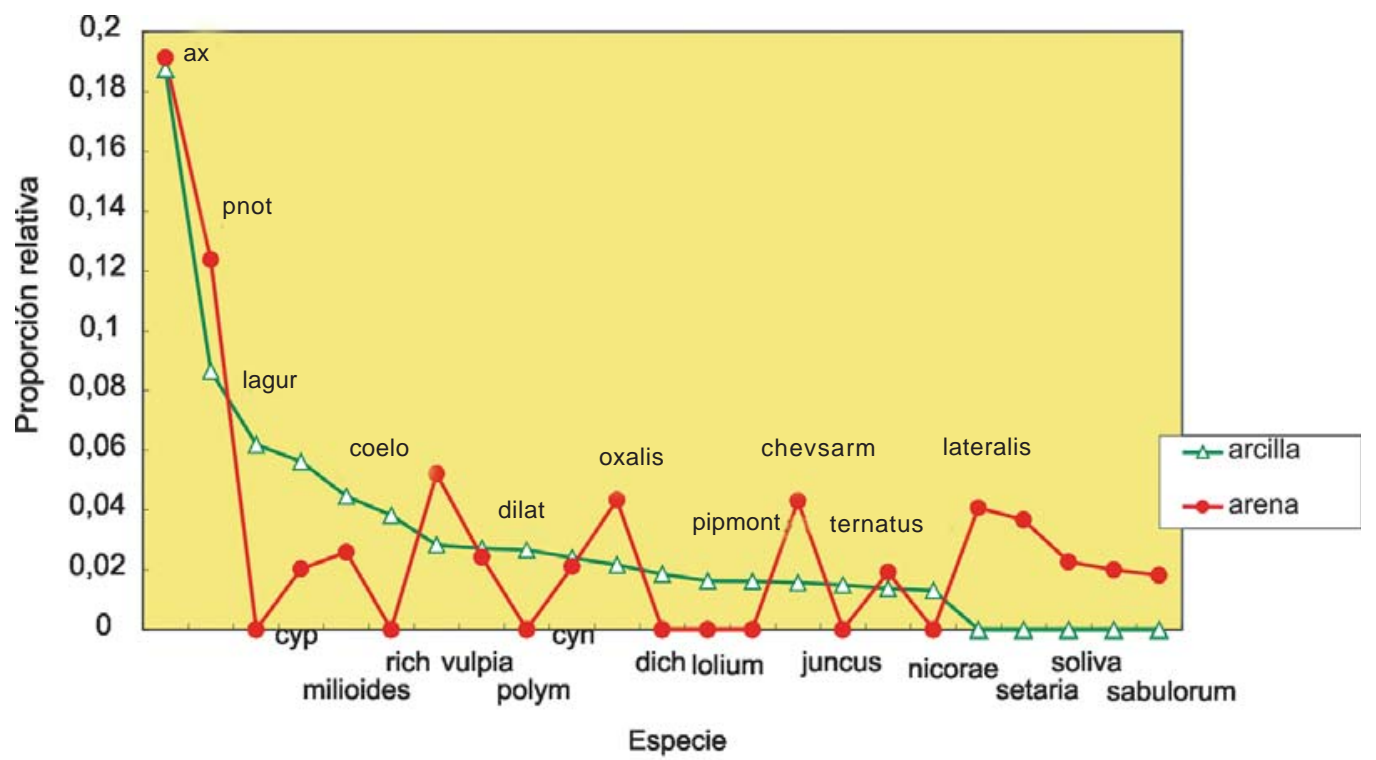

Figura 5. Proporción relativa de especies en suelos arenosos y arcillosos en la región noreste considerando las especies que contribuyen al 70 \% del recubrimiento de la vegetación. 


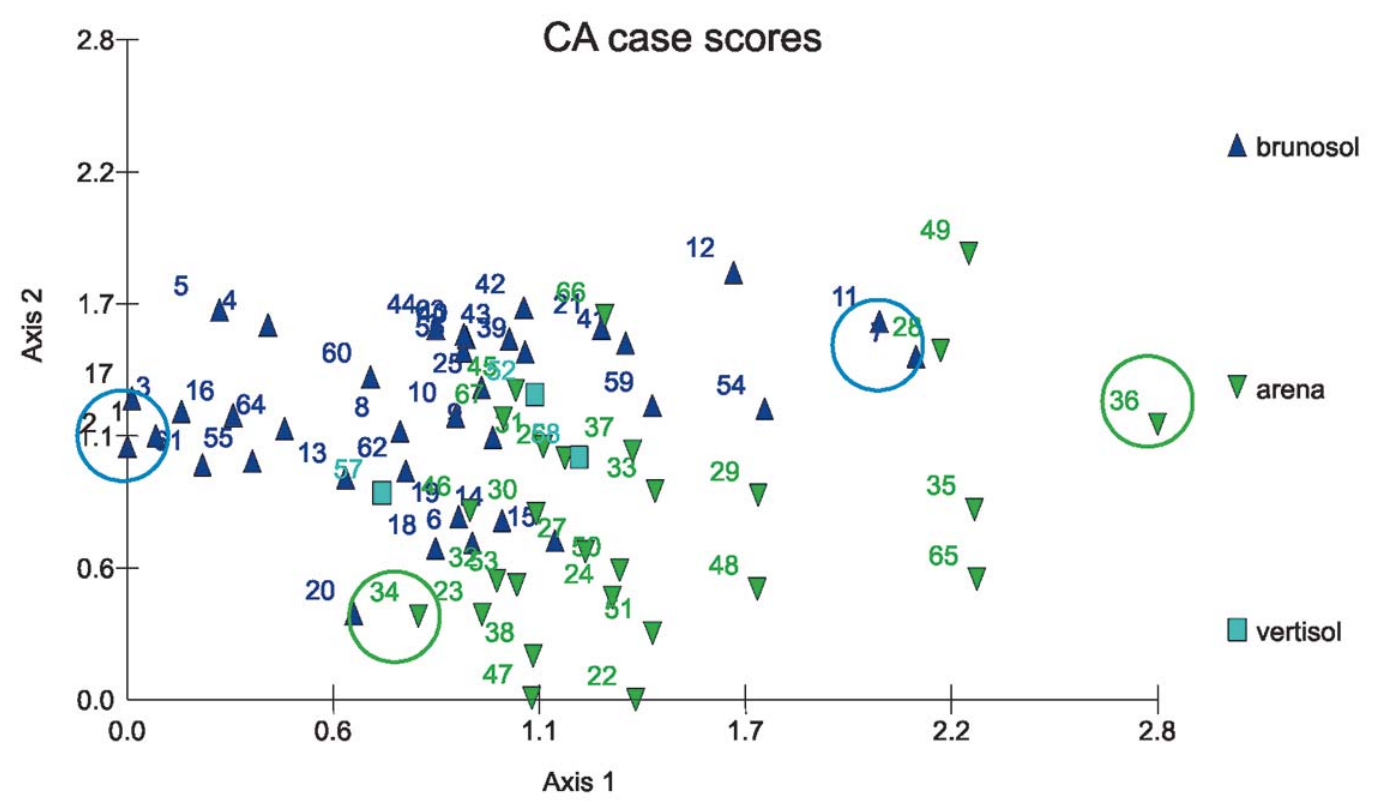

Figura 6. Análisis de correspondencia en base a los componentes de la vegetación para 67 relevamientos en la región noreste.

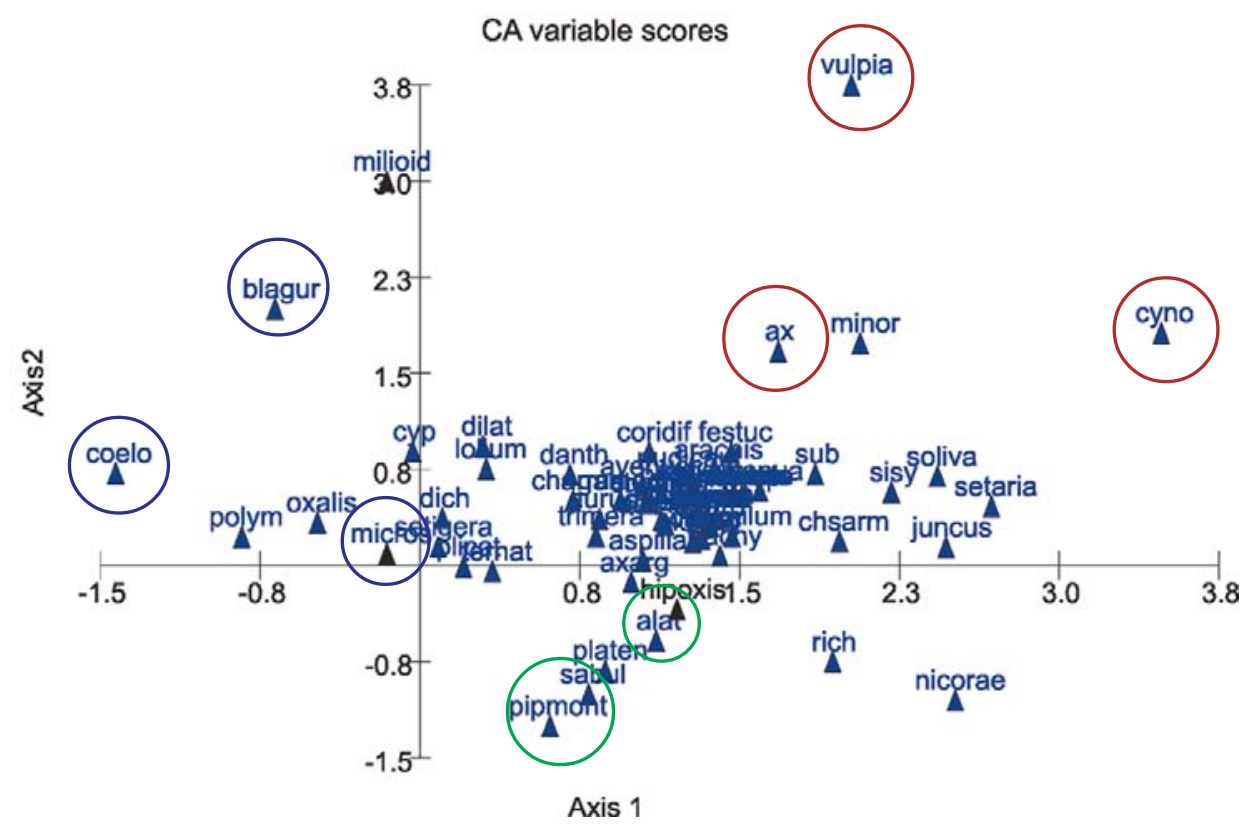

Figura 7. Distribución de las especies en base al Análisis de Correspondencia de 67 relevamientos en la región noreste. 
Bothriochloa laguroides, Paspalum dilatatum, Schizachyrium microstachyum, Stipa setigera, Andropogon ternatus y en cambio hacia el grupo indicador menos productivo encontramos Cynodon dactylon, Setaria geniculata, Soliva pterosperma, Richardia sp., Axonopus affinis, Juncus sp. entre otras especies. Para el caso del segundo eje (ordenadas) se puede interpretar que el mismo respondería a variaciones de la carga o intensidad de pastoreo asociado también en algún relevamiento a la presencia de una chacra con más de 15 años, tomando como referencia principalmente lo que ocurre en los suelos arenosos; en este sentido en el cuadrante superior derecho se encuentran Axonopus affinis y Cynodon dactylon dos especies de crecimiento rastrero y relativamente menos productivas asociadas a Vulpia australis de ciclo anual por un lado y por otro en el cuadrante inferior derecho tenemos dos especies de crecimiento erecto y relativamente más productivas como Andropogon lateralis y Piptochaetium montevidensis.

Tomando la información física y química correspondiente al suelo de cada sitio y la información descriptiva de cada sitio conjuntamente con la composición botánica se realizó un análisis canónico. En la Figura 8 se observa que con una distribución similar de las especies a la Figura 7 las principales variables ambientales que intervienen principalmente en el primer eje indican que existe una asociación positiva con la intensidad de la explotación, la artificialización y la carga animal hacia la derecha del segundo eje encontrándose especies como Cynodon dactylon, Setaria geniculata, Vulpia australis y Paspalum nicorae asociadas; en cambio una asociación negativa con estos factores encuentran especies como Coelorachis selloana, Bothriochloa laguroides, Paspalum dilatatum, Paspalum plicatulum, Panicum milioides en los cuadrantes a la izquierda del segundo eje. Con respecto a parámetros que involucran fundamentalmente el suelo el grupo identificado principalmente con $C$. selloana se encuentra asociado a valores más altos de fertilidad en general y lo contrario ocurre con el grupo identificado hacia la derecha del segundo eje. Al mismo tiempo otras especies cespitosas se encuentra asociada a una mayor disponibilidad de forraje en la pastura conjuntamente con Coelorachis selloana, en cambio el grupo con especies de crecimiento rastrero como Axonopus affinis, Cynodon dactylon y Paspalum nicorae presentan un comportamiento inverso.

Estos resultados indicarían que tanto el tipo de suelo, la historia del potrero, así como la presión de pastoreo afectan la composición botánica de la pastura natural a escala regional.

\section{Correlaciones}

Para contribuir a una mejor comprensión de la relación entre la composición botánica de la pastura y los componentes ambientales de los diferentes sitios se realizaron correlaciones entre las principales variables ambientales en cada sitio, entre las especies propiamente dichas y entre las especies y las variables ambientales.

\section{Relaciones entre variables ambientales}

En el Cuadro 1 se reportan las correlaciones y su significación entre seis variables ambientales incluyendo el índice de diversidad, el número de especies presentes de cada comunidad, la homogeneidad en la distribución de las especies, la carga animal, la intensidad de pastoreo y la disponibilidad de forraje. El índice de diversidad de Shannon se correlacionó fuerte y positivamente tanto con la homogeneidad en la distribución de las especies como con el número de estas; mostrando que el índice se incrementó con el número de especies pero a su vez con la mayor homogeneidad en su distribución. También se constató una correlación positiva entre la homogeneidad y el número de especies. La carga animal se correlacionó positivamente con la intensidad de pastoreo. El número de especies se correlacionó negativamente con la carga animal. Como una tendencia puede razonarse la relación negativa entre el número de especies y la intensidad de pastoreo $(P<0,13)$ del mismo modo que el índice de diversidad de especies tendió a 

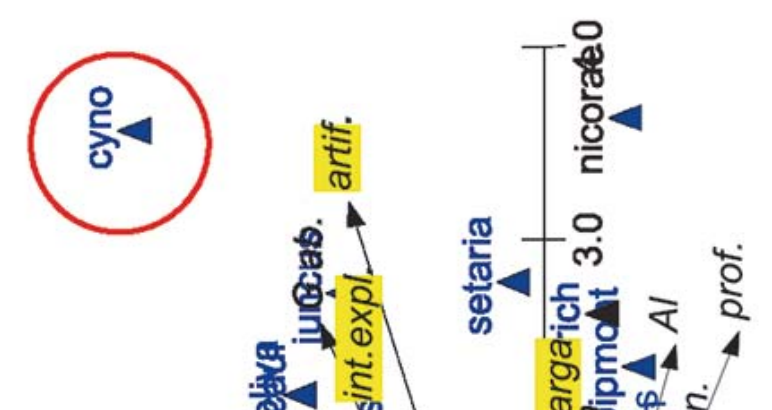

느ㅇㅡㅡㄴ

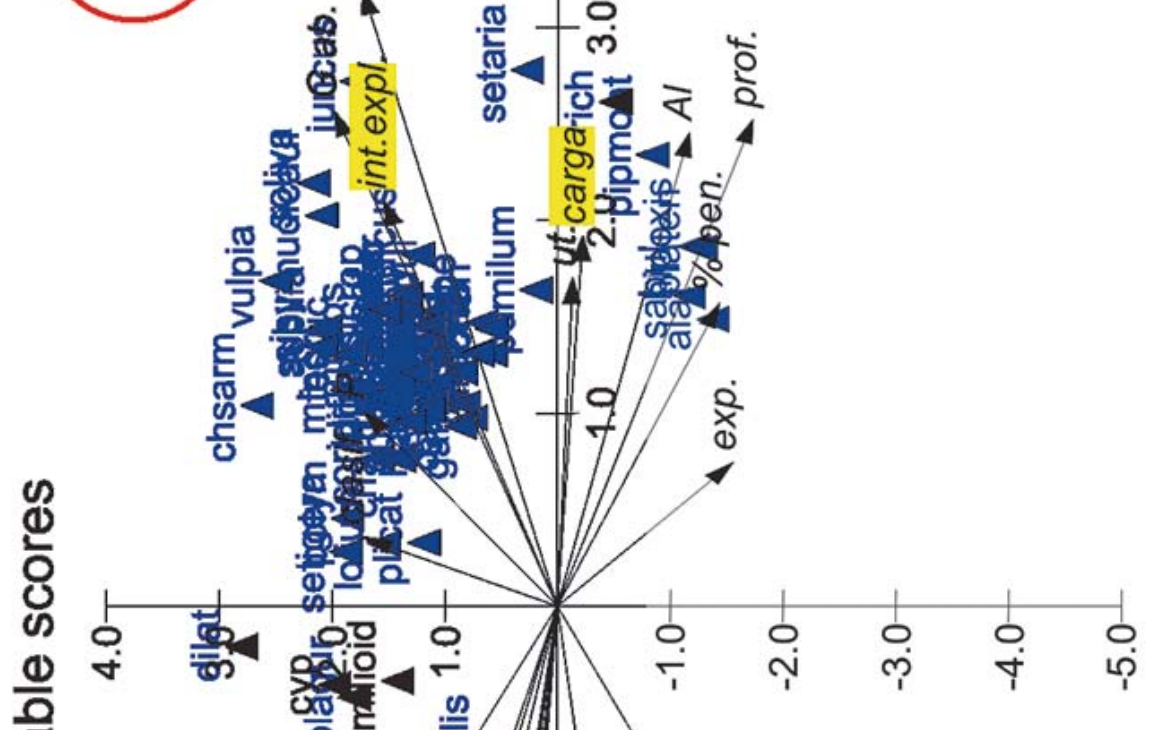

$\frac{\pi}{ㅇ ㅡ ㅁ ~}$

$\frac{2}{2}$

$\stackrel{\widetilde{\sigma}}{5}$

ฮ

$=$

은

$\therefore$

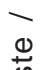

ले

흥

要

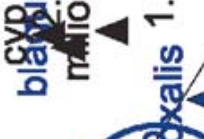

진

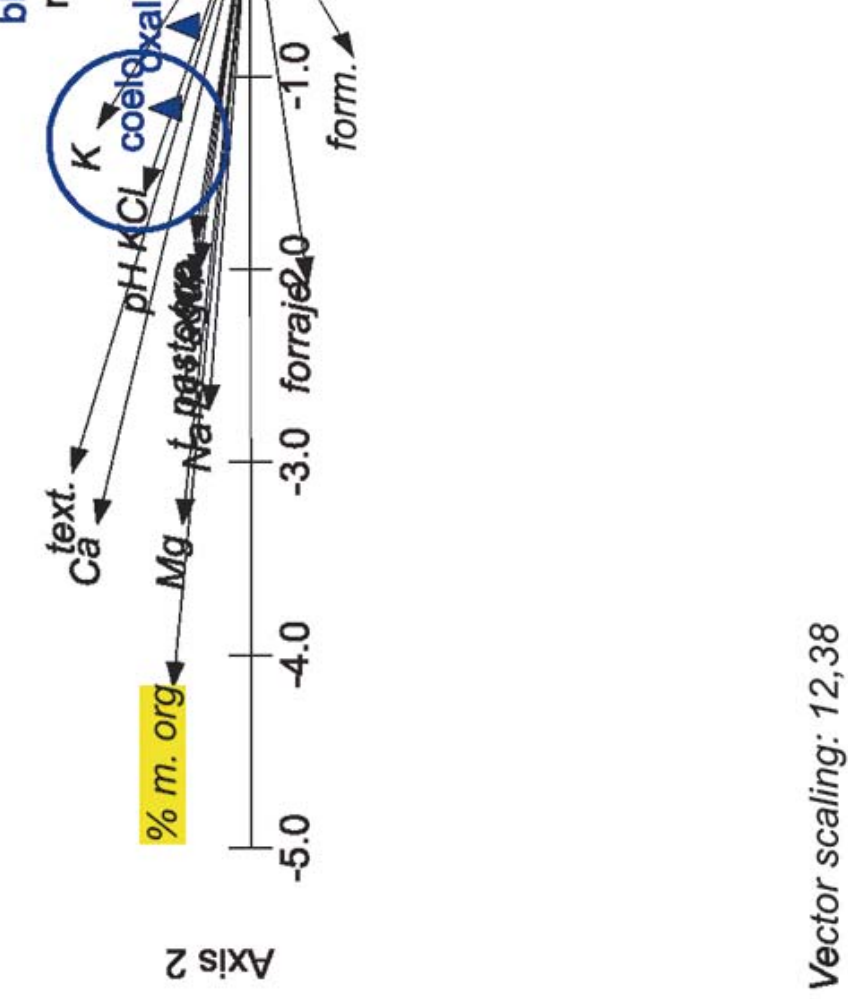


Cuadro 1. Coeficientes de correlación entre algunas variables de sitio en pasturas naturales en la región noreste (triángulo abajo izquierdo $r$; triángulo arriba derecha P).

\begin{tabular}{|c|c|c|c|c|c|c|}
\hline & Índ.div. & Carga & Int. & Homog. & Número & Forraje \\
\hline Índice div. & 1,00 & 0,10 & 0,12 & 0,00 & 0,00 & 0,43 \\
\hline Carga & $-0,20$ & 1,00 & $5,0 \mathrm{E}-11$ & 0,42 & 0,05 & 3,8E-08 \\
\hline Intensidad & $-0,19$ & 0,70 & 1,00 & 0,30 & 0,13 & 7,3E-05 \\
\hline Homogeneidad & 0,87 & $-0,10$ & $-0,13$ & 1,00 & $6,5 E-05$ & 0,77 \\
\hline Número & 0,84 & $-0,24$ & $-0,19$ & 0,47 & 1,00 & 0,29 \\
\hline Forraje disp. & 0,10 & $-0,61$ & $-0,47$ & 0,04 & 0,13 & 1,00 \\
\hline
\end{tabular}

valores negativos con relación a la carga y la intensidad de pastoreo $(P<0,10$ y $P<0,12$ respectivamente). Se destaca claramente la relación negativa entre carga y la disponibilidad de forraje, a su vez la carga animal se relaciona negativamente con el número de especies presentes y positivamente con la intensidad de pastoreo.

\section{Relaciones entre especies en suelos arcillosos}

Un resumen de las relaciones entre especies componentes de la pastura en los suelos arcillosos se presenta en el Figura 9; para alcanzar esta síntesis se procedió al análisis de las correlaciones entre especies de interés agronómico utilizando el coeficiente de rango de Spearman (Di Rienzo et al., 2011). Para la constitución de grupos se tuvieron en cuenta tres niveles de significación, hasta $P \leq 0,05$ las especies que contribuirían a la generación del núcleo del grupo de especies, hasta $P \leq 0,10$ las especies acompañantes contribuirían a la consolidación del grupo indicando algún tipo de respuesta funcional y hasta $P \leq 0,20$ constituirían las especies accesorias al grupo. Las especies con menos de tres presencias en los relevamientos no fueron consideradas en el análisis.

En la Figura 9 se identificaron en un recuadro las especies principales dentro de cada grupo y especies asociadas a las mismas especies correlacionadas con la especie principal tanto positiva como negativamen- te; por ejemplo donde dice «setaria», significa que la especie esta correlacionada positivamente con la especie principal del grupo y donde dice «no setaria» la especie esta correlacionada negativamente con la especie principal del grupo.

En base a las especies principales de cada grupo tenemos que Coelorachis selloana se relaciona positivamente con Bothriochloa laguroides, esta con Paspalum notatum y Paspalum notatum con Coelorachis selloana, generando una especie de grupo que en forma de especie acompañante incluye Stipa setigera; al mismo tiempo, se encuentran asociadas, a este grupo, algunas especies en común como Chascolytrium sp., Setaria geniculata, Andropogon ternatus, Schizachyrium microstachyum y algunas especies que tienen una correlación negativa como Chevreulia sarmentosa, Oxalis sp., Polygala australis entre otras. Tomando a Coelorachis selloana como la especie central de este grupo observamos que se encuentra negativamente correlacionada con Axonopus affinis, así como con Cynodon dactylon (líneas azules).

Contrariamente a lo que ocurre con el grupo anterior Axonopus affinis muestra correlaciones positivas con Chevreulia sarmentosa, Trifolium repens, así como correlaciones positivas con Setaria geniculata y Vulpia australis que son parte del grupo de Coelorachis selloana. Estas correlaciones de los grupos indican una correlación general negativa pero con cierto grado de solapamiento en las especies acompañantes. 


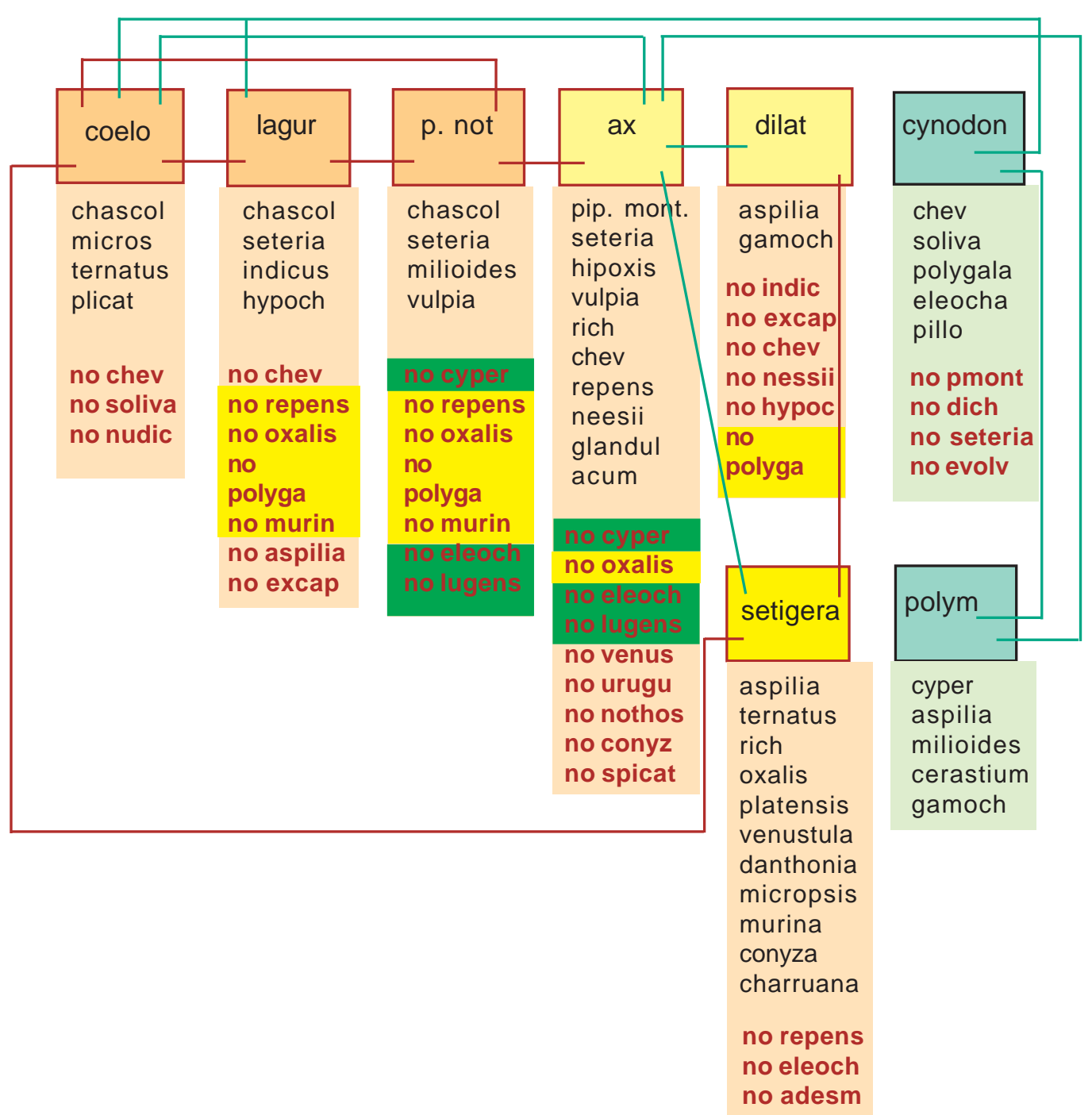

Figura 9. Asociación entre especies componentes de la pastura en suelos arcillosos. Las líneas enrojo indican correlaciones positivas y las líneas en azul correlaciones negativas para las especies principales de cada grupo.

Al mismo tiempo Axonopus affinis muestra una correlación positiva con Paspalum notatum y negativa con Stipa setigera y Paspalum dilatatum; estas dos ultimas especies prácticamente no muestran ninguna relación con el grupo de Axonopus affinis, tanto en las correlaciones positivas como negativas. Respecto a la correlación negativa de Axonopus affinis con Trifolium polymorphum podría estar explicada por la falta de correlaciones positivas semejantes así como la correlación negativa de Axonopus affinis con Cyperus sp., siendo que Cyperus $s p$. presenta una correlación positiva con Trifolium polymorphum.
Por su parte los grupos de Paspalum dilatatum y Stipa setigera presentan una correlación positiva en común con Aspilia montevidensis. Stipa setigera presenta en común una correlación positiva con Andropogon ternatus, especie perteneciente al grupo de Coelorachis selloana.

Cynodon dactylon se separa del grupo de Coelorachis selloana presentando correlaciones positivas con Chevreulia sarmentosa y Polygala australis las cuales tienen una correlación negativa con Coelorachis selloana. También se distingue por su correlación negativa con Trifolium polymorphum y Setaria geniculata, especie esta última que se en- 
cuentra positivamente correlacionada con el grupo de Coelorachis selloana.

Las especies presentes hacia la izquierda del cuadro presentan en general un tipo de forma de crecimiento erecto, en cambio hacia el lado de Axonopus affinis - Paspalum dilatatum aparecen proporcionalmente más especies de crecimiento más rastrero.

Asumiendo una distribución de tipo Gaussiana y ejemplificando en un plano, tenemos una representación de la posición relativa de algunas especies forrajeras de interés agronómico y los grupos determinados en la Figura 10.

El grupo de Coelorachis selloana, de acuerdo al análisis de correspondencia ca- nónico, estaría asociado a condiciones de mayor alivio respecto a la presión de pastoreo y a una menor intensificación en el uso de los recursos. Asociada a este grupo de especies estivales se encuentra Stipa setigera. Tomando a Coelorachis selloana como especie representativa de este grupo, observamos que la misma se encuentra correlacionada negativamente con Axonopus affinis y Cynodon dactylon. Cynodon dactylon podemos estimar que es una especie que representaría una máxima intensificación e intervención en el uso de los recursos naturales, ya que se trata de una especie exótica introducida.

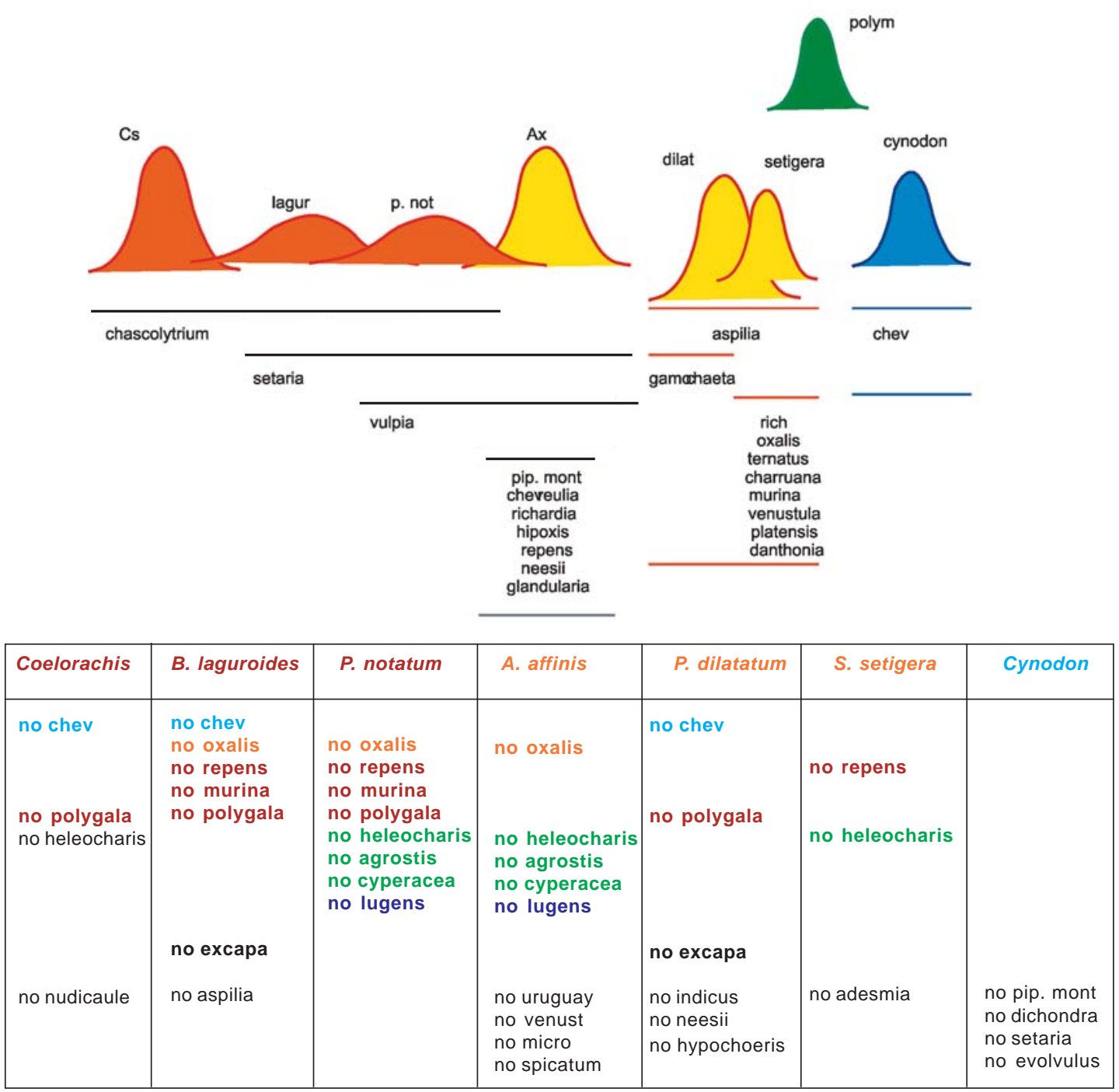

Figura 10. Diagrama sintético de grupos de especies identificados en las pasturas naturales de la región noreste, en los suelos arcillosos, en base a correlaciones ínter especificas. 
La intensificación se encuentra asociada con una mayor carga animal, con una mayor artificialización del ambiente, con una mayor intensidad de la explotación y con una menor disponibilidad de forraje (Cuadro 1).

En una situación intermedia se encuentra Axonopus affinis, considerando el eje Coelorachis - Cynodon, sin embargo si consideramos solamente las especies nativas tendríamos que Axonopus se encuentra en el extremo de intensificación y alta carga con alta presión de pastoreo en condiciones naturales. En esta situación si tendríamos colocado a Paspalum notatum en medio de un eventual eje Coelorachis - Axonopus ya que $P$. notatum se vincula positivamente tanto con Coelorachis y Bothriochloa laguroides como con Axonopus affinis. Este comportamiento relativo podría estar asociado a las formas de vida y crecimiento vegetativo de las especies; en este sentido Coelorachis selloana presenta un tipo de crecimiento erecto (cespitosa) (Rosengurtt, 1979), en cambio Axonopus affinis presenta un tipo de crecimiento rastrero estolonífero.

Aparentemente existen otros ejes de respuesta que es necesario profundizar en su análisis y eventualmente intensificar el número de registros de campo para corroborar alguna hipótesis. Este es el caso de Paspalum dilatatum correlacionado fuerte y positivamente con Stipa setigera y a su vez ambas especies negativamente correlacionadas con Axonopus affinis; y por otro lado Trifolium polymorphum que también presenta una correlación negativa con Axonopus, pero que por otro lado presenta pocas asociaciones positivas con otras especies forrajeras. En estas especies se pueden identificar algún tipo de mecanismo de respuesta funcional específica a los cambios en los factores ecológicos como son los períodos de estrés hídrico, períodos de estrés térmico o características morfo-fisiológicas propias como la latencia de las semilla en Paspalum dilatatum (Coll, 1991) o la semilla basal presente en Stipa setigera (Rosengurtt et al., 1960), y los diferentes métodos de reproducción en Trifolium polymorphum (Izaguirre y Beyhaut, 1997).

Yendo a los casos más específicos de especies acompañantes asociadas a las principales especies, de los grupos tenemos que
Coelorachis selloana se correlaciona con Schizachyrium microstachyum, Paspalum plicatulum y Andropogon ternatus; $B$. laguroides se correlaciona positivamente con Sporobolus indicus e Hypochoeris sp.; Paspalum notatum con Panicum milioides (grupo de transición); Axonopus affinis se correlaciona positivamente con Piptochaetium montevidense, Richardia sp., Chevreulia sarmentosa, Hipoxis decumbens, Eragrostis neesii, Chevreulia acuminata, Glandularia sp., y T. repens. En el grupo Paspalum dilatatum Stipa setigera es esta última la que presenta mayores correlaciones positivas como ser con A. ternatus, S. platensis, A. venustula, A. murina, Danthonia sp., Conyza sp. Stipa charruana, Micropsis sp., Oxalis sp., Richardia sp., en cambio $P$. dilatatum solamente con Gamochaeta spicata. Por su parte Cynodon dactylon presenta correlaciones positivas con Chevreulia sarmentosa, Eleocharis sp., Polygala australis y Soliva ptersoperma.

Estos agrupamientos son definidos tanto por las asociaciones positivas como negativas entre las especies. En la parte inferior de la Figura 10 se presenta una especie de escalonamiento en la secuencia Coelorachis selloana $\longrightarrow$ Axonopus affinis contribuyendo marcadamente a la separación de los subgrupos. Respecto a las asociaciones negativas tenemos que Coelorachis selloana se correlaciona negativamente con Chevreulia sarmentosa, Soliva pterosperma, Eryngium nudicaule, Eleocharis sp., Polygala australis. En este sentido tenemos a las correlaciones negativas que incluyen Chevreulia sarmentosa con Coelorachis selloana y Bothrichloa laguroides; las que incluyen correlaciones negativas con Oxalis sp. como Bothrichloa laguroides, Paspalum notatum y Axonopus affinis; las que incluyen correlaciones negativas con T. repens, con Aristida murina y correlaciones negativas de Polygala australis con Bothrichloa laguroides y Paspalum notatum; las que incluyen correlaciones negativas con Eleocharis sp. y correlaciones negativas de Cyperus sp. con Paspalum notatum y Axonopus affinis; presentándose además interacciones individuales específicas. Algunas especies acompañantes que tienen correlaciones negativas en un subgrupo pueden ser positivas en el otro subgrupo opuesto. 
Para el caso de Axonopus affinis además de los mencionados anteriormente tenemos con correlación negativa a Aristida uruguayensis, Aristida venustula, Eragrostis lugens, Schizachyrium microstachyum, Nothoscordum sp., Conyza sp. y Schizachyrium spicatum. En el caso extremo inicial tenemos a Coelorachis selloana con correlaciones negativas además de con Chevreulia sarmentosa con Soliva ptersoperma, Eryngium nudicaule, Heleocharis sp. y Polygala australis. Bothrichloa laguroides presenta además correlaciones negativas con Aspilia montevidensis y Chaptalia excapa. Paspalum dilatatum presenta correlaciones negativas con Chevreulia sarmentosa, Chaptalia excapa, Sporobolus indicus, Polygala australis, Eragrostis neesii e Hypochoeris sp. Por su parte Stipa setigera tiene correlaciones negativas con Adesmia bicolor, T. repens y Eleocharis sp. Finalmente Cynodon dactylon tiene correlaciones negativas con Piptochaetium montevidense, Dichondra microcalyx, Setaria geniculata y Evolvulus sericeus.

Estas asociaciones específicas serían las que contribuyen a consolidar las asociaciones de las especies principales así como su identificación con mecanismos funcionales de respuesta a los diversos factores ecológicos. Por ejemplo Stipa setigera al tener una relación negativa con $T$. repens se interpreta como opuestas en su comporta- miento respecto al balance hídrico, siendo esta última sensible a los déficit hídricos y en cambio Stipa setigera altamente tolerante de los mismos (Olmos, 1990). Cynodon dactylon presenta una relación negativa $(P<0,16)$ con Piptochaetium montevidense pero esta a su vez tiene correlaciones positivas con Axonopus affinis $(P<0,15)$ y Richardia sp. $(P<0,01)$ lo cual la ubica claramente como una especie de transición. Paspalum plicatulum presenta correlaciones positivas con Schizachyrium microstachyum $(P<0,11)$ y Sporobolus indicus $(P<0,09)$, especies todas que tienen una forma de crecimiento similar como plantas erectas cespitosas.

\section{Descripción de grupos extremos}

En base a las correlaciones de rango de Spearman, se analizaron más en detalle las relaciones entre los grupos extremos del continuo básicamente relacionado a la intensificación en el uso de los recursos, entre las especies y los diferentes sitios. En el Cuadro 2 se muestran los valores de la probabilidad de la correlación entre las especies identificadas en el grupo de alivio y las especies identificadas con el grupo de mayor intensificación. En el mismo se visualiza claramente los valores significativos y negativos de muchas correlaciones, así como valores no significativos y solamente una correlación con valores positivos, lo cual contribuye a la consolidación de ambos grupos.

Cuadro 2. Valor de la probabilidad y signo de la correlación entre especies que representan los extremos de un eje de intensificación en el uso de los recursos en pasturas naturales sobre suelos arcillosos (triángulo abajo izquierdo r; triángulo arriba derecha P).

\begin{tabular}{|l|c|c|c|r|r|r|c|}
\hline \multirow{2}{*}{ Grupo de alivio } & \multicolumn{7}{|c|}{ Grupo de intensificación mayor } \\
\cline { 2 - 9 } & Axonopus & Vulpia & Nudic. & \multicolumn{1}{c|}{ Soliva } & \multicolumn{1}{c|}{ Chev. } & Polygala & Cynodon \\
\hline Coelorachis & $-0,02$ & n. s. & $-0,10$ & $-0,08$ & $-0,0001$ & $-0,02$ & $-0,002$ \\
\hline Micros & n. s. & n. s. & n. s. & $-0,02$ & $-0,01$ & n. s. & n. s. \\
\hline Ternatus & n. s. & $-0,01$ & $+0,17$ & $-0,0002$ & $-0,002$ & n. s. & n. s. \\
\hline Laguroides & n. s. & n. s. & n. s. & n. s. & $-0,07$ & $-0,02$ & $-0,09$ \\
\hline Setigera & $-0,02$ & n. s. & n. s. & n. s. & n. s. & n. s. & $-0,06$ \\
\hline Plicatulum & n. s. & n. s. & n. s. & $-0,04$ & n. s. & $-0,02$ & n. s. \\
\hline Dilatatum & $-0,08$ & n. s. & n. s. & n. s. & $-0,15$ & $-0,16$ & n. s. \\
\hline Platensis & n. s. & $-0,17$ & n. s. & $-0,07$ & $-0,07$ & n. s. & n. s. \\
\hline
\end{tabular}


En las Figuras 11 y 12 se destacan los valores de las probabilidades para las correlaciones entre las especies identificatorias tanto del grupo de alivio como del grupo de mayor intensificación respectivamente. En el caso del grupo de alivio se destaca un grupo de especies que constituyen el centro del grupo como son Coelorachis selloana, Stipa

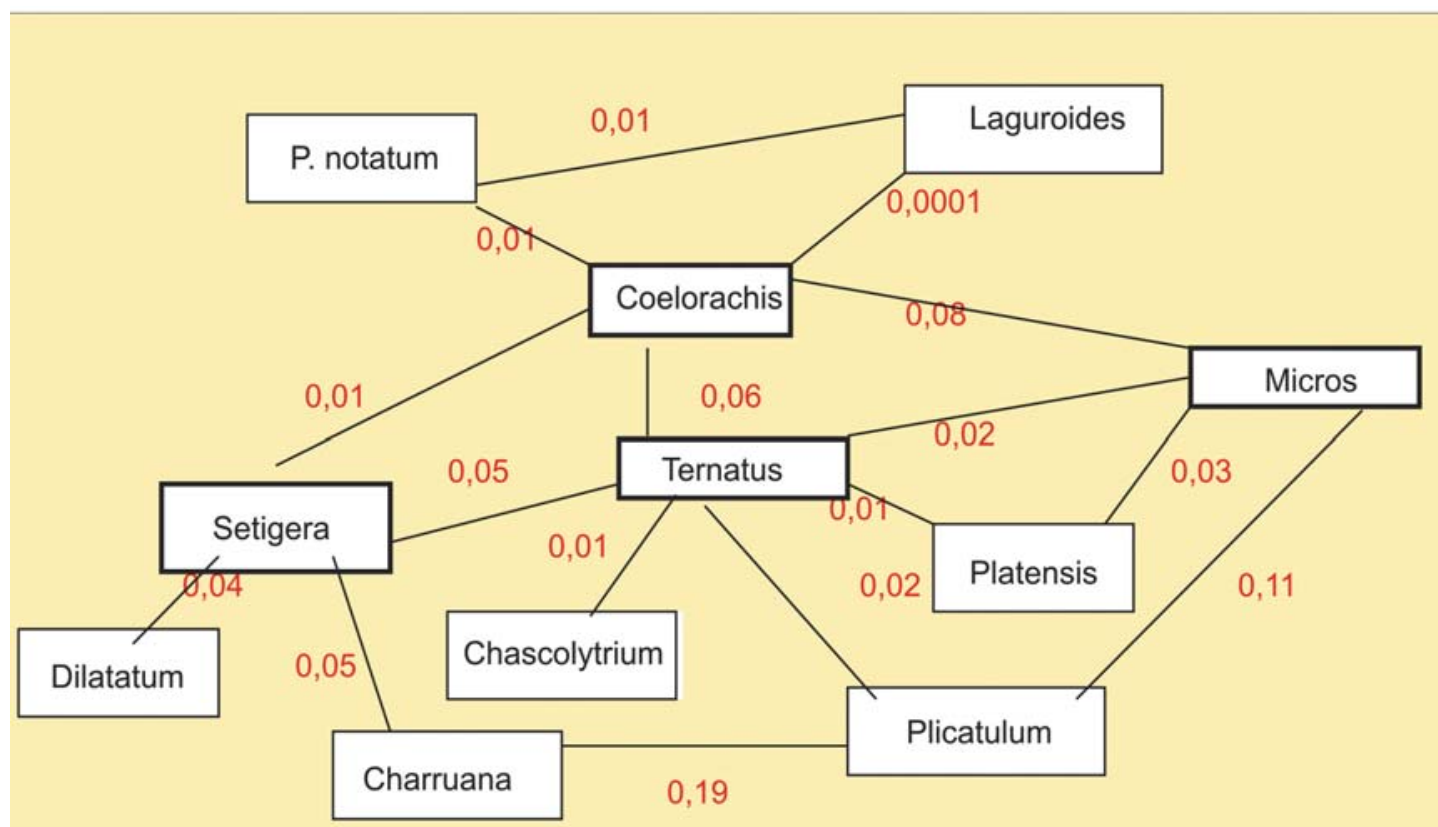

Figura 11. Valor de la probabilidad de las correlaciones entre especies del grupo de alivio de pasturas naturales sobre suelos arcillosos.

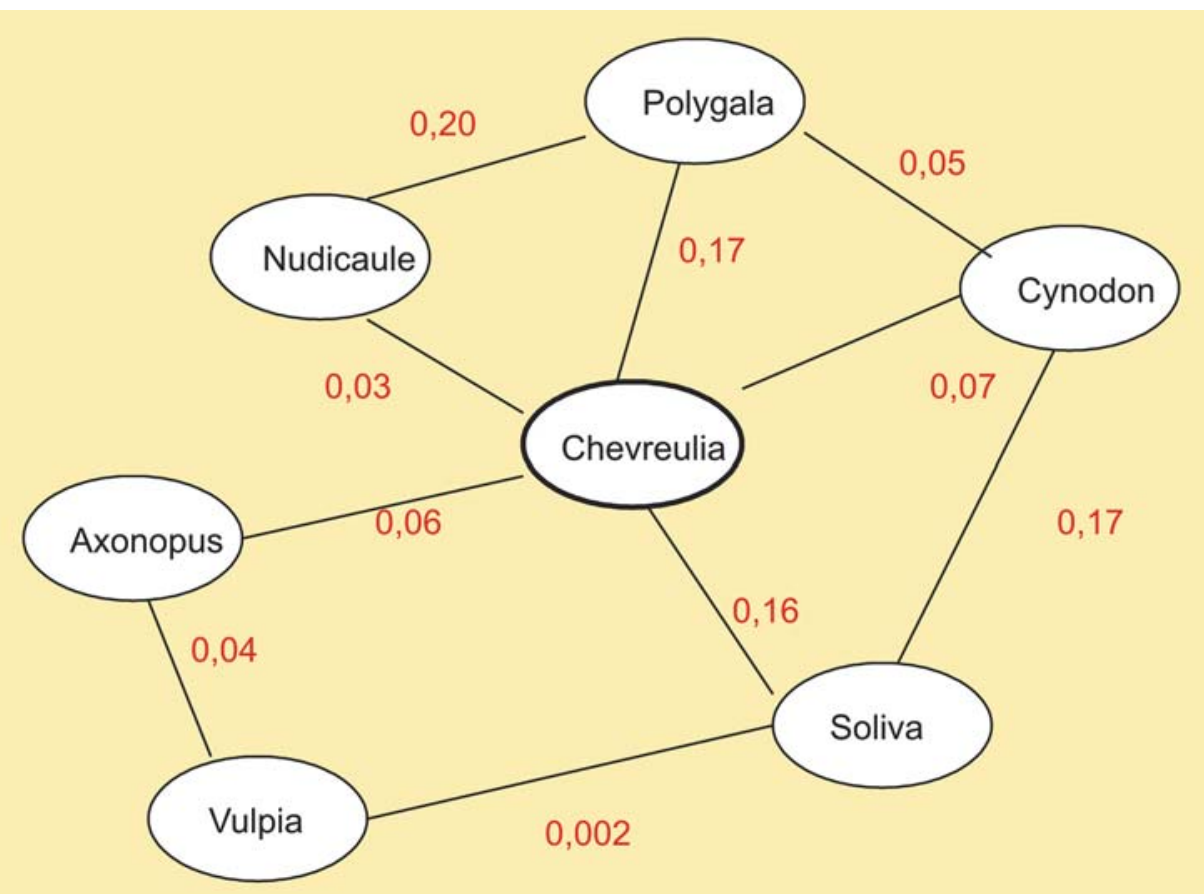

Figura 12. Valores de probabilidad de las correlaciones entre especies del grupo de alta intensificación en el uso de los recursos en pasturas naturales sobre suelos arcillosos. 
setigera, Schizachyrium microstachyum y Andropogon ternatus y luego un grupo consolidado de especies acompañantes como Bothriohloa laguroides, Paspalum notatum, Chascolytrum sp., Sporobolus platensis y algo más distantes Stipa charruana y Paspalum dilatatum.

En el caso del extremo de máxima intensificación aparece Chevreulia sarmentosa como una especie indicadora en el centro del grupo y como especies acompañantes Cynodon dactylon, que es una especie exótica, conjuntamente con Polygala australis, Eryngium nudicaule, Soliva pterosperma, Axonopus affinis y Vulpia australis.

\section{Análisis de Correspondencia Canónica en suelos arcillosos}

Otra forma de analizar la información generada en los relevamientos regionales es a través del Análisis de Correspondencia Canónico dentro de cada tipo de suelo, a los efectos de detectar alguna tendencia diferen- cial del comportamiento de las especies dentro de los mismos. En este sentido en la Figura 13 se observa la posición relativa de las diferentes especies entre los dos primeros ejes destacándose la presencia de Cynodon dactylon en el extremo derecho del primer eje para el suelo arcilloso. Respecto a los vectores que representan el componente ambiental tenemos hacia la izquierda superior los que expresan un grado importante respecto a niveles de fertilidad de los suelos (\% materia orgánica, $\mathrm{Ca}, \mathrm{Mg}, \mathrm{K}, \mathrm{Na}$ ), en la izquierda inferior aspectos relativos a la profundidad de suelo y la disponibilidad de forraje, hacia el lado derecho de la figura se encuentra aspectos relativos al pH del suelo así como al grado de intervención en la comunidad vegetal.

En la Figura 14 se han efectuado algunos cambios a la Figura 13 a los efectos de facilitar una primera interpretación; en la misma se presentan las especies en los primero dos ejes del análisis sin los vectores ambientales y sin la presencia de Cynodon dactylon. Así tenemos por un lado las espe-

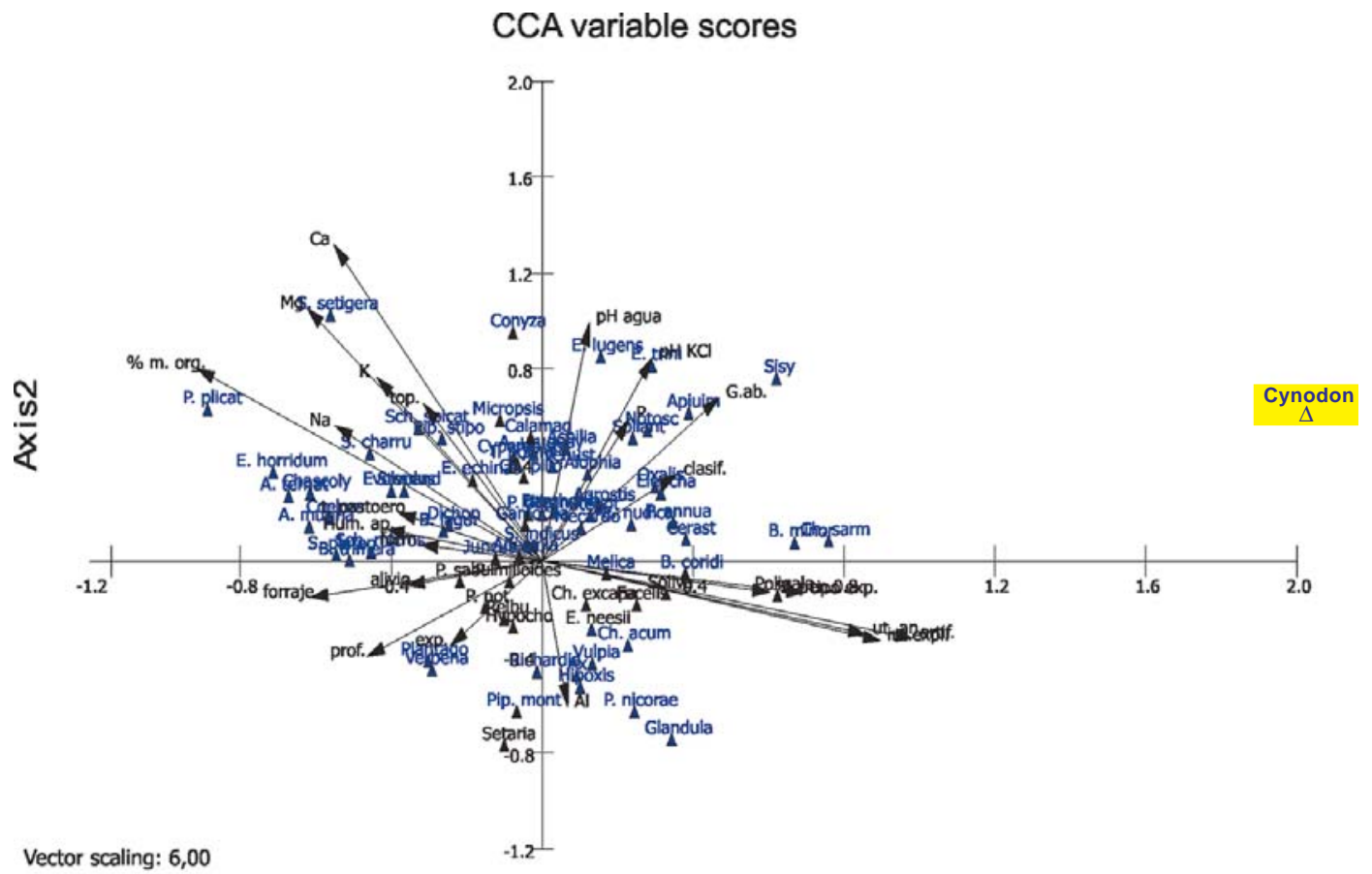

Axis 1

Figura 13. Resultado del análisis de correspondencia canónico para los relevamientos efectuados sobre suelos arcillosos. 


\section{CCA variable scores}

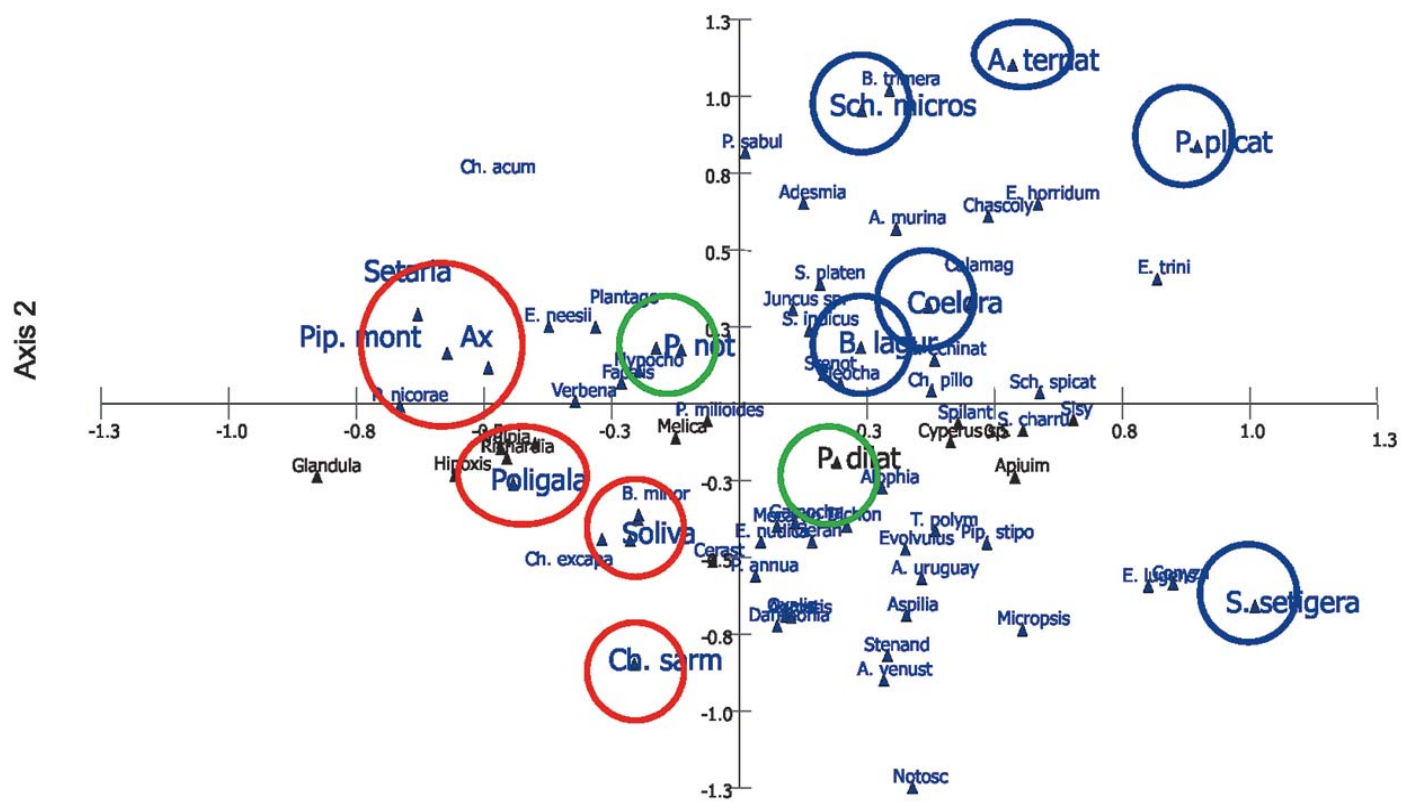

Axis 1

Figura 14. Análisis correspondencia canónico para suelos arcillosos excluyendo a los vectores ambientales.

cies que se asocian al grupo de manejo más aliviado con un círculo azul como Schizachyrium microstachyum, Bothrichloa laguroides, Stipa setigera, Andropogon ternatus, Coelorachis selloana, Paspalum plicatulum y por otro las especies más asociadas a un manejo intensivo de los recursos (círculos rojos) como, Soliva pterosperma, Polygala australis, Setaria geniculata, Piptochaetium montevidense, Axonopus affinis, Chevreulia sarmentosa; en forma intermedia se encuentran Paspalum dilatatum y Paspalum notatum (círculos verdes).

Para profundizar en algunas relaciones especies ambiente más relevantes se excluyeron del análisis algunas especies y variables ambientales con escasa contribución a la conformación de la nube de puntos. En la Figura 15 se observa la consolidación de la tendencia de las especies a formar tres núcleos de respuesta según las variables ambientales; el grupo de especies asociadas al manejo aliviado (círculo azul), las especies que son consideradas asociadas en el grupo de mayor intensificación (círculo rojo) y el grupo de especies de respuesta intermedia (círculo verde).

Nuevamente tenemos las especies como Schizachyrium microstachyum, Paspalum plicatulum, Andropogon ternatus, Bothrichloa laguroides y Coelorachis selloana, asociadas fuertemente con el $\mathrm{pH}$ del suelo, el nivel de nutrientes (\% MO, Ca, Mg, Na) y la topografía (recuadros amarillos) así como con menor intensidad de explotación con la disponibilidad de forraje, la humedad aparente del sitio, el potasio disponible y el fósforo. El grupo de mayor intensificación, constituido básicamente por Soliva pterosperma, Chevreulia acuminata, Vulpia australis, Eryngium nudicaule, Setaria geniculata, se encuentra más asociado a los vectores ambientales que representan la intensidad de la explotación, la carga animal, la artificialización, la concentración de aluminio en el suelo principalmente y en forma accesoria y con menor intensidad con la profundidad del suelo.

En la Figura 16 y a modo de ejemplificación de una profundización un poco más exploratoria, se redujo el número de especies 

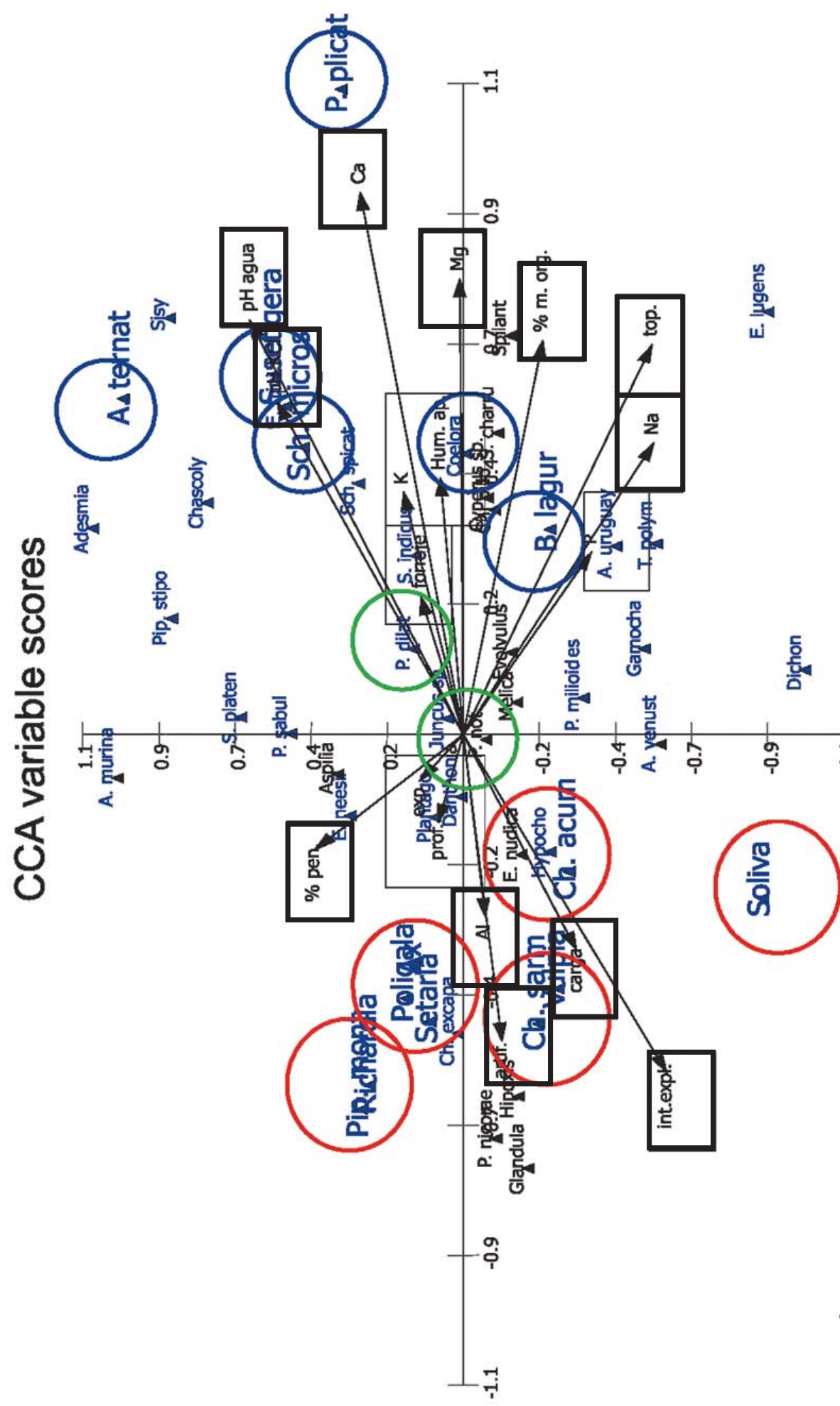


\section{CCA variable scores}

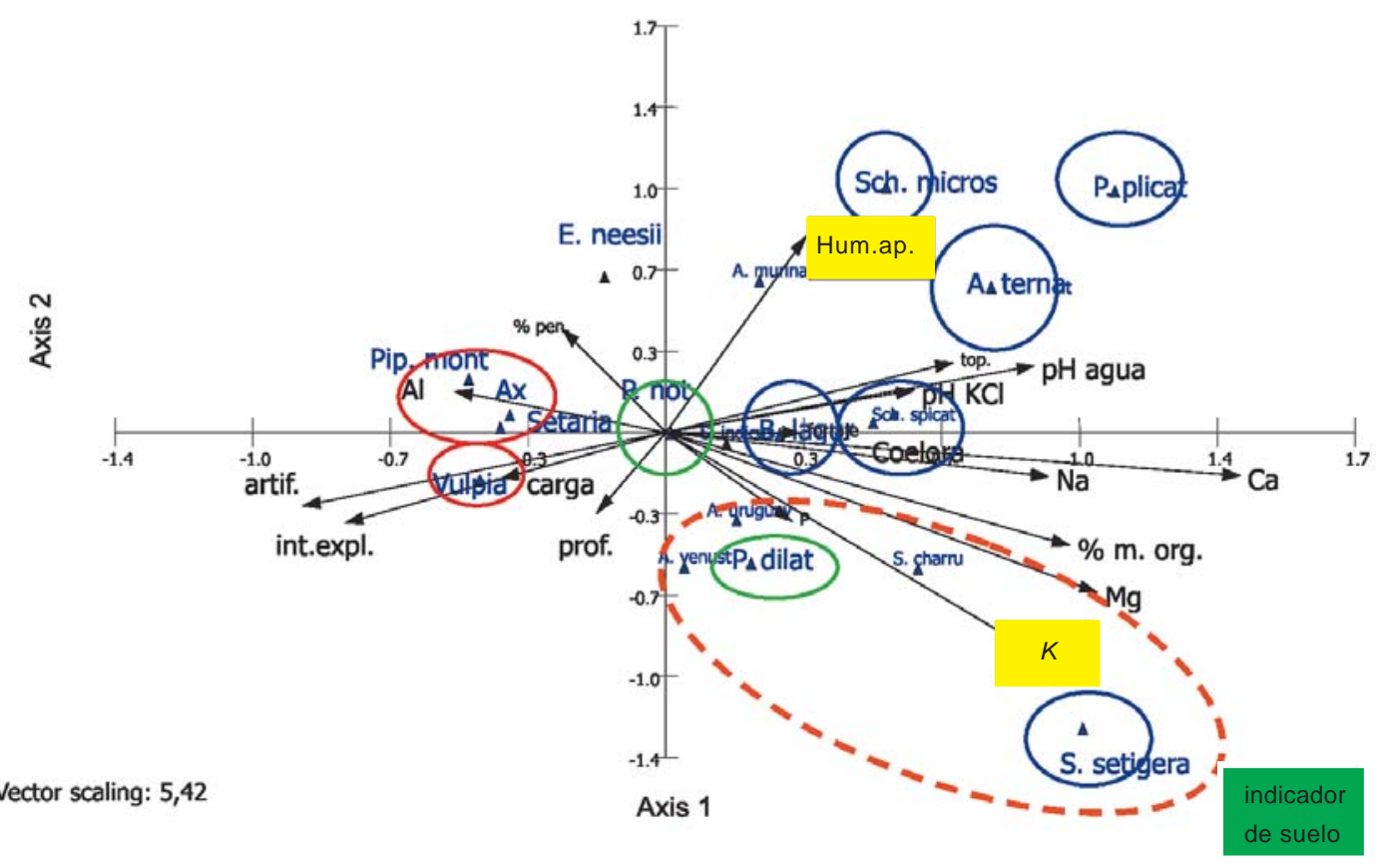

Figura 16. Esquema simplificado de los resultados de los dos primeros ejes del análisis de correspondencia canónico en suelos arcillosos.

y las variables ambientales involucradas en el análisis. El resultado indica igualmente que se mantienen las tendencias pero aparecen otras un poco más claras como es el caso de dos especies de aristidas, A. venustula y $A$. uruguayensis, vinculadas a Paspalum dilatatum, Stipa charruana y Stipa setigera conjuntamente con el vector $\mathrm{K}$, correspondiente a potasio en el suelo; esto podría tomarse como una asociación respecto a un tipo de suelo relativamente más arcilloso donde se destaca la presencia del K, y quizás mostrando un mayor tolerancia al estrés hídrico, por otro lado el vector correspondiente a la humedad aparente de cada sitio se expresa en otro sentido en el cuadrante superior de la figura.

\section{Relaciones entre las especies y las variables ambientales}

A los efectos de profundizar en detalle se seleccionaron especies dentro de cada grupo y se analizaron sus relaciones, mediante regresiones, con las principales variables ambientales que contribuyen a la generación de los grupos. En el Cuadro 3 se muestran las especies, el grupo al que pertenecen, la variable ambiental seleccionada y el valor $P$ para la regresión tanto positivas como negativas.

En este sentido para Coelorachis selloana la misma responde negativamente tanto al incremento de la carga como a la mayor artificialización, en cambio se correlaciona positivamente tanto con la disponibilidad forraje como con el porcentaje de materia orgánica del suelo. Para el grupo de intensificación las tres especies responden positivamente a la mayor artificialización del medio, al contrario que el grupo de alivio, también responden positivamente a la mayor concentración de Al en el suelo (Axonopus affinis y Vulpia australis) y a la intensidad de la explotación y mayor carga (Chevreulia sarmentosa); por otro lado presentan relaciones negativas con respecto al $\mathrm{pH}$ y contenido de nutrientes del suelo (Axonopus affinis y Vulpia australis). En el caso del grupo intermedio la mayor disponibilidad de fo- 
Cuadro 3. Relaciones $(P)$ entre las especies representativas de cada grupo de respuesta y la variables ambientales y de manejo.

\begin{tabular}{|c|c|c|c|}
\hline Grupo & Especie & Variable & Probabilidad (P) \\
\hline Alivio & Coelorachis selloana & $\begin{array}{l}\text { forraje } \\
\% \text { MO } \\
\text { artificialización } \\
\text { carga }\end{array}$ & $\begin{array}{r}0,0013 \\
0,0488 \\
-0,0002 \\
-0,1218\end{array}$ \\
\hline \multirow[t]{3}{*}{ Intensificación } & Axonopus affinis & $\begin{array}{l}{[\mathrm{Al}]} \\
\text { artificialización } \\
\mathrm{pH} \text { agua } \\
\mathrm{pH} \mathrm{KCl} \\
\mathrm{Ca} \\
\mathrm{Mg}\end{array}$ & $\begin{array}{r}0,0209 \\
0,1530 \\
-0,0232 \\
-0,0583 \\
-0,0013 \\
-0,0050\end{array}$ \\
\hline & Vulpia australis & $\begin{array}{l}{[\mathrm{Al}]} \\
\text { artificialización } \\
\mathrm{pH} \text { agua } \\
\mathrm{pH} \mathrm{KCl} \\
\mathrm{Ca}\end{array}$ & $\begin{array}{r}0,0306 \\
0,0546 \\
-0,0047 \\
-0,0046 \\
-0,0022 \\
\end{array}$ \\
\hline & Chevreulia sarmentosa & $\begin{array}{l}\text { artificialización } \\
\text { int. explotación } \\
\text { carga } \\
\text { humedad aparente }\end{array}$ & $\begin{array}{r}0,0655 \\
0,0001 \\
0,0115 \\
-0,0140\end{array}$ \\
\hline \multirow[t]{2}{*}{ Intermedio } & Paspalum notatum & $\begin{array}{l}\text { forraje } \\
{[\mathrm{Al}]} \\
\mathrm{pH} \text { agua } \\
\mathrm{pH} \mathrm{KCl}\end{array}$ & $\begin{array}{r}0,0167 \\
0,0194 \\
-0,0306 \\
-0,0630\end{array}$ \\
\hline & Paspalum dilatatum & $\begin{array}{l}\text { forraje } \\
\text { carga } \\
\mathrm{K}\end{array}$ & $\begin{array}{r}0,0110 \\
-0,0866 \\
0,0062\end{array}$ \\
\hline
\end{tabular}

rraje se correlaciona positivamente tanto con Paspalum notatum como con Paspalum dilatatum; sorpresivamente Paspalum notatum muestra una correlación alta con el incremento en Al en el suelo y negativo con el pH del mismo, quizás esta respuesta permita explicar su posición intermedia en el continuo eje de intensificación teniendo una correlación positiva con Coelorachis selloana por una mayor respuesta al alivio (más forraje disponible) y también una correlación positiva con Axonopus affinis por desarrollarse también en condiciones de relativa acidez en el suelo. En el caso de Paspalum dilatatum al igual que con Paspalum notatum el mismo responde al forraje disponible (alivio) y presenta una tendencia a una relación negativa con la carga animal, explicando su relación negativa con Axonopus affinis.

La Figura 17 presenta la respuesta conjunta de dos especies nativas, Coelorachis selloana y Axonopus affinis, al incremento en la artificialización al intensificarse el uso de los recursos, respaldando la posición relativa de las mismas en el eje continuo de intensificación descrito previamente. 


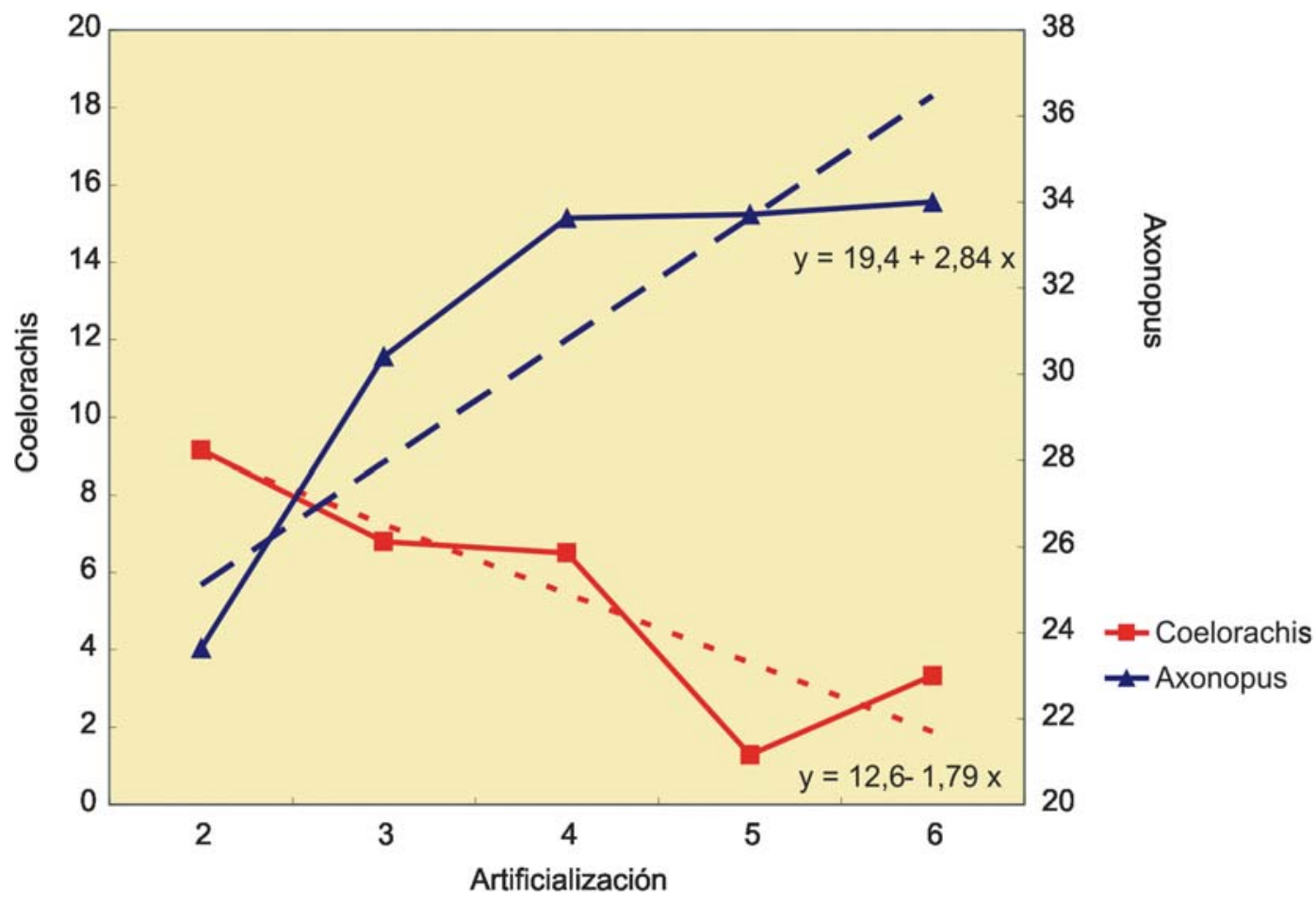

Figura 17. Relación entre el indicador de artificialización y la presencia de Coelorachis selloana y Axonopus affinis en cuarenta sitios sobre suelos arcillosos en la región noreste.

Estas regresiones analizadas si bien permiten profundizar en la relación de las especies con su hábitat, no dejan de ser exploratorias a los efectos de comenzar a interpretar y definir más claramente los perfiles ecológicos de cada una de ellas en relación a la productividad de las pasturas. Debe tenerse presente que la respuesta de una especie a una variable determinada es un conjunto de respuestas que involucran su ciclo de crecimiento, su propia biología funcional, sus diferentes etapas fenológicas, su forma reproductiva, su forma de crecimiento entre otras, vinculadas asimismo a la variabilidad climática estacional y anual, así como a los diferentes impactos producidos por el manejo del pastoreo.

\section{Grupos de especies herbáceas no gramíneas}

Respecto a las especies acompañantes herbáceas no gramíneas se propone establecer tres grupos de respuesta, un relacionado a un manejo aliviado asociado a
Coelorachis selloana (Cuadro 4), otro al otro extremo de un hipotético eje de intensificación en el uso del recurso forrajero que serían las especies asociadas a Cynodon dactylon y un intermedio con especies asociadas a Axonopus affinis. En la clasificación se incluyen algunas gramíneas que permiten comparar la respuesta al manejo de la pastura natural.

Con respecto a un manejo aliviado, con la mayor presencia de Coelorachis selloana, tenemos a, Eleocharis sp., Spilantes decumbens, Chaptalia piloselloidea, Hypochoeris sp., Oxalis sp., Andropogon ternatus, Stipa setigera, Melica brasiliana y Panicum sabulorum asociados positivamente; por su parte asociados negativamente Soliva pterosperma, Polygala australis, Chaptalia excapa, Setaria geniculata, Axonopus affinis.

Precisamente algunas de estas especies como Soliva pterosperma, Polygala australis y Chaptalia excapa se encuentran asociadas positivamente con Cynodon dactylon en el grupo de mayor intensificación además de 
Cuadro 4. Grupos de especies asociadas en respuesta a la intensificación en el uso de los recursos naturales $(+,-$, correlaciones positivas y negativas respectivamente en relación a la especie principal de cada grupo).

\begin{tabular}{|c|c|c|}
\hline Grupo 1 & Grupo 2 & Grupo 3 \\
\hline Coelorachis selloana & Axonopus affinis & Cynodon dactylon \\
\hline $\begin{array}{l}\text { Spilantes decumbens } \\
\text { Eleocharis sp. } \\
\text { Chaptalia piloselloidea } \\
\text { Hypochoeris sp. } \\
\text { Oxalis sp. } \\
\text { Andropogon ternatus } \\
\text { Stipa setigera } \\
\text { Panicum sabulorum } \\
\text { Melica brasiliana }\end{array}$ & $\begin{array}{l}\text { Richardia sp. (+) } \\
\text { Aspilia montevidensis } \\
\text { Chevreulia sarmentosa } \\
\text { Glandularia sp. } \\
\text { Piptochaetium } \\
\text { montevidense } \\
\text { Setaria geniculata } \\
\text { Danthonia sp. } \\
\text { Panicum milioides }\end{array}$ & $\begin{array}{l}\text { Polygala australis } \\
\text { Glandularia sp. } \\
\text { Chaptalia excapa } \\
\text { Plantago myosurus } \\
\text { Chevreulia sarmentosa } \\
\text { Soliva pterosperma } \\
\text { Eryngium nudicaule } \\
\text { Richardia sp. } \\
\text { Piptochaetium } \\
\text { montevidense } \\
\text { Eragrostis neesii } \\
\text { Vulpia australis }\end{array}$ \\
\hline $\begin{array}{l}\text { no Soliva pterosperma } \\
\text { no Polygala australis } \\
\text { no Chaptalia excapa } \\
\text { no Setaria geniculata } \\
\text { no Axonopus affinis }\end{array}$ & $(-)$ & $(-)$ \\
\hline
\end{tabular}

Glandularia sp., Chevreulia sarmentosa, Richardia sp., Plantago myosurus y Eryngium nudicaule; complementan este grupo otras especies que también se encontraron en el grupo intermedio como Piptochaetium montevidense, Danthonia sp., Eragrostis neesii y Vulpia australis.

En el grupo intermedio asociado a Axonopus affinis encontramos Aspilia montevidensis, Richardia sp., Glandularia sp., Chevreulia sarmentosa, Piptochaetium montevidense, Setaria geniculata, Danthonia sp., Panicum milioides.

En forma contrapuesta se ve claramente como Soliva pterosperma, Chaptalia excapa y Polygala australis se encuentran correlacionadas negativamente con Coelorachis selloana al mismo tiempo que se correlacionan positivamente con Cynodon dactylon. Soliva pterosperma por su parte también se encuentra correlacionada negativamente con Piptochaetium montevidense $(P<0,06)$, Paspalum plicatulum $(P<0,04)$
Andropogon ternatus $(\mathrm{P}<0,002)$, Schizachyrium microstachyum $(P<0,02)$, Schizachyrium spicatum $(P<0,09)$ y Aspilia montevidensis $(P$ $<0,14)$ colocándola en el propio extremo de intensificación de uso de los recursos.

\section{Grupo de compactación}

Este es un grupo con respuesta específica que se ha identificado. En este sentido de acuerdo a los antecedentes y a observaciones de campo (Rosengurtt, 1943), se especula que Juncus capillaceus es una especie que incrementa su presencia no solo con la intensificación en el uso de los recursos sin que también lo hace con el aumento en la compactación por sobre pisoteo y con el incremento en la carga animal. Así identificamos cuatro especies que presentan una correlación positiva con la misma: Soliva ptersoperma $(P<0,04)$, Sisyrinchium sp. $(P<0,04)$, Hipoxis decumbens $(P<0,08)$ y Sporobolus indicus $(P<0,08)$ conformando 
el grupo. Será necesario llevar adelante más relevamientos, registros y experimentos para confirmar la hipótesis de respuesta.

Los diferentes tipos de especies contribuyen a la comprensión e interpretación de los perfiles eco-fisiológicos de cada grupo. En este caso podríamos interpretar que $C$. selloana constituye un extremo de manejo aliviado de pastoreo, es una especie de crecimiento erecto con sistema de reservas (rizomas) asociada a especies como $S$. microstachyum, S. indicus especies también de crecimiento erecto y que son consumidas por el ganado en estados juveniles, siendo por tanto su presencia mayor con pastoreo aliviado, podría también ser el caso de $S$. charruana que nos es mayormente preferida en condiciones de baja presión de pastoreo, en cambio Axonopus affinis es una especie de crecimiento rastrero con raíces superficiales adaptada al sobrepastoreo.

Esta información se debe considerar para interpretar los posibles hábitats ecológicos característicos de cada especie, lo que luego permitirá, eventualmente, utilizar alguna de las especies como indicadora. La importancia a destacar es la extrema «sintonía fina» que con esta información es posible detectar. Se debería conocer más sobre las dinámicas poblacionales de estas especies así como en su propia ecofiosiología. La adaptación puede ser tanto por su ubicuidad espacio-temporal así como su propia interacción con los elementos físicos y biológicos del micro ambiente. Que significa que unas especies estén más correlacionadas entre sí que con otras: igual ciclo, tipo vegetativo, longevidad de plantas, tolerancia a estrés hídrico, forma de colonización vegetativa o reproductiva, amplitud ecológica, entre otros aspectos?

\section{Relaciones entre especies en suelos arenosos}

En el caso de los suelos arenosos se describió un número similar de grupos de especies a de los suelos arcillosos, sin embargo, los mismos están conformados por un número de especies más diverso y heterogéneo desde el punto de vista de las especies acompañantes.
Los ocho grupos describen una secuencia desde el extremo izquierdo de la Figura 18 donde tenemos una especie de núcleo en torno a Bothrichloa laguroides conjuntamente con Paspalum notatum y Coelorachis selloana y por otro lado al mismo extremo máximo, ya visto en los suelos arcillosos, como es Cynodon dactylon; registrándose como grupos intermedios a Axonopus affinis, Panicum milioides y Piptochaetium montevidense. Trifolium polymorphum se muestra con una correlación negativa con Cynodon.

En el grupo asociado a Bothriochloa laguroides se encuentran especies como Andropogon ternatus, Schizachyrium microstachyum, Aristida venustula que pueden describirse como especies de crecimiento erecto, cespitosas, asociados a manejo aliviado del pastoreo. Asimismo el grupo se encuentra negativamente correlacionado con especies como Polygala australis, Soliva pterosperma, Cynodon dactylon, Sisyrinchium sp., especies claramente asociadas un manejo intensivo de los recursos naturales, incluyendo el sobrepastoreo. A su vez Cynodon dactylon además de las correlaciones negativas con el grupo de alivio, presenta correlaciones positivas con especies como Soliva pterosperma y Sisyrinchium sp.

Los perfiles de cada grupo muestran una cierta graduación en sus componentes, sea en un sentido de mayor o menor intensidad de uso en los recursos forrajeros. Un ejemplo es el caso de Setaria geniculata que presenta una correlación negativa con Axonopus affinis pero positiva con Panicum milioides y Piptochaetium montevidense. Panicum milioides y Piptochaetium montevidense se presentan como dos especies de transición asociadas a un grupo intermedio en intensificación mostrando correlaciones positivas con A. ternatus, Hipoxis decumbens, Setaria geniculata, Glandularia sp., S. microstachyum entre otras.

Hacia el extremo de intensificación, pero considerando solo las especies nativas, tenemos a Axonopus affinis, que si bien presenta correlaciones positivas con Coelorachis selloana y Panicum milioides, también las tiene con Vulpia australis, Eryngium nudicaule y Polygala australis componentes 


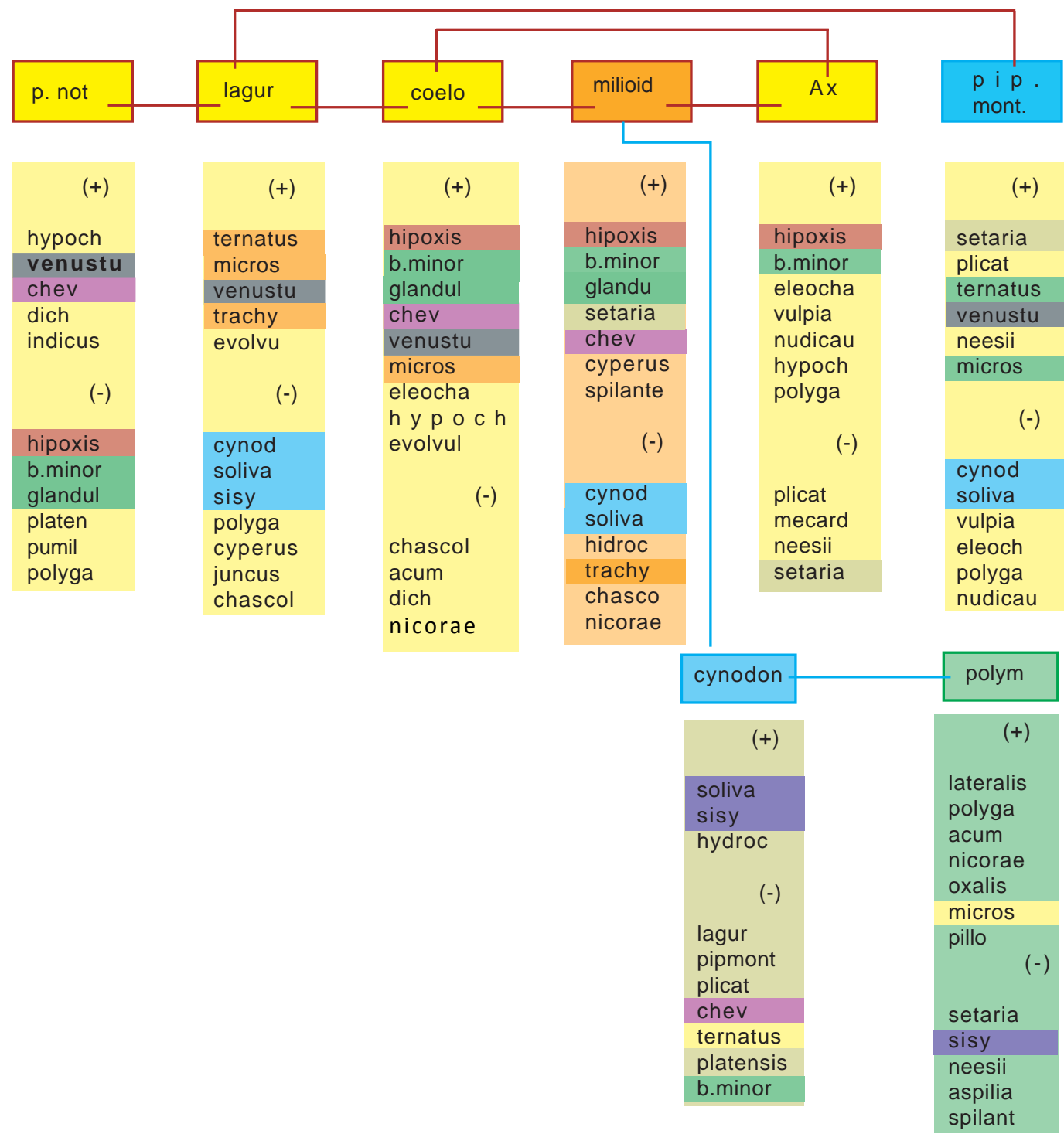

Figura 18. Asociación entre especies componentes de la pasturas en suelos arenosos. Las líneas en rojo indican correlaciones positivas y las líneas en azul correlaciones negativas para las especies principales de cada grupo (+ correlaciones positivas, - correlaciones negativas dentro de cada grupo).

estas del extremo de intensificación y se separa a su vez del grupo intermedio al tener a Setaria geniculata con una correlación negativa.

Trifolium polymorphum, similarmente a Cynodon, se presenta como una especie de perfil diferencial tal como presentó en los suelos arcillosos. Indudablemente esta especie tiene características muy especiales, es nativa, es perenne pero se comporta como una anual y además presenta tres mecanis- mos de sobrevivencia como la forma vegetativa a través de su raíz, las semillas subterráneas y las semillas aéreas; por otra parte presenta un ciclo de crecimiento muy definido otoño-inicio de primavera.

En el Cuadro 5 se jerarquizan los valores y signos de las correlaciones de los grupos de especies considerados en los extremos del eje de intensificación en el uso de los recursos. Se destacan claramente las correlaciones significativas y con signo negati- 
Cuadro 5. Correlaciones entre especies de dos grupos de respuesta a la intensificación en el uso de los recursos sobre suelos arenosos (rectángulo inferior izquierdo r; rectángulo superior derecho $\mathrm{P}$ ).

\begin{tabular}{|l|c|c|c|c|c|}
\hline \multirow{2}{*}{ Grupo de alivio } & \multicolumn{4}{|c|}{ Grupo de intensificación mayor } \\
\cline { 2 - 6 } & P. not & Polygala & Vulpia & Soliva & Cynodon \\
\hline Trachypogon & n. s. & n. s. & $-0,03$ & $-0,05$ & n. s. \\
\hline Micros & n. s. & n. s. & $-0,03$ & $-0,04$ & $-0,19$ \\
\hline Lagur & $+0,11$ & $-0,18$ & n. s. & $-0,03$ & $-0,04$ \\
\hline Ternatus & n. s. & n. s. & n. s. & $-0,002$ & $-0,03$ \\
\hline Platensis & $-0,004$ & n. s. & n. s. & n. s. & $-0,12$ \\
\hline Pillo & n. s. & n. s. & n. s. & n. s. & n. s. \\
\hline Plicatulum & n. s. & n. s. & n. s. & n. s. & $-0,06$ \\
\hline
\end{tabular}

vo entre los extremos mostrando también dentro del grupo extremo de mayor intensificación una cierta gradualidad según la especie involucrada. B. laguroides y $S$. microstachyum presentan ambas tres correlaciones negativas y Soliva pterosperma y Cynodon dactylon cuatro y cinco respectivamente. P. notatum podría estimarse como una especie intermedia en estos ambientes.

En forma esquemática se ejemplifican las relaciones entre las especies de cada grupo en las Figuras 19 y 20.

\section{Consideraciones sobre las correlaciones de algunas especies individuales}

Andropogon ternatus es una especie que se encuentra fuertemente ligada al grupo de alivio respecto al uso de los recursos, así se correlaciona fuerte y positivamente con Bothrichloa laguroides, Trachypogon montufari, Schizachyrium microstachyum, Aristida venustula, Sporobolus platensis, Paspalum plicatulum y fuerte y negativamen-

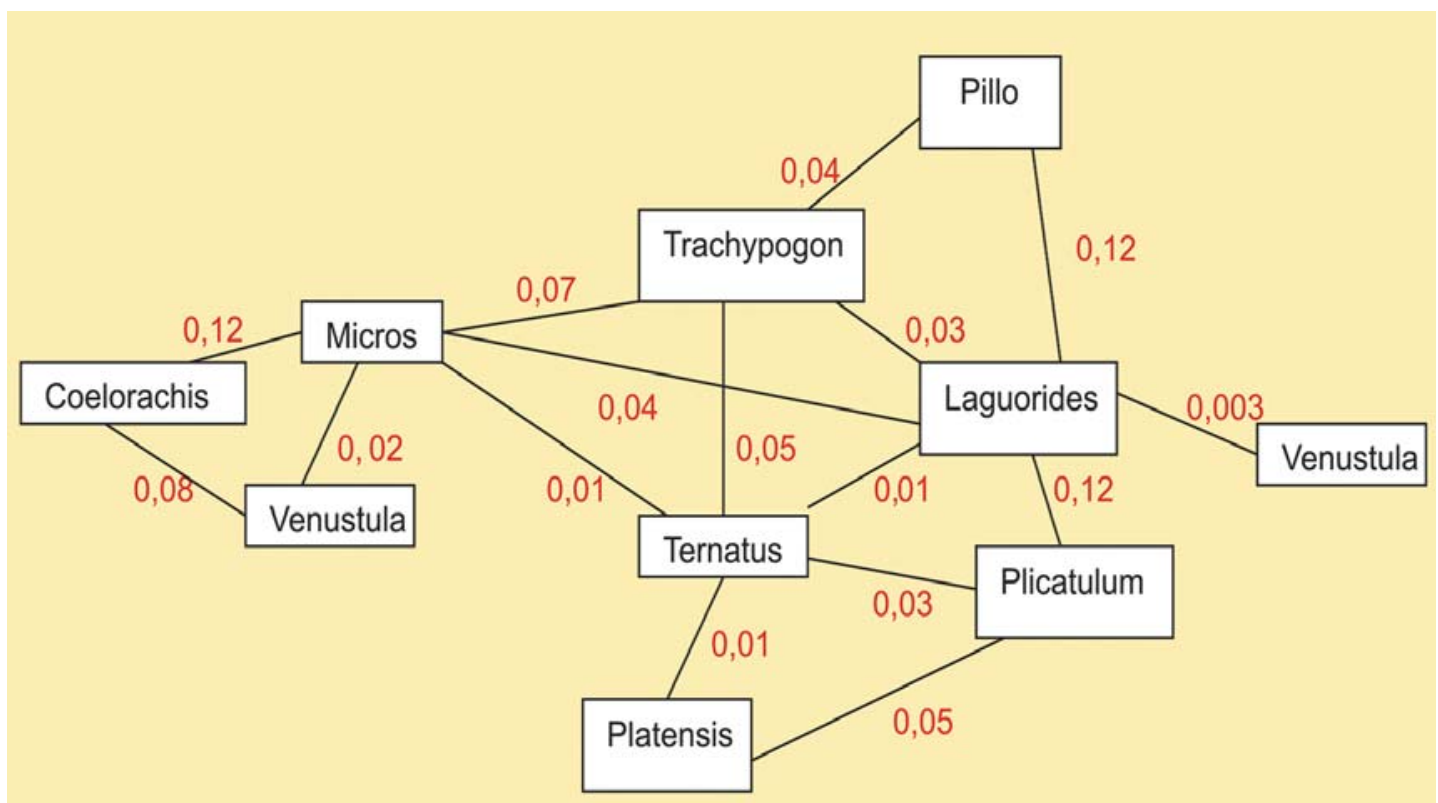

Figura 19. Valores de probabilidad de las correlaciones positivas entre las especies del grupo de alivio sobre suelos arenosos. 


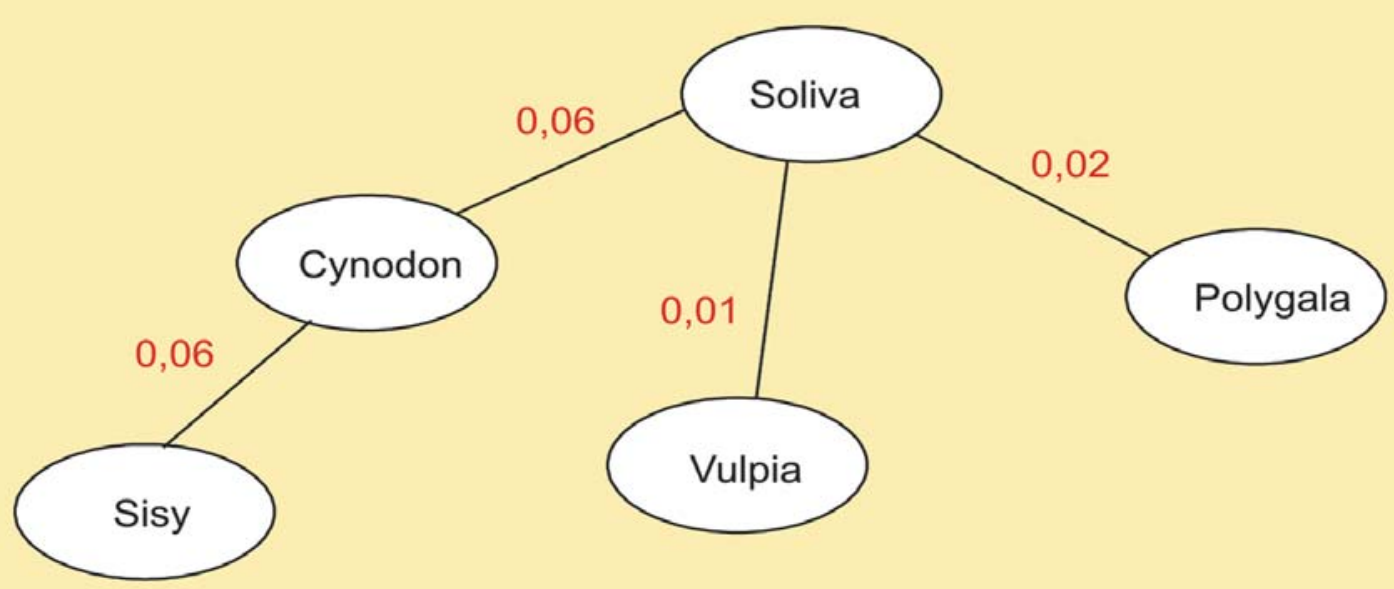

Figura 20. Valores de probabilidad de las correlaciones positivas entre las especies del grupo de mayor intensificación sobre suelos arenosos.

te con Cynodon dactylon, Juncus capillaceus y Soliva pterosperma. Al mismo tiempo presenta un número importante de correlaciones positivas con especies del grupo de transición como Piptochaetium montevidense, Eragrostis neesii y Setaria geniculata indicando que no solo es específica del grupo de alivio (Cuadro 6).

Paspalum notatum es una especie que hasta el momento, en general, la consideramos con una respuesta muy similar a
Axonopus affinis respecto a la intensificación; la evidencia detectada a través de estos nuevos análisis la ubica entre el grupo de especies asociadas al alivio y un cierto solapamiento hacia el área donde domina Axonopus affinis. Es decir su presencia puede ser destacada tanto cuando es sometida a una presión de pastoreo relativamente alta como cuando lo es a condiciones de más alivio en la intensidad de pastoreo; esto se puede visualizar por su $\mathrm{P}$ alta y positivo con

Cuadro 6. Perfil de correlaciones (+/-) para Andropogon ternatus en suelos arenosos ( $P-$ probabilidad).

\begin{tabular}{|l|c|l|r|}
\hline \multicolumn{2}{|c|}{ Andropogon ternatus } & \multicolumn{2}{c|}{$(\mathbf{( - )}$} \\
\hline Especie & P & Especie & P \\
\hline Laguroides & 0,01 & Cynodon & 0,03 \\
Pip. mont. & 0,05 & Nicorae & 0,04 \\
Setaria & 0,17 & Juncus & 0,02 \\
Plicatulum & 0,03 & Soliva & 0,002 \\
Sabulorum & 0,11 & Hydrocotyle & 0,16 \\
Platensis & 0,01 & Hypochoeris & 0,09 \\
Micros & 0,01 & & \\
Venustula & 0,05 & & \\
Neesii & 0,04 & & \\
Pillo & 0,07 & & \\
Glandularia & 0,20 & & \\
Trachypogon & 0,05 & & \\
Aspilia & 0,03 & & \\
Spilantes & 0,009 & & \\
\hline
\end{tabular}


Coelorachis selloana, relativamente alto con Bothrichloa laguroides, Hypochoeris sp. pero a su vez alto con Dichondra microcalyx y Sporobolus indicus, este último presenta una alta correlación con Juncus capillaceus en el grupo de alta compactación definido anteriormente en los suelos arcillosos y corroborado también en estos suelos (Cuadro 15); al mismo tiempo las correlaciones negativas «centran» a la especie en el continuo de intensificación como los valores observados con Briza minor y Polygala australis (Cuadro 7).

Con Paspalum plicatulum ocurre algo similar a lo identificado previamente en Paspalum notatum, desde el punto de vista de su estrategia funcional y forma de crecimiento esperaríamos una ubicación hacia el extremo de alivio del eje de intensificación en el uso del recurso, sin embargo en base a las correlaciones establecidas la debemos localizar ligeramente hacia la derecha en el diagrama (Figura 21) mostrando un cierto grado de solapamiento con el grupo de especies intermedias como Piptochaetium montevidense, Eragrostis neesii; Ilama la atención a su vez, la correlación negativa con Coelorachis selloana, lo cual como lo mencionamos anteriormente, es evidente que otros factores ecológicos o la respuesta ecofisiológica de las especies que no conocemos están afectando las relaciones (Cuadro 8).

Setaria geniculata la podemos considerar como una especie del grupo intermedio o de transición entre los extremos alivio-máxima intensificación en el uso de los recursos (Cuadro 9); esta asociada positivamente con

Cuadro 7. Perfil de correlaciones (+/-) para Paspalum notatum en suelos arenosos ( $P$ - probabilidad).

\begin{tabular}{|l|r|l|r|}
\hline \multicolumn{2}{|c|}{ Paspalum notatum } & \\
\hline Especie & P & Especie & P \\
\hline Dichondra & 0,02 & Platensis & 0,004 \\
Indicus & 0,002 & Micros & 0,01 \\
Hypochoeris & 0,09 & Pumilum & 0,09 \\
Venustula & 0,10 & Hipoxis & 0,14 \\
Lagur & 0,11 & Glandularia & 0,16 \\
Chevreulia & 0,19 & Polygala & 0,20 \\
\hline
\end{tabular}

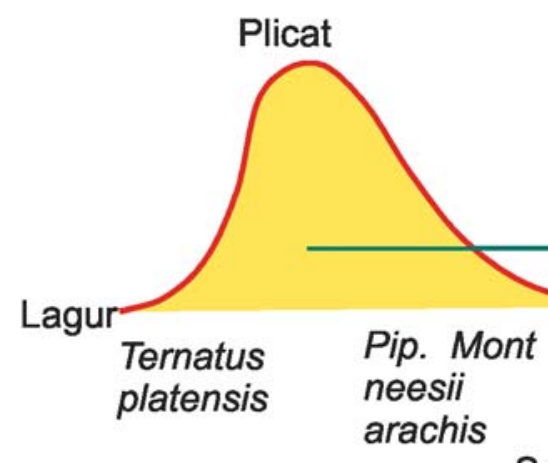

- Coelorachis

Figura 21. Diagrama representativo del perfil ecológico de Paspalum plicatulum respecto a sus relaciones con otras especies en un eje de intensificación en el uso de los recursos en suelos arenosos. 
algunas especies del grupo de alivio como Andropogon ternatus y con una $\mathrm{P}$ no muy alta con Paspalum plicatulum, a la vez se asocia negativamente con especies del grupo de máxima intensificación como Soliva pterosperma y Polygala australis, sin embargo su asociación más fuerte los es con otras especies del grupo intermedio como Piptochaetium montevidense, Eragrostis neesii y Panicum milioides en menor grado.

Panicum milioides perfectamente se agrupa con el grupo intermedio, en este sentido presenta correlaciones negativas con especies extremas de alivio como Trachypogon montufari y Chascolytrium sp., positivas con el grupo de alivio como Coelorachis selloana, Briza minor, Hipoxis decumbens así como otras especies de transición como Axonopus affinis, Setaria geniculata y a su vez negativa con el extremo de intensificación como Soliva pterosperma, Cynodon dactylon, Hydrocotyle sp. (Cuadro 10, Figura 22).

Piptochaetium montevidense por su parte mantiene un perfil ubicado en la zona media de intensificación (Cuadro 11) pero con un cierto sesgo hacia la zona de mayor alivio, en comparación con $P$. milioides ( Figura 22) y su ubicación en los suelos arcillosos (ver Figura 10); hay un grupo de correlaciones positivas mayoritariamente con el grupo de alivio y al mismo tiempo presenta correlaciones negativas con especies del grupo de mayor intensificación como Cynodon dactylon,

Cuadro 8. Perfil de correlaciones (+/-) para Paspalum plicatulum en suelos arenosos ( $P-$ probabilidad).

\begin{tabular}{|l|c|l|c|}
\hline \multicolumn{2}{|c|}{ Paspalum plicatulum } & \\
\hline Especie & P & Especie & P \\
\hline Laguroides & 0,12 & Axonopus & 0,04 \\
Pip. mont. & 0,02 & Cynodon & 0,06 \\
Setaria & 0,12 & Coelorachis & 0,12 \\
Ternatus & 0,03 & Juncus & 0,19 \\
Platensis & 0,05 & Ipoxis & 0,19 \\
Neesii & 0,01 & Gamochaeta & 0,19 \\
Arachis & 0,01 & A. uruguay & 0,08 \\
\hline
\end{tabular}

Cuadro 9. Perfil de correlaciones (+/-) para Setaria geniculata en suelos arenosos ( $\mathrm{P}-$ probabilidad).

\begin{tabular}{|l|r|l|r|}
\hline \multicolumn{2}{|c|}{ Setaria geniculata } & \\
\hline Especie & P & Especie & \multicolumn{1}{c|}{ P } \\
\hline Pip. mont. & 0,03 & Axonopus & 0,10 \\
Neesii & 0,002 & Polym & 0,003 \\
Spilantes & 0,07 & Oxalis & 0,004 \\
Milioides & 0,12 & Polygala & 0,05 \\
Plicat & 0,12 & Dichondra & 0,16 \\
Ternatus & 0,17 & Soliva & 0,20 \\
Arachis & 0,17 & Heleocharis & 0,18 \\
& & Alophia & 0,20 \\
& & A. uruguay & 0,17 \\
\hline
\end{tabular}


Cuadro 10. Perfil de correlaciones (+/-) para Panicum milioides en suelos arenosos $(P-$ probabilidad).

\begin{tabular}{|l|c|l|c|}
\hline \multicolumn{2}{|c|}{ Panicum milioides } & \\
\hline Especie & P & Especie & P \\
\hline Coelorachis & 0,02 & Hydrocotyle & 0,05 \\
Hipoxis & 0,05 & Trachypogon & 0,05 \\
Cyperus & 0,08 & Nicorae & 0,09 \\
B. minor & 0,08 & Cynodon & 0,10 \\
Axonopus & 0,12 & Chascolytrium & 0,11 \\
Setaria & 0,12 & Soliva & 0,12 \\
Glandularia & 0,13 & & \\
Spilantes & 0,14 & & \\
Chevreulia & 0,16 & & \\
\hline
\end{tabular}

$(-)$

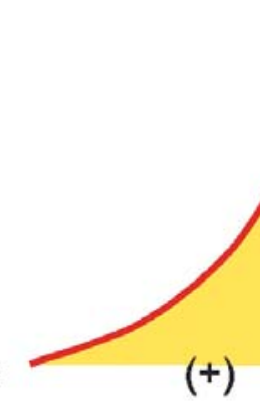

Trachypogon
chascolytrium
$(+)$

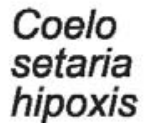

Chev

Minor

Glandulania

Spilantes

Figura 22. Diagrama representativo del perfil ecológico de Panicum milioides respecto a sus relaciones con otras especies en un eje de intensificación en el uso de los recursos en suelos arenosos.

Vulpia australis, Soliva pterosperma y del grupo intermedio como Axonopus affinis. Sin embargo presenta algunas correlaciones algo positivas con Eragrostis neesii y Richardia sp. especies estas vinculadas más a sitios utilizados más intensamente.

Hipoxis decumbens, pertenece al grupo de transición, presenta correlaciones positivas en casi todo el rango Coelorachis selloana Polygala australis, sin embargo encontramos valores de $P$ importantes asociados a
Axonopus affinis y Panicum milioides, con valores relativamente altos tanto con Briza minor por un lado como con Vulpia australis y Polygala australis por otro (Cuadro 12). Un valor a destacar son los valores negativos tanto con Paspalum notatum como con Paspalum plicatulum indicando a nuestro juicio, la presencia de un marcado segundo eje de respuesta que deberíamos interpretar: Axonopus affinis - Hipoxis decumbens - Panicum milioides Paspalum notatum - Paspalum plicatulum; al 
Cuadro 11. Perfil de correlaciones (+/-) para Piptochaetium montevidense en suelos arenosos ( $P$ - probabilidad).

\begin{tabular}{|l|c|l|r|}
\hline \multicolumn{2}{|c|}{ Piptochaetium montevidense } & \multicolumn{2}{|c|}{ (+) } \\
\hline Especie & P & Especie & P \\
\hline Ternatus & 0,005 & Soliva & 0,0007 \\
Plicat & 0,02 & Eleocharis & 0,02 \\
Setaria & 0,03 & Cynodon & 0,05 \\
Neesii & 0,05 & Vulpia & 0,05 \\
Venustula & 0,05 & Axonopus & 0,06 \\
Lagur & 0,06 & Polygala & 0,16 \\
Aspilia & 0,06 & & \\
Richardia & 0,12 & & \\
Micros & 0,18 & & \\
\hline
\end{tabular}

Cuadro 12. Perfil de correlaciones (+/-) para Hipoxis decumbens en suelos arenosos ( $P$ - probabilidad).

\begin{tabular}{|l|r|l|l|}
\hline \multicolumn{2}{|c|}{ Hipoxis decumbens } & & \multicolumn{2}{c|}{ (-) } \\
\hline Especie & P & Especie & P \\
\hline Axonopus & 0,01 & P. not & 0,14 \\
Milioides & 0,05 & Dichondra & 0,19 \\
Coelorachis & 0,08 & Plicat & 0,19 \\
Vulpia & 0,04 & Indicus & 0,12 \\
Sabulorum & 0,15 & Facelis & 0,05 \\
Platensis & 0,09 & Mecardonea & 0,05 \\
Minor & 0,002 & Trachypogon & 0,11 \\
Glandularia & 0,05 & & \\
Pumilum & 0,08 & & \\
Spilantes & 0,07 & & \\
Polygala & 0,04 & & \\
\hline
\end{tabular}

mismo tiempo la especie presenta una correlación negativa con el extremo de alivio Trachypogon montufari.

En el caso de Axonopus affinis (Cuadro 13) es muy similar a la respuesta de Panicum milioides dentro del grupo intermedio o de transición, sin embargo muestra, a nuestro juicio, un poco más de amplitud ecológica dados los valores de $\mathrm{P}$ de las correlaciones como con Coelorachis selloana, Hipoxis decumbens, Vulpia australis, Briza minor, Polygala australis, independientemente que también muestra valores negativos relativamente importantes con Setaria geniculata, Paspalum plicatulum y Eragrostis neesii. Creemos que estas relaciones nos están indicando que hay más factores ecológicos, además de la intensidad de uso, que afectan la presencia o ausencia de cada especie.

Chevreulia sarmentosa es una especie que la ubicamos en el grupo de transición ya que muestra tanto correlaciones positivas con el 
Cuadro 13. Perfil de correlaciones (+/-) para Axonopus affinis en suelos arenosos ( $P-$ probabilidad).

\begin{tabular}{|l|r|l|l|}
\hline \multicolumn{2}{|c|}{ Axonopus affinis } & & \multicolumn{2}{c|}{$(\mathbf{-})$} \\
\hline Especie & P & Especie & P \\
\hline Coelorachis & 0,001 & Mecardonea & 0,02 \\
Hipoxis & 0,01 & Plicat & 0,04 \\
Minor & 0,01 & Neesii & 0,06 \\
Eleocharis & 0,02 & Setaria & 0,10 \\
Vulpia & 0,06 & & \\
Polygala & 0,11 & & \\
Milioides & 0,12 & & \\
Hypochoeris & 0,18 & & \\
Nudicaule & 0,20 & & \\
\hline
\end{tabular}

grupo de alivio como con el grupo de transición (Coelorachis selloana, Hypochoeris sp., Sporobolus platensis y Paspalum notatum, Panicum milioides, Richardia sp. respectivamente), al mismo tiempo se destaca su correlación negativa con Cynodon dactylon (Cuadro 14).

Juncus capillaceus es una especie que siempre la hemos asociado a situaciones de pisoteo y suelo compactado, un grado extremo es lo que se aprecia en la Figura 23, donde se observa que en el campo de fútbol claramente la predominancia de la misma en la zona más transitada del campo de juego. Este efecto lo hemos documentado en una pastura natural que fue sometida a altas presiones de pas- toreo pasando de una situación con más de $3.000 \mathrm{~kg} \mathrm{MS} / \mathrm{ha}$ de disponibilidad en pie a valores cercanos a $500 \mathrm{~kg} \mathrm{MS} / \mathrm{ha}$, mostrando (Figura 24) como con la mayor presión de pastoreo se incrementa la presencia de Juncus capillaceus. Es así que esta especie y sus asociadas las consideramos para definir un grupo que representa lo que llamamos el grupo de compactación. Juncus capillaceus tiene correlaciones positivas con Sporobolus indicus e Hydrocotyle sp. y por otro lado correlaciones negativas con el grupo de alivio como Bothrichloa laguroides, Paspalum plicatulum, Andropogon ternatus, Schizachyrium microstachyum, Aristida

Cuadro 14. Perfil de correlaciones (+/-) para Chevreulia sarmentosa en suelos arenosos ( $P$ - probabilidad).

\begin{tabular}{|l|c|l|c|}
\hline \multicolumn{2}{|c|}{ Chevreulia sarmentosa } & \\
\hline Especie & P & Especie & P \\
\hline P. not & 0,19 & Cynodon & 0,03 \\
Milioides & 0,16 & A. uruguay & 0,10 \\
Richardia & 0,05 & & \\
Coelorachis & 0,08 & & \\
Platensis & 0,08 & & \\
Glandularia & 0,06 & & \\
Pumilum & 0,16 & & \\
Hypochoeris & 0,07 & & \\
Evolvulus & 0,20 & & \\
\hline
\end{tabular}




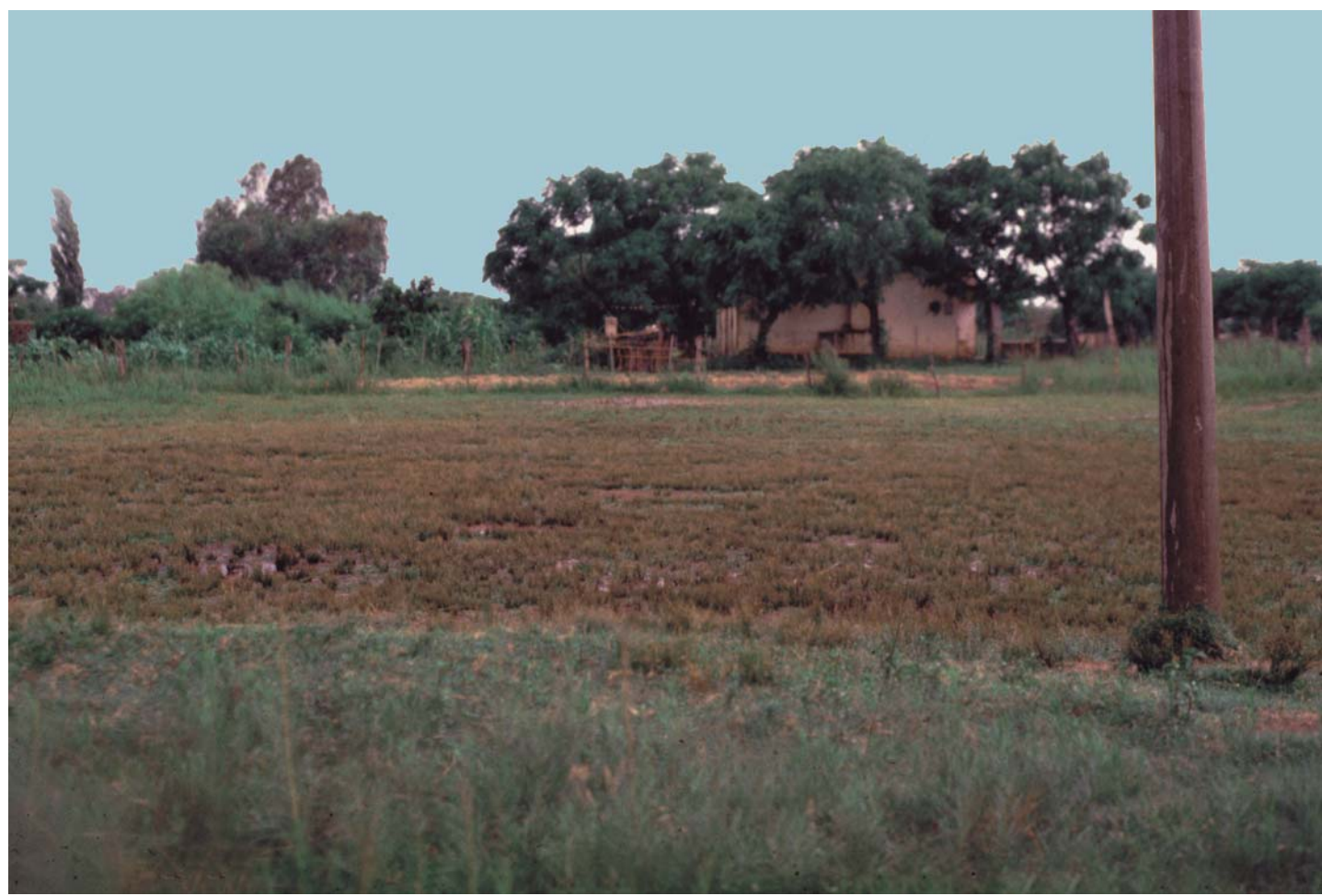

Figura 23. Juncus capillaceus dominando un área dedicada a la práctica intensiva de deportes en Tacuarembó.

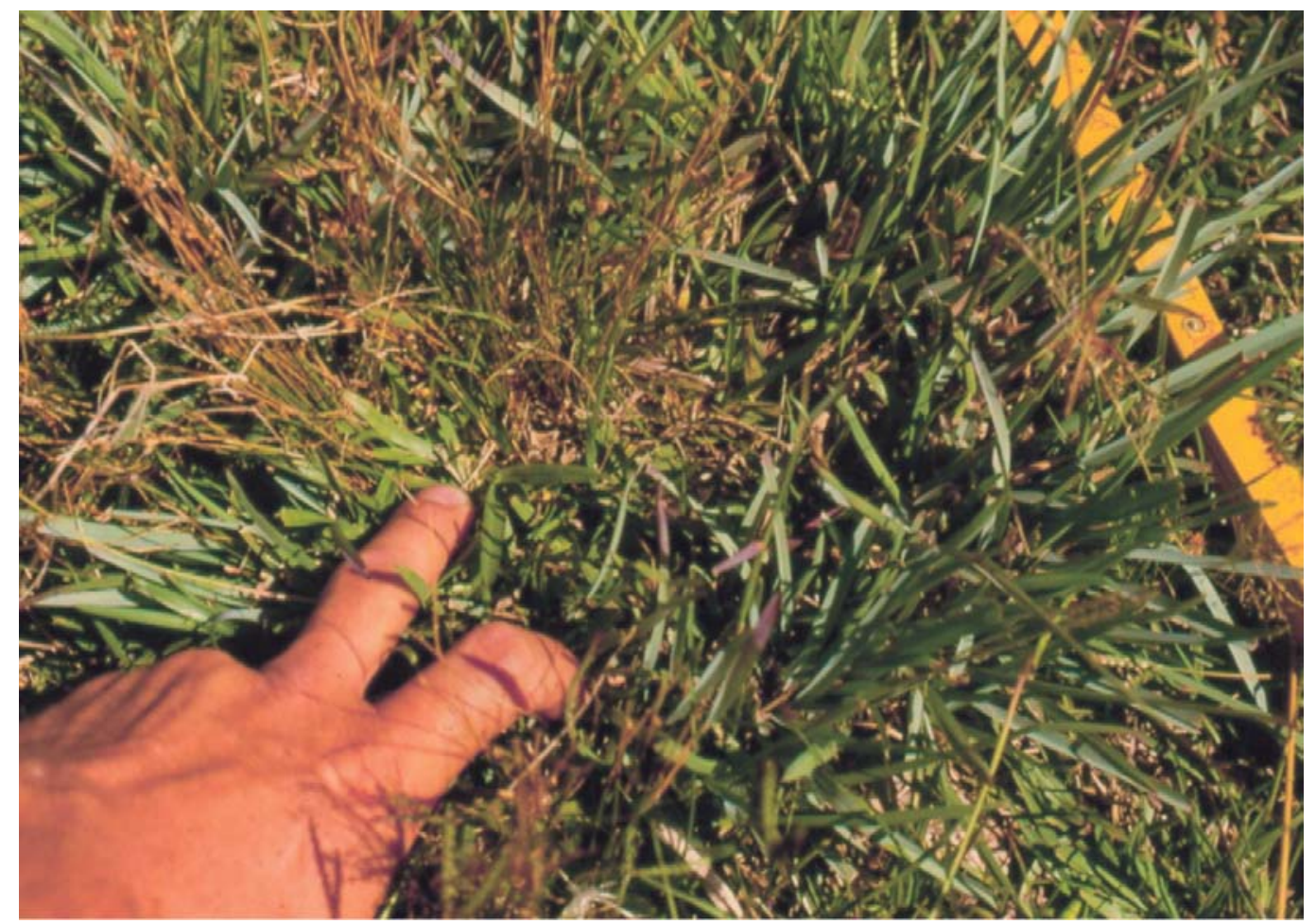

Figura 24. Ingreso de Juncus capillaceus en el centro de plantas de Andropogon lateralis sometidas a una alta presión de pastoreo en la Unidad Experimental La Magnolia, Tacuarembó. 
Cuadro 15. Perfil de correlaciones (+/-) para Juncus capillaceus en suelos arenosos ( $\mathrm{P}-$ probabilidad).

\begin{tabular}{|l|l|l|l|}
\hline \multicolumn{2}{|c|}{ Juncus capillaceus } & \multicolumn{2}{c|}{$(\mathbf{- )}$} \\
\hline Especie & $\mathbf{P}$ & Especie & $\mathbf{P}$ \\
\hline Indicus & 0,09 & Lagur & 0,16 \\
Hydrocotyle & 0,04 & Plicat & 0,19 \\
& & Ternatus & 0,02 \\
& & Platensis & 0,07 \\
& & Micros & 0,18 \\
& & Venustula & 0,19 \\
& & Spilantes & 0,04 \\
& & Trachypogon & 0,04 \\
\hline
\end{tabular}

venustula, Trachypogon montufari entre otras. En los suelos arcillosos también presentó una correlación positiva con Sporobolus indicus $(P<0,08)$ (Cuadro 15).

El caso de Andropogon lateralis aparece como una especie que tiene pocas correlaciones significativas con otras especies forrajeras (Cuadro 16). A nuestro juicio es una especie de gran amplitud ecológica ya que lo podemos encontrar a nivel regional en diferentes tipos de suelo, aunque localmente lo encontramos principalmente y muchas veces en forma dominante en lo suelos arenosos; se encuentra tanto en las zonas de laderas como en los bajos de los suelos arenosos, en menor proporción en los suelos arcillosos, pero también se encuentra en los suelos sobre basalto incluso en los suelos superficiales de la zona basáltica. Es una especie que en casos favorables puede acumular importante volúmenes de forraje en pie (4.000 kg MS/ha) siendo el mismo consumido en pleno período otoño invernal por el ganado; cuando es mucha la acumulación hacia fin de verano-otoño es muy común en los alrededores de Tacuarembó - Rivera observar la quema a fines de invierno de los campos para favorecer su rebrote.

En base a estas consideraciones vemos que la especie se encuentra mayoritariamente asociada a especies de poco porte como $T$. polymorphum, Oxalis sp., P. sabulorum, Alophia amoena, Polygala australis, Chevreulia acuminata (Cuadro 16).

Cuadro 16. Perfil de correlaciones (+/-) para Andropogon lateralis en suelos arenosos ( $P$ - probabilidad).

\begin{tabular}{|l|r|l|r|}
\hline \multicolumn{2}{|c|}{ Andropogon lateralis } & & \multicolumn{2}{c|}{ (+) } \\
\hline Especie & P & Especie & \multicolumn{1}{|c|}{ P } \\
\hline Polym & 0,01 & Richardia & 0,001 \\
Nicorae & 0,16 & Vulpia & 0,18 \\
Oxalis & 0,05 & Sisy & 0,16 \\
Sabul & 0,02 & Venustula & 0,14 \\
Eleocharis & 0,07 & & \\
Alophia & 0,04 & & \\
Arachis & 0,002 & & \\
Polygala & 0,03 & & \\
Acum & 0,01 & & \\
\hline
\end{tabular}


Una consideración aparte puede merecer también Andropogon lateralis, que si bien aparece con valores relativamente bajos en las correlaciones con las otras especies, presenta sin embargo, una correlación negativa con Axonopus affinis $(-0,36 ; \mathrm{P}<0,06)$ indicando una mayor presencia relativa de la misma en sitios de manejo menos intensivos y probablemente con mayor disponibilidad de forraje (Figura 25).

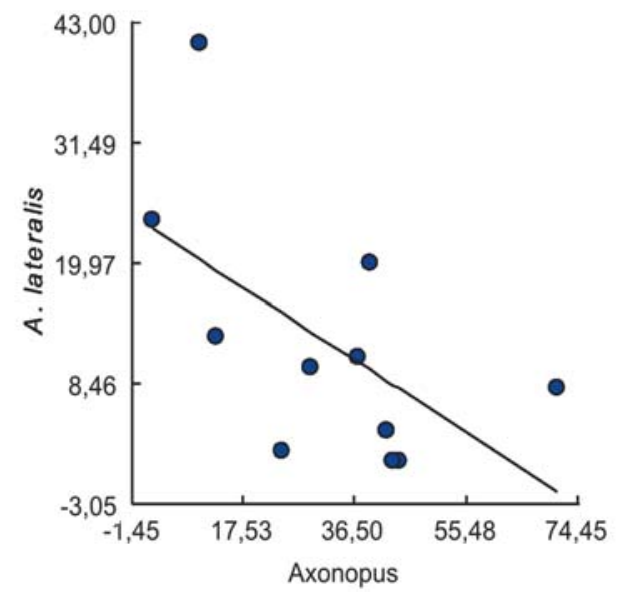

Figura 25. Relación entre la presencia de Andropogon lateralis y Axonopus affinis en suelos arenosos.
Como corolario de los resultados presentados anteriormente en la Figura 26 se esboza un esquema gráfico sintético de las relaciones entre las especies y un eje de intensificación en el uso de los recursos naturales en los suelos arenosos.

Se describen dos grupos extremos y una serie de especies intermedias todas posicionadas relativamente en base a los valores de las correlaciones, por un lado el grupo de manejo aliviado incluyendo Trachypogon montufari como la más extrema y Bothrichloa laguroides como la central del grupo, por el otro lado el grupo de mayor intensificación centrado en Cynodon dactylon y en el medio un grupo más amplio centrado en Axonopus affinis; se presenta un segundo eje de comportamiento que será preciso identificar más adelante en profundidad con un número mayor de relevamientos, pero podría estar relacionado con una suerte de compactación o especies que resisten más este tipo de proceso dado la presencia en el extremo inferior de Juncus capillaceus y Sporobolus indicus, también no debería destacarse que estas especies al mismo tiempo tienen un hábito de crecimiento contrastante con el de Axonopus affinis hacia el otro extremo. En el extremo inferior derecho la presencia de

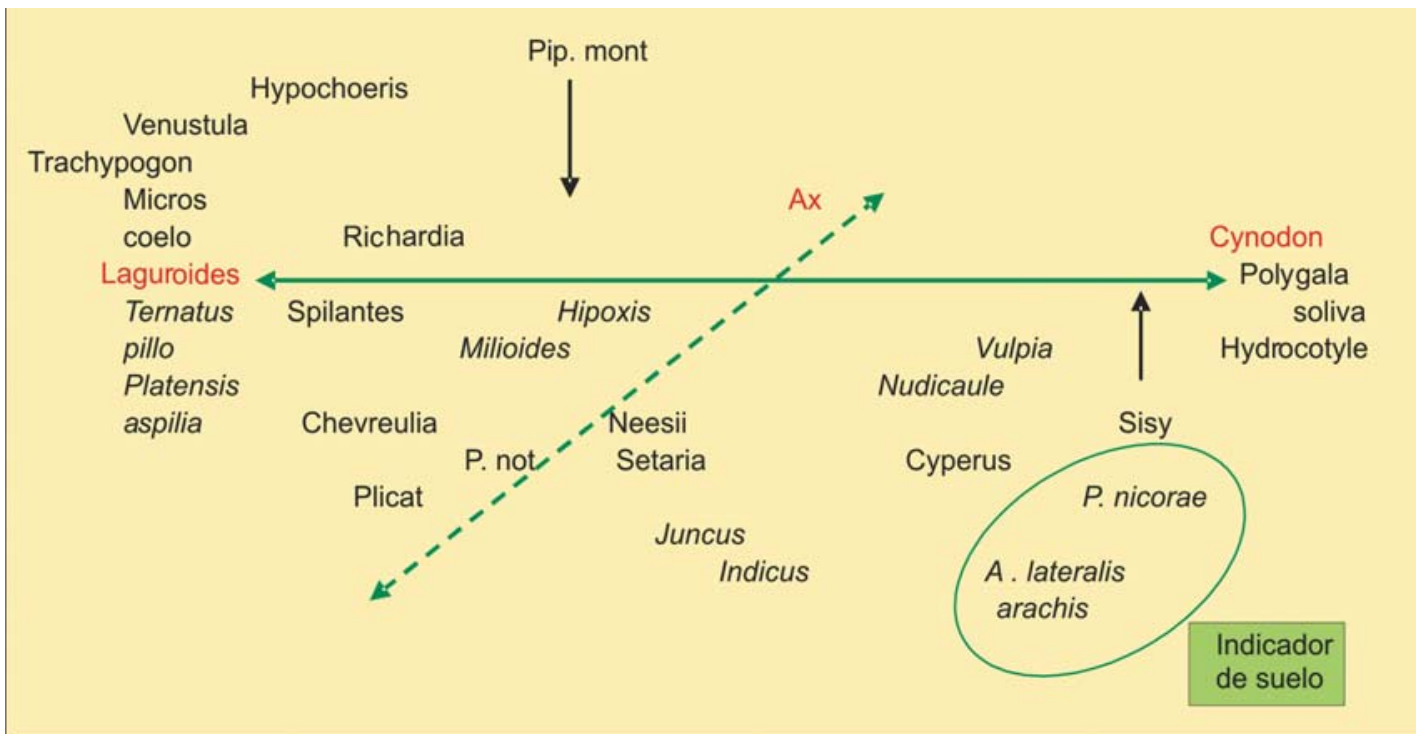

Figura 26. Relación entre las principales especies componentes de las comunidades de pasturas naturales en relación a un eje de manejo e intensificación en el uso de los recursos naturales; izquierda intensificación menor, derecha máxima intensificación, centro intensificación media o grupo de transición. 
Paspalum nicorae, Andropogon lateralis y Arachis sp. se interpreta como un indicador de suelo, en este caso suelo arenoso.

Observaciones en condiciones de invernáculo nos muestran que $S$. indicus sobrevive condiciones relativamente extremas de estrés hídrico, produce mucha semilla viable y se vuelve a instalar rápidamente a partir de la misma. En este sentido se asocia positivamente con $P$. milioides el cual lo hemos clasificado como representante de una situación 2-3 en un rango 0-5 de evolución de un campo bruto roturado a un campo bruto.

\section{Análisis de Correspondencia Canónica en Suelos Arenosos}

A los efectos de profundizar en el comportamiento de las especies dentro del mismo suelo se llevó adelante el Análisis de Correspondencia Canónico con los relevamientos de los suelos arenosos. En la Figura 27 se observa la distribución de las especies sin los vectores ambientales y se destaca claramente la separación de Cynodon dactylon en un extremo así como una separación entre los extremos de inten- sificación vistos anteriormente; dentro de los círculos rojos las especies más próximas a una mayor intensificación, Soliva pterosperma, Vulpia australis, Setaria geniculata, con círculos azules las especies asociadas a un manejo aliviado, Andropogon ternatus, Schizchyrium microstachyum, Bothriochloa laguroides y en forma intermedia el círculo verde donde se encuentra Paspalum notatum como una especie de respuesta intermedia. Andropogon lateralis en el extremo izquierdo superior muestra una presencia diferencial.

En la Figura 28 se integran los vectores ambientales indicando una asociación de las especies en el primer eje mayormente con la intensidad de la explotación, la carga animal, el contenido de $P$ en el suelo y la artificialización (recuadros amarillos); hacia la izquierda mayormente corresponde con indicadores de fertilidad como \% materia orgánica en el suelo y $\mathrm{pH}$ del suelo; se destaca la relación casi directa de $A$. lateralis con la cantidad de forraje disponible en el cuadrante izquierdo superior.

En la Figura 29 se presentan los resultados sin la presencia en el análisis de Cynodon

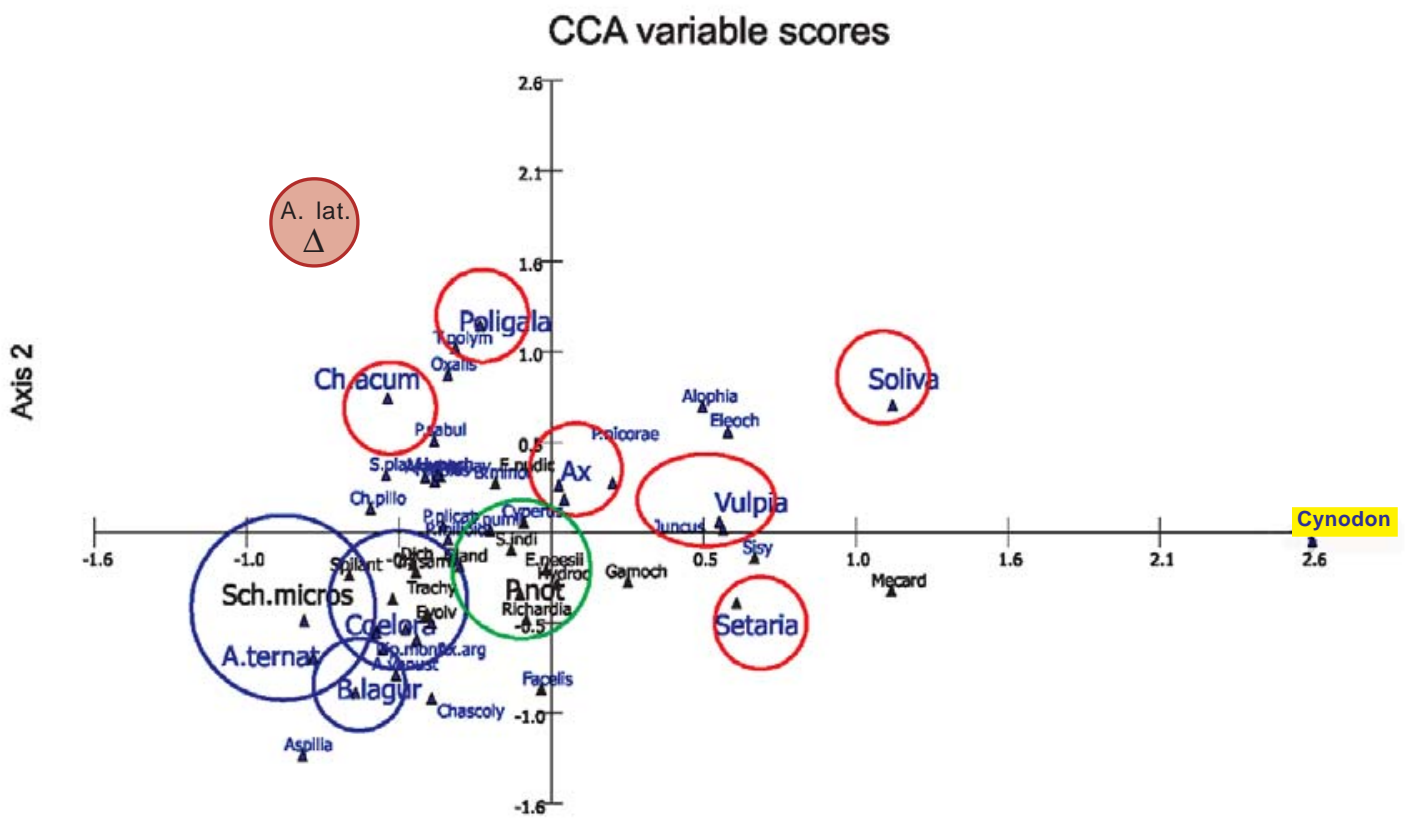

Axis 1

Figura 27. Análisis Correspondencia Canónico en los suelos arenosos sin los vectores ambientales. 


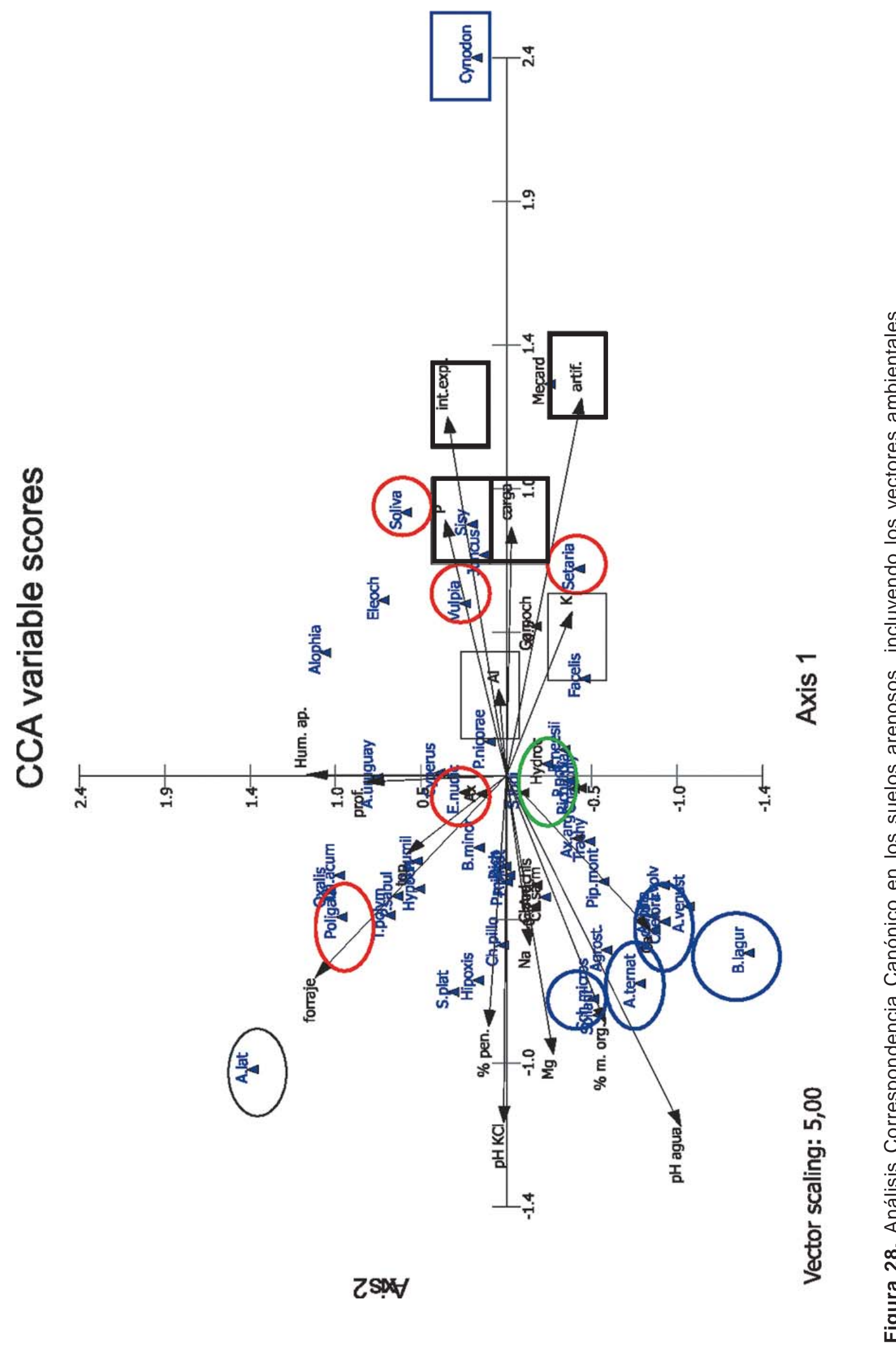




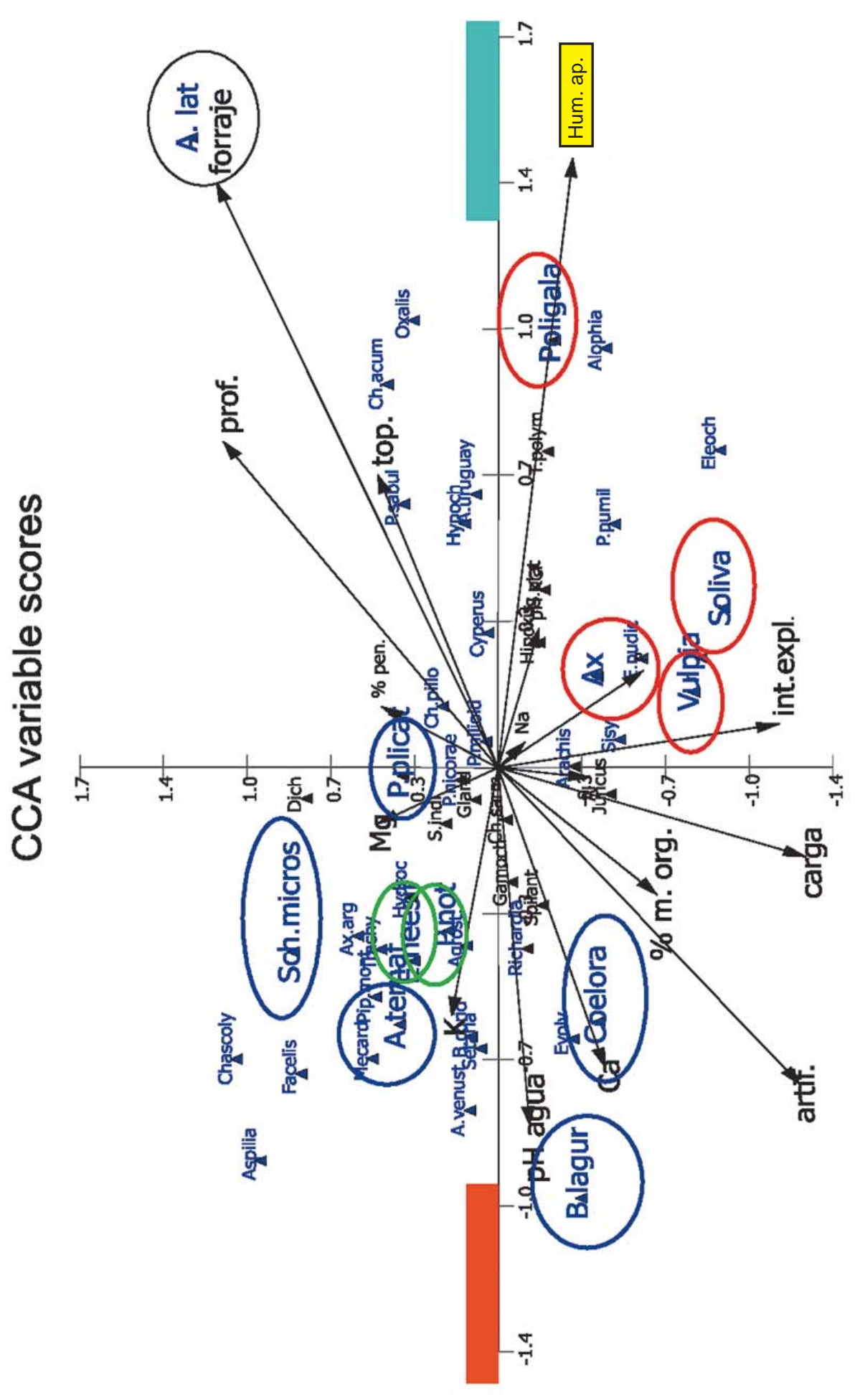

$Z \operatorname{six} \forall$

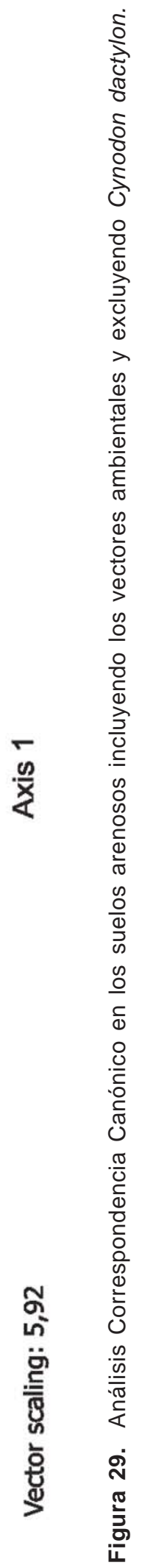


dactylon. Se destaca la interpretación del primer eje donde tenemos hacia un extremo la respuesta a la humedad aparente del sitio (recuadro amarillo) y por el otro extremo interpretamos la presencia de las especies adaptadas a ambientes relativamente secos como Bothrichloa laguroides (Rosengurtt, 1970). La distribución de las especies respecto a los vectores ambientales es similar a la figura precedente con Vulpia australis, Soliva pterosperma, Axonopus affinis vinculados a una mayor carga e intensificación en el uso del recurso (círculos rojos) y por otro lado $B$. laguroides, $A$. ternatus, $C$. selloana (círculos azules) vinculados a variables respecto al suelo como fertilidad y $\mathrm{pH}$; $A$. lateralis vinculado a la disponibilidad de forraje y la humedad del sitio.

En la Figura 30 se simplificó aún más extrayendo algunos vectores y especies que no contribuyen a la mejor tipificación de las especies en relación al ambiente. Las especies características de manejo intenso (círculos rojos) mantienen su vinculación con los vectores de carga e intensificación, Polygala australis al mismo tiempo expresa una relación positiva con la humedad del sitio; Bothrichloa laguroides aparece como la especie más extrema respecto a un manejo aliviado para los suelos arenosos (círculos azules), Paspalum notatum y Piptochaetium montevidense intermedias y en el extremo de mayor oferta de forraje asociada a cierta humedad del sitio Andropogon lateralis.

Otra forma de caracterización de las especies y su relación con el ambiente se ensaya en base a los elementos aportados por la Tabla elaborada por Rosengurtt (1970), a través de una síntesis pseudo - Gaussiana de los resultados.

Las principales características de los grupos de especies identificados en los análisis previos se destacan en los cuadros siguientes. En el Cuadro 17 correspondiente al grupo de alivio, se destaca la presencia de especies de campo restablecido, con una productividad relativamente media y en algunos casos especies asociadas a ambientes relativamente más secos; también algunas especies perennes se asocian con campos brutos. La mayoría son de ciclo de crecimiento estival.

De acuerdo a Rosengurtt (1970) campo restablecido se refiere a un campo abandonado luego de cultivo por más de diez años y con predominancia de especies perennes de ciclo largo y campo bruto por su parte, a un campo abandonado luego de cultivo entre cuatro a diez años y con predominancia de especies perennes de ciclo largo (Berreta y Do Nascimento, 1991).

En el caso del grupo intermedio transicional en el Cuadro 18 se observa igualmente una predominancia de especies de crecimiento estival acompañadas fundamentalmente por Piptochaetium montevidense de ciclo invernal. En este caso prácticamente todas las especies se asocian con una situación de campo bruto, algunas con situaciones relativamente más secas y una Panicum milioides que es descripta con presencia en sitios más húmedos. Todas las especies son perennes y una productividad muy variable incluyendo varias especies con productividad relativamente baja.

En el caso del extremo de intensificación claramente aparecen en forma destacada las especies de ciclo anual con un productividad predominantemente baja y muy poca apetecibilidad; asimismo mayoritariamente las especies son de ciclo invernal (Cuadro 19). Respecto al tipo vegetativo la relación de las especies corresponde a situaciones muy variables de sitio.

En la Figura 31 se realiza una interpretación gráfica de los grupos en relación a un eje principal de intensificación en el uso de los recursos, donde se ejemplifica hacia la izquierda con la presencia de las especies de campo restablecido y hacia la derecha asociado a condiciones de máxima intensificación las especies asociadas correspondientes; se incluye una línea de tendencia que contempla los niveles de productividad esperados así como valores relativos de apetecibilidad. En la parte baja de la figura se aplica la interpretación Gaussiana respecto a la distribución de las especies asociadas a cada situación caracterizada en el eje de intensificación. 


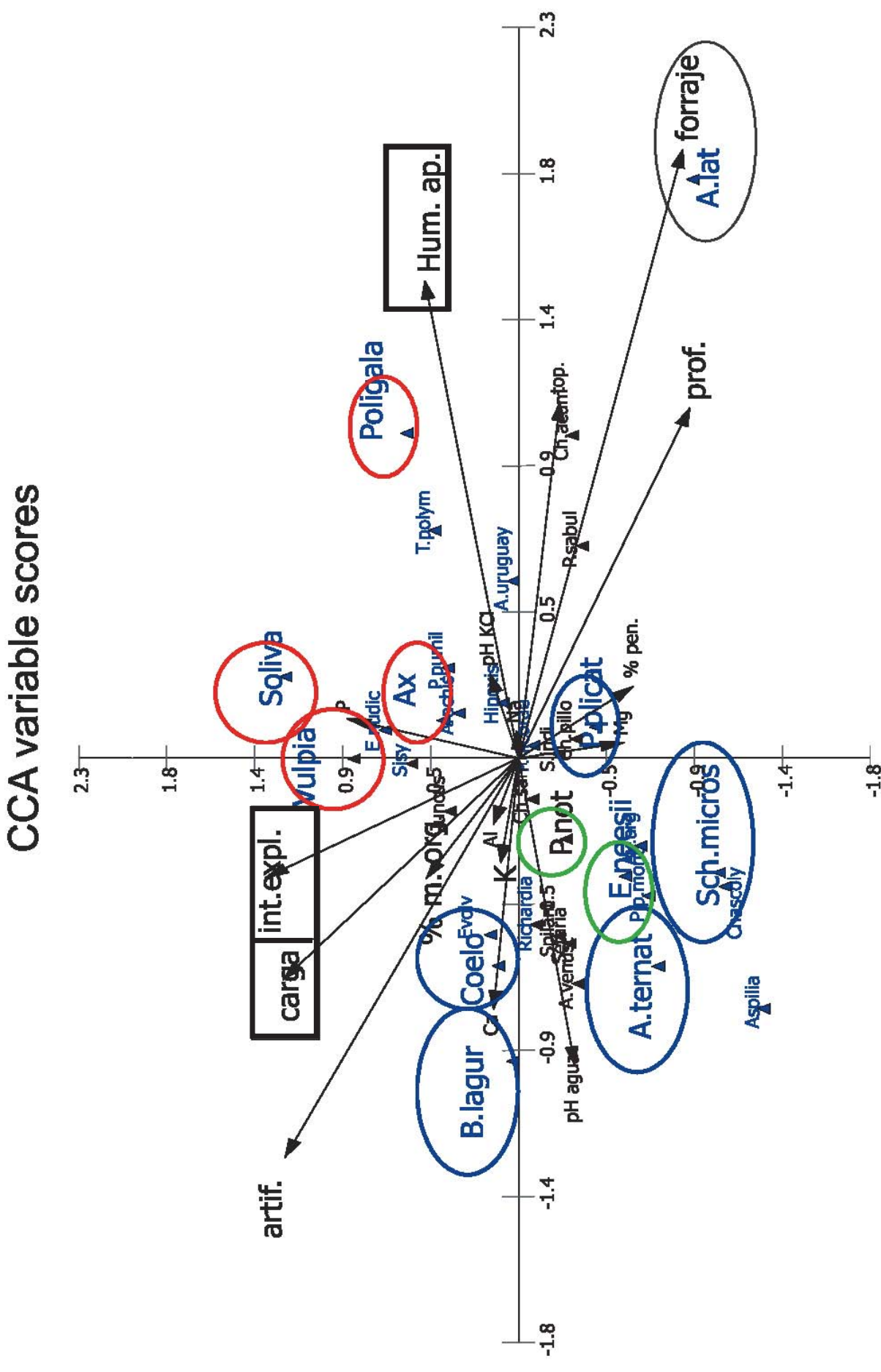

๘

镸
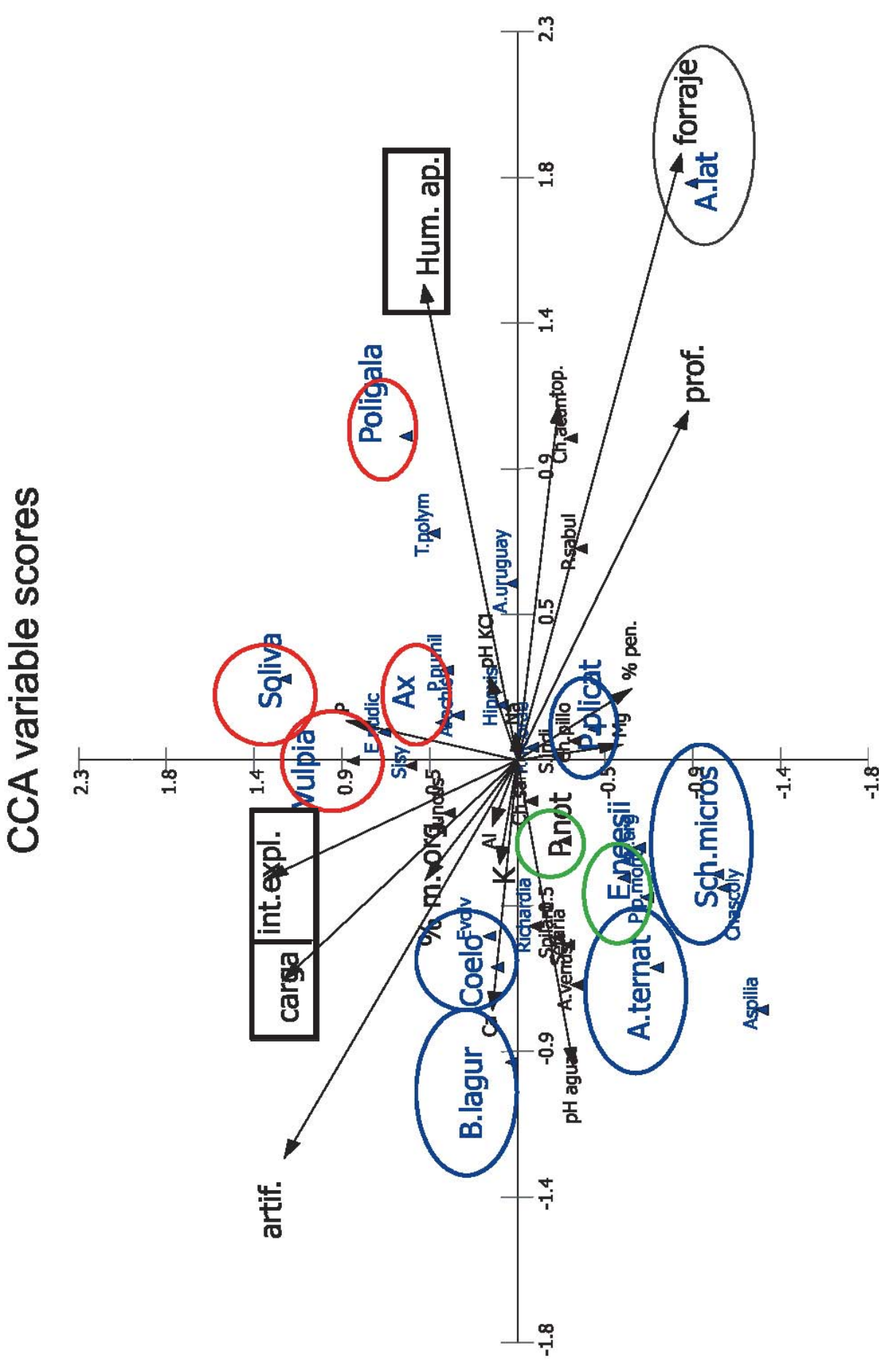

$\frac{8}{8}$

$Z \operatorname{six} \forall$

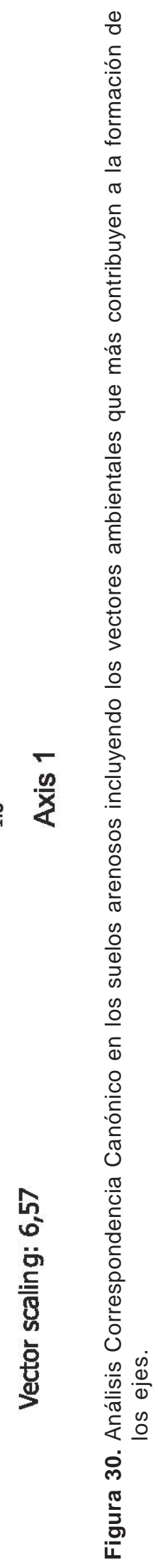


Cuadro 17. Características de las especies integrantes del grupo de alivio en suelos arenosos.

\begin{tabular}{|l|l|l|l|l|}
\hline Especie & Ciclo & Apetecibilidad & Productividad & \multicolumn{1}{|c|}{ Tipo vegetativo } \\
\hline Trachypogon & Estival & Muy joven & Baja & C. restablecido-p.-seco-arena \\
Coelorachis & Estival & Prolongada & Media & C. restablecido-p. \\
sp. Platensis & Estival & Joven & Medio-baja & C. restablecido-p. \\
Micros & Estival & Muy joven & Media & C. bruto-p.-arena \\
Laguroides & Estival & Joven & Media & C. bruto-p.-seco \\
Ternatus & Estival & Joven & Media & C. bruto-p.-seco \\
Hypochoeris & Invernal & Baja & Mínima & C. varios-anual-arrosetada \\
Venustula & Estival & Muy joven & Muy baja & C. bruto-p.-seco \\
Chascolytrium & Invernal & Joven & Baja & C. bruto-p. \\
Aspilia & Estival & Baja & Baja & C. bruto-p. \\
Spilantes & Estival & Baja & Baja & C. bruto-p. \\
\hline
\end{tabular}

Cuadro 18. Características de las especies integrantes del grupo intermedio- transicional en suelos arenosos.

\begin{tabular}{|l|l|l|l|l|}
\hline Especie & Ciclo & Apetecibilidad & Productividad & \multicolumn{1}{|c|}{ Tipo vegetativo } \\
\hline Pip. mont & Invernal & Prolongada & Medio-baja & C. bruto-p. \\
P. milioide & Estival & Prolongada & Media & C. bruto-p.-ulig. \\
P. no & Estival & Prolongada & Baja & C. bruto-p. \\
Trichardia & Estival & Mínima & Mínima & C. bruto-p.-seco \\
Axonopus & Estival & Media & Baja & C. bruto-p.-arena \\
Neesii & Estival & Joven & Muy baja & C. bruto-p.-seco \\
Plicat & Estival & Joven & Media & C. bruto-p.-seco \\
Juncus & Estival & Muy baja & Baja & C. bruto-p. \\
Indicus & Estival & Joven & Media & C. bruto-p. \\
Hipoxis & & & & \\
Chevreulia & Estival & No apeticida & Mínima & C. bruto-p. \\
\hline
\end{tabular}

Cuadro 19. Características de las especies integrantes del grupo extremo de intensificación en suelos arenosos.

\begin{tabular}{|l|l|l|l|l|}
\hline Especie & Ciclo & Apetecibilidad & Productividad & \multicolumn{1}{|c|}{ Tipo vegetativo } \\
\hline Soliva & Invernal & Mínima & Mínima & Anual-varios-seco \\
Cynodon & Estival & Muy joven & Baja & P.-varios-seco \\
Sisy & Invernal & Baja tóxica & Baja & Anual-seco \\
Polygala & Invernal & No apetecida & Mínima & Anual-varios \\
Vulpia & Invernal & Joven & Mínima & Anual-varios \\
Setaria & Estival & Joven & Baja & P.-varios-rastrojo \\
Nudicaule & Invernal & Mínima & Baja & C. bruto-subarrosetada \\
Cyperus & Estival & Baja & Media baja & C. bruto-restablecido-p. \\
P. nicorae & Estival & Joven & Media & P.-arena \\
Lateralis & Estival & Muy joven & Alta & C. bruto-arena \\
Arachis & Estival & Media & Baja & C. restablecido \\
\hline
\end{tabular}




\section{Trachypogon}

coelorachis

sp. platensis
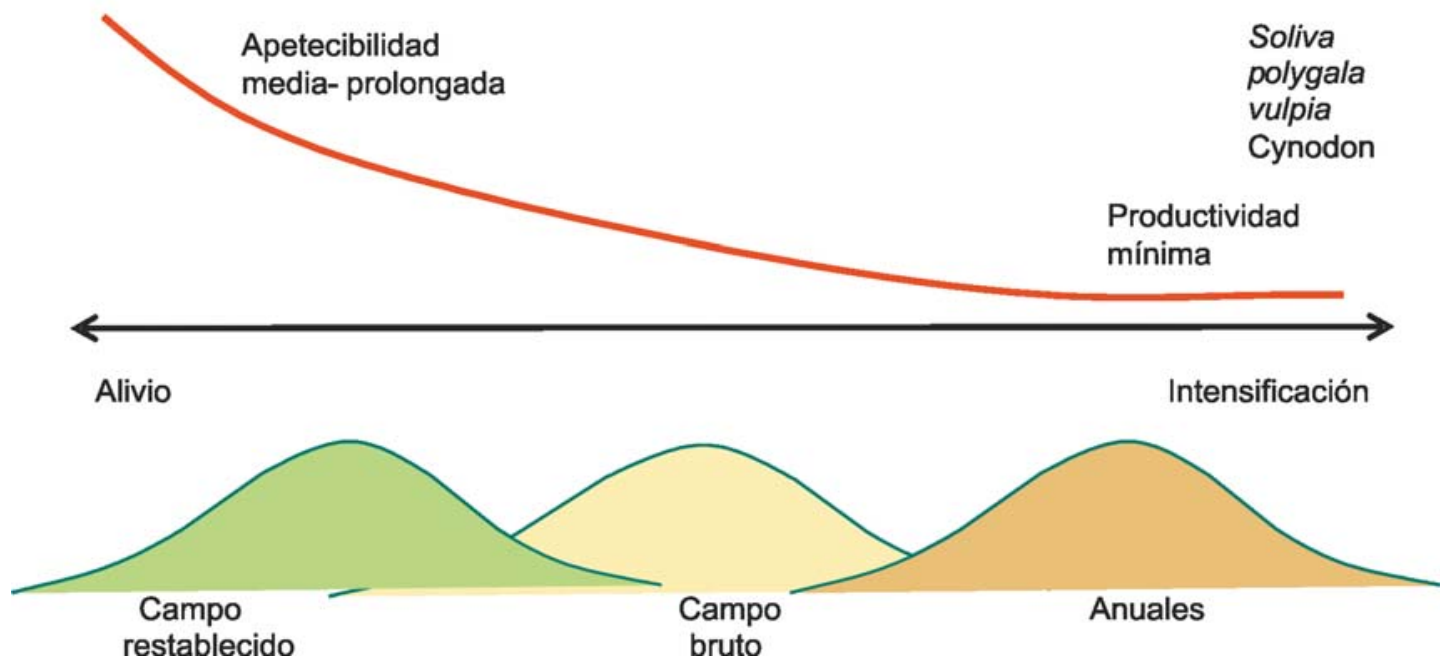

Figura 31. Interpretación gráfica de la relación entre las especies y el ambiente en suelos arenosos.

En el Cuadro 20 se resume una caracterización de los grupos en el eje mencionado, siendo que para el campo restablecido la comunidad se compone mayoritariamente de especies cespitosas y en un $100 \%$ gramíneas forrajeras, con apetecibilidad relativamente más prolongada y de ciclo ce crecimiento estival. En el caso del campo bruto la situación cambia con un menor porcentaje de especies cespitosas, una apetecibilidad relativamente menor e incluyendo especies de ciclo de crecimiento invernal y no gramíneas.

En el caso del grupo de máxima intensificación la mayoría de las especies son de crecimiento anual e invernal, con muy poca o escasa apetecibilidad y un número aún menor de gramíneas comparado con el grupo de campo bruto o intermedio.

Cuadro 20. Características de las especies integrantes de los tres grupos identificados en el eje de intensificación en suelos arenosos.

\begin{tabular}{|l|c|c|c|}
\hline \multirow{2}{*}{ Indicadores } & \multicolumn{3}{|c|}{ Grupo } \\
\cline { 2 - 4 } & Campo restablecido & Campo bruto & Intensificación \\
\hline $\begin{array}{l}\text { Tipo vegetativo } \\
\text { Apetecibilidad }\end{array}$ & $\begin{array}{l}80 \% \text { cespitosas } \\
\text { Muy joven - prolongada }\end{array}$ & $\begin{array}{l}60 \% \text { cespitosas } \\
\text { Mínima - prolongada }\end{array}$ & $\begin{array}{l}80 \% \text { anuales } \\
\text { No apetecida- } \\
\text { tóxica-mínima- } \\
\text { muy joven }\end{array}$ \\
\hline $\begin{array}{l}\text { Ciclo estival/invernal } \\
\text { Número gramíneas } \\
\text { forrajeras }\end{array}$ & $5 / 0$ & $8 / 2$ & $1 / 4$ \\
\hline
\end{tabular}




\section{Análisis de las relaciones entre las especies y los factores ambientales en pasturas sobre suelos arenosos}

En base a las correlaciones establecidas y utilizando los resultados más relevantes desde el punto de vista del manejo de las pasturas se discuten a continuación diversas relaciones entre el ambiente y las plantas de interés agronómico. En el Cuadro 21 se describen las relaciones analizadas incluyendo la especie y su pertenencia a los grupos identificados previamente conjuntamente con la variable ecológica y el valor $\mathrm{P}$ (probabilidad) del coeficiente de regresión.
En el caso de Bothrichloa laguroides es clara su relación negativa con el incremento en la carga animal, situación inversa a la que se observa con Vulpia australis (Cuadro 21 y Figura 32); asimismo Bothrichloa laguroides se encuentra relacionada positivamente con aspectos relativos a la fertilidad como $\% \mathrm{~m}$. orgánica, pH y contenido de Ca en el suelo, presentando un valor negativo respecto a la profundidad del suelo, aspecto este que concuerda con lo reportado por Rosengurtt (1970) que la ubica en hábitats relativamente más secos. Vulpia australis, por su parte, se relaciona positivamente con la intensidad de explotación así como con la artificialización y negativamente con el $\mathrm{pH}$ del suelo, al contrario de Bothrichloa laguroides.

Cuadro 21. Análisis de la relación entre las especies y los factores ecológicos de acuerdo a los grupos de especies en suelos arenosos.

\begin{tabular}{|c|c|c|c|}
\hline Grupo & Especie & Variable & Probabilidad \\
\hline Alivio & Bothrichloa laguroides & $\begin{array}{l}\text { Carga } \\
\text { Intensidad explotación } \\
\% \mathrm{MO} \\
\mathrm{pH} \text { agua } \\
\mathrm{Ca} \\
\text { Profundidad }\end{array}$ & $\begin{array}{r}-0,0544 \\
-0,0040 \\
0,0003 \\
0,0168 \\
0,0002 \\
-0,0123\end{array}$ \\
\hline Intensificación & $\begin{array}{l}\text { Vulpia australis } \\
\text { Axonopus affinis } \\
\text { Richardia sp. }\end{array}$ & $\begin{array}{l}\text { Carga } \\
\text { Intensidad explotación } \\
\text { Artificialización } \\
\mathrm{pH} \text { agua } \\
\% \mathrm{MO} \\
\text { Profundidad } \\
\mathrm{Ca} \\
\mathrm{pH} \mathrm{KCl} \\
\text { [Al] } \\
\text { Artificialización } \\
\text { Carga }\end{array}$ & $\begin{array}{r}0,0289 \\
0,0186 \\
0,0352 \\
-0,0674 \\
0,0018 \\
-0,0096 \\
0,0213 \\
0,0345 \\
0,0401 \\
0,1048 \\
0,1191 \\
\end{array}$ \\
\hline Intermedio & Panicum sabulorum & $\begin{array}{l}\text { Artificialización } \\
\text { Forraje } \\
\text { Humedad aparente }\end{array}$ & $\begin{array}{r}-0,0402 \\
0,0527 \\
0,0752\end{array}$ \\
\hline 2do. eje & Andropogon lateralis & $\begin{array}{l}\text { Carga } \\
\text { Intensidad explotación } \\
\text { Artificialización } \\
\text { Forraje } \\
\text { Humedad aparente } \\
\text { Profundidad }\end{array}$ & $\begin{array}{r}-0,0043 \\
-0,0055 \\
-0,0002 \\
0,0001 \\
0,0503 \\
0,0839\end{array}$ \\
\hline
\end{tabular}




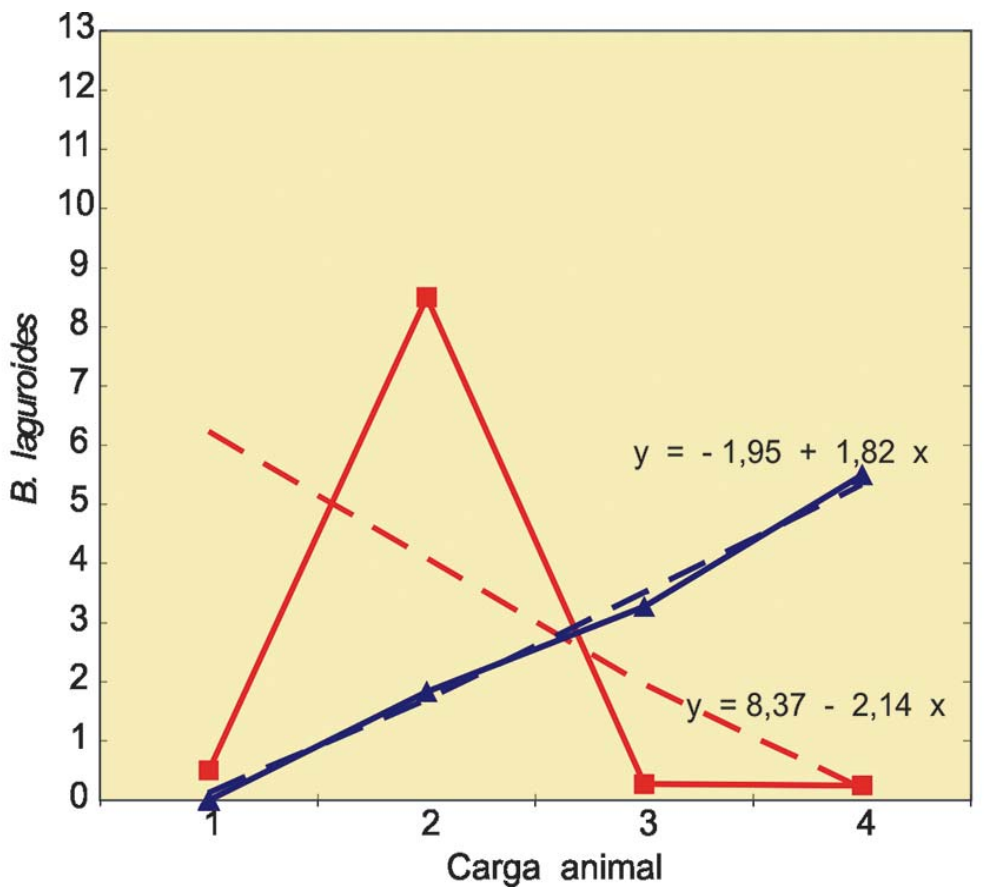

13

12

11

10

9

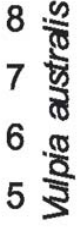

4

3

$2=-$ B. laguroides

$1 \pm$ Vulpia australis

Figura 32. Relación entre el indicador de carga animal y la presencia de Bothrichloa laguroides y Vulpia australis en 27 sitios sobre suelos arenosos en la región noreste.

Axonopus affinis, dentro de los suelos arenosos, se relaciona positivamente con mejores valores de fertilidad (\% materia orgánica, $\mathrm{Ca}, \mathrm{pH} \mathrm{KCl}$ ) y negativamente con profundidad del suelo; en este último caso se puede especular que sea una consecuencia de la competencia, por ejemplo con Andropogon lateralis, que con un mayor potencial de crecimiento explotaría mejor un suelo profundo tendiendo a excluir en estas circunstancias a Axonopus affinis dado su habito de crecimiento rastrero y raíces poco profundas. Esta consideración se basa en la relación registrada entre ambas especies en este tipo de suelos (ver Figura 25).

Richardia sp. presenta una marcada relación positiva con la mayor presencia de aluminio en el suelo, la artificialización y la carga animal, colocando a la especie claramente en la zona de mayor intensificación de estos suelos.

En el caso del grupo intermedio, ejemplificado con Panicum sabulorum, el mismo presenta una correlación negativa respecto a la artificialización del medio al mismo tiempo que relaciones positivas con el forraje disponible (alivio) y con la humedad aparente en cada sitio; los dos primeros factores tienden a separarlo del grupo de mayor intensificación y el tercer del grupo de alivio en el sentido que Bothrichloa laguroides tiende a ser favorecida en sitios relativamente secos.

Andropogon lateralis tiene una relación neta negativa tanto con la carga animal, la intensidad de la explotación como con la artificialización y por otro lado relaciones positivas con la disponibilidad de forraje, la humedad del sitio y la profundidad del suelo (Figura $33 \mathrm{a}, \mathrm{b}$ ), respuestas estas que lo separa en su perfil claramente de las otras especies.

En el caso de Juncus capillaceus la especie se encuentra positivamente correlacionada con el contenido de Al en el suelo, respondiendo esta tendencia a historias de manejo del suelo donde en la medida que ha habido una mayor intensificación en su uso el contenido de Al se incrementa; el coeficiente para la concentración de Al es 5,55 con un nivel de $\mathrm{P} \leq 0,023$ (Figura 34).

En la elipse de la izquierda de la Figura 32 se observa la posición relativa de los potreros 2 y 4 de la Unidad Experimental La Magnolia, donde el potrero 2 corresponde a 

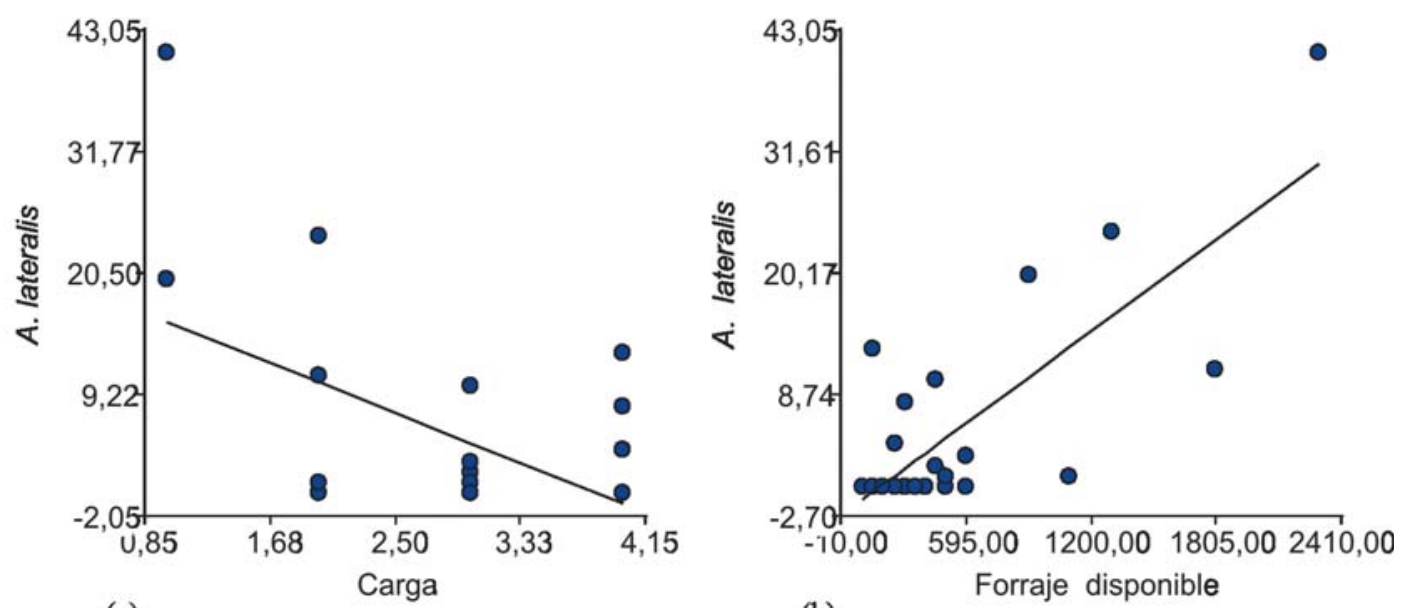

(a)

$$
\begin{array}{r}
y=21,55-5,62 x \\
P<-0,004
\end{array}
$$

(b)

$$
y=-2,56+0,001 x
$$

Figura 33. Relación entre la presencia de Andropogon lateralis con la carga animal (a) y el forraje disponible (b) en suelos arenosos de la región noreste.

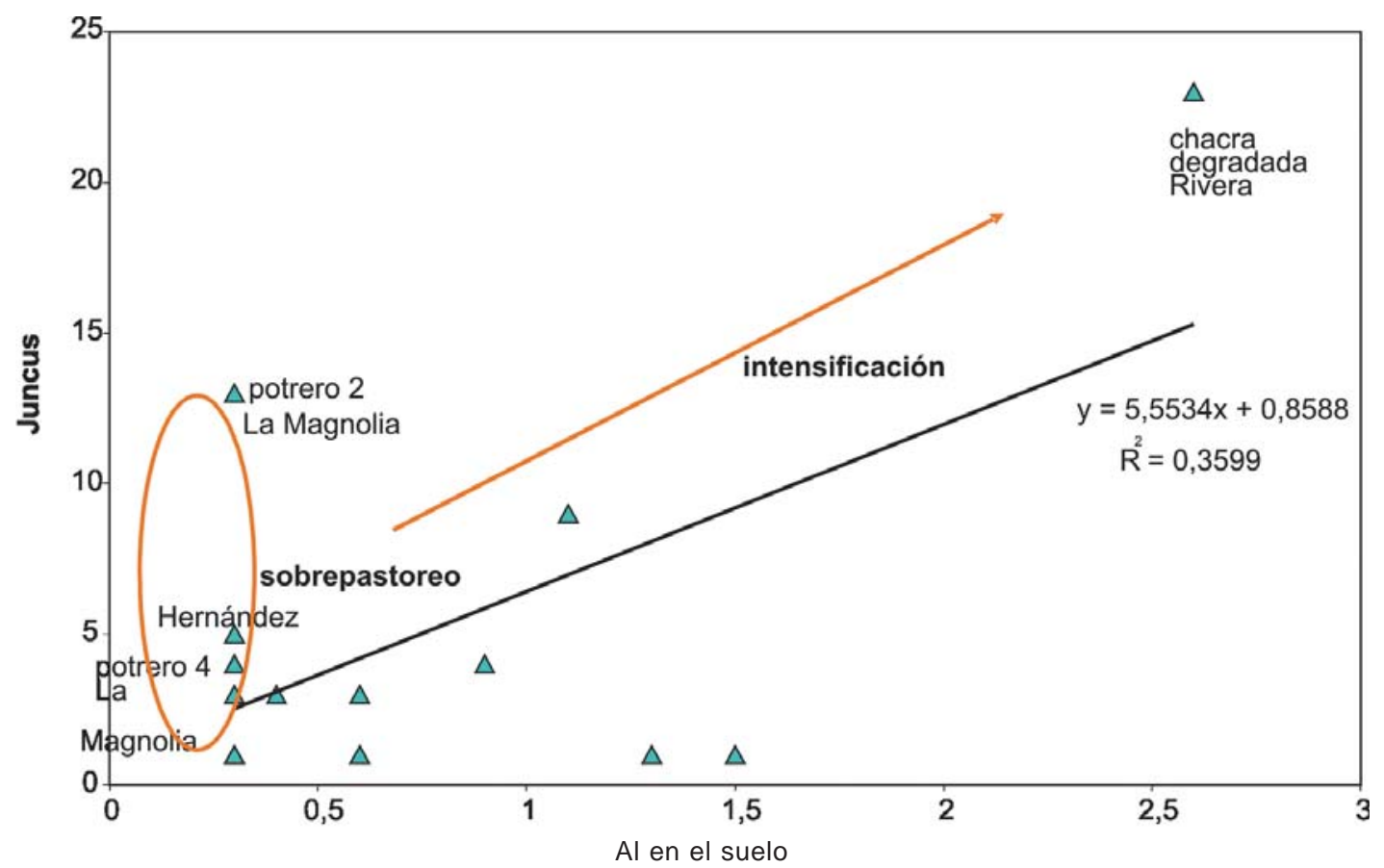

Figura 34. Variación en el contenido de Juncus capillaceus en relación a la concentración de Al en el suelo, en suelos arenosos de la región noreste.

una especie de piquete manejado con alta carga y el potrero 4 a un campo natural con manejo aliviado con ganado de cría; la máxima presencia de Juncus capillaceus se registra en una chacra degradada en el departamento de Rivera. La primer diferencia se- ría consecuencia del manejo del pastoreo generando situaciones de mayor compactación del suelo y la segunda al proceso de degradación del suelo como consecuencia de la agricultura. 


\section{Consideraciones generales}

Desde el punto de vista de la caracterización de la estructura básica de las pasturas naturales de la región se avanzó con la implementación de una metodología práctica y que proponemos sea aplicada en los trabajos que impliquen su utilización.

La aplicación de métodos multivariados, correlaciones, regresiones permitió la discriminación de los diferentes tipos de pasturas encontradas en la región en un amplio rango de características tanto por el tipo de suelo como por el manejo histórico de cada sitio. De este modo se identificaron especies y grupos de especies asociadas a las diferentes situaciones, elementos que permitirán su utilización como elementos diagnóstico. Al mismo tiempo los resultados permiten consolidar conceptos respecto a la respuesta de los diferentes tipos de especies (tipos vegetativos) con relación a los factores ecológicos.

La información obtenida permitirá la consolidación de perfiles ecológicos básicos de las principales especies herbáceas de interés. Sobre estos conocimientos se deberá profundizar respecto a la biología poblacional de las especies desde el punto de vista ecofisiológico y lo que contribuirá a la identificación de especies indicadoras.

\section{PRODUCTIVIDAD FORRAJERA Y ESTRUCTURA EN COMUNIDADES DE PASTURAS NATURALES DE LAREGIÓN NORESTE}

A partir de la caracterización de las comunidades en el año 1987, se seleccionaron 10 sitios de los 67 relevados, cuatro sobre suelos arenosos seis sobre suelos arcillosos, para estudiar la relación entre la composición botánica y la productividad estacional de forraje.

En los suelos arenosos se seleccionó un potrero sobrepastoreado (a-1) y otro adyacente donde la pastura es utilizada con un rodeo de cría (a-2), los otros dos sitios fueron, uno donde había habido cultivos previa- mente y luego se instaló una pradera convencional (diez años antes) (a-5) y otro donde había habido solo cultivo de soja diez años atrás (campo bruto) (a-4). En el caso de los suelos arcillosos se seleccionó un sitio con más de treinta años de sobrepastoreo (b-3), otro sitio que había sido mejorado con introducción de algunas leguminosas y fertilización veinte años atrás (b-6), otro calle por medio del anterior con un suelo similar pero menos profundo y sin mejoras utilizado para cría de ganado (b-7), en otro establecimiento un potrero de cría de ganado vacuno (b-8), otro de invernada (b-9) y otro donde se había realizado solamente un cultivo y se dejó recuperar la pastura natural sin ninguna otra intervención (b-10), los tres últimos contiguos uno del otro (Figura 35).

Se realizó el estudio del área mínima fitosociológica en cada sitio y en cada estación; y se utilizaron transectas de $10 \mathrm{~m}$ para el análisis de la composición botánica (Olmos y Godron, 1990). La producción de forraje se realizó utilizando cinco jaulas de exclusión en cada pastura. Los registros fueron obtenidos en el período 1989 - 1991 durante siete estaciones de crecimiento.

\section{Productividad de las pasturas}

La productividad de las pasturas dependió tanto de la estación de crecimiento así como del año. En el Cuadro 22 se presenta la tasa de crecimiento estacional de ocho comunidades herbáceas de la región noreste desde el invierno de 1989 hasta el verano del año 1990-91; prácticamente todas las comparaciones resultaron estadísticamente significativas, salvo el caso de la comparación invierno-90 vs. verano 89-90 $(P<0,85)$ y otoño-90 vs. primavera-90 $(P<0,99)$. Aparentemente las diferencias se pueden explicar por las diferencias en el balance hídrico del ambiente en base a la relación lluvia / evaporación y la temperatura: en el año 19871988 antes del inicio de los registros la relación entre la lluvia y la evaporación fue relativamente equilibrada (Figura 36), en el año 1989-1990 la lluvia fue sensiblemente menor a la evaporación, en el año 1989-90 el primer semestre fue relativamente seco y el segun- 


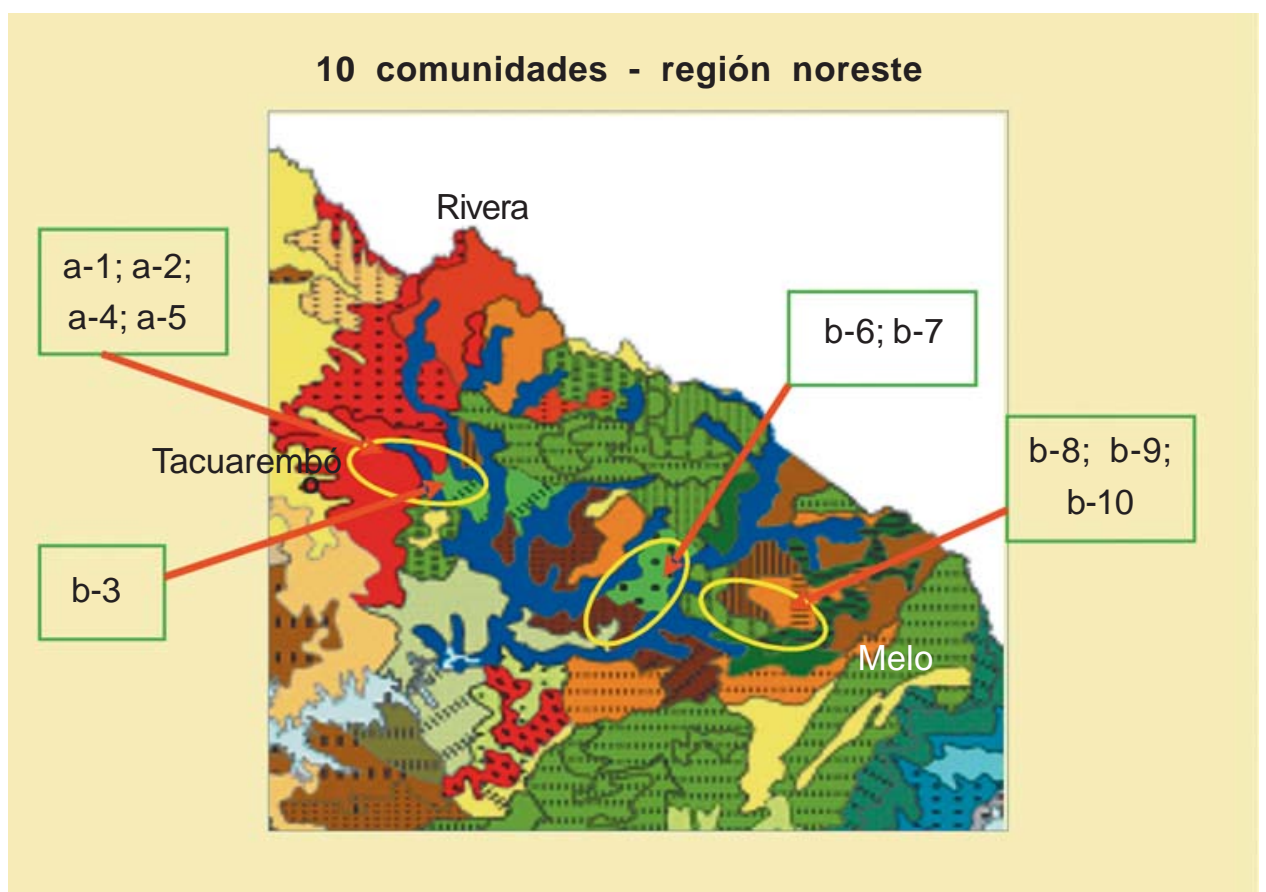

Figura 35. Localización de diez comunidades monitoreadas sobre suelos arenosos y arcillosos en la región noreste

Cuadro 22. Tasa crecimiento estacional en ocho comunidades herbáceas de la región noreste,

\begin{tabular}{|l|c|c|c|c|c|c|c|}
\hline \multirow{2}{*}{ Estación } & \multirow{2}{*}{$\begin{array}{c}\text { Media kg IMS } \\
\text { ha }^{-1} \text { día }^{-1}\end{array}$} & \multicolumn{7}{|c|}{ Probabilidad (<) } \\
\cline { 5 - 8 } & Inv.- 90 & Ot. - 90 & Prim.-89 & Prim.-90 & Ver. - 89 & Ver. - 90 \\
\hline Inv.- 89 & 3,7 & 0,0001 & 0,0001 & 0,0001 & 0,0001 & 0,0001 & 0,0001 \\
\hline Inv.-90 & 16,6 & & 0,0001 & 0,0001 & 0,0001 & 0,8517 & 0,0001 \\
\hline Ot. -90 & 9,7 & & & 0,9999 & 0,0001 & 0,0001 & 0,0001 \\
\hline Prim.- 89 & 9,6 & & & & 0,0001 & 0,0001 & 0,0001 \\
\hline Prim.-90 & 39,8 & & & & & 0,0001 & 0,0001 \\
\hline Ver. - 89 & 15,8 & & & & & & 0,0001 \\
\hline Ver. -90 & 19,5 & & & & & & \\
\hline
\end{tabular}

do relativamente húmedo y el año 1990-91 fue inverso al anterior en el primer semestre relativamente húmedo y el segundo relativamente seco. Respecto a las temperaturas en el Cuadro 23 se observan las medias estacionales.

En la Figura 36 se observa que desde 1987 hasta 1991 las cuatros estaciones de crecimiento fueron completamente diferentes desde el punto de vista climático; en el primer verano 1987-1988 el ambiente fue relativamente húmedo con mayor cantidad de lluvia que evaporación; en el segundo verano
1988-199 fue relativamente más seco con mayores valores de evaporación comparado con los niveles de las lluvias; en el tercer verano 1998-1990, en la primer parte de la estación de crecimiento el ambiente fue relativamente más seco comparado con la segunda parte que fue relativamente más húmeda; en el cuarto año 1990-1991, la primera parte de la estación de crecimiento fue relativamente más húmeda y la segunda relativamente más seca. Estas variaciones en los registros climáticos son típicos para la región (IICA, 1978; Corsi y Olmos, 1982). 


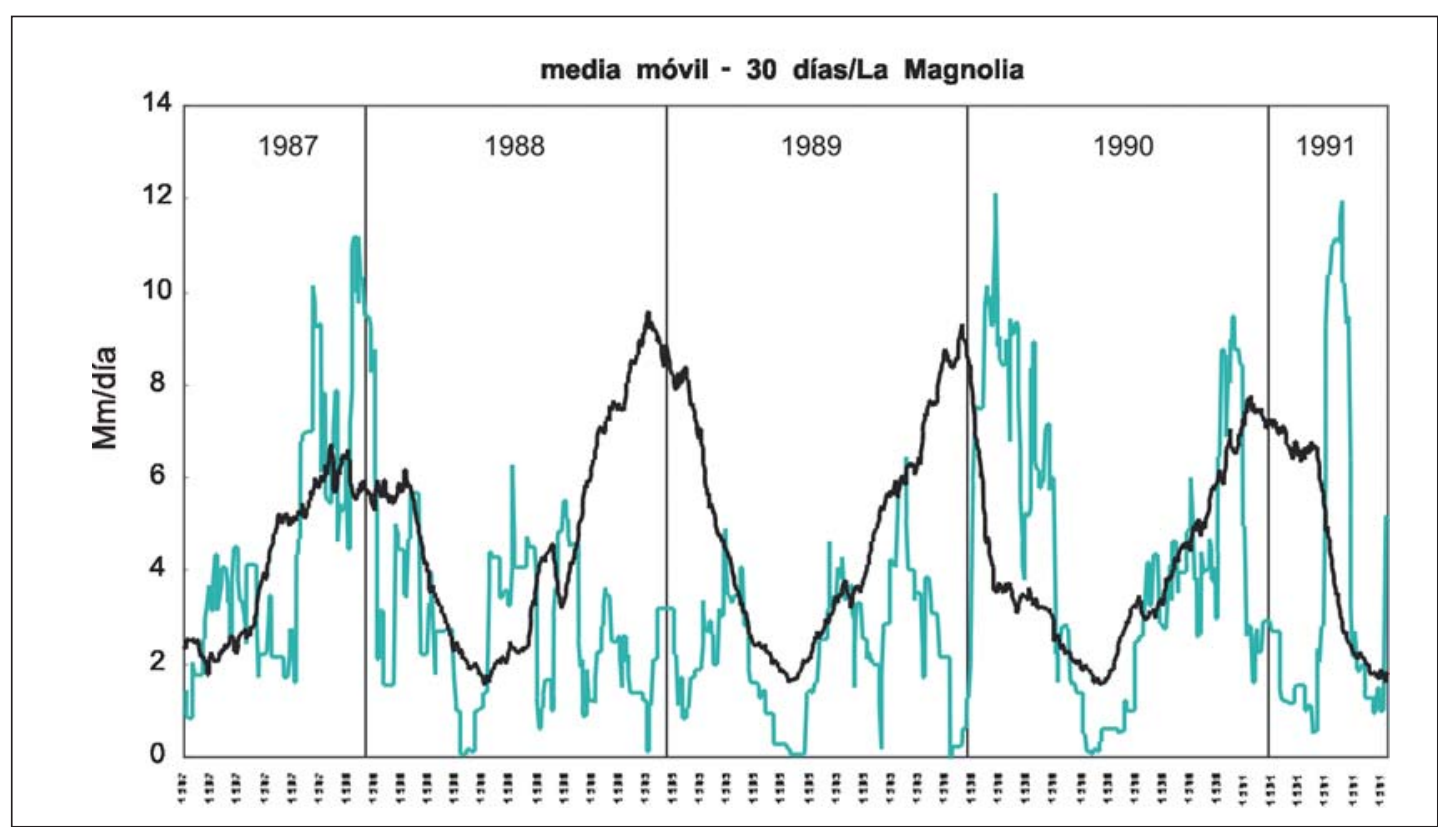

Figura 36. Variación de la media móvil cada 30 días de la lluvia (línea azul) y la evaporación (línea negra) cada 30 días en base a la Estación Meteorológica de la Unidad Experimental La Magnolia.

Cuadro 23. Temperatura media estacional $\left({ }^{\circ} \mathrm{C}\right)$ en la Unidad Experimental La Magnolia.

\begin{tabular}{|c|c|c|c|c|c|c|}
\hline $\begin{array}{c}\text { Invierno } \\
\mathbf{8 9}\end{array}$ & $\begin{array}{c}\text { Primavera } \\
\mathbf{8 9}\end{array}$ & $\begin{array}{c}\text { Verano } \\
\mathbf{8 9 - 9 0}\end{array}$ & $\begin{array}{c}\text { Otoño } \\
\mathbf{9 0}\end{array}$ & $\begin{array}{c}\text { Invierno } \\
\mathbf{9 0}\end{array}$ & $\begin{array}{c}\text { Primavera } \\
\mathbf{9 0}\end{array}$ & $\begin{array}{c}\text { Verano } \\
\mathbf{9 0 - 9 1}\end{array}$ \\
\hline 11,7 & 16,3 & 23,5 & 17,1 & 11,1 & 17,3 & 21,2 \\
\hline
\end{tabular}

Estas variaciones en el régimen de lluvias asociadas a la variación estacional de la evaporación conjuntamente con la temperatura determinan diferentes tasas de crecimiento de las pasturas estacionales e interanuales. La productividad forrajera de la primavera de 1990 fue cuatro veces superior a la primavera de 1989 (Figura 37; Cuadro 22), esta diferencia se puede explicar en principio por el mejor balance hídrico de la primavera 1990, siendo la relación lluvia / evaporación 1 para 1990 y algo más de 0,6 para 1989; asimismo puede especularse que el período de sequía previa a la primavera 1990 determinó una mayor disponibilidad de nitrógeno mineral favoreciendo el crecimiento primaveral en 1990. En la comparación de la tasa de crecimiento invernal los resultados son similares a la primavera siendo el valor para el invierno 1990 cuatro veces mayor que para el invierno 1989 (Figura 37; Cuadro 22). El invierno de 1989 no solo fue seco sino que vino precedido de una primavera y vera- no relativamente secos, en cambio el invierno 1990 fue precedido de un verano húmedo así como de un otoño también húmedo. Respecto a los registros obtenidos en verano, si bien los resultados no son tan contrastantes como los anteriores, si son estadísticamente significativas las diferencias con valores mayores para el verano 1990 respecto de 1989. Para el único caso con registros en otoño aparentemente el exceso de lluvias al final del verano y en el propio otoño determinaron una reducción en la productividad lo cual, al mismo tiempo, puede asociarse a una menor intensidad de radiación solar disponible para el crecimiento (Figura 37; Cuadro 22).

La importancia de estos registros radica en que la tendencia es independiente del manejo realizado en cada una de las pasturas, siendo que la relación lluvia / evaporación es un componente importante en la determinación de la productividad en sistemas de producción en ecosistemas naturales. 


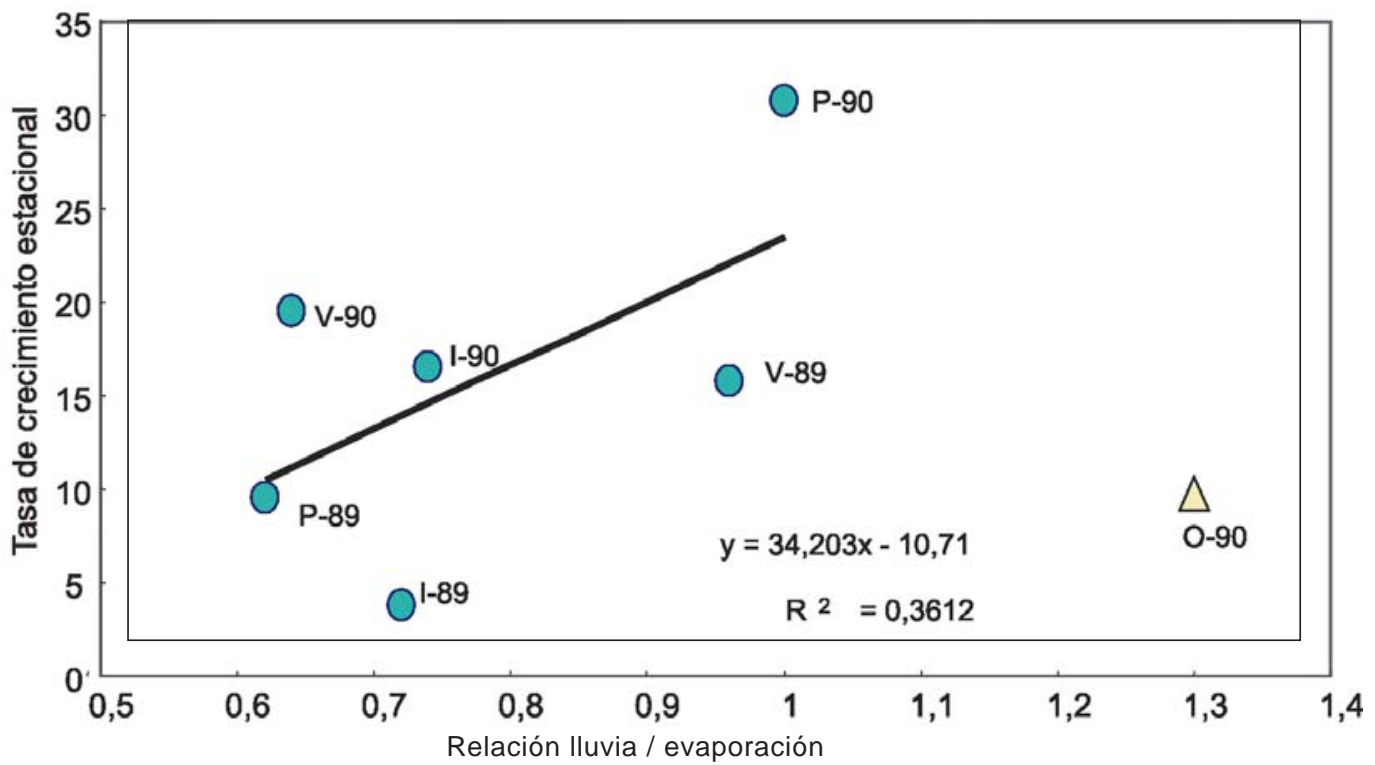

Figura 37. Tasa de crecimiento estacional en $\mathrm{kg} / \mathrm{MS} \mathrm{ha}^{-1} \mathrm{dí}^{-1}$ en siete estaciones y regresión para seis estaciones según la relación lluvia / evaporación.

El impacto de las variaciones interanuales del régimen hídrico sobre la productividad de las pasturas se observa claramente en la Figura 38, donde tanto para los suelos arenosos como para los arcillosos la productividad forrajera fue significativamente menor en el año relativamente más seco comparado con el año más húmedo.

Adicionalmente a las variaciones interanuales en la productividad forrajera, tam- bién se han registrado variaciones en productividad de acuerdo al tipo de suelo, OImos (1997), ha postulado que las diferencias encontradas entre los suelos arenosos y arcillosos se debe básicamente al balance hídrico estival, que en la región noreste favorece a los suelos arenosos debido a la estructura de su perfil mineralógico.

El mejor balance hídrico estival en los suelos arenosos favorece la presencia de

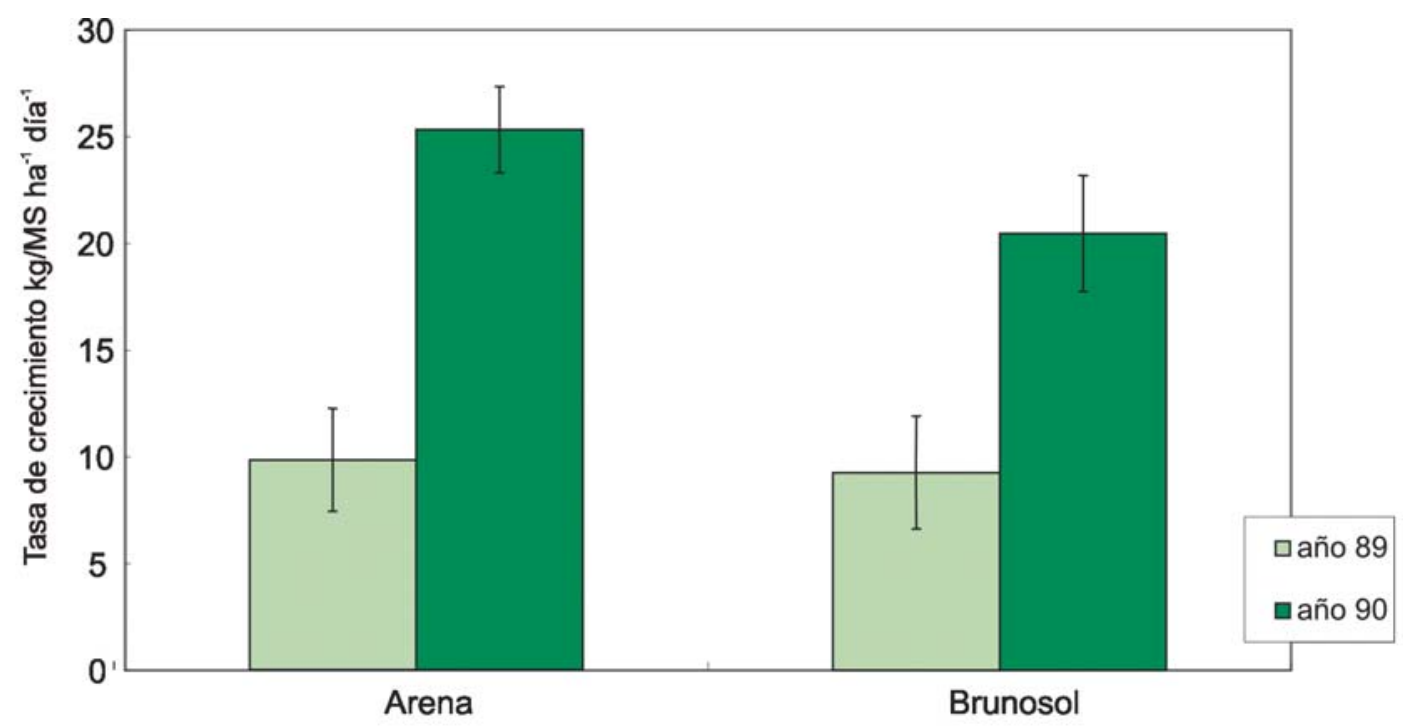

Figura 38. Variación en la tasa de crecimiento ( \pm error estándar), promedio de invierno primavera y verano, de pasturas naturales en la región noreste en dos tipos de suelo en dos años. 
especies con crecimiento de verano en estos suelos comparado con su presencia en los suelos arcillosos $(P<0,0047)$ (Figura 39).

Esta dependencia climática de la productividad se destaca en la Figura 40 donde se grafica la relación entre la productividad forrajera en otoño en relación a la proporción de especies de ciclo estival en cada pastura. El clima fue relativamente seco hasta febrero 1990, luego las lluvias comenzaron a partir del día 10 de febrero (ver Figura 36). La relación lluvia / evaporación hasta el inicio

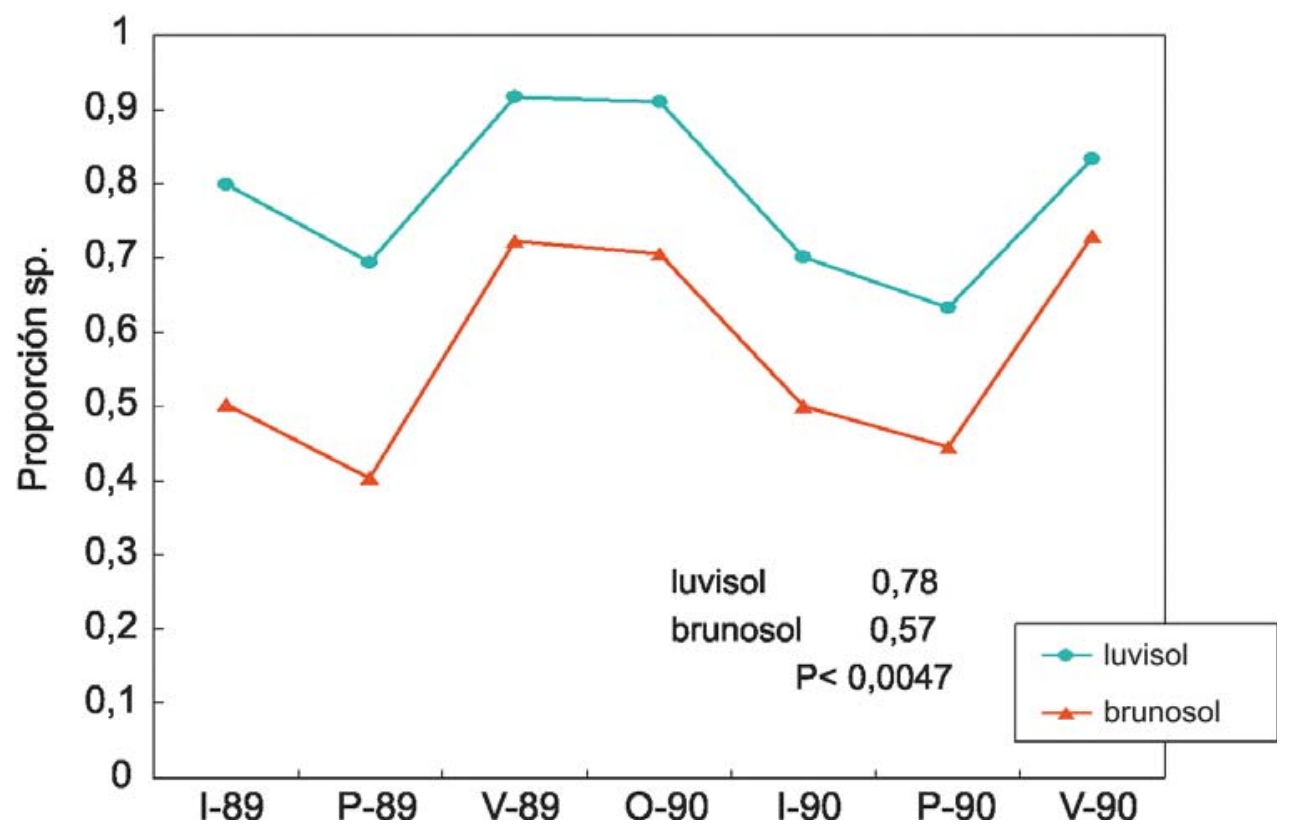

Figura 39. Proporción estacional de especies forrajeras estivales según el tipo de suelo en la región noreste.

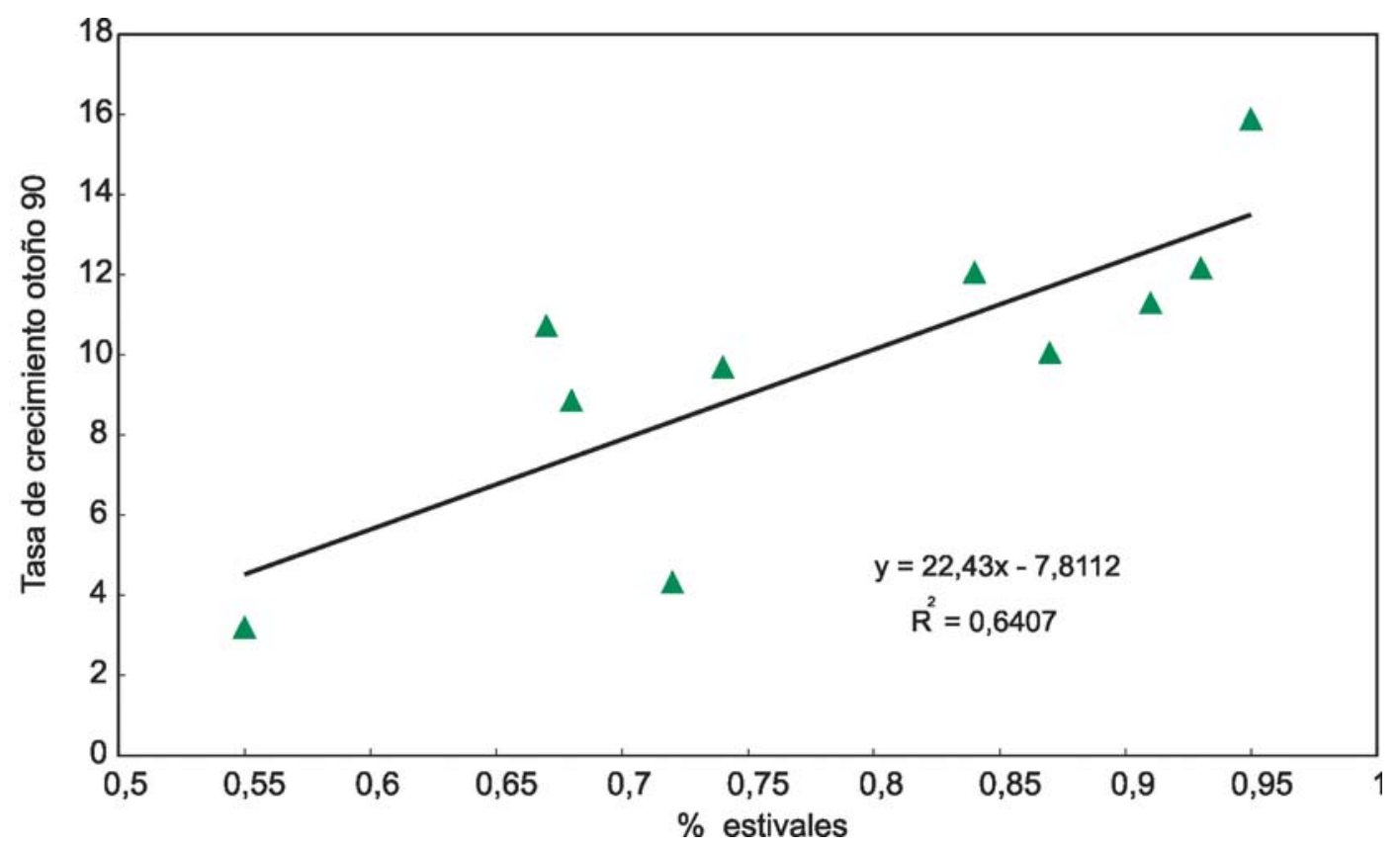

Figura 40. Tasa de crecimiento otoñal en diez pasturas naturales de la región noreste, según la proporción de especies estivales en la misma. 
de las lluvias fue 0,15 , en cambio al completar la estación de verano la relación alcanzó un valor promedio para los 90 días de 0,96. En el otoño la relación lluevia / evaporación fue 1,30. La tasa de crecimiento de la pastura se incrementó con el incremento de la proporción de especies de ciclo estival en la pastura en condiciones favorables de lluvia y temperatura para el crecimiento en la segunda parte del verano y durante el otoño.

Desde el punto de vista de la composición botánica en las diez comunidades se registró una importante variación en la proporción de los tipos vegetativos presentes; en este sentido una caracterización general se grafica en la Figura 41, mostrando el contenido proporcional de las especies de hábito de crecimiento rastrero encada pastura.

En la figura se observa que tanto en los suelos arenosos como en los arcillosos (brunosoles) con el incremento en la intensificación del uso del suelo existe una tendencia a incrementar también la proporción de especies de hábito de crecimiento rastrero en la pastura. En el caso de la arena el sitio a-2 es un potrero de cría de ganado con pastoreo aliviado, el sitio a-1 es contiguo al anterior pero completamente sobrepastoreado y los sitios a-4 y a-5 fueron en algún mo- mento rastrojo de chacra. En el caso de lo suelos arcillosos, la pastura b-9 comprende a un potrero de invernada de ganado vacuno, el sitio b-10 a una pastura donde se realizó una chacra en algún momento y el sitio b-3 corresponde a una situación de completo sobrepastoreo por muchos años consecutivos, los demás casos son intermedios a estas situaciones, siendo pasturas que han sido manejadas en forma aliviada desde el punto de vista de la intensidad del pastoreo.

\section{Suelos arenosos}

Dentro de los suelos arenosos se registraron diferencias estadísticamente significativas en la productividad forrajera de acuerdo al manejo de la pastura. En el primer año de registros el potrero 4 con manejo aliviado del pastoreo (a-2), con ganado de cría y con relativa mayor disponibilidad de forraje presentó una tasa de crecimiento significativamente mayor $(P<0.05)$ que un potrero contiguo considerado casi un piquete (a-1) y mucho menor cantidad de forraje disponible (Cuadro 24). La pastura que luego de un cultivo (probablemente papa) recibió la instalación de un pradera convencional y luego se volvió campo bruto presentó una productividad significativamente superior $(P<0,001)$ a un

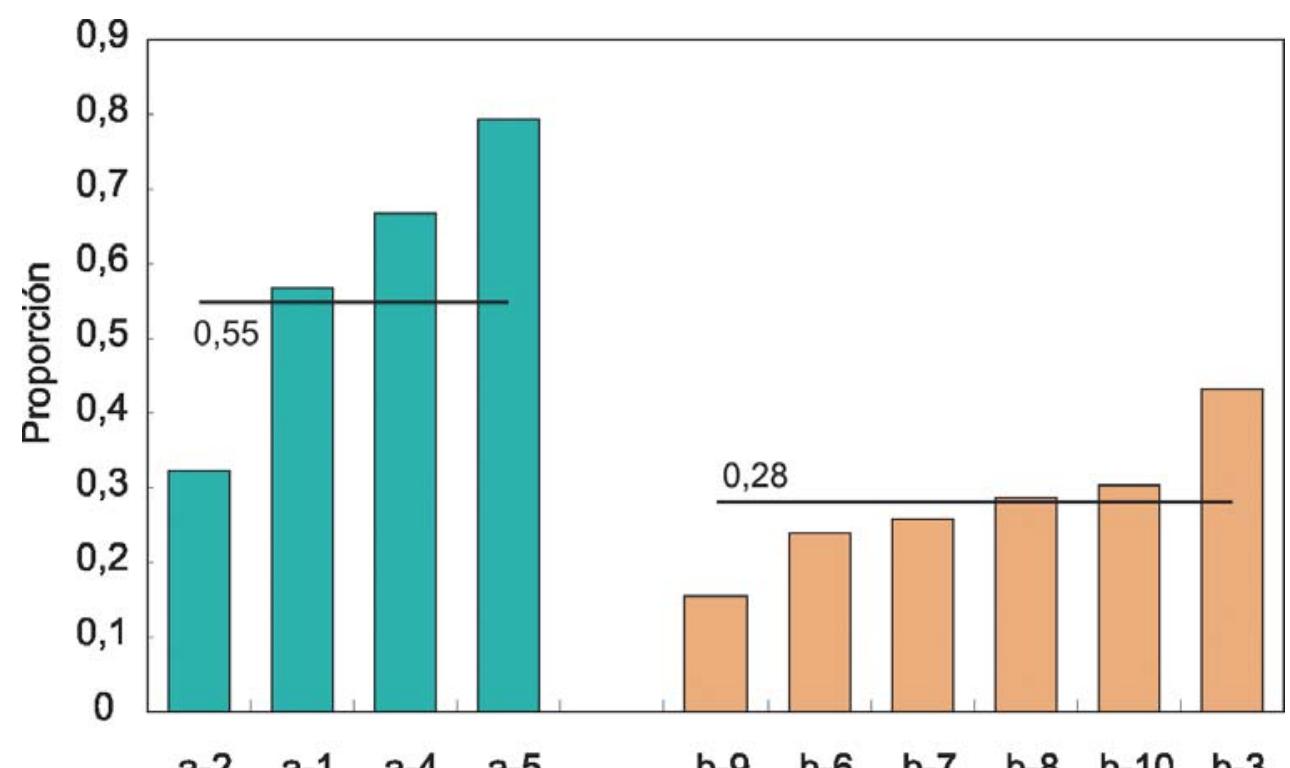

Figura 41. Proporción de especies de hábito rastrero de acuerdo al suelo y el manejo del pastoreo en diez comunidades de pasturas naturales de la región noreste. 
Cuadro 24. Tasa crecimiento en cuatro comunidades herbáceas durante el primer año en suelos arenosos.

\begin{tabular}{|l|c|c|c|c|}
\hline \multirow{2}{*}{ Pastura } & Media kg I MS & \multicolumn{3}{|c|}{ Probabilidad (<) } \\
\cline { 3 - 5 } ha-1 $^{-1}$ día $^{-1}$ & $\begin{array}{l}\text { Potrero 4 - LM } \\
\text { aliviado }\end{array}$ & $\begin{array}{c}\text { Campo bruto } \\
\text { pos soja }\end{array}$ & $\begin{array}{c}\text { Campo bruto } \\
\text { cultivo-pradera }\end{array}$ \\
\hline $\begin{array}{l}\text { Potrero 2 - LM } \\
\text { sobrepastoreado }\end{array}$ & 9,8 & 0,0290 & 0,0001 & 0,6697 \\
\hline Potrero 4 - L Maliviado & 11,9 & & 0,0001 & 0,0098 \\
\hline Campo bruto pos soja & 9,4 & & & 0,0001 \\
\hline $\begin{array}{l}\text { Campo bruto cultivo } \\
\text {-pradera }\end{array}$ & 15,8 & & & \\
\hline
\end{tabular}

campo bruto luego de un cultivo de soja pero que no tuvo previamente un pradera convencional (Cuadro 24).

Cuando se toman los diferentes suelos y el manejo aplicada a cada pastura se observa aún una variación en la productividad en relación a estos factores.

Luego del primer año de registros la pastura a-5 cultivo-pradera-campo bruto fue convertida a una plantación forestal por lo que se suspendieron los registros. Considerando las siete estaciones donde se registro la productividad forrajera (Figura 42) se observa una tendencia general de recuperación de la productividad luego del período de máximo estrés hídrico en el año 1989-1990, básicamente mirando los valores para cada invierno y siendo en el verano donde la pastura manejada con una mayor disponibilidad de forraje (a-2, pastura aliviada) presenta mayor productividad comparada con la pastura sobre pastoreada (a-1, sobrepastoreo. La pastura a-4 (campo bruto luego de soja) fue la que mantuvo la menor productividad

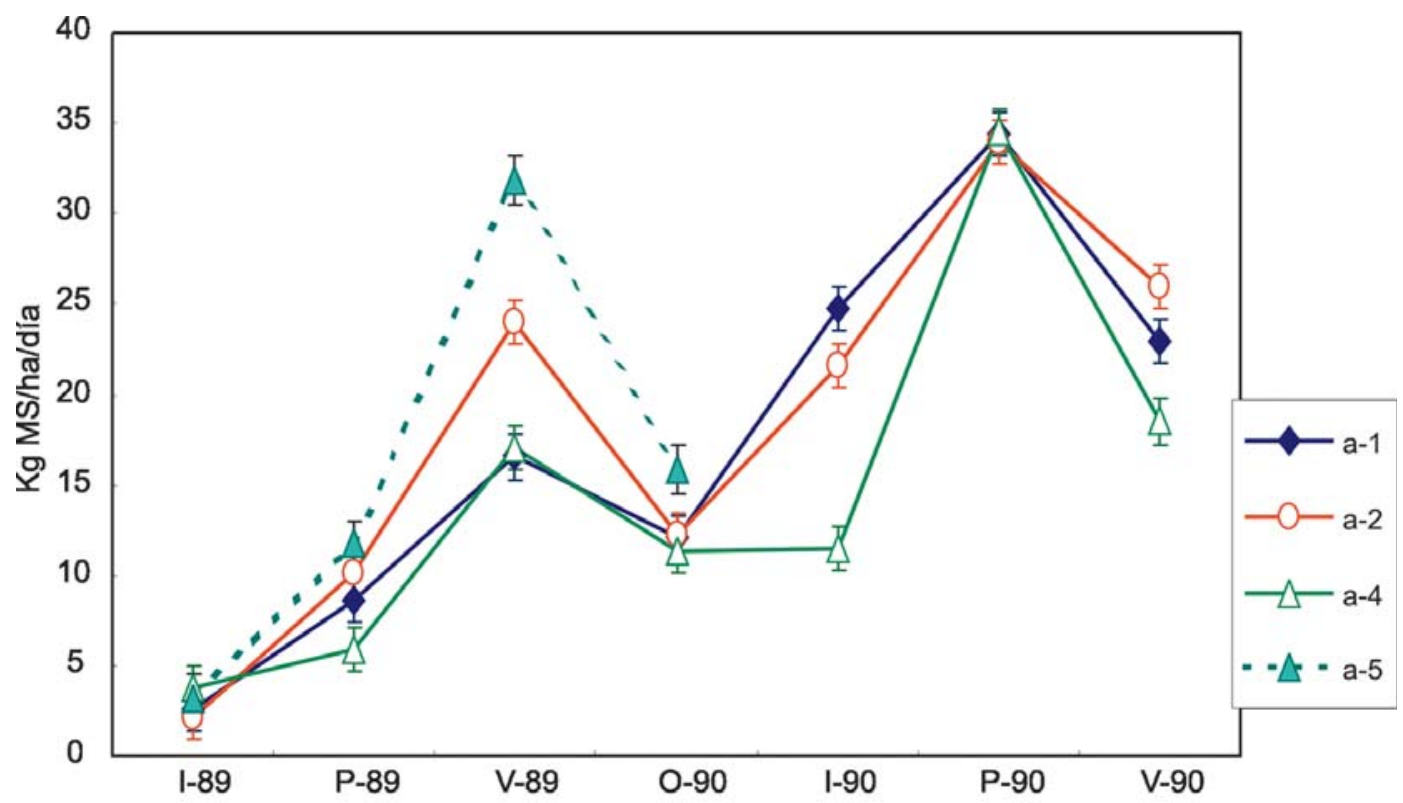

Figura 42. Tasa de crecimiento estacional ( \pm error estándar) en cuatro pasturas sobre suelos arenosos.

Referencias:

a - 1: potrero 2 - sobre pastoreado.

a - 2: potrero 4 - aliviado cría vacuna.

a - 4: potrero pos soja - campo bruto luego de soja.

a - 5: potrero pos pradera - campo bruto luego de cultivos y pradera. 
forrajera en todo el período de registros, más marcadamente en el invierno 1990, probablemente por estar preferentemente dominada por Cynodon dactylon.

\section{Brunosoles}

En la Cuadro 25 se reportan las tasas de crecimiento para las seis pasturas naturales creciendo sobre brunosoles, en donde prácticamente los valores medios para el primer año difieren significativamente entre ellos salvo el caso de las pasturas b-7 y b-8.

Las pasturas que presentan una menor productividad son el campo bruto (b-10) y la pastura sobre pastoreada (b-3) (Cuadro 25), por el contrario la mayor productividad se registró en la pastura con mejor manejo y que en algún momento fue fertilizada mejorada (b-6), con valores intermedios se registraron en las pasturas con ganado de cría y la invernada (Figura 43).

Cuadro 25. Tasa de crecimiento en seis comunidades en el primer año sobre brunosoles.

\begin{tabular}{|l|c|c|c|c|c|c|}
\hline Pastura & Media kg / MS & \multicolumn{5}{|c|}{ Probabilidad (<) } \\
\cline { 5 - 7 } & ha $^{-1}$ día $^{-1}$ & $\begin{array}{c}\text { Pastura } \\
\text { mejorada } \\
\text { 20 años } \\
\text { atrás }\end{array}$ & $\begin{array}{c}\text { Suelo } \\
\text { superficial } \\
\text { aliviado }\end{array}$ & $\begin{array}{c}\text { Aliviado cría } \\
\text { vacuna }\end{array}$ & $\begin{array}{c}\text { Aliviado } \\
\text { invernada }\end{array}$ & $\begin{array}{c}\text { Campo bruto } \\
\text { pos } \\
\text { cultivo }\end{array}$ \\
\hline Sobrepastoreo & 5,02 & 0,0001 & 0,0001 & 0,0001 & 0,0001 & 0,0001 \\
\hline $\begin{array}{l}\text { Pastura mejorada } \\
20 \text { años atrás }\end{array}$ & 10,82 & & 0,0001 & 0,8431 & 0,0278 & 0,0001 \\
\hline $\begin{array}{l}\text { Suelo superficial } \\
\text { aliviado }\end{array}$ & 15,16 & & & 0,0001 & 0,0001 & 0,0001 \\
\hline $\begin{array}{l}\text { Aliviado cría } \\
\text { vacuna }\end{array}$ & 10,95 & & & & 0,0172 & 0,0001 \\
\hline Aliviado invernada & 9,18 & & & & & 0,0001 \\
\hline $\begin{array}{l}\text { Campo bruto } \\
\text { pos cultivo }\end{array}$ & 3,28 & & & & & \\
\hline
\end{tabular}

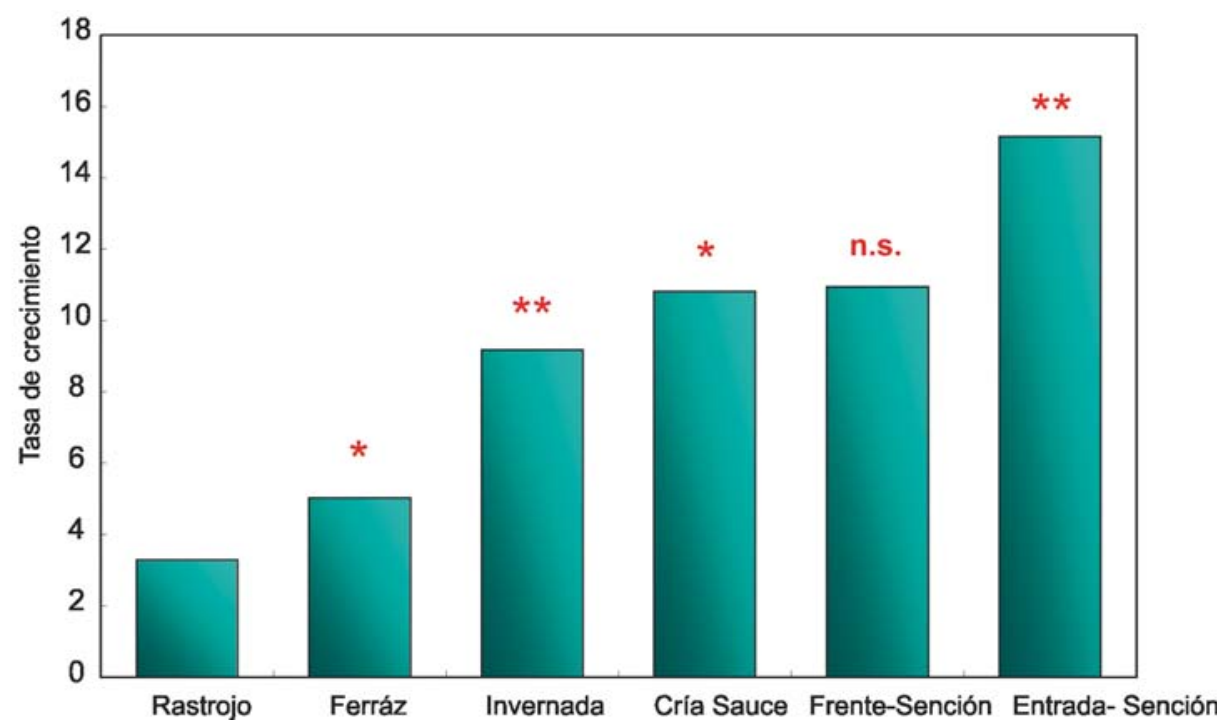

Figura 43. Impacto de las prácticas de manejo en la productividad forrajera de seiscomunidades sobre brunosoles en la región noreste: rastrojo (b-10), Ferráz (b-3), invernada (b-9), cría Sauce (b-8), frente-Sención (b-7), entrada-Sención (b-6). 
Al igual que lo registrado en los suelos arenosos las pasturas recuperaron la productividad forrajera en general en el segundo año (Figura 44), siendo mayores los incrementos en los sitios donde los pasturas fueron mejor manejadas: b-6, b-7, b-8 y b-9. Claramente para todo el período de registros la pastura degradada pos cultivo (b-10) así como la sobrepastoreada (b-3) muestran valores significativamente menores en productividad y por otro lado los valores significativamente mayores se registraron en la pastura b-6 que fue mejorada en algún momento de su historia. Las otras pasturas presentan en general un productividad forrajera intermedia entre las anteriores (en invierno 1990 no se obtuvieron registros para la pastura b-9).

\section{General}

Desde el punto de vista de las prácticas de manejo aplicadas en cada pastura, se registraron diferencias en la tasa de creci- miento entre las mismas cuando se consideraron en forma conjunta durante dos años en ocho de los sitios estudiados con datos completos (Cuadro 26; Figura 45).

De las 28 comparaciones realizadas entre las diferentes medias, 23 presentaron diferencias estadísticamente significativas. Las pasturas donde anteriormente se realizó algún tipo de cultivo y / o fueron sometidas a sobrepastoreo, tendieron a registrar una menor tasa de crecimiento: 2- campo bruto pos cultivo, 3- sobrepastoreado, 4campo bruto pos cultivo; por otro lado las pasturas que han sido promocionadas en su crecimiento por la inclusión de fertilizantes y especies de mayor crecimiento tendieron a presentar una mayor productividad: 8- mejorado previamente; en una situación intermedia se encuentran las pasturas que han sido menos intervenidas, por ejemplo los potreros de cría vacuna con pastoreo aliviado: 1- cría aliviado, 6- aliviado cría LM, 7superficial.

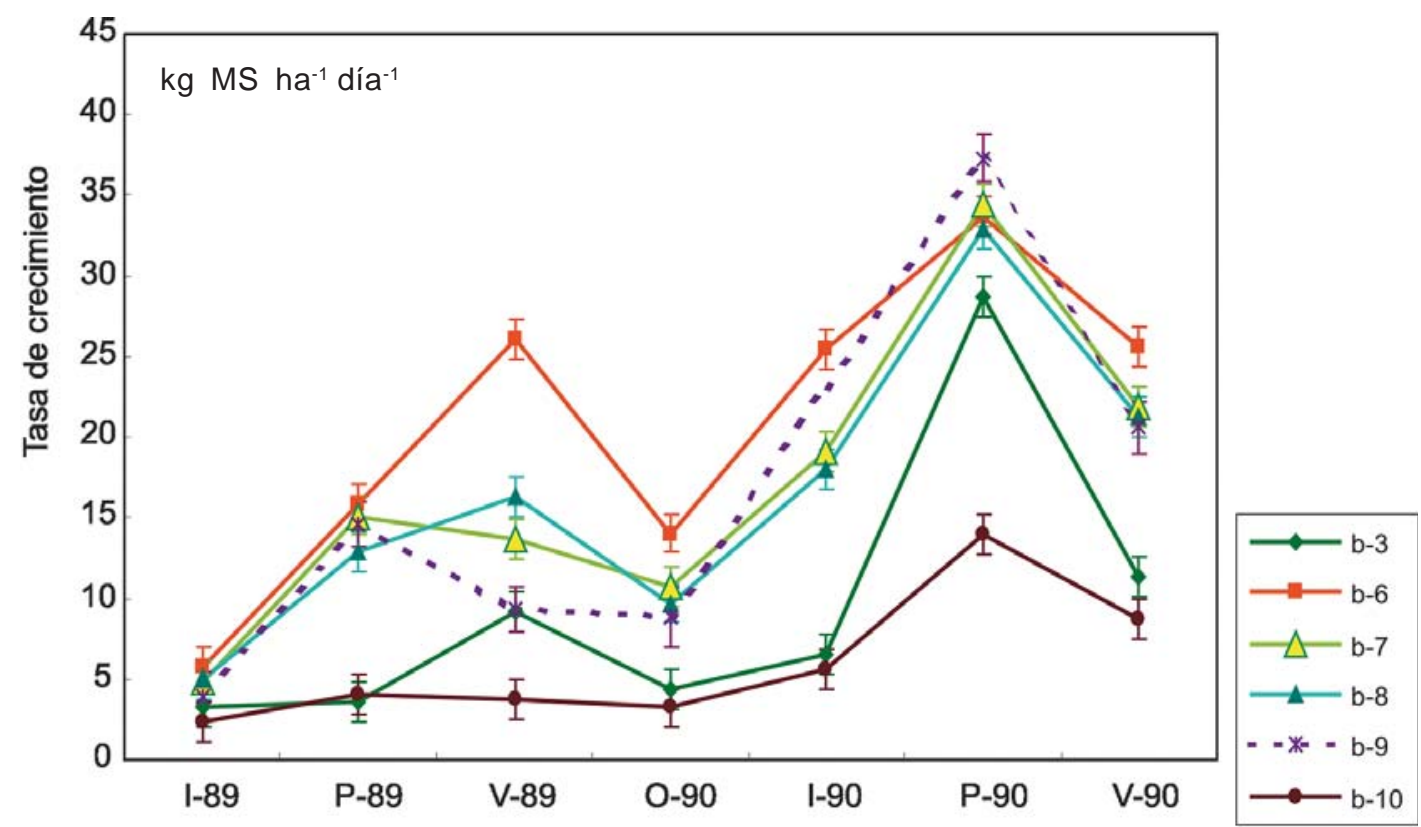

Figura 44. Tasa de crecimiento estacional ( \pm error estándar) en seis pasturas sobre suelos arcillosos general.

Referencias:

b-3 : sobre pastoreo.

b-6 : pastura mejorada 20 años antes.

b-7 : similar a 6 pero sin mejoramiento y suelo más superficial.

b-8 : potrero de cría vacuna.

b-9 : potrero de invernada.

b-10 : campo bruto luego de un año de cultivo. 
Cuadro 26.Tasa de crecimiento $\mathrm{kg} / \mathrm{MS} \mathrm{ha}^{-1} \mathrm{día}^{-1}$ en ocho comunidades herbáceas de la región noreste durante siete estaciones de crecimiento.

\begin{tabular}{|c|c|c|c|c|c|c|c|c|}
\hline \multirow[t]{2}{*}{ Pastura } & \multirow{2}{*}{$\begin{array}{l}\text { Media kg / MS } \\
\text { ha }^{-1} \text { día }^{-1}\end{array}$} & \multicolumn{7}{|c|}{ Probabilidad (<) } \\
\hline & & 2 & 3 & 4 & 5 & 6 & 7 & 8 \\
\hline $\begin{array}{l}1 \text { - Cría } \\
\text { aliviado }\end{array}$ & 16,57 & 0,0001 & 0,0001 & 0,0392 & 0,8726 & 0,0223 & 0,9891 & 0,0001 \\
\hline $\begin{array}{l}2 \text { - C. bruto } \\
\text { pos cultivo }\end{array}$ & 5,93 & & 0,0001 & 0,0001 & 0,0001 & 0,0001 & 0,0001 & 0,0001 \\
\hline $\begin{array}{l}3 \text { - Sobre } \\
\text { pastoreado }\end{array}$ & 9,57 & & & 0,0001 & 0,0001 & 0,0001 & 0,0001 & 0,0001 \\
\hline $\begin{array}{l}4 \text { - C. bruto } \\
\text { pos soja }\end{array}$ & 14,67 & & & & 0,0001 & 0,0001 & 0,0024 & 0,0001 \\
\hline $\begin{array}{l}5 \text { - Sobre } \\
\text { pastoreado LM }\end{array}$ & 17,39 & & & & & 0,5070 & 0,9997 & 0,0001 \\
\hline 6 - Aliviado LM & 18,57 & & & & & & 0,2275 & 0,0030 \\
\hline 7 - Superficial & 17,09 & & & & & & & 0,0001 \\
\hline $\begin{array}{l}8 \text { - Mejorado } \\
\text { previamente }\end{array}$ & 20,92 & & & & & & & \\
\hline
\end{tabular}

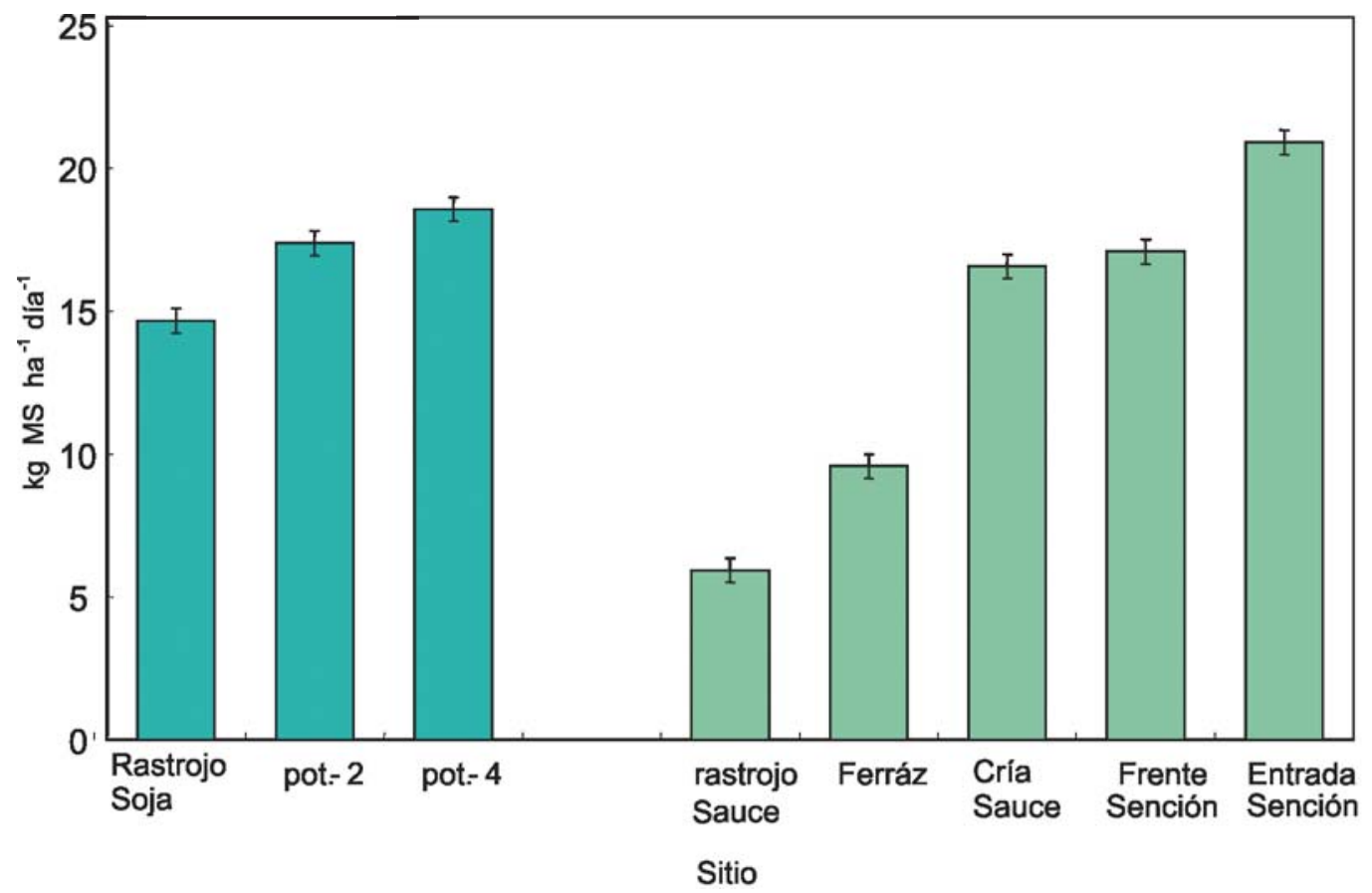

Figura 45. Tasa de crecimiento promedio ( \pm error estándar) según el tipo de manejo en ocho pasturas naturales de la región noreste. 


\section{Estructura y composición botánica}

\section{Suelos arenosos}

En las comunidades naturales de pasturas se pueden identificar tanto especies de ciclo de crecimiento estival e invernal. Dentro de los suelos arenosos la pastura más aliviada tendió a ser la que presentó un mayor proporción de especies estivales comparada con el campo sobrepastoreado y las pasturas que provinieron luego de un cultivo presentaron valores intermedios (Figura 46).

Respecto a la proporción de especies cespitosas igualmente la pastura aliviada fue la que presentó la proporción más alta en la composición botánica, por su parte las pasturas con mayor artificialización (soja, pradera) presentaron los menores valores y en la pastura sobrepastoreada se registraron valores intermedios (Figura 47). Aparentemente sería durante el período invernal e inicio de la primavera donde se generan las mayores diferencias en la proporción de especies cespitosas.
Estos resultados confirman la predominancia de especies de ciclo estival en los suelos arenosos y al mismo tiempo muestran que, según las condiciones de manejo, mayormente la intensidad de la explotación, presión de pastoreo, artificialización, tienen un impacto tal que determinan cambios en la composición botánica tendiendo las comunidades manejadas con menor intensidad a presentar una dominancia de especies de crecimiento erecto (cespitosas) y esto contribuye a su mayor productividad forrajera.

Desde el punto de vista estructural y tal como se reportó anteriormente las cuatro comunidades presentan curvas de concentración muy similares a alas registradas en los relevamientos previos (Figura 3), donde prácticamente el $70 \%$ del recubrimiento de la vegetación la genera el $30 \%$ de las especies de la comunidad; en este caso el $30 \%$ de las especies varía entre 5-8 especies según la pastura (Figuras 48 a 51). Las pasturas más intervenidas (soja a-4, pradera a-5) tienden a tener una menor diversidad y alcanzan el $70 \%$ del recubrimiento con 5 especies en promedio (Figuras 50 y 51) en cambio las

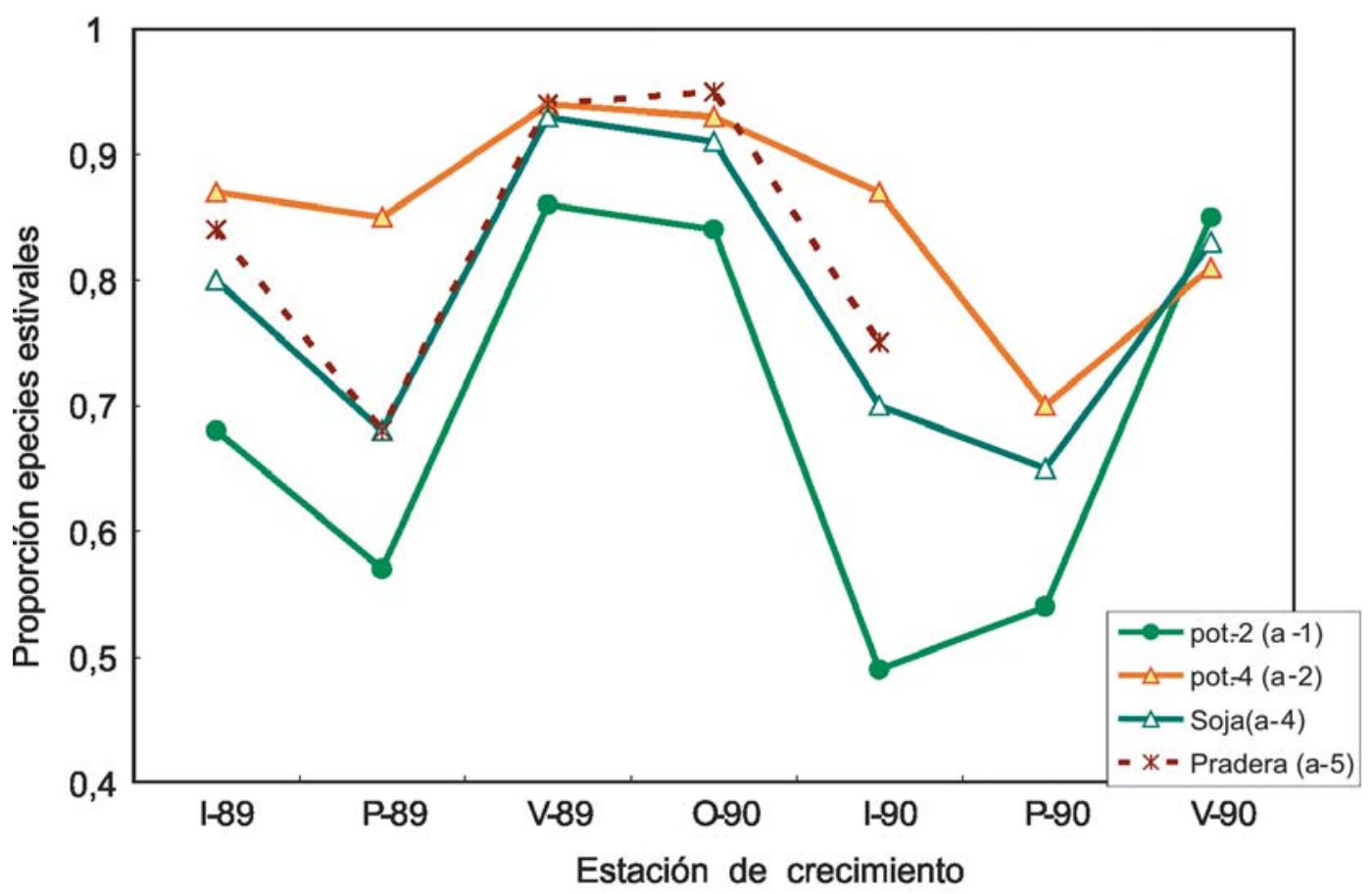

Figura 46. Proporción de especies de ciclo estival en cuatro comunidades sobre suelos arenosos: sobrepastoreado (pot. 2 LM, a-1), pastoreo aliviado (pot. 4 LM, a-2), campo bruto luego de cultivos de soja (a-4), campo bruto luego de cultivos y praderas convencionales (a-5). 


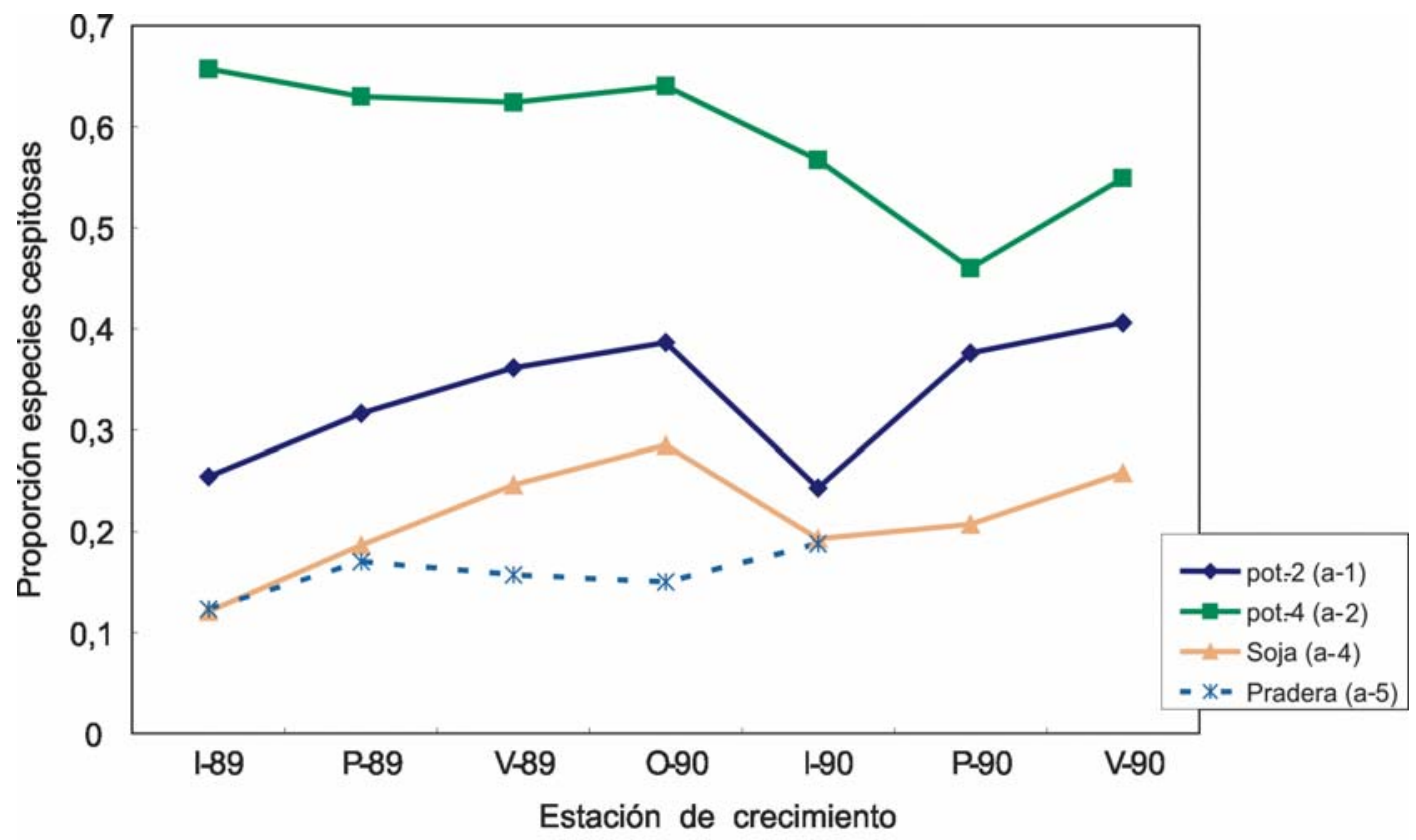

Figura 47. Proporción de especies cespitosas en cuatro pasturas sobre suelos arenosos en siete estaciones de crecimiento.

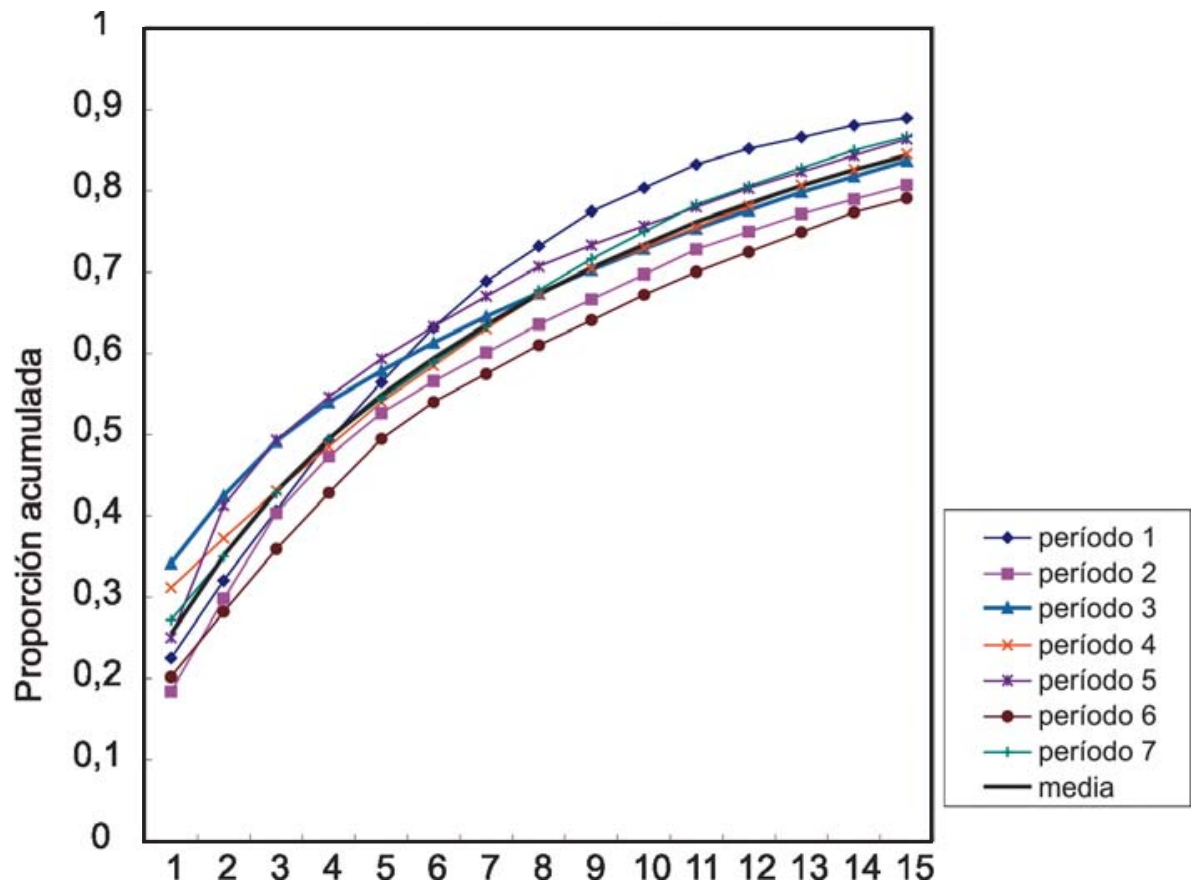

Figura 48. Contribución a la cobertura de las primeras 15 especies en la pastura sobrepastoreada sobre suelos arenosos, potrero 2 La Magnolia, en siete estaciones de registros. 


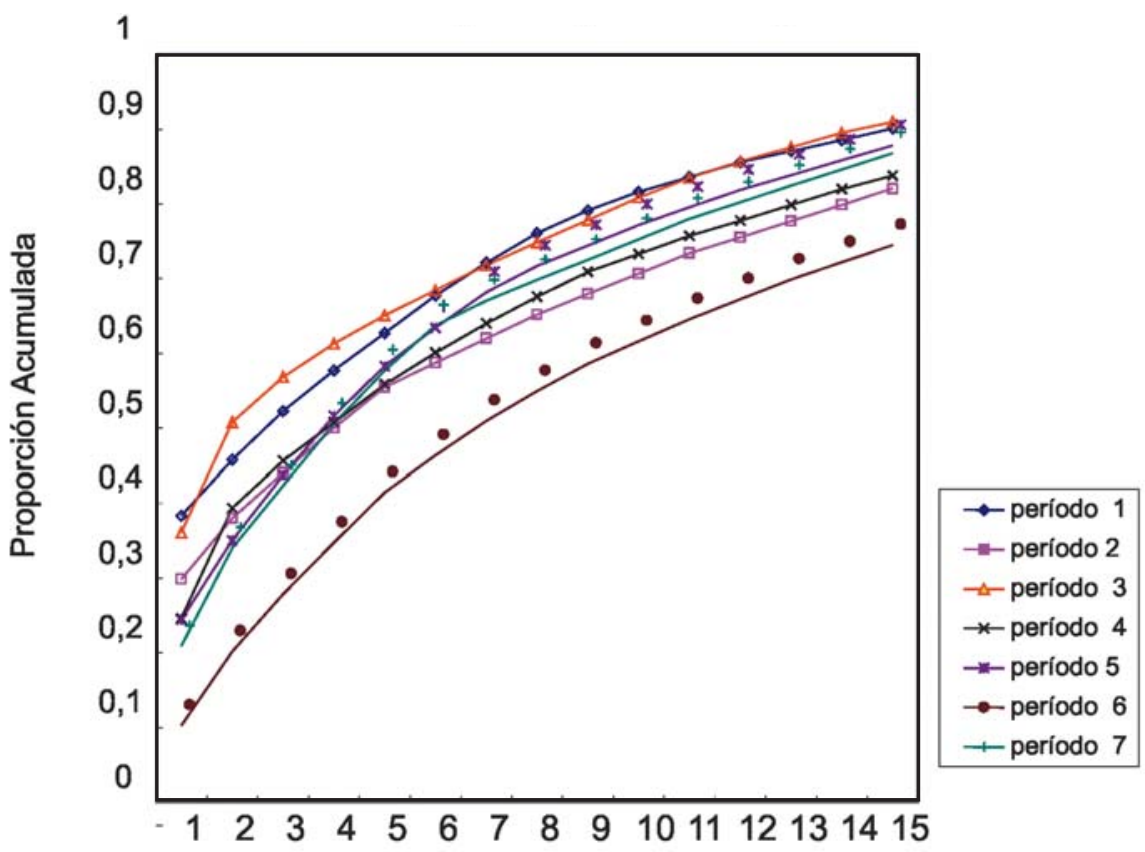

Figura 49. Contribución a la cobertura de las primeras 15 especies en la pastura con pastoreo aliviado sobre suelos arenosos, potrero 4 La Magnolia, en siete estaciones de registros.

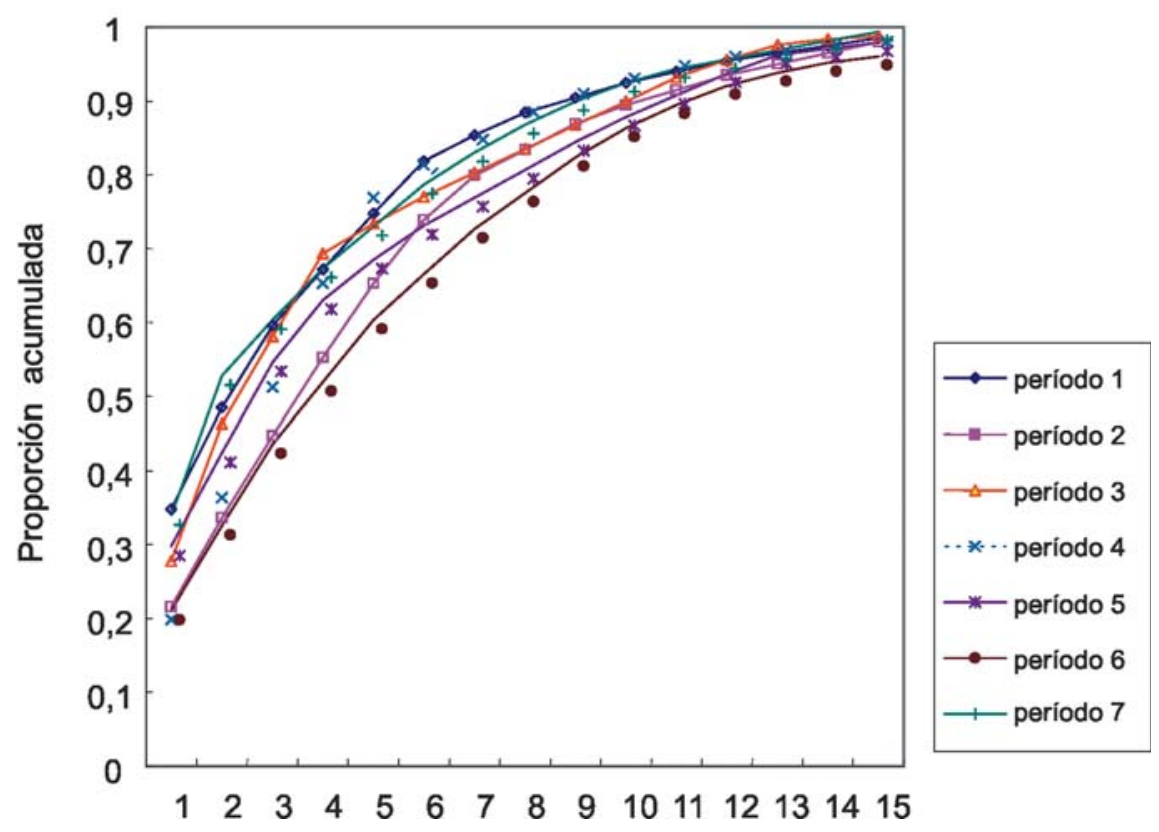

Figura 50. Contribución a la cobertura de las primeras 15 especies en la pastura restablecida luego del cultivo de soja sobre suelos arenosos, en siete estaciones de registros. 

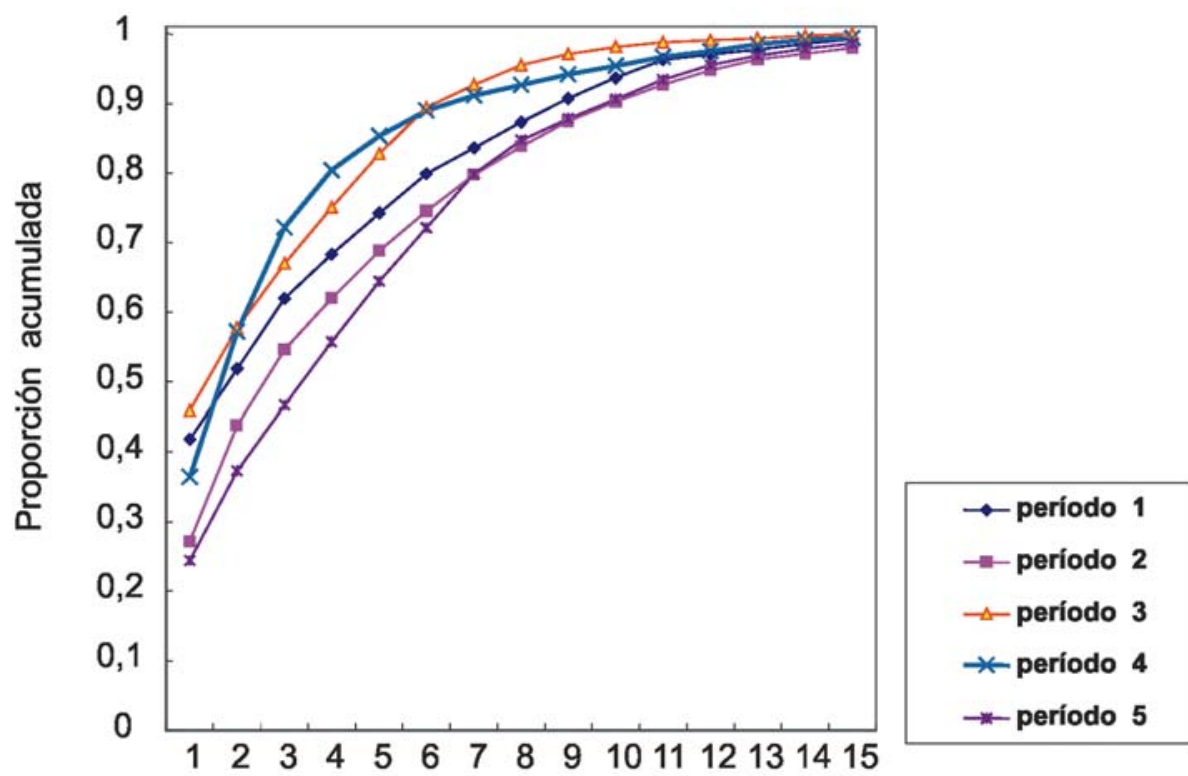

Figura 51 Contribución a la cobertura de las primeras 15 especies en la pastura restablecida luego de cultivos y praderas sobre suelos arenosos, en cinco estaciones de registros.

menos artificializadas lo alcanzan con 8 especies (Figuras 48 y 49 ).

El número total de especies presentes en cada sitio fue sensiblemente superior en las pasturas con un manejo con menor interven- ción, es decir donde no se había realizado ningún cultivo previo, por lo menos en los últimos veinte años (Figura 52), comparado con las pasturas donde se había realizado el laboreo del suelo previamente. El número

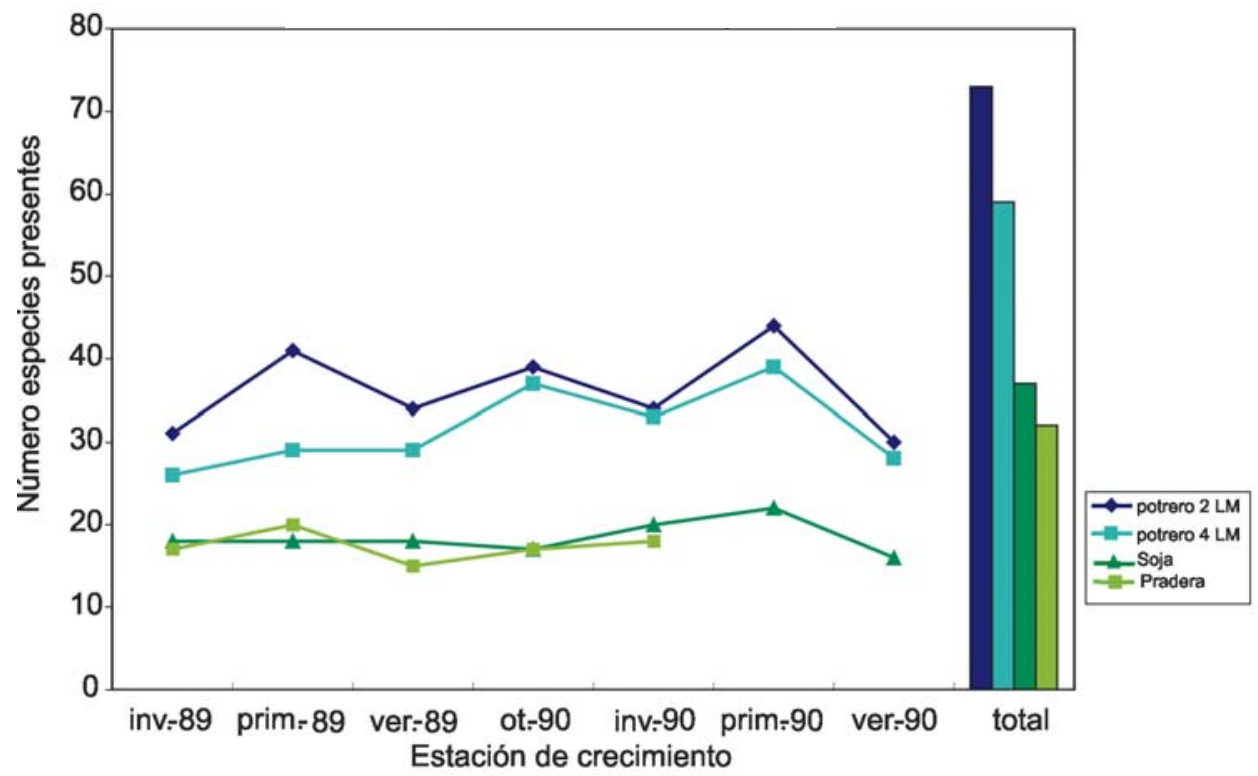

Figura 52. Número total de especies en cuatro pasturas sobre suelos arenosos en la región noreste, en siete fechas de registro estacionales (líneas) y total acumulado (barras) (potrero 2 LM a-1, potrero 4 LM a-2, soja a-4, pradera a-5) suelos arcillosos. 
total acumulado en los siete períodos de registro prácticamente fue el doble en los sitios pastoreados comparados con los sitios donde hubo un cultivo previo a la pastura presente, indicado por las barras en la Figura 52.

\section{Suelo arcilloso}

Respecto a la proporción de especies estivales en las pasturas desarrolladas sobre brunosoles (suelos arcillosos) la misma varía según la historia de cada sitio. El campo bruto, campo recuperado luego de cultivo (b-10) y la pastura en suelo con menor profundidad manejada para cría (b-7), tendieron a presentar los menores valores de especies estivales, en cambio el potrero sobrepastoreado (b-3) y la invernada (b-9) tendieron a presentar una mayor proporción de especies estivales (Figura 53). Las otras dos pasturas, entrada Sención (b-6) y cría-8 (b-8) presentaron valores intermedios.

En los brunosoles también la proporción de especies cespitosas tendió a ser mayor en las pasturas menos intervenidas o artificializadas, siendo la que presentó valores relativamente mayores la pastura natural utilizada como invernada (b-9) y en contraposición la pastura fuertemente sobrepastoreada (b-3) en la que se registraron los menores valores (Figura 54); las otras pasturas presentaron valores intermedios. Independientemente de la variabilidad climática la presencia de un cierto tipo de especies característico, se encontró asociada principalmente a la historia de manejo recibida por la pastura en cada potrero.

Cuando se consideran las curvas de concentración en los suelos arcillosos las mismas tienden a presentar un número mayor de especies para alcanzar el $70 \%$ del recubrimiento de la vegetación (Figuras 55 a 60) comparado con los suelos arenosos (Figuras 48 a 51), llegando a valores próximos a 10.

Claramente se observa que las pasturas con mayor artificialización tienden a alcanzar el valor de $70 \%$ de recubrimiento de la vegetación con un menor número de especies (6-8) (Figuras 55 y 60), correspondiendo, respectivamente, a la pastura sobrepastoreada (b-3) en el sitio Ferráz para la primera figura y a la pastura que previamente fue laboreado el suelo la segunda (b-10). Respecto a las pasturas que han recibido una menor intervención o artificialización se requirieron 9-10 especies para llegar al $70 \%$ del recubrimiento (Figuras 56, 57, 58 y 59). El menor número de especies necesario en cada pastura, para alcanzar el $70 \%$ del recubrimiento de la vegetación, en pasturas con mayor grado de intervención o artificiali-

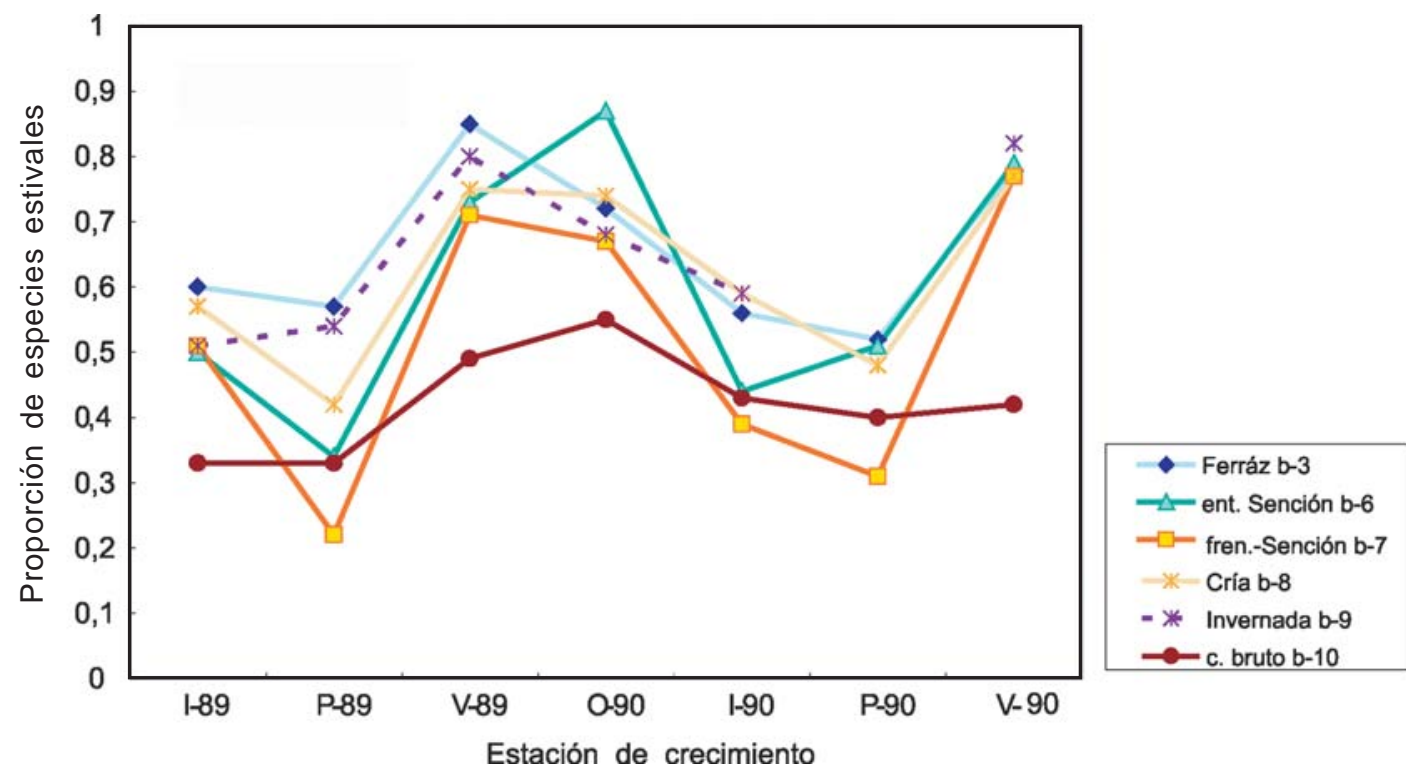

Figura 53. Proporción de especies de crecimiento estival en seis pasturas sobre suelos arcillosos en siete estaciones de registro en la región noreste. 


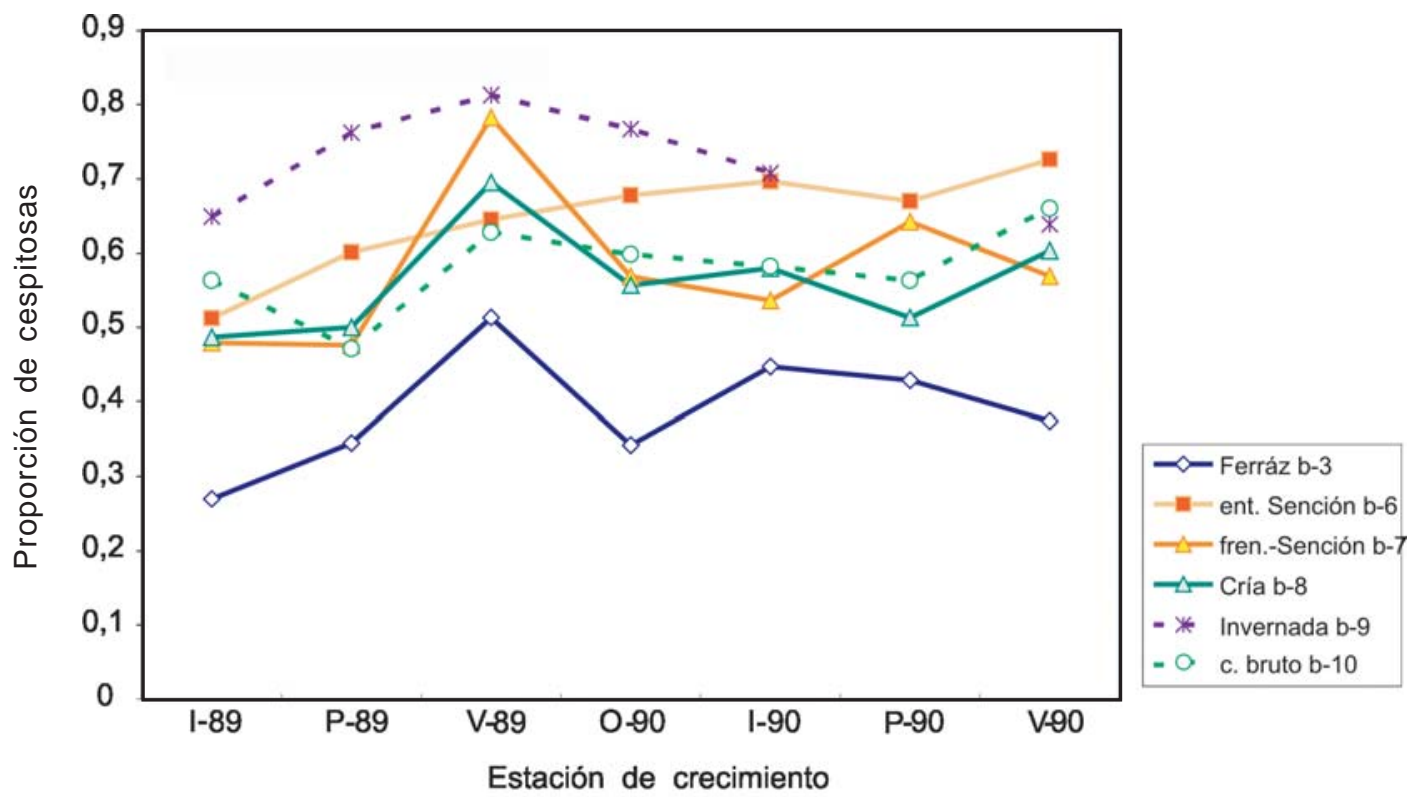

Figura 54. Proporción de especies cespitosas en seis pasturas naturales de la región noreste en siete estaciones de registro.

zación, es coincidente con los reportados en párrafos anteriores en los suelos arenosos.

En cuanto al número de especies en los suelos arcillosos en la Figura 61 se reportan los registros obtenidos en las seis comunidades naturales en siete estaciones de crecimiento. Se destaca el mayor número de especies presentes en las pasturas con un mejor manejo histórico tanto en el sentido de la presión de pastoreo como con la aplicación de fertilizantes (pastura Sención b-6, superficial enfrente Sención b-7); en contraste con estos valores se encuentra la pastura restablecida luego de chacra con laboreo del suelo (b-10). Las pasturas con manejos intermedios, también presentan valores intermedios en el número de especies presentes.

Cuando se considera el total de especies registradas en los siete períodos, se registró tanto en la pastura luego de chacra como en la sobrepastoreada (Ferráz) un número sensiblemente menor de especies comparado con las pasturas mejor manejadas como Sención (b-6) y superficial (b-7), siendo tanto para la pastura con el manejo del rodeo de cría como la invernada los valores intermedios.
A los efectos de visualizar los impactos de la agricultura sobre la sucesión posterior en una pastura restablecida a campo bruto, luego de diez años pos agricultura, en la Figura 62 se grafican los registros obtenidos en dos pasturas contiguas, separadas por un alambrado, en un mismo tipo de suelo, en dos condiciones contrastantes: pastoreo aliviado de ganado de cría y campo bruto luego de agricultura. Se destacan claramente los valores mayores en los registros del número total de especies presente en la pastura (b-8) un campo con pastoreo aliviado con cría de ganado, comparado con la pastura que fue intervenida previamente con agricultura (b-10) independientemente de que se observan fluctuaciones estacionales, en virtud de la variabilidad en la composición botánica y las condiciones ambientales de lluvia y temperatura.

Aparentemente cuando el período de relativo estrés hídrico, desarrollado en el verano 1988-1989 (ver Figura 36), las pasturas tendieron a converger hacia un valor similar en el número de especies en el invierno 1989, sin embargo al mejorar las condiciones ambientales en la primavera siguiente y a partir del otoño 1990 los valores difirieron marcadamente hasta el final del período de registros en el verano 1990. 


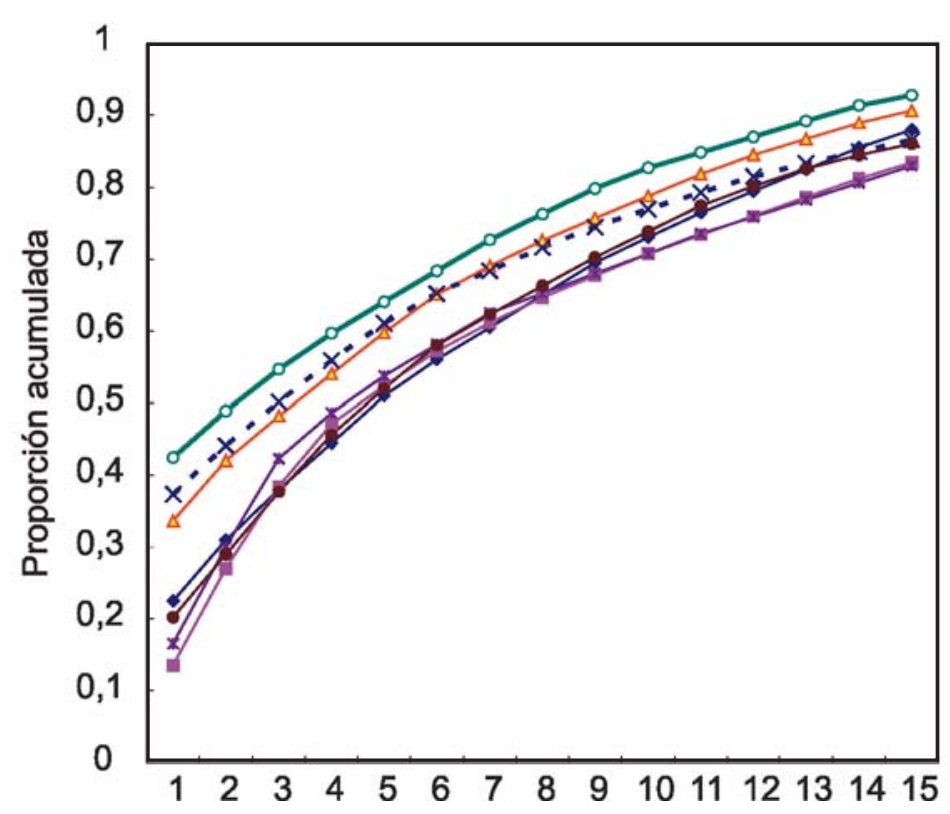

$\longrightarrow$ período 1

$\longrightarrow$ período 2

$\triangle$ - período 3

- * - período 4

\#- período 5

$\longrightarrow$ período 6

$\multimap$ período 7

Figura 55. Contribución a la cobertura de las primeras 15 especies en una pastura sobrepastoreada sobre suelo arcilloso, en siete estaciones de registro (b-3; Ferráz).

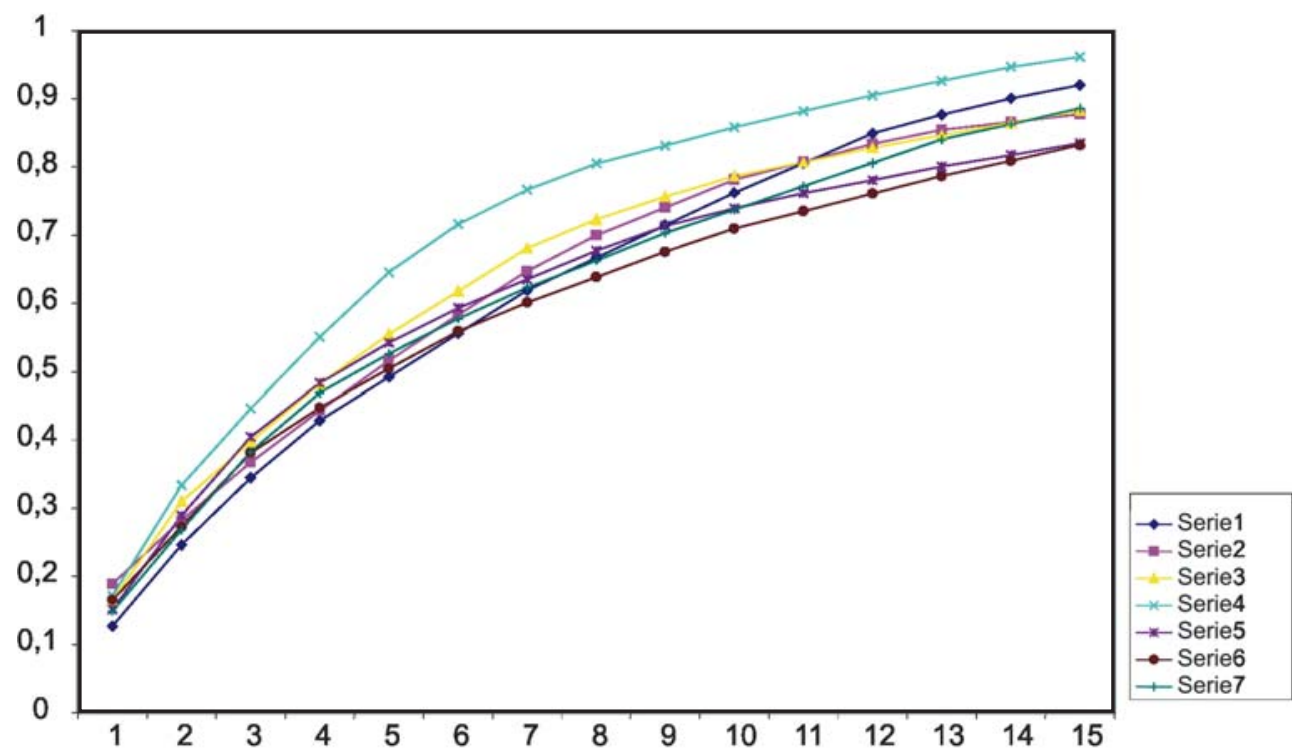

Figura 56. Contribución a la cobertura de las primeras 15 especies en una pastura con pastoreo aliviado sobre suelo arcilloso, en siete estaciones de registro (b-6; frente Sención). 


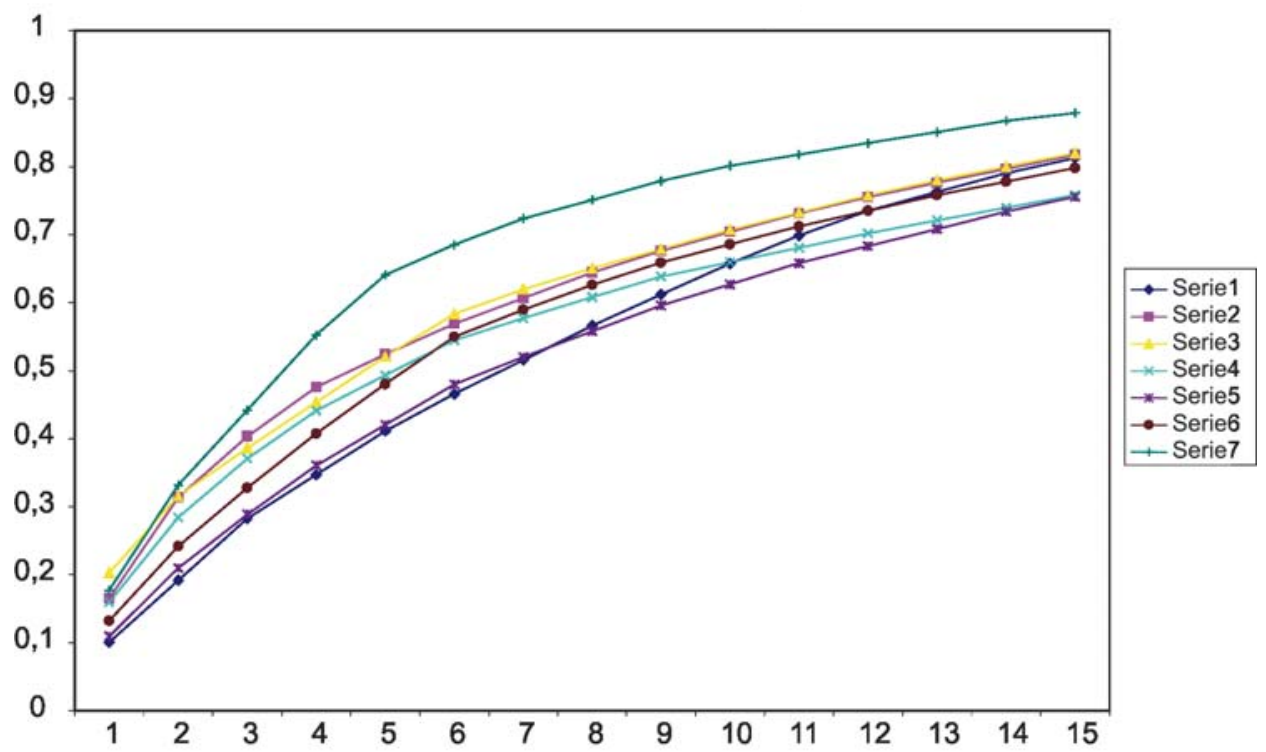

Figura 57. Contribución a la cobertura de las primeras 15 especies en una pastura con pastoreo aliviado sobre suelo arcilloso relativamente superficial, en siete estaciones de registro (b-7; frente Sención).

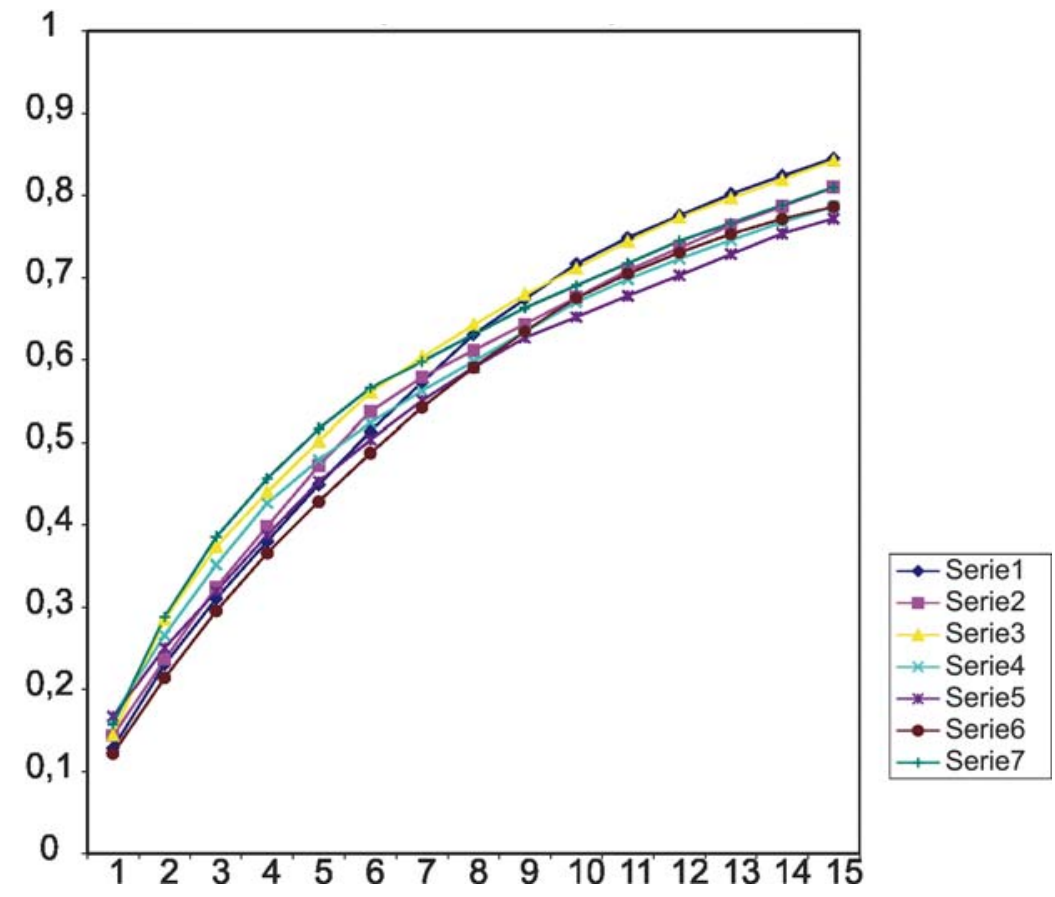

Figura 58. Contribución a la cobertura de las primeras 15 especies en una pastura con pastoreo aliviado y ganado de cría sobre suelo arcilloso, en siete estaciones de registro (b-8; cría). 


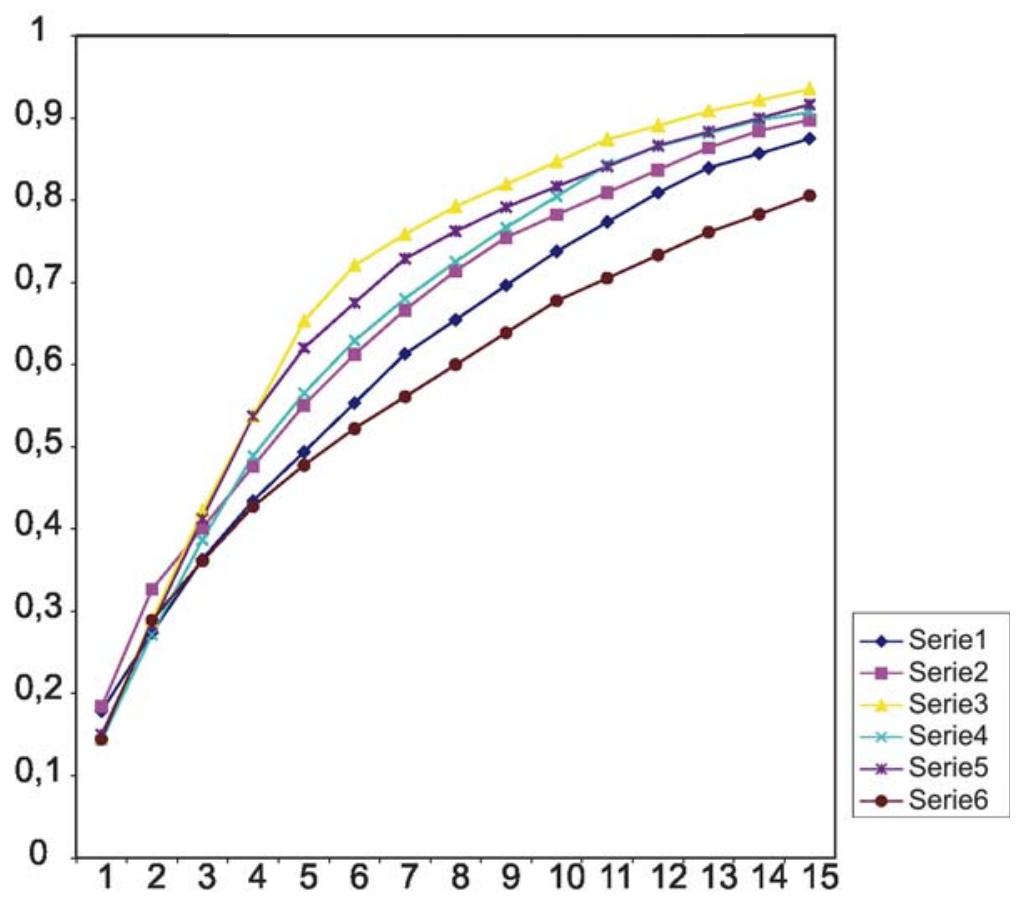

Figura 59. Contribución a la cobertura de las primeras 15 especies en una pastura con pastoreo aliviado y ganado de invernada sobre suelo arcilloso, en seis estaciones de registro (b-9; invernada).

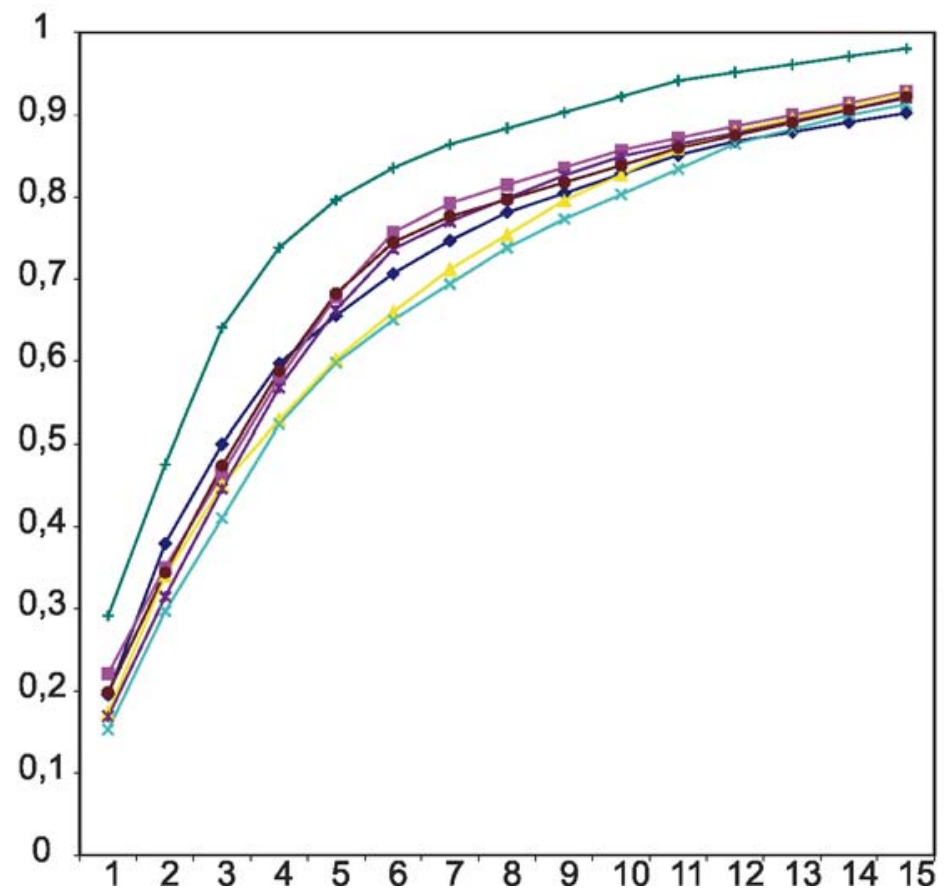

Serie1

Serie2

Serie3

Serie4

Serie5

Serie6

Serie7

Figura 60. Contribución a la cobertura de las primeras 15 especies en una pastura de campo bruto luego de un período de cultivos, sobre suelo arcilloso, en siete estaciones de registro (b-10; campo bruto). 


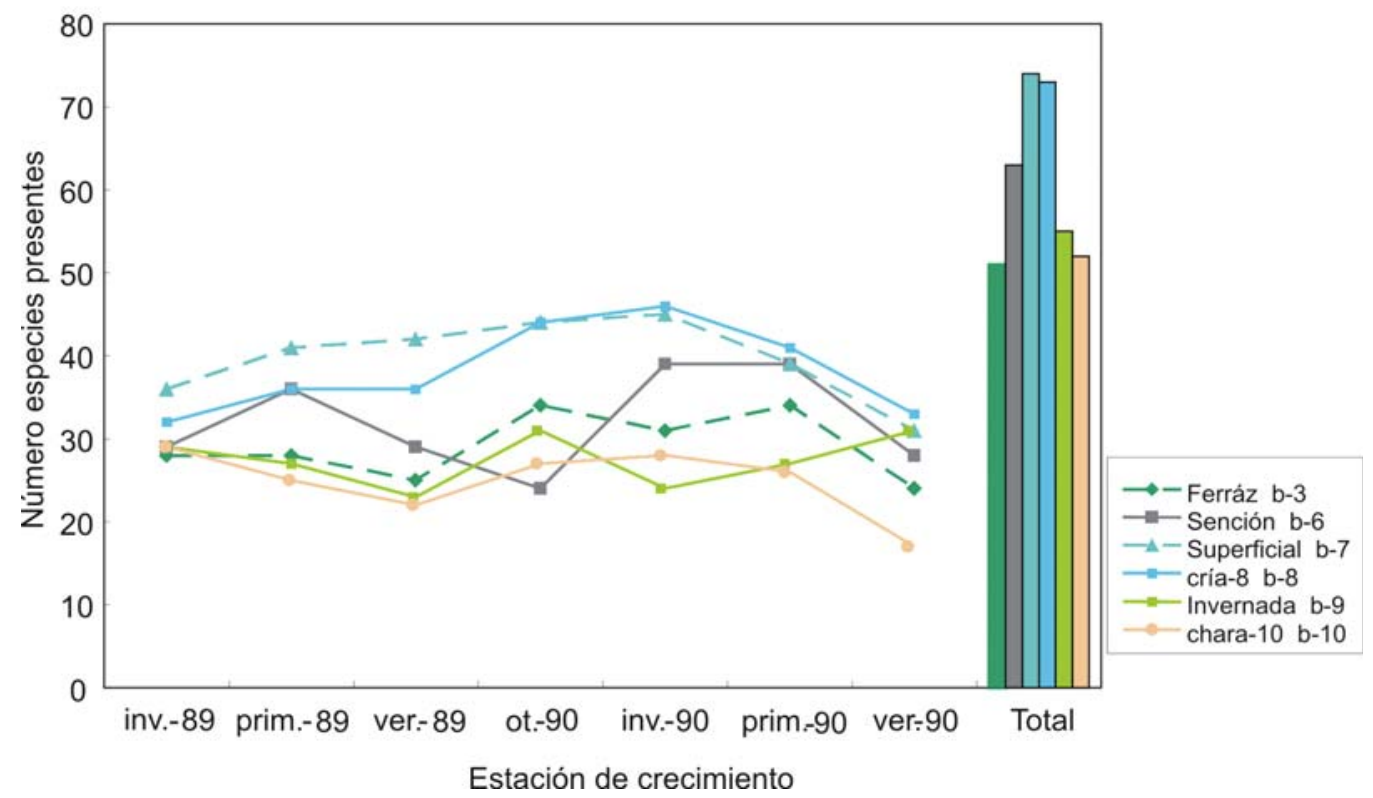

Figura 61. Número total de especies en seis pasturas sobre suelos arcillosos en la región noreste, en siete fechas de registro estacionales (líneas) y total acumulado (barras).

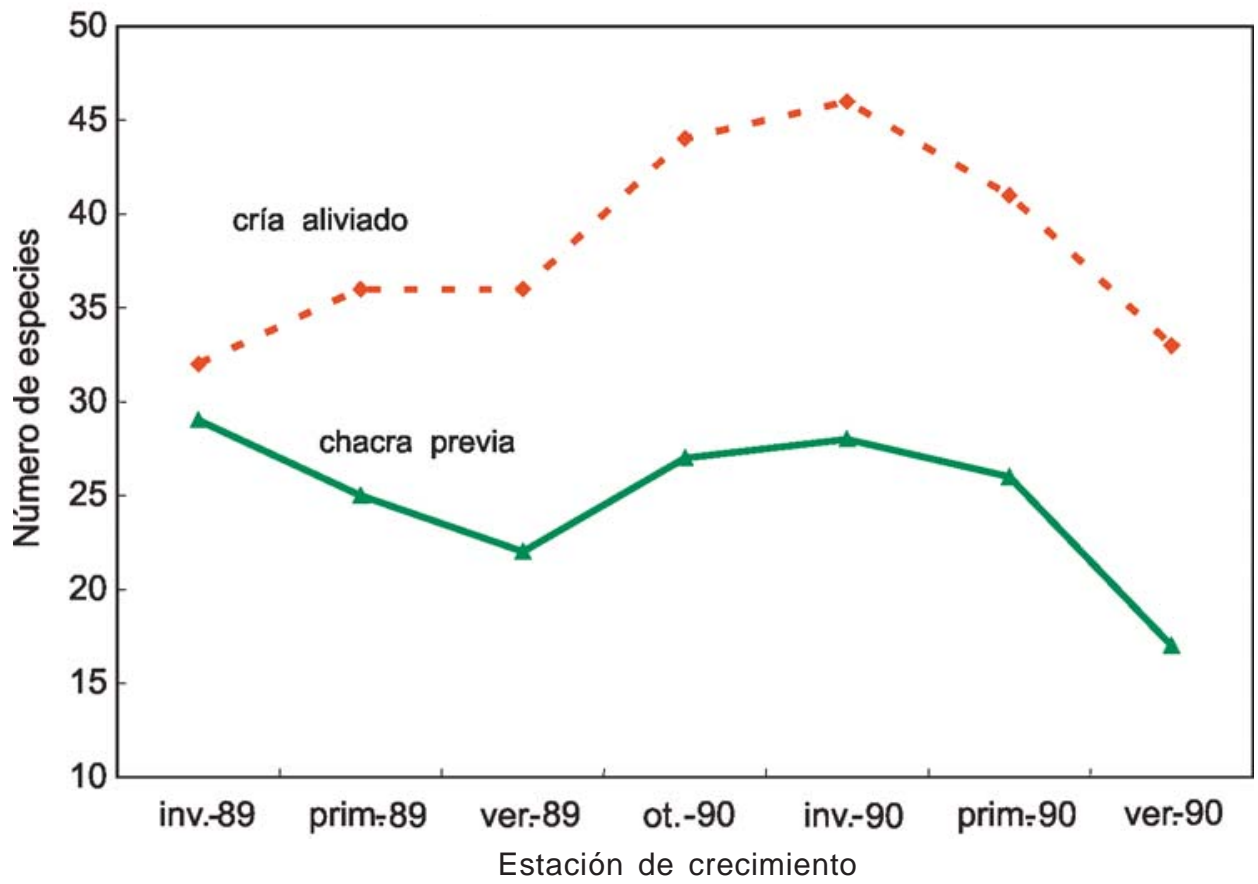

Figura 62. Variación en el número de especies registradas en dos comunidades vegetales sometidas a diferentes manejos, pastoreo aliviado con ganado de cría y campo restablecido luego de chacra, en suelos arcillosos de la región noreste. 


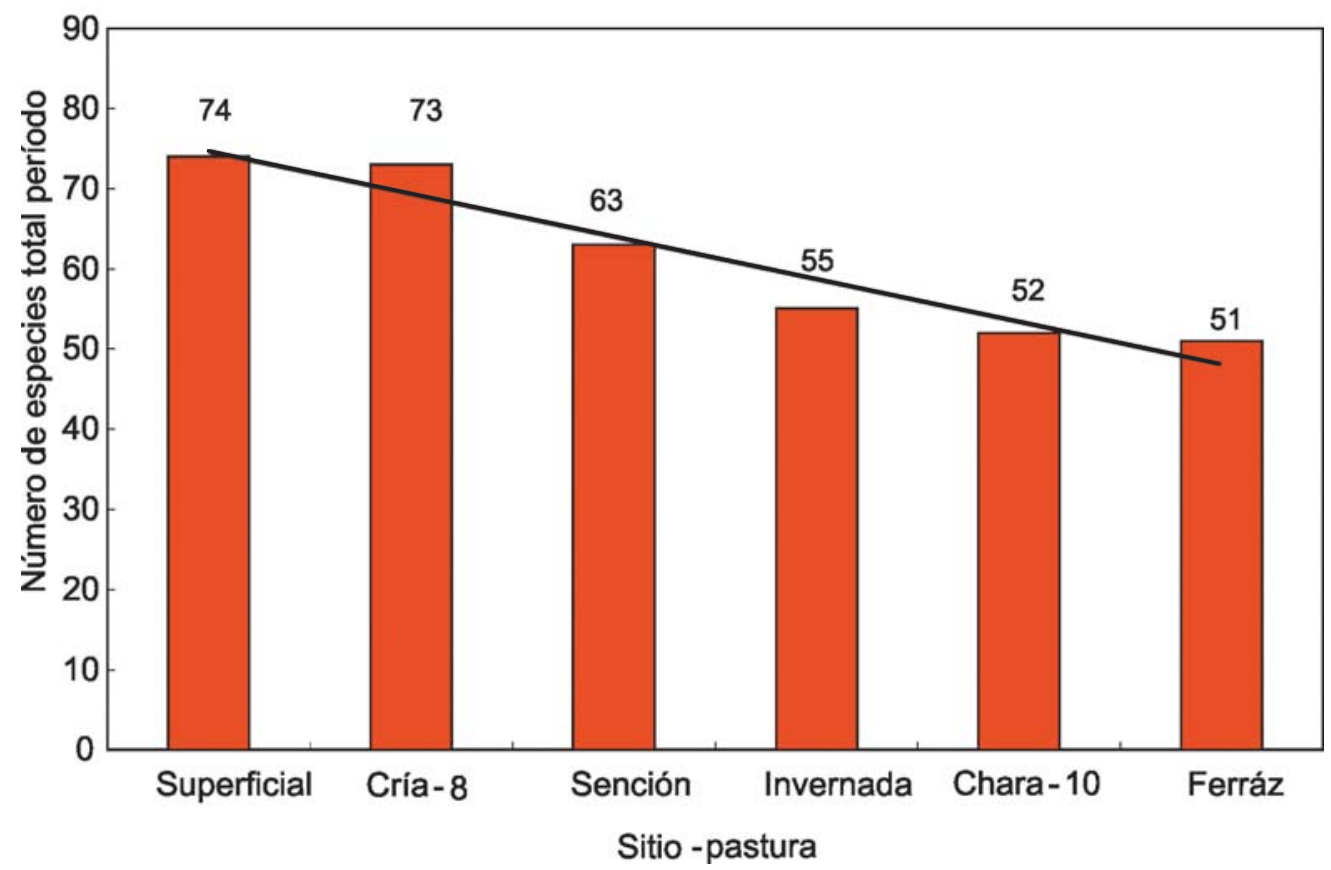

Figura 63. Número de especies presentes en seis pasturas naturales sobre suelos arcillosos de la región noreste (superficial b-7, cría-8 b-8, Sención b-6, invernada b-9, chacra-10 b-10, Ferráz b-3).

Tomando en consideración las seis pasturas desarrolladas sobre suelos arcillosos, a modo de síntesis, se ordenaron los valores de mayor a menor para el número total de especies en cada una en la Figura 63. Surge de los registros que en las pasturas menos intervenidas como superficial $(b-7)$ y cría (b-8) se observó un mayor número de especies, valores intermedios en Sención (b6) la cual en algún momento ha sido intervenida con la aplicación de fertilizaciones fosfatadas, menores valores en la invernada la cual se maneja en general con una alta disponibilidad de forraje (intervención moderada) y menores valores aún en las pasturas con mayor intervención como es el laboreo del suelo (chacra-10, b-10) y el sobrepastoreo con alta carga animal (Ferráz, b-3). La mayor intervención, favoreciendo tanto la productividad (b-6 y b-9), como la menor productividad (b-3 y b-10) aparentemente generó un menor número de especies presentes en la pastura, en cambio un manejo más aliviado registró un número relativamente mayor de especies presentes en la pastura.

\section{SENSIBILIDAD ESPECÍFICA - ESTACIONAL EN COMUNIDADES NATURALES}

En esta sección se reportan los resultados correspondientes a los registros de las especies presentes en dos transectas de cien puntos cada una, realizadas en cada pastura durante siete estaciones de crecimiento en pasturas naturales de la región noreste. Se realizó la separación de las especies según el hábito de crecimiento rastrero y de crecimiento erecto o cespitosas, de anuales y perennes de acuerdo a Rosengurtt (1979).

\section{Suelos arenosos}

En los suelos arenosos se analizan las mismas pasturas reportadas en párrafos anteriores. En el caso de la pastura sobrepastoreada sobre suelo arenosos (potrero 2, LM, a-1) desde el punto de vista de las especies de crecimiento rastrero Paspalum notatum marca claramente la estacionalidad del si- 
tio, al mismo tiempo que la variación interanual (Figura 64). Basados en la información climática reportada en párrafos anteriores (ver Figura 36) tenemos que $P$. notatum tiene una curva invierno-primavera-verano similar para el año 1989 y el año 1990, en cambio Trifolium polymorphum presenta meno- res valores en el invierno 1989 (seco) que en el invierno 1990 (húmedo); por otra parte al cambiar la escala al omitir la presencia de $P$. notatum, en la Figura 65, se observa la evolución estacional de las otras especies. Hacia el final del período de registros incrementan su presencia Richardia sp.,

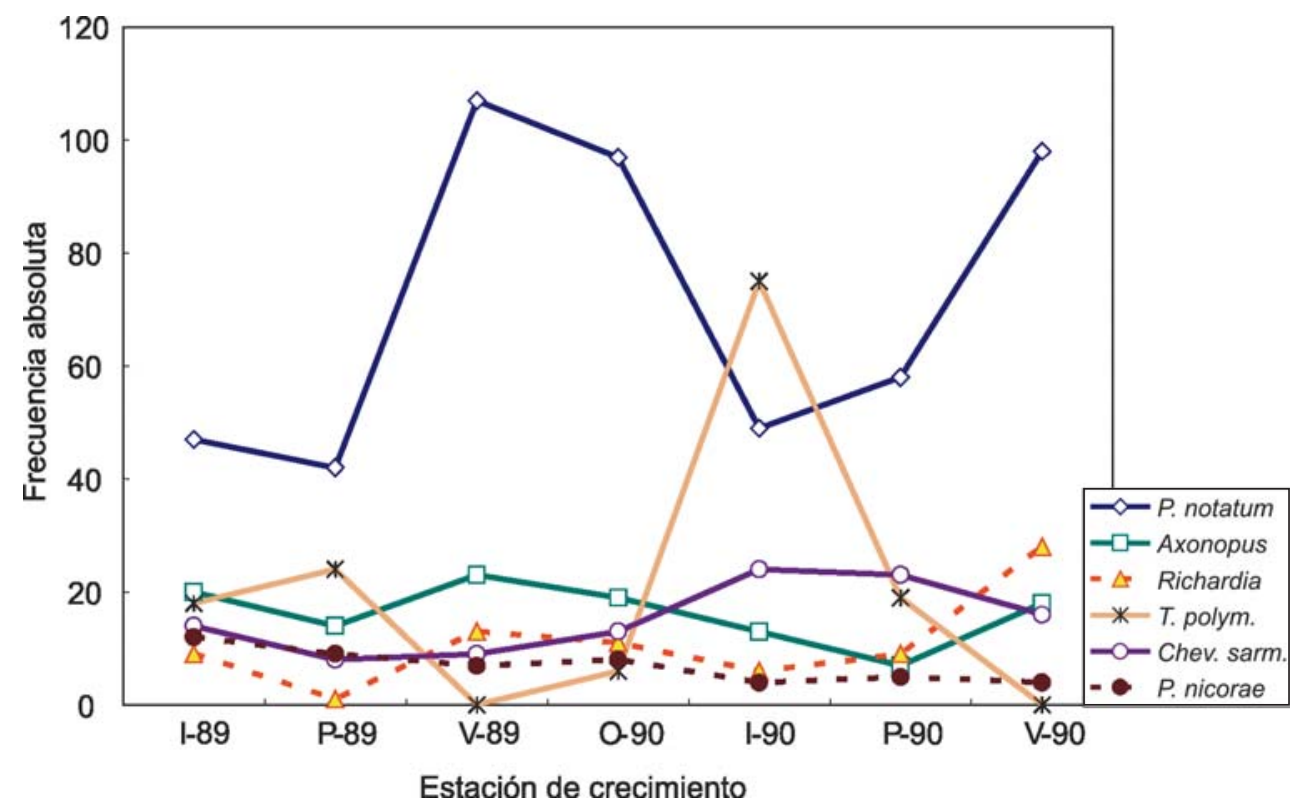

Figura 64. Variación estacional en la presencia de especies de crecimiento rastrero en una pastura sobrepastoreada (potrero 2, LM, a-1) sobre suelo arenoso.

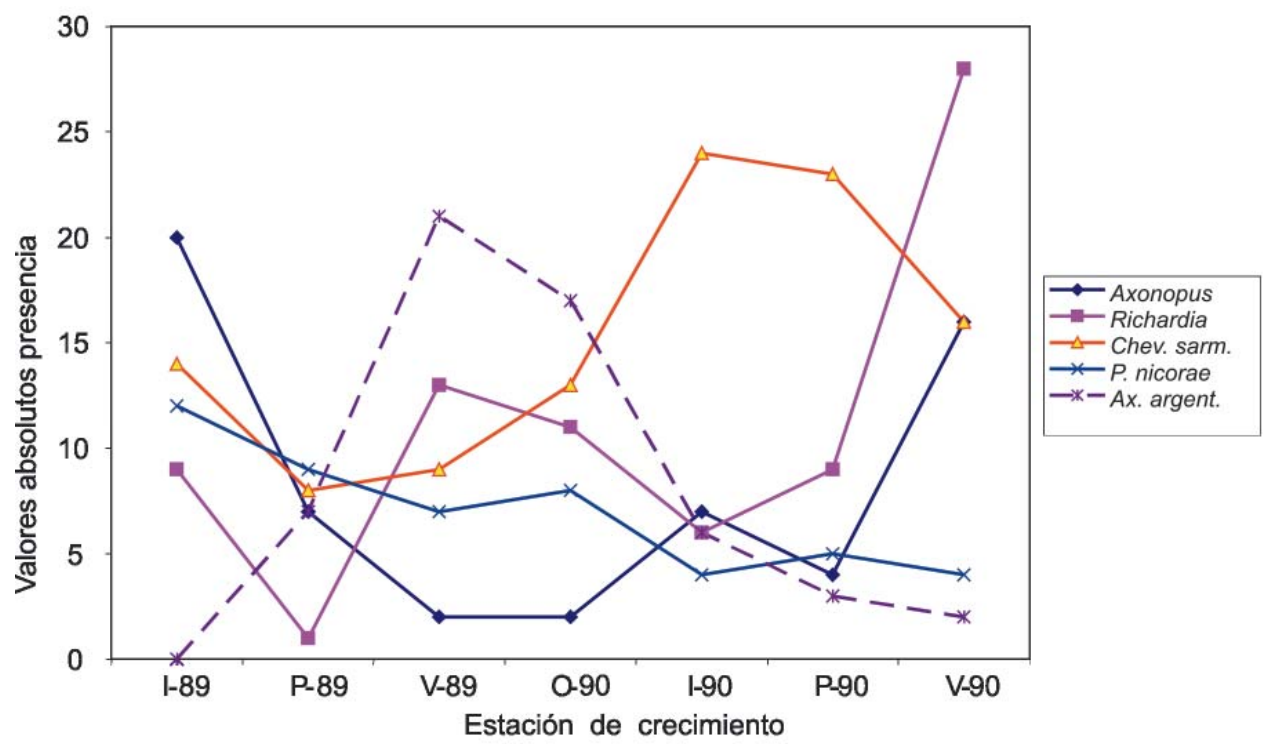

Figura 65. Variación estacional en la presencia de especies de crecimiento rastrero en una pastura sobrepastoreada (potrero 2, LM, a-1) sobre suelo arenoso. 
Chevreulia sarmentosa y Axonopus affinis; este último muestra un comportamiento contrastante con Axonopus argentinus; Paspalum nicorae por su parte disminuye constantemente en el ciclo de evaluación. El caso de Axonopus affinis podría interpretarse que luego de un período relativamente seco al inicio del período redujo su presencia recuperándose su aporte al mejorar el balance hídrico del sitio en 1990. Su comportamiento contrasta en cierta medida con Paspalum notatum que fue más estable en su presencia en el mismo período.

Respeto a las especies de crecimiento erecto la Figura 66 muestra su evolución durante el período de registros; a pesar de su aparente complejidad la misma reporta comportamientos disímiles y destacables entre las diferentes especies. Se observa como Coelorachis selloana y Schizachyrium microstachyum responden similarmente en ambos años incrementando su presencia hacia el verano, Setaria geniculata y Paspalum plicatulum presentan un pico hacia el verano-otoño 1990 y Panicum milioides responde en forma incremental desde el año relativamente más seco (1989) hasta el año relativamente húmedo (1990); Oxalis sp. presentó un comportamiento inverso primaveral y Piptochaetium montevidense un comportamiento invernal-primaveral-estival en su presencia. El grupo de Cyperaceas tuvo una respuesta similar a $P$. milioides pero más acentuado positivamente en su presencia cuando las condiciones hídricas mejoraron en el segundo año.

En el caso de la pastura con manejo aliviado en el potrero 4 de La Magnolia (a-2) la principal especie de hábito de crecimiento rastrero fue también Paspalum notatum (Figura 67), con un perfil similar al registrado para el sitio sobrepastoreado (potrero $2 \mathrm{LM}$, a-1). Es de destacar que los valores absolutos de presencia para esta especie en este caso fueron la mitad en el sitio aliviado comparado con el sitio sobrepastoreado. Aparece en una proporción importante Dichondra microcalyx que se incrementa hacia el final del período de registro. Paspalum nicorae mostró un comportamiento contrastante con el registrado en el sitio sobrepastoreado, incrementado su presencia en el segundo año. Axonopus affinis presentó una tendencia a incrementar su presencia en el segundo año en condiciones hídricas más favorables para el crecimiento

La pastura aliviada del potrero 4 de La Magnolia (a-2) desde el punto de vista de las

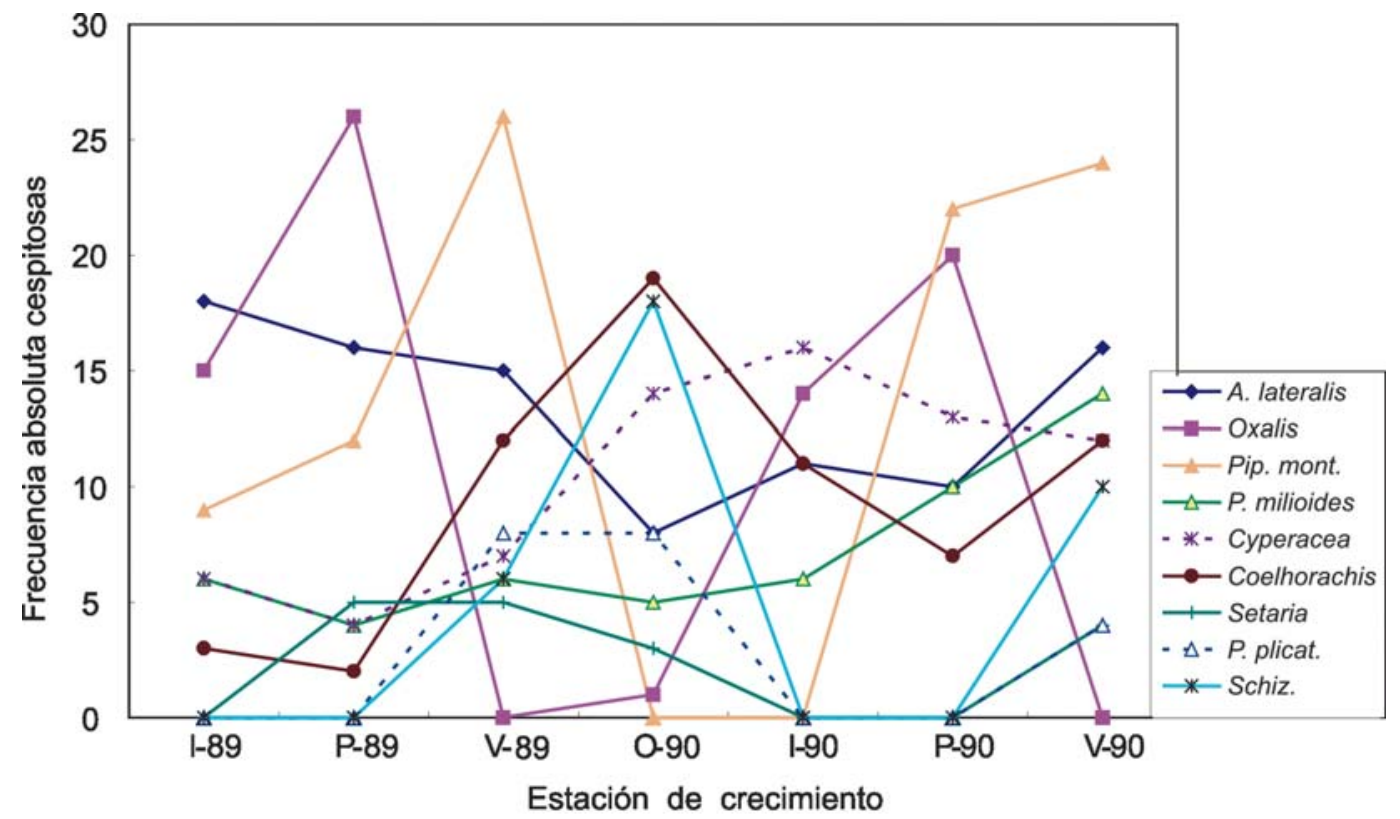

Figura 66. Variación estacional en la presencia de especies cespitosas en el potrero 2 LM (a-1), sobre suelo arenoso. 


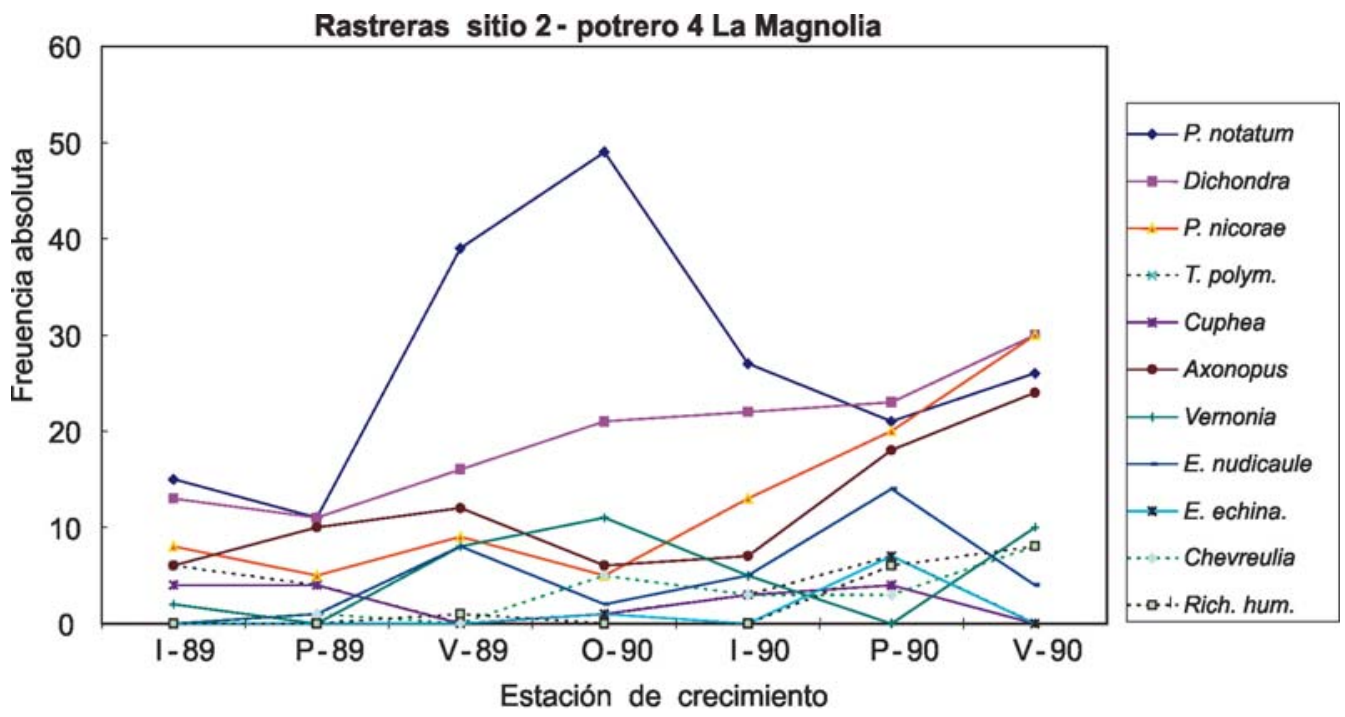

Figura 67. Presencia de especies de hábito de crecimiento rastrero en una pastura con manejo aliviado (potrero 4 LM, a-2) sobre un suelo arenoso.

especies cespitosas estuvo fundamentalmente dominada por la presencia de Andropogon lateralis (Figura 68); esta especie tendió a presentar valores menores en los registros de primavera.

Hacia el final del período de registros Piptochaetium montevidense y el grupo de Cyperaceas incrementaron su presencia, estando las demás especies con muy poca variación en los registros de presencia.
En el caso del sitio de campo bruto luego de un rastrojo de soja (a-4), la especie rastrera predominante registrada fue Cynodon dactylon (Figura 69), se registró a su vez una presencia importante de Paspalum notatum y Axonopus affinis, los que hacia el final del período evolucionaron diferencialmente con una mayor presencia de la primera respecto de la segunda. Paspalum nicorae también tendió a reducir su presencia hacia el final

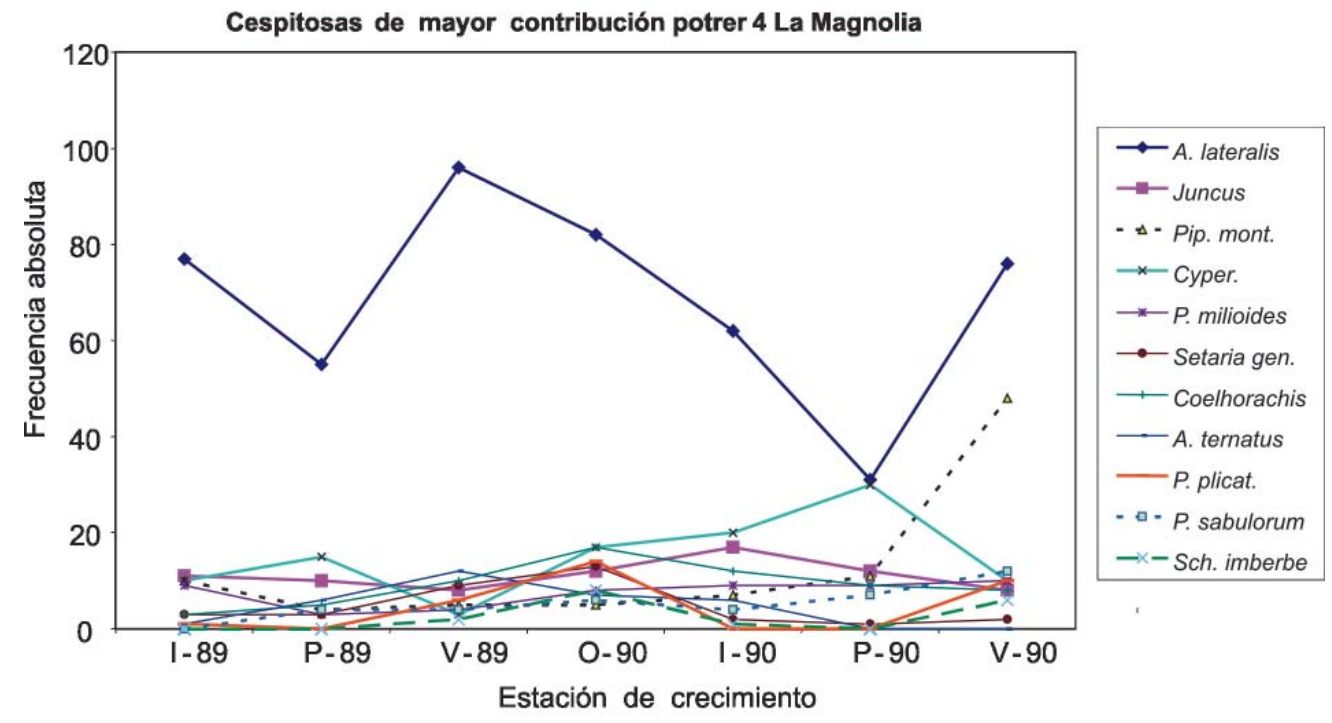

Figura 68. Presencia de especies de hábito cespitoso en una pastura con manejo aliviado (potrero 4 LM, a-2) en suelo arenoso 


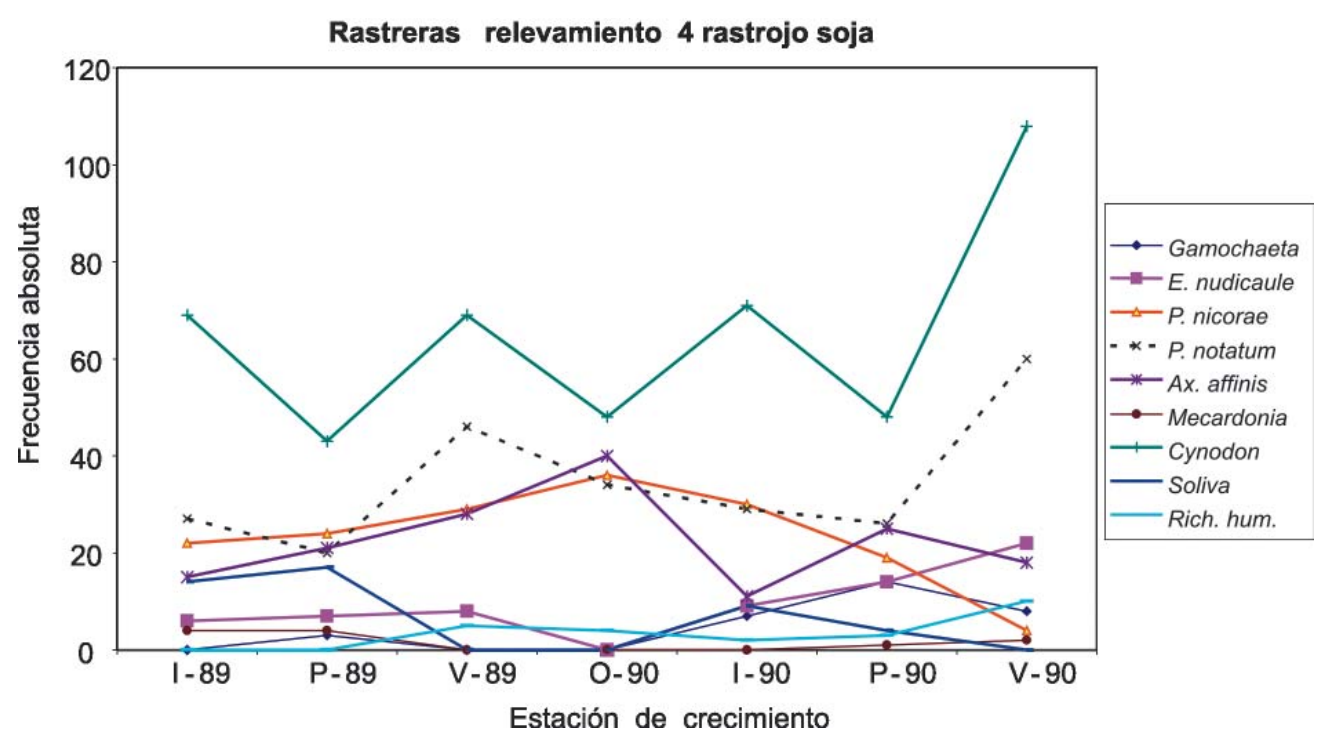

Figura 69. Frecuencia absoluta de especies de hábito de crecimiento rastrero en una pastura luego de cultivos de soja (campo bruto, a-4) en un suelo arenoso.

de los registros con un pico intermedio. Soliva pterosperma presentó valores de presencia superiores en el período más seco, en cambio Richardia sp. incrementó su presencia relativa en el último verano que fue más húmedo.

En cuanto a las cespitosas en el campo bruto -rastrojo de soja (a-4) hacia el final del ciclo de registros tenemos un incremento de Piptochaetium montevidense, Panicum milioides, Setaria geniculata, el grupo de
Cyperaceas y en menor medida Eragrostis neesii (Figura 70. Setaria geniculata presentó un pico en otoño 1990. El grupo de Cyperaceas presentó un pico de presencia en el otoño intermedio, en cambio Oxalis $s p$. lo hizo en forma similar tanto en invierno como en primavera en los dos años consecutivos. Cerastium sp. presentó un pico en la primavera 1989 y el invierno -primavera 1990 similar a Oxalis sp. pero en menor proporción.

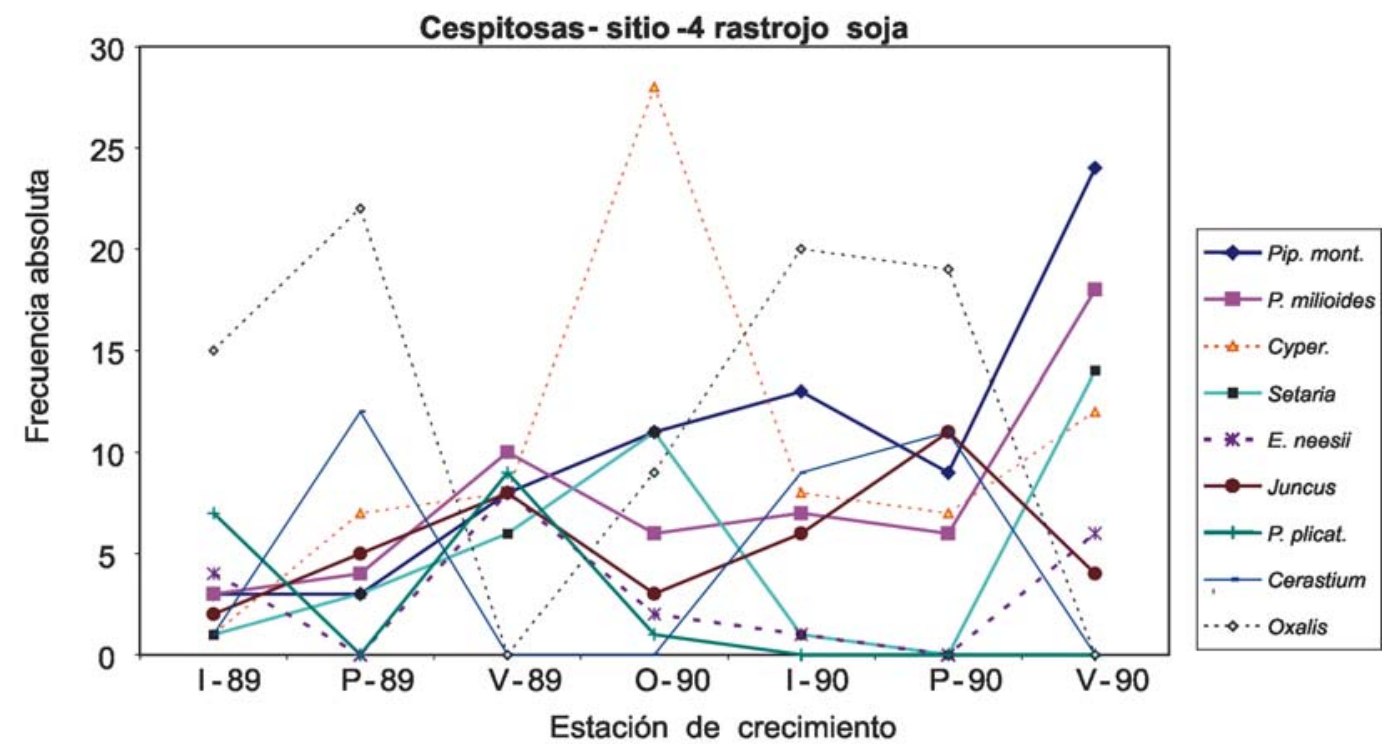

Figura 70. Frecuencia absoluta de especies de hábito de crecimiento cespitoso en una pastura luego de cultivos de soja (campo bruto, a-5) en un suelo arenoso. 
Similarmente al sitio campo bruto-rastrojo de soja es el caso donde fue cultivo y luego pradera y finalmente campo bruto (a-5) la especie rastrera dominante fue Cynodon dactylon hasta que se instaló una plantación de eucaliptos luego del quinto período de registros (Figura 71). También se observó una mayor presencia de Soliva pterosperma en el año relativamente más seco, Paspalum nicorae incrementó su presencia hasta la mitad del período de registros lo mismo que Paspalum notatum. Axonopus affinis y Trifolium subterraneum se mantuvieron con una presencia relativamente estable.

En cuanto a las especies cespitosas, notoriamente el grupo de Cyperaceas marcó un incremento continuo en el período de registro (Figura 72). Oxalis sp. incrementó su

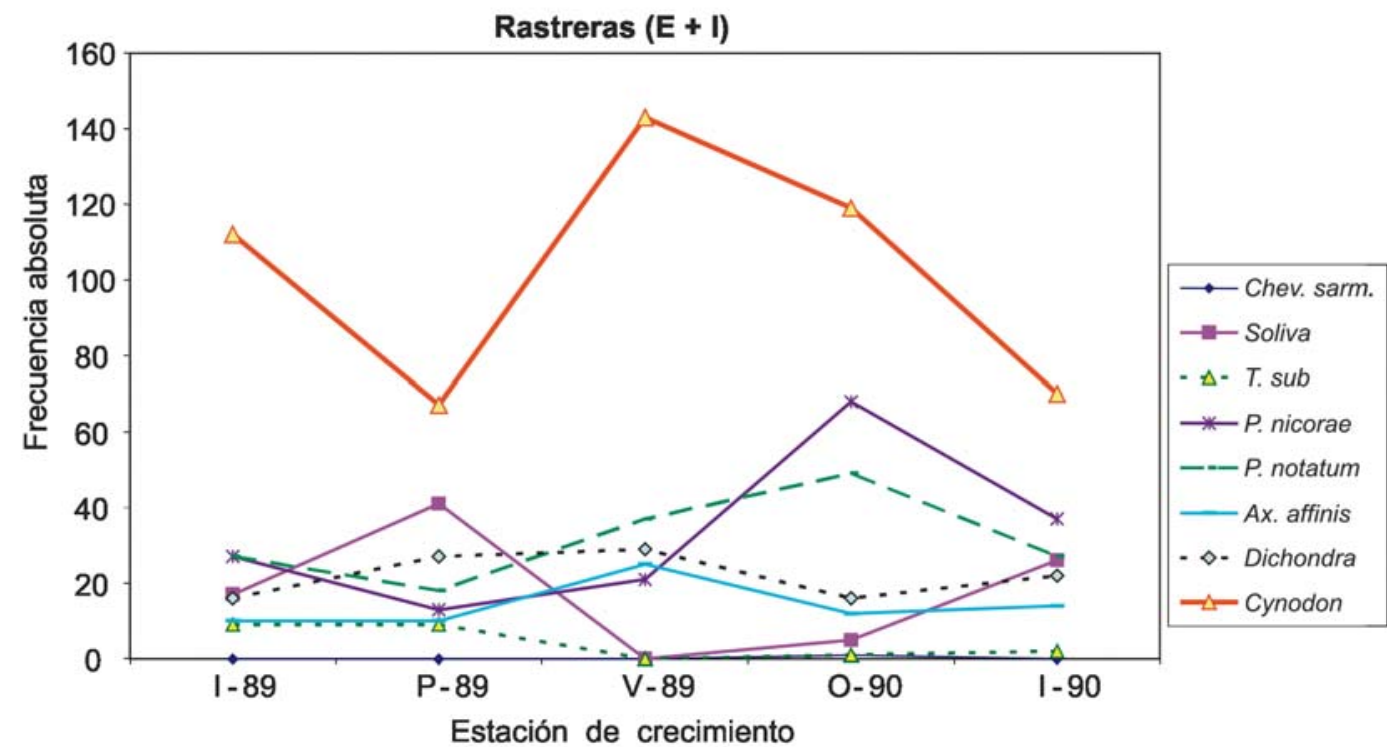

Figura 71. Frecuencia absoluta de especies de hábito de crecimiento rastrero en una pastura luego de cultivos y praderas artificiales (campo bruto) (a-5) en un suelo arenoso.

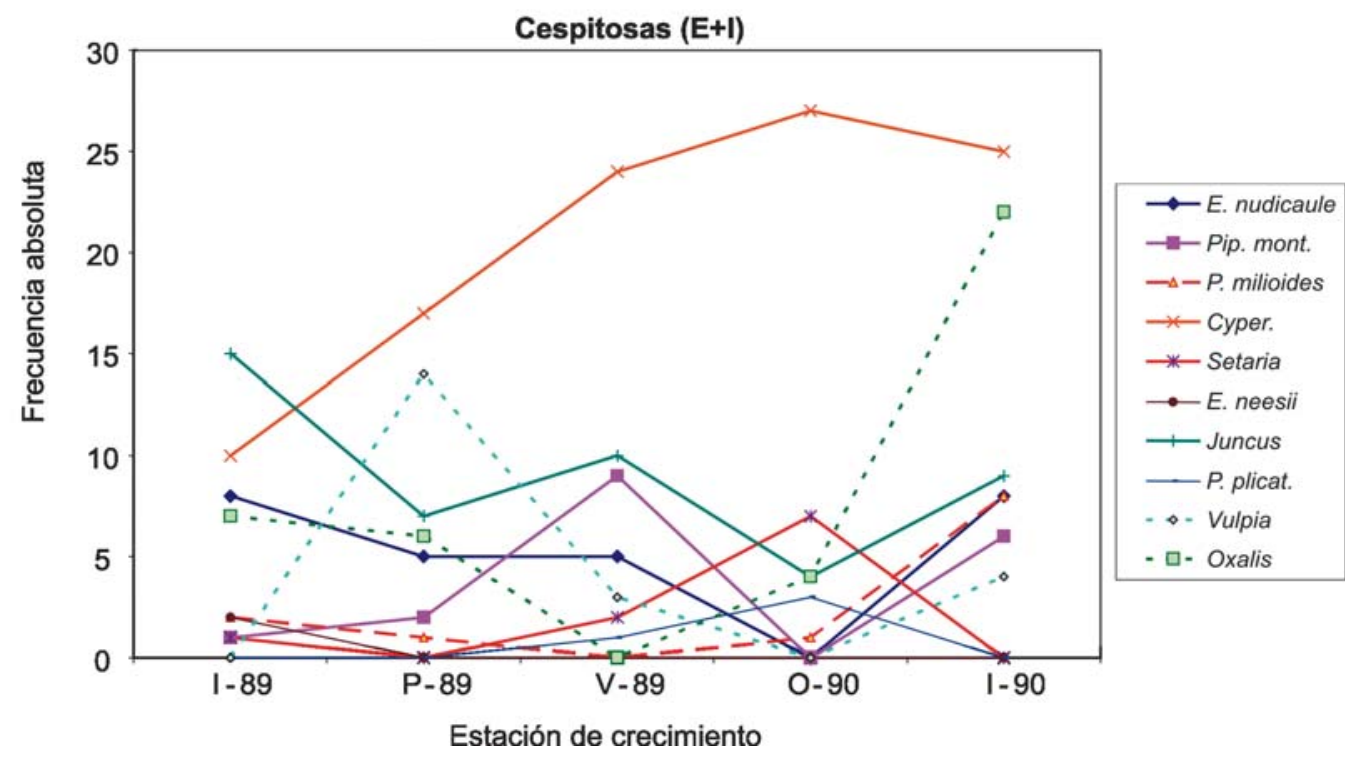

Figura 72. Frecuencia absoluta de especies de hábito de crecimiento cespitoso en una pastura luego de cultivos y praderas artificiales (campo bruto) (a-5) en un suelo arenoso brunosoles - suelos arcillosos. 
presencia sensiblemente hacia el segundo invierno lo mismo que Piptochaetium montevidense, sin embargo en el verano 8990 ambas especies presentaron un comportamiento opuesto. Panicum milioides incrementó su presencia hacia el final del período de registros cuando las condiciones ambientales para el crecimiento fueron mejores que en los períodos previos. Juncus capillaceus por su parte tendió a disminuir su presencia en el segundo invierno, en cambio Eryngium nudicaule se mantuvo relativamente estable en su presencia. Setaria geniculata, al igual que en los sitios anteriores mostró un incremento en su presencia relativa hacia el otoño.

En el caso de los suelos arcillosos (brunosoles), en los siguientes párrafos, se realiza el análisis del comportamiento de los diferentes grupos de especies en siete estaciones de crecimiento.

En el caso de la pastura sobrepastoreada, en el sitio Ferráz (b-3), dentro del grupo de las especies de crecimiento rastrero sobresalen los registros de Paspalum notatum con valores anuales relativamente más altos en verano (Figura 73), cuando se retira del análisis a Paspalum notatum se destaca Chevreulia sarmentosa y Richardia stellaris así como Trifolium polymorphum en forma similar con picos de primavera en su presencia (Figura 74). Soliva pterosperma en su segundo invierno incrementó su presencia en relación al primero, en cambio en la segunda primavera su valor es inferior al de la primer primavera. Mecardonia montevidensis y Richardia humistrata tienden a disminuir hacia el final del período de registros; Axonopus affinis se mantiene estable con valores relativamente bajos. Stenachenium campestre mostró dos picos (primavera-1989 y otoño1990) de presencia lo que parece más asociado a un situación de un pastura más estresada en el primer año de registros.

Respecto a las especies cespitosas, en la Figura 75 se observa un cúmulo de especies confundidas en su presencia, mostrando la relativa complejidad de las comunidades naturales y la variación en la contribución estacional de cada especie identificada; sin embargo a los efectos de un mejor análisis y facilitar la interpretación se ha simplificado la presencia de especies cespitosas incluyendo algunas malezas enanas y malezas menores en la Figura 76 y solamente con la presencia de especies forrajeras destacadas en la Figura 77.

En esta pastura es clara la mayor presencia de especies enanas y de menor productividad como Evolvulus sericeus,

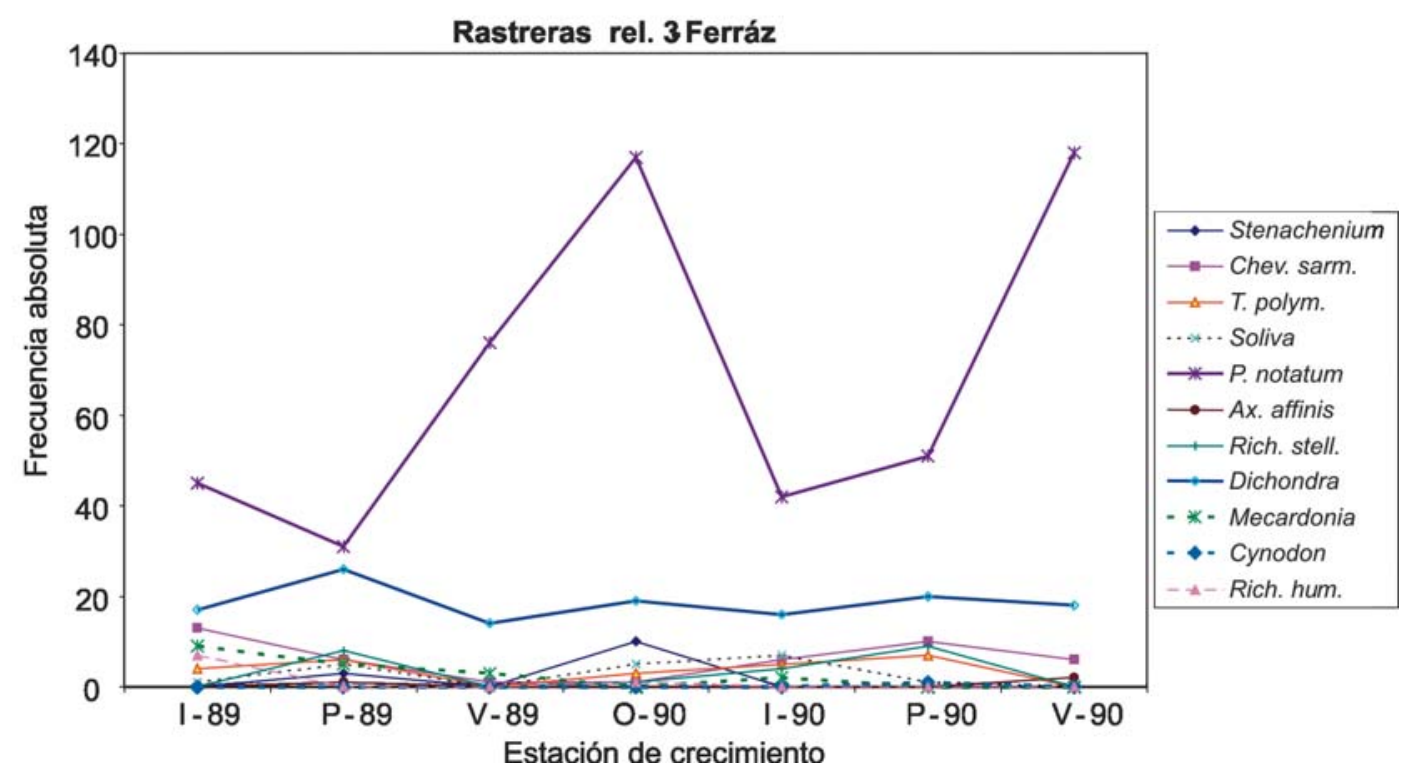

Figura 73. Presencia de especies de hábito de crecimiento rastrero en una pastura sobrepastoreada (b-3) sobre suelo arcilloso. 


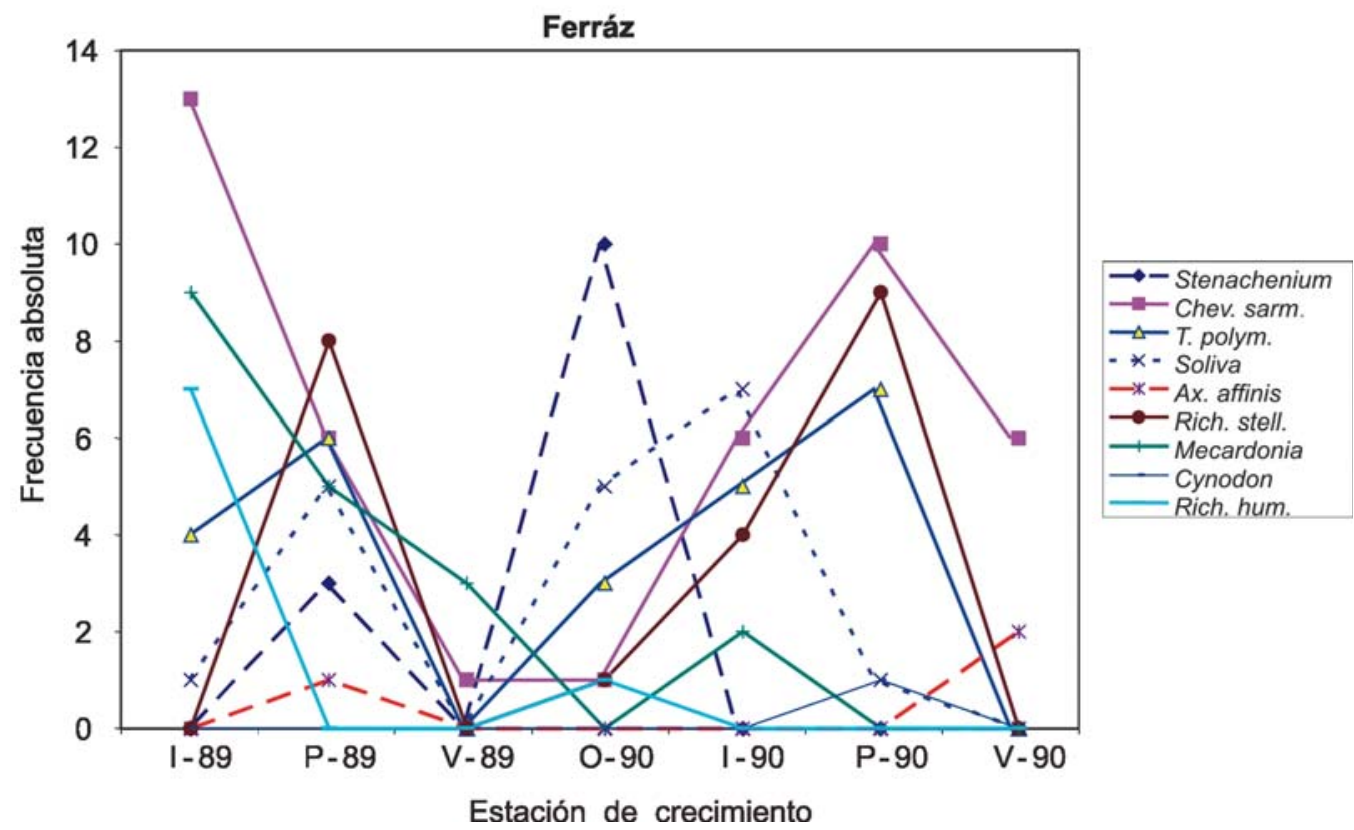

Figura 74. Presencia de especies de hábito de crecimiento rastrero, excluyendo la presencia de Paspalum notatum, en una pastura sobrepastoreada (b-3) sobre suelo arcilloso.

Chaptalia pilloselloidea, Chaptalia excapa entre otras, por lo que para un análisis más sencillo se han excluido las mismas de la Figura 76 conjuntamente con algunas forrajeras con escaso aporte y se analiza la evolución estacional de las especies de mayor interés forrajero en la Figura 77.

El grupo de especies que constituye Cyperaceas presentó dos picos muy marcados en los dos años básicamente en prima-

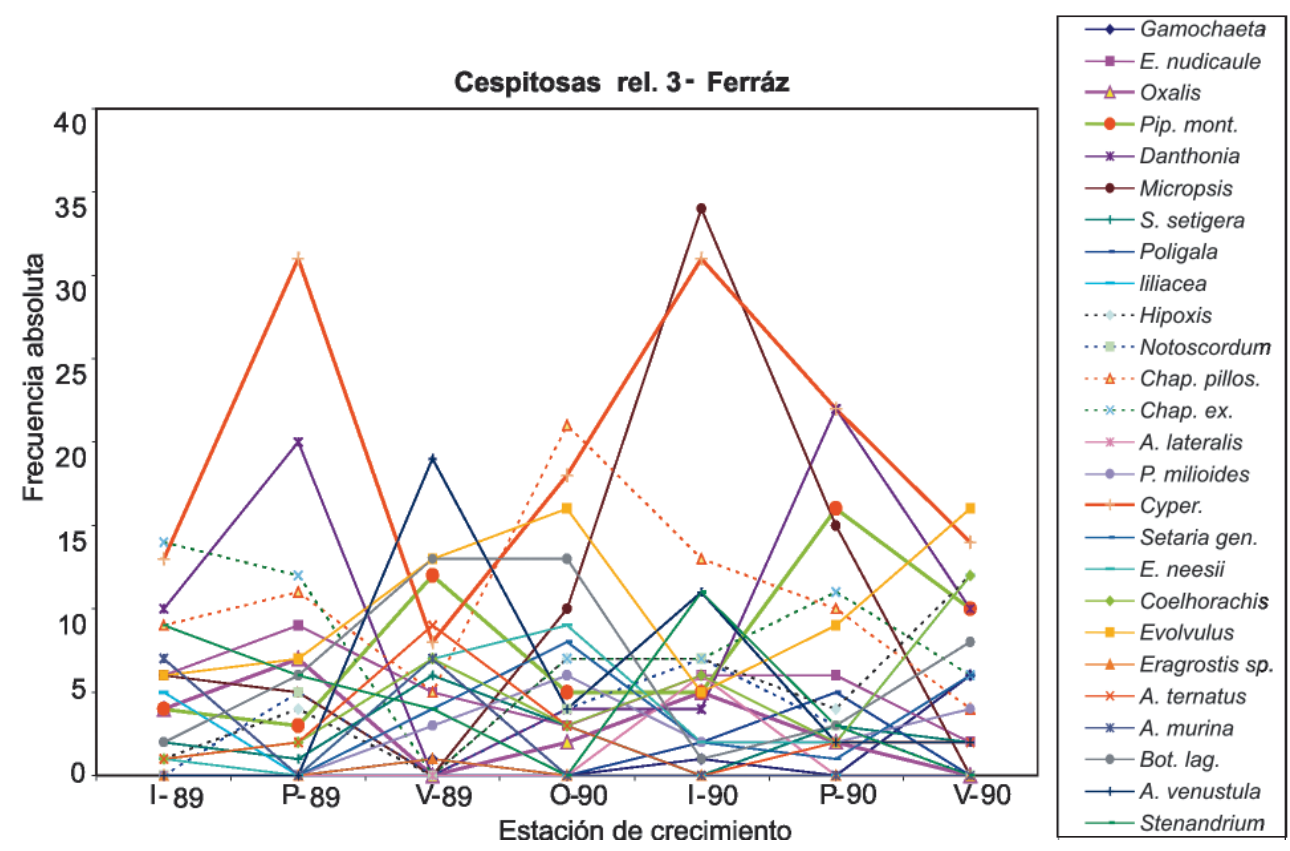

Figura 75. Presencia de especies de hábito de crecimiento cespitoso en una pastura sobrepastoreada (b-3) sobre suelo arcilloso. 


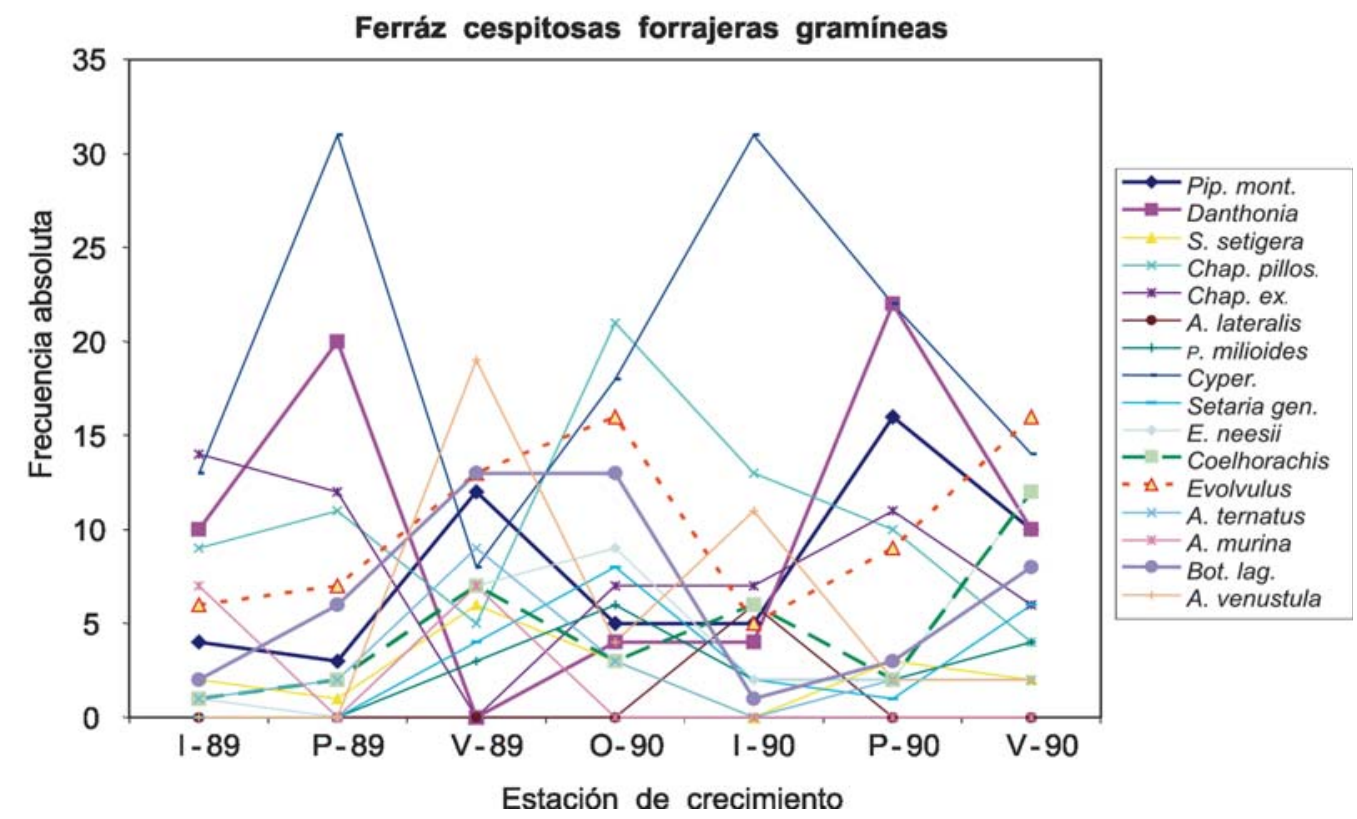

Figura 76. Presencia de especies de hábito de crecimiento cespitoso de mayor contribución al recubrimiento de la vegetación en una pastura sobrepastoreada (b-3) sobre suelo arenoso.

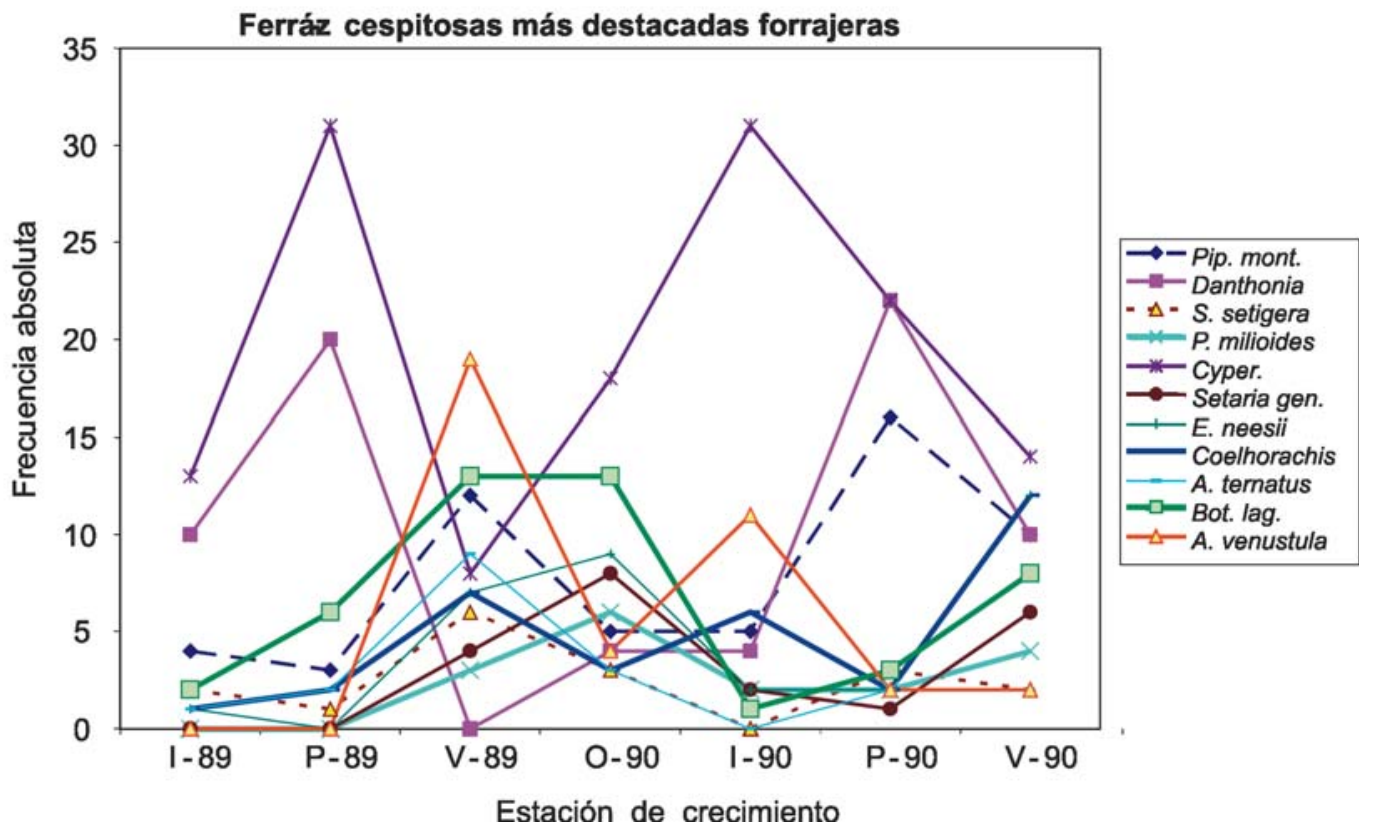

Figura 77. Presencia de especies de hábito de crecimiento cespitoso de interés forrajero en una pastura sobrepastoreada (b-3) sobre suelo arenoso.

vera en el primer año e invierno en el segundo, los valores del segundo verano fueron relativamente más altos que en el primer verano, igualmente sucedió con el segundo y primer inverno.
En la Figura 77 observa a Danthonia sp. y a Piptochaetium montevidense con perfiles relativamente similares en sus picos con mayor presencia primaveral, lo que confirma en cierta mediad su ciclo de crecimien- 
to inverno-primaveral.Piptochaetium montevidense como en otros casos en verano-89 tendió a mantener valores de presencia relativamente altos. Bothriochloa laguroides tendió a atener un pico de presencia en verano, en este caso el primer año más seco con valores de presencia relativamente más altos. Setaria geniculata, Panicum milioides y Eragrostis neesii presentaron un perfil similar con un pico en otoño 1990 y valores relativamente más bajos de presencia en verano 1990.

Coelorachis selloana presentó dos picos, uno en cada verano mostrando una cierta sensibilidad ambiental estacional independientemente de la alta presión de pastoreo en el sitio, incrementando su presencia en el segundo año. Stipa setigera por su parte, presentó una variación en su presencia similar a la de Coelorachis selloana, pero con un perfil más invernal y una mayor presencia relativa en el ciclo más seco (1989); asimismo Aristida venustula tuvo un pico claramente marcado el primer verano (más seco) y tendió a reducir su presencia relativa en el segundo verano. Andropogon ternatus incrementó su presencia en los dos veranos.

En el sitio de mayor productividad, entrada-Sención (b-6), la principal especie de hábito de crecimiento rastrero también fue
Paspalum notatum, con una presencia mayor en primavera en el segundo año respecto del primero y por el contrario una menor presencia en verano del segundo año respecto del primero (Figura 78). Axonopus affinis y Dichondra microcalyx tienden a incrementar su presencia hacia el final del período de registros, en cambio Cynodon dactylon, Soliva pterosperma y Trifolium polymorphum tendieron a reducir su presencia en el segundo año de registros. Chevreulia sarmentosa mostró una mayor presencia en los registros en el ciclo de crecimiento primavero-estival y valores bajos en invierno. Richardia humistrata mantuvo una presencia relativamente estable y baja en todo el período.

Respecto a las especies de hábito de crecimiento cespitoso, en este sitio apareció marcadamente con un ciclo de crecimiento invernal primaveral el raigras anual (Lolium multiflorum), que seguramente es consecuencia de la historia del sitio, el cual fue mejorado con fosfatos y leguminosas 25 años atrás (Figura 79).

En las Figuras 80 y 81 se descomponen los componentes de la Figura 79 para facilitar su interpretación, dada la riqueza específica presente en la misma. Bothriochloa laguroides, Setaria geniculata y el grupo de

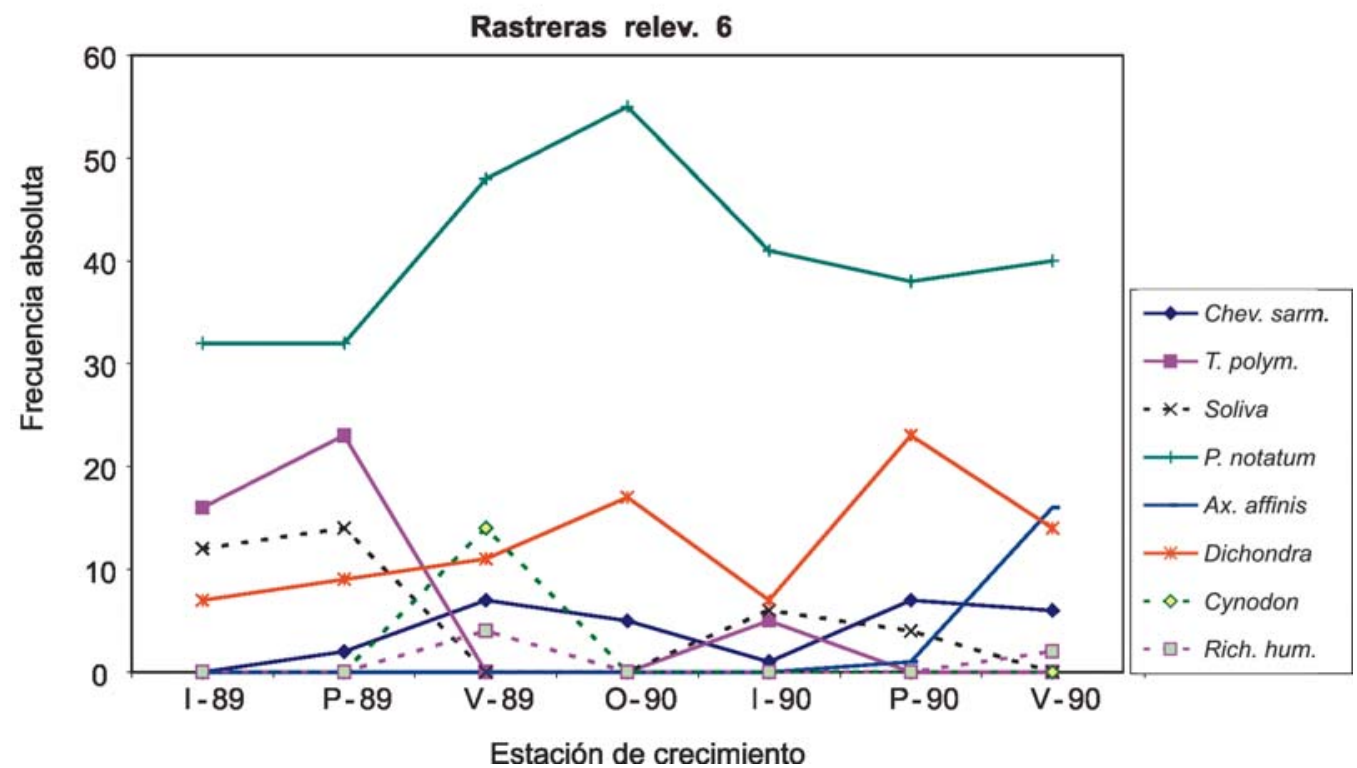

Figura 78. Presencia de especies de hábito de crecimiento rastrero en una pastura con manejo aliviado (b-6) sobre suelo arcilloso en la región noreste. 


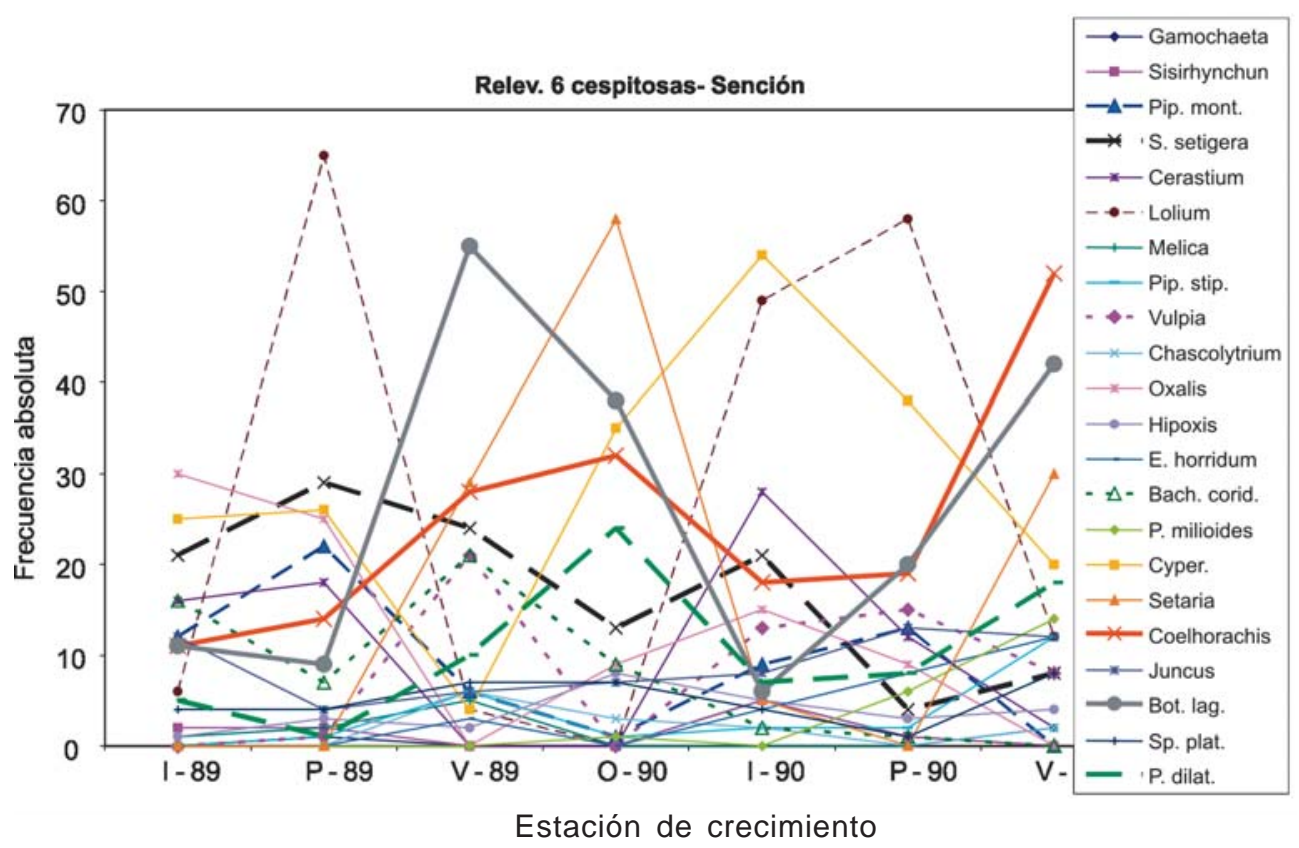

Figura 79. Presencia de especies en una pastura con manejo aliviado (b-6) sobre suelo arcilloso en la región noreste.

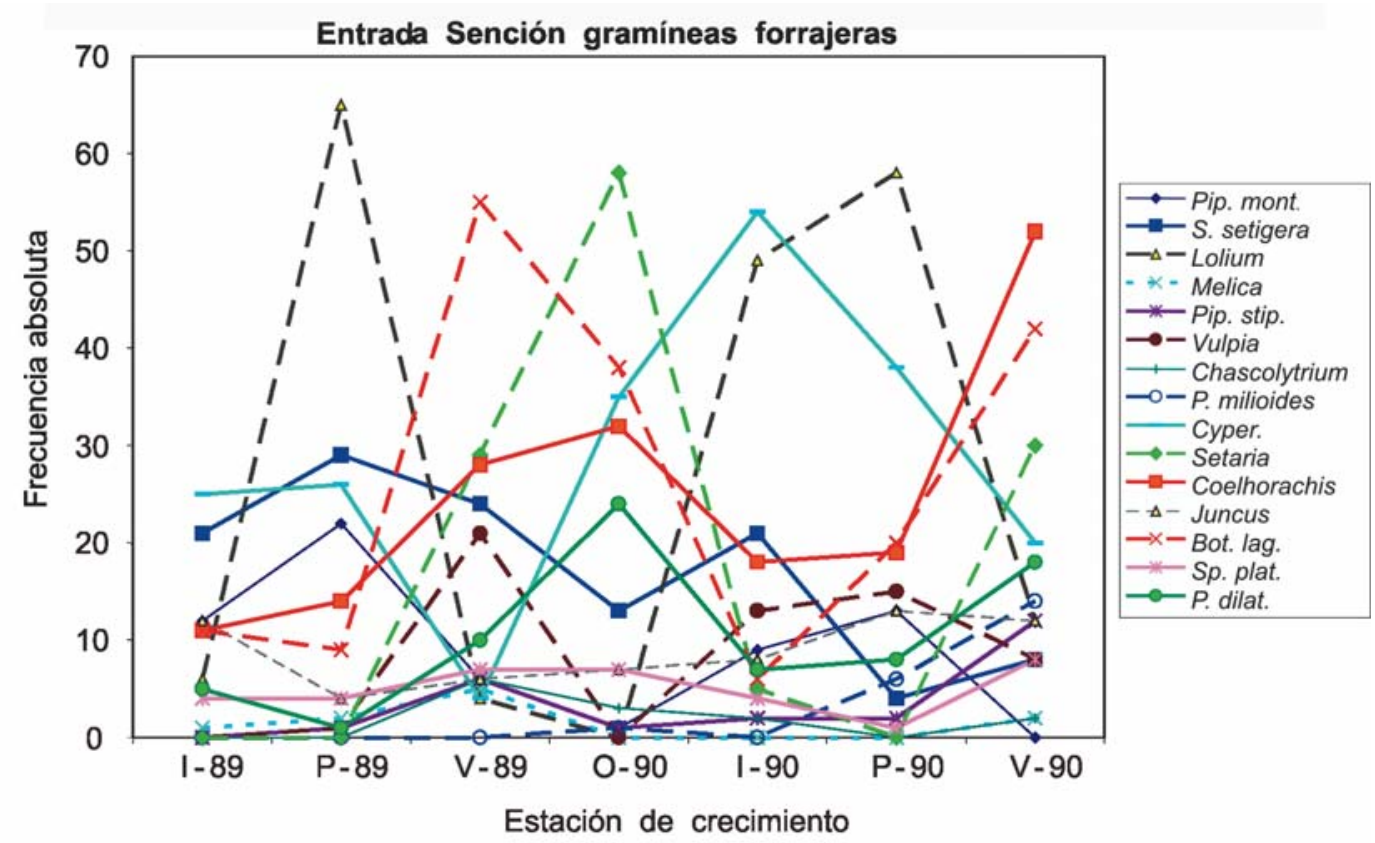

Figuras 80. Presencia de especies forrajeras de hábito de crecimiento cespitoso en una pastura con manejo aliviado (b-6) sobre suelo arcilloso en la región noreste.

Cyperaceas son las especies que presentaron los picos más altos de especies nativas, la primera con mayor presencia en el ciclo relativamente más seco (1989-90), Setaria geniculata por su parte también con valores de presencia mayores en el primer verano- otoño que en el segundo ciclo y el grupo de Cyperaceas con una marcada mayor proporción de presencias en el segundo inviernoprimavera (más húmedo) que en el primero (Figura 80). Coelorachis selloana incrementó su presencia sensiblemente en el segundo 
verano contraponiéndose en los valores con Bothrichloa laguroides de ciclo de crecimiento similar; Paspalum dilatatum presenta un perfil similar a Coelorachis selloana aunque con valores más homogéneos. Stipa setigera en el segundo ciclo, 1990, presentó valores menores para el período invierno-primavera que en el período más seco, 1989.

Juncus capillaceus, Sporobolus platensis, Melica brasiliana, Piptochaetium stipoides y Chascolytrium sp. presentaron valores estables y bajos a lo largo del período de registros; Panicum milioides si bien tuvo registros relativamente bajos los valores de los mismos se incrementaron hacia el segundo año de mejor balance hídrico. Piptochaetium montevidense y Vulpia australis tendieron a reducir su presencia en el segundo año.

Respecto a las malezas menores y enanas Oxalis sp. tendió a reducir su presencia en el segundo período inverno-primaveral ( $\mathrm{Fi}$ gura 81), Cerastium glomeratum por su parte registró una mayor presencia en el segundo invierno, Bacharis coridifolia presentó un pico de presencia en el primer verano. Juncus capillaceus e Hipoxis decumbens presenta- ron valores de presencia relativamente más estables, aunque la segunda incrementó algo su presencia en el segundo año; Sisyrinchium sp. evolucionó en forma similar a las especies anteriores pero con valores promedios menores en su presencia. Eryngium horridum registró una mayor presencia en el segundo verano en contraposición a Bacharis coridifolia. Gamochaeta spicata prácticamente registro una presencia muy baja en todo el período de evaluación.

En el sitio enfrente-Sención (b-7), con suelo más superficial que en el sitio anterior (Figura 82), Paspalum notatum y Chevreulia sarmentosa fueron las especies que presentaron valores más altos, siendo para ambos casos los valores sensiblemente mayores en el segundo verano (1990), también presentaron un pico en otoño 1990. Trifolium polymorphum registró una mayor presencia en la primavera 1989 comparada con la del segundo año. Dichondra microcalyx conjuntamente con Richardia sp., Aspilia montevidense y Soliva pterosperma tendieron a presentar valores más altos en el período otoño-invierno 1990 y reducir su pre-

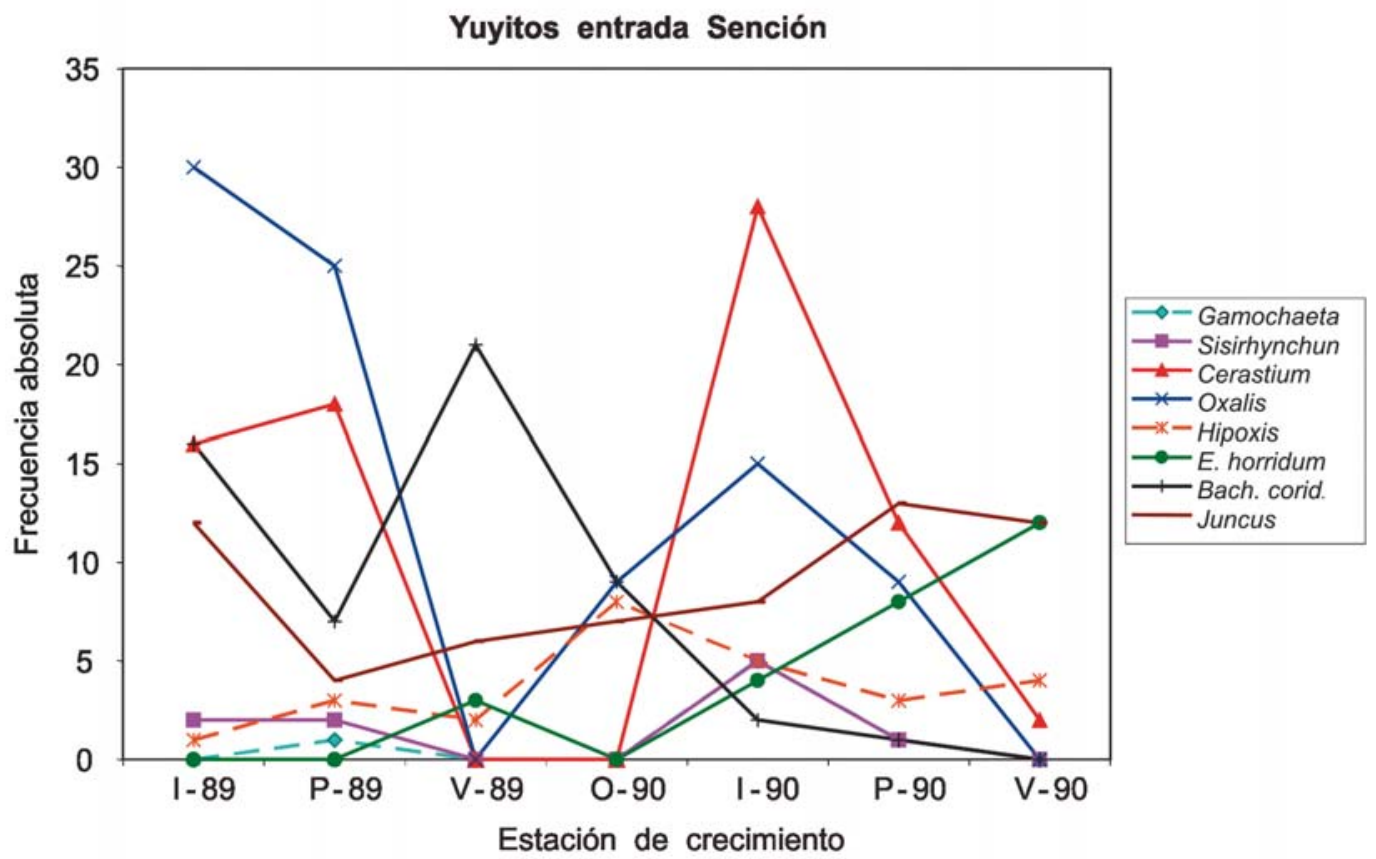

Figuras 81. Presencia de especies malezas menores y enanas en una pastura con manejo aliviado (b-6) sobre suelo arcilloso en la región noreste. 


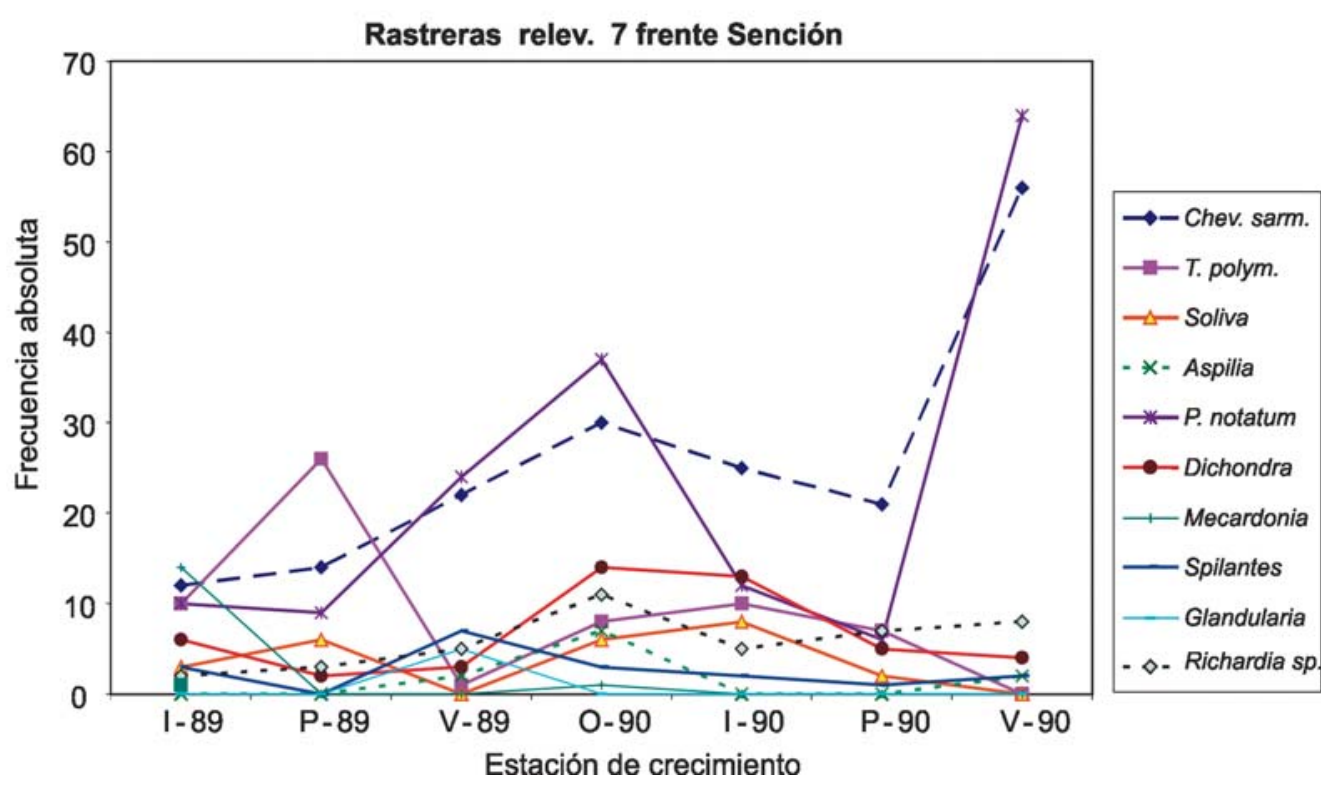

Figura 82. Presencia de especies de hábito de crecimiento rastrero en una pastura con manejo aliviado (b-7) sobre suelo arcilloso relativamente superficial en la región noreste.

sencia hacia el final de los registros. Glandularia sp. y Spilantes decumbens registraron un pequeño pico en verano 1989 y apenas imperceptible Mecardonea montevidense en otoño 1990.

En cuanto a las especies de hábito de crecimiento cespitoso y con mayor interés forrajero, en este sitio con un suelo relativamente superficial, las dos especies con picos más pronunciados en cuanto a su presencia fueron Bothriochloa laguroides y Setaria geniculata, la primera tuvo valores relativamente más bajos en el segundo verano, en cambio Setaria mantuvo los valores similares durante los dos veranos (Figura 83). En los dos inviernos Setaria geniculata tendió a presentar menores registros que Bothriochloa laguroides. Vulpia australis y Piptochaetium montevidense presentaron dos picos en sus registros en invierno-primavera con valores algo menores en el segundo año. Oxalis sp. por su parte mantuvo relativamente estable los registros tanto en invierno como en primavera en los dos años. El grupo de Cyperaceas incrementó sus valores en el segundo invierno. Danthonia sp. presentó valores destacados con un pico en la primavera 1989, pero muy bajos en la segunda primavera, Stipa setigera también presentó valores más altos en el primer año y menores en el segundo pero más estables que Danthonia sp. Coelorachis selloana registró valores bajos y relativamente homogéneos en el período de evaluación pero con una tendencia a incrementar hacia el final del período; Andropogon ternatus registró valores muy similares a Coelorachis selloana. Sporobolus platensis incrementó sus valores en los dos veranos, con una tendencia a valores más altos en el segundo verano, la forma de su respuesta estacional fue muy similar a Bothrichloa laguroides. Juncus capillaceus registró valores relativamente bajos y estables en los dos años de evaluación. Aristida murina presentó un pico en el primer verano de 1989 decayendo en el segundo.

En el sitio con ganado de cría y pastoreo aliviado (b-8), las especies Paspalum notatum, Axonopus affinis y Aspilia montevidense presentaron un mismo tipo de respuesta pero con valores más altos en Paspalum notatum y más bajos en las otras dos especies (Figura 84); Paspalum notatum mostró su marcada sensibilidad estacional. Richardia sp. incrementó su proporción en el segundo verano, en cambio Trifolium polymorphum mantuvo un registro mayor en el invierno del segundo año comparado con el primero. Dichondra microcalyx registró valo- 


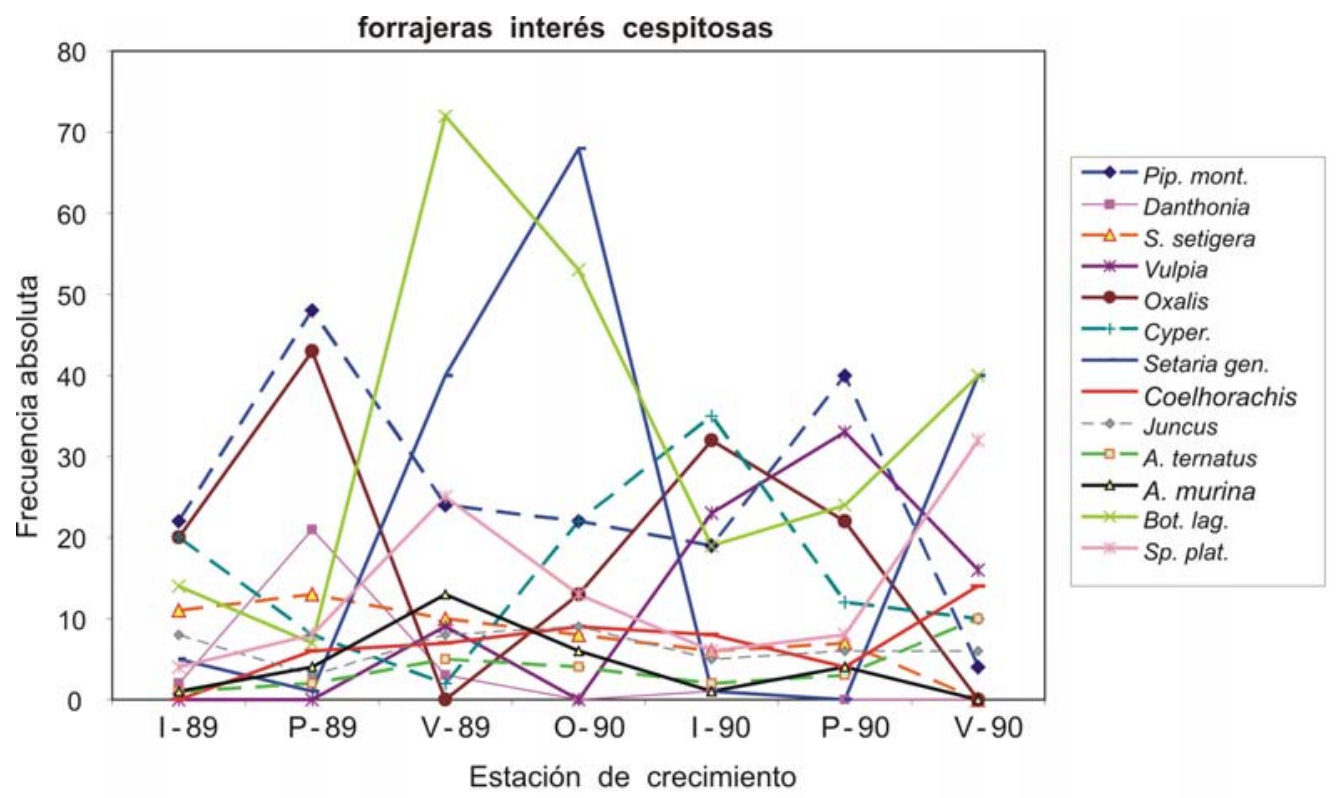

Figura 83. Presencia de especies forrajeras de hábito de crecimiento cespitoso en una pastura con manejo aliviado (b-7) sobre suelo arcilloso relativamente superficial en la región noreste.

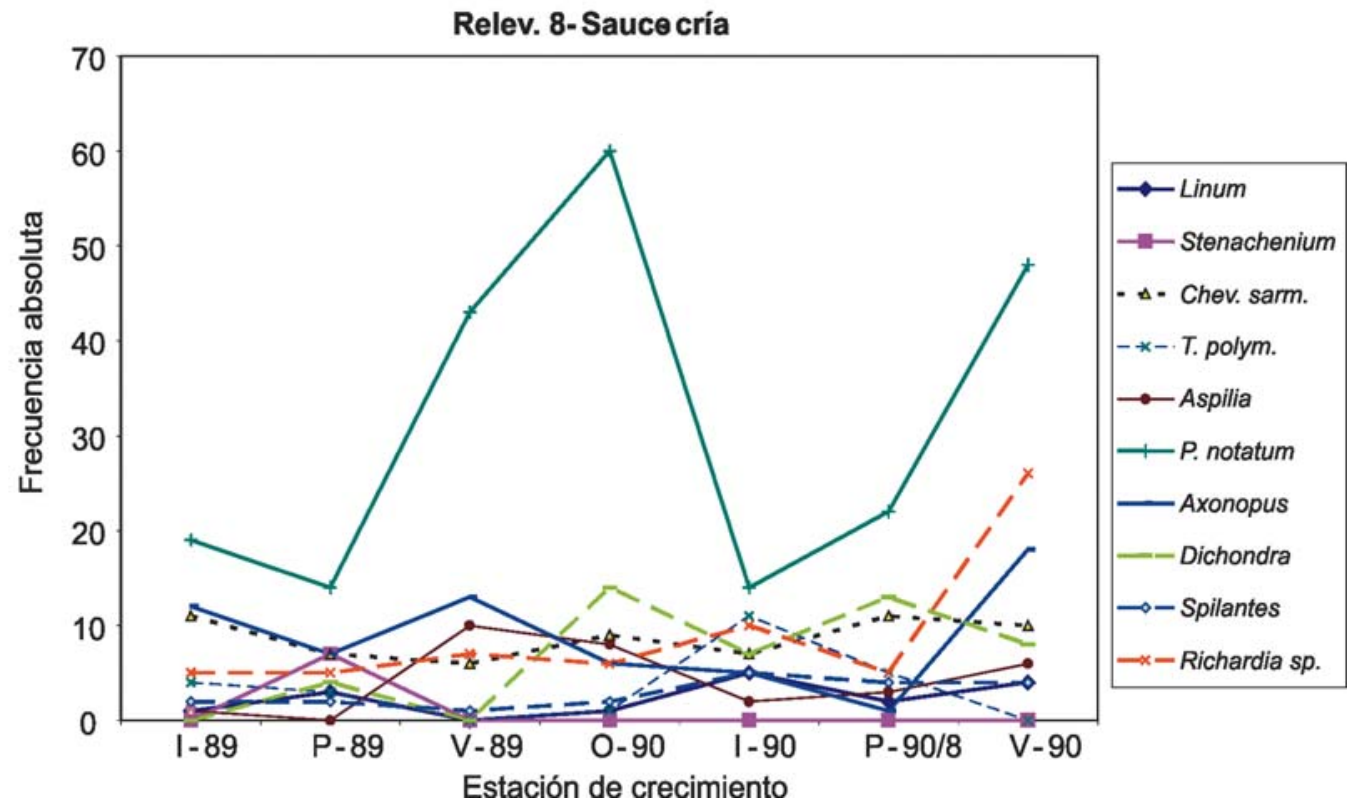

Figura 84. Presencia de especies forrajeras de hábito de crecimiento rastrero en una pastura con ganado de cría y manejo aliviado (b-8) sobre suelo arcilloso en la región noreste.

res mayores en el segundo año marcadamente, similarmente lo hizo Spilantes decumbens pero con valores menores. Chevreulia sarmentosa mantuvo los valores relativamente estables en todo el período de registro.
Dentro del grupo de especies cespitosas se destaca Bothriochloa laguroides con picos altos en el verano, tendiendo los registros a valores mayores en el segundo verano; una curva de respuesta similar con valo- 


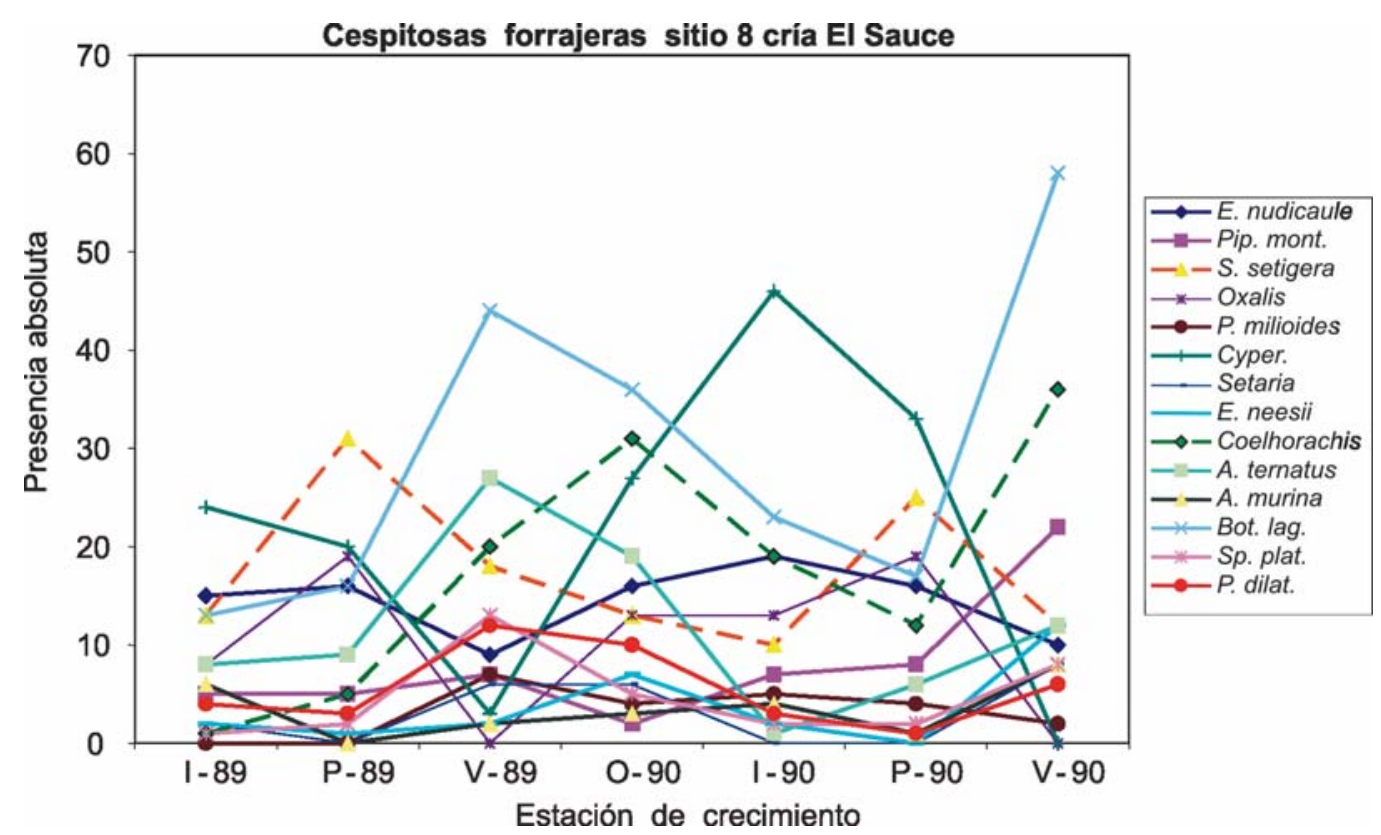

Figura 85. Presencia de especies forrajeras cespitosas en una pastura con ganado de cría y manejo aliviado (b-8) sobre suelo arcilloso en la región noreste.

res sucesivamente menores la siguen Andropogon ternatus, Paspalum dilatatum y Sporobolus platensis (Figura 85). Coelorachis selloana y Eragrostis neesii presentaron un curva de registros similar con picos en otoño 1990 y verano 1990, los valores de Coelorachis selloana fueron sensiblemente superiores a los de Setaria geniculata.

El grupo de Cyperaceas registró valores superiores en el segundo año comparado con el primero, tanto en el invierno como en la primavera. Stipa setigera registró un pico en cada primavera en su presencia, con un valor un algo menor en el segundo año. Piptochaetium montevidense por su parte incrementó sus valores en verano, siendo los mismos mayores en el segundo año. Eryngium nudicaule presentó valores importantes en sus registros pero relativamente estables en el período de evaluación, en cambio Oxalis sp. incrementó su presencia en el segundo año. Panicum milioides presentó valores bajos y relativamente estables en los dos años de evaluación.

En el sitio de invernada (b-9) se realizaron siete registros faltando el correspondiente a la primavera de 1990. Respecto a las especies de hábito de crecimiento rastrero, tanto Paspalum notatum como Aspilia montevidense presentaron un perfil de registros similar con picos en verano, pero con valores más altos en el caso de Paspalum notatum (Figura 86). Trachypogon montufari, con crecimiento rizomatoso, tuvo una evolución inversa, incrementó su presencia al final del período con valores mayores que al principio.

En el caso de las especies de hábito de crecimiento cespitoso Bothrichloa laguroides conjuntamente con Stipa setigera, Andropogon ternatus, Coelorachis selloana y el grupo de Cyperaceas fueron de las cespitosas las que presentaron un mayor variación en los valores de presencia (Figura 87). Bothriochloa laguroides con un pico mayor en el primer verano comparado con el segundo, Andropogon ternatus con mayores valores en el segundo año, Stipa setigera redujo su presencia sensiblemente en el segundo año, Coelorachis selloana también presentó valores relativamente menores en el segundo verano y el grupo de Cyperaceas incremento en el segundo invierno. Sporobolus platensis con valores intermedios presentó dos picos en verano con valores algo mayores en el segundo verano, Paspalum dilatatum si bien tuvo valores menores que Sporobolus platensis al inicio presentó un perfil similar a esta especie. 


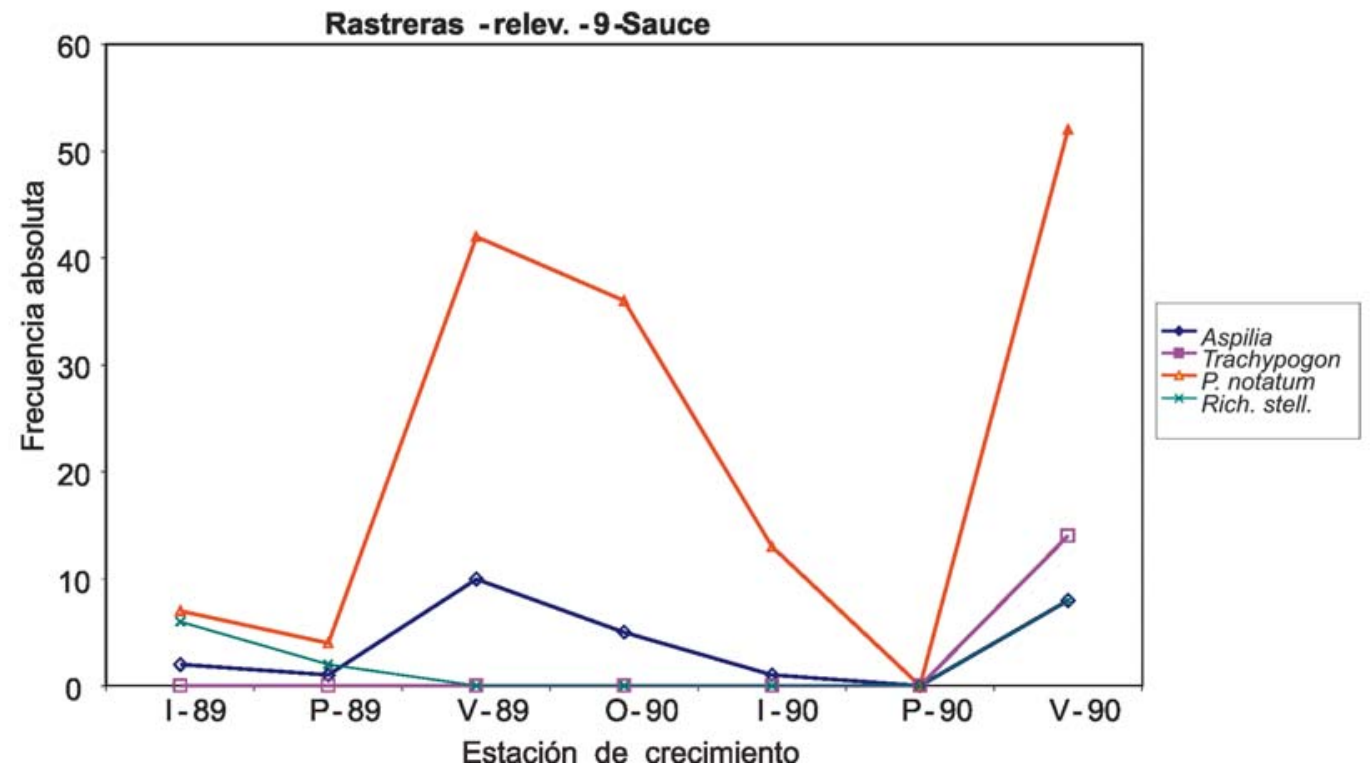

Figura 86. Presencia de especies de hábito de crecimiento rastrero, en una pastura utilizada como invernada (b-9) sobre suelo arcilloso en la región noreste.

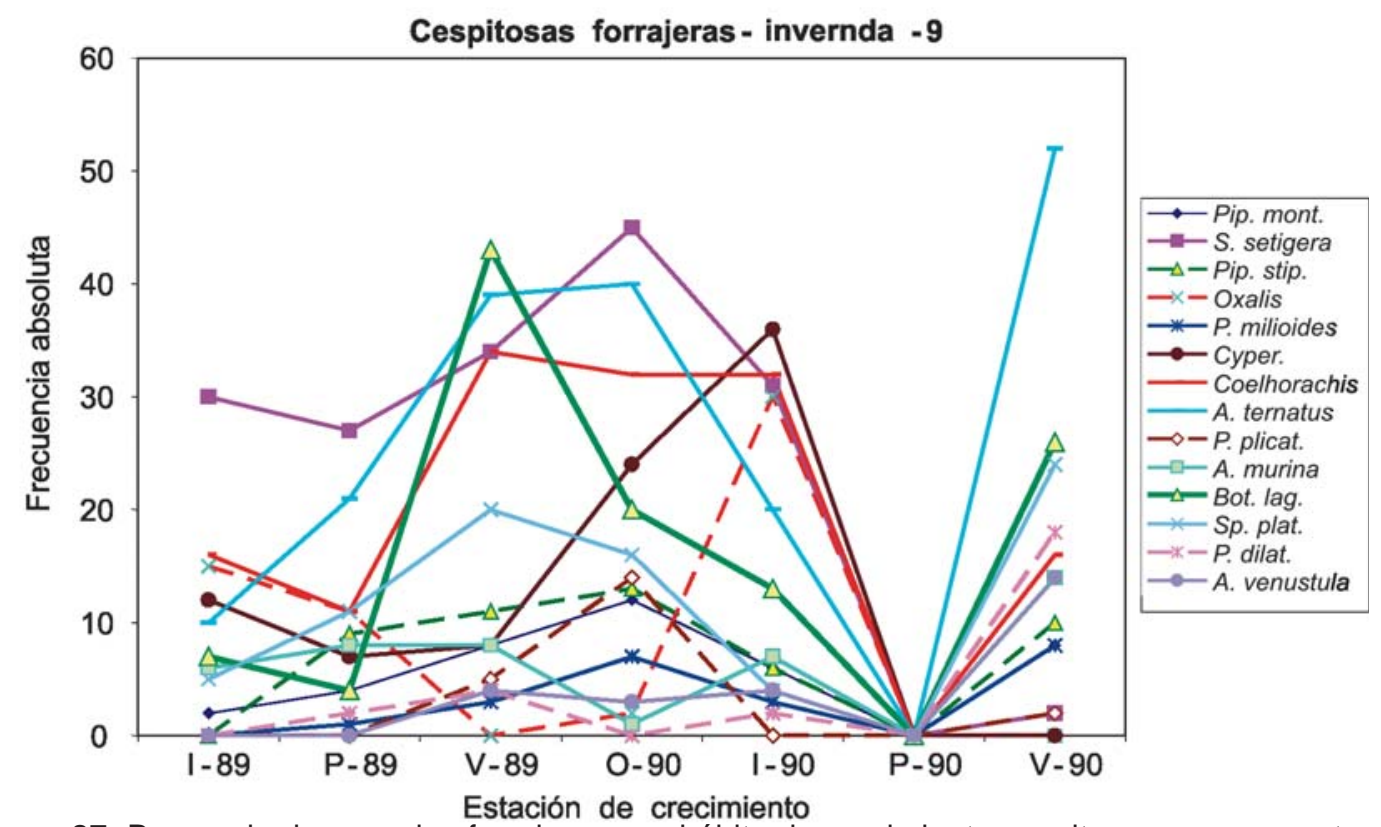

Figura 87. Presencia de especies forrajeras con hábito de crecimiento cespitoso, en una pastura manejada como invernada (b-9) sobre suelo arcilloso en la región noreste.

Paspalum plicatulum incrementó su presencia hacia el otoño 1989 pero en el verano 1990 los valores fueron relativamente menores, Panicum milioides incremento en otoño 1989 y verano 1990. Oxalis sp. por su parte incrementó marcadamente en el segundo invierno. Piptochaetium montevidense y Piptochaetium stipoides registraron un com- portamiento similar con incremento de presencia hacia otoño 1990 y nuevamente en el verano 1990.

En la pastura restablecida a campo bruto luego de un período de cultivo (b-10), dentro de las especies de hábito de crecimiento rastrero, Richardia sp. registró mayores valores en el segundo invierno y primavera, en cambio 


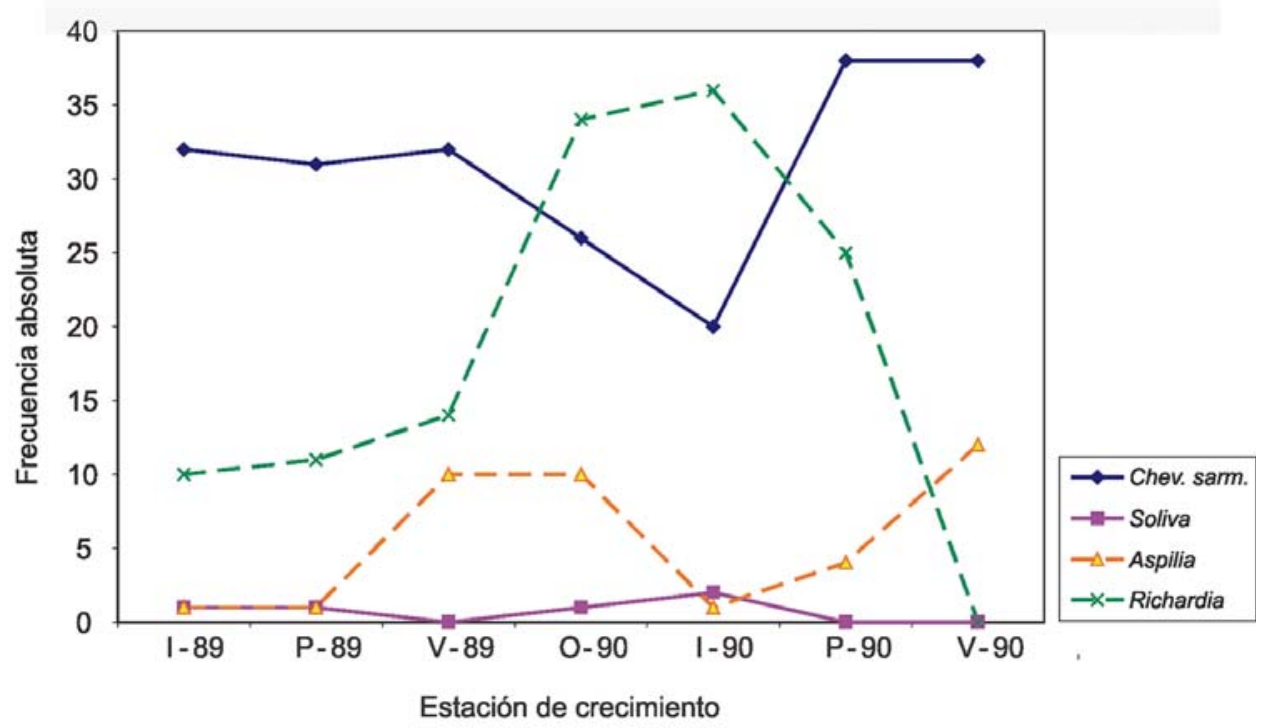

Figura 88. Presencia de especies con hábito de crecimiento rastrero, en una pastura recuperada luego de un ciclo de cultivo (b-10) sobre suelo arcilloso.

los valores fueron menores en el segundo verano (Figura 88). Aspilia montevidense por su parte, presentó valores similares para los dos veranos y Chevreulia sarmentosa, con valores relativamente estables, tendió a valores mayores en la segunda primavera-verano; Soliva pterosperma mostró escaso aporte en el período de evaluación.

Respecto a las cespitosas Piptochaetium stipoides registró los valores más altos tendiendo a valores mayores en la segunda primavera-verano comparado con el primer año. Bothrichloa laguroides en el segundo verano registró valores más altos; esta especie al igual que en otros sitios tendió a presentar un pico en verano antes que Coelorachis selloana en otoño. Coelorachis selloana y Setaria geniculata registraron un perfil similar pero la primera con valores más altos tendiendo a incrementarlos en el segundo verano (Figura 89). El grupo de Cyperaceas y Oxalis sp. a su vez presentaron un ciclo de registros también similares con un pico en el inverno 1990. Paspalum dilatatum registró un pico de valores de presencia en el primer verano, luego descendió y se mantuvo estable hasta el final del ciclo. Stipa setigera con un pico en el segundo invierno mostró valores similares con los dos primaveras y un valor relativamente menor en el registro del segundo verano.

\section{Correlaciones y presencias absolutas}

En forma complementaria a las secciones previas, se discute en los siguientes párrafos la presencia de diferentes especies y las correlaciones registradas entre las mismas, en dos pasturas estudiadas en la región noreste.

Este tipo de análisis pretende contribuir a un mejor conocimiento de la respuesta de las diferentes especies a los distintos factores ecológicos, contemplando al mismo tiempo las características vegetativas propias de cada especie. En un sentido ecológico funcional se pretende una visualización del comportamiento de las poblaciones de las diferentes especies frente a la matriz ambiental.

En la Figura 90 se grafica la relación de la frecuencia absoluta, a través de las estaciones de registro, entre tres especies en el sitio de campo bruto donde previamente hubo un cultivo de verano (b-10). Independientemente de los valores, más altos o más bajos, dada la forma de las gráficas individuales de cada especie que son muy similares en su tendencia, generaron valores de las correlaciones positivos y muy cercanos a uno. Bothrichloa laguroides tuvo una correlación de 0,86 con Coelorachis selloana y 0,88 con Piptochaetium montevidense; esta última a 


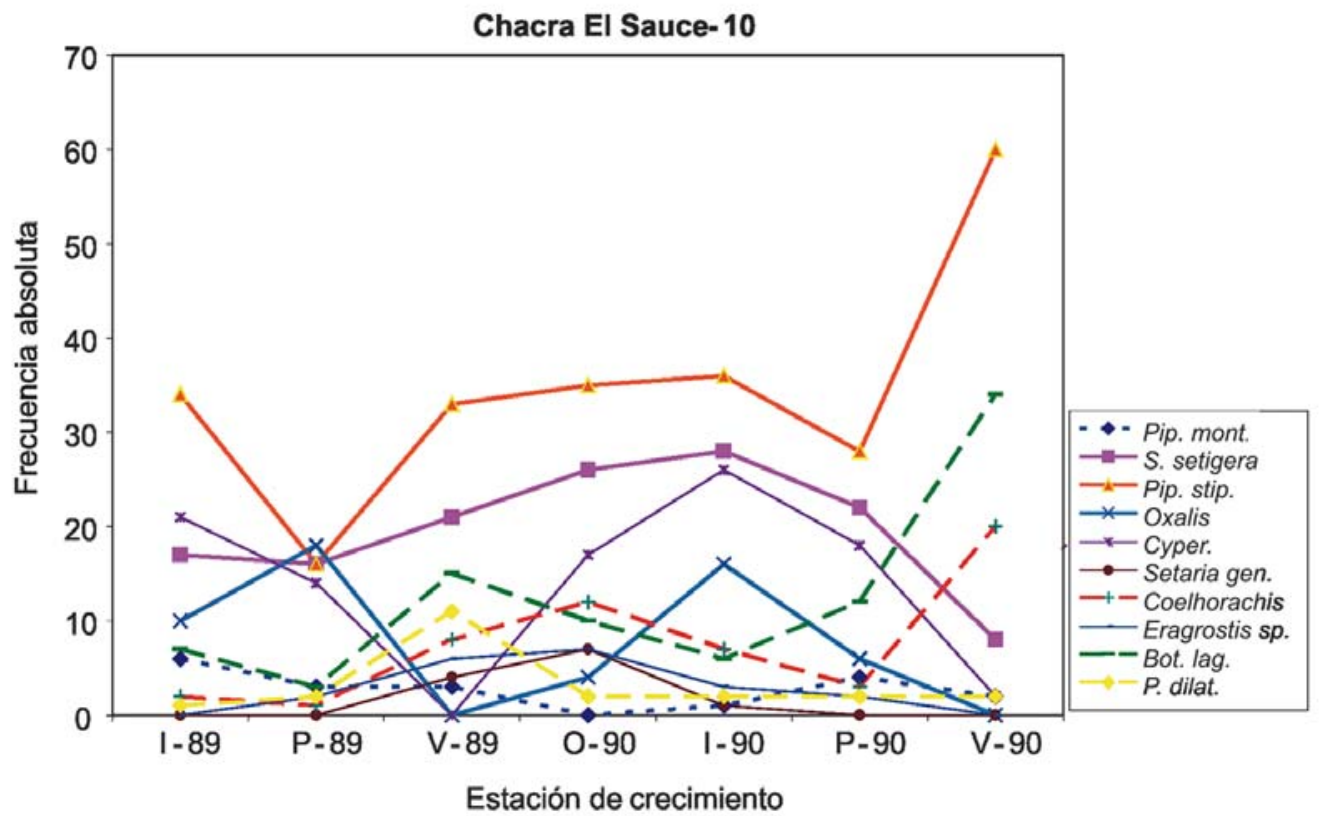

Figura 89. Presencia de especies forrajeras con hábito de crecimiento cespitoso, en una pastura recuperada luego de un ciclo de cultivo (b-10) sobre suelo arcilloso correlaciones y presencias absolutas.

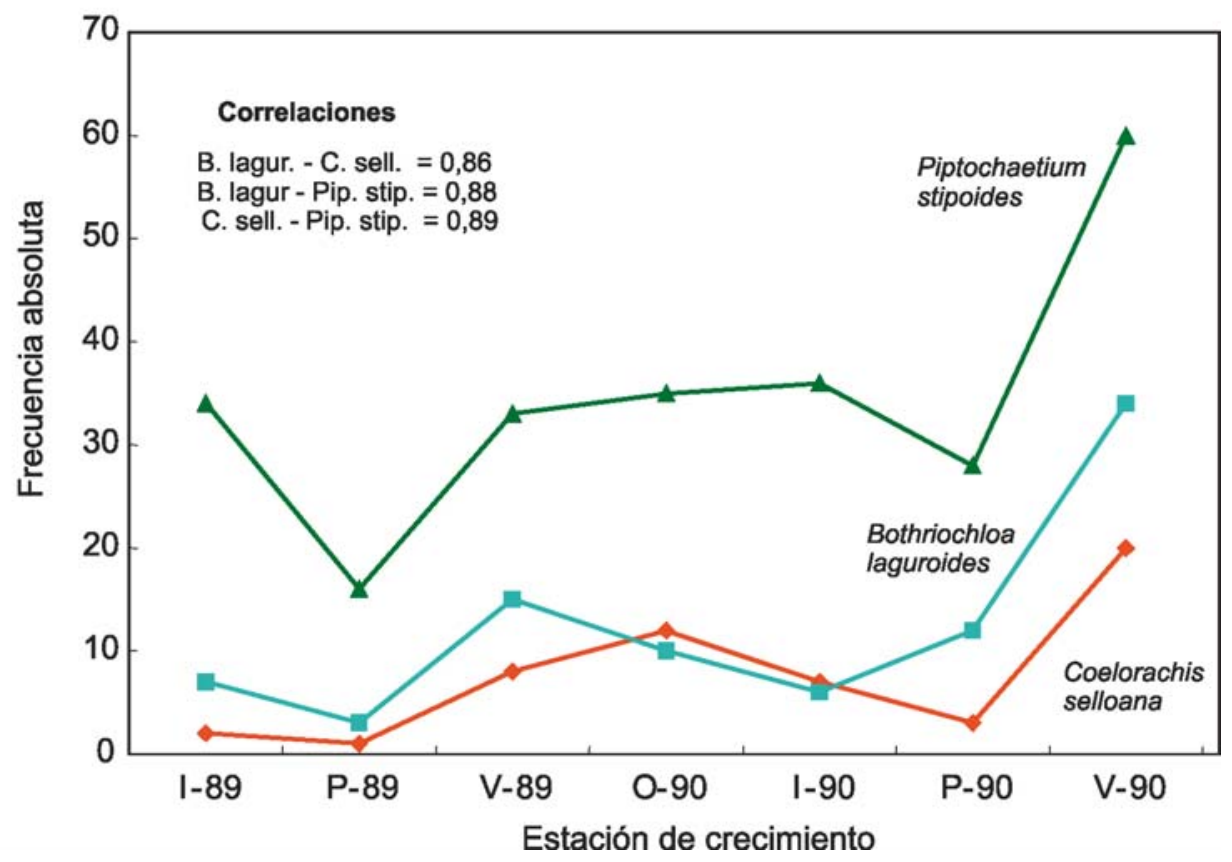

Figura 90. Frecuencia absoluta de tres especies forrajeras en un campo bruto luego de cultivo (b-10) sobre suelo arcilloso en la región noreste.

su vez, tuvo una correlación de 0,89 con Coelorachis selloana.

En el caso de la Figura 91, se presentan los valores absolutos de cinco especies fo- rrajeras en siete estaciones de crecimiento en una pastura con manejo aliviado (b-6) y que en algún momento previo (más de dos décadas) había sido fertilizada. En la figura 


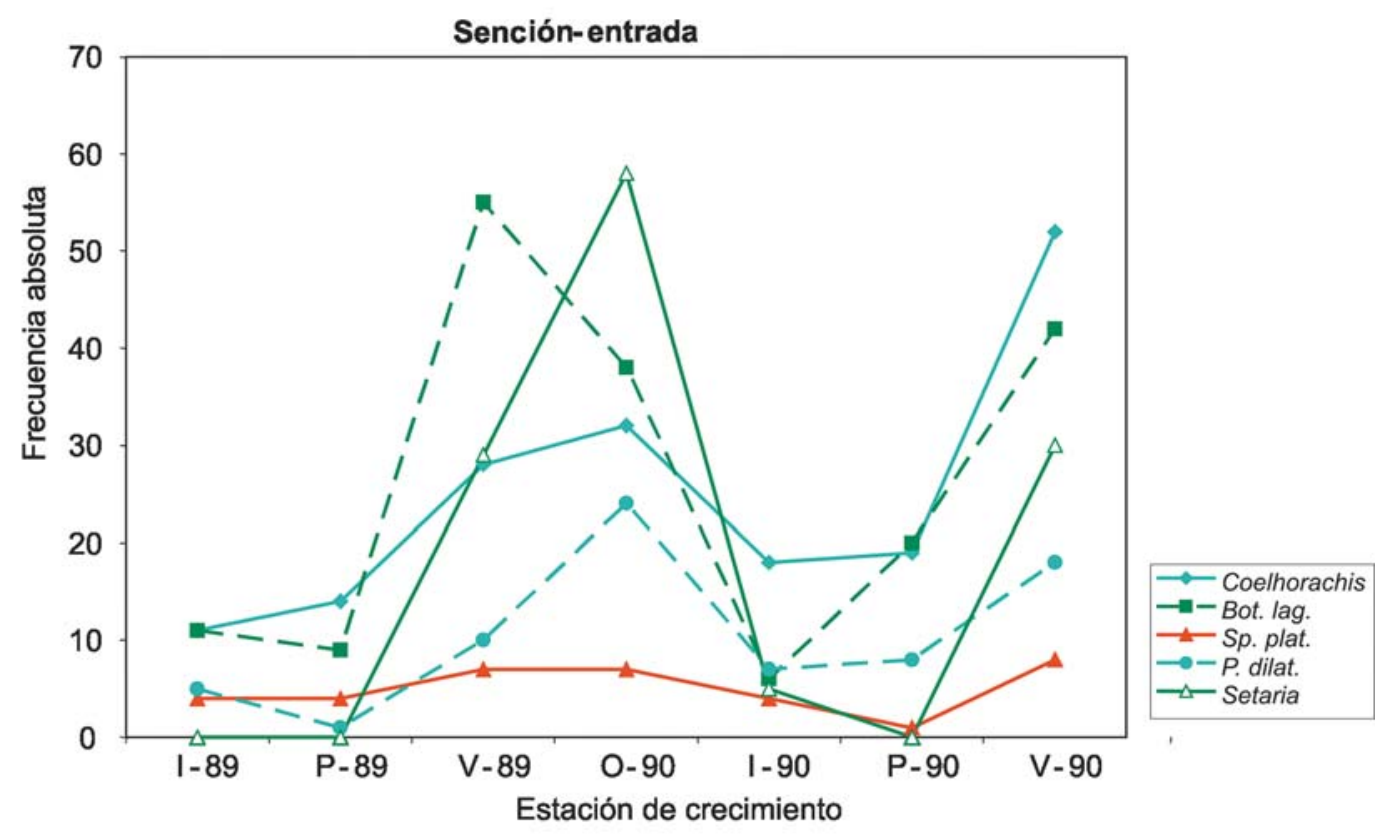

correlaciones

B. laguroides vs. C. selloana $=0,73$

B. laguroides vs. S. platensis $=0,73$

B. laguroides vs. $P$. dilatatum $=0,65$

C. selloana vs. $P$. dilatatum $=0,77$

B. laguroides vs. $P$. dilatatum $=0,75$
B. laguroides vs. Setaria $=0,75$

Setaria vs. $P$. dilatatum $=0,92$

Figura 91. Frecuencia absoluta de cinco especies forrajeras en una pastura aliviada (b-6) sobre un suelo arcilloso en la región noreste y algunas correlaciones entre ellas.

se aprecia claramente que los valores absolutos de cada especie, si bien varían en forma similar estacionalmente, no lo hicieron tan armónicamente como en la figura previa (Figura 90). Las correlaciones reportadas en esta figura varían entre 0,65 y 0,92; en la figura es posible destacar que tanto la magnitud de los valores como la estacionalidad de los mismos contribuirían claramente a la generación de los valores del coeficiente de correlación. En este sentido el menor valor de 0,65 entre Bothrichloa laguroides y Paspalum dilatatum puede explicarse en base a los picos de mayor presencia separados en el tiempo entre las mismas, así como los valores máximos y mínimos de cada una en cada estación de crecimiento. Bothriochloa laguroides presenta el primer pico de máxima en el verano 1989, en cambio Paspalum dilatatum lo hace en otoño 1990, en invierno 1990 presentaron prácticamente los mismos valores pero hacia el verano siguiente $B$. laguroides alcanzó a presentar en el verano 1990 valores dos veces mayores que $P$. dilatatum. Los mayores valores de las correla- ciones que involucran a Paspalum dilatatum con Coelorachis selloana y con Setaria geniculata se podrían explicar por los valores de la Figura 91, donde las tres especies entre ellas registraron valores con una tendencia estacional similar y menores fluctuaciones en la amplitud de los valores, en menor medida en el caso de C. selloana y en mayor medida en el caso de $S$. geniculata.

En la Figura 92 se incluyen las frecuencias absolutas de cuatro especies forrajeras en siete estaciones de crecimiento en la misma pastura aliviada considerada previamente (b-6), pero incluyendo, en este caso, una calificada de crecimiento invernal como, Stipa setigera (Rosengurtt, 1979). En esta figura las correlaciones variaron entre $-0,80$ y 0,50 ; el valor mayor negativo de $-0,80$ entre Coelorachis selloana y Piptochaetium montevidense surgiría de la fluctuación prácticamente opuesta en los valores estacionales de las dos especies. Por el contrario los mayores valores positivos entre Piptochaetium montevidense y Stipa setigera $(0,50)$ se explicarían por un ciclo de crecimiento 


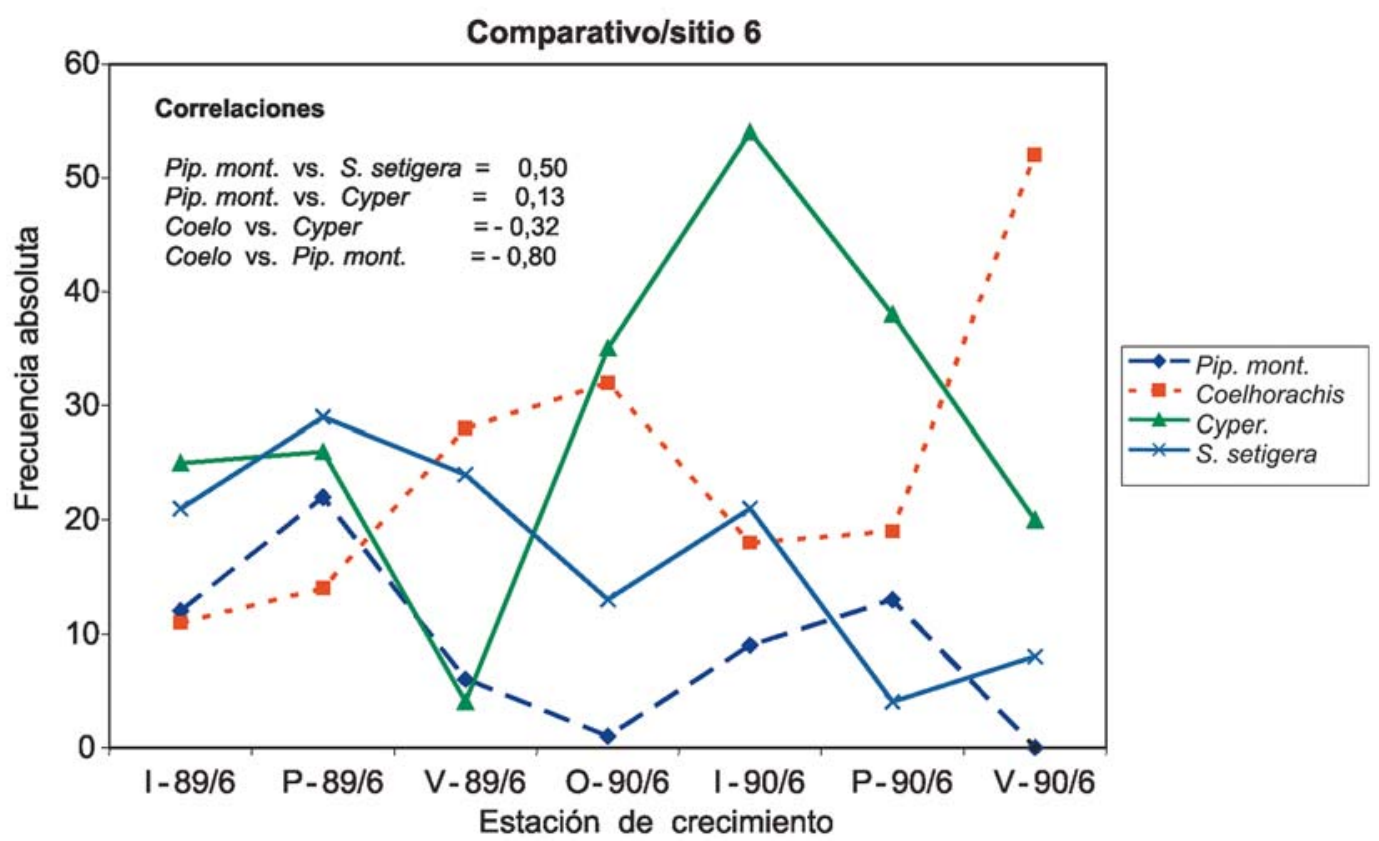

Figura 92. Frecuencia absoluta de cuatro especies forrajeras de diferente ciclo de producción en una pastura aliviada (b-6) sobre un suelo arcilloso en la región noreste.

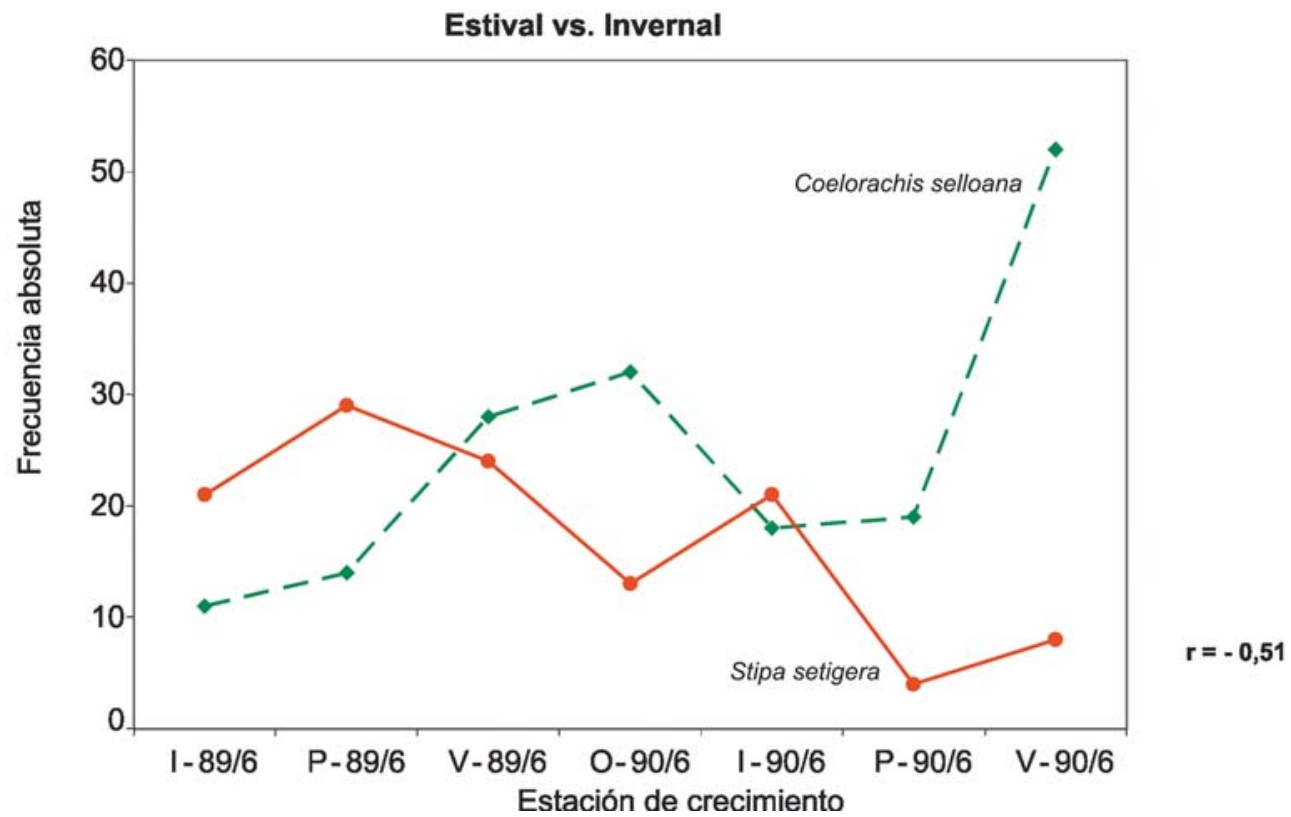

Figura 93. Frecuencia absoluta de dos especies forrajeras una de ciclo invernal,Stipa setigera y otra de ciclo estival Coelorachis selloana, en una pastura aliviada (b-6) sobre un suelo arcilloso en la región noreste.

estacional similar entre ambas, por la tendencia a través del período así como la fluctuación de los valores absolutos en el tiempo de evaluación.
Como corolario de esta descripción analítica en la Figura 93 se describe la relación entre Coelorachis selloana y Stipa setigera, dos especies reconocidas por su aporte de 
forraje estival y primaveral en las pasturas naturales respectivamente, según la frecuencia absoluta de presencia estacional. Estos valores corresponden a una pastura natural con manejo aliviado del pastoreo (b-6) y se destaca tanto la evolución estacional de los valores de cada especie en forma opuesta, lo cual generaría el valor de - 0,51 de la correlación entre ambas.

Este análisis descriptivo de las correlaciones entre especies contribuye a comenzar a interpretar las relaciones físico temporales entre los componentes de interés de las pasturas naturales. Las causas reales deberían analizarse más en profundidad considerando la dinámica poblacional de cada una de las especies (nacimientos, muertes, densidad de propágulos, longevidad individual, niveles de resiembra) teniendo en cuenta su biología, forma de reproducción y estrategias de colonización en relación a las condiciones ambientales del suelo, así como los impactos del manejo del pastoreo con animales y algunas otras variables como la estrategias de fertilización estacional con diferentes nutrientes.

\section{Comportamiento específico - estacional bajo diferentes sistemas de manejo en pasturas naturales de la región noreste}

A partir de la presencia estacional de cada especie en cada sitio se realizó un análisis descriptivo gráfico tomando como eje a cada especie, considerando el manejo recibido en cada una de las pasturas en forma diferencial históricamente y durante el período de registros. En las siguientes figuras se consideran para el análisis diecinueve especies herbáceas, incluyendo tanto especies forrajeras propiamente dichas así como otras consideradas malezas menores o con escaso aporte forrajero en las pasturas naturales.

\section{Coelorachis selloana}

La evolución de Coelorachis selloana durante siete estaciones de crecimiento en seis pasturas sobre brunosoles se describe en la Figura 94. En prácticamente todos los casos los valores se incrementaron en el segundo verano salvo en el caso del potrero de

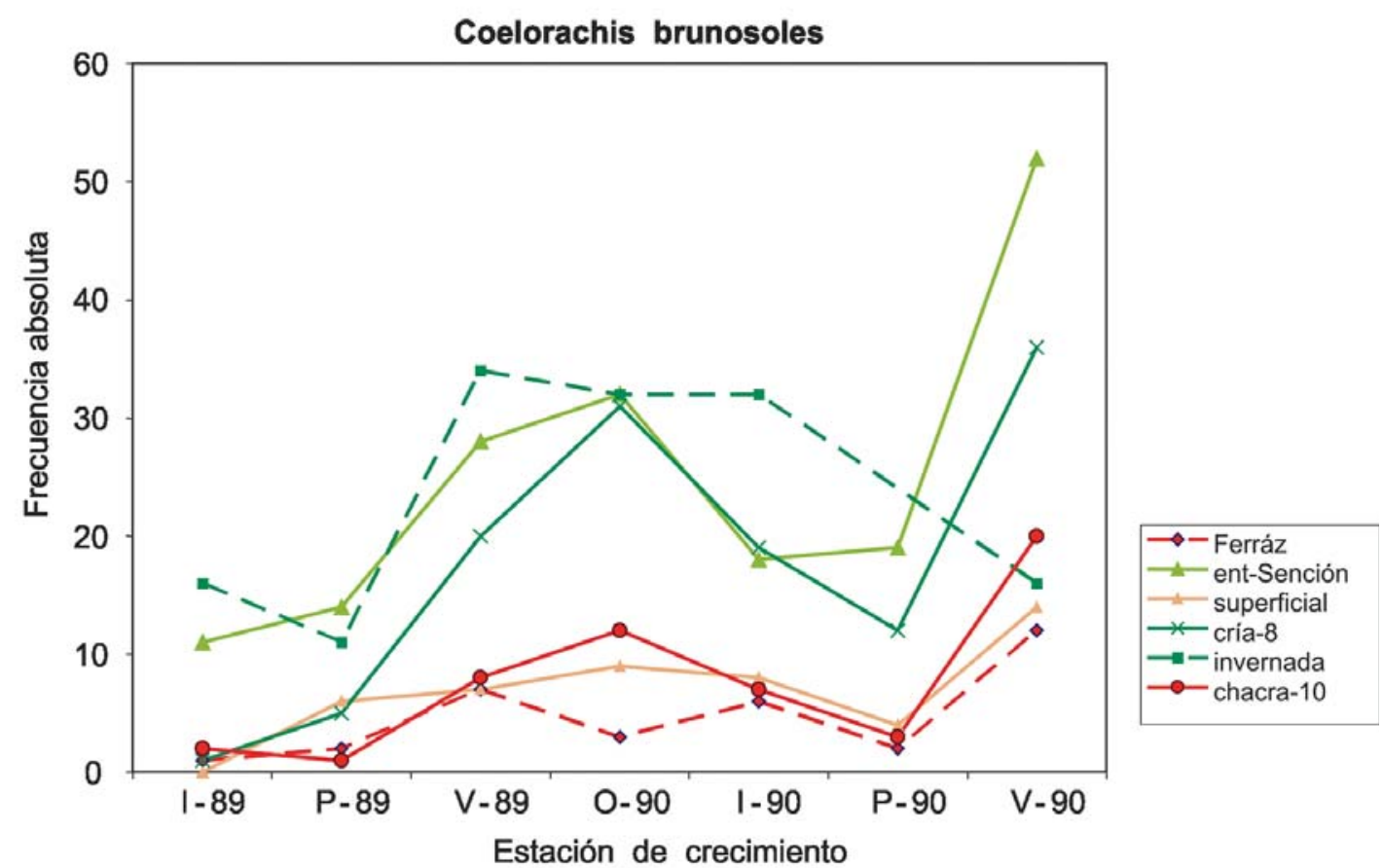

Figura 94. Variación estacional de Coelorachis selloana en seis pasturas naturales sobre suelo arcilloso de la región noreste. 
invernada donde los registros de presencia son relativamente menores. Tanto la pastura sobrepastoreada (Ferráz), la que fue chacra y luego se recuperó a campo bruto como la que estaba sobre suelo más superficial registraron valores en promedio menores que los potreros de cría e invernada así como el potrero Sención que ha registrado las mayores tasa de crecimiento; estas tres pasturas han sido históricamente manejadas en forma menos intensa y con pastoreos aliviados y moderados. En el potrero de invernada en la primavera no se realizaron registros en eses sitio. La especie muestra la sensibilidad estacional, interanual así como la respuesta histórica a un manejo específico en cada sitio, se podría considerar que en las situaciones de mejor manejo de la pastura la presencia de Coelorachis sellloana prácticamente triplica su valor con respecto a las de manejo relativmaente más intenso.

\section{Panicum milioides}

Respecto a Panicum milioides, teniendo en cuenta los valores iniciales en el invierno y primavera 1989, en el segundo año los re- gistros tendieron a incrementar su valor con condiciones hídricas más favorables siendo los valores mayores en los sitios con manejo más aliviado (Sención, invernada) que en el sitio con sobrepastoreo (Ferráz) y valores intermedios en el sitio cría-8 (Figura 95).

\section{Sitpa setigera}

Una especie perenne de crecimiento invernal como Stipa setigera presentó tembién una cierta variación estacional en su presencia en las pasturas, pero con los valores tendiendo a ser menor al final del período comparado con Coelorachis selloana; también se registró una variación de acuerdo a la historia del sito (Figura 96). Los menores valores se registraron en la pastura sobrepastoreada y los más altos en el potrero de invernada; en el potrero de cría-8 y en el potrero con historia de chacra mostraron valores en promedio algo inferiores a la invernada y la pastura sobre suelo superficial valores aún relativamente más bajos y contrastantes; en el potrero Sención, con pastoreo aliviado, en el año más seco tuvo valores altos y tendió a valores bajos en el segundo año más húmedo.

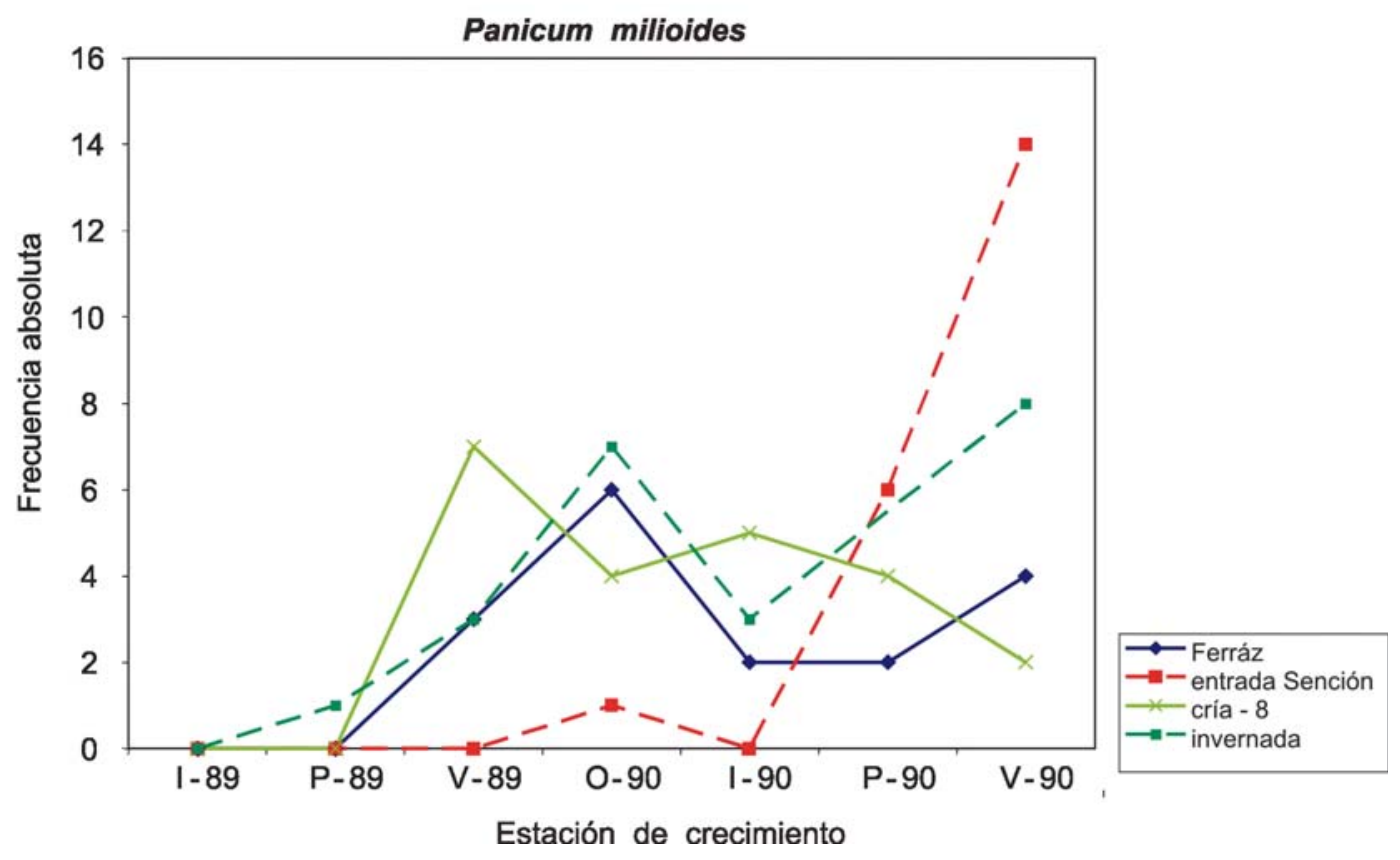

Figura 95. Variación estacional de Panicum milioides en cuatro pasturas naturales sobre suelo arcilloso de la región noreste. 


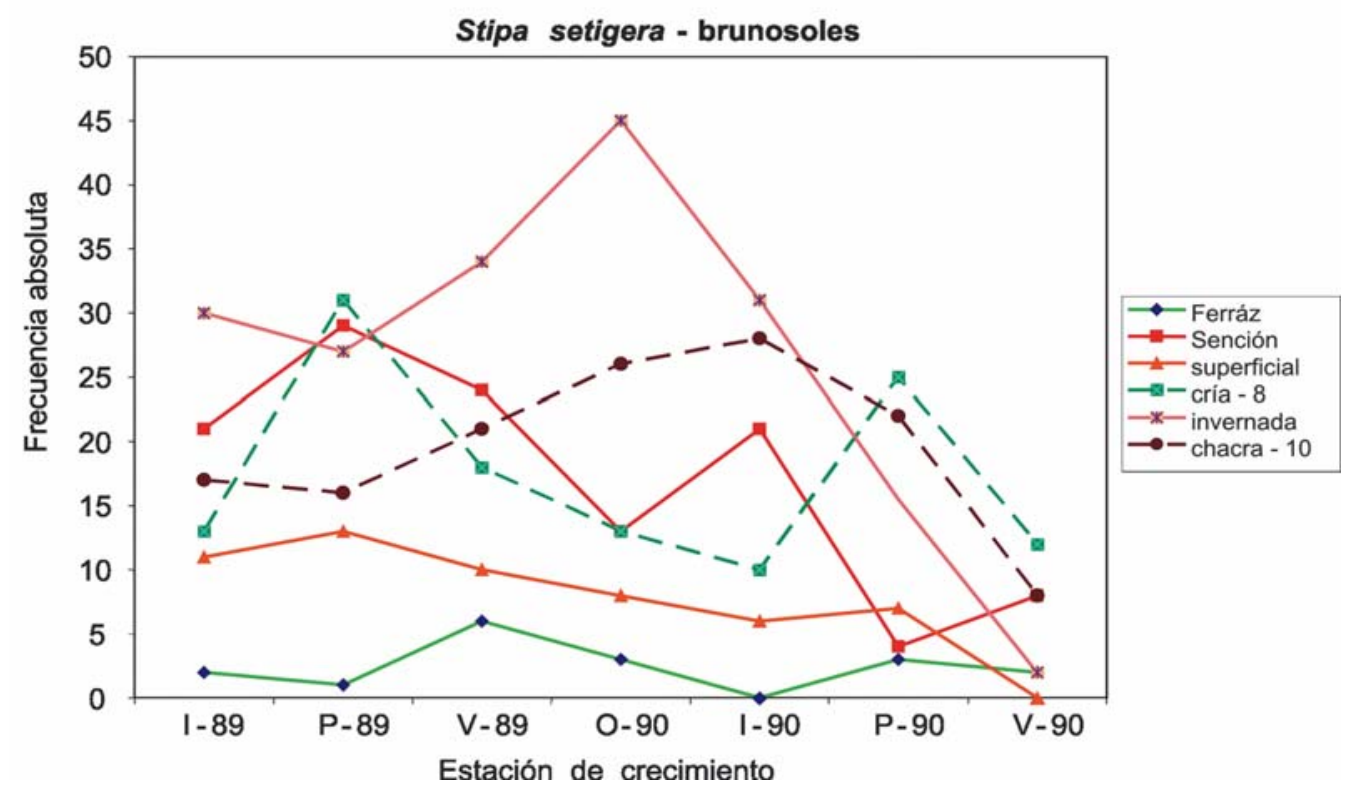

Figura 96. Variación estacional de Stipa setigera en seis pasturas naturales sobre suelo arcilloso de la región noreste.

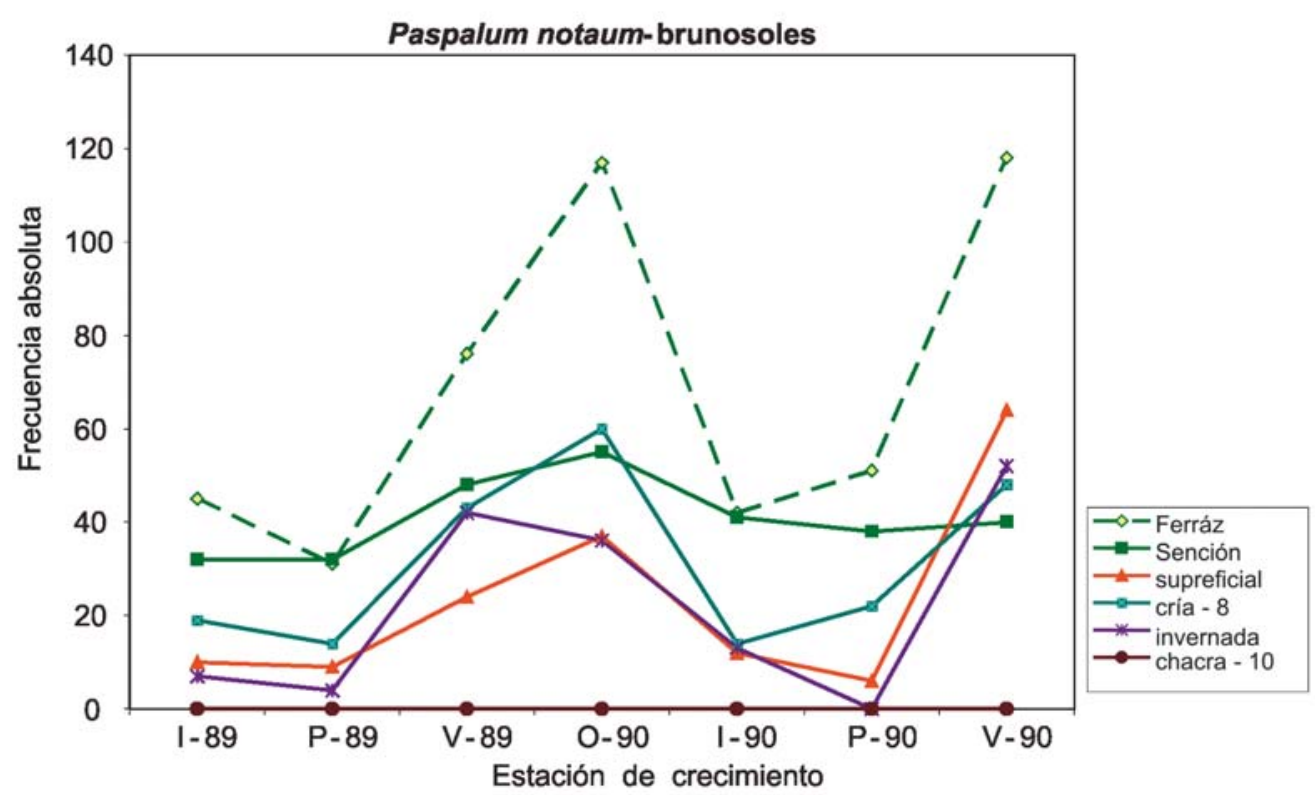

Figura 97. Variación estacional de Paspalum notatum en seis pasturas naturales sobre suelo arcilloso de la región noreste.

\section{Paspalum notatum}

Paspalum notatum es una de las especies que más marcadamente registró su estacionalidad con valores muy altos hacia fines de verano (Figura 97); siendo los valores de presencia mayores en el sitio donde la pastura ha estado sobrepastoreada duran- te mucho tiempo (Ferráz) y los valores menores tendieron a estar en el potrero de invernada y de suelo superficial, la pastura de cría-8 y pastoreo aliviado tuvieron valores intermedios;; en el caso donde anteriormente hubo chacra no se registró la presencia de Paspalum notatum en el período de evaluación (chacra-10). Esta última información 
es muy relevante ya que el potrero de invernada se encontraba alambrado por medio del sitio donde se hizo la chacra, lo cual podría indicar el alto impacto de la actividad agrícola sobre esta especie, aún luego de haberse vuelto campo bruto luego de más de diez años.

\section{Bothriochloa laguroides}

En el caso de Bothrichloa laguroides su perfil indica que claramente incrementó su presencia en los dos veranos (Figura 98), siendo en el segundo verano los valores menores que en el anterior (superficial, Sención, invernada, Ferráz) en cambio en cría-8 los valores fueron mayores en el segundo verano. En el caso del potrero con el suelo más superficial los valores tendieron a ser más altos en general, así como los valores en el sitio sobrepastoreado (Ferráz) los menores. Esta especie es de hábito cespitoso y tendió a mantenerse con mayor presencia en los suelos con pasturas más aliviadas frente a los sitios donde había sido chacra o sobrepastoreo; en el caso del suelo más superficial en cierta medida esta información se compatibiliza con la proporcionada por
Rosengurtt (1979) donde manifiesta que la especie se encuentra preferentemente en sitios relativamente más secos.

\section{Axonopus affinis}

Axonopus affinis fue analizado considerando diferentes sitios en ambos tipos de suelo en primera instancia y luego en casos más específicos (Figuras 99, 100, 101). En general en los suelos arenosos se registró una mayor presencia de Axonopus affinis comparado con los suelos arcillosos (Figura 99), la pastura con valores mayores fue donde se habían realizado chacras con cultivo de soja, luego cierta variación estacional correspondió al sitio con sobrepastoreo en el potrero 2 -LM y en el potrero 4-LM con manejo aliviado valores de presencia, en promedio, menores que en el potrero 2-LM así como la pastura del potrero de cría-8 (Figura 101). La pastura sobrepastoreada en el sitio Ferráz, así como la de Sención incremento hacia el final del período, al mismo tiempo en el sitio de invernada y chacra-10 con valores nulos no se registró presencia de la especie. En el caso en el que hubo chacra, luego pradera y luego campo bruto y que finalmente terminó en una plantación de

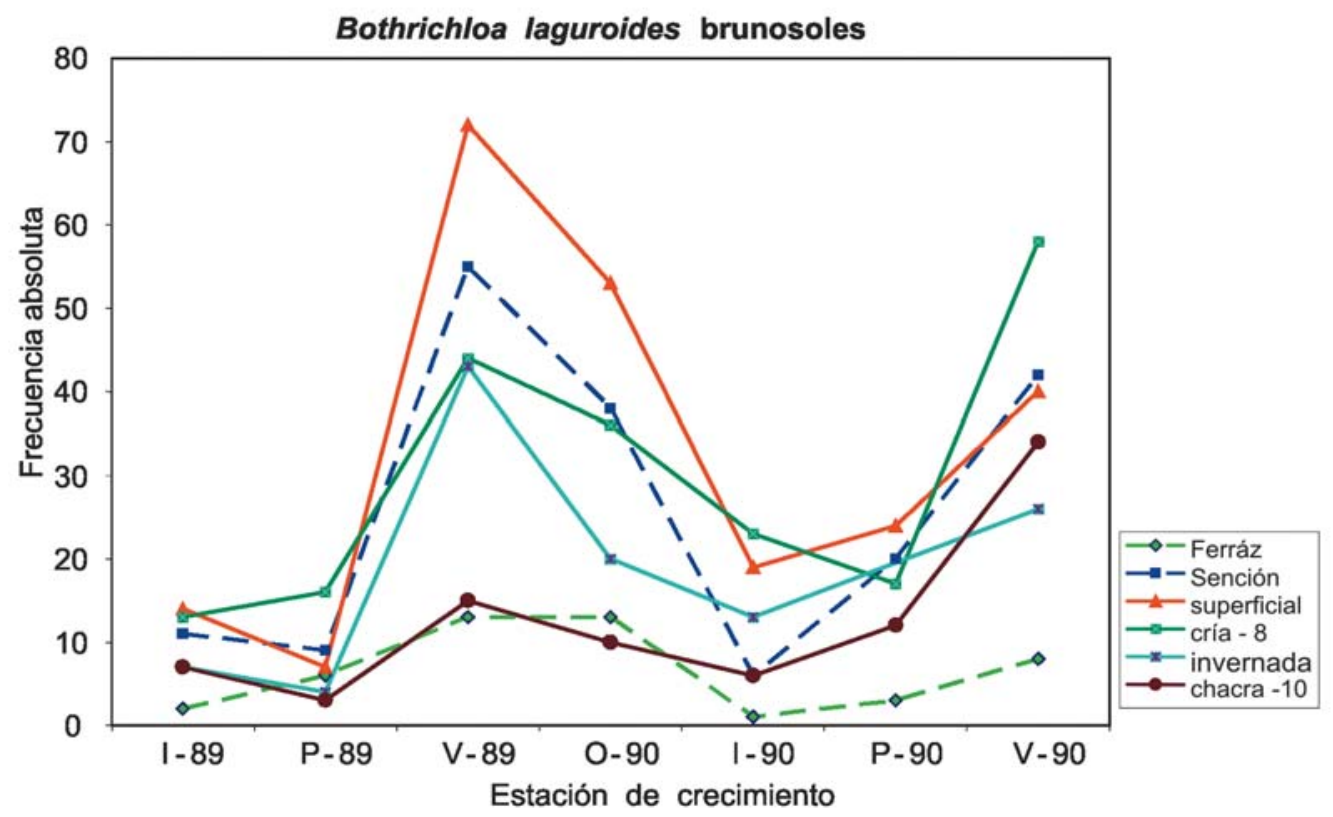

Figura 98. Variación estacional de Bothrichloa laguroides en seis pasturas naturales sobre suelo arcilloso de la región noreste. 


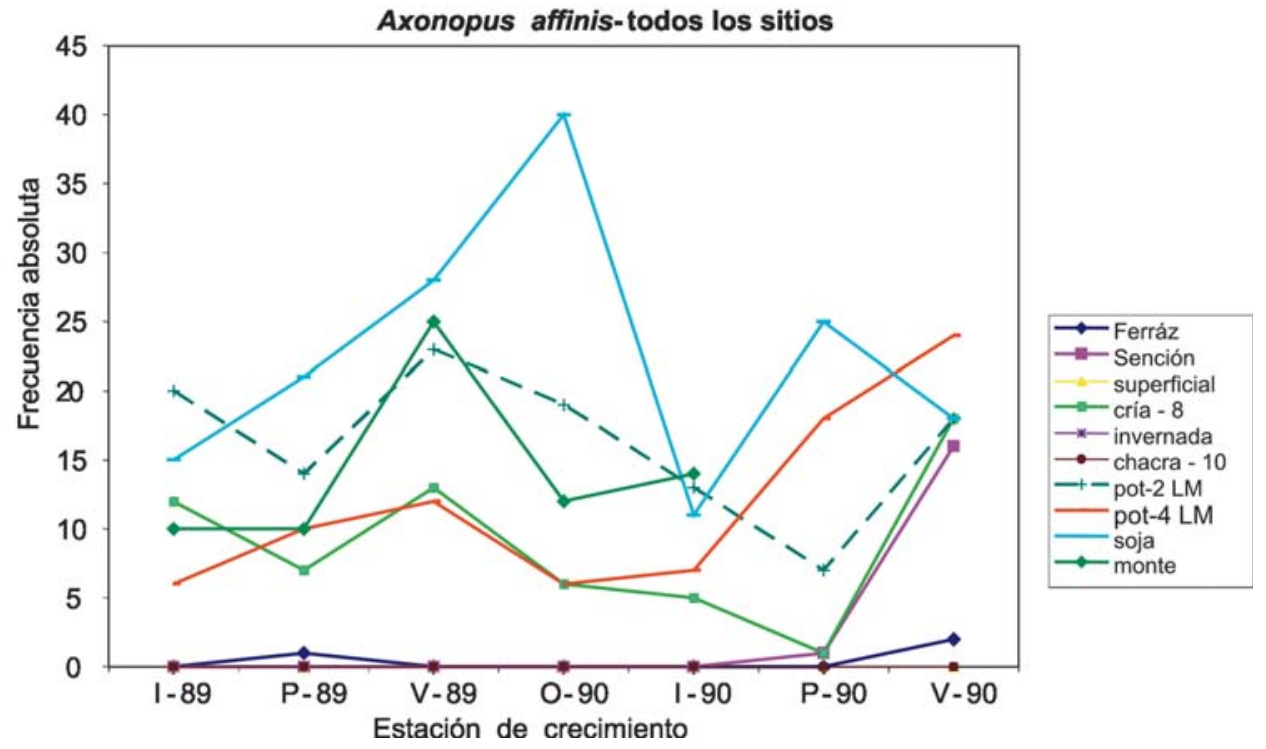

Figura 99. Variación estacional de Axonopus affinis en diez pasturas naturales sobre suelos arcillosos y arenosos de la región noreste.

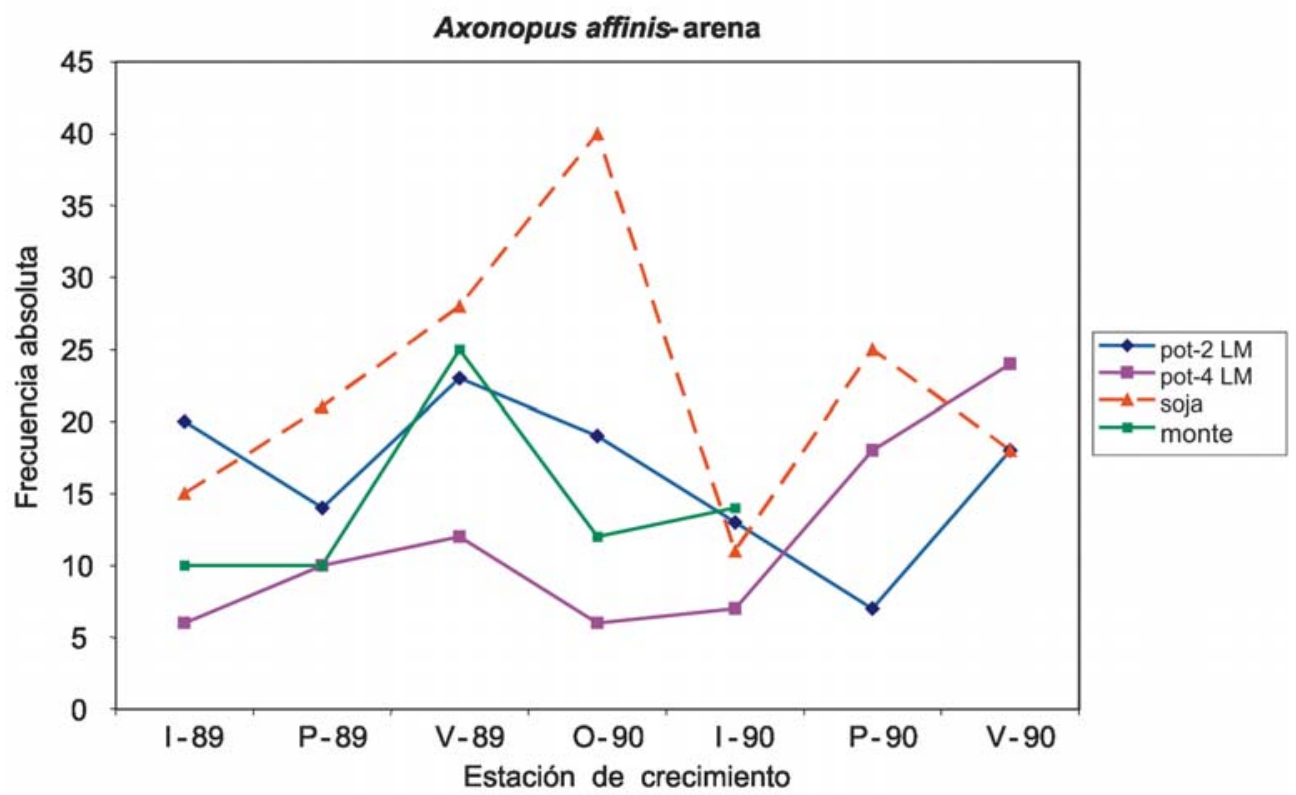

Figura 100. Variación estacional de Axonopus affinis en cuatro pasturas naturales sobre suelos arenosos de la región noreste.

Eucalyptus, los valores fueron similares a los del potrero 2-LM sobrepastoreado. Hacia el final del período de mayor estrés hídrico, otoño 1990, (Figura 100) se destaca un incremento de que los valores de Axonopus affinis hacia el verano cuando comenzaron las lluvias y en el caso del rastrojo de soja se man- tuvo hasta el otoño, todos los valores cayeron luego en el invierno siguiente (1990) y hacia el siguiente verano en todos los sitios se incrementó su presencia respecto al invierno previo; los picos mayores de la pastura luego de soja pueden deberse a que dicha pastura estuvo compuesta por un número menor de especies. 


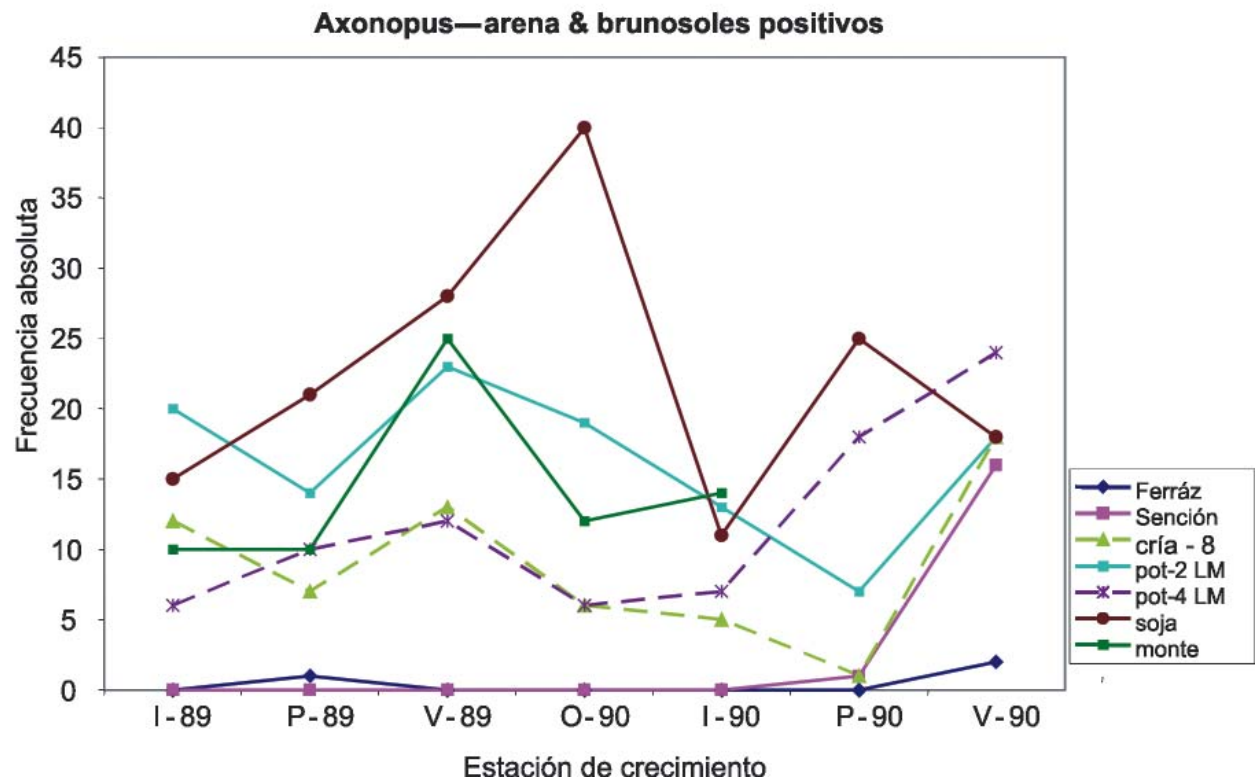

Figura 101. Variación estacional de Axonopus affinis en siete pasturas naturales sobre tres suelos arcillosos y cuatro arenosos de la región noreste Cyperaceas.

Dentro del grupo de Cyperaceas, una de las especies involucradas en muchos casos es Carex bonaeriensis que esta clasificada como una especie de productividad invernal baja (Rosengurtt, 1979); en la Figura 102, se destaca la mayor presencia del grupo en el inverno 1990 que en el invierno 1989 sensiblemente más seco; los valores más altos en el año de major balance hídrico correspondieron a la pastura mejor manejada y con mayor tasa de crecimiento (Sención) y los valores más bajos en el sitio donde había sido chacra previamente, en la pastura sobrepastoreada (Ferráz), en la de suelo superficial y en el potrero de invernada los valores fueron bajos, en cambio en el potrero

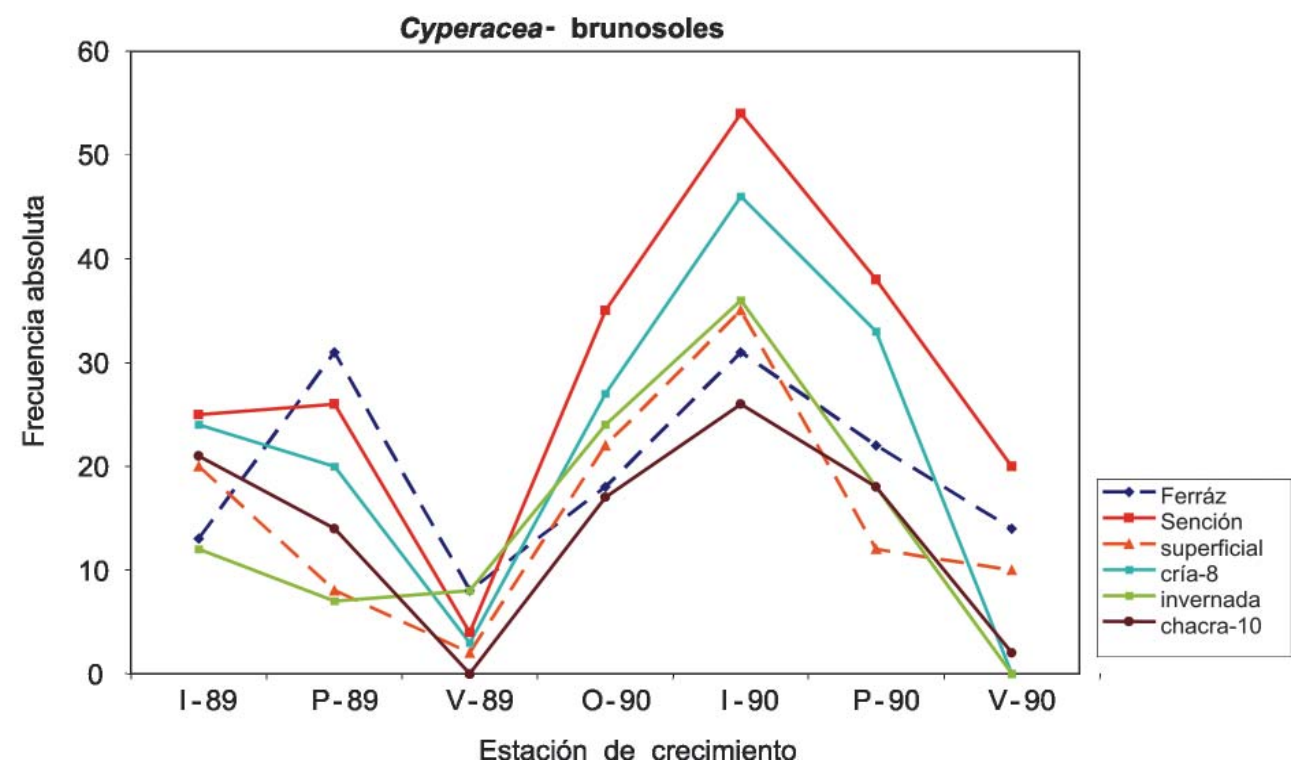

Figura 102. Variación estacional del grupo Cyperaceas en seis pasturas naturales sobre suelos arcillosos de la región noreste. 
cría-8 los valores fueron más cercanos a los máximos en el período invierno-primavera del segundo año.

\section{Paspalum dilatatum}

Paspalum dilatatum incrementó en cuatro de las seis pasturas evaluadas sobre brunosoles en el primer verano cuando comenzaron las lluvias (Figura 103) siendo la respuesta mayor y hasta el otoño en la pastura con manejo aliviado y alta tasa de crecimiento (Sención), los menores valores para el suelo relativamente superficial, valores intermedios de mayor a menor para cría-8, chacra e invernada; en el caso de la pastura sobrepastoreada los registros en todo el período fueron nulos. En el segundo verano se mantuvo el incremento en el verano en la presencia de la especie pero en forma algo diferencial, manteniendo la pastura Sención el mayor valor pero conjuntamente con el sitio invernada, en cambio el rastrojo de chacra no se recuperó y el potrero cría-8 con el superficial se mantuvieron intermedios. Paspalum dilatatum se destaca como una especie estival que responde al manejo y a las condiciones hídricas ambientales estacionales.

\section{Piptochaetium montevidense}

Respecto a Piptochaetium montevidense se registró una mayor presencia en el sitio de campo bruto luego de chacra (chacra-10) y en la pastura sobre suelo superficial (Figura 104), valores menores e observaron en el potrero de cría-8, algo menor en el potrero de invernada y valores intermedios en el sitio sobrepastoreado (Ferráz) y en el potrero de al diversidad de Sención. La respuesta ubica nuevamente a Piptochaetium montevidense como un a especie vinculada a estadios tempranos intermedios en la transición desde una chacra hasta el campo bruto restablecido, incluso de acuerdo a estos resultados, aparece como adaptada a situaciones con relativo estrés hídrico, como puede ser la pastura sobre suelo superficial, a su vez aparentemente el sobrepastoreo determinaría una disminución en su presencia en las pasturas comparado el suelo superficial con el sitio Ferráz.

\section{Andropogon lateralis}

En el caso de Andropogon lateralis se evaluó su presencia solamente en suelos arenosos dada su adaptación preferencial a los mismos (Figura 105), claramente en con-

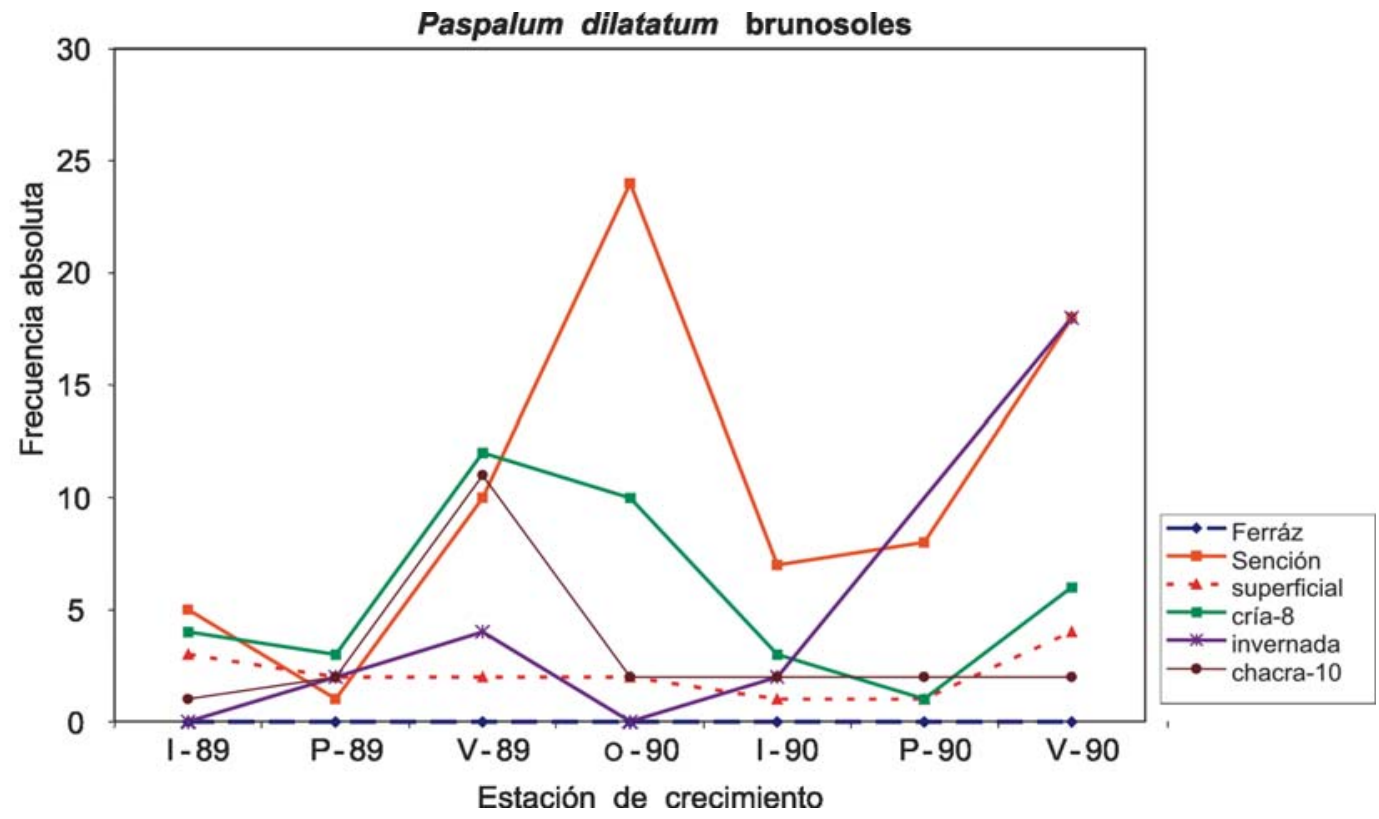

Figura 103. Variación estacional de Paspalum dilatatum en seis pasturas naturales sobre suelos arcillosos de la región noreste. 


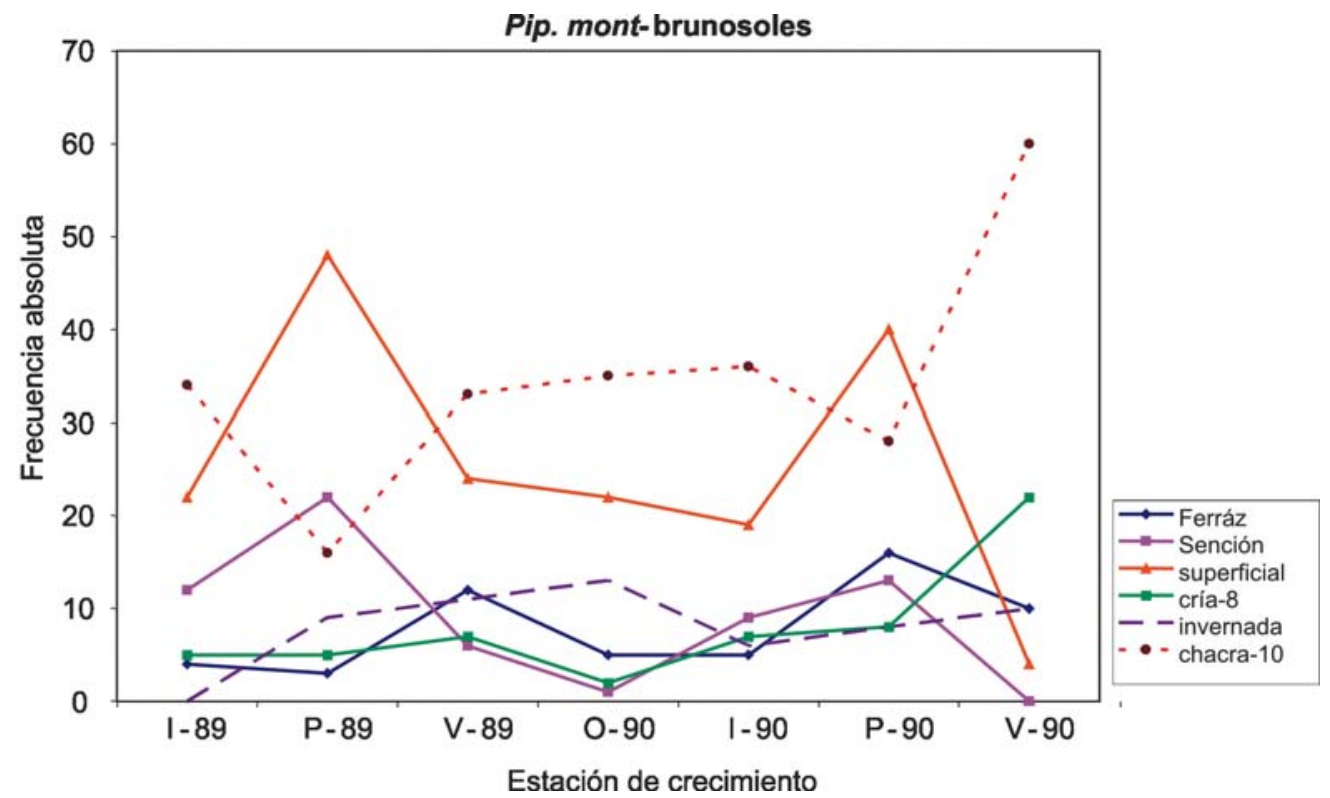

Figura 104. Variación estacional de Piptochaetium montevidense en seis pasturas naturales sobre suelos arcillosos de la región noreste.

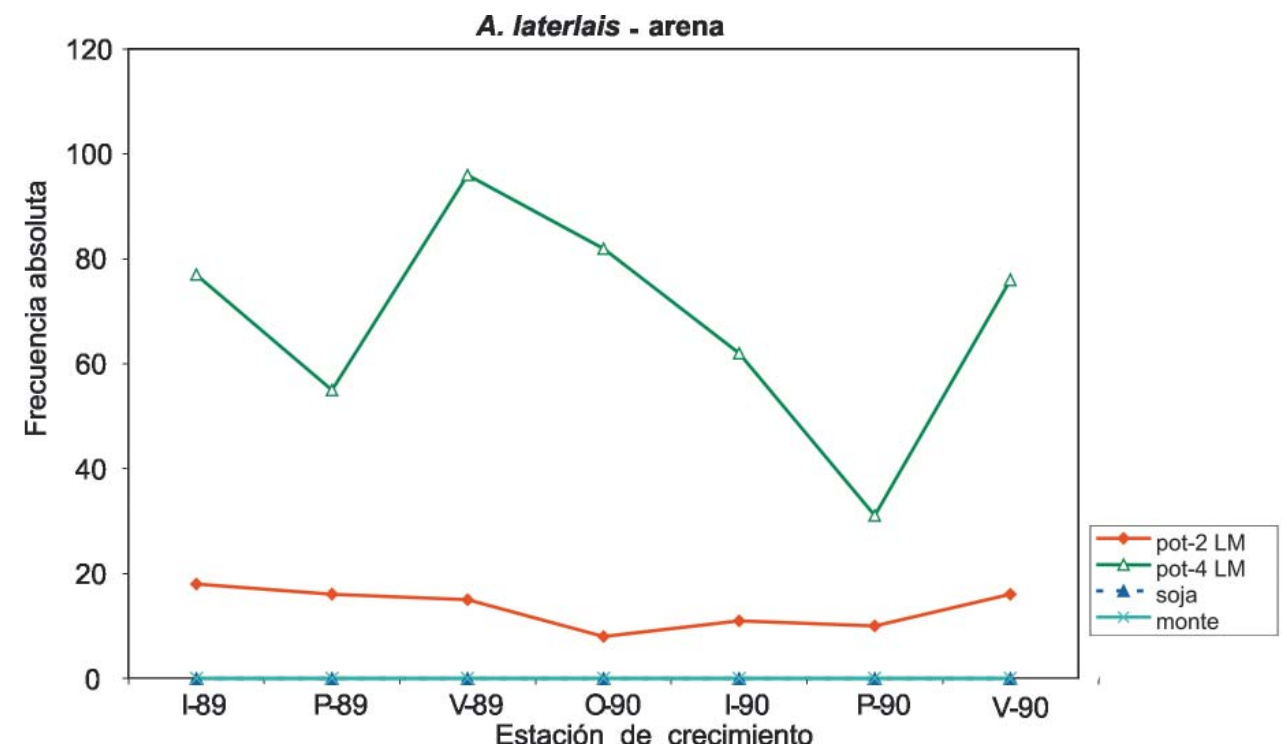

Figura 105. Variación estacional de Andropogon lateralis en cuatro pasturas naturales sobre suelos arenosos de la región noreste.

diciones de pastoreo aliviado se registró una mayor presencia de la especie comparado con el sitio con alta presión de pastoreo (potrero 2-LM); no se registró la presencia de la especie en ninguno de los dos sitios donde anteriormente se realizaron cultivos (rastrojo de soja y monte de Eucalyptus).

\section{Setaria geniculata}

En el caso de Setaria geniculata la especie mostró su perfil de comportamiento estival en los dos veranos y en el otoño evaluado (Figura 106), para ambos veranos los valores en las diferentes pasturas fueron simi- 


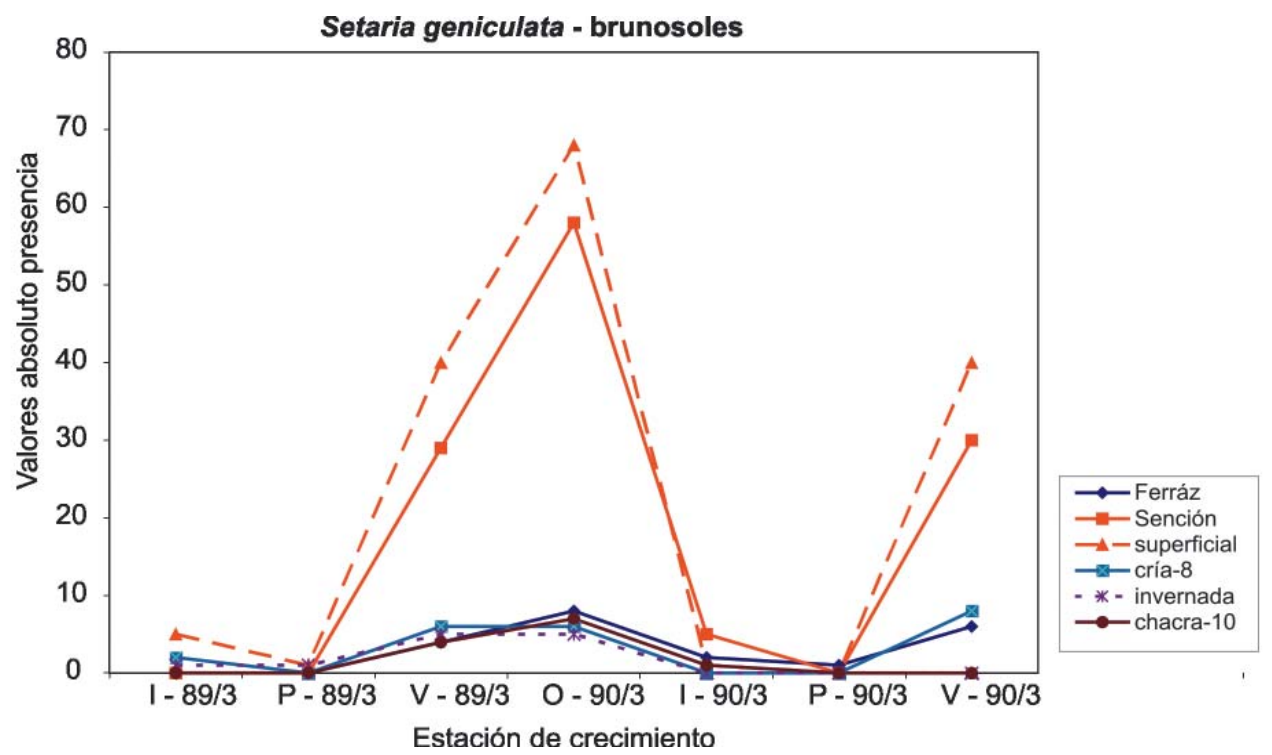

Figura 106. Variación estacional de Setaria geniculata en seis pasturas naturales sobre suelos arcillosos de la región noreste.

lares, salvo para los potreros de invernada y chacra-10 que fueron bajos en el segundo verano. Lo que se destaca en la Figura 106 es la gran respuesta registrada en la presencia de la especie en las pasturas Sención y de suelo superficial, ambas con manejadas con pastoreos relativamente aliviados, pero lo mismo sucede con cría-8 e invernada y no presentaron la misma respuesta; este desarrollo habría que interpretarlo por algún otro factor histórico por ejemplo algún nivel de fertilidad en estas pasturas 10-20 años atrás que generaron algún banco de semillas, el cual luego del período de estrés hídrico se expreso con un incremento en el número de plantas.

\section{Andropogon ternatus}

Andropogon ternatus es una especie que aparentemente responde claramente al manejo histórico de la pastura, en la Figura 107 se registró una mayor presencia en el potrero de invernada, luego siguen los valores en el potrero de cría-8 y luego el potrero sobrepastoreado (Ferráz) como en el suelo más superficial; en las pasturas Sención y chacra-10 no fue registrada la especie. Para el caso del potrero invernada tanto el segundo invierno como el segundo verano mostraron valores mayores que en los primeros pe- ríodos respectivamente, en los otros sitios lo valores fueron relativamente más estables. Si bien no se disponen los registros previos a los manejos de los potreros previo a estos registros, es interesante destacar que las pasturas cría-8, invernada y chacra-10 son contiguas y separadas por un alambrado, lo cual permite hipotetizar el impacto sobre la presencia de esta especie con la realización de agricultura, similarmente se puede argumentar con los valores registrados en la pastura sobrepastoreada o en los suelos superficiales, donde la presión de pastoreo disminuyó su presencia (factor biótico) o el potencial mayor estrés hídrico en el segundo reduciría también su presencia.

\section{Chevreulia sarmentosa}

Del mismo modo que Andropogon ternatus no fue registrada en la pastura que había sido chacra previamente (chacra-10), en este caso con Chevreulia sarmentosa ocurrió exactamente lo contrario con la mayor presencia en esta pastura de la especie y el no registro de la misma en la invernada (Figura 108). En el caso del suelo relativamente más seco la especie incrementó su presencia hacia el segundo año con condiciones hídricas más favorables, en los otros casos mantuvo una presencia estable con alguna variación 


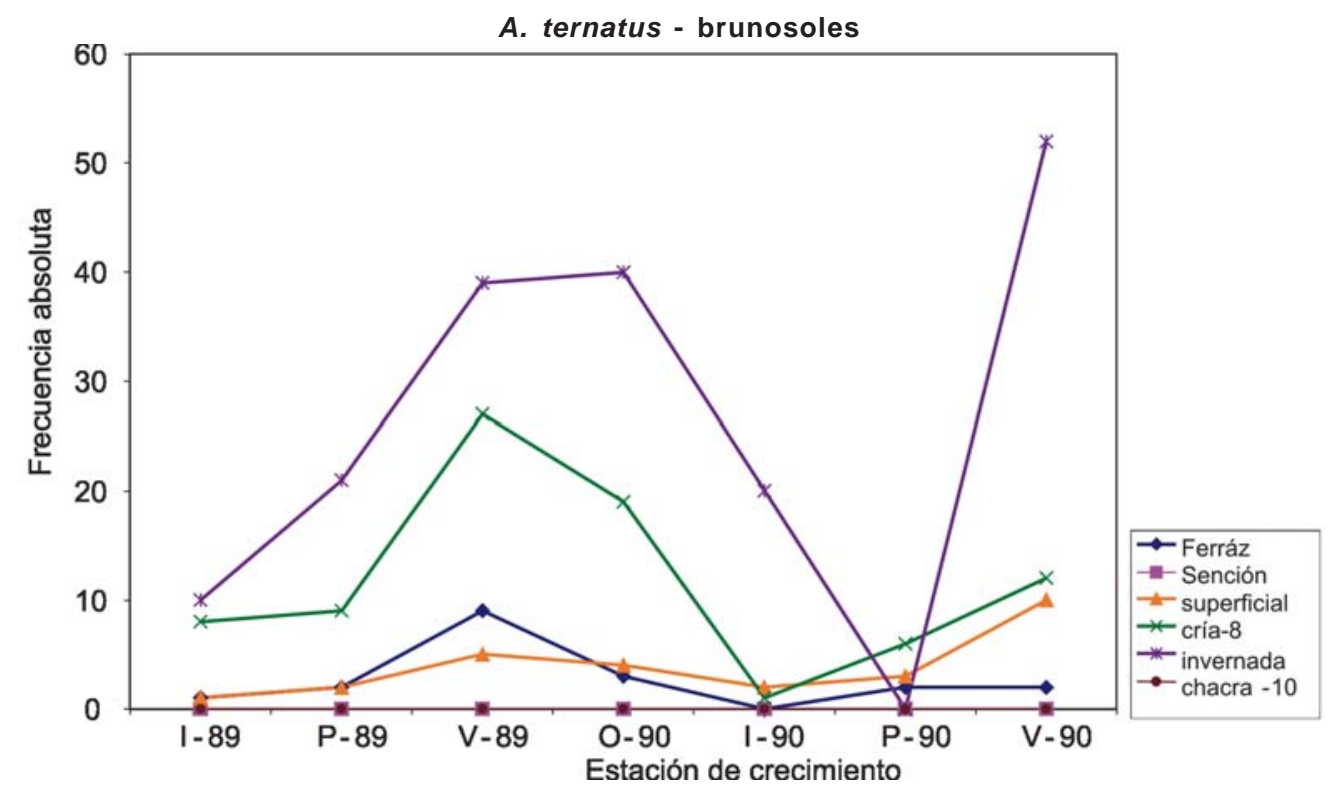

Figura 107. Variación estacional de Andropogon ternatus en seis pasturas naturales sobre suelos arcillosos de la región noreste.

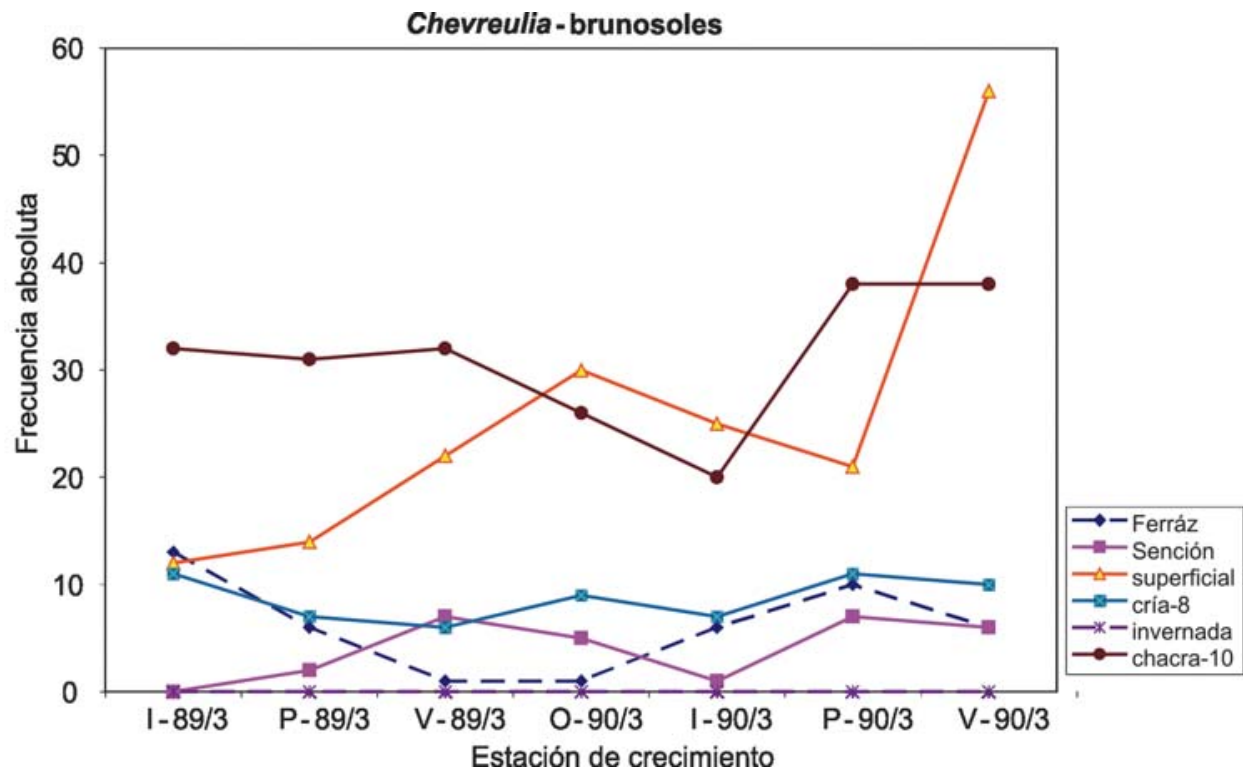

Figura 108. Variación estacional de Chevreulia sarmentosa en seis pasturas naturales sobre suelos arcillosos de la región noreste.

estacional como en el caso de Sención y Ferráz; muchas de estas micro variaciones podrían explicarse por la variación a su vez de la presencia de otras especies con otros ciclos en la misma pastura.

\section{Trifolium polymorphum}

Trifolium polymorphum es una de las leguminosas presentes en las pasturas naturales de la región noreste comportándose en su crecimiento y aporte de forraje como una 
especie anual invernal, pero en realidad, la sobrevivencia interanual mayoritariamente ocurre a través de su sistema radicular con una raíz paquirriza (Rosengurtt, 1979) que le permite sobrevivir durante el verano (Olmos, 2000). La evolución registrada en el período de evaluación mostró una mayor presencia de la especie en el período invernal-primaveral de 1989 que en el mismo período 1990 en los sitios Sención y superficial (Figura 109 ), en cambio en sentido inverso, con mayores valores en el segundo año en el caso de la pastura Ferráz (sobrepastoreada) y cría8; en el caso de la invernada y chacra-10 no se registró la presencia de la especie. Estos resultados confirman el ciclo de aporte de forraje de la especie inverno-primaveral por un lado, asimismo podría argumentarse que la situación de mayor presencia correspondería a la propia historia de manejo aliviado y un primer año que respondería como «anual» luego del estrés hídrico y en el segundo, los mejores condiciones para le crecimiento de las estivales perennes tendería a reducir su presencia (Sención y suelo superficial), por otro lado en las pasturas cría8 y Ferráz sería una respuesta desde la degradación mostrando un incremento en presencia en condiciones más favorables, de todos maneras en el caso del potrero cría-8 no sería una posición de degradación sino algo intermedia y habría que considerar además otros elementos que afectarían su respuesta.

Oxalis sp. al igual que Trifolium polymorphum es una especie perenne pero que recomienza su aporte foliar mayormente a partir de rebrotes del bulbo subterráneo en otoñoinvierno comportándose prácticamente con una especie de crecimiento invernal-anual. En el caso de la pastura sobrepastoreada en general se mantuvo con valores relativamente menores de presencia (Figura 110 y en el suelo superficial con manejo relativamente aliviado en mayor proporción. Al igual que Trifolium polymorphum en algunas pasturas los valores fueron más altos en el primer año de registros y menor en el segundo (Sención) y lo mismo ocurrió con la pastura de invernada; en una situación más homogénea estuvieron los sitios chacra-10 y cría-8. Quizás las mismas explicaciones aplicados a Trifolium polymorphum se podría aplicar para Oxalis sp., donde desde situaciones más favorables y con el estrés hídrico hubo una mayor expresión de la presencia de la especie (Sención, sitio superficial) luego disminuyó por competencia con las estivales en el segundo año, y en los

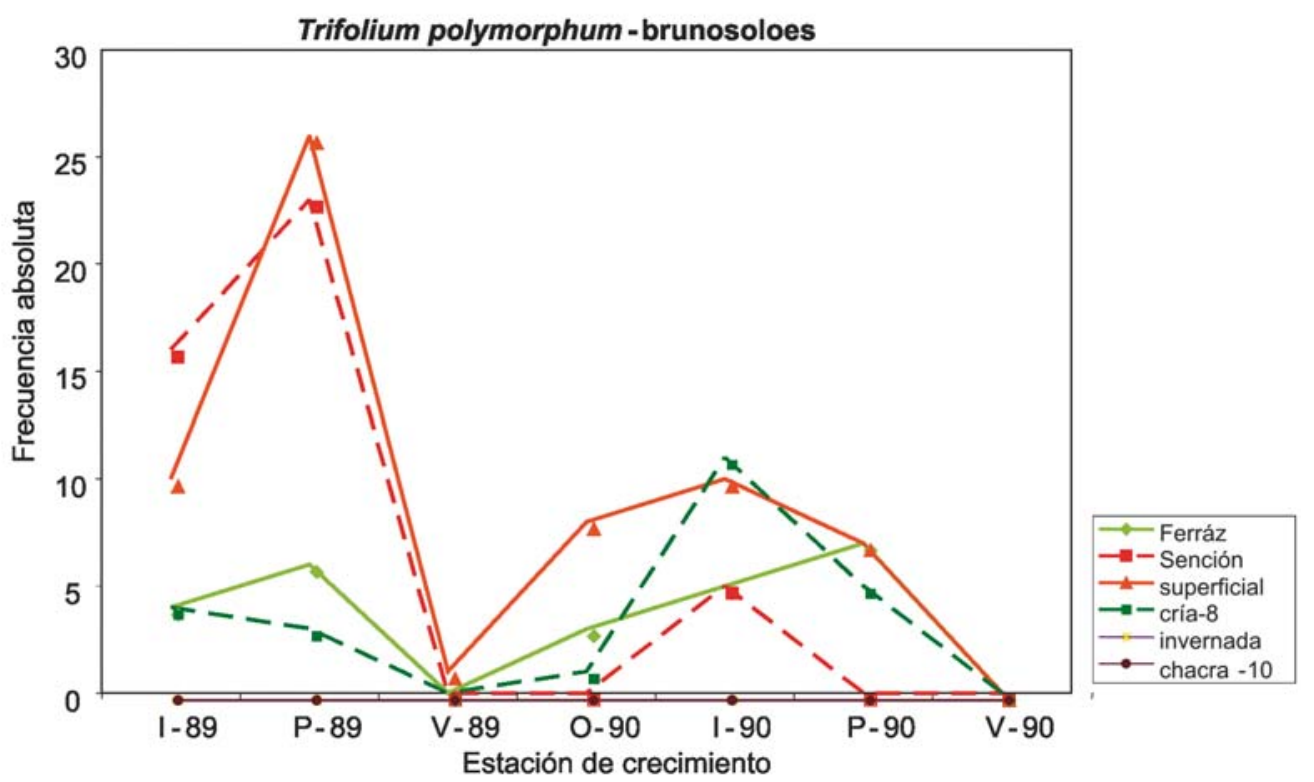

Figura 109. Variación estacional de Trifolium polymorphum en seis pasturas naturales sobre suelos arcillosos de la región noreste Oxalis sp. 


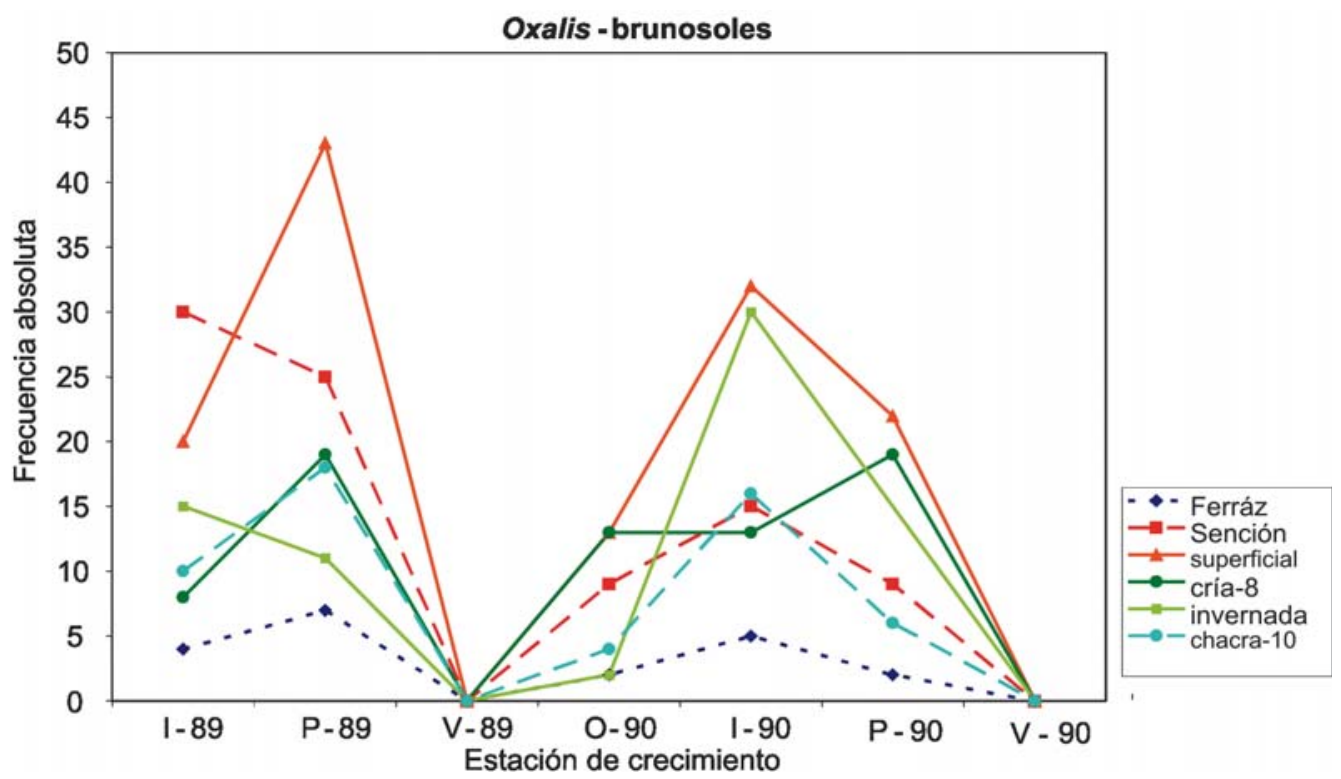

Figura 110. Variación estacional de Oxalis sp. en seis pasturas naturales sobre suelos arcillosos de la región noreste.

otros sitios una respuesta más ambiental anual donde en las condiciones más favorables de 1990 tuvo una mayor expresión; resulta interesante el valor registrado luego de chacra poniéndole a en una especie similar a Piptochaetium montevidense (ver Figura 103) y por otro lado al escaso aporte en la situación del sitio con sobrepastoreo (Ferráz).

\section{Chaptalia pilloselloidea}

Chaptalia pilloselloidea esta descripta como una especie de campo bruto con mayor presencia en ambientes relativamente más secos (Rosengurtt, 1979), en el caso de los registros realizados en la región noreste apareció con muy escasa presencia en el sitio donde había sido chacra y mucho mayor presencia en el sitio sobrepastoreado (Figura 111), en cuatro de los seis sitios so-

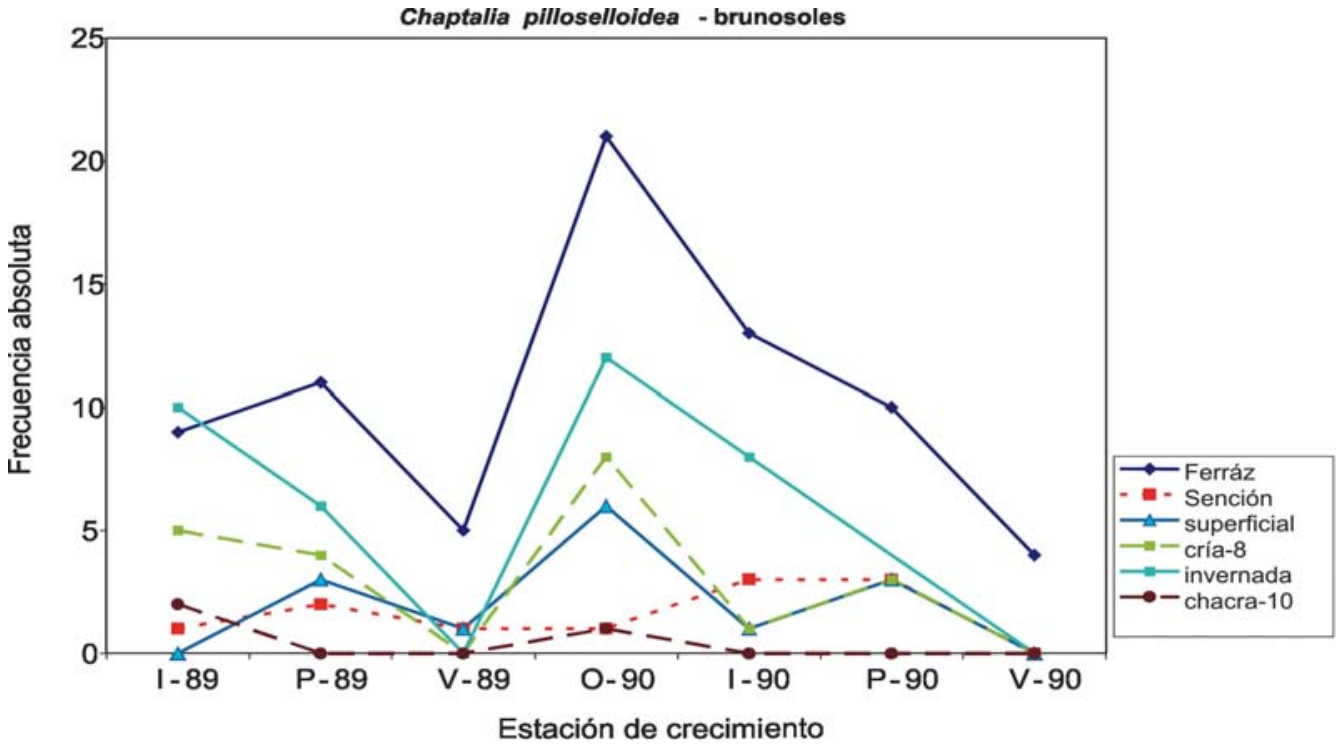

Figura 111. Variación estacional de Chaptalia pilloselloidea en seis pasturas naturales sobre suelos arcillosos de la región noreste. 
bre brunosoles su presencia mostró un pico en otoño 1990. Es curioso que en el sitio de invernada se presenta una curva de evolución estacional muy similar al sitio de sobrepastoreo y en menor medida en los sitios cría-8 y superficial, evidenciando que algunas de las características propias de la especie en relación al ambiente las desconocemos, quizás esto se deba a pasturas más intervenidas como el sobrepastoreo, alivio máximo en invernado y chacra-10 que modulan su presencia en la pastura.

\section{Dichondra microcalyx}

Dichondra microcalyx es una especie perenne estolonífera con un ciclo de productividad mínima estival (Rosengurtt, 1979) considerada, a su vez, como una especie no apetecida por el ganado. En la Figura 112 la pastura sobrepastoreada fue la que mostró una mayor presencia de la especie, en cambio en los sitios donde se realizó invernada y chacra-10 su presencia fue menor, en ambos casos con algunos variaciones estacionales en la presencia. En el caso de Sención y cría-8 la especie tendió a tener una mayor presencia en el segundo año, por su parte en el sitio con el suelo más superficial incrementó en el segundo año pero al final redujo nuevamente su presencia en el verano aunque con valores levemente mayor al primer verano, en su segundo invierno en este sitio incremento sensiblemente su presencia con respecto al inverno 1989. La interpretación de estos registros indicaría que la especie tiende a incrementar su presencia en condiciones de degradación tanto por su hábito de crecimiento rastrero así como por su nula o escasa apetecibilidad por el ganado, lo que en condiciones de alta presión de pastoreo la beneficiaría; en los casos Sención y cría-8 que incrementó su presencia sería interpretado como una respuesta ambiental en el segundo año en pasturas con manejo aliviado, en el caso del suelo superficial quizás podría estar relativamente limitada su presencia por el estrés hídrico estival, en el caso de la invernada es notorio en este sitio el mayor porcentaje de presencia de especies erectas dado su manejo y en la chacra podría haberse visto afectada su presencia por el laboreo del suelo.

\section{Eryngium nudicaule}

En la Figura 113 se observa como evolucionó la presencia de Eryngium nudicaule en las pasturas sobre brunosoles, una especie de ciclo de producción invernal y mínima (Rosengurtt, 1979). El potrero de cría-8 mostró los mayores valores para le especie con

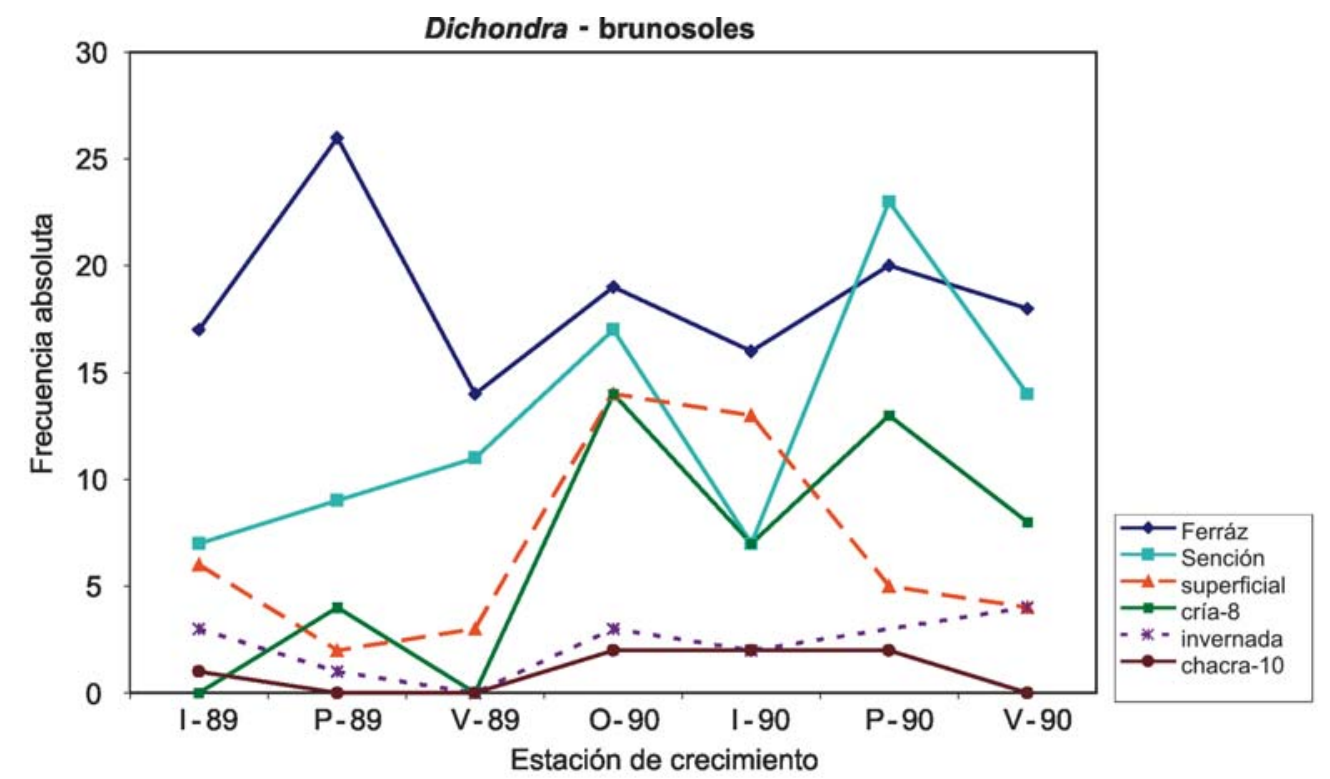

Figura 112. Variación estacional de Dichondra microcalyx en seis pasturas naturales sobre suelos arcillosos de la región noreste. 


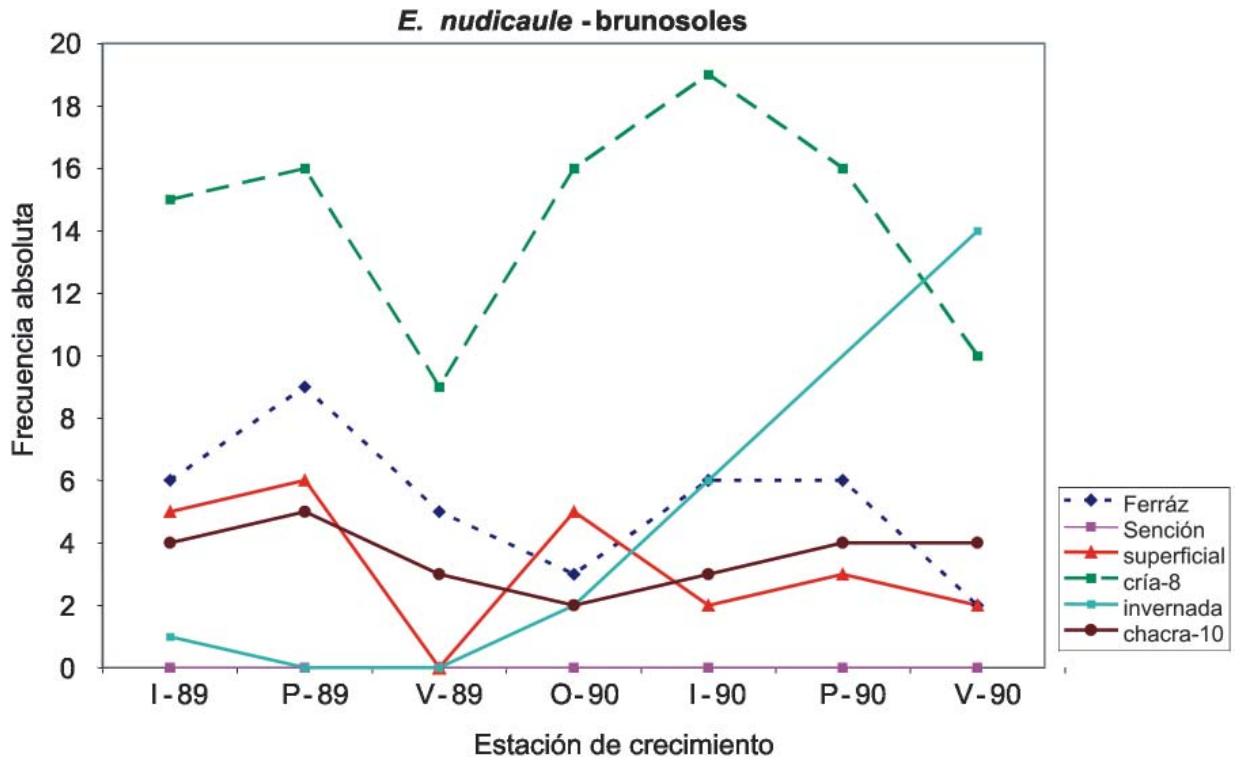

Figura 113. Variación estacional de Eryngium nudicaule en seis pasturas naturales sobre suelos arcillosos de la región noreste.

reducciones en cada verano. Los tres sitios que registraron valores intermedios, el suelo superficial, Ferráz y la chacra-10, en alguna medida incrementaron su presencia en los períodos inverno-primaverales de cada año; el sitio de invernada comenzó con valores bajos incrementando fuertemente hacia el final del ciclo; finalmente Sención no presentó ningún registro de la especie en el período de evaluación. En el caso de Sención puede explicarse la ausencia de registros por su alta productividad, diversidad e historia de manejo siendo la mejor pastura de las evaluadas. Es muy difícil interpretar los mayores valores del sitio cría-8, seguramente algún manejo histórico puntual ha determinado este posicionamiento relativo actual, sin embargo la curva estacional es muy similar al sitio sobrepastoreado, el superficial y la chacra-10. En el caso de la invernada lo podemos interpretar por el lado de la respuesta ambiental donde el manejo aliviado luego del período de estrés hídrico generó espacios para su instalación en el año siguiente.

\section{Soliva pterosperma}

Soliva pterosperma, roseta, manca-perros, es una especie anual de productividad mínima invernal (Rosengurtt, 1979) y presenta características, en su presencia, similares a Trifolium polymorphum, Oxalis sp., con picos de presencia en invierno-primavera (Figura 114). Salvo el caso de la invernada que no presentó ningún registro y el caso del sitio Sención, las cuatro pasturas restantes incrementaron sus valores en el segundo año, siendo en el caso del sobrepastoreo (Ferráz) y el suelo superficial los valores relativamente mayores que en el caso de cría-8 y chacra-10. En el caso de pasturas promocionadas con la aplicación de fertilizantes generalmente incrementó la presencia de algunas especies de crecimiento anual como raigras, medicago y en este caso del sitio Sención, el cual tiene esas características, no solo ha favorecido la presencia de raigras (Figura 114) sino que sería también el caso de una especie anual como Soliva pterosperma; se puede estimar que el mejor crecimiento de las perennes estivales, luego de un fin de verano con mejor balance hídrico 1989-1990 llevó a disminuir la presencia en el segundo año de esta especie. La mayor presencia relativa en el suelo superficial y sobrepastoreado en cierta forma confirman la descripción propuesta por Rosengurtt (1979), favorece relativamente más secos y con pasturas «abiertas» para la instalación de anuales. No se registró su presencia en el potrero de invernada donde no se había fertilizado. 


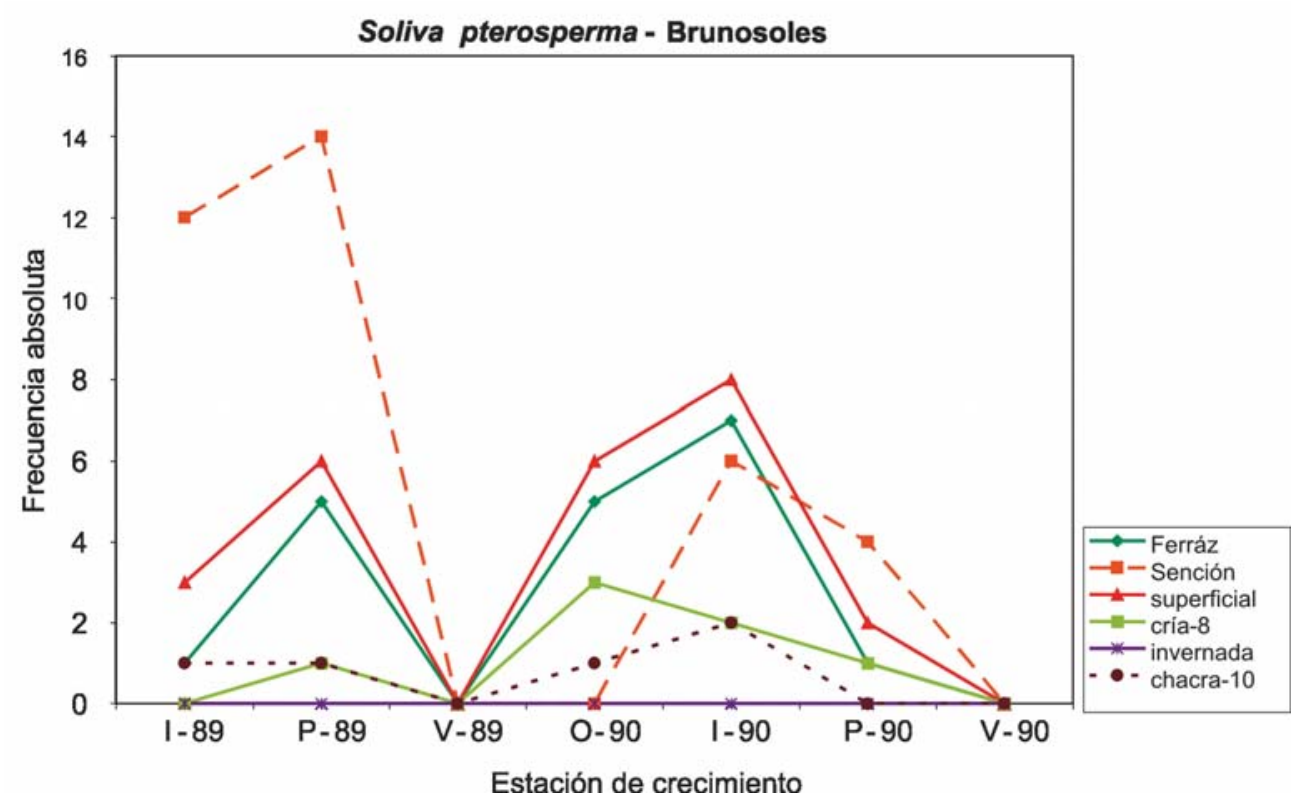

Figura 114. Variación estacional de Soliva pterosperma en seis pasturas naturales sobre suelos arcillosos de la región noreste consideraciones generales 10-comunidades.

\section{Consideraciones generales}

Si bien la productividad estacional y anual varió en las diez pasturas monitoreadas, se destaca que en virtud del manejo histórico que cada una ha recibido su composición botánica es diferente entre ellas. Luego del análisis detallado en sus componentes y dinámica específica de las diez pasturas naturales, en la Figura 115 se presentan los resultados de una análisis de similitud entre las diez comunidades en base a su composición botánica.

El método de agrupamiento WPGMA (MVSP, 2004) permitió discriminar entre las pasturas que tuvieron precedentemente un cultivo por lo menos (a-4, a-5, b-10), las que tienen un manejo relativamente aliviado y mejorado (a-2, b-6, b-7, b-8, b-9) y las que se encuentran sometidas a intenso sobrepastoreo (a-1, b-3), así como discriminar las pasturas sobre suelos arenosos de los arcillosos salvo en un caso, el de la pastura b-3; donde quizás el impacto del sobrepastoreo sea más importante que el tipo de suelo y la presencia mayoritaria de especies de crecimiento rastrero las presenta como relativamente similares. El método de agrupamiento realizado, con las especies presentes en la transecta, agrupó prácticamente en todos los casos, al nivel de mayor similitud en el dendrograma la misma pastura en los dos años sucesivos, salvo una pequeña diferencia con la pastura a-5.

Los resultados de este análisis permiten fácilmente, no solo la discriminación de las diferentes pasturas, sino que de acuerdo a la información disponible desde el punto de vista de su manejo histórico de cada una, el método es lo suficientemente sensible para interpretar, por la metodología inversa, la historia de una pastura en base a su composición botánica actual. Esta contribución preliminar es de suma importancia tanto para el monitoreo regional del estado de las pasturas como para el monitoreo puntual dentro de un establecimeinto donde se diseñen planes de manejo específicos para cada sitio en relación a su eventual productividad.

Desde un punto de vista más general, en esta segunda parte del capítulo se ha destacado como el tipo de suelo, la historia de manejo de la pastura, la diferente composición botánica, la densidad relativa de los diferentes tipos vegetativos, la variabilidad climática estacional e interanual, afectan directamente la productividad de las pasturas naturales en la región noreste. Uno de los 


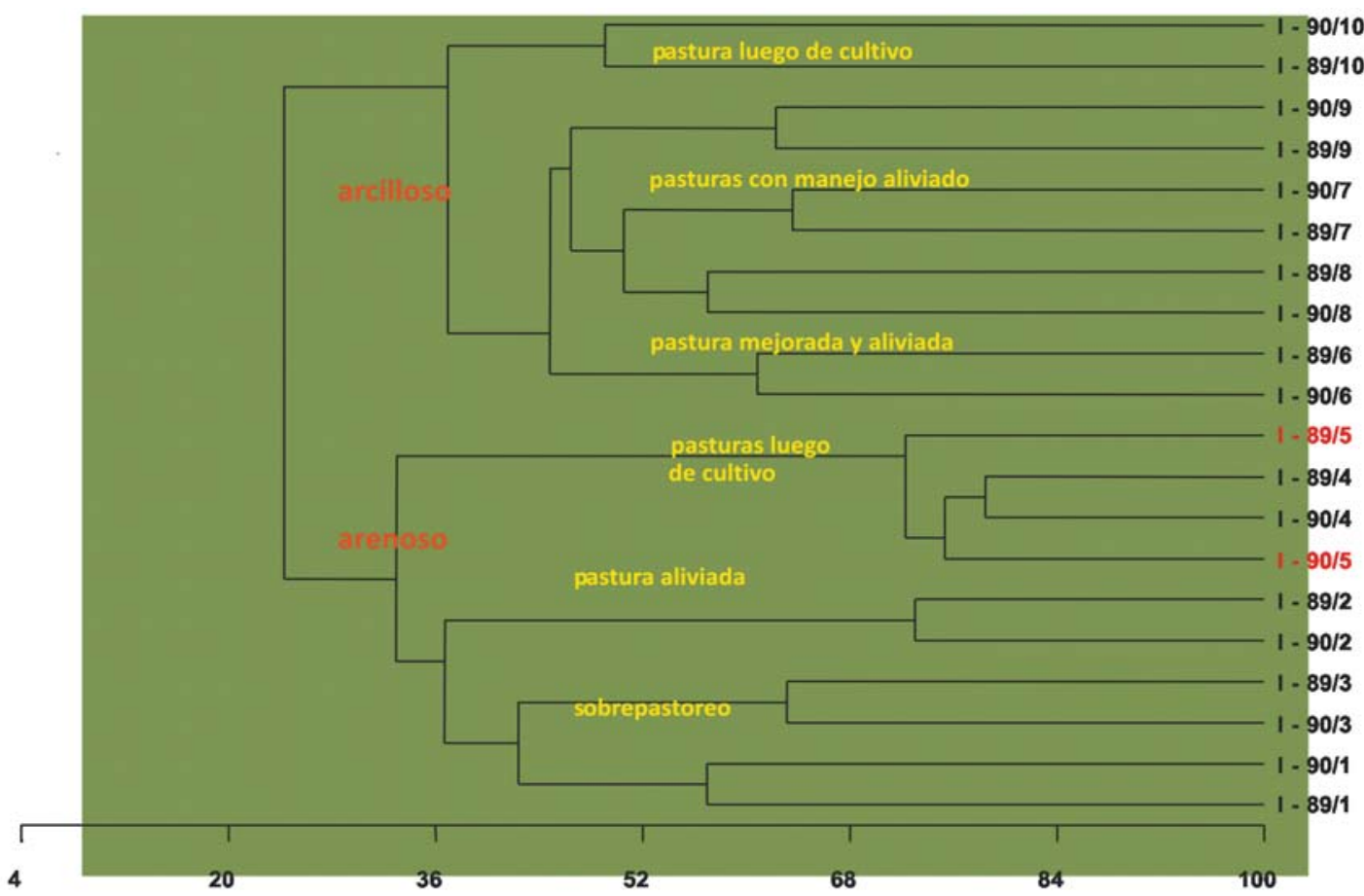

Figura 115. Ordenamiento de diez comunidades naturales utilizando el coeficiente de similitud WPGMA en base a la composición botánica en dos años sucesivos.

elementos centrales en el diagnóstico y monitoreo de estas pasturas naturales constituye el conocimiento de las especies herbáceas que constituyen la composición botánica de la comunidad natural.

En forma de síntesis enla Figura 116, se incluye en forma conjunta el índice de diversidad de Shannon con los niveles de productividad de cada una de las pasturas naturales. La productividad en b-9 y a-5 no se incluyó por no disponer de la información completa para el período de análisis. En la figura se aprecia que la diversidad tiende a presentar sus mayores valores en niveles medios de productividad, cuanto la pastura es más intervenida, tanto por un manejo intensivo como por un manejo aliviado, la diversidad tiende a ser menor.

Los resultados indican un fuerte impacto negativo tanto sobre la composición botáni- ca de las pasturas como en los niveles de productividad de las actividades agrícolas en los dos tipos de suelo (b-10, a-4, a-5).

Se registró una importante variación dentro de un mismo tipo de suelo en la productividad de las pasturas, siendo la misma similar en rango a las observadas para diferentes tipos de suelo; en el caso de estas diez comunidades la variación respondió a la historia de manejo recibido por cada pastura. La composición botánica resultó ser un buen indicador del estado de la pastura y de su eventual recuperación.

Con estos elementos sería posible establecer pasturas de referencia regionales, dentro de cada tipo de suelo, y así determinar el estado de las pasturas naturales en relación a su potencial. En base a ello determinar planes de manejo para su eventual recuperación en casos de extrema degradación. 


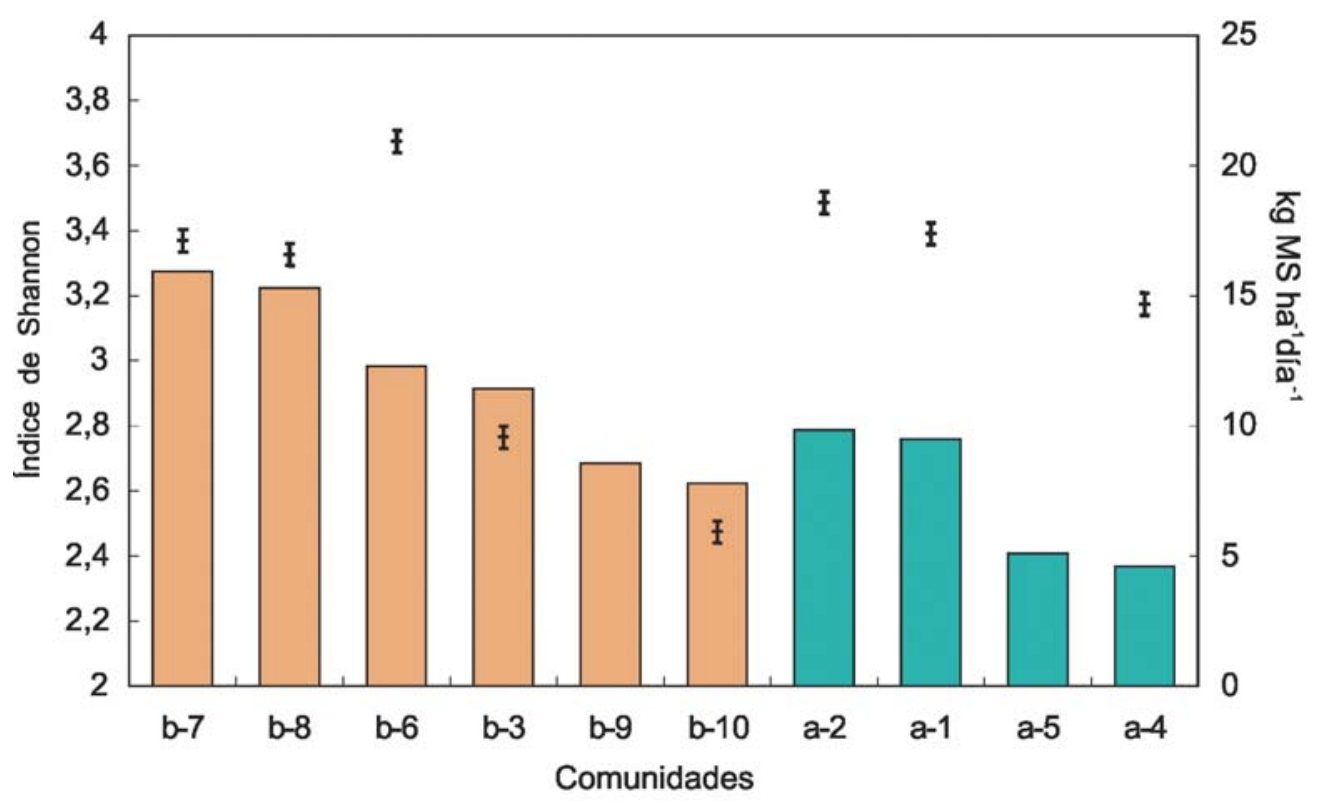

Figura 116. Indice de Diversidad de Shannon (barras) y productividad (kg MS ha-1 día-1) de diez pasturas naturales sobre suelos de la región noreste.

\section{UTILIZACIÓN DE PASTURA NATURALES CON LANARES - CECC - CARAGUATÁ}

En 1984 se inició un experimento de utilización de campo natural con el objetivo de interpretar el efecto del método de pastoreo y la carga animal sobre la productividad y evolución de la pastura.

El sitio elegido se ubicó próximo a la intersección de las rutas 6 y 26 en la localidad de Cuchilla de Caraguatá, en el predio del Sr. Román Sención, en el departamento de Tacuarembó en el centro de la región noreste del Uruguay (CECC). Los suelos del sitio se corresponden con la Unidad de Suelos Cuchilla de Caraguatá y son brunosoles subeutricos, con pH 5,2, un contenido de materia orgánica de $4,2 \%$, un contenido de fósforo de 7,4 ppm por el método Bray y una profundidad promedio del solum de $42 \mathrm{~cm}$ (Altamirano et al., 1976).

El sitio se consideró representativo del área de brunosoles de la región que comprenden unas 900.000 hectáreas y que fueron incluídos en los 67 relevamientos realizados en 1987 presentados previamente en este capítulo, así como la evolución de la productividad en 10 comunidades tambén vistos anteriormente en este mismo capítulo.

El experimento consitió de cinco tratamientos de pastoreo considerando un ciclo de uso de ocho semanas:

1- carga animal 0,6 UG / ha pastoreo contínuo

5- carga animal 0,8 UG / ha pastoreo contínuo

2- carga animal 0,8 UG / ha pastoreo alternado 4 semanas pastoreo / 4 semanas libre

3- carga animal 0,8 UG / ha pastoreo alternado 2 semanas pastoreo / 6 semanas libre

4- carga animal 0,8 UG / ha. pastoreo alternado 1 semana pastoreo / 7 semanas libre

En el caso de los trataminetos con pastoreo contínuo se utilizaron cuatro ovinos por tratamiento estimándose que cada animal aportaba 0,16 UG/ha. En el último año las cargas se aumentaron de 0,6 a 0,8 UG/ha y de 0,8 a 1,0 UG/ha respectivamente. Cada tratamiento tuvo dos repeticiones. Se estudió la composición botánica de la pastura y 
su productividad de forraje estacional en los cinco tratamientos durante el período marzo 1984-marzo 1988. En el caso de la productividad animal, se utilizaron para el análisis los tratamientos 1 y 5 con pastoreo contínuo.

En el caso de la productividad de la pastura se utilizaron tres jaulas de exclusión en cada tratamiento y repetición totalizando treinta jaulas en cada determinación; en el período experimental se realizó la evaluación de quince ciclos de crecimiento totalizando la determinación del crecimeinto de las pasturas en 450 jaulas. La composición botánica se realizó mediante transectas de cien puntos en cada tratamiento y repetición en otoño 1984, otoño 1985 y otoño 1988.

A los efectos de realizar un análisis comparativo entre los diferentes ciclos, los tratamientos y el efecto del año se utilizó la tasa de crecimiento diario de la pastura expresada en kg MS/ha/año. En el Cuadro 27 se presentan los resultados para el período experimental de la productividad de la pastura en la que se registró un efecto significatvio del año de evaluación, de los tratamientos aplicados a la pastura así como de la estacionalidad de los distintos ciclos evaluados durante los cuatro años.

Cuadro 27. Productividad estacional y anual de una pastura natural pastoreo con pastoreo contínuo y alternado.

\begin{tabular}{|l|c|}
\hline Fuente de variación & P \\
\hline Año & 0,0001 \\
\hline Tratamiento (contínuo-alternado) & 0,0168 \\
\hline Ciclo & 0,0001 \\
\hline
\end{tabular}

La Figura 117 muestra la mayor productividad media de los años 1985-1986 y 19871988 comparados con 1986-1987 y 19941995, asimismo el primer año 1984-1985 fue el de menor productividad.

Por otro lado, la Figura 118 muestra el efecto estadísticamente positivo del sistema de pastoreo rotativo sobre la pastura (tratamientos 2, 3 y 4) comparado con el pastoreo contínuo (tratamientos 1 y 5).

La importancia de estos resultados se complementa al realizar el análisis para el primer año del experimento cuando se ins-

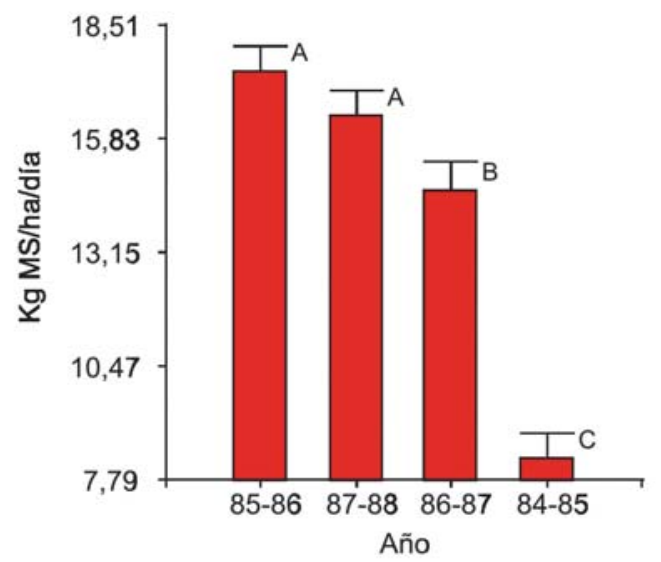

Figura 117. Productividad forrajera anual (kg MS/ha/día) en pasturas naturales de la región noreste.

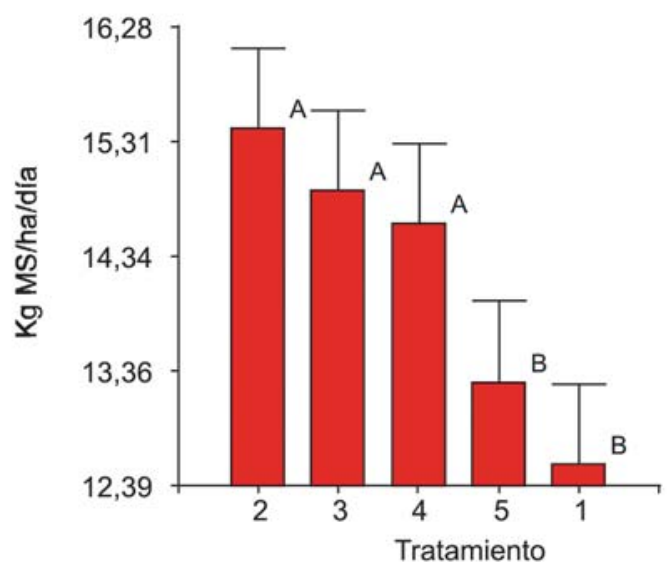

Figura 118. Productividad forrajera (kg MS/ha/ día) en pasturas naturales de la región noreste según el tratamiento de pastoreo, contínuo (1-5) alternado (2-3-4).

talaron los tratamientos y no se registró un diferencia significativa entre los tratamientos (Cuadro 28), en cambio luego del segundo año los registron indicaron si diferencias estadísticamente significativas entre los tratamientos de pastoreo, siendo la tasa de crecimiento de la pastura mayor para el pastoreo rotatvio o con descanso, comparado con al pastoreo contínuo (Figura 119).

Cuando se realizazó la evaluación del forraje disponible en los ciclos de pastoreo cada ocho semanas, se observó una tendencia similar a la productividad estacional y 
Cuadro 28. Efecto del tratamiento del pastoreo en la productividad de pasturas naturales de acuerdo al período de evaluación.

\begin{tabular}{|c|c|c|}
\hline Año & Tratamiento $\mathrm{P}$ & Probabilidad \\
\hline 1984-1985 & Sistema pastore & 0,3877 \\
\hline $1985-1988$ & Sistema pastore & 0,0406 \\
\hline
\end{tabular}

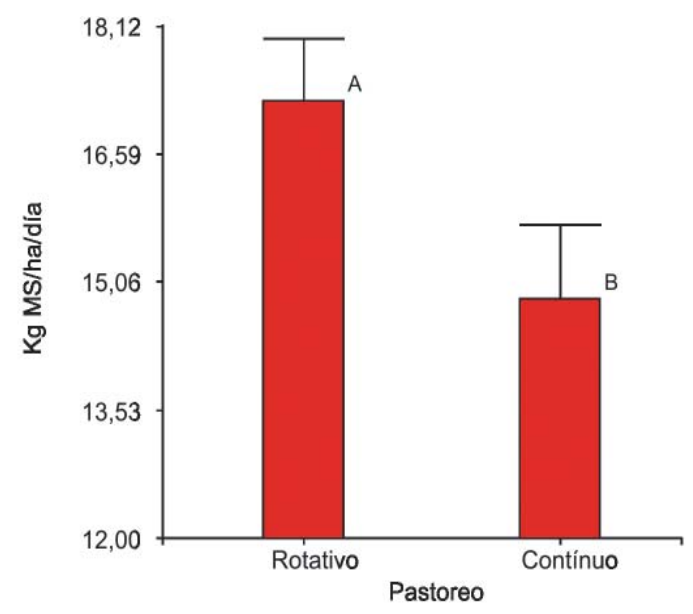

Figura 119. Productividad forrajera en pasturas naturales según el tratamiento del pastoreo, rotativo o alternado y pastoreo contínuo en la región noreste. anual evaluada con las jaulas de exclusión, incrementando los valores a partir del segundo año. En la Figura 120 se observa la evolución promedio de los tratamientos con pastoreo contínuo y rotativo o alternado en los cuadro años duraante 25 ciclos de estudio (200 semanas); claramente durante los primeros ciclos los valores son similares, pero con el tiempo los tratamientos con pastoreo rotativo o alternado tendieron a presentar valores mayores, salvo en los ciclos 18, 19 y 20.

A los efectos de analizar más detalladamente en la Figura 121 se grafican las tendencias para los dos tipos de pastoreo en los primeros 15 ciclos de evaluación, mostrando claramente la mayor tasa registrada en el pastoreos con descanso o alternado comparado con el pastoreo contínuo.

Asimismo la evolución de la «recuperación» de la pastura se analizó estudiando el forraje disponible en el mes de junio de cada año, luego de la estación de crecimiento de las especies estivales de la pastura; para ello se consideraron los ciclos $1,8,14$ y 21 correspondientes al incio del período invernal en los años 1984, 1985, 1986 y 1987 respectivamente (Figura 122). En el Cuadro 29 se indica un efecto estadísticamente signifi-

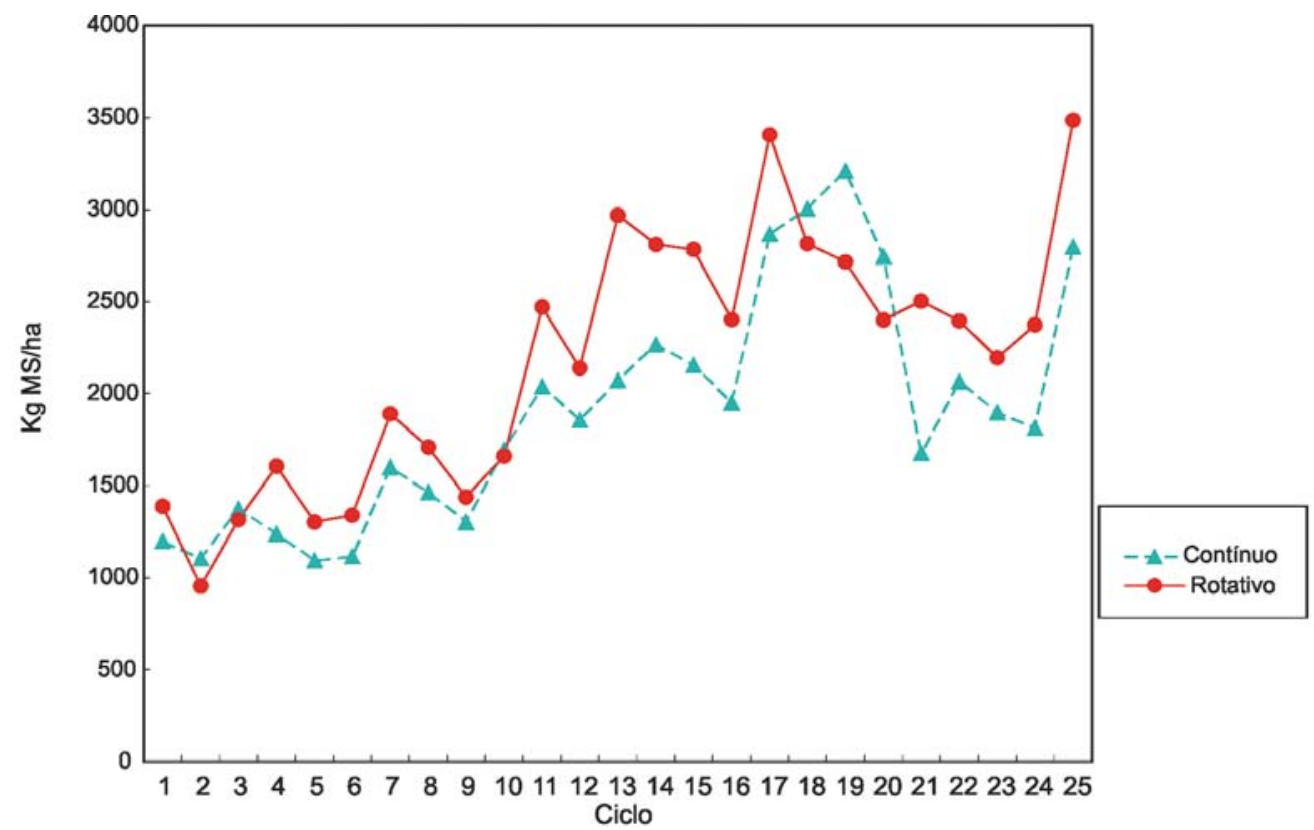

Figura 120. Forraje disponible en 25 ciclos de evaluación en pasturas sometidas a pastoreo rotativo o alternado y pastoreo contínuo en la región noreste. 


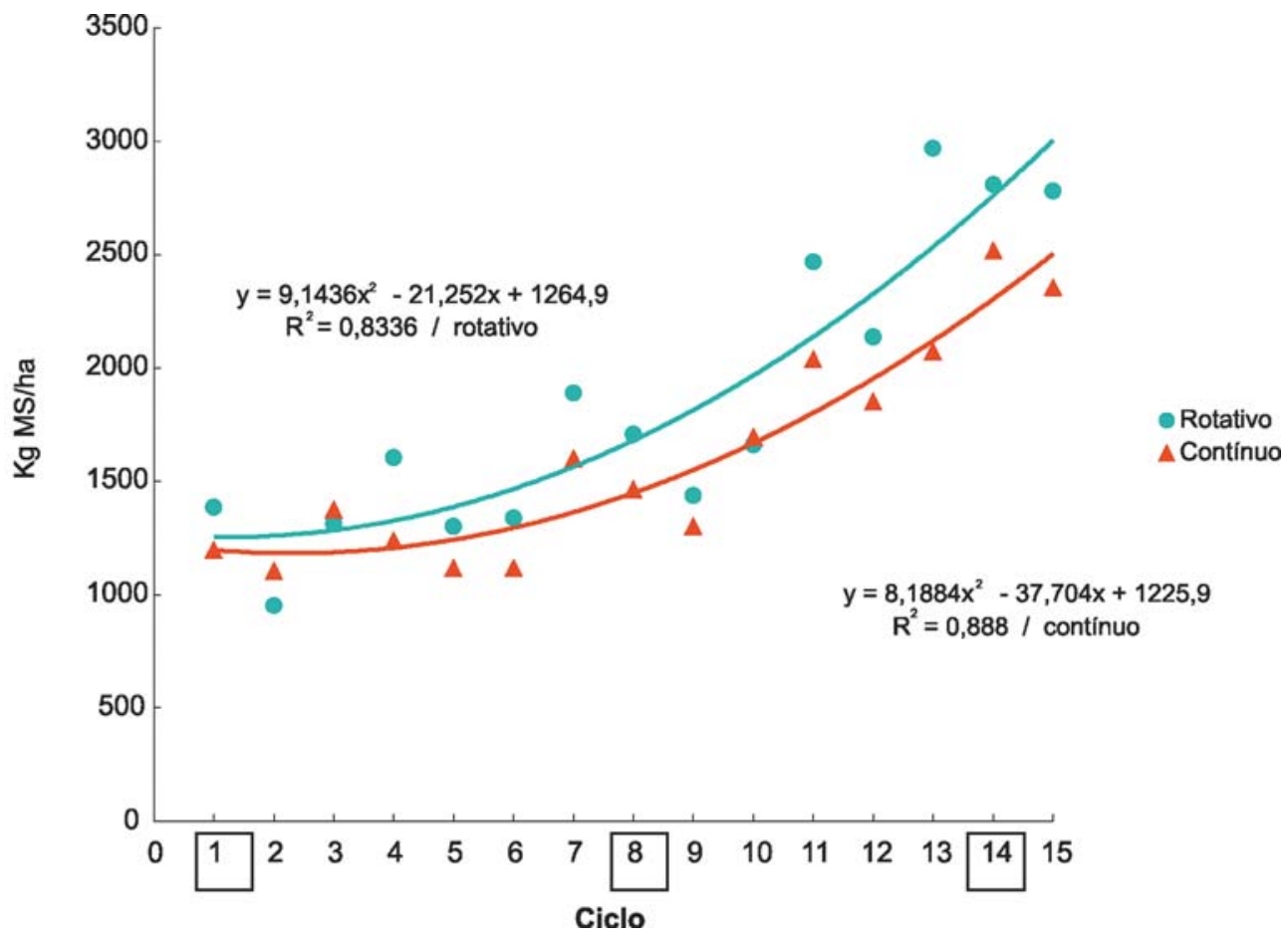

Figura 121. Tendencia en la disponibilidad de forraje en pasturas naturales de la región noreste, de acuerdo al sistema de pastoreo aplicado.

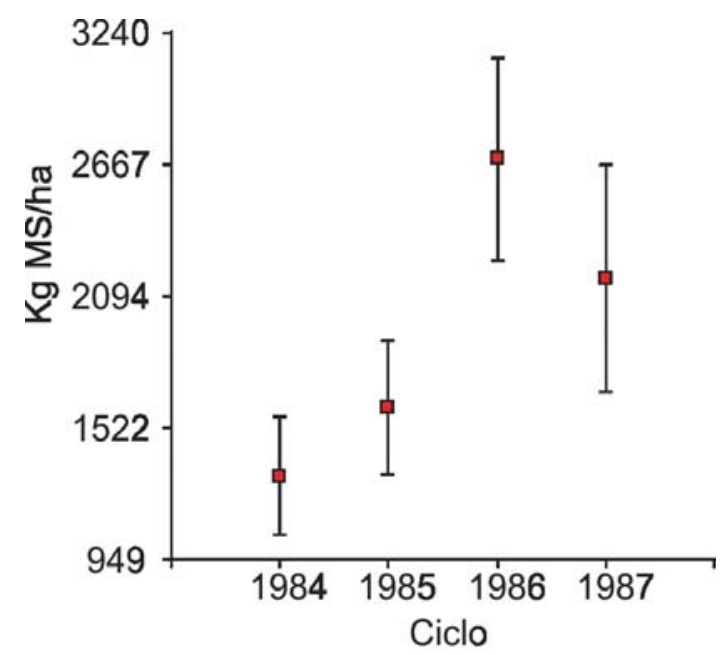

Figura 122. Forraje disponible (kg MS/ha) e intervalo de confianza al $95 \%$ en el mes de junio de cada año de evaluación de pasturas naturales en la región noreste.

cativo del año sobre el forraje disponible con valores que se incrementaron hacia el tercer y cuarto invierno (Figura 122); en el caso de los tratamientos de pastoreo sobre la pastura el efecto no alcanzaron un efecto significativo al $\mathrm{P}<0,05$.
Cuadro 29. Efectos estadísticos del sistema de pastoreo y el año en la disponibilidad de forraje de la pastura en el mes de junio de cada año.

\begin{tabular}{|l|l|}
\hline \multicolumn{1}{|c|}{ Fuente variación } & Probabilidad \\
\hline Tratamiento pastoreo & $\mathrm{P}<0,0647$ \\
\hline Ciclo - año & $\mathrm{P}<0,0001$ \\
\hline
\end{tabular}

Como se mencionó previamente en el tercer año la carga animal se incrementó un $25 \%$ lo que, conjuntamente con una temperatura media relativamente menor (Figura 123 , ciclos 12-13), pueden haber afectado la cantidad de forraje disponible en el último invierno reduciéndola relativamente. Este incremento de la disponibilidad de forraje hacia el fin del otoño inicio del período invernal, puede interpretarse como una respuesta al manejo, en este caso debido a una menor presión de pastoreo, de un cmapo natural cuya composición botánica esta mayoritariamente compuesta por especies de ciclo estival (apéndice). 


\section{Respuesta macro ambiental}

En esta sección se consideran la evolución de la productividad de la pastura en relación a variables climáticas, lluvia, temperatura y evaporación. En la Figura 123 se observa como la temperatura media mantuvo un ciclo estacional relativamente estable a través de los años y en cambio la productividad forrajera (tasa de crecimiento) no solo presentó variaciones estacionales sino que también valores relativamente menores al inicio del período experimental, luego se incrementó sensiblemente en los años 19861987 y posteriormente bajó a un valor intermedio en el año 1988. Se detectó una tendencia general que con mayor temperatura ambiente se alcanzó una mayor tasa de crecimiento, sin embargo hubo ciclos o estaciones donde fuera por déficit de agua (escasez de lluvias) como en el verano de 1985 en el ciclo 4, o por exceso de lluvias, como en el ciclo 9, la productividad disminuyó independientemente de los tratamientos de pastoreo aplicados a la pastura (Figura 124).
Dado que la pastura se encuentra compuesta principalmente por especies de verano se realizó un análisis de la tasa de crecimiento de la misma en relación a las variables ambientales durante el ciclo estival de cada año (Figura 125). Al disponer en forma creciente los valores de la tasa de crecimiento en el eje de las abscisas se ve claramente su directa vinculación con la relación Iluvia / evaporación y en cambio, su desempeño relativamente independiente de la temperatura media; es decir, cuanto mayor porporción del agua evaporada se repuso por el régimen de lluvias, la proudctividad, expresada como kg MS/ha /día, fue mayor.

Esta directa relación entre la tasa de crecimiento y la relación lluvia / evaporación cotrasto con los valores generales obtenidos cuando fueron considerados todos los registros estacionales (Cuadro 30). En este cuadro se destaca que la tasa de crecimiento de la pastura se correlaciona positivamnte con la temperatura y la evaporación, en cambio la correlación es negativa con la relación lluvia / evaporación. La importancia de estos

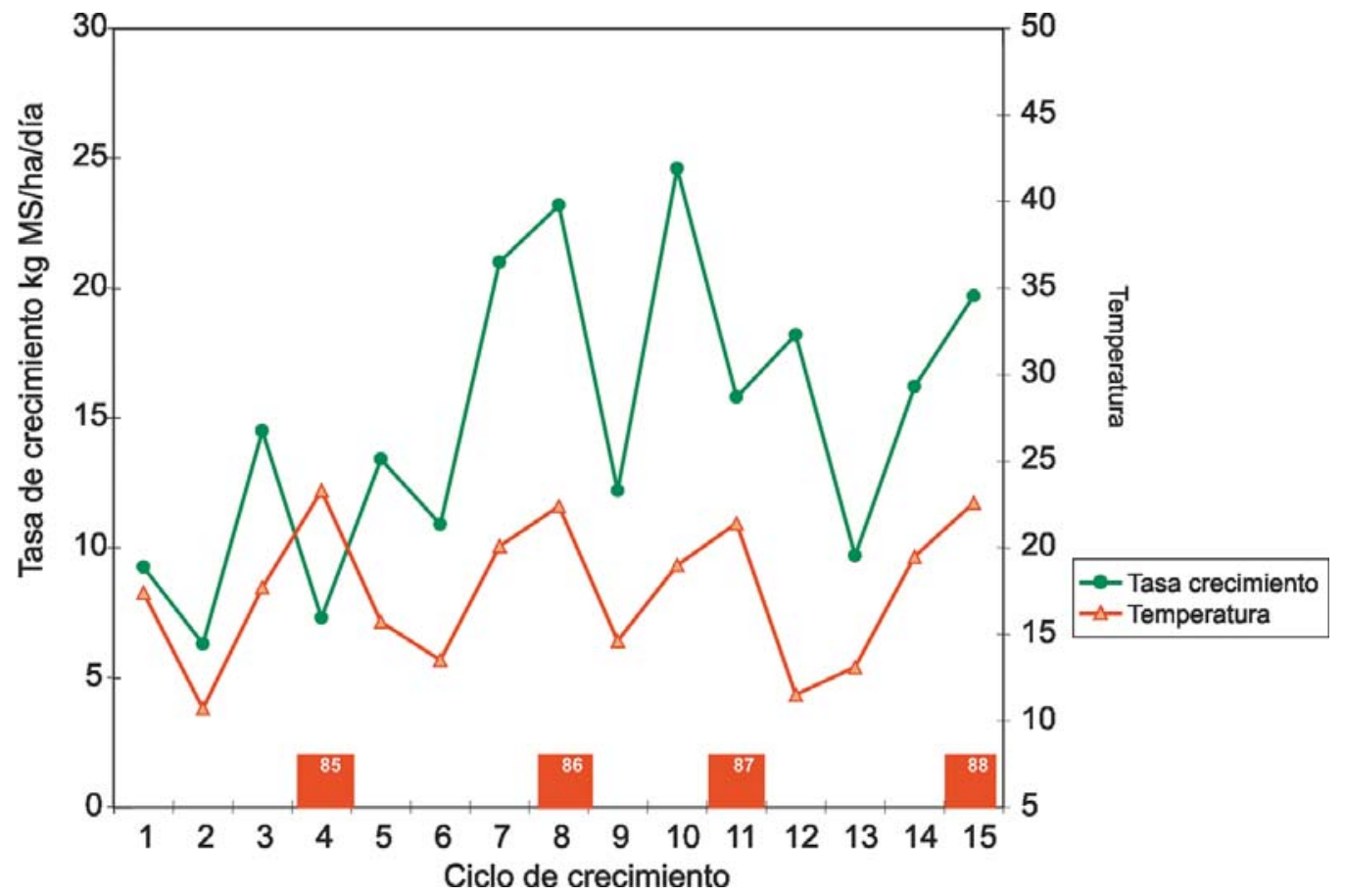

Figura 123. Productividad etacional de pasturas naturales $\left(\mathrm{kg} \mathrm{MS} \mathrm{ha}^{-1} \mathrm{dí}^{-1}\right)$ en 15 ciclos de crecimiento en relación a la temperatura media ${ }^{\circ} \mathrm{C}$ (barras-verano). 


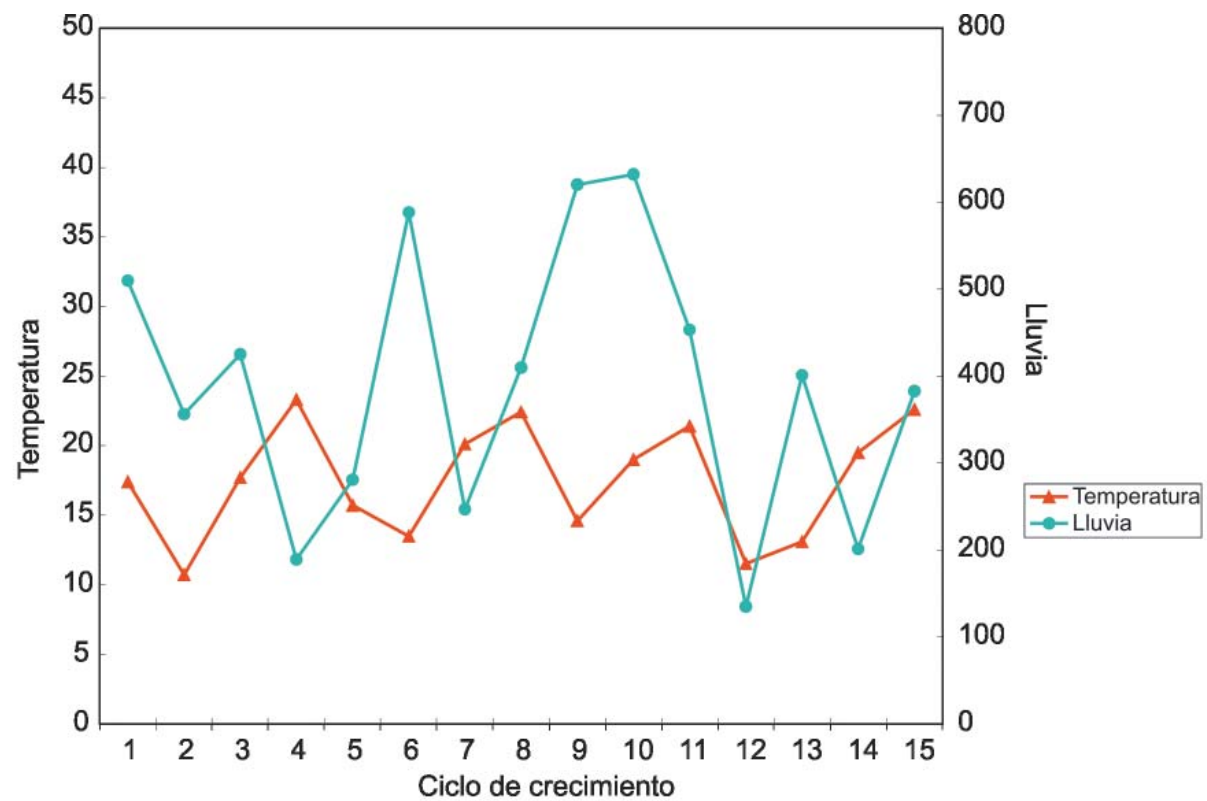

Figura 124. Variación de la temperatura $\left({ }^{\circ} \mathrm{C}\right)$ y los valores de lluvia $(\mathrm{mm})$ durante 15 estaciones de crecimiento.

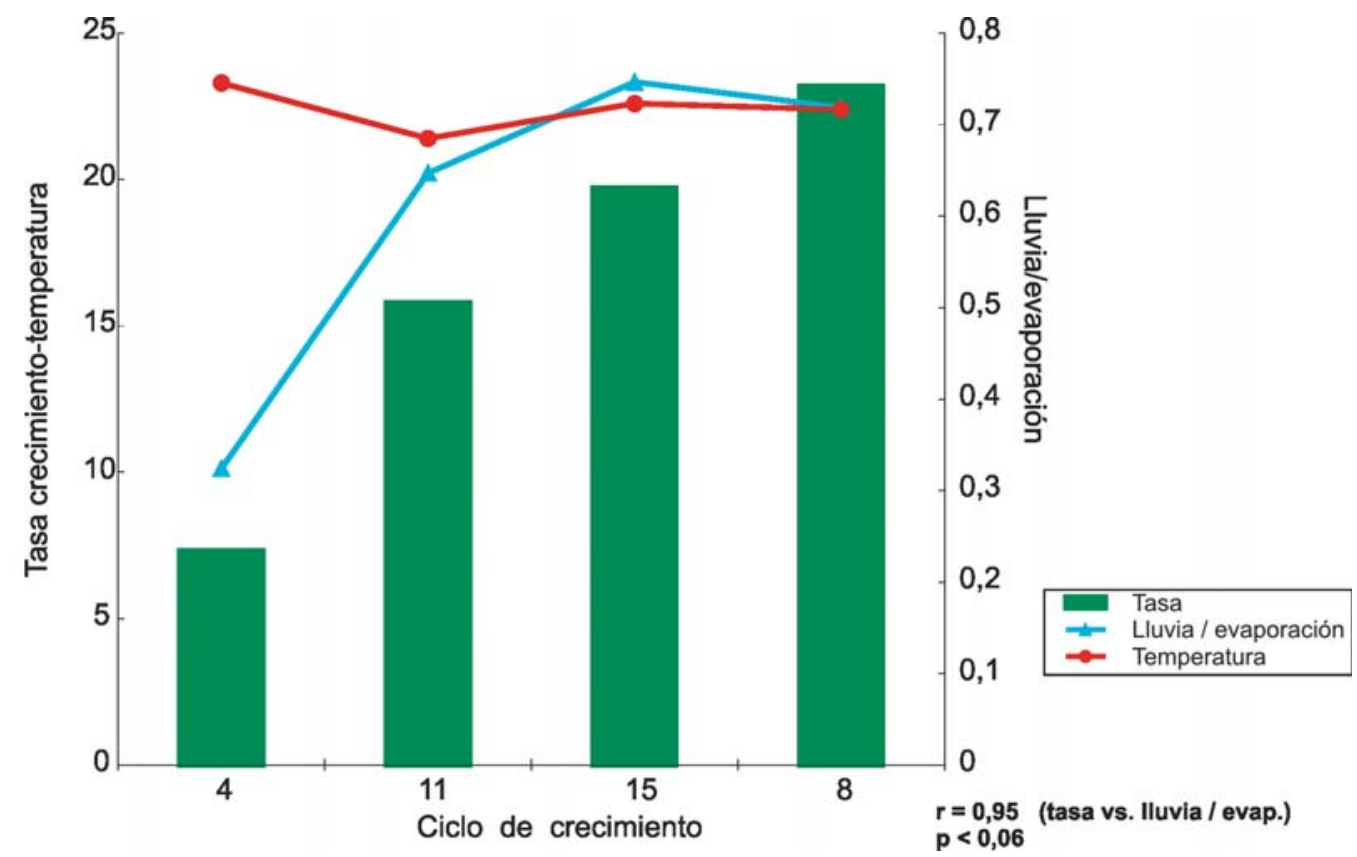

Figura 125. Relación entre la tase de crecimiento de pasturas naturales, la temperatura media y la relación lluvia/evaporación en la región noreste. 
Cuadro 30.Relación entre la tasa de crecimiento de pasturas naturales en la región noreste y las principales variables ambientales (triángulo abajo izquierda valor $r$, triángulo arriba derecha $P$ ) .

\begin{tabular}{|l|c|c|c|c|c|}
\hline & Tasa & Temperatura & Lluvia & Evaporación & Lluvia/evap. \\
\hline Tasa & $\mathbf{1 , 0 0}$ & $\mathbf{0 , 1 0}$ & 0,91 & $\mathbf{0 , 0 6}$ & $\mathbf{0 , 0 7}$ \\
\hline Temperatura & $\mathbf{0 , 4 4}$ & $\mathbf{1 , 0 0}$ & 0,76 & $\mathbf{1 , 9 E}-04$ & $\mathbf{7 , 4 E}-04$ \\
\hline Lluvia & 0,03 & $-0,09$ & $\mathbf{1 , 0 0}$ & 0,61 & $\mathbf{0 , 0 9}$ \\
\hline Evaporación & $\mathbf{0 , 5 0}$ & $\mathbf{0 , 8 2}$ & 0,15 & $\mathbf{1 , 0 0}$ & $\mathbf{1 , 3 E}-03$ \\
\hline Lluvia / evap. & $\mathbf{- 0 , 4 8}$ & $-\mathbf{0 , 7 7}$ & $\mathbf{0 , 4 5}$ & $-\mathbf{0 , 7 5}$ & $\mathbf{1 , 0 0}$ \\
\hline
\end{tabular}

registros radica en que claramente la interrelación tasa de crecimiento de la pastura con los valores de las variables ambientales esta modulada por la composición botánica de la pastura.

Desde el punto de vista ambiental la temperatura esta correlacionada positivamente con la evaporación y negativamente con la relación lluvia / evaporación; con mayor temperatura mayor evaporación, lo cual, de acuerdo al regimen de lluvias determinará el nivel de estrés hídrico presente en el ambiente. En el centro de la estación de crecimiento, verano, con una pastura compuesta predominantemente por especies de ciclo estival, dada una misma temperatura media, el mayor crecimiento de la pastura se alcanza con el incremento de los $\mathrm{mm}$ de lluvia (Figura 125). La relación de la tasa de crecimiento con la relación lluvia / evaporación, pasa de un valor general anual de - 0,48 (Cuadro 30) a una correlación de 0,95 (Figura 125) cuando se considera la principal estación de crecimiento.

A modo de síntesis en la Figura 126 se presentan las principales relaciones de la productividad forrajera con las variables ambientales climáticas; la tasa de crecimiento se incrementa con la temperatura media estacional alcanzando los valores máximos con los valores de la temperatura cercanos a la media del mes más cálido (enero) y los

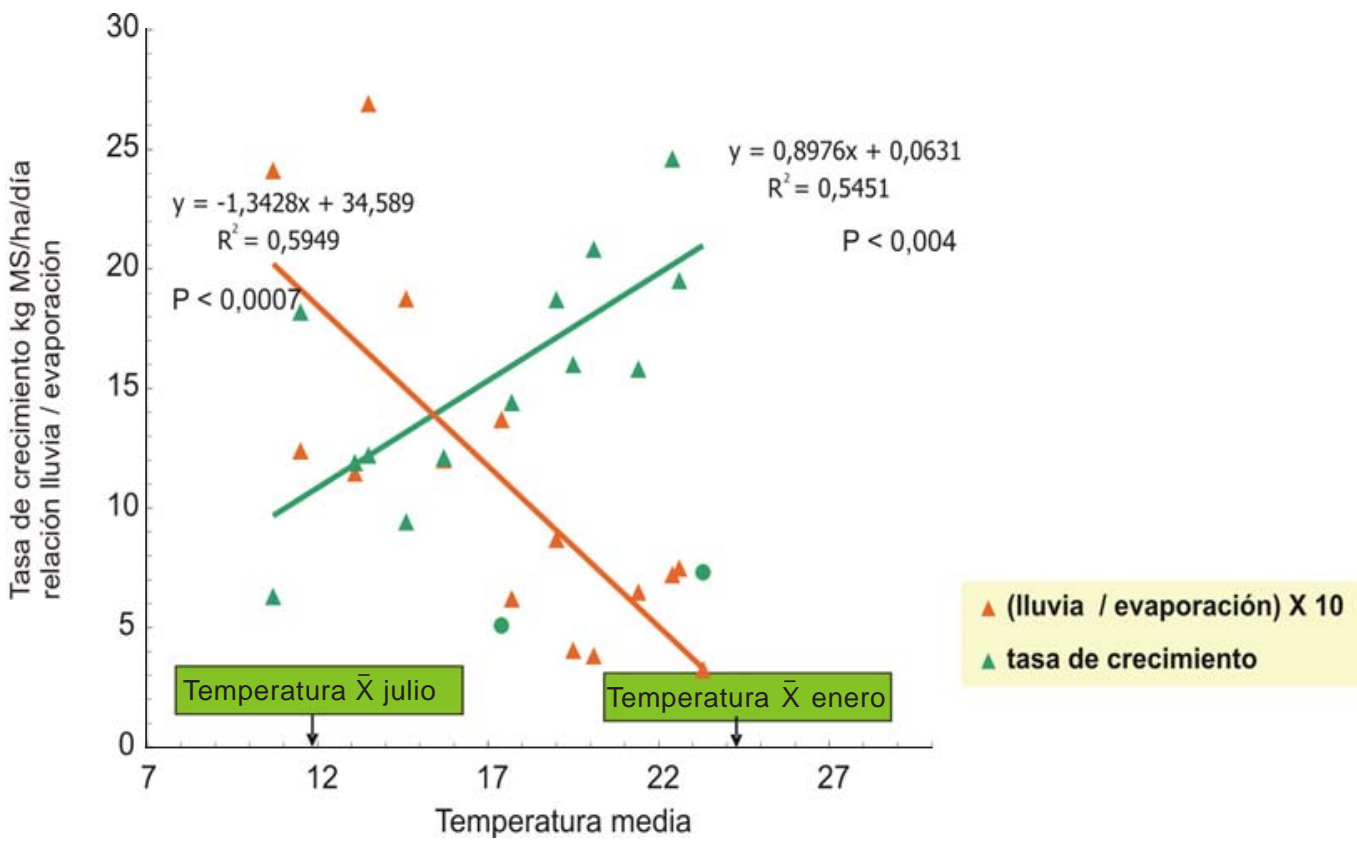

Figura 126. Relaciones entre la temperatura media, la relación lluvia / evaporación y la tasa de crecimiento en pasturas naturales de la región noreste (datos no incluidos en la regresión •). 
valores menores con los valores de la temperatura cercanos a los de la media del mes más frío (julio).

Por el contrario la relación lluvia / evaporación, a diferencia de la tasa de crecimiento, disminuye sus valores con el incremento de la temperatura; corroborando que una mayor temperatura ambiente contribuye fuertemente al incremento de la evaporación estacional.

Por otro lado en la Figura 127, se grafica la relación entre la tasa de crecimiento (productividad) y la relación lluvia / evaporación; en la misma se reporta un incremento en la productividad desde relaciones relativamente bajas como 0,35 hasta valores cercanos a 0,8 , luego existiría un umbral con valores entre 0,8 y 1,0 de la relación a partir del cual un incremento en la misma determina tasas de crecimiento menores. Estos valores de la relación Iluvia/evaporación coinciden con períodos de relativa sequía y exceso de lluvias en los puntos extremos, respectivmaente 0,35 y 2,7 .

En la Figura 128 se grafica el contenido de agua en el suelo en la parte alta del sitio experimental en tres profundidades conjuntamente con la productividad forrajera de los primero cuatro ciclos de evaluación. Se destaca el mayor contenido de agua en el suelo para el período otoño-invernal el cual disminuye gradualmente en la primavera y desciende a valores mínimos en el verano, este efecto es más marcado en los primeros $20 \mathrm{~cm}$, menos marcado en la profundidad 40$60 \mathrm{~cm}$ y con valores intermedios en la profundidad intermedia $20-40 \mathrm{~cm}$. Los datos de productividad indican que tanto con los valores más altos como con los valores más bajos en el contenido de agua en el suelo, la tasa de crecimiento fue relativametne menor que con valores intermedios de agua en el suelo. Los ciclos 1, 2 y 4 de los quince evaluados en productividad durante cuatro años fueron los que produjeron significativamente menos cantidad de materia seca que el resto de los ciclos (apéndice ciclos).

Esta información respalda la síntesis presentada en la Figura 127 y permitiría estimar, en base a la frecuencia de eventos climáticos regionales, la probabilidad estacional de eventos tanto con exceso como con déficit de agua en el suelo y por lo tanto su impacto en la productividad general del sistema ganadero en estos ecosistemas naturales.

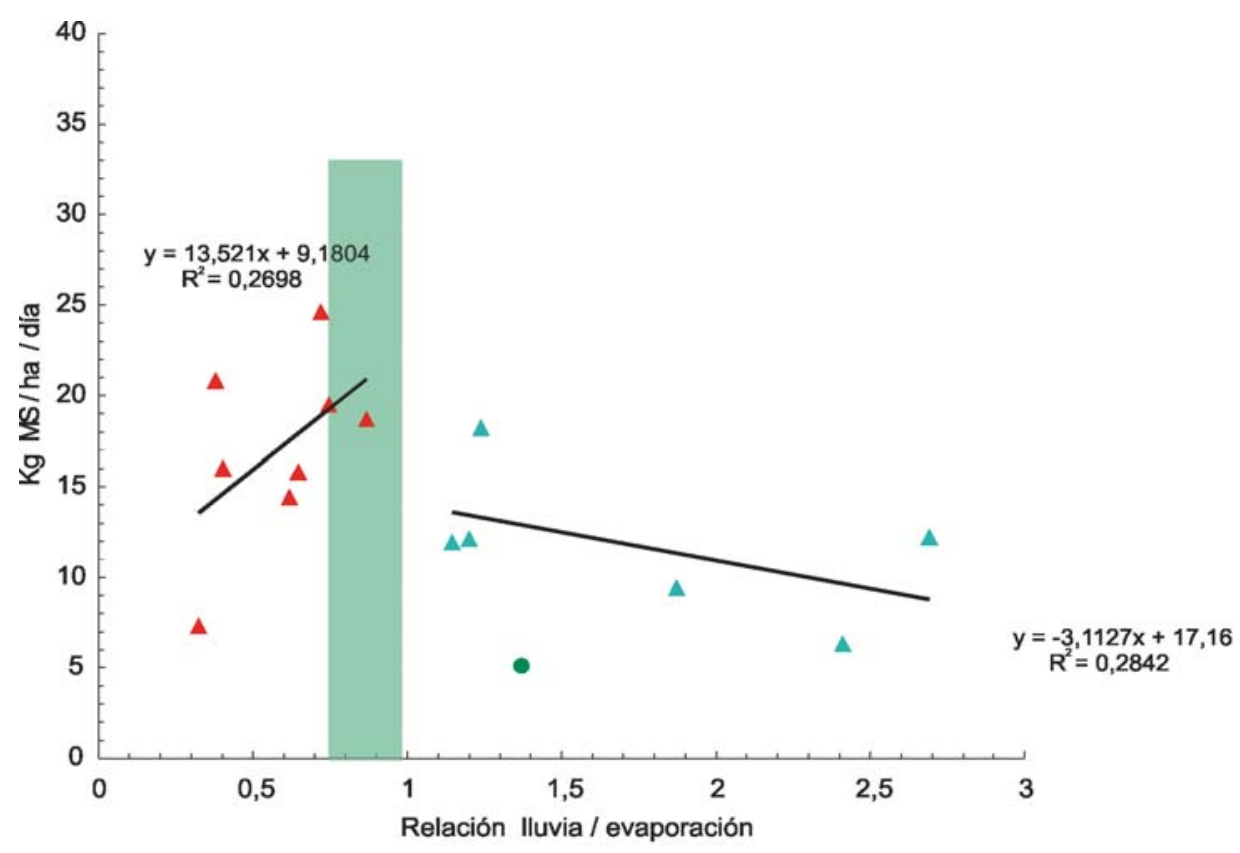

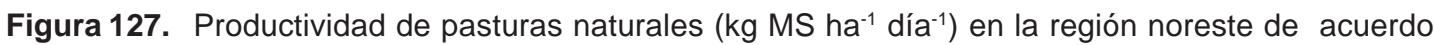
a la relación lluvia / evaporación (datos no incluídos en la regresión @). 


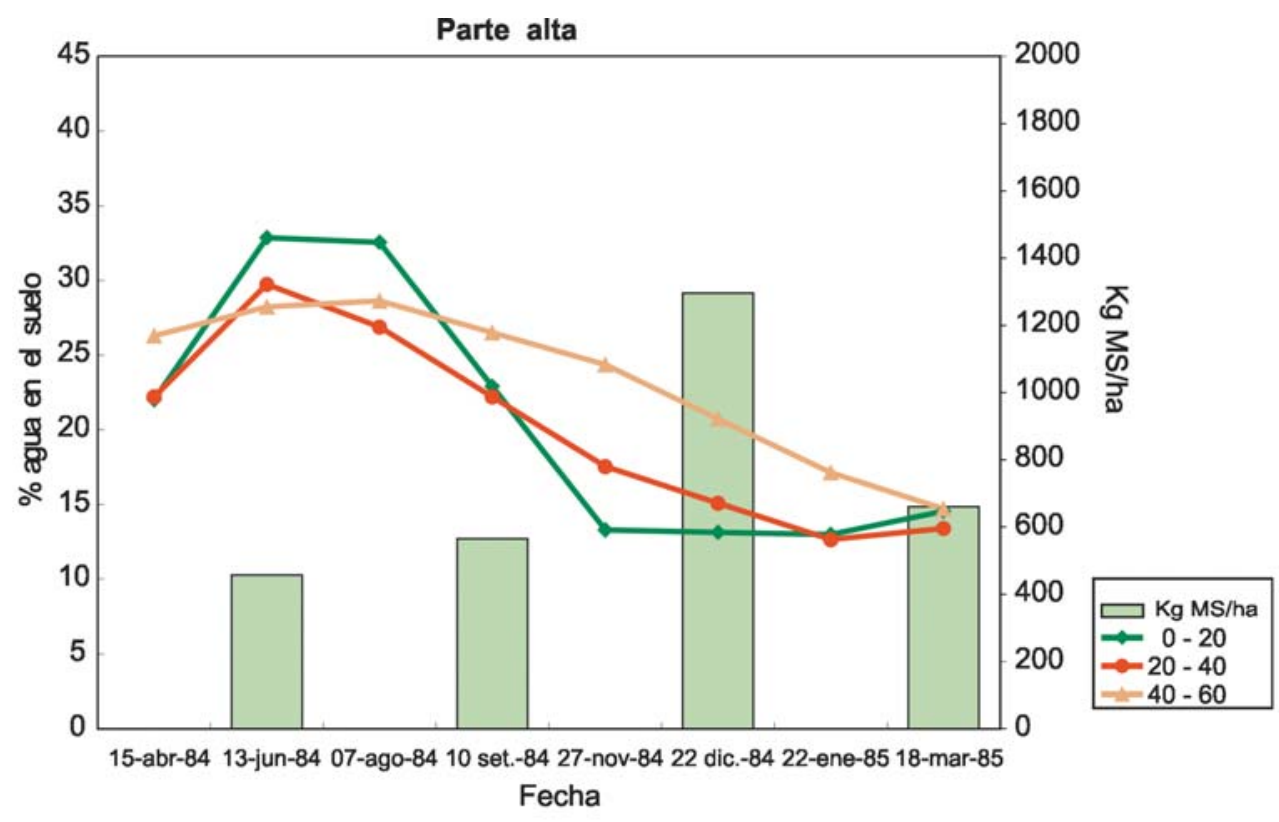

Figura 128. Porcentaje de agua en el suelo en la parte alta de la ladera, en tres profundidades 0-20, 20-40 y 40-60 cm en suelos de la Unidad Cuchilla de Caraguatá, productividad forrajera (kg MS ha-1 día-1) en el período 1984-1985.

Para la parte relativamente más baja la tendencia fue similar a la de la parte más alta, aunque con valores más altos de agua en el suelo para el período otoño-invierno, $40 \%$ y $33 \%$ para la parte baja y alta respectivamente; con valores similares del orden del $15 \%$ en el contendio de agua en el suelo para los dos sitios al final del ciclo en el verano 1985 (Figura 129).

Cuando se compararon los primeros 20 $\mathrm{cm}$. de suelo, tanto en otoño, invierno como en primavera el contenido de agua en el suelo fue superior en la zona más baja del relieve, sin embargo al llegar el verano los valores en los tres sitios, ladera alta, ladera media y ladera baja fueron muy similares en torno a 15-16 \% (Figura 130).

Estos resultados pueden compararse con valores obtenidos en brunosoles similares de la región de Caraguatá; tomando un perfil típico de estos suelos encontramos un horizonte $A$ de $0-17 \mathrm{~cm}$, un horizonte $B-C$ de 17-34 cm. y un $C$ de más de $37 \mathrm{~cm}$ (Altamirano et al., 1976) y tomando los valores de contenido de arcilla, limo, arena y materia orgánica del mismo, de acuerdo a Alvarez et al. (1990) se calcularon los puntos de marchitez permanente y la capacidad de campo (Cuadro 31). En el caso del suelo típico descripto por la Dirección de Suelos (Altamirano et al., 1976) los valores utilizados fueron, $19,7 \%$ de arena, 34,4 \% de arcilla, $45,9 \%$ de limo y $6 \%$ de materia orgánica.

Los valores indican que efectivamente en el período invernal el suelo se encontraba completamente saturado de agua ya que el contenido del mismo se encontraba por encima del valor de capacidad de campo 35,4\% (Cuadro 31) o con valores muy cercanos al mismo y por otra parte, en el período estival el contenido de agua fue muy similar al valor del coeficiente de marchitez permannente alcanzado en ese tipo de suelo de 18,4 \% (Cuadro 31) comparado con el estimado en el ciclo experimental de 15-16 \% (Figura 130). Vale decir por lo tanto, que la vegetación se desarrolló entre los dos extremos de contenido de agua este tipo de suelo en un período menor a un año, que conjuntamente con la temperatura media generan diferentes valores en la productividad de materia seca: con exceso de agua y baja temperatura (período otoño-invierno) se registró una baja productividad forrajera $\left(5,7 \mathrm{~kg} \mathrm{MS} \mathrm{ha-1}\right.$ día $\left.^{-1}\right)$, con contenido de agua intermedios en el suelo y una temperatura relativamente mayor al pe- 


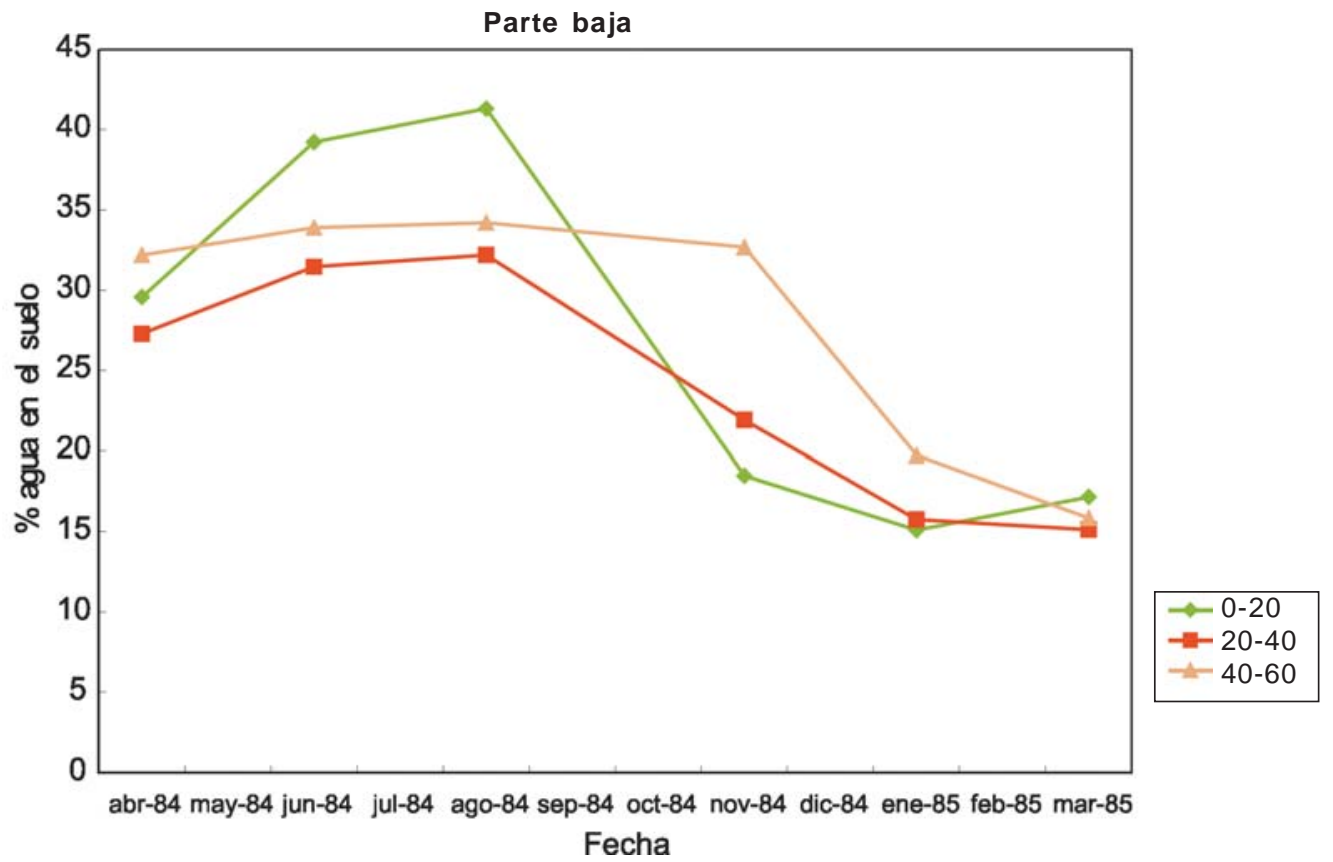

Figura 129. Porcentaje de agua en el suelo en la parte baja de la ladera, en tres profundidades 020, 20-40 y 40-60 cm en suelos de la Unidad Cuchilla de Caraguatá, en el período 1984-1985.

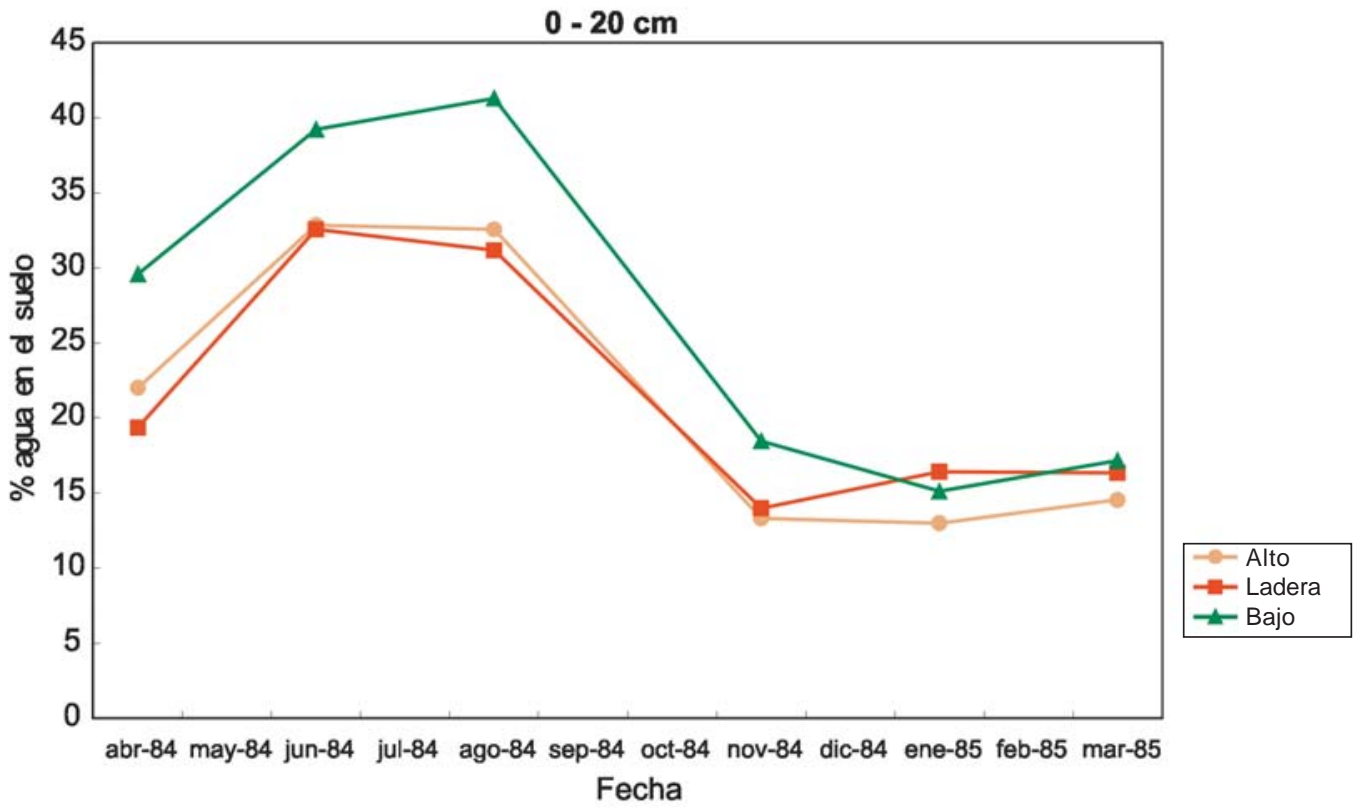

Figura 130. Porcentaje de agua en el suelo en tres zonas topográficas en una ladera sobre suelos de la Unidad Cuchilla de Caraguatá, en el período 1984-1985.

ríodo invernal (primavera) la productividad fue mayor $\left(14,4 \mathrm{~kg} \mathrm{MS} \mathrm{ha}^{-1}\right.$ día $\left.^{-1}\right)$ y con un bajo contenido de agua en el suelo y altas tempe- raturas (período estival) la productividad forrajera también se vio restringida (7,3 kg MS ha-1 día-1). 
Cuadro 31. Valores de capacidad de campo y punto de marchitez permanente para cuatro sitios sobre brunosoles en la región noreste (adaptado de Olmos, 2000).

\begin{tabular}{|l|c|c|}
\hline Sitio & $\begin{array}{c}\text { Capacitad de } \\
\text { Campo \% }\end{array}$ & $\begin{array}{c}\text { Punto de Marchitez } \\
\text { Permanente \% }\end{array}$ \\
\hline Berruti & 26,5 & 13,4 \\
\hline CECO - Campo Exp. Cuchilla del Ombú & 28,3 & 14,9 \\
\hline López & 23,0 & 11,5 \\
\hline Unidad Cuchilla Caraguatá - MGAP & 35,4 & 18,3 \\
\hline
\end{tabular}

\section{CAMBIOS EN LA COMPOSICIÓN BOTÁNICA}

En esta sección se realiza el análisis de los registros respecto a la composición botánica y su dinámica, utilizando la distribución de Poisson para el análisis de la presencia de una especie en una transecta, tomando el número de presencias en la misma. Este analisis se aplicó a otras variables basadas en conteos.

\section{Tipos vegetativos}

En el período experimental se observó una tendencia general donde, por un lado, las se incrementaron hacia el final del período y por otro lado, las especies de hábito de crecimiento rastrero tendieron a disminuír su proporción en la pastura durante el mismo período (Figura 131). Del mismo modo en ese período experimental los tratamientos de la pastura con pastoreo contínuo mantuvieron proporcionalmente más especies de hábito de crecimiento rastrero que en los tratamientos con pastoreo rotativo o alternado (Figura 132).

En los Cuadros 32 y 33 se observan los resultados del análisis de los registros efectuados en la pastura natural; en general se registró un efecto estadísticamente significatvio de la variación en el contenido de especies en las pastura de acuerdo al

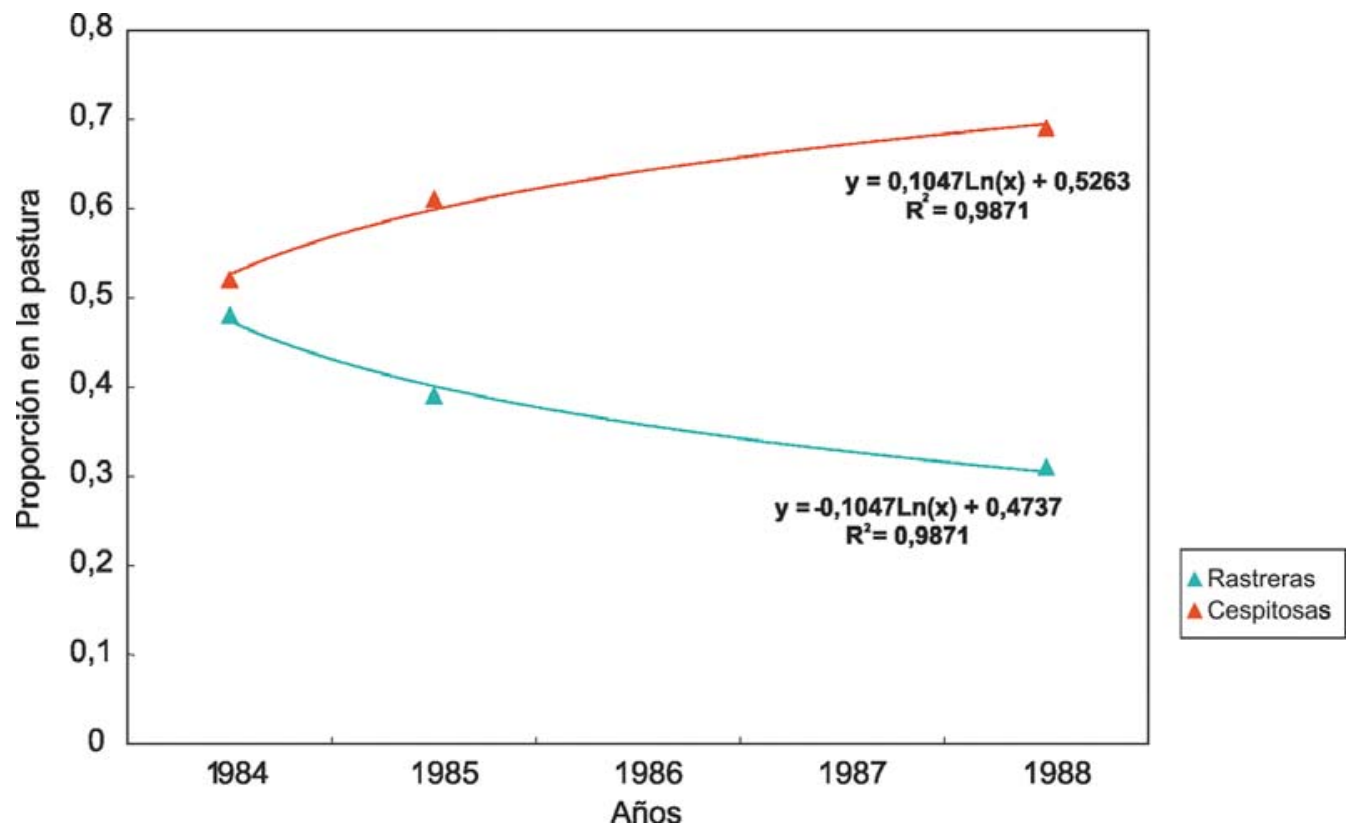

Figura 131. Variación de la proporción de especies rastreras y cespitosas en pasturas naturales de la región noreste en el período 1984-1988. 


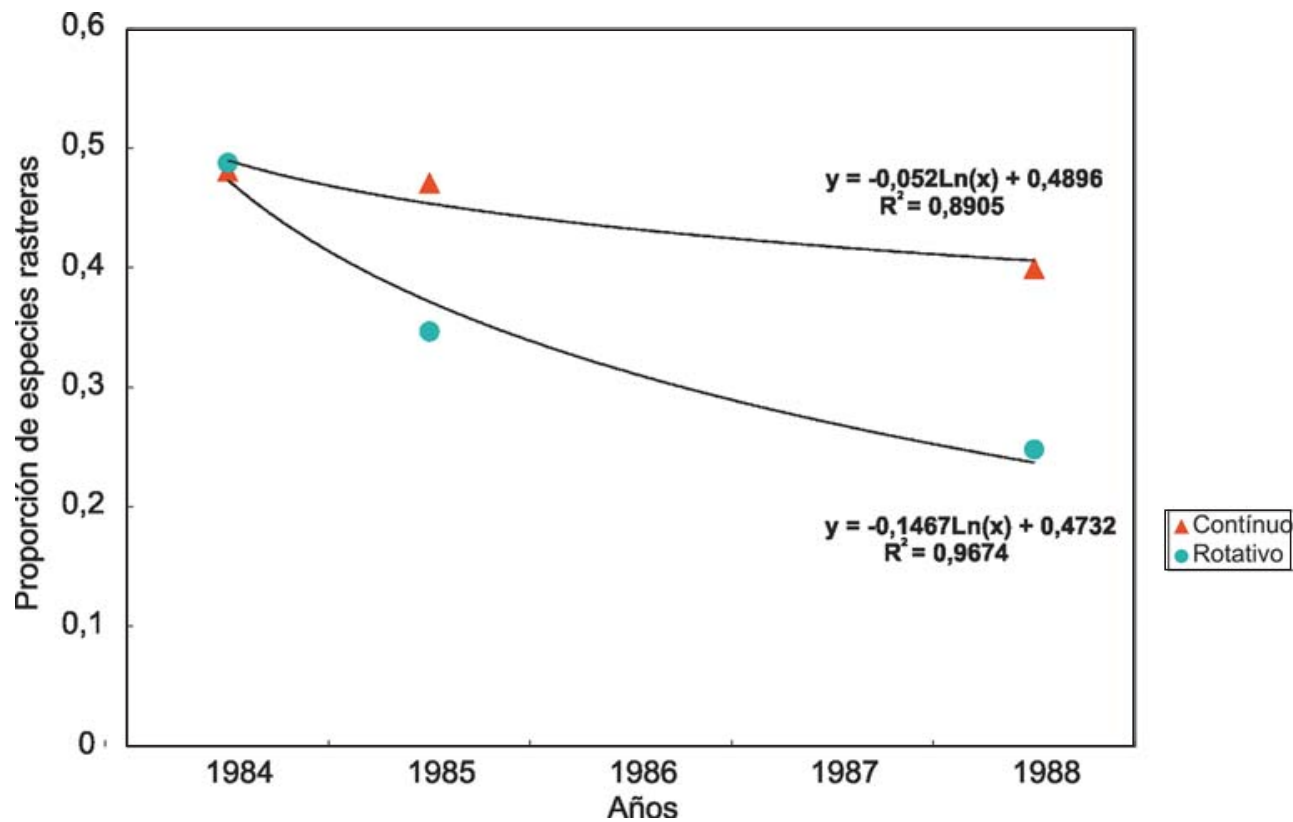

Figura 132. Variación en la proporción de especies rastreras en pasturas naturales de la región noreste según el sistema de pastoreo: contínuo o rotativo en el período 1984 - 1988.

Cuadro 32. Resultados del análisis general de la proporción de los diferentes tipos vegetativos en relación al año, el tipo de pastoreo y sus interacciones en pasturas naturales de la región noreste.

\begin{tabular}{|lccc|}
\hline Fuente de variación & Probabilidad & & \\
\hline Tipo Vegetativo & 0,0002 & & \\
Año & 0,3441 & & \\
Pastoreo & 0,9788 & & \\
Tipo x año & 0,0365 & & \\
Tipo x pastoreo & 0,0643 & & \\
\hline Cespitosa & 86,7 & A & \\
Rastrera & 59,7 & & B \\
\hline Cespitosa rotativo & 93,2 & A & \\
Cespitosa contínuo & 80,3 & A & \\
Rastrera rotativo & 66,0 & & B \\
Rastrera contínuo & 53,4 & & B \\
\hline
\end{tabular}

Cuadro 33. Resultados del análisis estadístico del efecto del tipo de pastoreo en la presencia de tipos vegetativos diferentes en tres años de registro en pasturas naturales de la región noreste.

\begin{tabular}{|lc|ll|lc|}
\hline \multicolumn{2}{|c|}{1984} & \multicolumn{2}{c|}{1985} & \multicolumn{2}{c|}{1988} \\
\hline Fuente & $\mathbf{P}$ & Fuente & P & Fuente & P \\
\hline Pastoreo & 0,3340 & Pastoreo & 0,3957 & Pastoreo & 0,9860 \\
Tipo Veg. & 0,5039 & Tipo Veg. & 0,0104 & Tipo Veg. & 0,0082 \\
Pastoreo $\times$ Tipo & 0,8529 & Pastoreo $\times$ Tipo & 0,0570 & Pastoreo $\times$ Tipo & 0,2150 \\
\hline
\end{tabular}


tipo vegetativo y de la variación con los años de registro.

La proporción de los dos tipos de especies no fue estadísticamente diferente en el año 1984, en cambio si lo fue en los años 1985 y 1988 de acuerdo al tipo de pastoreo aplicado a la patura en los diez potreros (cinco tratamientos y dos repeticiones) (Figura 133).

A modo de sintetizar esta tendencia, en la Figura 134 se destaca la evolución en el período experimental de la proporción de los dos tipos de especies analizados, de hábito

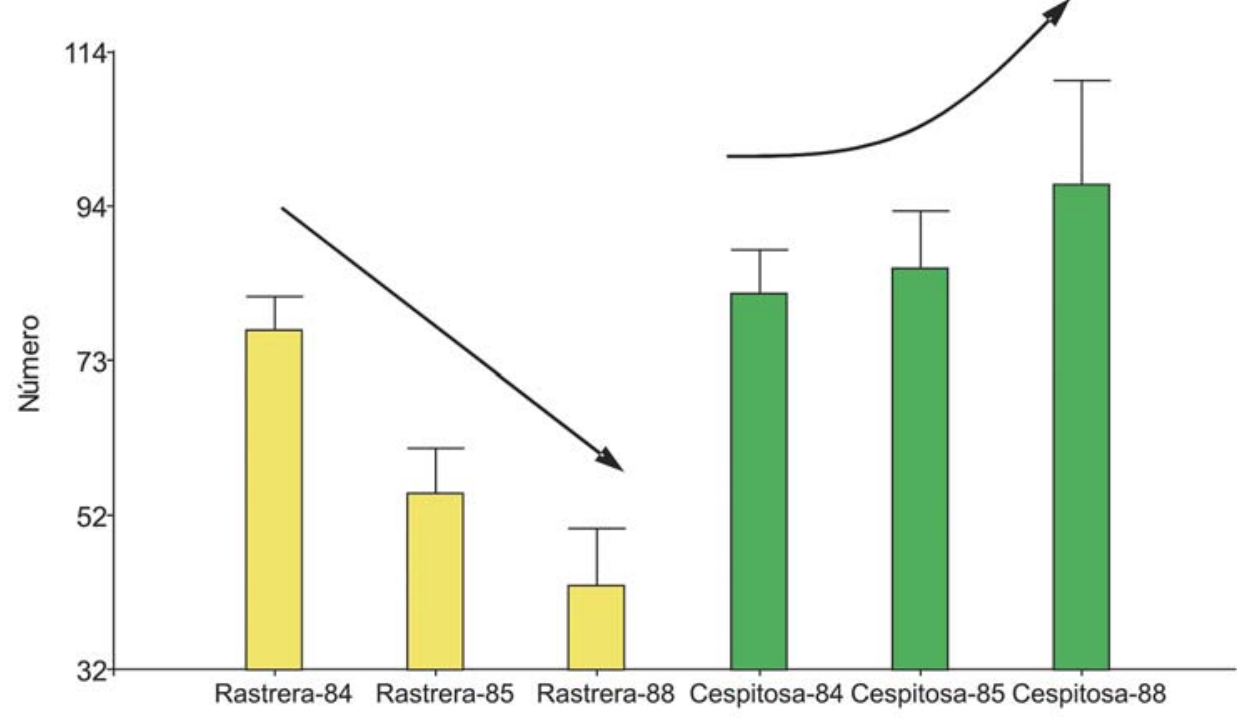

Figura 133. Variación en la presencia (número) de especies de crecimiento rastrero y cespitoso en pasturas naturales de la región noreste, período 1984-1988.

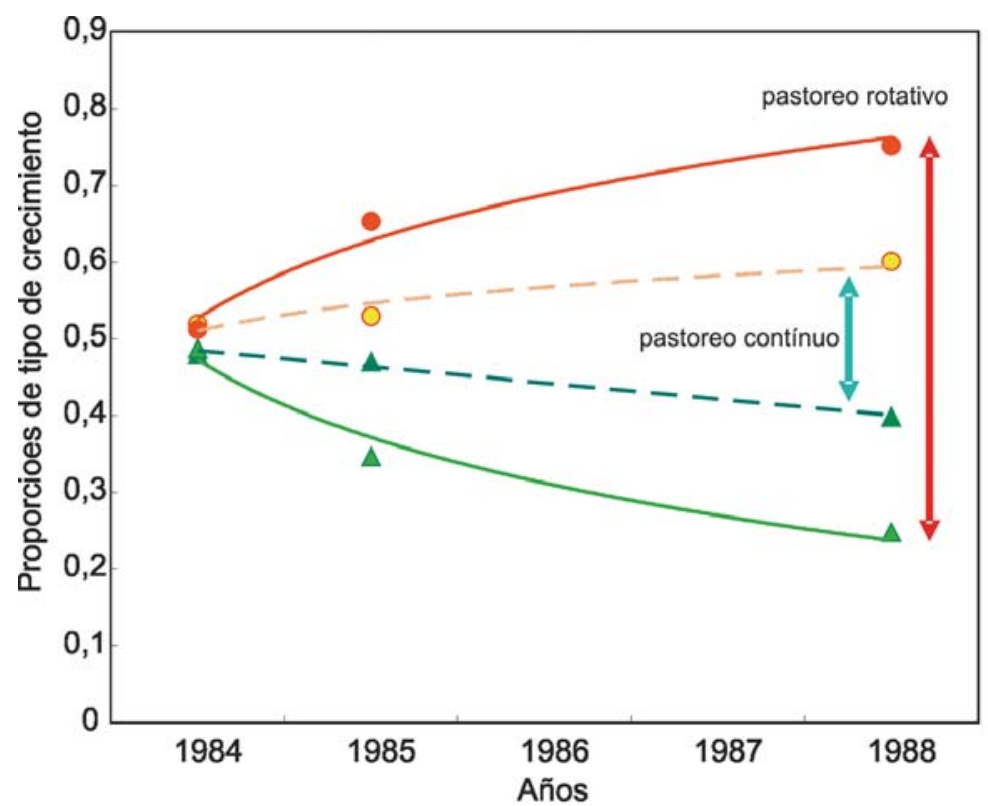

Figura 134. Variación en la proporción de especies de hábito de crecimiento rastrero y cespitoso de acuerdo al sistema de pastoreo (rotativo o continuo) y el año en pasturas naturales de la región noreste. 
de crecimiento rastrero y de hábito de crecimiento erecto o cespitosa en dos condiciones de manejo de la pastura, con pastoreo contínuo y pastoreo rotativo.

En ambos casos se incrementó la presencia de especies de crecimiento erecto a expensas de una menor proporción de las especies de crecimiento rastrero, sin embargo esta tendencia fue más marcada cuando se realizaó el pastoreo rotativo.

\section{Enmalezamiento}

Para el análisis de malezas se clasificaron las especies en dos tipos: arbustos y malezas menores de acuerdo a Rosengurtt (1979) y los registros se analizaron respecto a los tratamientos del pastoreo en los diferentes años. Un análisis general indicó que tanto para la composición de especies, para el sistema de pastoreo así como para el efecto año los resultados fueron altamente significativos (Cuadro 34).

Cuadro 34. Análisis del efecto del año el sistema de pastoreo y la presencia de diferentes tipos vegetativos en el enmalezamiento de pasturas naturales de la región noreste.

\begin{tabular}{|l|c|}
\hline Fuente de variación & Probabilidad \\
\hline Año & 0,0001 \\
\hline Tratamiento & 0,0001 \\
\hline Tipo vegetativo & 0,0001 \\
\hline
\end{tabular}

Las malezas menores incrementaron su presencia hacia el segundo año del período experimental (1985), en cambio los arbustos lo hicieron hacia el final del mismo período (1988), Figura 135.

Esto estaría indicando que las malezas menores respondieron antes que los arbustos al cambio en el tipo de pastoreo, de forma similar a como evolucionó la productividad general del experimento desde 1984. Por otro lado también resultó un efecto estadísticamente significativo sobre la diferente proporción de maleza menor y arbusto el sistema de pastoreo en los años 1985 y 1988 (Cuadro 35).

El efecto principal de cambio en la presencia de los dos tipos de especies se produce básicamente en base a su mayor presencia en los tratamientos de la pastura con pastoreo rotativo comparado con el pastoreo contínuo (Cuadro 35, Figura 136).

Este desplazamiento diferencial de la respuesta al manejo del pastoreo de las malezas menores comparado con los arbustos podría explicarse por su ciclo, siendo especies predominantemente anuales las malezas menores y por otro lado de ciclo perennes los arbustos (Rosengurtt, 1979).

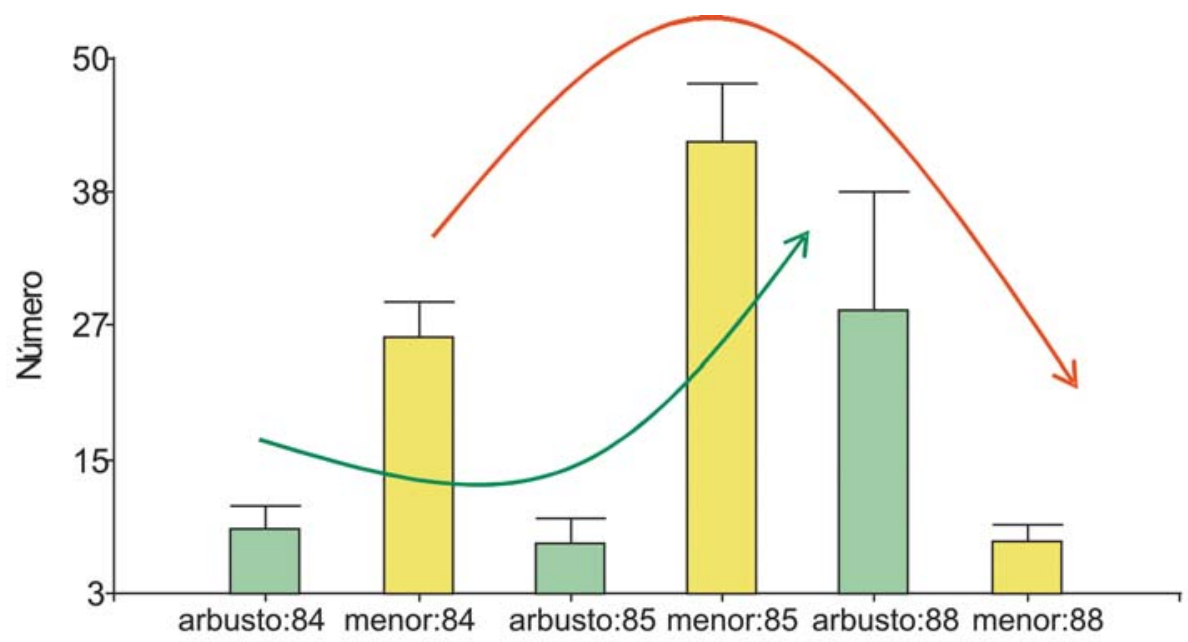

Figura 135. Cambio en la presencia de malezas menores y arbustos en pasturas naturales de la región noreste en el período 1984-1988. 
Cuadro 35. Efecto del sistema de pastoreo en la presencia de diferentes tipos vegetativos en pasturas naturales de la región noreste en el período 1984 - 1988

\begin{tabular}{|ll|lr|ll|}
\hline \multicolumn{2}{|c|}{1984} & \multicolumn{2}{|c|}{1985} & \multicolumn{2}{c|}{1988} \\
\hline Pastoreo & $\mathrm{P}<0,2655$ & Pastoreo & $\mathrm{P}<0,0001$ & Pastoreo & $\mathrm{P}<0,0035$ \\
Tipo & $\mathrm{P}<0,0001$ & Tipo & $\mathrm{P}<0,0001$ & Tipo & $\mathrm{P}<0,0001$ \\
\hline
\end{tabular}

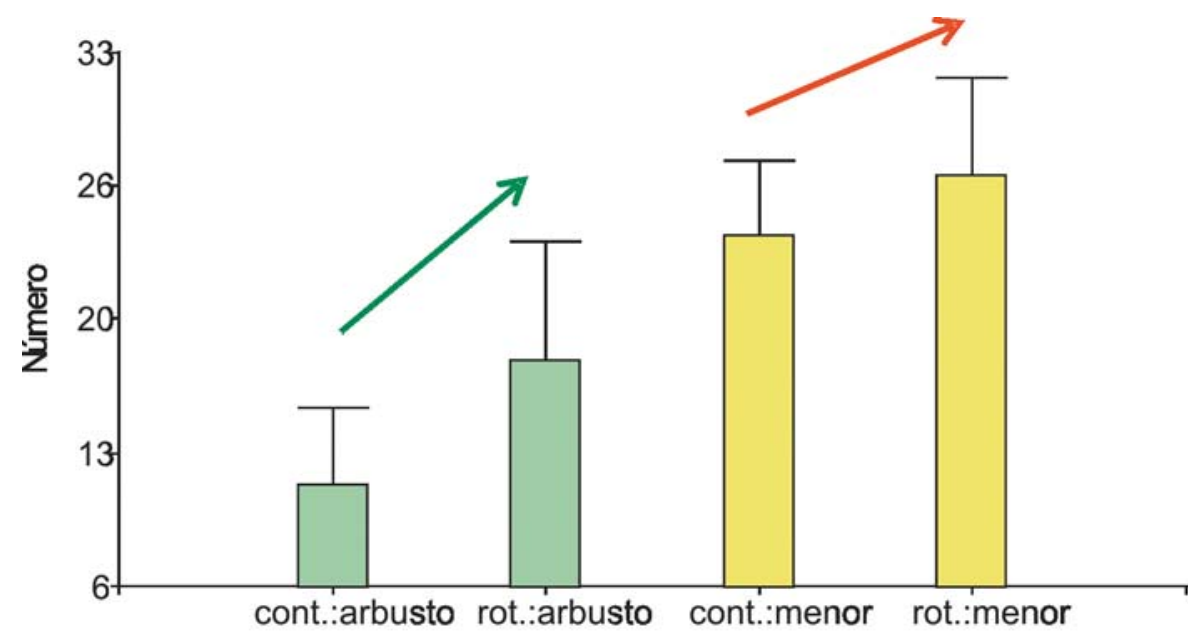

Figura 136. Cambio en la presencia de arbustos y malezas menores en pasturas naturales de la región noreste según el sistema de pastoreo: contínuo o rotativo.

\section{ANÁLISIS DE LA EVOLUCIÓN DE LAS PRINCIPALES ESPECIES FORRAJERAS}

\section{Coelorachis selloana}

Una de las especies de mayor interés forrajero, por su productividad y tipo de crecimiento erecto, en la región noreste es Coelorachis selloana. En el Cuadro 36 se presenta un resúmen de los resultados de los análisis efectuados, mostrando que el efecto del sistema de pastoreo sobre la pre- sencia de Coelorachis en la pastura se manifestó a partir del segundo año, 1985. Con el sistema de pastoreo rotativo Coelorachis selloana incrementó significativamente su presencia en la pastura, con valores $40 \%$ superiores para este sistema comparado con el pastoreo contínuo (Figura 137).

Este efecto si bien comenzó a registrarse en el segundo año del período experimental, el mismo se manifestó marcadamente hacia el final del período en el año 1988 (Figura 138).

Cuadro 36. Efecto del sistema de pastoreo y el año en la presencia de Coelorachis selloana en pasturas naturales de la región noreste.

\begin{tabular}{|l|l|c|}
\hline Año & Tratamiento & P \\
\hline 1984 & Sistema de pastoreo & 0,4889 \\
$1985-1988$ & Sistema de pastoreo & 0,0011 \\
1985 vs.1988 & Sistema de pastoreo & 0,0011 \\
& Año & 0,0005 \\
\hline
\end{tabular}




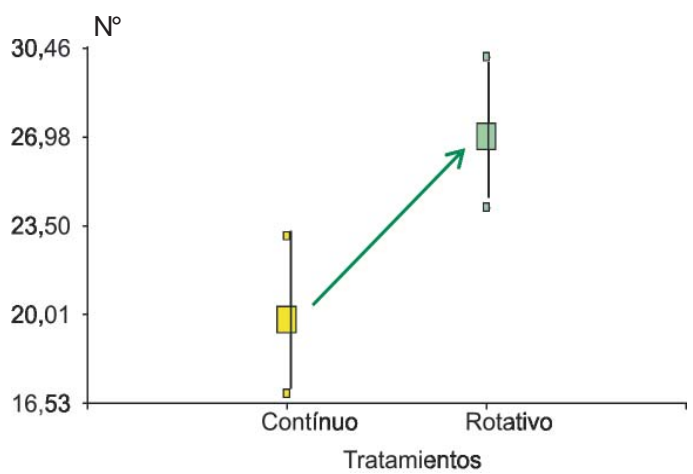

Figura 137. Cambio en la presencia de Coelorachis selloana en pasturas naturales de la región noreste según el sistema de pastoreo.

\section{Axonopus affinis}

Axonopus affinis es una especie de hábito de crecimiento rastrero y a continuación se presentan los resultados de los análisis realizados según el tipo de pastoreo en cada año del período experimental.

Los resultados indican claramente la disminución con el tiempo, desde 1984 a 1988 de la presencia de la especie en la pastura, sin embargo esta disminución es significativamente mayor en los tratamientos de la pastura con un sistema de pastoreo rotativo comparado con el pastoreo contínuo (Cuadro 37; Figura 139).

En el año 1984 y prácticamente en el año 1985 el sistema de pastoreo no tuvo efecto significativo sobre la presencia de Axonopus affinis en la pastura (Cuadro 37), sin embargo cuando se agruparon los registros en los años 1985-1988 se constató un efecto esta-

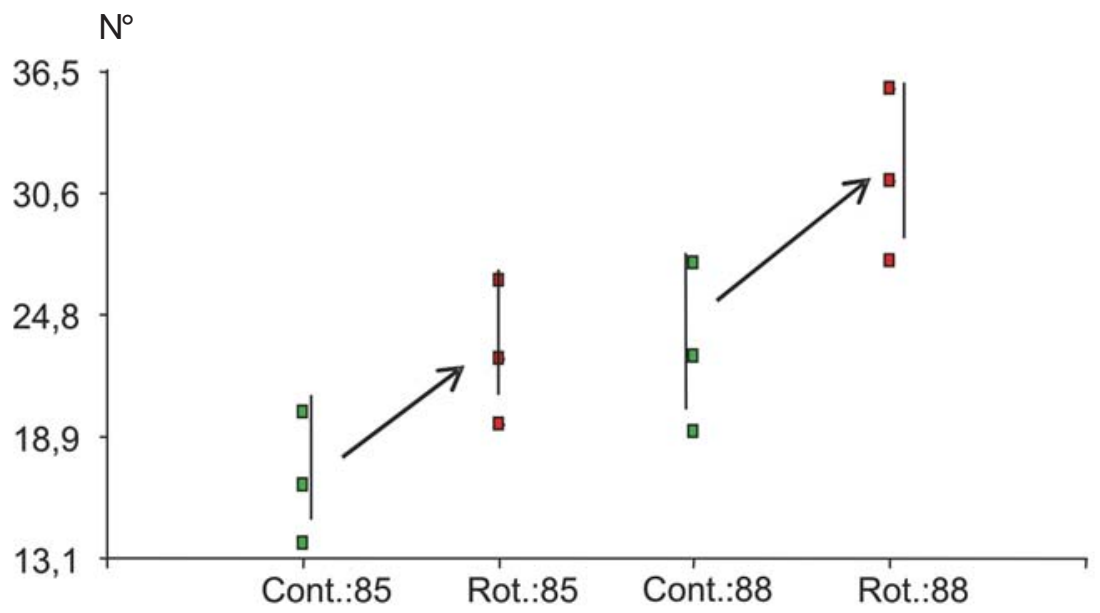

Figura 138. Variación en la presencia de Coelorachis selloana según el año y el sistema de pastoreo: contínuo o rotativo en pasturas naturales de la región noreste (intervalo de confianza 95 \%).

Cuadro 37.Efecto del sistema de pastoreo en la presencia de Axonopus affinis en pasturas naturales de la región noreste en el período 1984 - 1988.

\begin{tabular}{|l|c|c|}
\hline Año & Tratamiento & P \\
\hline 1984 & Sistema de pastoreo & 0,9568 \\
1985 & Sistema de pastoreo & 0,0568 \\
1988 & Sistema de pastoreo & 0,0001 \\
$1985-1988$ & Sistema de pastoreo & 0,0001 \\
\hline
\end{tabular}




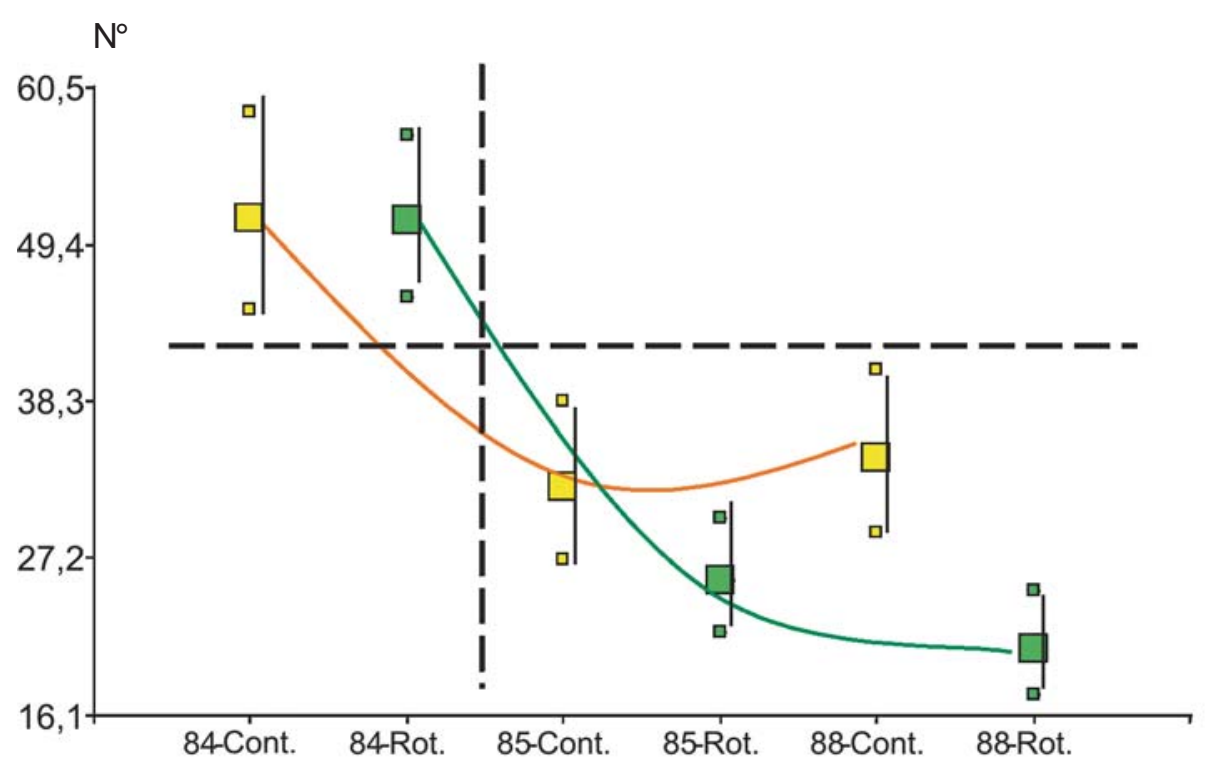

Figura 139. Variación en la presencia de Axonopus affinis en pasturas naturales de la región noreste según el sistema de pastoreo:rotativo o contínuo en el período 1984 -1988.

dísticamente significativo del sistema de pastoreo, siendo los valores mayores para el sistema de pastoreo contínuo comparado con el pastroeo rotativo (Figura 140).

La disminución en su presencia es de la misma magnitud observada en Coelorachis selloana en párrafos antreriores, pero con un sentido opuesto.

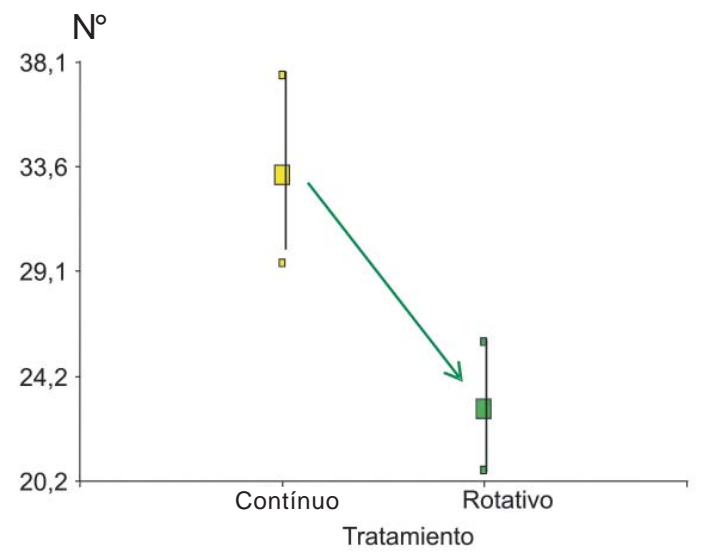

Figura 140. Cambio en la presencia de Axonopus affinis en pasturas naturales de la región noreste según el sistema de pastoreo: contínuo o rotativo Paspalum notatum.

\section{Paspalun notatum}

En el caso de Paspalun notatum los resultados son similares a los observados para Axonopus affinis, disminuyendo significativamente hacia el final del ciclo experimental (Cuadro 38; Figura 141) y presentando, al mismo tiempo, valores menores estadísticamente en los tratamientos de pastoreo contínuo comparado los tratamientos de pastoreo rotativo.

\section{Bothriochloa laguroides}

Esta especie no mostró diferencias en su presencia en la pastura natural según los tratamientos en el primer año, sin embargo acumulando la información en los años 1985 y 1988 el sistema de pastoreo rotativo tendió a presentar una mayor presencia de la especie (Cuadro 39; Figuras 142 y 143); en el sistema de pastoreo contínuo redujo significativamente su presencia desde el año 1984 al año 1988 (Figura 142).

Bothriochloa laguroides es una especie de crecimiento erecto (cespitosa) que fue identificada como asociada al grupo de Coelorachis selloana en los relevamientos realizado en la región noreste. 
Cuadro 38.Efecto del año y el sistema de pastoreo en la presencia de Paspalum notatum en pasturas naturales de la región noreste Paspalum notatum.

\begin{tabular}{|l|l|c|}
\hline Año & Tratamiento & P \\
\hline Modelo general & Sistema de pastoreo & 0,0001 \\
& Año & 0,0001 \\
1984 & Sistema de pastoreo & 0,0326 \\
1985 & Sistema de pastoreo & 0,0451 \\
1988 & Sistema de pastoreo & 0,0003 \\
\hline
\end{tabular}

$\mathrm{N}^{\circ}$

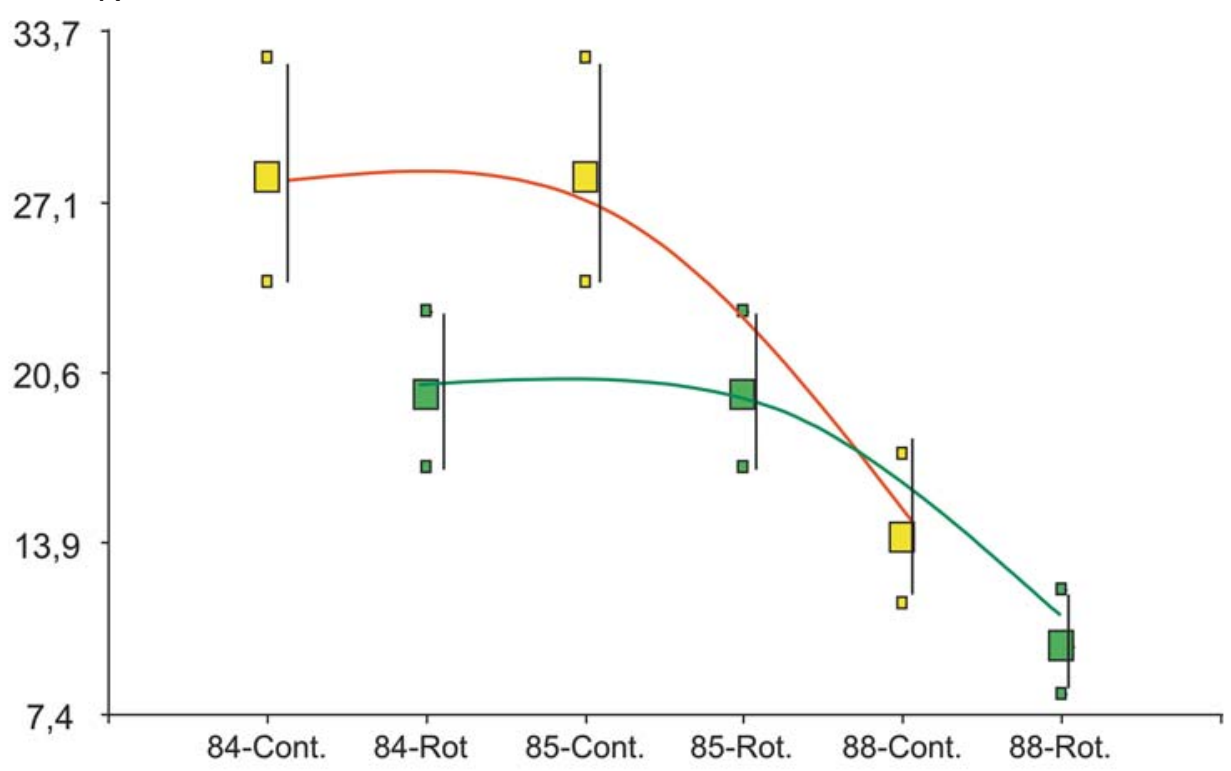

Figura 141. Cambio en la presencia de Paspalum notatum con pastoreo contínuo (amarillo) y pastoreo rotativo (verde) en el período 1984-1988 en pasturas naturales de la región noreste.

Cuadro 39. Efecto del año y el sistema de pastoreo sobre la presencia de Bothrichloa laguroides en pasturas naturales de la región noreste.

\begin{tabular}{|l|l|c|}
\hline \multicolumn{1}{|c|}{ Año } & Tratamiento & P \\
\hline Modelo general & Año & 0,0274 \\
& Sistema de pastoreo & 0,3706 \\
1984 & Sistema de pastoreo & 0,2436 \\
1985 & Sistema de pastoreo & 0,1452 \\
1988 & Sistema de pastoreo & 0,1482 \\
$1985-1988$ & Sistema de pastoreo & 0,0407 \\
\hline
\end{tabular}




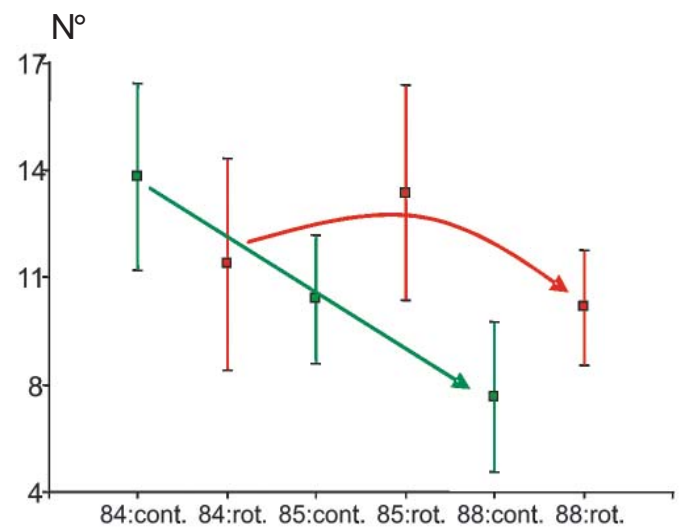

Figura 142. Cambio en la presencia de Bothrichloa laguroides según el sistema de pastoreo en pasturas naturales de la reigón noreste en el período 1984-1988.

\section{Cyperáceas}

Este grupo de especies no presentó variaciones significativas en su presencia en pasturas naturales de la región noreste de acuerdo al sistema de pastoreo, sin embargo presentó cierta variación en los diferentes años (Cuadro 40).

Este grupo de especies presentó mayor presencia en la pasturas en el año 1985 y menores valores al inicio y final del período experimental (Figura 144).

\section{Andropogon ternatus}

La especie varió en su presencia como efecto del año y del sistema de pastoreo empleado sobre la pastura (Cuadro 41) en

Cuadro 40. Efecto del año y el sistema de pastoreo en la presencia del grupo de Cyperáceas en pasturas naturales de la región noreste.

\begin{tabular}{|l|c|}
\hline \multicolumn{1}{|c|}{ Tratamiento } & $\mathbf{P}$ \\
\hline Año & 0,0001 \\
Sistema de pastoreo & 0,2489 \\
1984 & 0,6140 \\
1985 & 0,7409 \\
1988 & 0,0959 \\
$1985-1988$ & 0,2949 \\
\hline
\end{tabular}

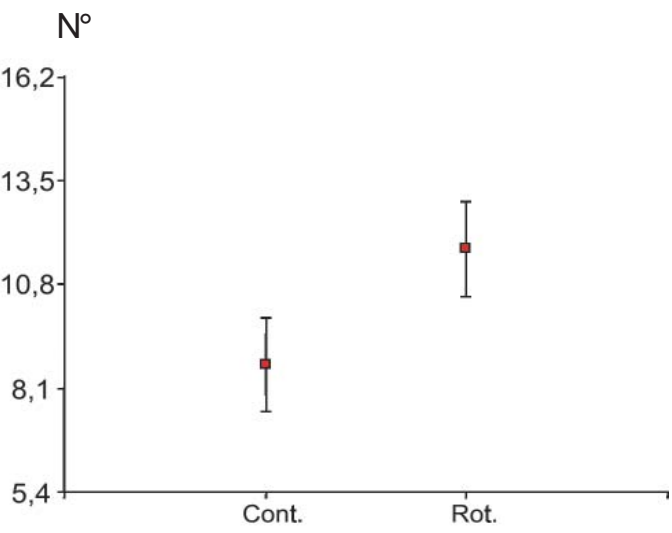

Figura 143. Efecto del sistema de pastoreo, rotativo o contínuo en la presencia de Bothrichloa laguroides en pasturas naturales de la región noreste en el período 1985-1988 (intervalo de confianza $95 \%)$.

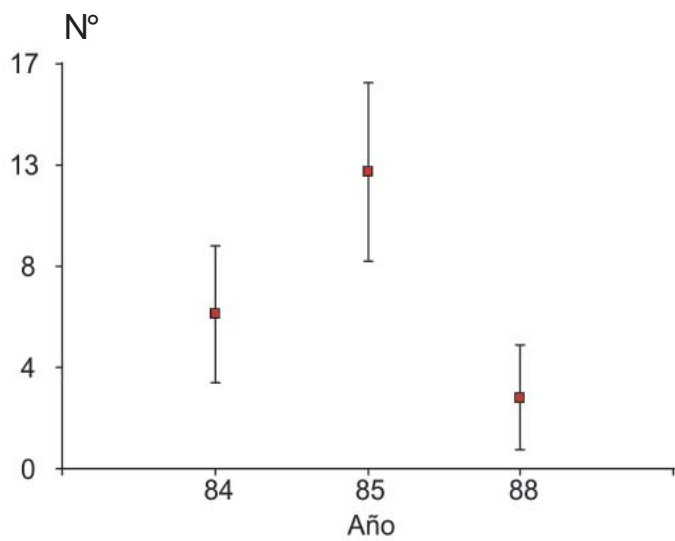

Figura 144. Intervalo de confianza al $95 \%$ para la presencia del grupo de Cyperáceas en pasturas naturales de la región noreste en el período 1984-1988.

Cuadro 41. Efecto del año y el sistema de pastoreo sobre la presencia de Adropogon ternatus en pasturas naturales de la región noreste.

\begin{tabular}{|l|c|}
\hline Tratamiento & P \\
\hline Año & 0,0001 \\
Sistema de pastoreo & 0,0003 \\
1984 & 0,0001 \\
1985 & 0,3242 \\
1988 & 0,0670 \\
\hline
\end{tabular}


general, sin embargo la diferencia debida al sistema se presentó en el año de instalación del experimento (1984) y luego tendió a desaparecer (1985 y 1988).

La presencia de Andropogon ternatus se incrementó significativamente hacia el final del período de evaluación en 1988 (Figura 145).

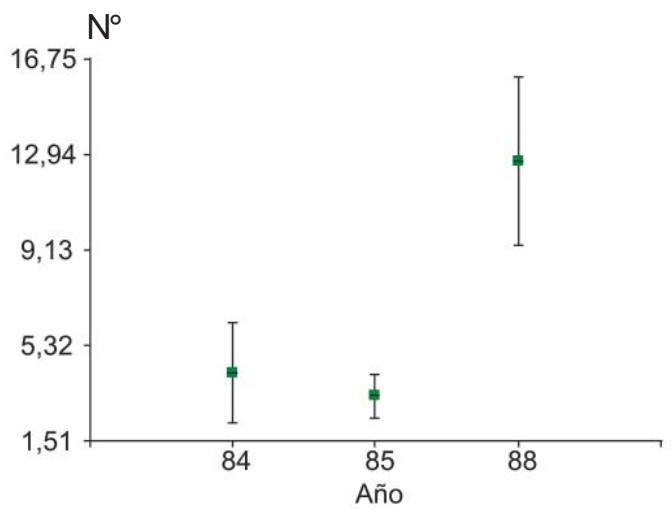

Figura 145. Variación en la presencia de Andropogon ternatus en pasturas naturales de la región noreste en el período 1984-1988 (intervalo de confianza $95 \%$ ).

\section{Panicum milioides}

En el año inicial de los tratamientos experimentales 1984, no se registró la presencia de Panicum milioides, sin embargo a partir del segundo año el sistema de pastoreo afectó significativamente su presencia en la pastura (Cuadro 42).

Cuadro 42. Efecto del año y el sistema de pastoreo sobre la presencia de Panicum milioides en pasturas naturales de la región noreste en el período 1984-1988.

\begin{tabular}{|l|l|}
\hline \multicolumn{1}{|c|}{ Tratamiento } & \multicolumn{1}{|c|}{$\mathbf{P}$} \\
\hline Año & 0,0001 \\
Sistema de pastoreo & 0,0032 \\
1984 & Sin presencia \\
1985 & 0,0100 \\
1988 & 0,1301 \\
$1985-1988$ & 0,0032 \\
\hline
\end{tabular}

En base a los registros de la presencia de la especie en 1985 y 1988 la Figura 146 se muestran los mayores valores registrados para el sistema de pastoreo rotativo comparado con el pastoreo contínuo.

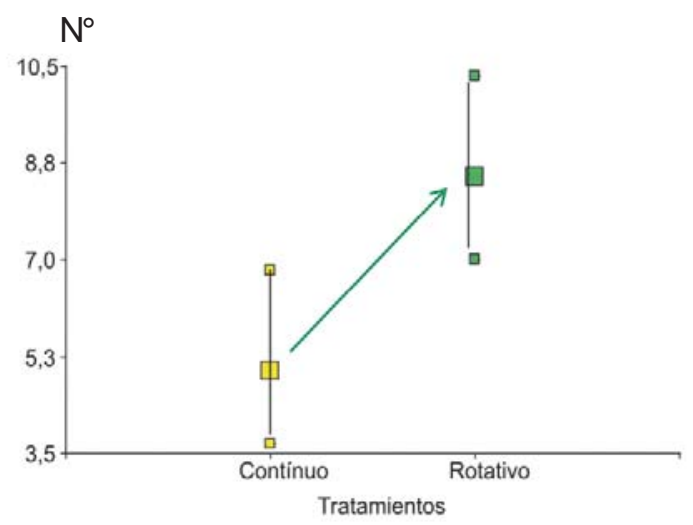

Figura 146. Contenido de Panicum milioides en pasturas naturales de la región noreste egún el sistema de pastoreo contínuo o rotativo en el período 1985-1988 (intervalo de confianza $95 \%)$.

\section{Paspalum dilatatum}

En Paspalun dilatatum se registró una diferencia estadísticamente significativa en su presencia tanto por el efecto del año como por el sistema de pastoreo (Cuadro 43). En el primer año los diferentes tratamientos de pastoreo presentaron valores mayores que al final del ciclo en el año 1988, aunque se mantuvieron estadísticamente significativas las diferencias (Figura 147); en el segundo

Cuadro 43. Efecto del año y el sistema de pastoreo sobre la presencia de Paspalum dilatatum en pasturas naturales de la región noreste en el período 1984-1988.

\begin{tabular}{|l|c|}
\hline \multicolumn{1}{|c|}{ Tratamiento } & $\mathbf{P}$ \\
\hline Año & 0,0113 \\
Sistema de pastoreo & 0,0004 \\
1984 & 0,0113 \\
1985 & 0,2691 \\
1988 & 0,0132 \\
$1985-1988$ & 0,0122 \\
\hline
\end{tabular}




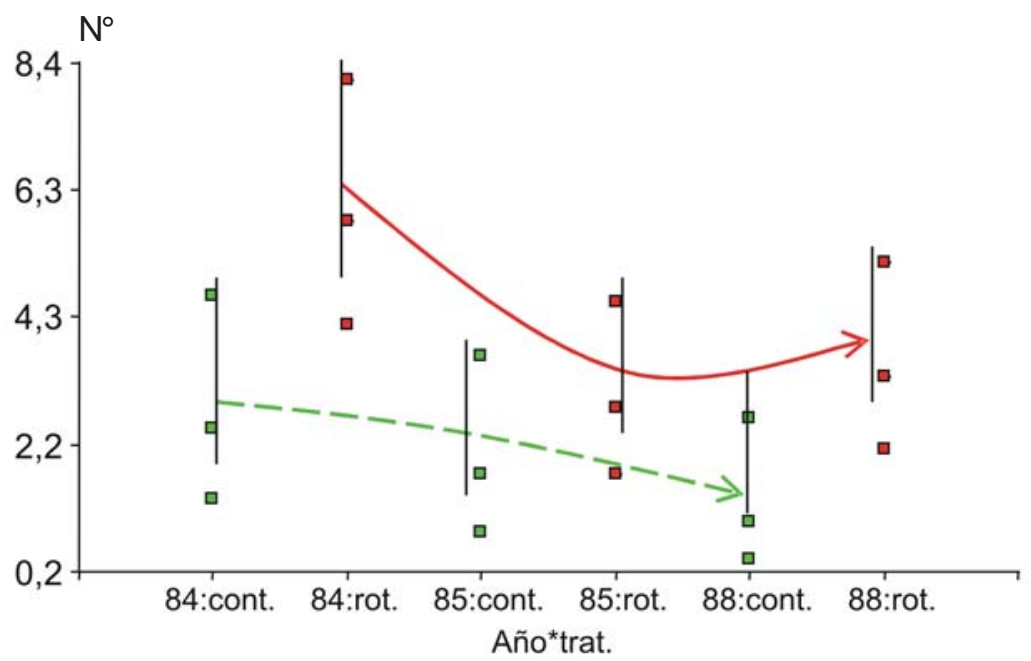

Figura 147. Variación en la presencia de Paspalum dilatatum en pasturas naturales de la región noreste, según el sistema de pastoreo, rotativo o contínuo, en el período 1984-1988.

período de registros el sistema de pastoreo no presentó diferencia significativa entre los tratamientos (Cuadro 43).

Aparentemente Paspalum dilatatum, dentro de estas especies analizadas, fue una de las que presentó menor variación en su presencia en la pastura. Las diferencias originales del incio del período experimental, se mantuvieron relativamente durante el ciclo de registros, indicando que otros facto- res, como topográficos, de suelo, de manejo previo pueden haber determinado este tipo de comportamiento, o la propia modalidd de crecimiento de la especie de presentar una mayor tolerancia o amplitud ecológica en su respuesta a las variables mencionadas comparado con las otras especies analizadas. Los tratamientos con pastoreo rotativo tendieron a registrar un mayor número de presencias de la especie (Figura 148).

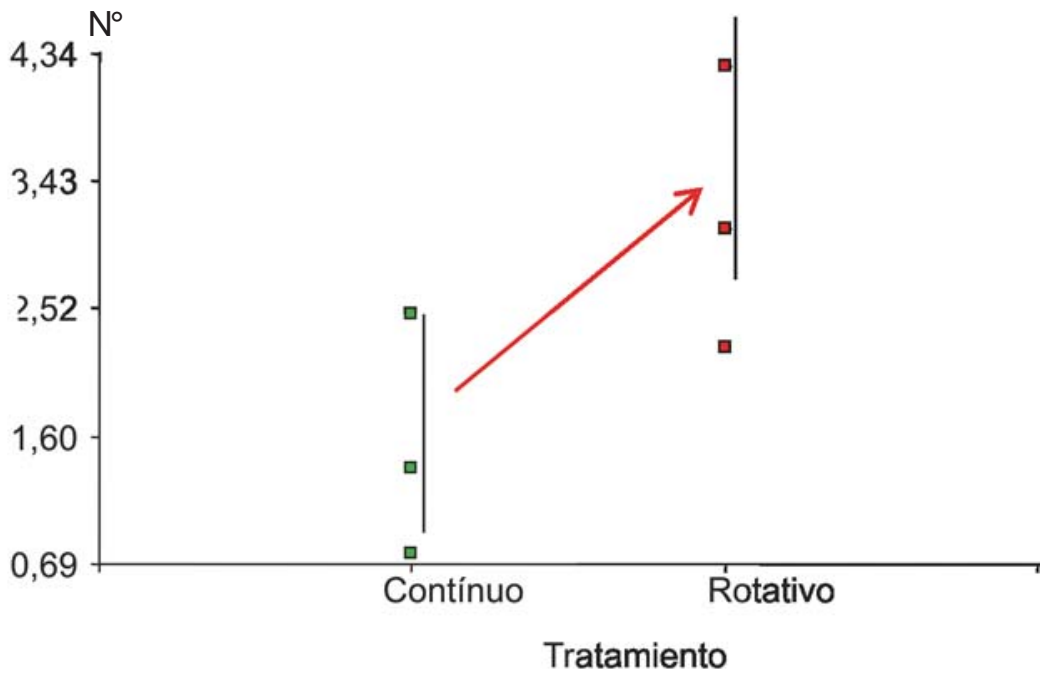

Figura 148. Variación en la presencia de Paspalum dilatatum en pasturas naturales de la región noreste, según el sistema de pastoreo: rotativo o contínuo. 


\section{Agrostis sp.}

Similarmente a los resultados obtenidos con Paspalum dilatatum el contenido de Agrostis sp. en la pastura tendió a disminuír hacia el final del ciclo experimental (Cuadro 44; Figura 149), destacándose un efecto significatvio de los tratamientos. Si bien el efecto del sistema de pastoreo fue estadísticamente significativo en el primer año, los valores indican que la mayor presencia de la especie se registró con pastoreo contínuo (Figura 149), situación que se revirtió en el período experimental 1985-1988, constatándose el incremento de la presencia de la especie en los tratamientos con pastoreo rotativo comparado con el pastoreo contínuo (Figura 150).
Cuadro 44. Efecto del año y el sistema de pastoreo sobre la presencia de Agrostis sp. en pasturas naturales de la región noreste en el período 1984-1988.

\begin{tabular}{|l|c|}
\hline Tratamiento & P \\
\hline Año & 0,0161 \\
Sistema de pastoreo & 0,3275 \\
1984 & 0,0263 \\
1985 & 0,0011 \\
1988 & 0,0319 \\
$1985-1988$ & 0,0001 \\
\hline
\end{tabular}

Figura 149. Variación en la presencia de Agrostis sp.en pasturas naturales de la región noreste según el sistema de pastoreo: rotativo o contínuo, en el período 1984-1988.
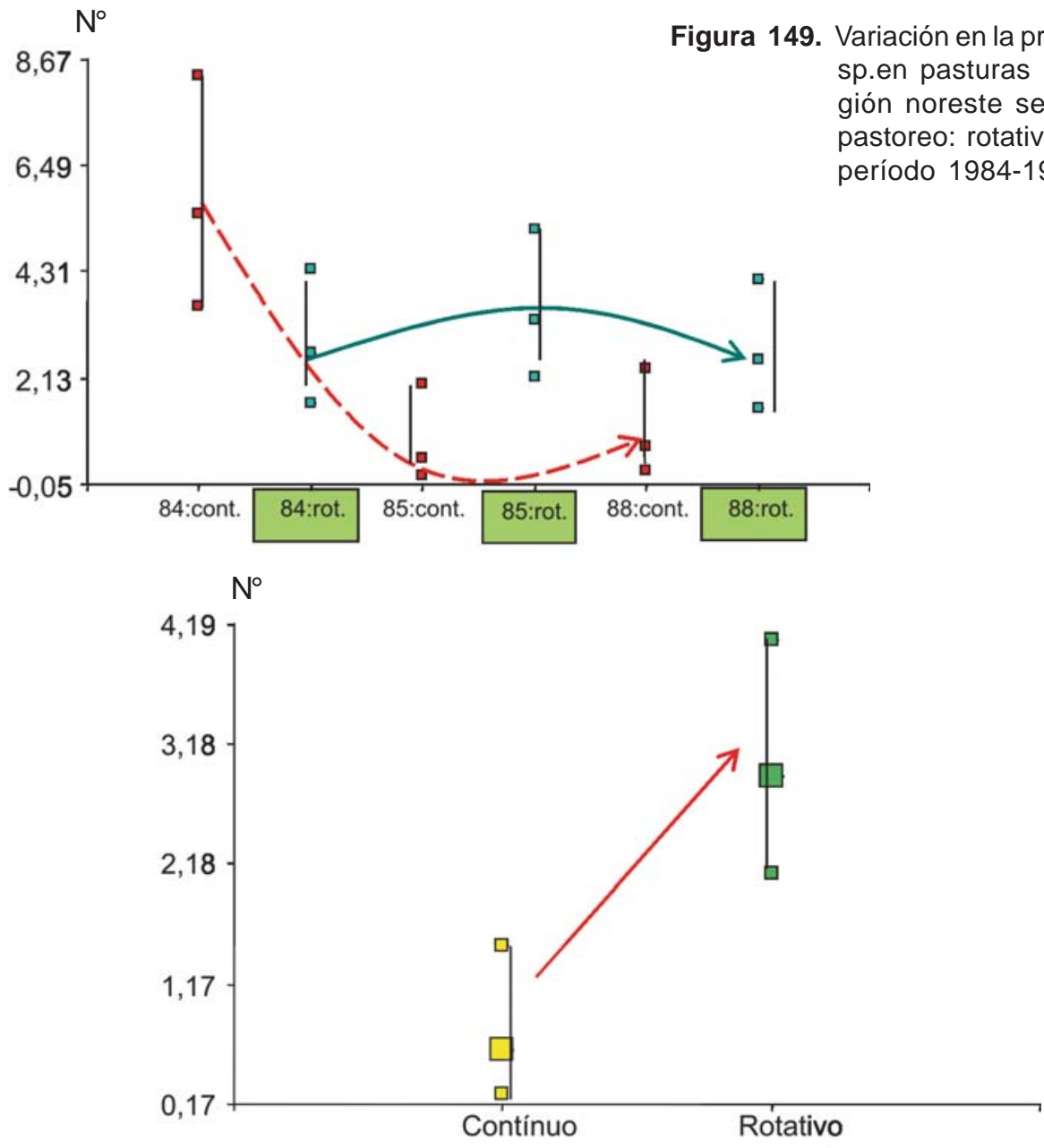

Figura 150. Variación en la presencia de Agrostis sp.en pasturas naturales de la región noreste según el sistema de pastoreo: rotativo o contínuo, en el período 1985-1988. 


\section{Piptochaetium stipoides}

Respecto a Piptochaeitum stipoides los resultados del análisis estadístico indicaron solo un efecto significatvio de acuerdo al año de registro, incrementando su valor hacia el final del período experimental (Cuadro 45; Figura 151) independientemente del sistema de pastoreo aplicado a la pastura.

Cuadro 45. Efecto del año y el sistema de pastoreo sobre la presencia de Piptochaeitum stipoides en pasturas naturales de la región noreste en el período 1984-1988.

\begin{tabular}{|l|c|}
\hline \multicolumn{1}{|c|}{ Tratamiento } & P \\
\hline Año & 0,0420 \\
Sistema de pastoreo & 0,4567 \\
1984 & 0,1904 \\
1985 & 0,2549 \\
1988 & 0,3049 \\
$1985-1988$ & 0,1263 \\
\hline
\end{tabular}

\section{Restos secos}

El contenido de los restos secos en la pastura se incrementó significativaemte ha-
Cuadro 46. Efecto del año y el sistema de pastoreo sobre la presencia de restos secos en pasturas naturales de la región noreste en el período 1984- 1988.

\begin{tabular}{|l|c|}
\hline \multicolumn{1}{|c|}{ Tratamiento } & $\mathbf{P}$ \\
\hline Año & 0,0001 \\
Sistema de pastoreo & 0,9633 \\
1984 & 0,1895 \\
1985 & 0,6052 \\
1988 & 0,1024 \\
$1985-1988$ & 0,3557 \\
\hline
\end{tabular}

cia el año 1998 (Cuadro 46; Figura 152), no observándose un efecto sobre su proporción en el caso de los diferentes sistemas de pastoreo aplicados.

\section{Suelo desnudo}

Contrariamente a lo registrado para el contenido de restos secos de la pastura, la cantidad de suelo desnudo disminuyó en forma estadísticamente significativa hacia el final del período experimental, bajando su registro desde el segundo año de evaluaci/ón (Cuadro 47; Figura 153), independientemente del sistema de pastoreo aplicado.

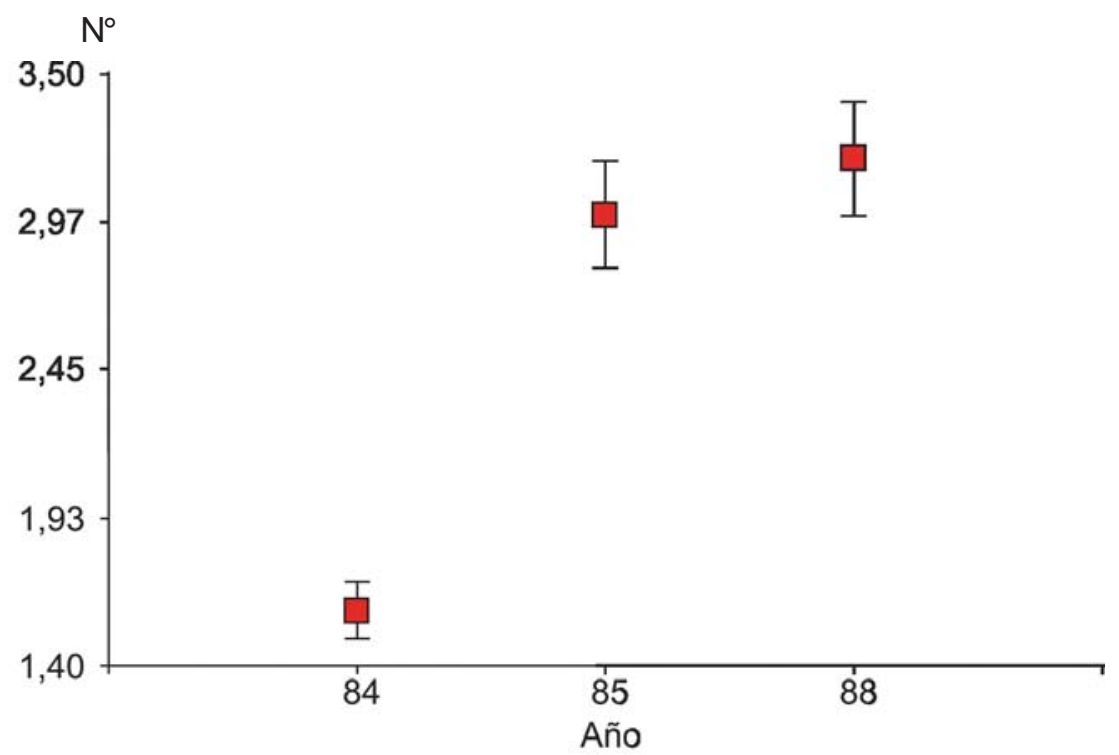

Figura 151. Variación en la presencia de Piptochaeiutm stipoides en pasturas naturales de la región noreste en el período 1985 - 1988. 


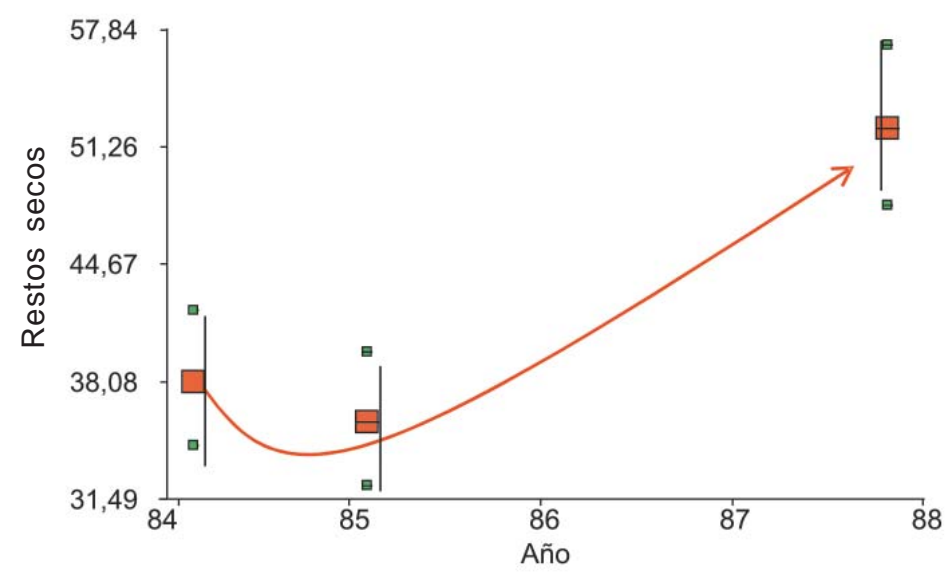

Figura 152. Variación en la presencia de los restos secos presentes en pasturas naturales de la región noreste en el período 1985-1988.

Cuadro 47. Efecto del año y el sistema de pastoreo sobre la presencia del contenido de suelo desnudo en pasturas naturales de la región noreste en el período 1984-1988.

\begin{tabular}{|l|c|}
\hline \multicolumn{1}{|c|}{ Tratamiento } & $\mathbf{P}$ \\
\hline Año & 0,0001 \\
Sistema de pastoreo & 0,1773 \\
1984 & 0,4729 \\
1985 & 0,5556 \\
1988 & 0,1836 \\
$1985-1988$ & 0,1723 \\
\hline
\end{tabular}

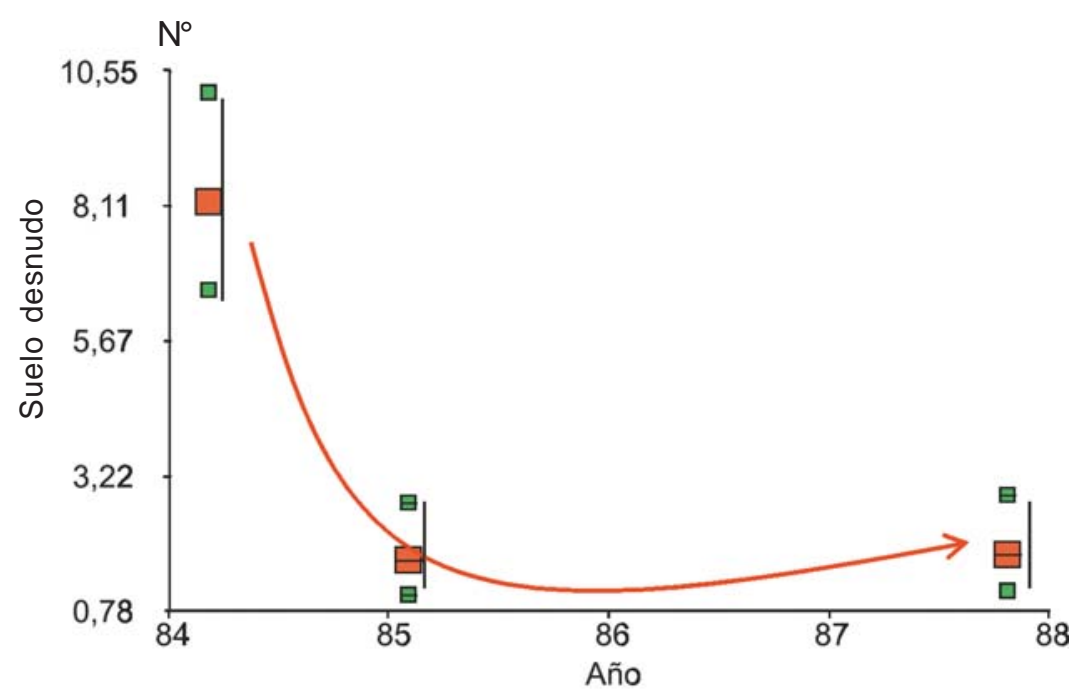

Figura 153. Variación en la presencia de suelo desnudo en pasturas naturales de la región noreste en el período 1985-1988. 


\section{Número de especies y diversidad}

El número de especies total en cada tratamiento varió durante el período experimental siendo los valores relativamente menores al inicio y el final del mismo (Cuadro 48; Figura 154). Se registró un efecto estadísticamente significativo del año de registro, en cambio el sistema de pastoreo no tuvo efecto significativo sobre el número de especies presentes en la pastura.

Cuadro 48.Efecto del año y el sistema de pastoreo en el Indice de Diversidad Shannon-Wiener pasturas naturales de la región noreste en el período 1984-1988.

\begin{tabular}{|c|c|}
\hline Fuente de variación & Probabilidad \\
\hline Año & 0,0024 \\
Tratamientos & 0,3311 \\
Año x Tratamiento & 0,7054 \\
\hline
\end{tabular}

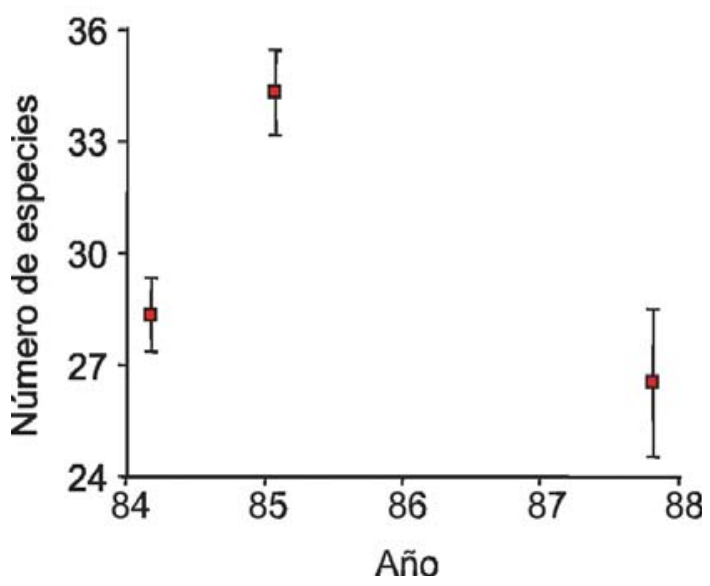

Figura 154. Variación en el número de especies presentes en pasturas naturales de la región noreste en el período 1985-1988.

Desde el punto de vista de la diversidad de especies se observa una respuesta positiva hacia el segundo año de registros, incrementándose el valor del índice de diversidad Shannon-Wiener en el año 1985 respecto al inicio en forma significativa (Cuadro 49; Figura 155), luego hacia el final del ciclo
Cuadro 49. Efecto del año y el sistema de pastoreo en el Indice de Diversidad Shannon-Wiener pasturas naturales de la región noreste en el período 1984-1988.

\begin{tabular}{|l|c|}
\hline Fuente de variación & Probabilidad \\
\hline Año & 0,0182 \\
Tratamientos & 0,7463 \\
Año x Tratamiento & 0,6734 \\
\hline
\end{tabular}

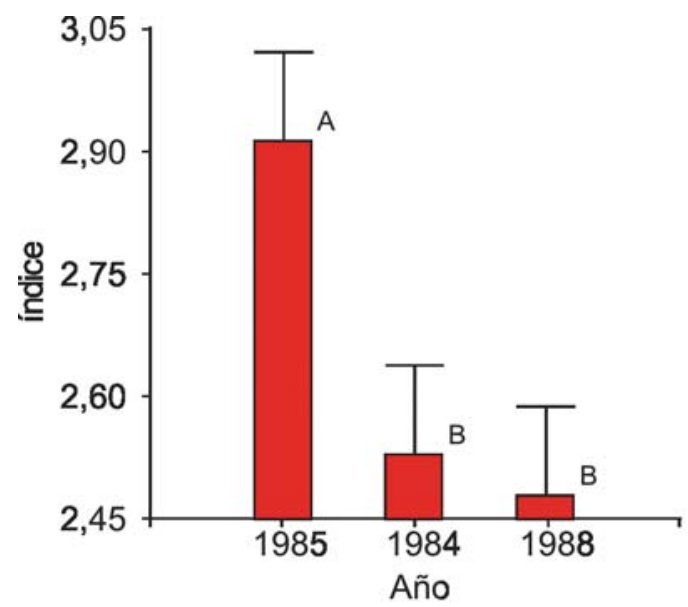

Figura 155. Variación en el Indice de Diversidad Shannon-Wiener en pasturas naturales e la región noreste en el período 1985-1988.

de registros el mismo índice disminuye significativamente en el año 1988.

En el Cuadro 50 se destaca que además del efecto año, hacia la mitad y final del ciclo experimental, los tratamientos con pastoreo rotativo tendieron a presentar valores del índice relativamente mayores que para el caso del pastoreo contínuo.

\section{Homogeneidad de la distribución I Evenness}

En cuanto a la variable que indica la homogeneidad en la distribución de los valores de las especies (evenness), expresada como la relación entre el índice actual/el índice máximo posible de diversidad ocurrió algo similar a lo ocurrido con el índice de diversidad, destacándose una diferencia significativa, en base al DGC - InfoStat 
Cuadro 50.Efecto del año y el sistema de pastoreo en el Indice de Diversidad Shannon-Wiener pasturas naturales de la región noreste en el período 1984-1988.

\begin{tabular}{|cl|c|c|}
\hline Año & & Indice Shannon-Wiener & BAC - inf-sup \\
\hline \multirow{2}{*}{1984} & pastoreo contínuo & 2,77 & $2,56-2,89$ \\
& pastoreo rotativo & 2,74 & $2,48-2,97$ \\
\hline \multirow{2}{*}{1985} & pastoreo contínuo & 3,03 & $2,88-3,12$ \\
& pastoreo rotativo & 3,35 & $3,19-3,49$ \\
\hline \multirow{2}{*}{1988} & pastoreo contínuo & 2,91 & $2,74-2,98$ \\
& pastoreo rotativo & 3,14 & $2,95-3,28$ \\
\hline
\end{tabular}

$(P<0,05)$ con un mayor valor relativo en 1985 respecto a 1984 y 1988 (Cuadro 51; Figura 156).

Tanto el número de especies como el Indice de Diversidad Shannon-Wiener presentaron una alta correlación estadística con el valor de «evenness» (Cuadro 52).

Considerando globalmente los resultados de los análisis de la evoluicón de la composición botánica se puede conluír claramente que hubo una respuesta de I amisma segun el sistema de pastoreo durante el período experimental. Se distinguen dos grupos de especies, rastreras y erectas, donde las primeras decrecieron en su presencia en función del incremento del segundo tipo, así

Cuadro 51. Efecto del año y el sistema de pastoreo en el valor de «evenness» en pasturas naturales de la región noreste en el período 1984-1988.

\begin{tabular}{|l|c|}
\hline Fuente de variación & Probabilidad \\
\hline Año & 0,0624 \\
Tratamientos & 0,9382 \\
Año x Tratamiento & 0,5714 \\
\hline
\end{tabular}

como también evolucionaron concordantemente el valor de suelo desnudo y los restos secos durante el mismo período; es decir hubo una mayor proporción de restos secos y de menor suelo desnudo con la recuperación productiva de la pastura.

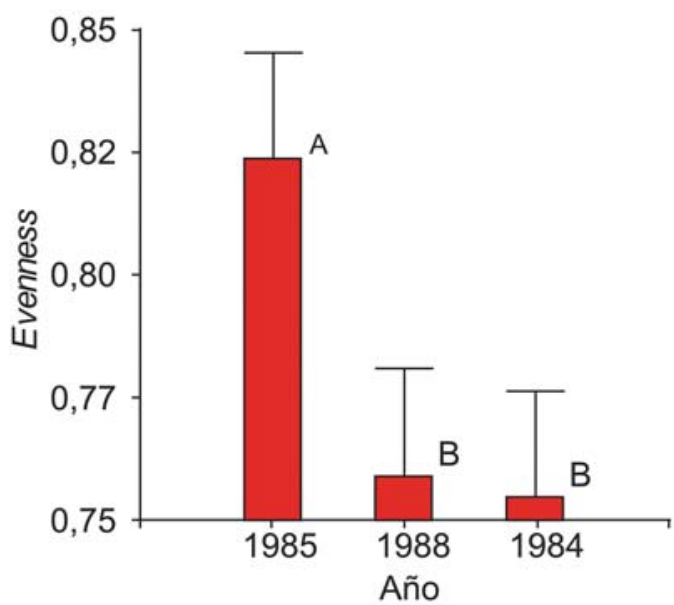

Figura 156. Efecto del año en el valor de «evenness» en pasturas naturales de la región noreste en el período 1984 - 1988.

Cuadro 52. Coeficientes de correlación de Pearson (parte inferior izquierda) y probabilidades (parte superior derecha) entre «evenness», indíce de diversidad Shannon-Wiener y el número de especies presentes en pasturas naturales de la región noreste.

\begin{tabular}{|l|c|c|c|}
\hline & Evenness & Número & Índice \\
\hline Evenness & 1,0000 & $2,8 \mathrm{E}-08$ & 0,0000 \\
Número & 0,8206 & 1,0000 & 0,0000 \\
Índice & 0,9739 & 0,9286 & 1,0000 \\
\hline
\end{tabular}


Los otros tres indicadores, el número de especies, el índice de Shannon-Wiener y la homogeneidad en la distribución de las especeis se incrementaron hacia la mitad del ciclo experimental en el año 1985, con el cambio en el número de especies también se incremento el índice de Shannon-Wiener y la homogeneidad; hacia el final del período (1988) si bien el número de especies tendió a ser similar al valor incial (1984) el cambio principal lo constituyó el tipo de especie presente, siendo una proporción mayor de las especies cespitosas que las rastreras en 1988 comparado con el períod inical (1984).

\section{PRODUCTIVIDAD EN LANA}

Si bien el experimento no fue planificado para realizar un análisis exhaustivo de la productividad animal, algunos registros permitieron analizar la respuesta animal en virtud de la productividad forrajera anual y la carga animal en los tratamientos con pastoreo contínuo de la pastura.

En el Cuadro 53, se observa un efecto estadísticamente significativo tanto del año como de la carga animal, siendo los tratamientos con mayor carga animal los de mayor productividad y los años 2 y 4 los de mayor producción de lana comparado con los años 1 y 3.
Estos resultados podrían interpretarse para el caso del año 2, luego del primer año de inicio de los tratamientos se observó un incremento general en la productiviad; en el caso del tercer año la menor producción de lana puede deberse a que la esquila se realizó prácticamente dos meses antes comparado con los otros años; al mismo tiempo también en los años tercero y cuarto las temperaturas fueron relativametne más bajas que en los otros períodos, reduciendo la producción de forraje. En el año incluso se incrementó la carga animal en el experimento en un $25 \%$ en todos los tratamientos. Durante el período experimental en forma general la mayor carga $(0,8)$ animal produjo significativamente más lana que la caraga menor $(0,6)$ (Cuadro 53).

Similarmente a lo ocurrido con la producción de lana, la ganancia en peso vivo animal varió con el año, pero al mismo tiempo se registró un efecto estadísticamente significativo de la carga aniaml, con valores más altos para la carga más alta comparada con la carga animal más baja por hectárea (Cuadro 54).

Esta diferencia en productividad animal podría explicarse en base a la mayor productividad forrajera de los diferentes tratamientos de la pastura así como a las variaciones anuales; en el año 2 se puede esti-

Cuadro 53. Efecto del año y el efecto de los tratamientos en la produccción de lana por hectárea en pasturas naturales de la región noreste en el período $1984-1988$.

\begin{tabular}{|c|c|c|c|}
\hline \multicolumn{2}{|l|}{ Fuente de variación } & \multicolumn{2}{|c|}{ Probabilidad } \\
\hline \multirow{2}{*}{\multicolumn{2}{|c|}{$\begin{array}{l}\text { Tratamiento } \\
\text { Año }\end{array}$}} & \multicolumn{2}{|c|}{0,0008} \\
\hline & & \multicolumn{2}{|c|}{0,0001} \\
\hline \multicolumn{2}{|c|}{ Contínuo carga $0,8 \quad 21,92 \mathrm{~kg}$ lana ha-1 } & \multirow[b]{2}{*}{ A } & \multirow[b]{2}{*}{ B } \\
\hline Contínuo carga 0,6 & $18,38 \mathrm{~kg}$ lana ha-1 & & \\
\hline Año 2 & 24,45 kg lana ha-1 & \multicolumn{2}{|l|}{ A } \\
\hline Año 4 & $21,40 \mathrm{~kg}$ lana ha ${ }^{-1}$ & \multicolumn{2}{|c|}{$A$} \\
\hline 17,63 & $17,63 \mathrm{~kg}$ lana ha-1 & \multicolumn{2}{|r|}{$\mathrm{B}$} \\
\hline Año 3 & $17,13 \mathrm{~kg}$ lana ha-1 & & B \\
\hline
\end{tabular}

Año 2 - respuesta a manejo

Año 3 - más frío, esquila antes en el tiempo comparado años anteriores

Año 4 - respuesta a incremento de la carga 
mar una respuesta general del área a un manejo más aliviado de la pastura respecto al recibido previamente; en el año 4 se interpreta como una respuesta también al incremento de un $25 \%$ de la carga dada la gran disponibilidad de forraje existente. Por otro lado en el año 3 se interpreta tanto un año relativamente más frío con exceso de forraje así como una época de esquila más temprana (28 octubre 1986) de los animales en relación a la realizada los otros años (30 noviembre 1984, 5 dciembre 1985, 29 setiembre 1987).

Desde el punto de vista del peso vivo animal la respuesta fue similar a la anterior para la producción de lana, con mayores valores, estadísticamente significativos, para la carga alta comparado con la carga baja (Cuadro 54) así como diferentes valores en los distintos años de registro (Figura157).

Como respaldo a la interpretación de los resultados de los párrafos anteriores respecto a la productividad animal, expresados en pro-

Cuadro 54. Efecto del año y la carga animal en la ganancia de peso vivo animal por hectárea en pasturas naturales de la región noreste en el período 1984-1988.

\begin{tabular}{|l|c|}
\hline Fuente de Variación & Probabilidad \\
\hline Año & 0,0003 \\
Carga Animal & 0,0271 \\
\hline
\end{tabular}

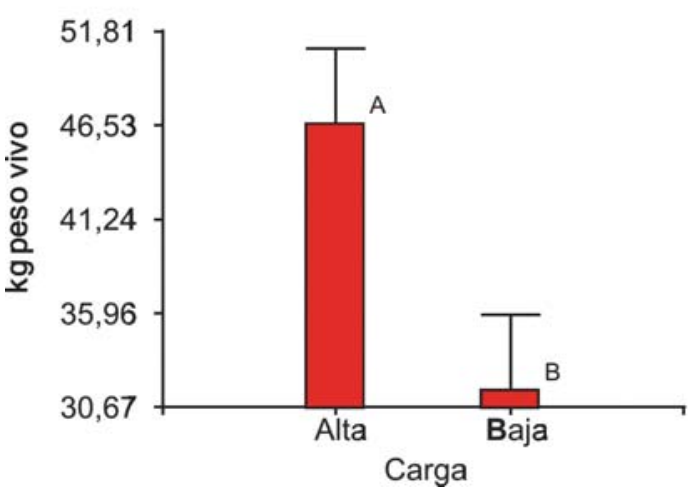

Figura 157. Variación en la ganancia de peso vivo por hectárea en pasturas naturales de la región noreste según la carga animal alta $(0,8)$ y baja $(0,6)$ en el período 1984-1988. ducción de lana y kg. de peso vivo, abajo se presentan los resultados del análisis para la cantidad de forraje disponible según cada ciclo de pastoreo de ocho semanas cada uno, así como del método de pastoreo (Cuadro 55).

Los resultados indican claramente un efecto significativo de los ciclos fundamentalmente asociados a eventos macroclimaticos estacionales, vistos en secciones anteriores y al efecto del sistema de pastoreo mostrando una mayor disponibilidad de forraje en los tratamientos con pastoreo rotativo comparado con el pastoreo contínuo (Cuadro 55).

En la Figura 158 se visualiza la relación entre la oferta de forraje, expresada como los kg MS verde/kg Peso Vivo animal/ha en las abscisas y la ganancia o pérdida de peso vivo animal/ha en las ordenadas, durante 16 ciclos de análisis para la carga animal 0,6 y 0,8 U.G./ha. En dicha figura se puede apreciar que la ganacia animal depende fuertemente de la oferta de forraje, incrementando la ganancia animal con el incremento en la oferta forrajera y al mismo tiempo dicha respuesta es relativamente mayor en la carga 0,8 U.G./ha comparada con la carga de 0,6 U.G./ha.

Del mismo modo en la Figura 159, se observa una respuesta directa de la ganancia o pérdida de peso animal/ha en relación a la tasa de crecimiento de la pastura, aunque con una tendencia curvilínea con los valores medios más altos, probablemenete como consecuencia quizás, de una mayor necesidad de una carga animal mayor por hectárea para consumir la mayor cantidad producida estacionalmente. La carga más alta presentó una pequeña mayor respuesta en producción animal comparado con la carga animal más baja, aunque en los valores más altos de la tasa de crecimiento los valores de ganancia fueron similares para ambas cargas animales.

Si bien la relación entre la oferta de forraje y el peso vivo animal presenta cierto rango de incertidumbre, a lo hora de tomar decisiones en el manejo del rodeo, la misma constituye una herramienta esencial de mucha utilidad. Sin embargo, la estimación de la misma en condiciones de campo requiere 


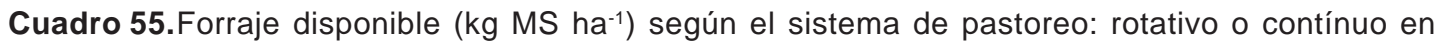
25 ciclos de evaluación en pasturas naturales de la región noreste.

\begin{tabular}{|l|c|c|}
\hline Fuente de variación & Media $\mathbf{( k g}$ MS ha-1) & Probabilidad \\
\hline Tratamiento & & 0,0228 \\
Ciclo & & 0,0001 \\
\hline Tratamiento -4 - pastoreo rotativo & 2.207 & $\mathrm{~A}$ \\
Tratamiento -2 - pastoreo rotativo & 2.173 & $\mathrm{~A}$ \\
Tratamiento -3 - pastoreo rotativo & 2.135 & $\mathrm{~A}$ \\
\hline Tratamiento $-5-$ pastoreo contínuo & 1.983 & \multicolumn{2}{|c|}{$\mathrm{B}$} \\
Tratamiento $-1-$ pastoreo contínuo & 1.859 & \multicolumn{2}{c|}{ B } \\
\hline
\end{tabular}

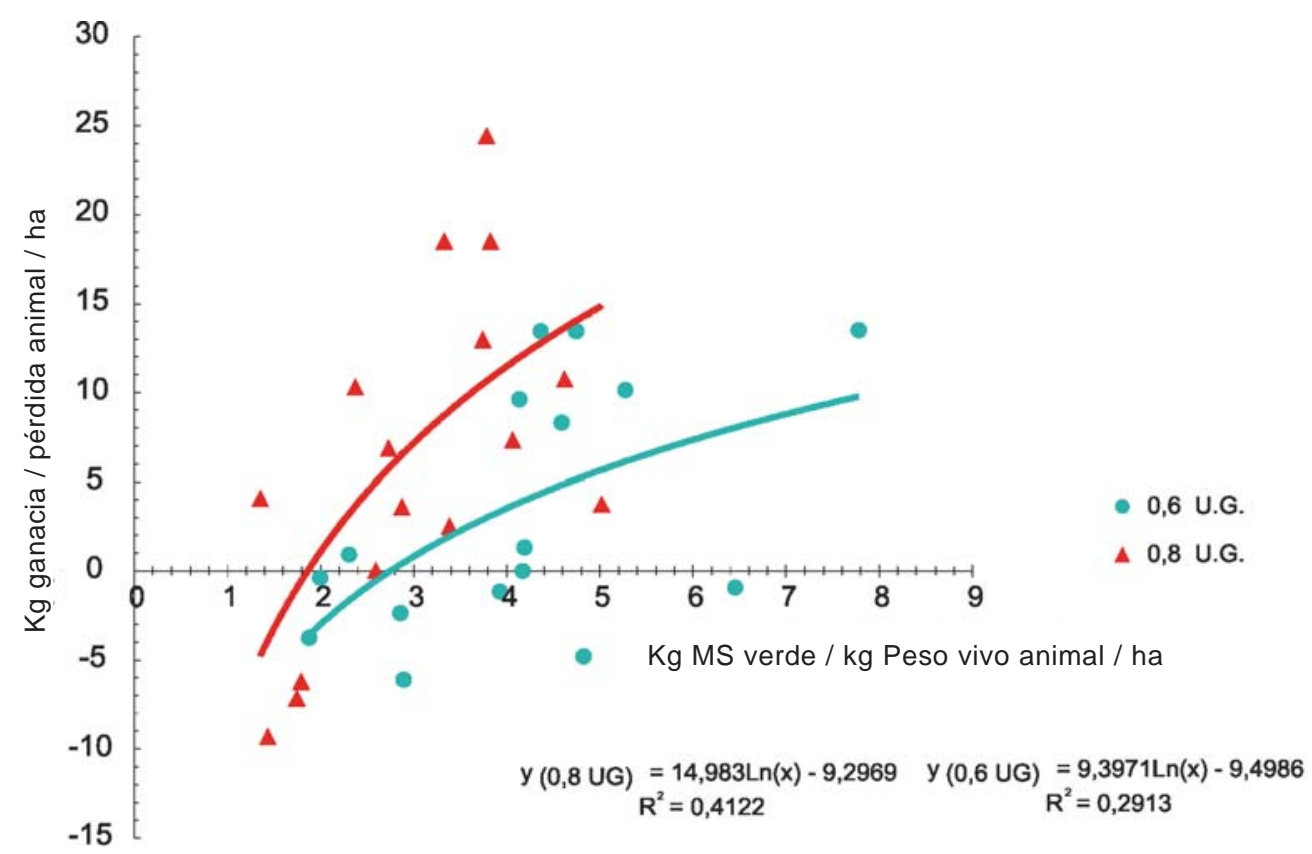

Figura 158. Ganancia o pérdida de kg de peso vivo animal por hectárea según la oferta de forraje verde por hectárea por $\mathrm{kg}$ de peso vivo animal en pasturas naturales de la región noreste con dos niveles de carga animal: 0,6 y 0, 8 UG/ha.

de cierta destreza tanto en la estimación del peso vivo animal como la disponibilidad de forraje en la pastura; en este sentido un elemento auxiliar y de mucha practicidad puede ser el uso de la altura de la pastura como un elemento indicador del forraje disponible por hectárea.

En la Figura 160 se grafica la relación entre altura de la pastura y forraje disponible de los registros realizados durante un año en el área experimental de Caraguatá. En la misma se observa una relación directa y estadísticamente significativa de la cantidad de forraje disponible con la altura, siendo mayor aquella cuando esta es mayor. La importancia de estos resultados por su parte, es que en este mismo período tanto las variables climáticas, el contenido de agua en el suelo, así como la productividad de la pastura han oxilado entre los valores máximo de sus rangos promedios, lo cual valoriza el uso de esta herramienta en condiciones reales de campo. Los resultados indican que con una altura de la pastura en el orden de los 5-6 cm tenemos una alta probabilidad de tener forraje disponible en el orden de los 


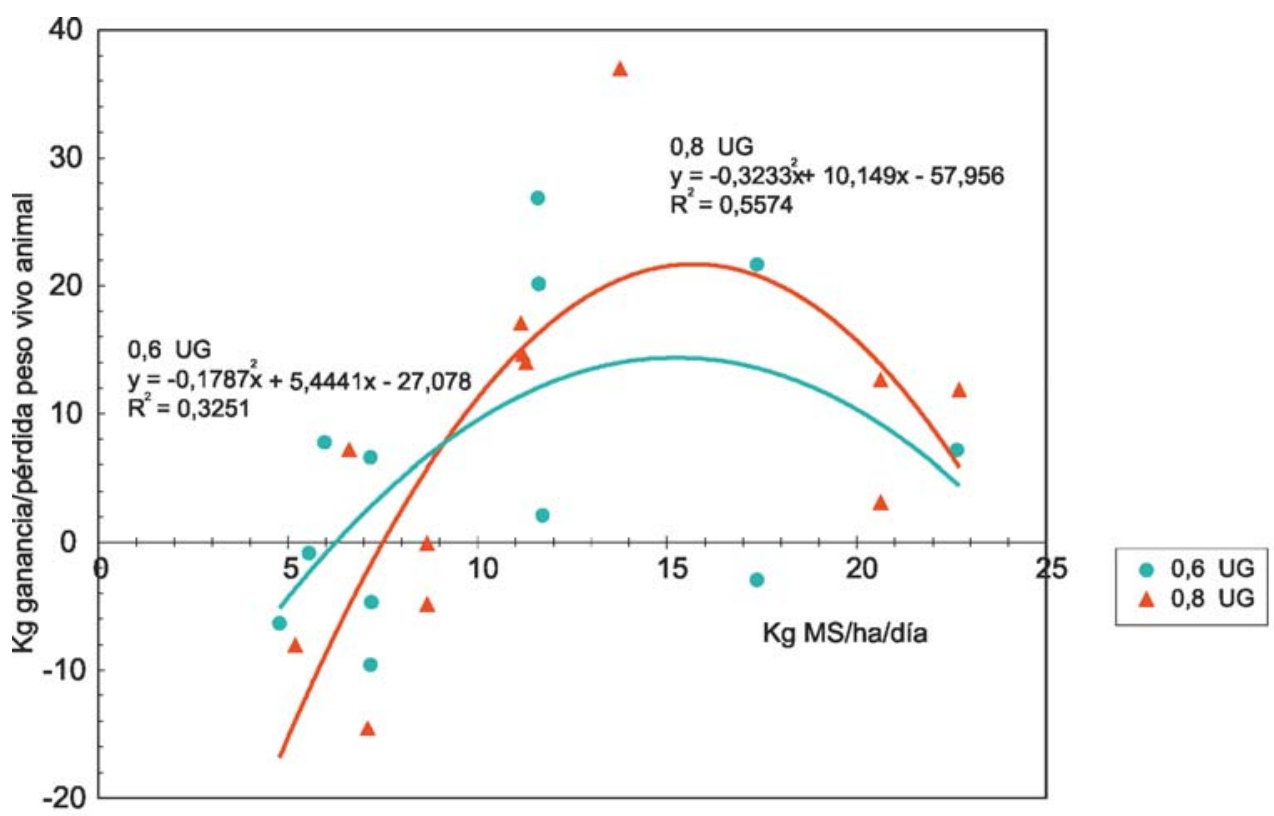

Figura 159. Ganancia o pérdida de kg de peso vivo animal por hectárea según la tasa de crecimiento de la pastura en $\mathrm{kg}$ MS ha día en pasturas naturales de la región noreste con dos niveles de carga animal: 0,6 y 0, 8 UG/ha.

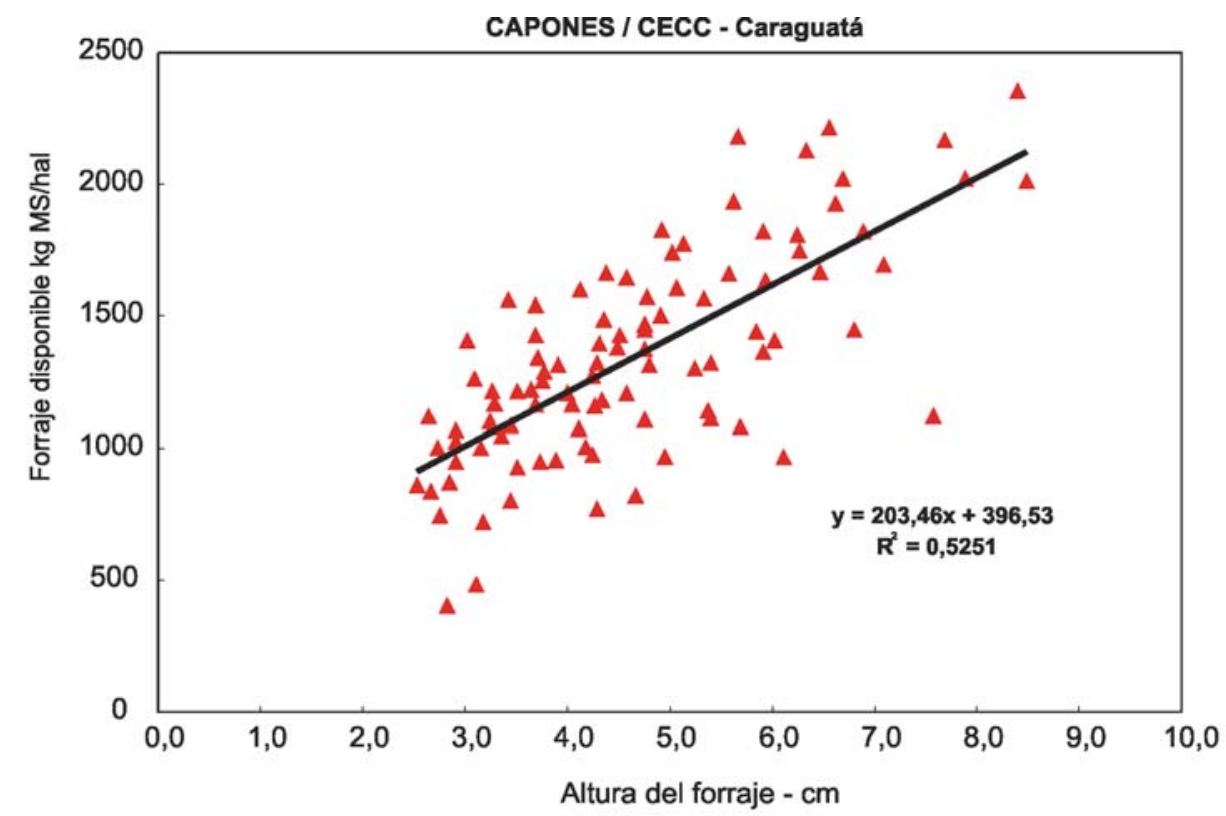

Figura 160. Forraje disonible en $\mathrm{kg} \mathrm{MS} \mathrm{ha}^{-1}$ en relación a la altura del forraje disponible $(\mathrm{cm})$ en pasturas naturales de la región noreste. 


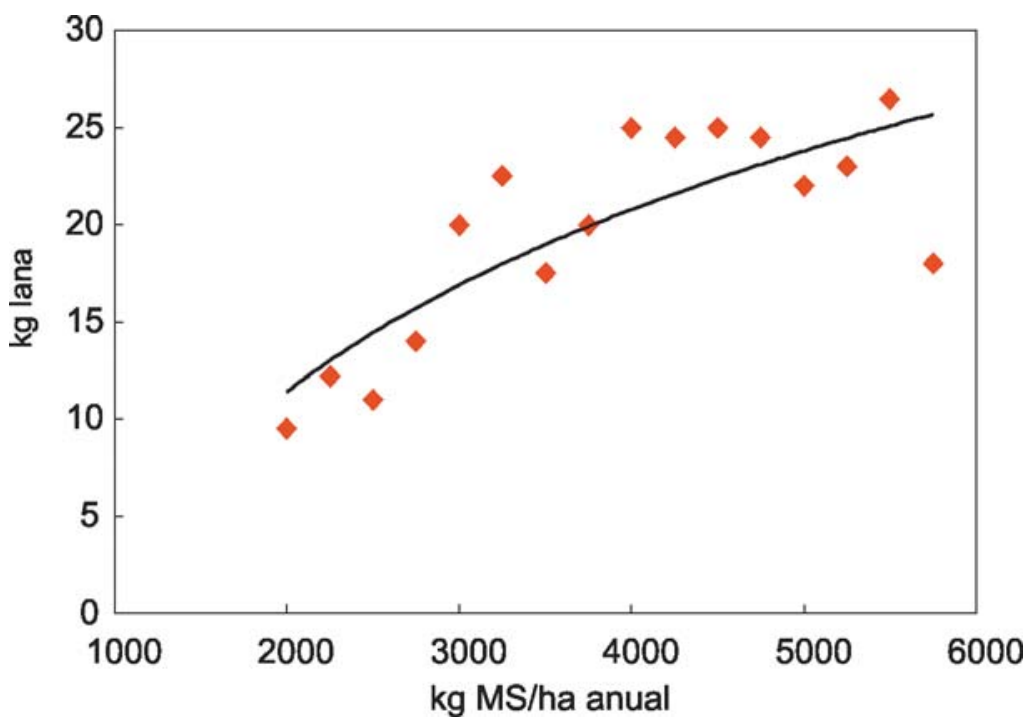

Figura 161. Producción de lana según la producción de Materia Seca - Caraguatá.

$1.500 \mathrm{~kg} \mathrm{MS} / \mathrm{ha}$ determinando una oferta de $5 \mathrm{~kg} \mathrm{MS} / \mathrm{kg}$ P.Vivo animal/ha para animales de $300 \mathrm{~kg}$ de peso vivo y generando una performance animal con balance positivo (ver Figura 158).

La producción de lana por hectárea varió de acuerdo a la evolución de la pastura y la carga animal; en la Figura 161 se ve la relación entre la producción de lana y la producción de forraje anual.

\section{IMPLICANCIAS PRÁCTICAS DE ÉSTOS RESULTADOS}

Uno de los resultados más importantes de este experimento consiste en la rápida resuesta experimentada por la pastura natural al manejo dle pastoreo así como la carga animal o presión de pastoreo. Si bien esta respuesta se consolidó en cuatro años de evaluación, la misma siempre estuvo modulada por los eventos climáticos estacionales y sus variaciones interanuales.
De los cambios ocurridos en la pastura surgen que determinados criterios pueden ser utilizados como elementos diagnóstico de las mismas, tanto en su estado como en su evolución; estos elementos son la proporción de los diferentes tipos vegetativos de las especies forrajeras presetnes, la identificación de especies que se pueden utilizar como indicadoras de la presión de pastoreo, el número de especies y el índice de diversidad Shannon-Wiener.

Debe destarcse que los cambios operados en la pastura natural no solo tuvieron impacto sobre la estructura propia de la misma, sino que también hubieron efectos significativos sobre la productividad del sistema en su conjunto.

Un último corolario práctico para el manejo de las pasturas naturales es que la disponibilidad de forraje puede calcularse tanto utilizando una balanza, en forma visual o por la altura del forraje, contribuyendo a una mejor estimación de la carga animal o presión de pastoreo. 


\section{APÉNDICE}

Cuadro 1. Orden de mayor a menor en la presencia de las primeras 12 especies en los suelos arenosos y arcillosos en 10 comunidades de la región noreste

\section{Suelo arenoso}

\begin{tabular}{|l|l|l|l|l|}
\hline $\mathbf{s p .}$ & \multicolumn{1}{|c|}{ a-1 } & \multicolumn{1}{c|}{ a-2 } & \multicolumn{1}{c|}{ a-4 } & a-5 \\
\hline $\mathbf{1}$ & P. notatum & A. lateralis & Cynodon & Cynodon \\
$\mathbf{2}$ & T. polym. & P. notatum & P. notatum & P. nicorae \\
$\mathbf{3}$ & Pip. mont. & Dichondra & P. nicorae & P. notatum \\
$\mathbf{4}$ & Chev. sarm. & Cyper. & Ax. affinis & Dichondra \\
$\mathbf{5}$ & A. lateralis & Pip. mont. & Cyper. & Cyper. \\
$\mathbf{6}$ & Cyper. & P. nicorae & Pip. mont. & Ax. affinis \\
$\mathbf{7}$ & Coelorachis & Juncus & P. milioides & Juncus \\
$\mathbf{8}$ & Ax. affinis & Coelorachis & Juncus & Vulpia \\
$\mathbf{9}$ & Ax. argent. & Ax. affinis & Setaria gen. & Pip. mont. \\
$\mathbf{1 0}$ & P. sabulorum & P. milioides & Cerastium & P. milioides \\
$\mathbf{1 1}$ & P. milioides & P. sabulorum & E. neesii & Setaria gen. \\
$\mathbf{1 2}$ & P. nicorae & Vernonia & P. plicat. & Agrostis \\
$\%$ recubrim. & 0,79 & 0,82 & 0,96 & 0,98 \\
\hline
\end{tabular}

\section{Suelo arcilloso}

\begin{tabular}{|c|c|c|c|c|c|c|}
\hline sp. & b-3 & b-6 & b-7 & b-8 & b-9 & b-10 \\
\hline 1 & P. notatum & P. notatum & Bot. lag. & P. notatum & A. ternatus & Chev. sarm. \\
\hline 2 & Cyper. & Cyper. & Chev. sarm. & Bot. lag. & S. setigera & Pip. stip. \\
\hline 3 & Dichondra & Lolium & Pip. mont. & Cyper. & P. notatum & S. setigera \\
\hline 4 & Evolvulus & Bot. lag. & P. notatum & Coelorachis & Coelorachis & Cyper. \\
\hline 5 & Danthonia & Coelorachis & Setaria gen. & S. setigera & Bot. lag. & Bot. lag. \\
\hline 6 & Micropsis & Setaria gen. & Cyper. & A. ternatus & Cyper. & Coelorachis \\
\hline 7 & Pip. mont. & S. setigera & Sp. plat. & Chev. sarm. & Sp. plat. & Aspilia \\
\hline 8 & Bot. lag. & Dichondra & Vulpia & Pip. mont. & Pip. stip. & Pip. bicolor \\
\hline 9 & Chev. sarm. & Cerastium & T. polym. & S. pauciciliata & A. murina & P. dilat. \\
\hline 10 & A. venustula & P. dilat. & S. setigera & Dichondra & Pip. mont. & Eragrostis sp. \\
\hline 11 & E. neesii & Pip. mont. & Coelorachis & Ax. affinis & Aspilia & Pip. mont. \\
\hline 12 & Coelorachis & Juncus & Dichondra & P. dilat. & P. dilat. & Juncus \\
\hline$\%$ recubrim. & 0,87 & 0,82 & 0,76 & 0,74 & 0,84 & 0,89 \\
\hline
\end{tabular}


Cuadro 2. Tasa de crecimiento estacional en 10 potreros pastoreados con capones durante $15 \mathrm{c}$ iclos de crecimiento en el período 1984-1988 en Suelos de la Unidad Cuchilla de Caraguatá en la región noreste.

\begin{tabular}{|c|c|c|c|c|c|c|c|c|}
\hline Ciclo & Medias & $\mathbf{n}$ & E.E. & & & & & \\
\hline 8 & 24,59 & 10 & 1,18 & $A$ & & & & \\
\hline 7 & 20,85 & 10 & 1,18 & & B & & & \\
\hline 15 & 19,46 & 10 & 1,18 & & $B$ & & & \\
\hline 10 & 18,68 & 10 & 1,18 & & $B$ & & & \\
\hline 12 & 18,21 & 10 & 1,18 & & B & & & \\
\hline 14 & 16,03 & 10 & 1,18 & & & C & & \\
\hline 11 & 15,79 & 10 & 1,18 & & & C & & \\
\hline 3 & 14,40 & 10 & 1,18 & & & C & & \\
\hline 6 & 12,21 & 10 & 1,18 & & & & $D$ & \\
\hline 5 & 12,10 & 10 & 1,18 & & & & D & \\
\hline 13 & 11,89 & 10 & 1,18 & & & & D & \\
\hline 9 & 9,42 & 10 & 1,18 & & & & D & \\
\hline 4 & 7,34 & 10 & 1,18 & & & & & $E$ \\
\hline 2 & 6,28 & 10 & 1,18 & & & & & $E$ \\
\hline 1 & 5,09 & 10 & 1,18 & & & & & $E$ \\
\hline
\end{tabular}

Medias con una letra común no son significativamente diferentes $(p<=0,05)$.

Test: DGC Alfa $=0,05$.

\section{BIBLIOGRAFÍA}

ALLEGRI M.; FORMOSO, F. 1978. Región noreste. In: Avances en Pasturas IV. CIAAB. Miscelánea No. 18. pp.: 83-110.

ALTAMIRANO, A.; DA SILVA, H.; DURÁN, A.; ECHEVARRÍA, D.; PUENTES, R. 1976. Clasificación de suelos. Carta de reconocimiento de suelos del Uruguay. Dirección de suelos y fertilizantes. Ministerio de Agricultura y Pesca. Montevideo. Uruguay. Tomo I.

ALVAREZ, C.; CAYSSIALS, R.; MOLFINO, J. H. 1990. Estimación del almacenaje de agua en las tierras de Uruguay. In: II Seminario Nacional de Campo Natural. Tacuarembó. Uruguay. Ed. Hemisferio Sur. pp.: 63-75.

BERRETA, E. J.; DO NASCIMENTO, D. 1991. Glosario estructurado de términos sobre pasturas y producción animal. Español-portugués. Diálogo XXXII. IICA.Montevideo. Uruguay. $16 \mathrm{p}$.

CARÁMBULA, M. 1978. Producción de pasturas. In: Pasturas IV. Miscelánea No. 18. Centro Investigaciones Agrícolas A. Boerger. MAP. pp.: 5-7.
CASTRO, E. 1979. Pasturas naturales. In: 2da. Jornada Ganadera de Suelos Arenosos. Estación Experimental del Norte. CIAAB. Tacuarembó. 40 p.

COLL, J. 1991. Producción de semilla de Paspalum dilatatum. INIA. Serie Técnica No. 4. $20 \mathrm{p}$.

DI RIENZO, J.A.; CASANOVES, F.; BALZARINI, M.G.; GONZALEZ, L.; TABLADA, M.; ROBLEDO, C.W. InfoStat versión 2011. Grupo InfoStat, FCA, Universidad Nacional de Córdoba, Argentina. URL http:// www.infostat.com.ar

FALCO, L. 1987. Departamento de Tacuarembó, Fotoplano F-14. Dirección General de Recursoso Naturales Renovables. Dirección de Suelos. MGAP. 50 p.

FORMOSO, F.; ALLEGRI, M. 1980. Leguminosas en le región noreste. Miscelánea No. 21. CIAAB. Estación Experimental Agropecuaria del Norte. 27 p.

FoRMoso, F.; ALLEGRI, M. 1983. Producción de pasturas en suelos del área Caraguatá -Las Toscas. In: 1ra. Jornada Agrícola-Ganadera de Caraguatá. Estación 
Experimental del Norte. CIAAB. Tacua rembó. $136 \mathrm{p}$.

FORMOSO, F.; ALLEGRI, M. 1984. Estudio comparativo de gramíneas perennes invernales en suelos arenosos, pesados e hidromórficos. In: Gramíneas perennes en la región noreste. Miscelánea No. 56. pp.: 1-18.

GALLINAL, J. P.; BERGALLI, L. U.; CAMPAL, E. F.; ARAGONE, L.; ROSENGURTT, B. 1938. Estudios sobre praderas naturales del Uruguay. Primera Contribución. Imp. Germano Uruguaya Montevideo. $208 \mathrm{p}$.

GODRON, M.; DAGET, G.; LONG, CH.; SAUVAGE, L.; EMBERGER, E.; LE FLOCH, J.P.; WACQUANT, J. 1983. Code pour le relevé méthodique de la végétation et du milieu. Ëditions du Centre National de la Recherche Scientifique. París. France. 292 p.

IICA. 1978. Recursos Naturales. In: Estudio socioeconómico de la agricultura en la región noreste. Montevideo. Tomo II. Instituto Interamericano de Cooperación para la Agricultura. Fondo Simón Bolívar. Ministerio de Agricultura y Pesca.

IZAGUIRRE P.; BEYHAUT, E. 1997. Las leguminosas en Uruguay y regiones vecinas. Parte 1. Papilionoideae. Ed. Hemisferio Sur. Montevideo. 548 p.

KENT, M.; COKER, P. 1992. Vegetation Description and Analysis. A Practical Approach. John Wiley \& Sons Ltd. England. 363 p.

MVSP. Multivariate Statistical Package. 2004. Version 3.13. Kovach Computing Services.

OLMOS, F. 1983. La pastura natural de los suelos arenosos y sus posibilidades de mejoramiento actual. In: 1ra. Jornada Agrícola-Ganadera de Caraguatá. Estación Experimental del Norte. CIAAB. Tacuarembó. $136 \mathrm{p}$.

OLMOS, F. 1990 a. Caracterización de comunidades naturales en la región noreste. In: II Seminario Nacional de Campo Natural. Tacuarembó. Uruguay. Ed. Hemisferio Sur. pp.: 3-9.
OLMOS, F. 1990 b. Utilización de pasturas con animales: avances y propuestas. In: II Seminario Nacional de Campo Natural. Tacuarembó. Uruguay. Ed. Hemisferio Sur. pp.: 35-48.

OLMOS, F. 1997 a. La productividad de pasturas en relación a los principalesparámetros del clima. In: Efectos climáticos sobre la productividad de pasturas en la región noreste. Boletín de Divulgación No. 64. INIA Tacuarembó. pp.: 1-12.

OLMOS F. 1997 b. Desarrollo agropecuario y agro-industrial en Tacuarembó. In: Tacuarembó de Puertas Abiertas. Eds. R. Esquivo y R. Zilli. Editorial Prisma. pp.: 79-94.

OLMOS, F.; CORSI, W. 1982. Caracterización climática de la región noreste. In.: Reunión Técnica de cultivos de verano. Centro Investigaciones Agrícolas A. Boerger. Estación Experimental del Norte.

OLMOS, F.; GODRON, M. 1990. Relevamiento fito-ecológico en el noreste uruguayo. In: II Seminario Nacional de Campo Natural. Tacuarembó. Uruguay. Ed. Hemisferio Sur. pp.: 278-288.

PITTAlugA, O.; ALLEGRI, M.; Formoso, F. 1978. Utilización de pasturas con bovinos en la región noreste. Unidades Tacuarembó y Fraile Muerto. In: Avances en Pasturas IV. CIAAB. Miscelánea No. 18. pp.: 193-203.

PITTALUGA, O. 1983. Alternativas de intensificación en la producción de carne. In: 1ra. ornada Agrícola-Ganadera de Caraguatá. Estación Experimental del Norte. CIAAB. Tacuarembó. 136 p.

ROSENGURTT B. 1943. Estudios sobre praderas naturales del Uruguay. 3ra. Contribución. Casa Barreiro y Ramos. Montevideo. $281 \mathrm{p}$.

ROSENGURTT B. 1979. Tabla comportamiento de las especies de plantas de campos naturales en el Uruguay. Dirección General Extensión Universitaria. Facultad de Agronomía. Universidad de la Republica. Montevideo. Uruguay. $86 \mathrm{p}$.

ROSENGURTT B., B. R. ARRILLAGA, B. SIERRA DE SORIANO. 1960. Revista de la Facultad de Agronomía No. 47. 164 p. 



\section{EL CLIMA Y SUS IMPACTOS Sensibilidad de los ecosistemas naturales}

\section{CONCEPTOS GENERALES SOBRE EL CLIMA REGIONAL}

El clima local en la región noreste del país, se explica en forma general por el efecto de la acción de variables que actúan a diferentes escalas; algunas de estas variables operan a escala planetaria mientras que otras son el resultado de interacciones con el relieve local así como la posición latitudinal en la que se encuentra el país.

De acuerdo a la latitud, Uruguay se encuentra en la región donde principalmente llegan los vientos cálidos y húmedos desde la zona tropical a través del mecanismo de las células de Hadley $\left(35^{\circ}\right)$, siendo conducidas estas masas de aire (de origen amazónico) fundamentalmente través del borde occidental del centro de alta presión del Brasil (fuerzas de Coriollis) y la cordillera de Los Andes (Figura 1). Esta acción continental se traduce en la llegada de la corriente en chorro que principalmente aporta humedad al sur del continente pasando por encima del territorio boliviano (Vera et al., 2006 a); la intensidad y variaciones interanuales de estos aportes están condicionadas por la presencia de sistemas de alta o baja presión en la zona sureste de Brasil (Carvalho et al., 2004).

Esta dinámica estacional, anual e interanual se ve afectada con diversa intensidad por otros efectos en otras regiones que repercuten localmente como la variabilidad en la presencia de frentes fríos desde el sur de América del Sur (Linacre y Geerts, 1997), la dinámica del ENSO (EI Niño Southern OsciIlation) en el Océano Pacífico Ecuatorial (Allan et al., 1996), la Madden-Julian OsciIlation (MJO) (Shimizu y Ambrizzi, 2014; Vera, 2014), el Océano Atlántico Ecuatorial o aún el posible efecto invernadero que se genere a escala planetaria en las próximas décadas (IPCC, 2007). La llegada de vientos fríos más o menos secos desde la región patagónica son el resultado tanto del centro de alta presión del océano Pacífico como de

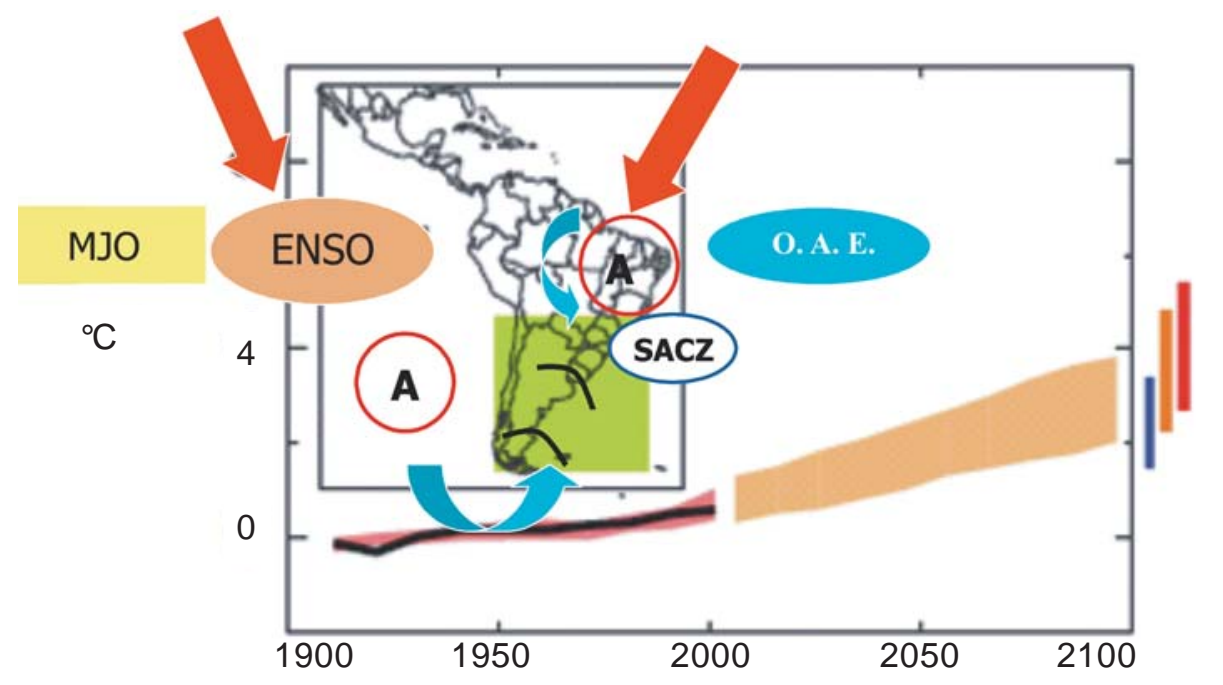

Figura 1. Dinámica atmosférica en América del Sur y su relación con eventos extra regionales en el hipotético escenario de cambio climático hacia el año 2100 (IPCC - 2007). 
la propia cordillera de Los Andes. Este centro de alta presión si bien originalmente aporta aire cargado de humedad, mayoritariamente la misma cae como lluvia en el lado este de la cordillera generando un clima frío y muy húmedo, siendo el lado este de la cordillera caracterizado por un clima árido frío y relativamente seco.

En los últimos años se consolidado la información científica entorno al fenómeno del El Niño, evento este que se manifiesta inicialmente en el $\mathrm{O}$. Pacífico pero que tiene repercusiones en muchas regiones del planeta. En la literatura el fenómeno es conocido como ENSO (EI Niño Southern Oscilation) y se refiere a las variaciones en la temperatura superficial de la superficie del Océano Pacífico principalmente en la zona ecuatorial (Figura 2). En la figura se describen las condiciones de la temperatura $\left({ }^{\circ} \mathrm{C}\right)$ en el Océano Pacífico para los eventos de El Niño y La Niña y sus respectivos desvíos de los valores respecto a los valores medios (C.P.C., 2013). En el caso de El Niño en la región ecuatorial este del $\mathrm{O}$. Pacífico se incrementa la temperatura del océano, en cambio cuando los episodios corresponden a la fase de La Niña la temperatura en esta región se encuentra relativamente más baja.

Para nuestra región la presencia del fenómeno de El Niño (temperaturas más calidas en la superficie del océano) se encuentra asociado a períodos con excesos de lluvias respecto al promedio, en cambio el fenómeno de La Niña (temperaturas más frías en la superficie del océano), para nuestras condiciones, se encuentra asociado principalmente con períodos de lluvias proporcionalmente menores a los valores promedios (Allan et al., 1996).

En los años con presencia del fenómeno del Niño, se incrementa el aporte de masas de aire cálido cargadas de humedad al sistema amazónico desde el este del Océano Pacífico, el cual termina aportando importantes masas de aire húmedo hacia el sur de América del Sur; lo contrario sucede con la presencia del fenómeno de La Niña, siendo que los vientos en el Pacifico Ecuatorial se dirigen hacia el oeste habiendo un menor aporte de aire cálido y húmedo hacia el sistema amazónico lo que se traduce con menor aporte de humedad hacia el sur de América del Sur. En menor medida se conocen

\section{Temperatura oceánica $\left({ }^{\circ} \mathrm{C}\right)$}

El Niño

Enero-marzo 1998

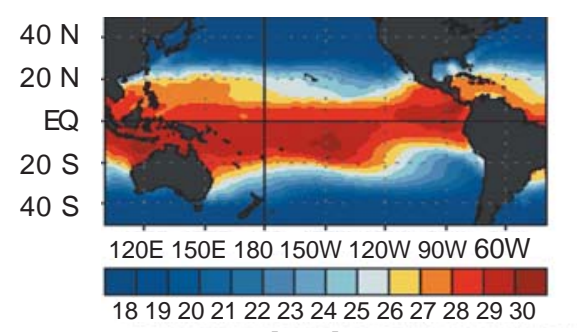

La Niña

Enero-marzo 1989

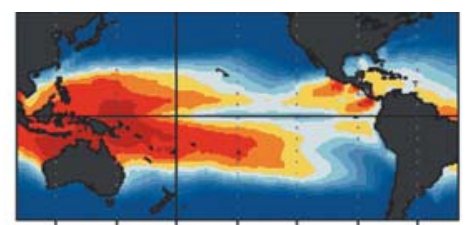

120E 150E 180 150W 120W 90W 60W
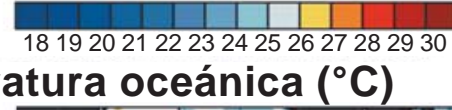
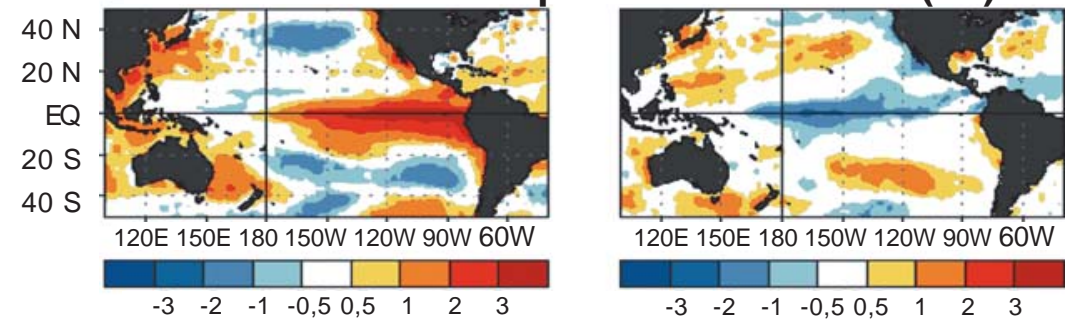

Figura 2.Caracterización de eventos extremos en el Océano Pacífico Ecuatorial indicando la temperatura de la superficie del agua y sus variaciones (Climate Prediction Center, 2013). 
los posibles aportes al sistema amazónico del Océano Atlántico Ecuatorial así como de las corrientes marinas en las costas del este de América del Sur.

Estos efectos que se generan a escala planetaria extra regional, determinan conjuntamente con la ubicación geográfica de la región noreste, las principales característica estacionales de nuestro clima; sin embargo existen otros elementos relativamente locales como la Zona de Convergencia del Atlántico Sur o de América del Sur (SACZ, South American o South Atlantic Convergence Zone), o la trayectoria de los frentes fríos desde la Patagonia o la South American Low Level Jet (SALLJ) contra la Cordillera de Los Andes al oeste de la cuenca amazónica, generan variaciones climáticas incluso dentro de las estaciones.

Estos últimos fenómenos mencionados, son componentes esenciales de lo que se ha denominado el SAMS (South American Monsoon System), el sistema de vientos monsónicos sobre América del Sur (Vera et al., 2006 b; Marengo et al., 2010). Los componentes de la estructura del SAMS lo constituyen los sistemas de alta presión y de circulación anticiclónica en la parte oceánica subtropical tanto del O. Pacífico como del O. Atlántico, el Centro Termal de Baja en el Chaco en el norte de Argentina, la Zona de Convergencia del Atlántico Sur (SACZ) y la corriente sudamericana a bajo nivel (SALLJ) que se extiende desde el sur oeste Amazónico hacia el sur este de América del Sur (SESA). La dinámica climática estacional como interanual de este sistema ha sido discutido y analizada por Marengo et al. (2010).

Otros autores (Carvalho et al., 2004) identificaron previamente como una característica especial en los regimenes de lluvias en América del Sur durante el verano el amplio rango de variación en los volúmenes de lluvias tanto en el tiempo como en el espacio. Gran parte de estas variaciones pueden atribuirse a la interrelación entre el establecimiento de la SACZ, la evolución del SAMS y las fases del ENSO en el Océano Pacífico.

Este fenómeno ENSO presenta variaciones interanuales así como tendencias de variaciones cada 10 años (Figura 3) Para la región de Tacuarembó, Olmos (1991), presentó evidencias que variaciones similares en las lluvias ocurren en períodos tomados cada diez años (Figura 4), estas tendencias podrían estar relacionadas con las oscilaciones en la temperatura superficial en el $\mathrm{O}$. Pacífico; en Treinta y Tres, para el caso del cultivo del arroz, se ha corroborado una relación negativa entre los rendimientos en grano del cultivo de arroz con los años donde se manifiesta el fenómeno de El Niño (Roel y Baethgen, 2005).

Desde el punto de vista del régimen de Iluvias, para la región noreste de Uruguay, el conocimiento de la dinámica del SAMS así como su interacción con el ENSO asociado a la posibilidad de tomar decisiones a nivel estacional y desde el punto de vista productivo, aparecen como prioritarios tanto desde el punto de vista informativo y del conocimiento básico, como de la necesidad como sociedad, de involucrarse en este tipo de estudios básicos del funcionamiento de los ecosistemas naturales.

\section{VARIABILIDAD REGIONAL}

La región noreste se caracteriza por valores anuales de lluvia que van desde 1076 mm en la ciudad de Melo en el extremo este de la misma, hasta valores de 1303 y 1441 mm para Tacuarembó y Rivera respectivamente en el extremo oeste y norte de la región (Corsi y Olmos, 1982; Olmos, 1983 a). Una de las características principales de los valores de las Iluvias tanto mensuales como estacionales es su alto coeficiente de variación el cual oscila en $75-80 \%$ de los valores medios (Corsi y Olmos, 1982).

La evaporación promedio varía desde valores diarios de $2 \mathrm{~mm}$ en invierno a 4-6 mm en primavera hasta alcanzar valores de 10$12 \mathrm{~mm}$ por día en el verano, en este sentido se genera un déficit de agua, fundamentalmente durante el período estival, donde la evaporación promedio estacional es relativamente mayor a las lluvias (Corsi y Olmos, 1982). Corsi (1982) realizó un balance hídrico para la región (Cuadro 1) y considerando una lámina de suelo con capacidad de retención de agua de 125 mm, identificó un déficit 
Oceanic Nino Index (ERSST.v3b ONI)
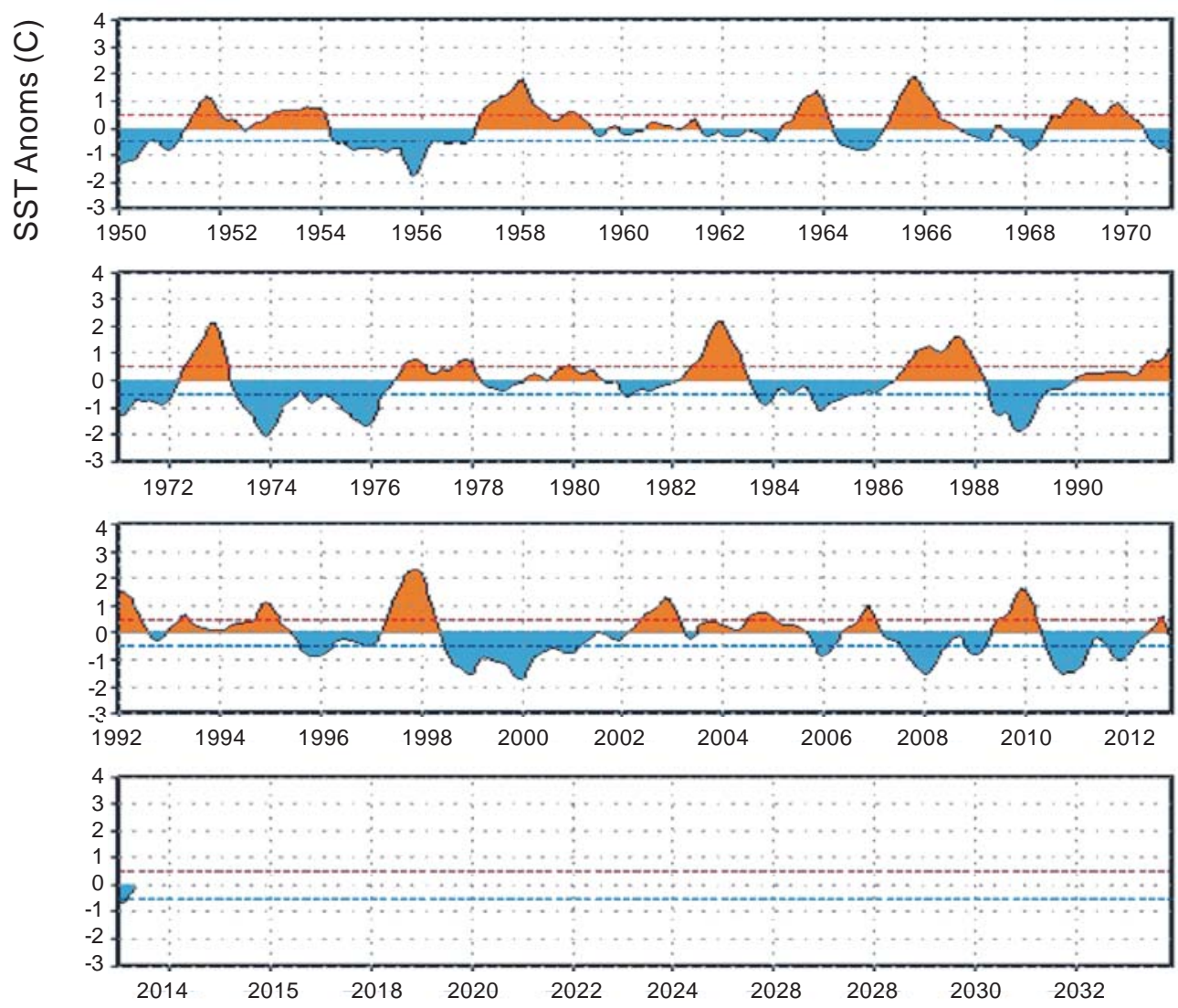

Figura 3. Variaciones de la temperatura $\left({ }^{\circ} \mathrm{C}\right)$ superficial del Océano Pacífico en el período 1950 2012 (Climate Prediction Center, 2013).

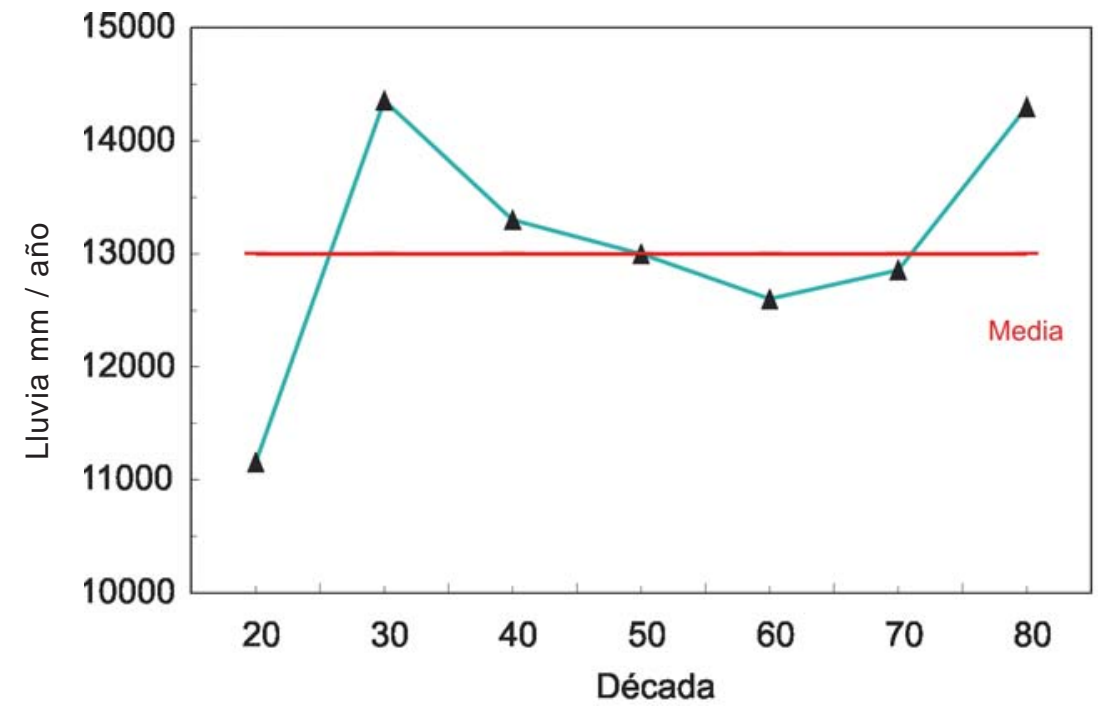

Figura 4. Variación en las lluvias totales anuales en Tacuarembó cada diez años (Olmos, 1991) y el valor medio para el mismo período. 
Cuadro 1. Balance hídrico en la región noreste para un suelo con capacidad de retención en una lámina de $125 \mathrm{~mm}$ (Corsi, 1982).

\begin{tabular}{|l|c|c|}
\hline Balance hídrico & Tacuarembó - Rivera & Cerro Largo \\
\hline Precipitación anual & $1.247 \mathrm{~mm}$ & $1.142 \mathrm{~mm}$ \\
Evaporación potencial & $894 \mathrm{~mm}$ & $877 \mathrm{~mm}$ \\
Exceso anual & $388 \mathrm{~mm}$ & $325 \mathrm{~mm}$ \\
Déficit anual & $35 \mathrm{~mm}$ & $60 \mathrm{~mm}$ \\
\hline
\end{tabular}

anual del orden de 35-60 $\mathrm{mm}$ y por otro lado, excesos de agua en el suelo entre 325-388 $\mathrm{mm}$ en el mismo período.

Al mismo tempo que se ha registrado la variabilidad mensual en el régimen de lluvias también se ha descrito tanto la variabilidad interanual así como interdecádica en las volúmenes de agua aportados por las lluvias. En la Figura 4 se describe la variación cada diez años en los totales anuales de lluvia para Tacuarembó, comparados con los valores medios en un período de setenta años.

En la Figura 5 se reportan los valores anuales de lluvia en Tacuarembó para un período de 25 años consecutivos en base a datos de la Unidad Experimental La Magnolia donde claramente se destaca la gran variabilidad anual sin un patrón definido en los registros.
En la Figura 6, para Cerro Largo y en otro período de tiempo, se grafican los valores anuales y promedio de lluvia, destacándose la misma variabilidad en los registros vistos en la figura anterior para Tacuarembó; esto permite establecer que históricamente la variabilidad en los volúmenes de las lluvias registradas ha estado presente en la región.

Desde el punto de vista productivo se ha visto que la relación entre la lluvia y la evaporación básicamente durante la estación de crecimiento, desde primavera hasta el otoño en los ecosistemas naturales, determina fuertemente los niveles de productividad (Capítulo II, esta publicación). En la Figura 7 se muestra para un período de veintidós años, la variación de los valores de la relación lluvia - evaporación (barras) en base a datos de la Dirección Nacional de Meteorología de

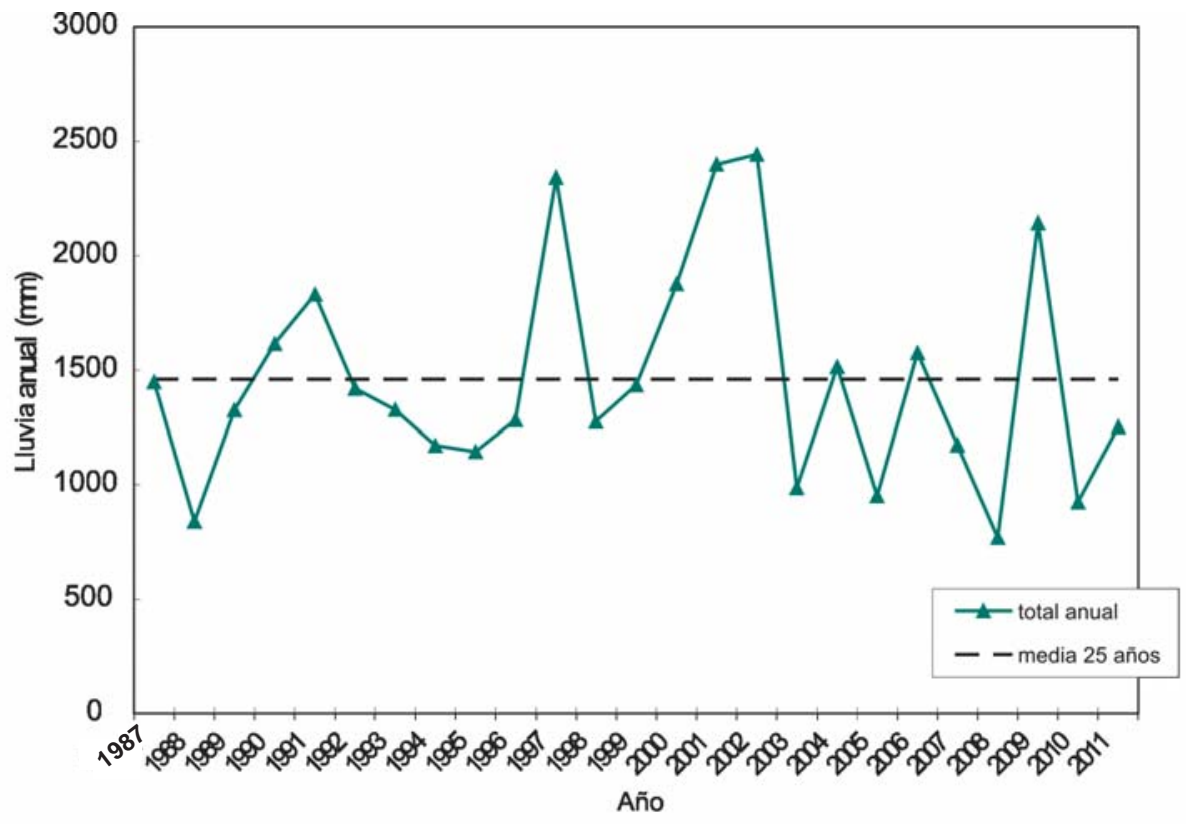

Figura 5. Lluvia anual en un período de veinticinco años en Tacuarembó, en base a datos de la Unidad Experimental La Magnolia. 


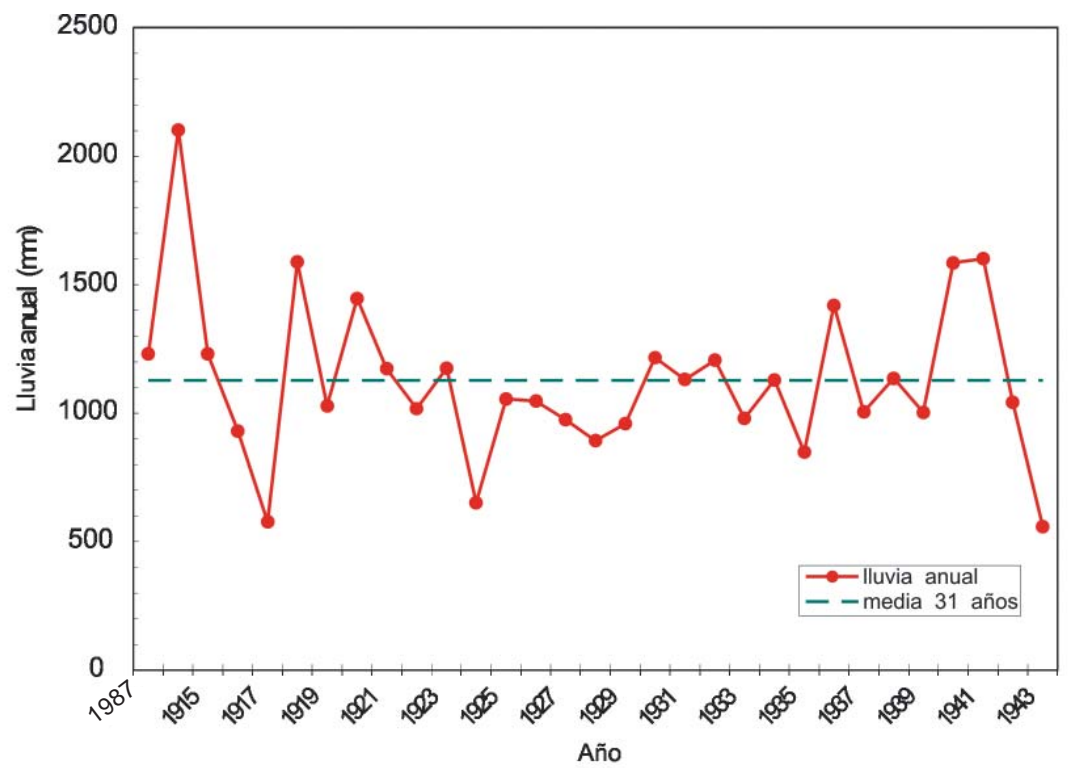

Figura 6. Lluvia anual en un período de treinta y un años en Cerro Largo en base a datos del Servicio Meteorológico del Uruguay (Spangenberg, 1944).

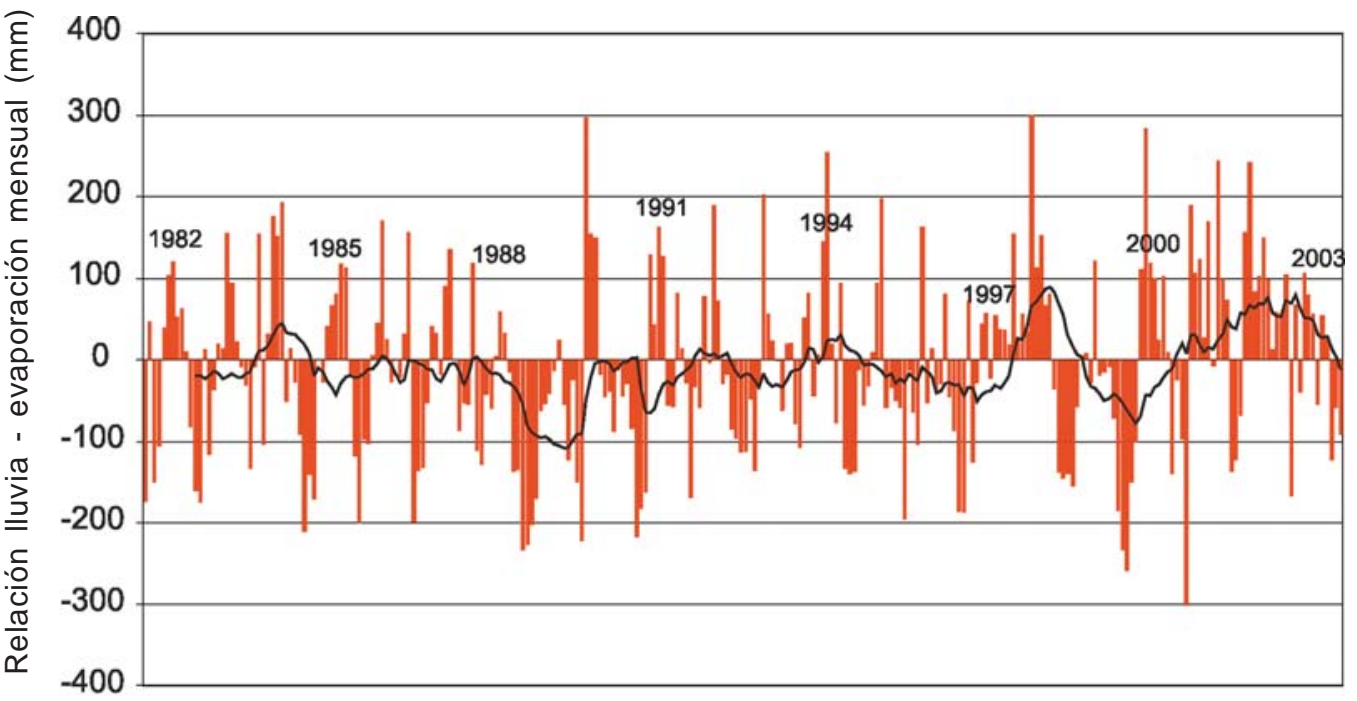

Figura 7. Variación de la relación lluvia - evaporación en Melo en el período 1982-2005, en base a datos de la Dirección Nacional de Meteorología.

Melo y una media móvil anual (línea continua), destacándose la variabilidad de la misma con ciclos de valores altos y bajos alternadamente pero de diferente intensidad y duración.

Del mismo modo en la Figura 8 se observa la relación lluvia/evaporación en forma estacional en base a datos de la Unidad Experimental la Magnolia en los alrededores de
Tacuarembó; conjuntamente se agrega el valor 0,6 para dicha relación (línea roja) y una banda de respuesta (azul claro) donde se ejemplifica para el primero, el nivel crítico de sobrevivencia de plantas para una especie introducida como trébol blanco propuesto por Olmos (2004) y la segunda, de acuerdo a lo visto en el capítulo precedente, donde la pro- 


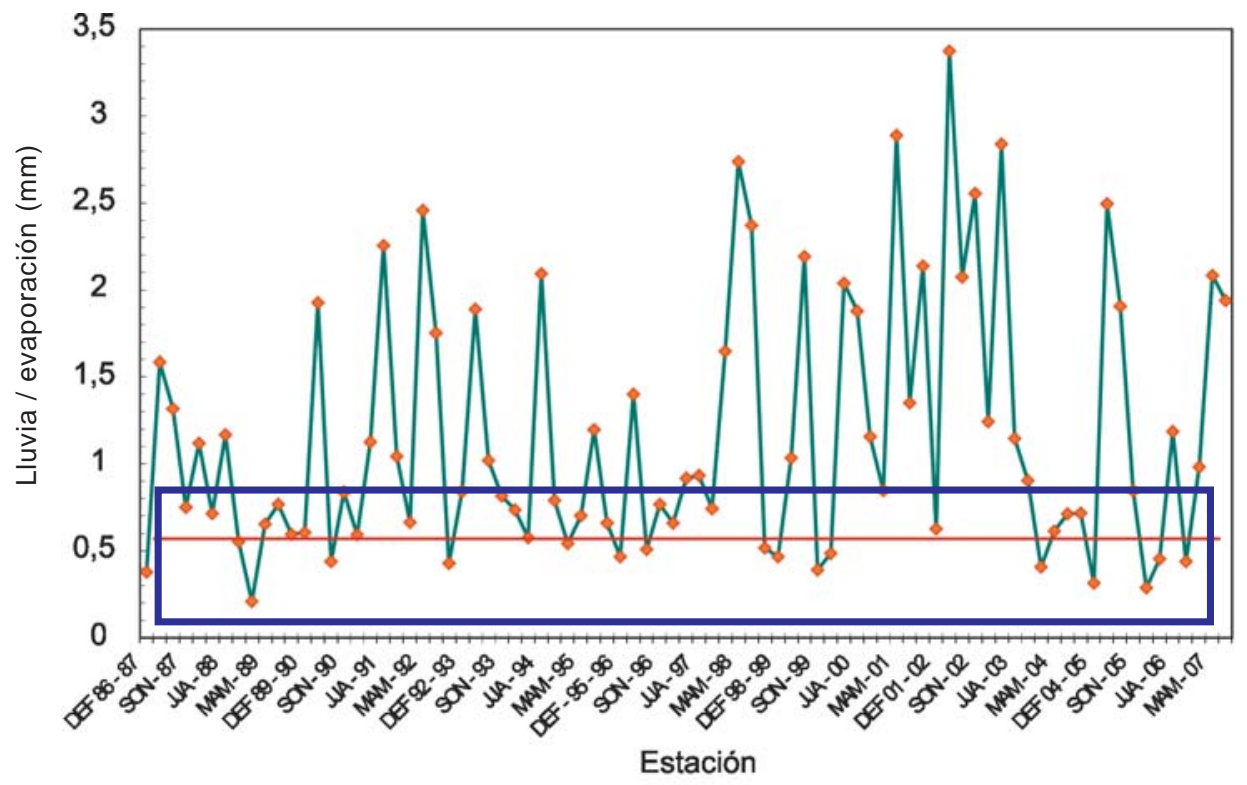

Figura 8. Variacion estacional de la relacion lluvia / evaporacion en el periodo 1986-2007, en base a datos de la Unidad Experimental La Magnolia.

ductividad de las pasturas naturales se incrementan en este rango destacado.

En torno al $40 \%$ de las estaciones, desde el punto de vista del trébol blanco, los valores de la relación Iluvia/evaporación se encuentran cercanos al valor crítico de sobrevivencia, en cambio las pasturas naturales siempre se recuperaron en su productividad aún con valores extremadamente bajos como los registrados en Figura 8.
Tomando en cuenta la estación de crecimiento para el ecosistema natural regional y asumiendo que en el período invernal se realiza la recarga del agua en el suelo se construyó la Figura 9, donde se reporta la variación anual de la relación lluvia / evaporación para la primavera (SON), el verano (DEF) y el otoño (MAM). En dicha figura se observa que tanto la primavera como el verano presentan valores cercanos o por debajo del crí-

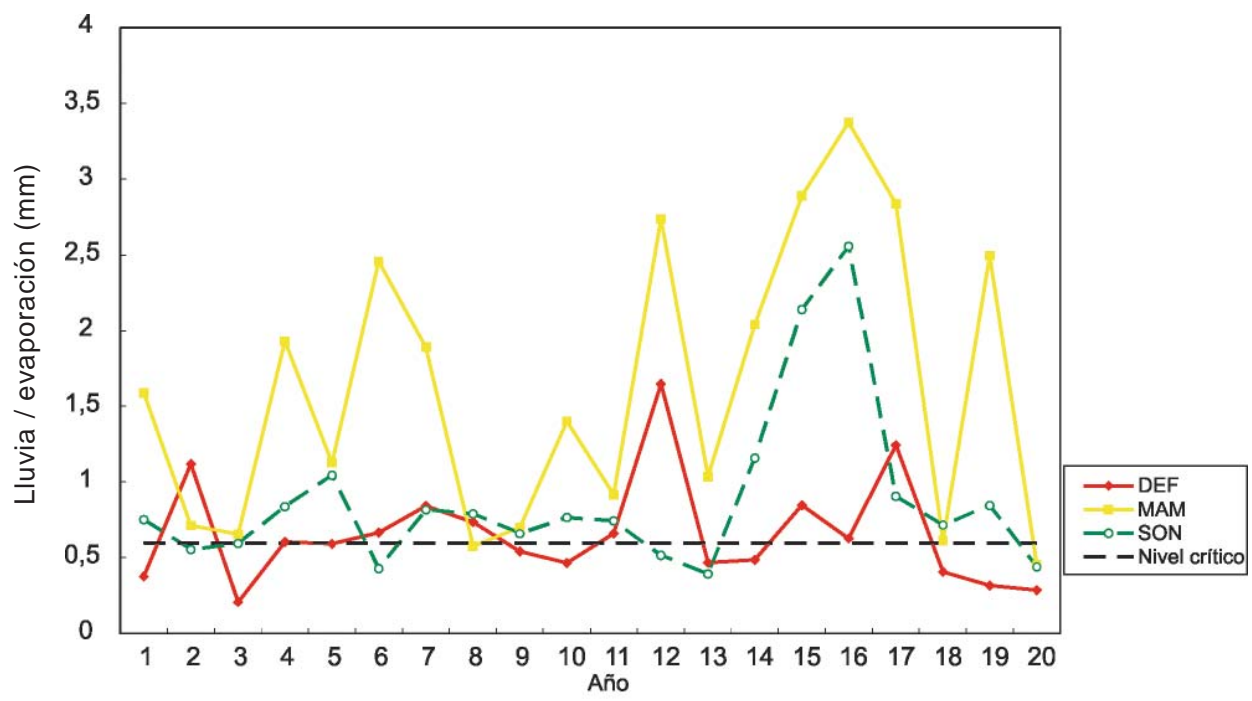

Figura 9. Variación anual de la relación lluvia / evaporación estacional en base a datos de la Unidad Experimental La Magnolia en un período de veinte años. 


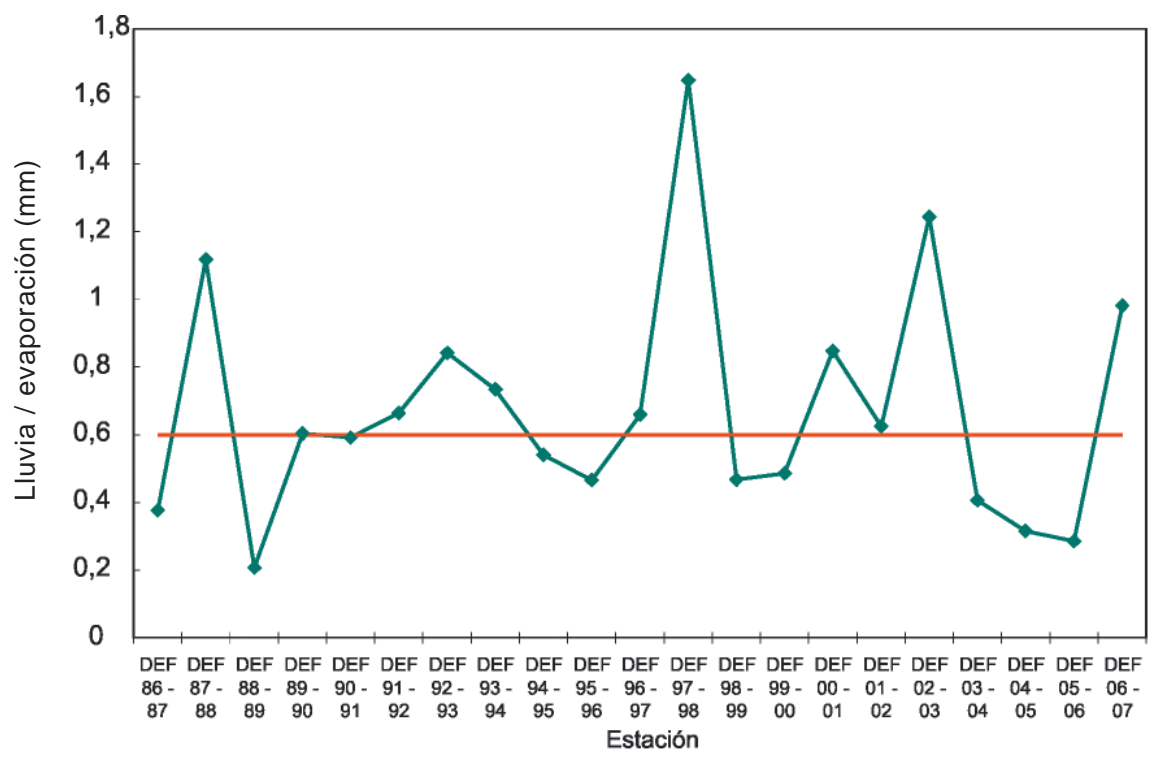

Figura 10. Valor de la relación lluvia / evaporación durante veinte años en verano (DEF), en base a registros de la Unidad Experimental La Magnolia.

tico para la sobrevivencia de trébol blanco, en cambio no ocurre lo mismo en el otoño ara un período de registros en la Unidad experimental La Magnolia de veinte años. Esta variabilidad seguramente debería determinar cambios en el manejo de las pasturas según los eventos climáticos predominantes.

En el caso del verano en la Figura 10 prácticamente en las dos terceras partes de las veces (2/3) el valor de la relación lluvia / evaporación se registró entorno al valor crítico de sobrevivencia de plantas de trébol blanco de 0,6.

Dado que los valores de evaporación son relativamente menos variables, el efecto principal sobre la relación lluvia / evaporación lo constituya la variabilidad del volumen de lluvias estacionales. Olmos (1997 a) reportó previamente y en base a datos de la Dirección Nacional de Meteorología la importante variación interanual tanto para el verano como para el otoño en Tacuarembó en un período de setenta años (1921-1990), en la Figura 11 se in-

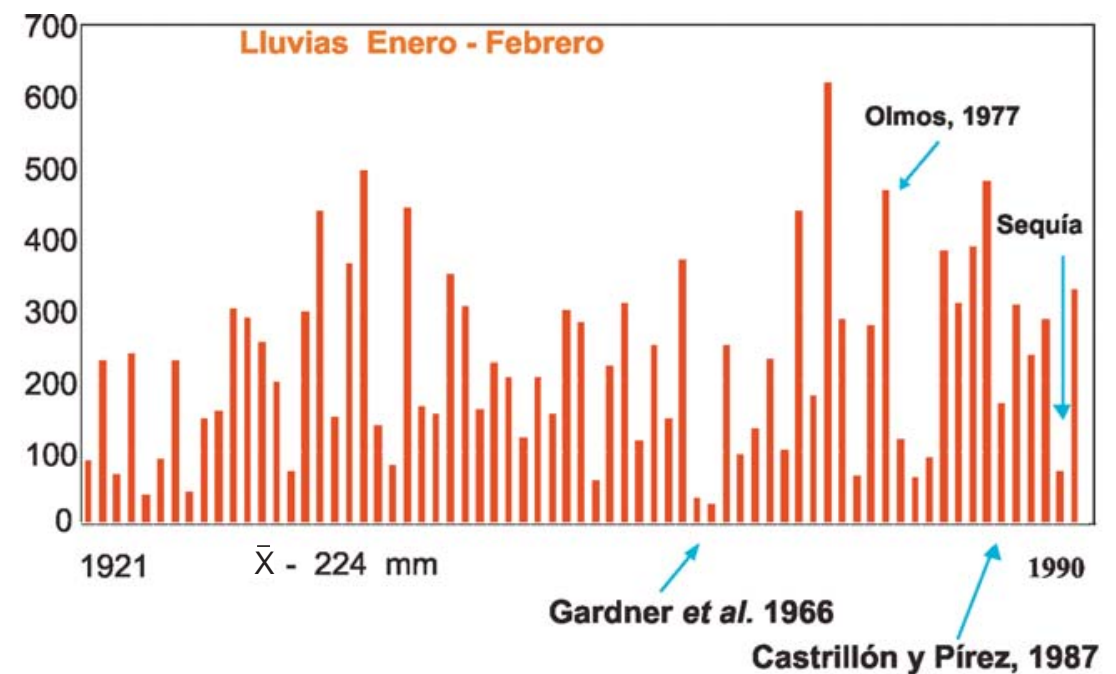

Figura 11. Lluvias en Tacuarembó en el período 1921-1990 en los meses de enero y febrero, en base a datos de la Dirección Nacional de Meteorología. 
dican los valores totales de lluvias para los meses de enero y febrero en dicho período.

Lo más importante a destacar de la figura es la ausencia de un patrón en el régimen de lluvias con secuencias muy diferentes en los distintos años en relación al valor de la media de $224 \mathrm{~mm}$. En la Figura 11 se identificaron algunos experimentos reportados como el de Gardner et al. (1966) quienes indicaron prácticamente la pérdida de la pastura y su posterior recuperación a partir de semillas de las leguminosas introducidas debido al estrés hídrico, el caso de Olmos1977 (Olmos, 1978) que registró 10.000 kg de grano de maíz producido en forma experimental con ese verano lluvioso el cual contrasta con los dos siguientes relativamente muy secos, en el caso de Castrillón y Pírez (1987) los autores registraron la sobrevivencia de trébol blanco luego de un verano con estrés hídrico a partir de las semillas producidas en la primavera previa y el caso del año 1989 recordado como de extrema sequía para la región norte del país.

Por su parte los valores de evaporación dependen básicamente de la temperatura, la velocidad del viento y el $\%$ de humedad relativa del aire. El déficit hídrico descrito por Corsi (1982) y Corsi y Olmos (1982) durante el ciclo estival es el resultado de una mayor temperatura como de una menor humedad relativa presente en el aire; en la Figura 12 se reporta la variación el porcentaje de humedad relativa estacional sobre la evaporación del tanque «A» en la Unidad Experimental La Magnolia indicando prácticamente una relación directa e inversa $(P<0,0001)$, donde con mayor porcentaje de humedad relativa se registra un menor evaporación, por el contrario con un aire relativamente más seco o sea con mayor demanda atmosférica la evaporación se incrementa.

La Figura 13 muestra para veinte años de información de la Unidad Experimental La Magnolia, los valores de la relación lluvia / evaporación secuenciales desde la primavera hasta el otoño. Se destaca la menor variación de los valores de la relación en la primavera, la mayor variación en el otoño y los valores intermedios para el verano con un desvío estándar de 0,54, 0,69 y 1,65 para primavera, verano y otoño respectivamente.

A los efectos de destacar la variabilidad extrema de la relación lluvia / evaporación en la región noreste, se graficaron los valores de la misma para tres estaciones de crecimiento consecutivas, destacándose el registro de valores similares en la primavera (SON), algo más variables y menores en verano (DEF) y ampliamente variables en el otoño (Figura 14).

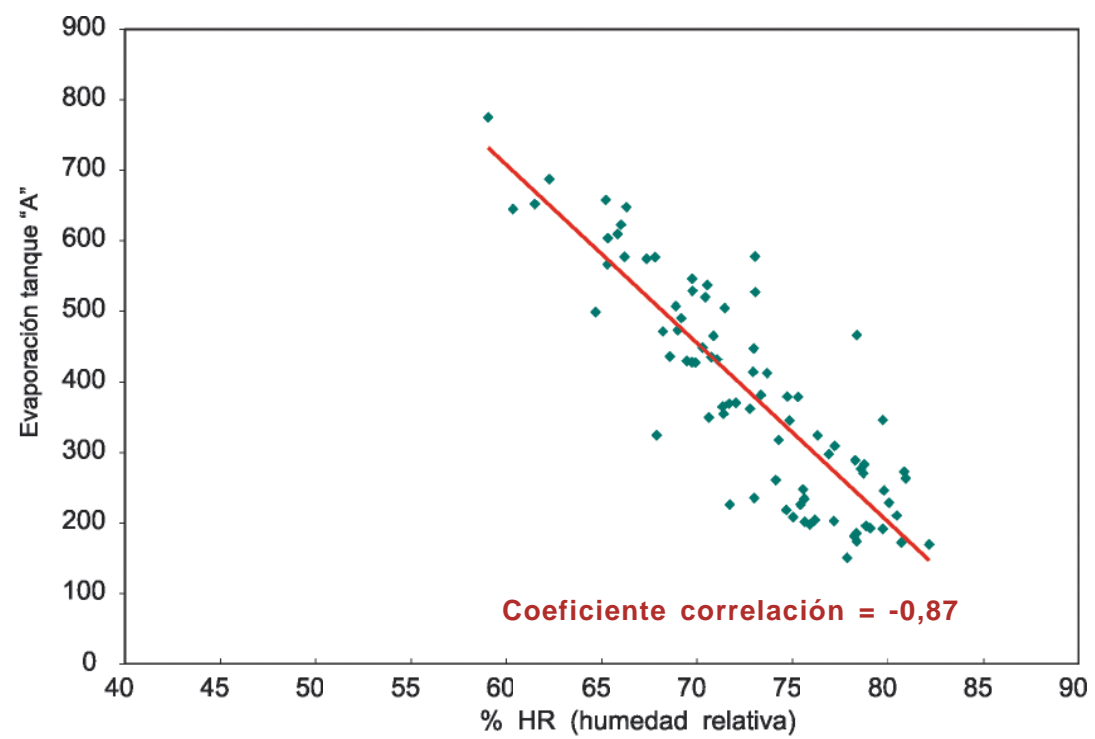

Figura 12. Relación entre el porcentaje de humedad relativa del aire y la evaporación en el tanque «A» en Tacuarembó, en base a datos de la Unidad Experimental La Magnolia. 


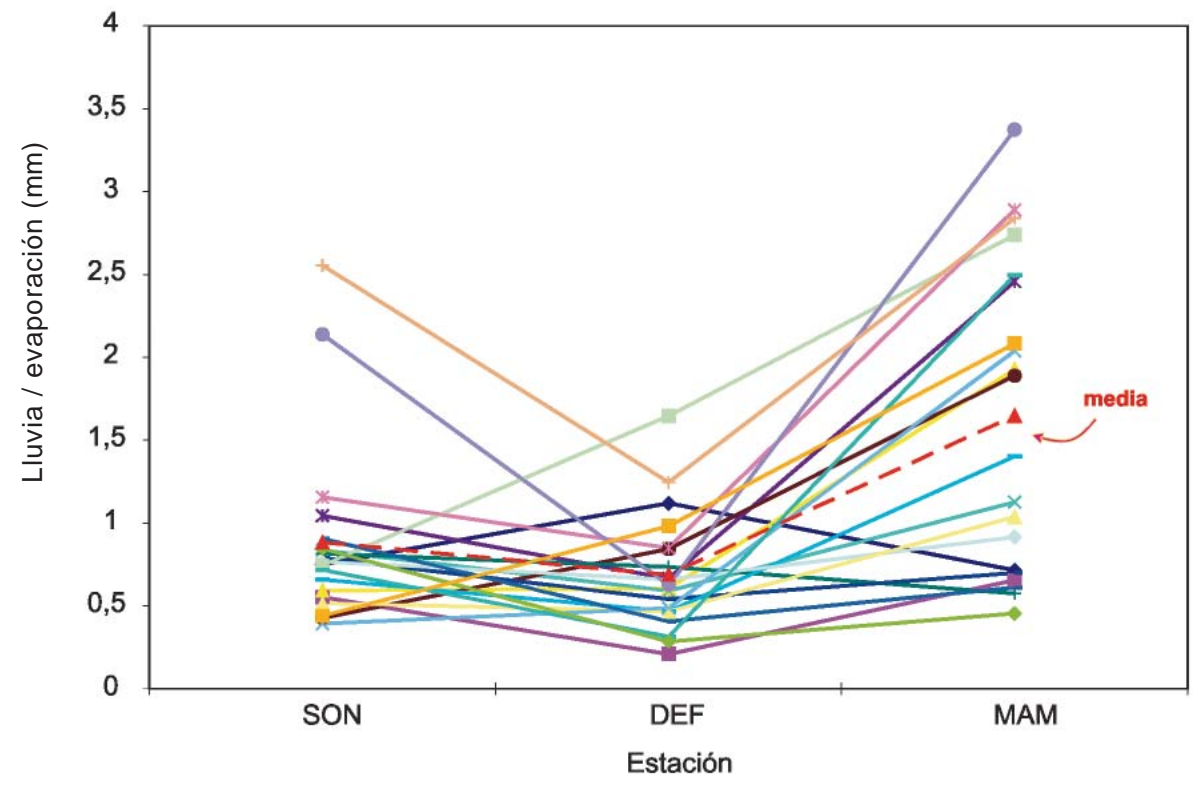

Figura 13. Valores de la relación lluvia / evaporación para la primavera (SON), el verano (DEF) y el otoño (MAM) en forma secuencial para veinte años sucesivos (Líneas continuas) en base a datos de la Unidad Experimental La Magnolia, comparado con la media (línea punteada).

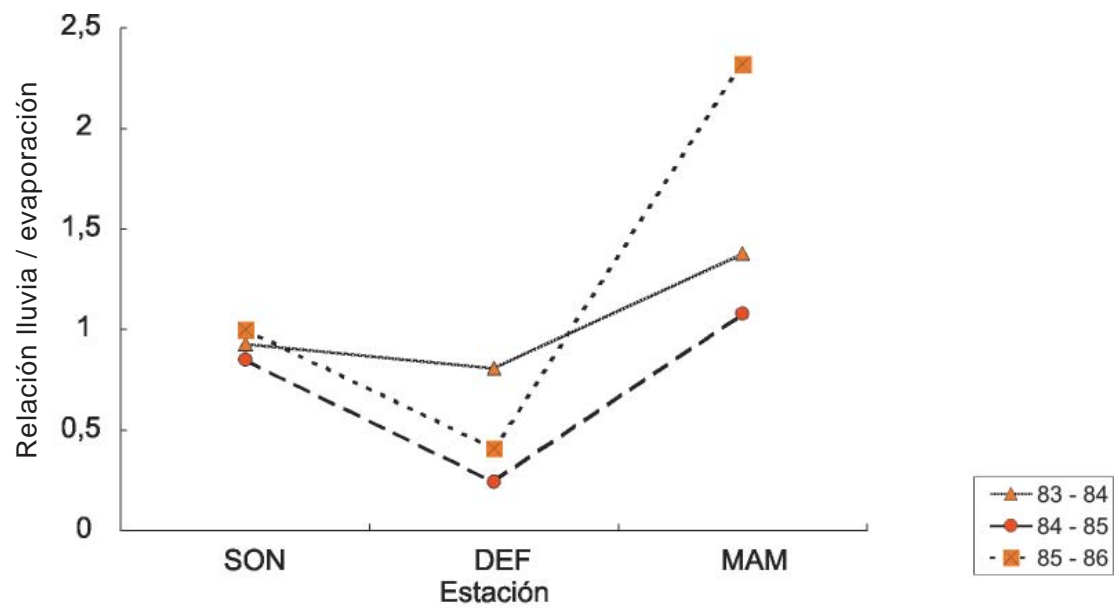

Figura 14. Variabilidad de la relación lluvia / evaporación en años sucesivos en la región noreste.

A los efectos de interpretar la relación de esta variabilidad presente en la región noreste, básicamente la variación en los volúmenes de lluvia, se cotejaron los valores estacionales de lluvia durante veinticinco años en la Unidad Experimental La Magnolia con el desarrollo de fenómenos relativamente extremos en el Océano Pacífico considerando la dinámica del ENSO (EI Niño
Southern Oscillation). Para ello a los datos de lluvia se le incorporaron los períodos definidos como el Niño (barras rojas) o La Niña (barras azules) según registro del Centro de Predicción Climática (CPC, 2013) en la Figura 15.

Claramente se observa casi una concordancia completa entre la presencia de la fase El Niño o La Niña con la mayor o menor can- 


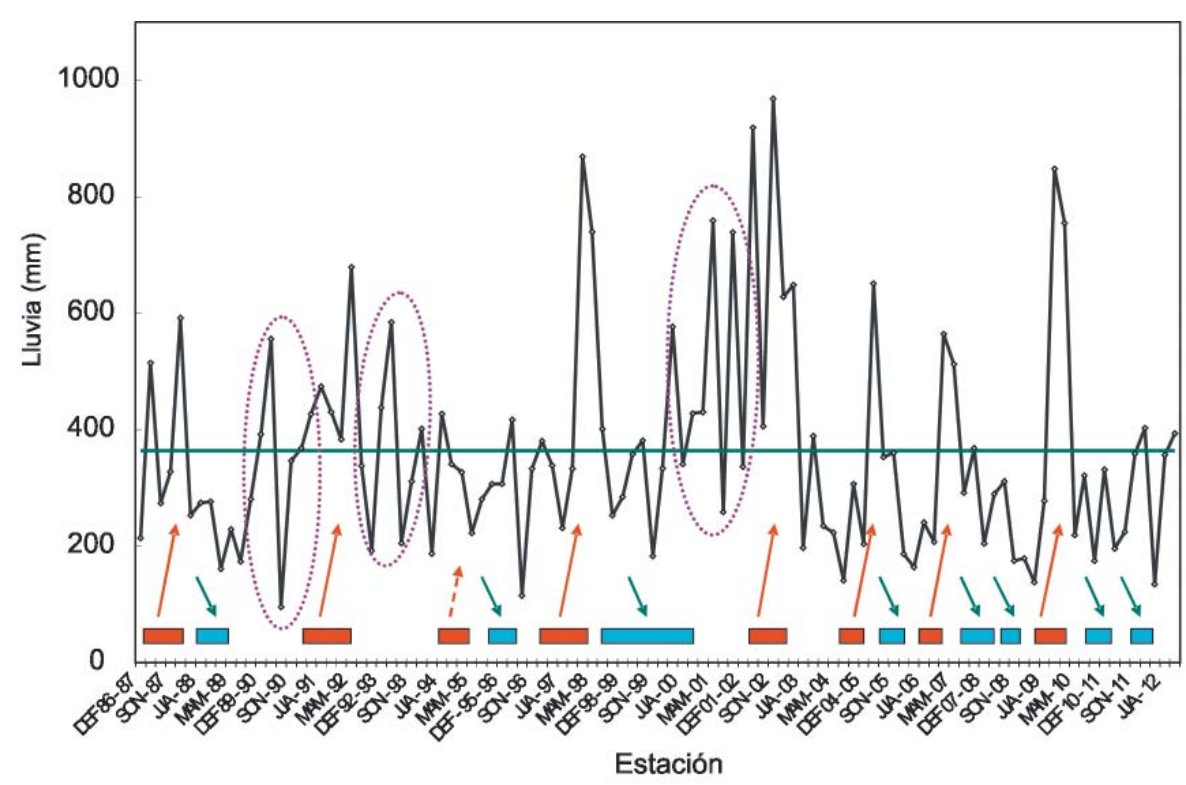

Figura 15. Registros de lluvias estacionales en la Unidad Experimental La Magnolia y eventos extremos en el Océano Pacífico de la dinámica del ENSO (barras rojas - El Niño, barras azules - La Niña) en base a datos del Centro de Predicción Climática (2013).

tidad de lluvias registradas en Tacuarembó respectivamente; en 15 de 16 casos extremos registrados en el $\mathrm{O}$. Pacífico la lluvia registrada estuvo por encima o por debajo de la media según la presencia del El Niño o La Niña. Tres casos, encerrados por las elipses en la figura, aparentemente no responden a la dinámica del ENSO, indicando que otros elementos seguramente están operando sobre los valores de lluvias registrados localmente. Esta variabilidad regional aparentemente ha sido una constante evolutiva de nuestra región (Iriondo y García, 1993).

Tomando en cuenta la temperatura, la radiación solar y las lluvias se puede establecer que a medida que nos trasladamos desde el invierno hacia el otoño la variabilidad climática se incrementa, siendo invierno la estación más predecible y estable (fría y húmeda) y el otoño la más variable en virtud de que puede partir de diferentes situaciones con primaveras previas secas o húmedas así como de veranos secos o húmedos, a su vez por su parte, el otoño puede ser tanto relativamente más seco como relativamente más húmedo (Olmos, 1997 a). Actualmente hay reportes (Chou et al., 2005) que estarían indicando la posibilidad de predecir las lluvias estacionales sobre América del
Sur, lo cual podría contribuir sustancialmente a la toma de desiciones a nivel predial.

\section{IMPACTOS DE LA VARIABILIDAD CLIMÁTICA EN LOS SISTEMAS DE PRODUCCIÓN}

La productividad de los ecosistemas naturales depende básicamente de las condiciones climáticas asociadas a un determinado tipo de suelo, la topografía, la vegetación y la historia de manejo del pastoreo en cada situación. En la Figura 16 se observa la variación estacional en la receptividad animal basa en la producción de forraje para los suelos arcillosos (brunosoles) de la región noreste, tomando en cuenta los valores de producción promedio y los años donde se produjeron los valores mínimos; las variaciones estacionales en la receptividad se corresponden tanto con los valores de la temperatura media, como del balance hídrico del suelo (Olmos, 1997 a) donde tenemos valores mínimos en invierno $\left(12^{\circ} \mathrm{C}\right)$ y máximo en verano $\left(24^{\circ} \mathrm{C}\right)$ para la temperatura (Corsi y Olmos, 1982), y desde el punto de vista del balance hídrico (Corsi, 1982) una utilización del agua a partir de la primavera, un déficit 


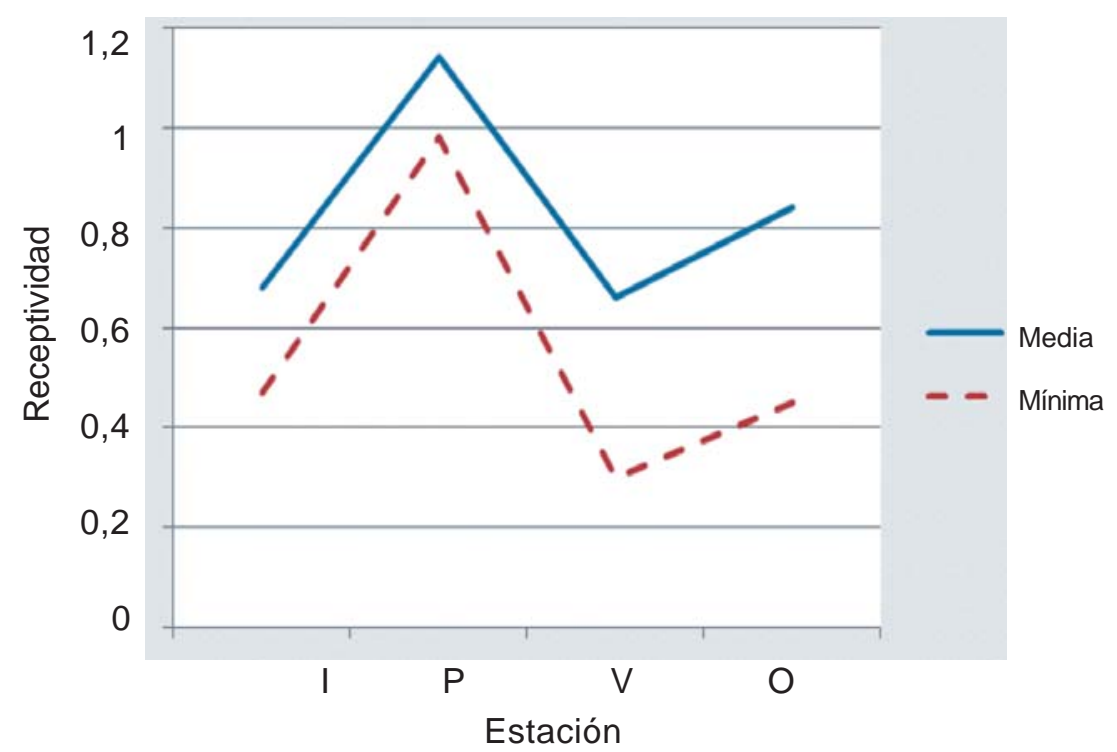

Figura 16. Variación estacional en la receptividad animal estacional (I-P-V-O) media y mínima por hectárea, de una pastura natural sobre brunosoles en la región noreste.

relativo en verano y un período de recarga de agua en el suelo en otoño-invierno.

Desde el punto de vista del manejo del rodeo vacuno en un sistema de cría o ciclo completo el período de entore generalmente se realiza hacia fines de la primavera e inicios del verano coincidiendo con el inicio de un déficit hídrico estacional. Si bien en la Figura 16 se muestran los valores de receptividad promedio para un campo natural sobre brunosoles, desde el punto de vista productivo es importante determinar los valores mínimos ya que los mismo pueden afectar la productividad general del rodeo; los valores mínimos en la misma son sensiblemente inferiores tanto en el verano como en el otoño.

Dadas las condiciones productivas en un determinado sitio como el suelo, la topografía, la vegetación y su manejo, la principal causa de variación en la productividad esta determinada por las variaciones climáticas y principalmente por las variaciones de las lluvias en cada estación. Este rango de variación estacional determina la productividad tanto de primavera, verano y otoño para los brunosoles como la del verano y otoño para los suelos arenosos (Figura 17).
Se destaca la marcada variabilidad en la producción de forraje en los suelos arcillosos (brunosoles) en prácticamente todas las estaciones, con un rango menor en el invierno. Por otro lado tanto el otoño como el invierno en los suelos arenosos presentan netamente una menor variación en la productividad comparados con la primavera y el verano, en cambio si tiende, este tipo de suelo, a una mayor productividad durante los veranos con valores mínimos relativamente más altos que en el caso de los brunosoles; esto estaría explicado por el mejor balance hídrico en estos suelos, dada su constitución con un horizonte $B$ arcilloso que facilita el agua disponible en el horizonte $A$ arenoso (Olmos. 1997 a).

En los veranos con relaciones lluvia / evaporación relativamente bajas cercanas a valores de 0,3 la productividad de las pasturas naturales puede descender a un $25 \%$ del posible con relaciones más cercanas a la unidad 0,75 (Figura 18); resultados similarmente contrastantes se presentan para Setaria anceps, una gramínea introducida perenne de crecimiento estival.

Esta misma tendencia fue registrada cuando se estudiaron diez comunidades na- 


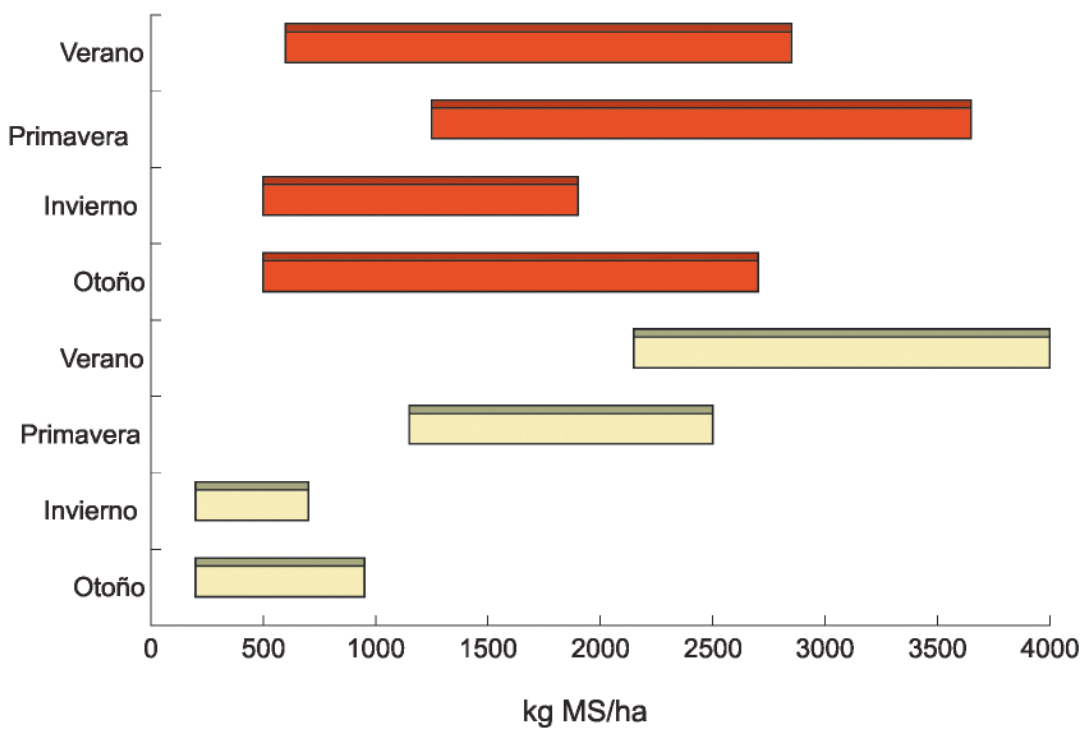

Figura 17. Varıacion estacional en la productıvidad de pasturas naturales sobre brunosoles (barras rojas) y suelos arenosos (barras amarillas) en la región noreste (Olmos, 1991).

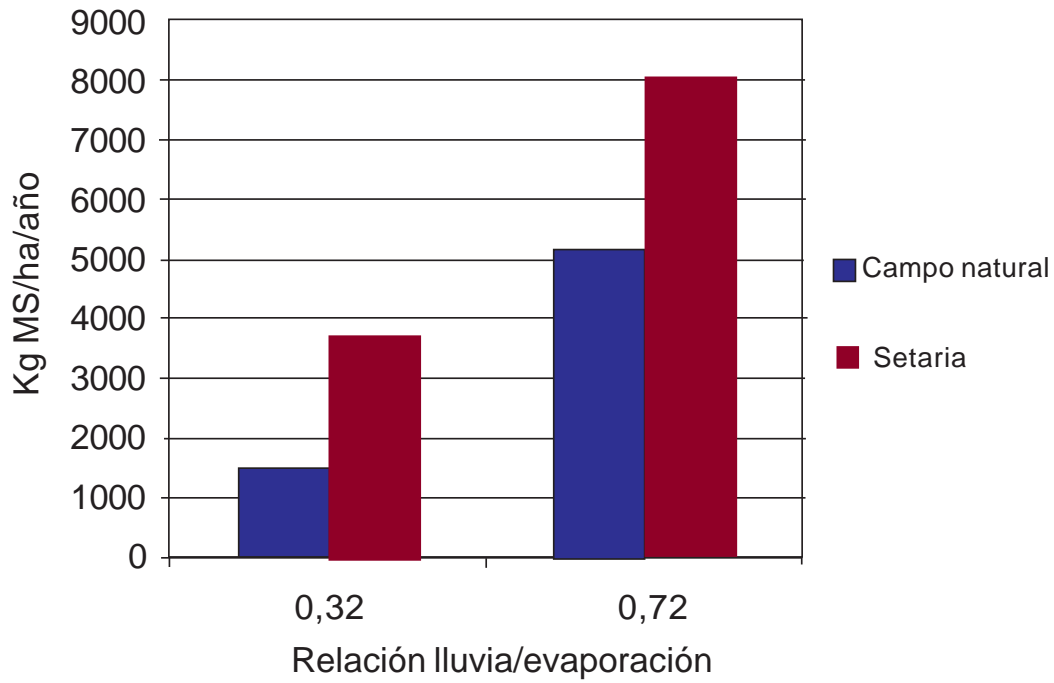

Figura 18. Productividad de pasturas naturales y de Setaria anceps sobre suelos de la Unidad Cuchilla de Caraguatá de acuerdo a la relación lluvia/evaporación, en la región noreste.

turales de la región noreste, en diferentes tipos de suelo y con diferente historia de manejo durante dos años (Olmos et al., 2005); en la Figura 19 se ve que en la medida que la relación lluvia / evaporación fue mayor, también mayor fue la producción estacional de forraje. En otoño con valores altos y extre- mos de la relación la producción de forraje fue menor.

Anteriormente Gallinal et al. (1938) reportaron para la región noreste, que el crecimiento de la vegetación de los campos vírgenes esta supeditada a las temperaturas medias mensuales; siendo que además, el 


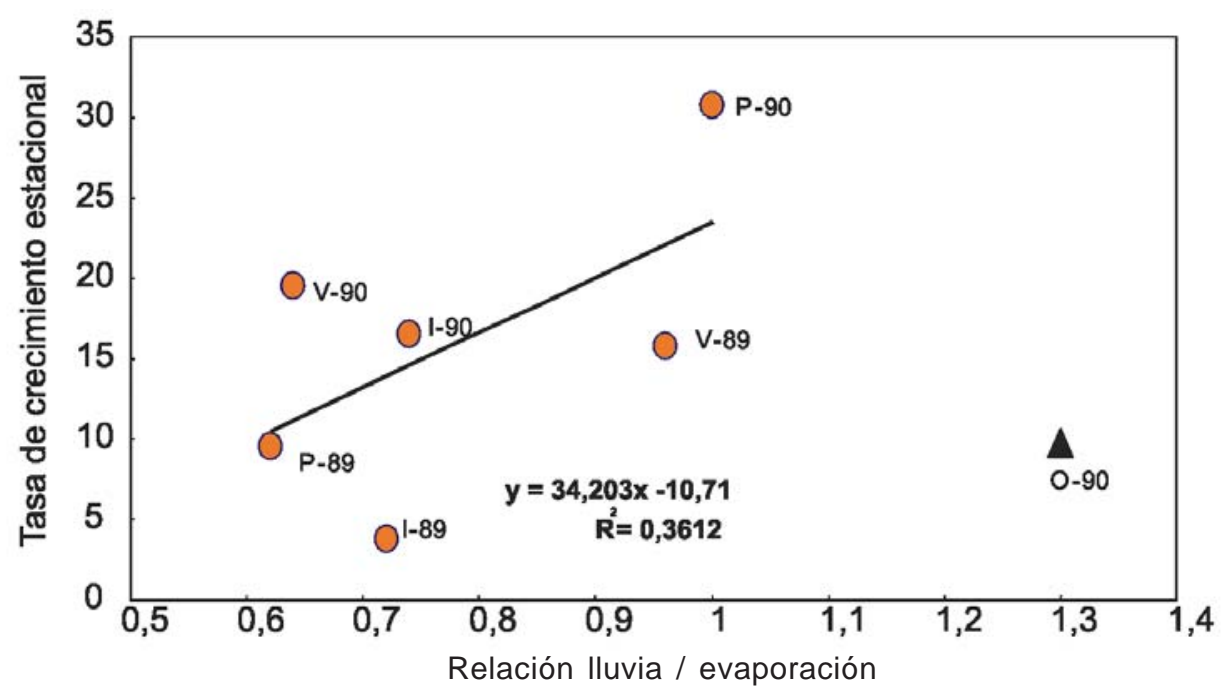

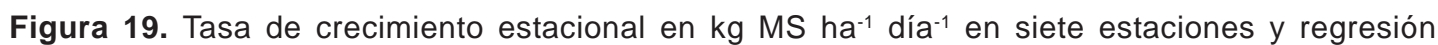
para seis estaciones según la relación lluvia / evaporación, en pasturas naturales de la región noreste.

crecimiento depende en gran medida de la ocurrencia oportuna de lluvias. Estos autores determinaron, a su vez, una correlación negativa entre la producción de forraje y los valores de evaporación registrados.

Dada la importancia de la producción de forraje primaveral para la recuperación de los animales en el período previo al entore vacuno, se realizó una comparación de la cantidad de terneros nacidos en una seccional del departamento de Tacuarembó con las lluvias registradas en el período agosto-diciembre del año anterior. Para ello se utilizaron los registros de DICOSE durante 16 años en la $8 v a$. Sección y los registros de la DNM y en la Figura 20 se observa que en trece de los dieciséis años el porcentaje de parición aumentó con el aumento de las lluvias y en los tres años restantes se corroboró el registro de lluvias por encima del promedio en los meses de enero y febrero (barras en verde) siguientes al período agosto-diciembre (Olmos, 1997 b). En el período analizado se registraron valores de 40 a $80 \%$ de parición indicando la importancia del impacto del régimen interanual de lluvias sobre la productividad de los ecosistemas naturales pastoriles.

Similares efectos a las pasturas naturales y gramíneas se observa en las pasturas cultivadas y leguminosas introducidas. La
Figura 21 muestra la variación en la composición botánica de pasturas cultivadas luego del verano en relación a la composición botánica en la primavera previa al verano en dos años sucesivos; cuando la relación lluvia / evaporación del verano fue superior a 0,8 la proporción de trébol blanco se incrementó en la pastura y la de Lotus corniculatus se redujo en el otoño posterior, cuando la relación fue algo inferior a 0,3 ocurrió lo opuesto, con mayor presencia de lotus que trébol blanco en el otoño siguiente.

Esta respuesta puede explicarse por mecanismo fisiológicos que operan en trébol blanco; se ha demostrado que los períodos de estrés hídrico, donde se presenta valores inferiores a 0,6 en la relación lluvia / evaporación afectan negativamente la presencia de la especie en condiciones de campo a través de la fragmentación de las plantas (Figuras 22 y 23) así como la reducción en el tamaño y simplificación de las estructuras de las plantas (Figuras 24 y 25) las cuales son más susceptibles al estrés hídrico y reducen la supervivencia de las plantas hacia el otoño (Olmos, 2004). Estos resultados son coincidentes con reportes anteriores en el país (Breakwell, 1962), donde se indicaba el impacto negativo de períodos de sequía sobre la sobrevivencia de especies de leguminosas introducidas. 
Variación número terneros nacidos - 8a. Sec. Caraguatá

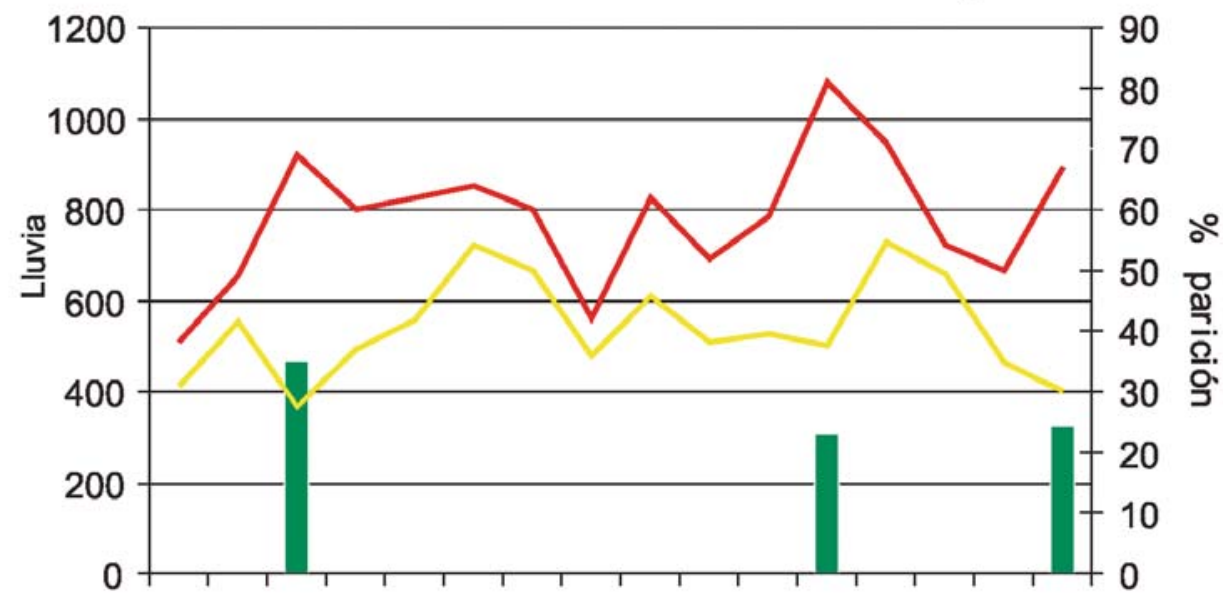

E - F - lluvia agosto-diciembre - \% parición

16 años - DICOSE - DNM

Figura 20. Variación en el porcentaje de parición de vacas al inicio de la primavera en la 8va. Sección de Caraguatá en relación a las lluvias en el período agosto-diciembre del año anterior (línea amarilla) y lluvia en enero - febrero (barras).

Proporción leguminosas en pasturas convencionales

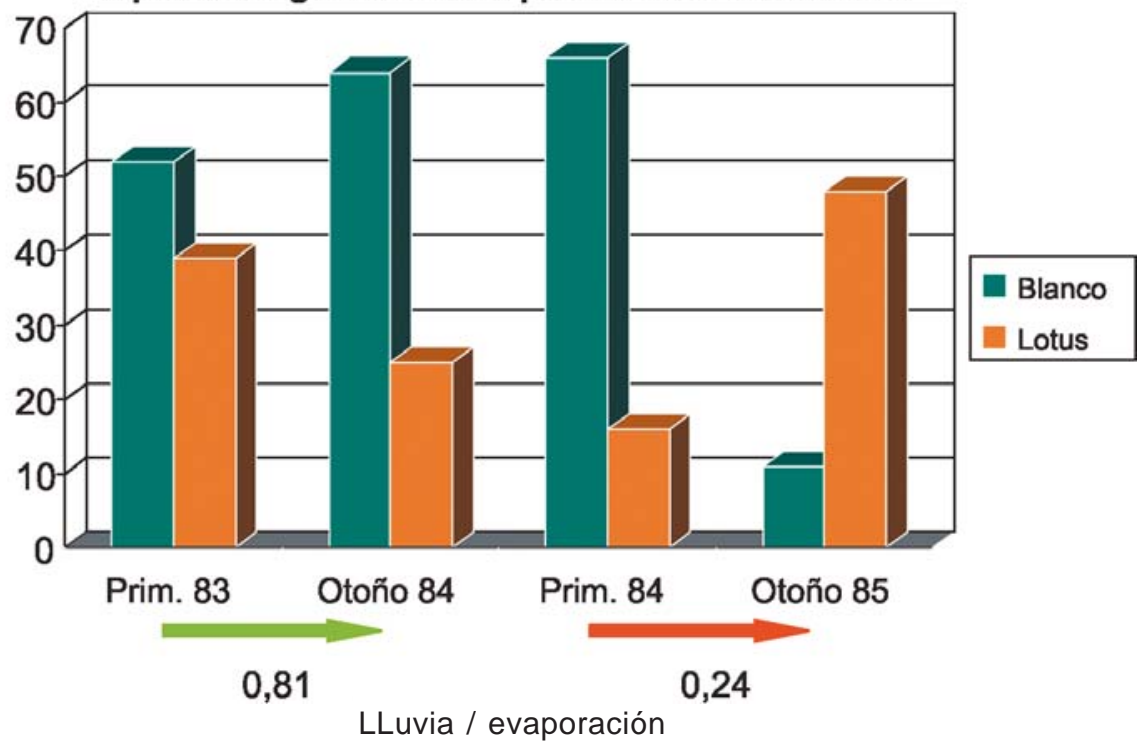

Figura 21. Variación estacional en la proporción de trébol blanco y lotus en pasturas cultivadas sobre brunosoles según la relación lluvia / evaporación en verano, en la región noreste.

En el caso de Lotus corniculatus la mayor sobrevivencia de las plantas, luego de veranos relativamente secos, puede atribuirse a su sistema radicular más profundo que el de trébol blanco; las raíces de lotus que pueden alcanzar las mismas profundidades que una especie del campo natural como Paspalum notatum en condiciones de estrés hídrico (Olmos, 2001). 


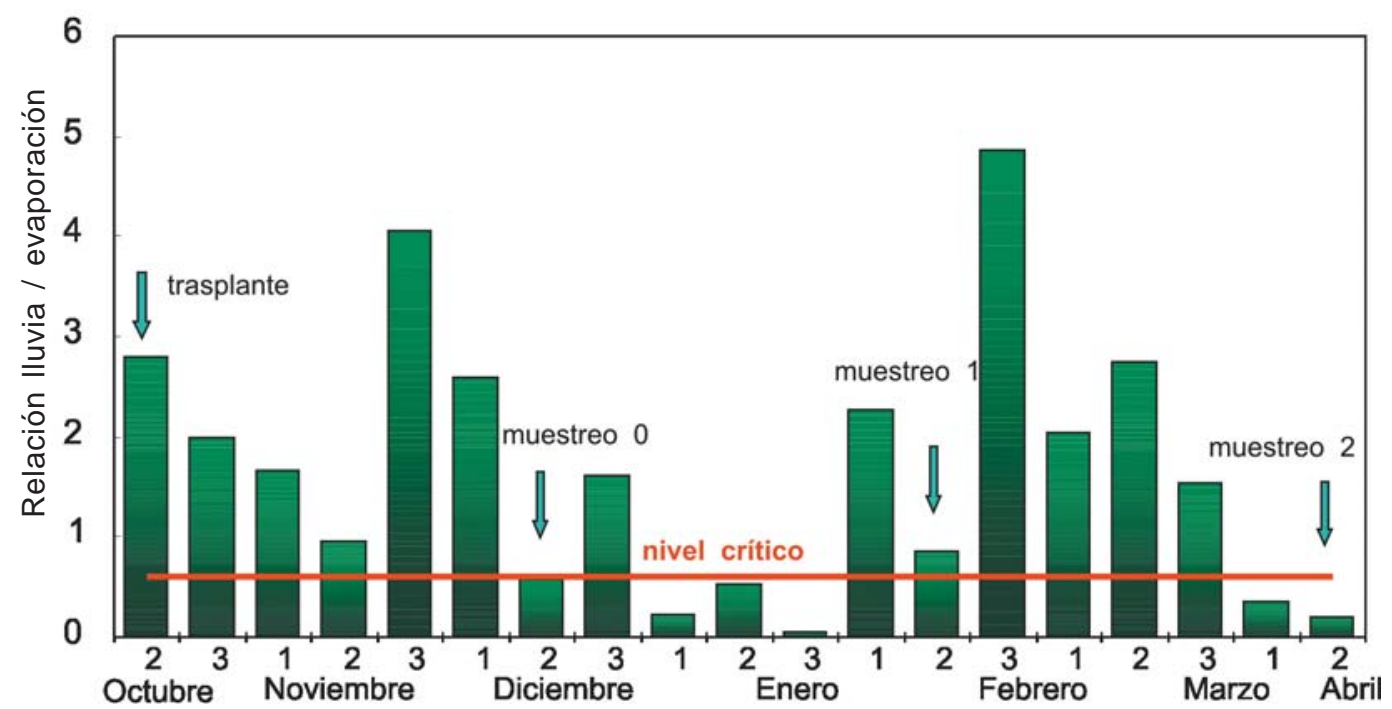

Figura 22. Relación lluvia / evaporación en el período primavera-verano-otoño durante el período experimental en brunosoles de la región noreste.

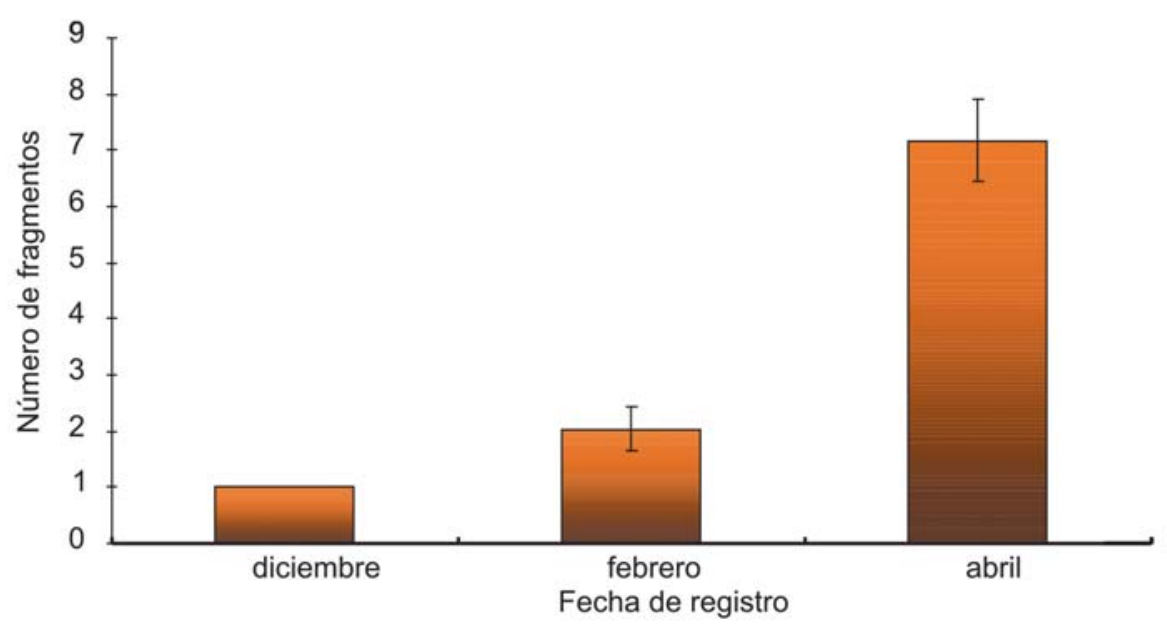

Figura 23. Número de fragmentos de plantas de trébol blanco en pasturas con trébol blanco sobre brunosoles de la región noreste, según la relación Iluvia/evaporación en la Figura 22.

Del mismo modo la producción agrícola estival de secano depende del volumen de lluvias en los meses de verano, como es el caso del cultivo de soja y el cultivo de maíz (Figura 26 y 27) (Olmos, 1983 b).

En la medida que hay mayores volúmenes de lluvia tanto en diciembre, enero y febrero para el maíz como en enero y febrero para la soja la producción de grano por hectárea se incrementa, básicamente porque en ambos períodos la mejor disponibilidad de agua en el suelo coincide con el inicio y establecimiento de la fase reproductiva de los cultivos.

La historia de la producción agropecuaria en el país y la región es la historia del impacto de la variabilidad climática presente en los ecosistemas naturales, fundamentalmente el régimen de lluvias. Hoy ante el incremento de la población mundial y la consecuente demanda por bienes, alimentos y servicios que ello conlleva, se incrementa 


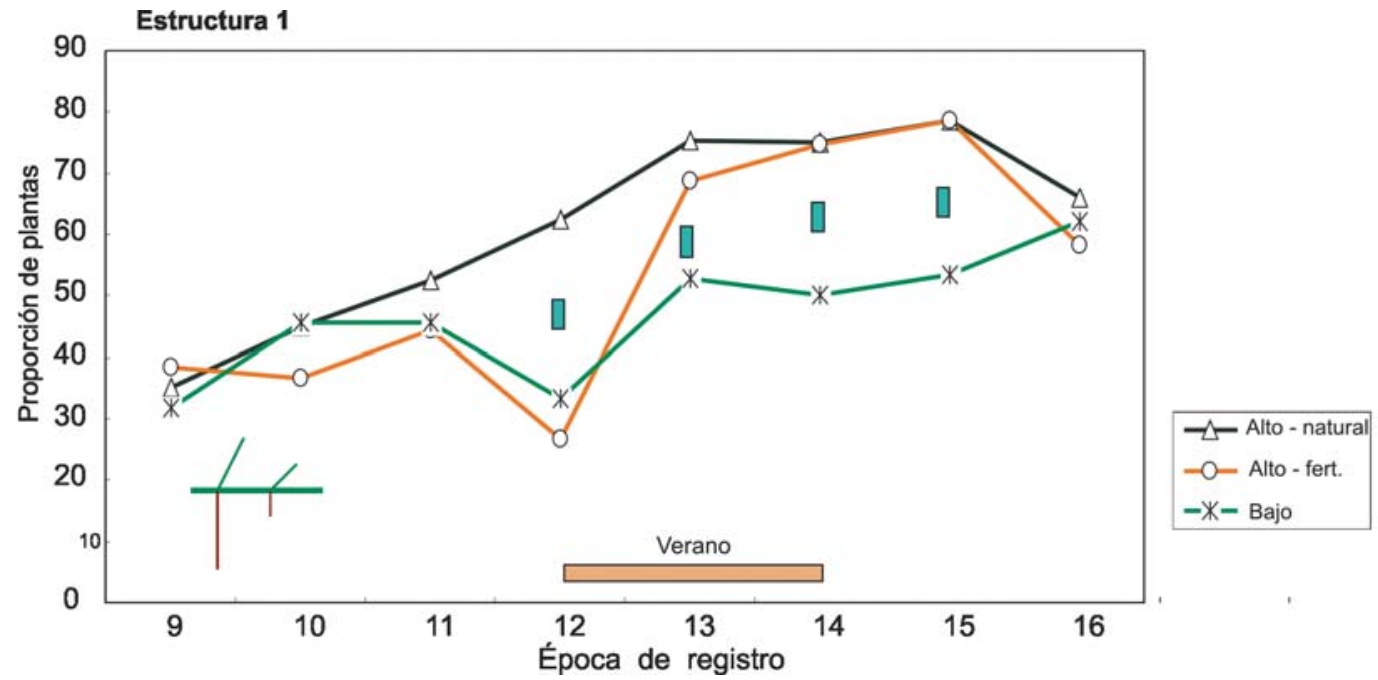

Figura 24. Variación en la proporción de plantas de trébol blanco de estructura uno, en pasturas de la región noreste, según la topografía, la fertilización y la época del año.

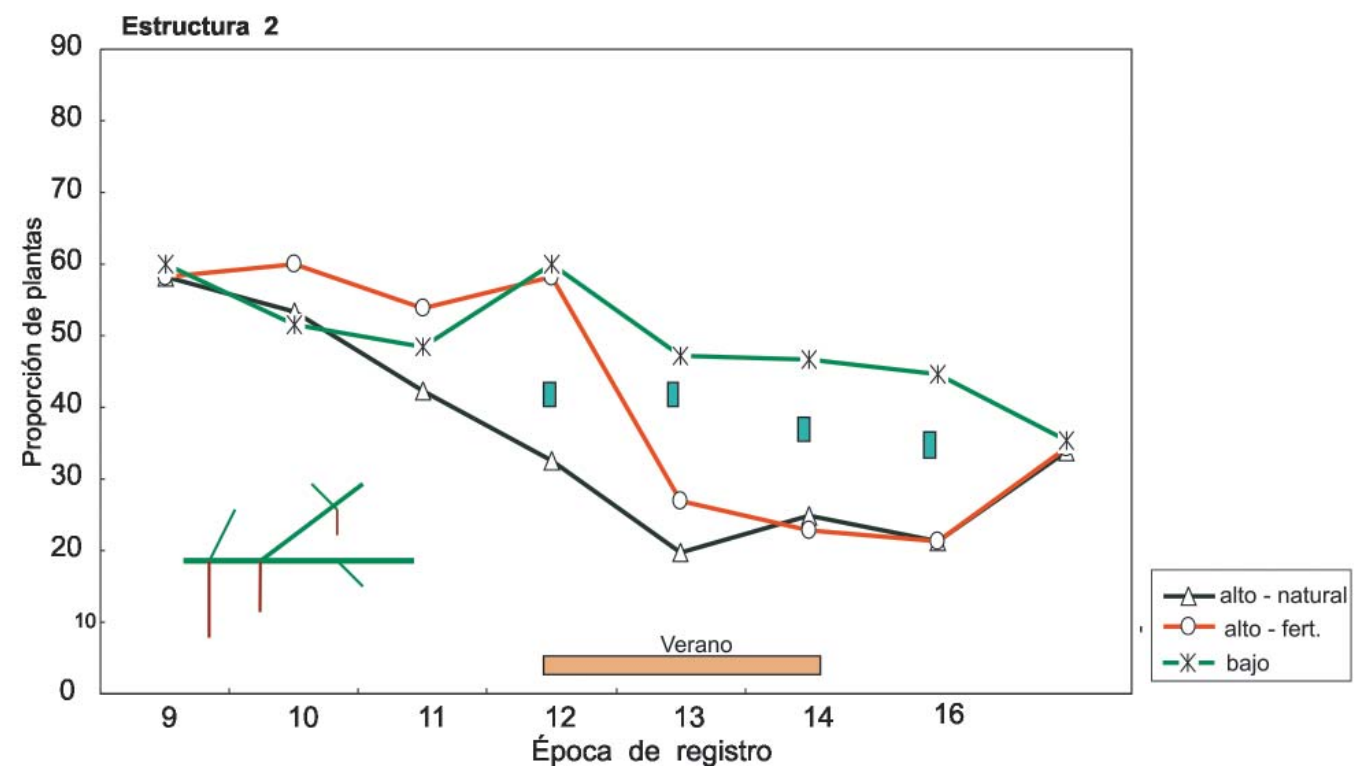

Figura 25. Variación en la proporción de plantas de trébol blanco de estructura dos, en pasturas de la región noreste, según la topografía, la fertilización y la época del año.

paulatinamente la presión productiva sobre los ecosistemas naturales proveedores de alimentos (Holechek, 2013).

En nuestra región esta presión ha significado el incremento en el área forestada, el área dedicada a cultivos graníferos de secano, la intensificación en la producción lechera y la intensificación en la producción ganadera. Sin embargo para los departamentos de Tacuarembó, Rivera y Cerro Largo todavía la producción ganadera basada en la productividad del campo natural es la principal actividad productiva (Figura 28).

Asimismo, la presión sobre el ecosistema se ha profundizado además, en el sentido que la propia forma de producción se ha intensificado tanto en el uso de insumos como en el acortamiento de los tiempos productivos. En los sistemas ganaderos actuales se destaca la propuesta en la reducción en el 


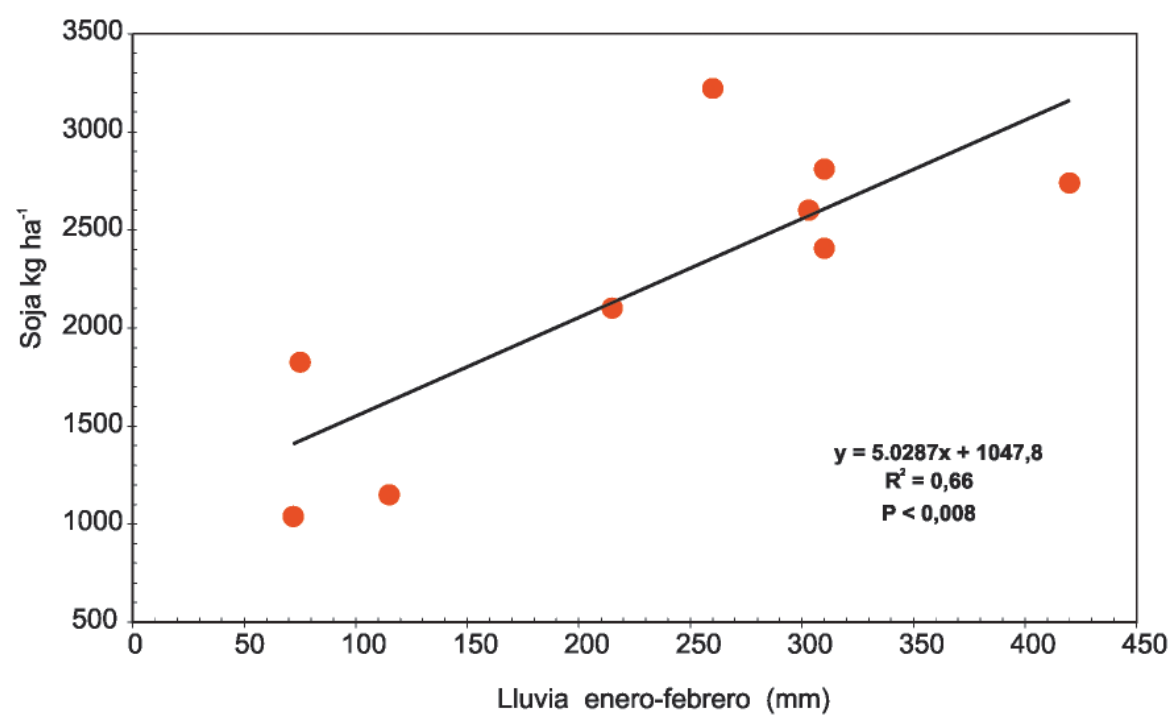

Figura 26. Variación en el rendimiento en grano de soja de variedades adaptadas,según la lluvia en verano (enero-febrero) en suelos de la región noreste.

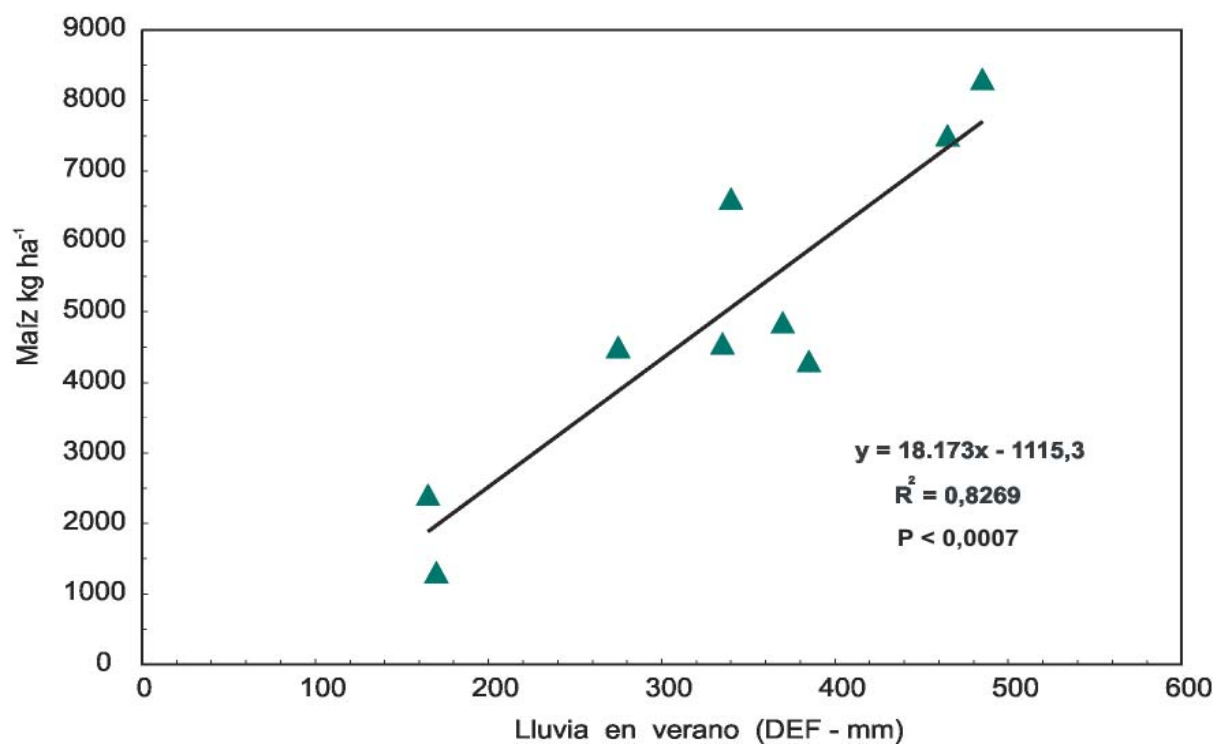

Figura 27.Variación en el rendimiento en grano de maíz de variedades adaptadas, según la lluvia en verano (diciembre-enero-febrero) en suelos de la región noreste.

período de engorde de los animales, el adelanto en la época del primer entore, el adelantamiento en la recría de las vaquillonas, entre otras actividades lo que ha llevado a un intensificación en el tiempo, es decir, producir lo mismo o más en menos tiempo (Bemhaja y Pittaluga, 2006). Este desarrollo ha sido traccionado fundamentalmente por el avance en el conocimiento científico de las actividades ganaderas y su transferencia hacia los productores, asociado al cambio en los precios de las commodities que seguramente están determinados por las demandas de la creciente población mundial.

Esta intensificación en los sistemas de producción basada en ecosistemas naturales, nos confronta con la variabilidad en los recursos naturales de suelo, topografía y el clima; en este sentido entonces la sensibilidad de los sistemas de producción a la va- 


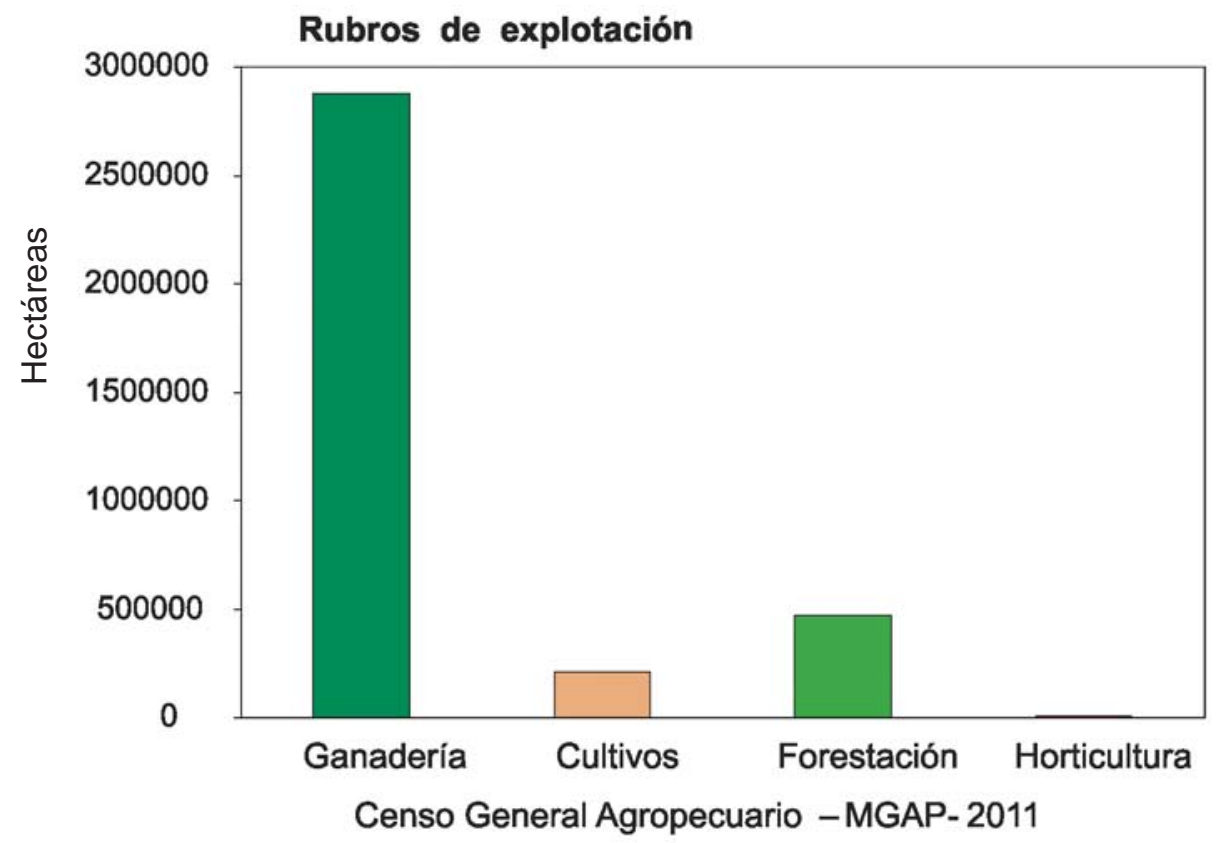

Figura 28. Superficie explotada según el rubro de producción en los departamentos de Tacuarembó, Rivera y Cerro Largo, en base a datos del Censo General Agropecuario - 2011.

riabilidad climática se ve incrementada, toda vez que las mismas actividades se realizan en menor tiempo, lo que determina por lo tanto que un período de estrés hídrico no será lo mismo en un sistema de ciclo completo con engorde de animales a más de cinco años comparado con un sistema donde se alcanza el engorde en tres o cuatro años, o con el acortamiento del período al primer entore de las vaquillonas. Cuanto más corto el ciclo de producción, el impacto de los períodos de estrés hídrico o del registro de eventos climáticos extremos será mayor sobre sistemas basados en los ecosistemas naturales.

En el mismo sentido del uso de modelos climáticos existen también propuestas de aplicación de modelos donde se analiza la interacción de la superficie con la variabilidad climática (Lawrence y Fisher, 2013). Estos modelos permiten, entre otras cosas, análisis tanto espaciales como temporales, la evaluación de las vulnerabilidades a eventuales cambios climáticos contribuyendo a un mejor entendimiento de los procesos hidrológicos y ecológicos.

\section{BIBLIOGRAFÍA}

ALLAN, R.; LINDESAY, J.; PARKER, D. 1996. El Niño Southern Oscillation \& Climatic Variability. CSIRO. Australia. 405 p.

BEMHAJA, M.; PITTALUGA, O. 2006. 30 años de investigación en suelos de areniscas. Serie Técnica No. 159. INIA Tacuarembó. $436 \mathrm{p}$

BREAKWELL, E. 1962. Reflexiones sobre pasturas. In: Anuario de la Sociedad Mejoramiento de Praderas. Montevideo. Uruguay. No. 6. pp.: 15-24.

CASTRILLÓN A.; PÍREZ, C. 1987. Evaluación de la capacidad de instalarse de especies forrajeras en el campo natural con diferentes tratamientos de laboreo. Tesis Agronomía. Universidad de la república, Facultad de Agronomía. Montevideo. 264 p.

CARVALHO, L. M.; JONES, CH.; LIEBMANN, B. 2004.The South Atlantic Convergence Zone: Intensity, Form, Persistence and Relationships with Intraseasonal to Interannual Activity and Extreme Rainfall. American Meteorologial Society. Vol 17: 88-108. 
CHON S. C.; BUSTAMANTE, J. F.; GOMES, J. L. 2005. Evaluation of Eta Model seasonal precipitation forecasts over South America. Nonliner Processes in Geophysics, 12: $537-555$.

CORSI, W. 1982. Regionalización agroclimática de Uruguay para cultivos. MAP. Centro Investigaciones Agrícolas A. Boerger. Estación Experimental Agropecuaria La Estanzuela. Miscelánea 40. 28 p.

CORSI, W.; OLMOS, F. 1982. Caracterización Climática de la Región Noreste. In: Reunión Técnica de Cultivos de Verano. MAP. Centro Investigaciones Agrícolas A. Boerger. Estación Experimental del Norte. Tacuarembó.

C. P. C. 2013. Climate Prediction Center. www.cpc.ncep.noaa.gov/products/ analysis_onitoring/enso_advisory. Consulta setiembre 2013.

GALLINAL, J. P.; BERGALLI, L. U.; CAMPAL, E. F.; ARAGONE, L.; B. ROSENGURTT, B. 1938. Estudios sobre Praderas Naturales del Uruguay. Primera Contribución. Imprenta Germano Uruguaya. Montevideo. 208 p.

GARDNER A.; ALBURQUERQUE, A.; CENTENO, G. 1966. Comportamiento de cinco variedades de Trifolium repens L. y Trifolium pratense L. bajo distintas frecuencias de pastoreo. Estación Experimental La Estanzuela. Centro de Investigaciones Agrícolas A. Boerger. Uruguay. Boletín Técnico No. 3. 28 p.

HOLENCHEK J. L. 2013. Global trends in population, energy use and climate: implications for policy development, rangeland management and rangeland users. The Rangeland Journal, 35: 117-129.

IPCC. 2007. Interguvernamental Pannel on Climatic Change. www.ipcc.ch/ publications_and_data/ar4/syr/es/ main.html. Cōnsultā setiembre 2013.

IRIONDO, M. H.; GARCíA, N.O. 1993.Climatic variations in the Argentine plains during the last 18.000 years. Palaeogeography, Palaeoclimatology, Palaeoecology. 101: 209 - 220. Elsevier Science Publishers. Amsterdam.

LAWRENCE, D.; FISHER, R. 2013. The Community Land Model Philosophy: model development and science applications. In: ileaps Newsletter. Integrated Land
Ecosystem - Atmosphere Process Study. GEWEX and iLEAPS land-surface modelling - Bridging the gaps. Issue No. 13 April. pp.: 16-19.

LINACRE, E.; GEERTS, B. 1997. Synoptic-Scale winds. In: Clmates \& Weather Explained. Routledge. London and New York. pp.:271-294.

MARENGO, J. A.; LIEBMANN, B.; GRIMM, A. M.; MISRA, V.; SILVADIAS, P. L.; CAVALCANTI,I. F. A.; CARVALHO, L. M. V.; BERBERY, E. H.; AMBRIZZI. T.; VERA, C. S.; SAULO, A. C.; NOGUES-PAEGLE, J.; ZIPSER, E.; SETH, A.; ALVES, L. M. 2010. Review. Recent developments on the South American monsoon system. International Journal of Climatology. (wileyonlinelibrary. com) DOI: 10.1002/joc.2254

OLMOS, F. 1978. Híbridos por densidad de plantas. In: Cultivos de verano en suelos arenosos. MAP. Centro Investigaciones Agrícolas A. Boerger. Estación Experimental del Norte. Día de Campo Unidad Experimental y Demostrativa de Producción La Magnolia. pp.: 2-4.

OLMOS, F. 1983 a. Características Agronómicas de la Región Noreste. In: 1ra. Jornada Agrícola-Ganadera de Caraguatá. MAP. Centro Investigaciones Agrícolas A. Boerger. Estación Experimental del Norte. Tacuarembó.

OLMOS, F. 1983 b. Registros climáticos. Relaciones con el rendimiento de los cultivos. In: Reunión Técnica Regional de Cultivos. MAP. Centro Investigaciones Agrícolas A. Boerger. Estación Experimental del Norte. Tacuarembó.

OLMOS, F. 1991 - Mejoramiento de pasturas naturales. Región Noreste. In: Pasturas y Producción Animal en Áreas de Ganadería Extensiva. INIA Serie Técnica No. 13. pp.: 91-102.

OLMOS, F. 1997 a. La productividad de pasturas en relación a los principales parámetros del clima. In: Efectos climáticos sobre la productividad de pasturas en la región noreste. Boletín divulgación No. 64. INIA Tacuarembó. pp.: 1-12.

OLMOS, F. 1997 b. Desarrollo agropecuario y agro-industrial en Tacuarembó. In: Tacuarembó de puertas abiertas. Eds. R. Esquivo y R. Zilli. Editorial Prisma. pp.: 79-94. 
OLMOS, F. 2001.Mejoramiento de pasturas con lotus en la región noreste. Serie Técnica No. 124. INIA Tacuarembó. 48 p.

OLMOS, F. 2004. Ecofisiología teórica y práctica. In: Factores que afectan la persistencia y productividad de pasturas mejoradas con trébol blanco (Trifolium repens). Serie Técnica No. 145. INIA Tacuarembó. pp.: 243-248.

OLMOS, F.; FRANCO. J.; SOSA, M. 2005. Impacto de las prácticas de manejo en la productividad y diversidad de pasturas naturales. In: Seminario de actualización técnica en manejo de campo natural. INIA. Serie Técnica No. 151. pp.: 93-103.

ROEL, A.; BAETHGEN, W. 2005. Asociación entre las fases de «El Niño» y la producción arrocera del Uruguay. Serie Técnica No. 148 . INIA Treinta y Tres. 19 p.

SHIMIZU, M. H.; AMBRIZZI, T. 2014. MJO influence on ENSO effects in precipitation and temperature over South America. WCRP Conference for Latin Amercia and Caribbean: developing, linking and applying Climate Knowledge. Abstracts. Montevideo. Uruguay. p.: 75.
SPANGENBERG, G. 1944. Tierras y pasturas del departamento de Cerro Largo. El problema que plantea la persistente sequía. Recuperación de pastoreos. Ministerio de Ganadería y Agricultura. Comisión Nacional de Estudio del Problema Forrajero. Apartado de la Revista de la Facultad de Agronomía No. 37, 31 p.

VERA, C. 2014. Regional Climate Monitoring: Current State and Perspectives.WCRP Conference for Latin Amercia and Caribbean: developing, linking and applying Climate Knowledge. Abstracts. Montevideo. Uruguay. p.: 57.

VERA, C.; BAEZ, J.; DOUGLAS, M.; EMMANUEL, C. B.; MARENGO, J.; MEITIN, J.; MNICOLINI, M.; NOGUES-PAEGLE, J. PAEGLE,J.; PENALBA, O.; SALIO, P.; SAULO, C.; SILVA DIAS, M. A.; SILVA DIAS, P.; ZIPSER, E. 2006 a. The south american low-level jet experiment. Bulletin of the American Meteorological Society, January 2006. 87: 63-77.

VERA C.; HIGGINS, W.; AMADOR, J.; AMBRIZZI, T.; GARREAUD, R.; GOCHIS, D.; GUTZLER, D.; LETTENMAIER, D.; MARENGO, J.; MECHOSO, C. R.; NOGUES-PAEGLE, J.; SILVA DIAS, P. L.; ZHANG, C. 2006 b. Toward a Unified View of the American Monsoon System. Journal of Climate. 19: 4977-5000. 



\section{ESTUDIO DE MICRO CASOS}

En este capítulo se presentan evidencias de adaptación y características locales de algunas especies herbáceas forrajeras. Las mismas deben ser consideradas como elementos de trabajo, herramientas o alternativas de uso en los sistemas ganaderos regionales.

\section{Bromus auleticus}

Bromus auleticus es una especie forrajera nativa de crecimiento otoño invernal que se encuentra en diferentes tipos de suelo en la región noreste así como en otras regiones del país. Evaluaciones regionales han permitido mostrar su valor como forrajera comparada con otras especies de alto potencial (Allegri y Formoso, 1978; Formoso y Allegri, 1984 a, 1984 b) mostrando que su productividad tanto otoñal como invernal (Figura 1) más que duplica los registros para los campos naturales de la región noreste sobre suelos arenosos y brunosoles (arcillosos).

Desde el punto de vista de la domesticación de la especie se han realizado diversos experimentos a los efectos de detectar el mejor método y con menor costo para la instalación de la especie. En este sentido en las Figuras 2 y 3 se reporta la mejor instalación de Bromus auleticus en la medida que se incrementa la densidad de siembra hasta $40 \mathrm{~kg} / \mathrm{ha}$ en cobertura sobre pasturas naturales en suelos arcillosos (brunosoles).

Asimismo, independientemente que se puedan instalar plántulas aún en condiciones extremas de sobrepastoreo como en el caso de la Figura 2, la protección o la reducción en la presión de pastoreo permitiría alcanzar un mayor número de plantas instaladas en siembras en cobertura sobre pasturas naturales.

En ambos casos, igualmente, aún a valores de siembra de $20 \mathrm{~kg} \mathrm{ha}^{-1}$ se alcanzó la instalación de 4-5 plántulas $/ \mathrm{dm}^{2}$, lo que en base a manejo de la pastura permitiría un cambio sustancial en el ciclo productivo con la presencia de una especie invernal como Bromus auleticus.

En la Figura 3 por otra parte, se graficó tanto la evolución de la proporción de Bromus auleticus con la aplicación de nitrógeno como con la introducción también de Lotus corniculatus en cobertura en la pastura; se observa un mayor proporción de bromus con las aplicaciones de nitrógeno, sobretodo en las densidades de siembra más bajas, com-

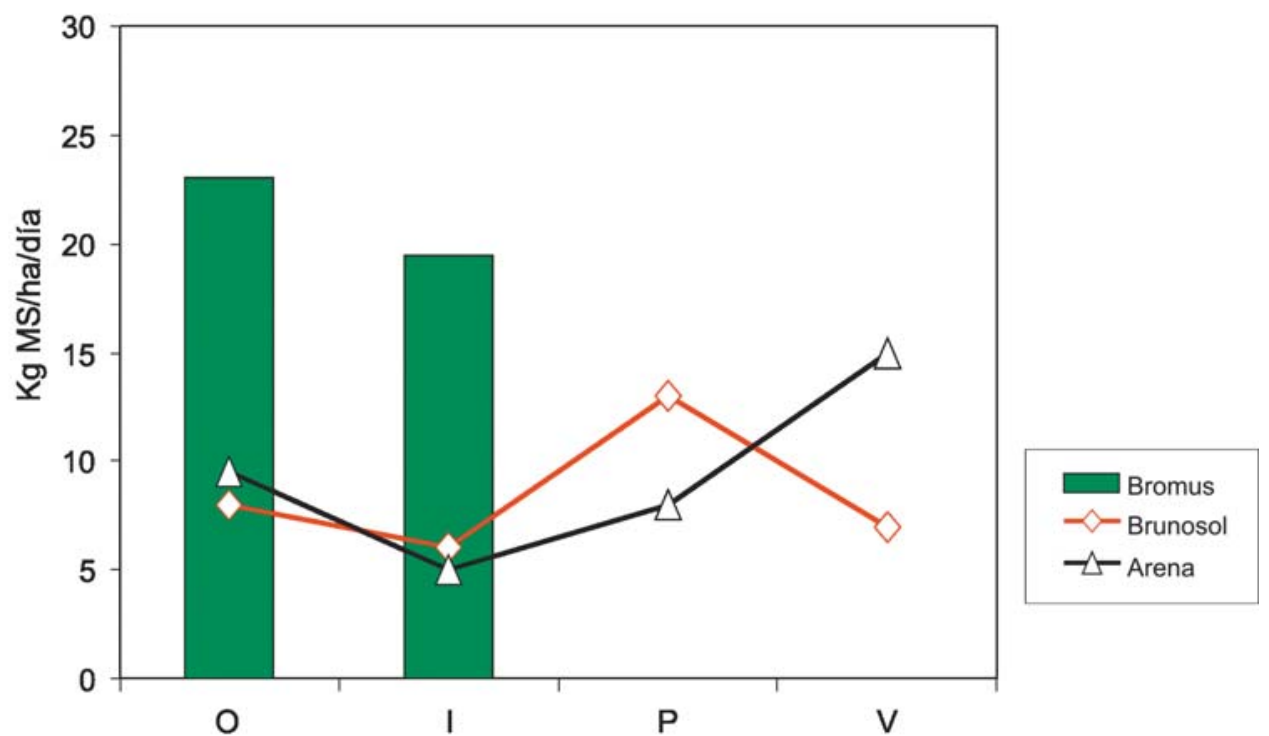

Figura 1. Productividad en kg MS/ha/día de Bromus auleticus en pasturas naturales de la región noreste sobre suelos arenosos y arcillosos (brunosoles). 


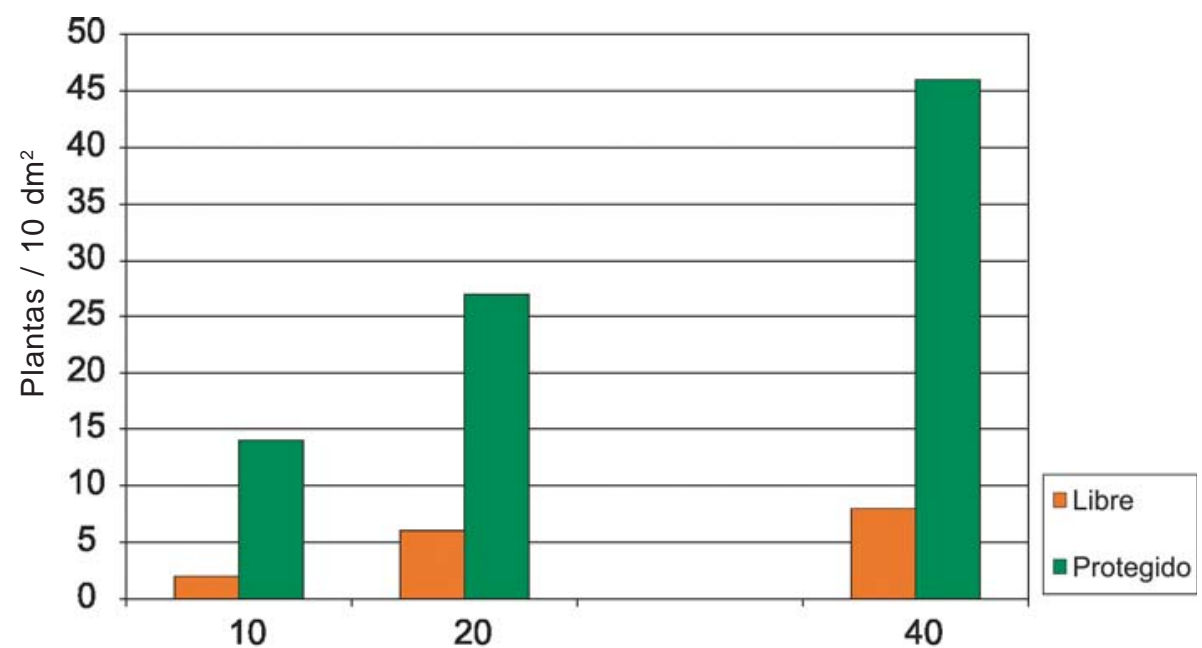

$\mathrm{Kg}$ semilla/ha

Figura 2. Instalación de plántulas de Bromus auleticus sembradas en cobertura sobre campo natural en suelos arcillosos de la región noreste (protegido-con jaulas de exclusión del pastoreo, libre-sin jaulas de exclusión).

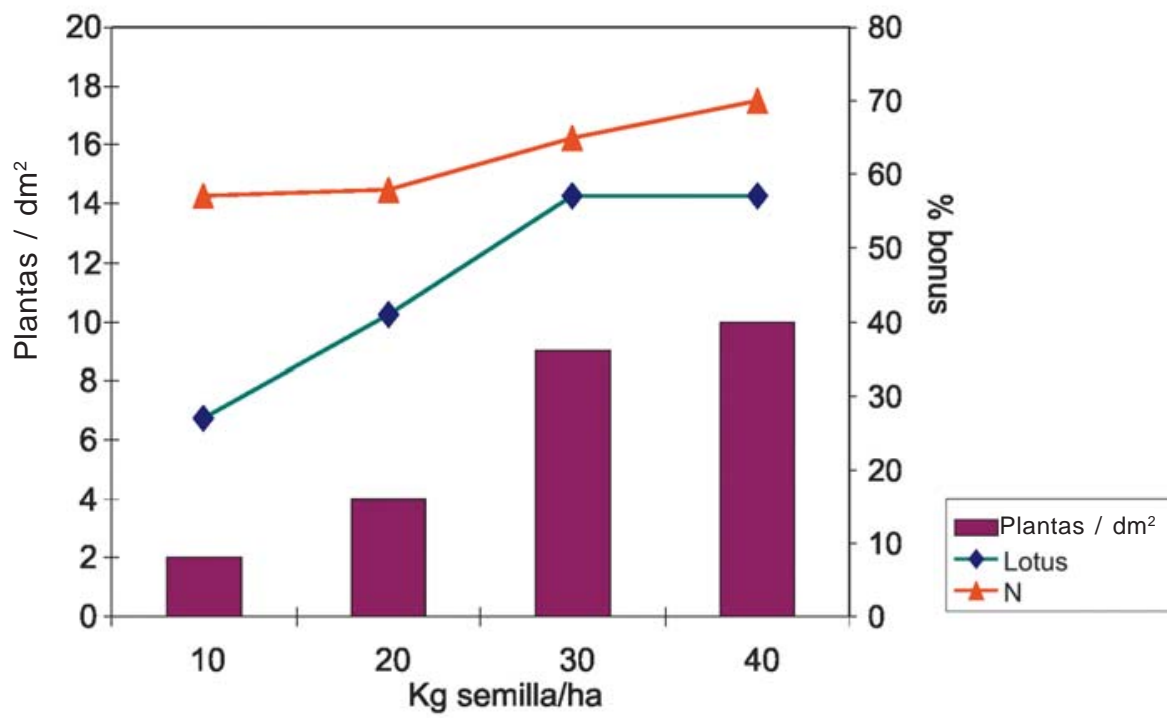

Figura 3. Instalación de plantas de Bromus auleticus (barras) en pasturas naturales obre suelos arcillosos de la región noreste y proporción de la especie en el segundo año según la densidad de siembra y la inclusión de Lotus corniculatus o nitrógeno mineral (líneas). Campo Experimental E. Castro-Cuchilla del Ombú.

parado con la presencia de lotus. Podría especularse que con baja densidad y nitrógeno se podría alcanzar una buena cobertura de la especie e incrementar la productividad asociada a un ciclo más otoño invernal y no tan estival como las pasturas naturales de la región en general (Figura 1). También puede especularse que el aporte de nitrógeno al sistema por parte de lotus ocurriría a mediano plazo con la presencia de animales en pastoreo (reciclaje) y no rápidamente como ocurrió con las aplicaciones de nitrógeno como urea.

Esta capacidad de instalarse de la especie cuando es sembrada en cobertura fue reportada inicialmente por Olmos (1985), Olmos (1993) y Castrillón y Pírez (1987) indicando, en comparación con otras especies, 
Cuadro 1. Instalación de seis especies forrajeras sobre pasturas naturales en suelos arcillosos (brunosoles) de la región noreste presencia 2do. año (especies con la misma letra no difieren estadísticamente). Fuente Castrillón y Pírez (1984).

\begin{tabular}{|c|c|c|c|c|c|c|c|}
\hline \multicolumn{2}{|c|}{ Disquera-vibro } & \multicolumn{2}{|c|}{ Disquera } & \multicolumn{2}{|c|}{ Vibro } & \multicolumn{2}{|c|}{ Campo natural } \\
\hline Holcus 61 & & Blanco & $45 \mathrm{~A}$ & Lotus & $38 \mathrm{~A}$ & Bromus & $11 \mathrm{~A}$ \\
\hline Blanco & $A B$ & Lotus & $28 \mathrm{AB}$ & Bromus & $26 \mathrm{AB}$ & Lotus & $11 \mathrm{~A}$ \\
\hline Lotus & B C & Holcus & $25 \mathrm{~B}$ & Holcus & 21 & Holcus & $0,7 \mathrm{~B}$ \\
\hline Subt. & C D & Bromus & $\mathrm{BC}$ & Blanco & 14 & Festuca & --- \\
\hline Bromus & $\mathrm{D}$ & Festuca & 8 BC & Festuca & 6 & Subt. & --- \\
\hline Festuca 11 & D & Subt. & $5 \quad C$ & Subt. & 6 & Blanco & --- \\
\hline
\end{tabular}

que la misma mejora su instalación cuando menos intervenida es la pastura natural donde se va a sembrar (Cuadro 1).

Además de sus características en productividad de forraje, Bromus auleticus presenta una alta calidad del mismo, con valores de proteína del orden de 18-20\% durante su principal ciclo de crecimiento (Olmos, 1993).

Desde el punto de vista de su multiplicación la especie muestra un amplio rango de producción de semilla entre $300-1.100 \mathrm{~kg} \mathrm{ha}^{-1}$ de fácil cosecha (Olmos, 1993), lo que conjuntamente con los atributos mencionados anteriormente la hace muy factible de utilizar en establecimientos comerciales. La consideración de los principales eventos fenológicos es crucial para lograr estos objetivos (Figura 4).

Durante el período invernal la primer especie nativa en la que se diferencia el ápice vegetativo en reproductivo es Poa lanigera, seguida por Bromus auleticus, Stipa setigera y finalmente Hordeum stenostachys, manteniéndose el mismo orden en los eventos de alargamiento del tallo floral y la maduración de la semilla.

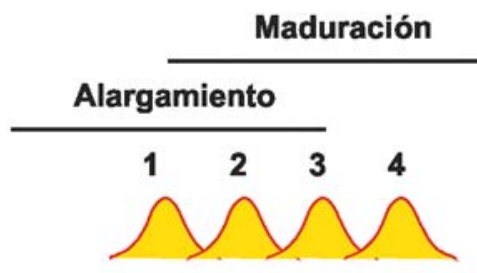

\section{Superficie del suelo}

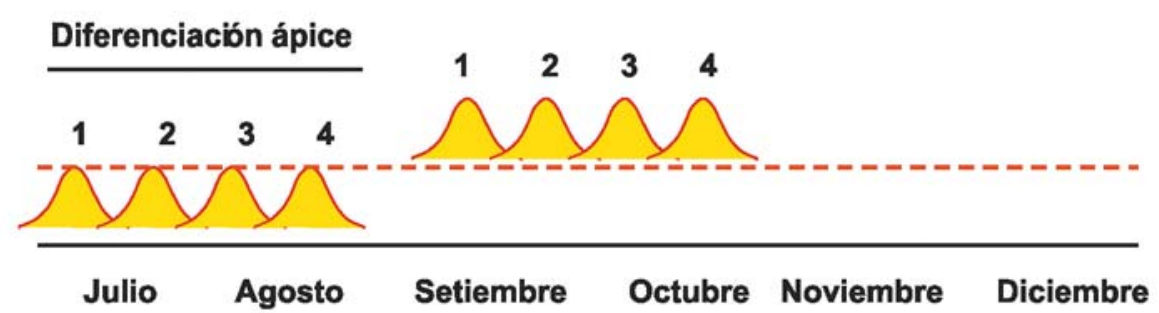

\section{1 - Poa 2 - Bromus 3 - Stipa 4 - Hordeum}

Figura 4. Diagrama comparativo de cuatro especies forrajeras nativas invernales indicando la posición del ápice reproductivo hasta la floración (Olmos, 1991). 


\section{Bothriochloa laguroides}

Bothriochloa laguroides es un componente interesante de las pasturas naturales ya que es una especie tolerante a los períodos de estrés hídrico o de sitios que por su topografía son relativamente más secos (Rosengurtt, 1979), aportando al sistema de producción un componente de resiliencia.

Esta es una especie de crecimiento erecto, cespitosa, que responde a los cambios en la intensidad de pastoreo, aumentando o disminuyendo su presencia en la pastura con menor o mayor presión de pastoreo respectivamente (Capitulo II, esta publicación). Estos resultados obtenidos en condiciones de campo fueron corroborados en condiciones de invernáculo donde se registró claramente que ante la presencia de tratamientos de corte intensivos, como cortes a dos centímetros de altura cada dos semanas, comparados con los tratamientos más aliviados con corte a cinco centímetros de altura cada cuatro semanas, plantas más chicas y con un menor número de macollos por planta en el primer caso comparado con el tratamiento menos intensivo (Figuras 5 y 6 ).

En el caso de los macollos en la Figura 6 , en condiciones de menor intensidad de corte la cantidad de los mismos es práctica-

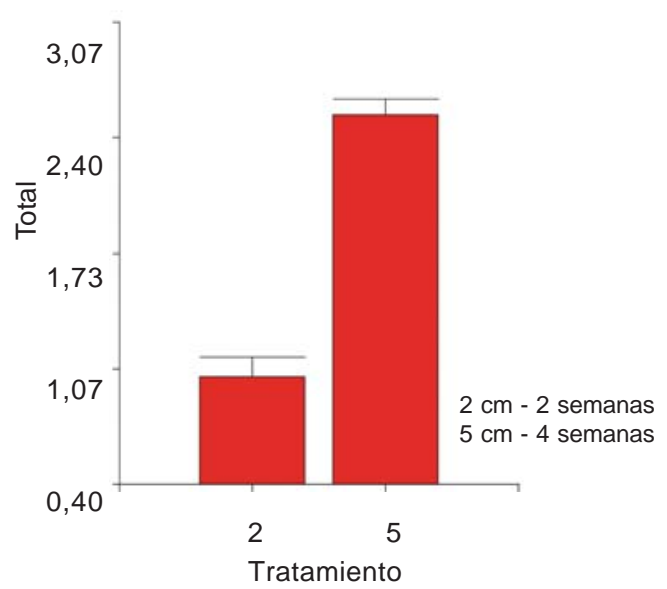

Figura 5. Peso total de plantas de Bothrichloa laguroides según el tratamiento de corte de forraje cada dos o cuatro semanas en condiciones de invernáculo. mente tres veces superior a la condición del tratamiento con mayor intensidad de corte cada dos semanas; 25 macollos para el primer caso comparado con 8 macollos de valore medio en el segundo caso.

Asimismo se pudo registrar que en los tratamientos de mayor intensidad de uso con corte cada dos semanas a dos centímetros de altura el número de plantas disminuyó prácticamente en un $50 \%$ comparado con el tratamiento más aliviado de corte cada cuatro semanas y a cinco centímetros de altura (Figura 7).

El corolario de estos resultados indica que el manejo propio del régimen de pastoreo en una pastura natural determina la mayor o menor presencia de algunas especies y eso se encuentra vinculado no solo a los niveles de productividad de las mismas sino que también su capacidad de resiliencia frente a diferentes impactos más o menos intensos, tal cual pueden ser los períodos de estrés hídricos comunes en estos ecosistemas naturales. Esta especie, además su relativa tolerancia al estrés hídrico tiene alto nivel de recuperación potencial de sus poblaciones toda vez que se ha constatado, luego de la cosecha en condiciones de campo de la semilla, valores de germinación mayores a $60 \%$.

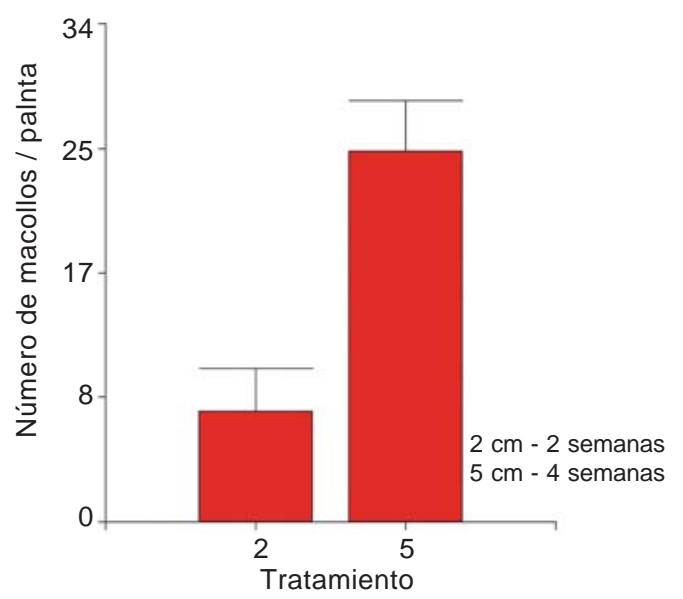

Figura 6.Número de macollos en plantas de Bothrichloa laguroides según el tratamiento de corte de forraje cada dos o cuatro semanas en condiciones de invernáculo. 


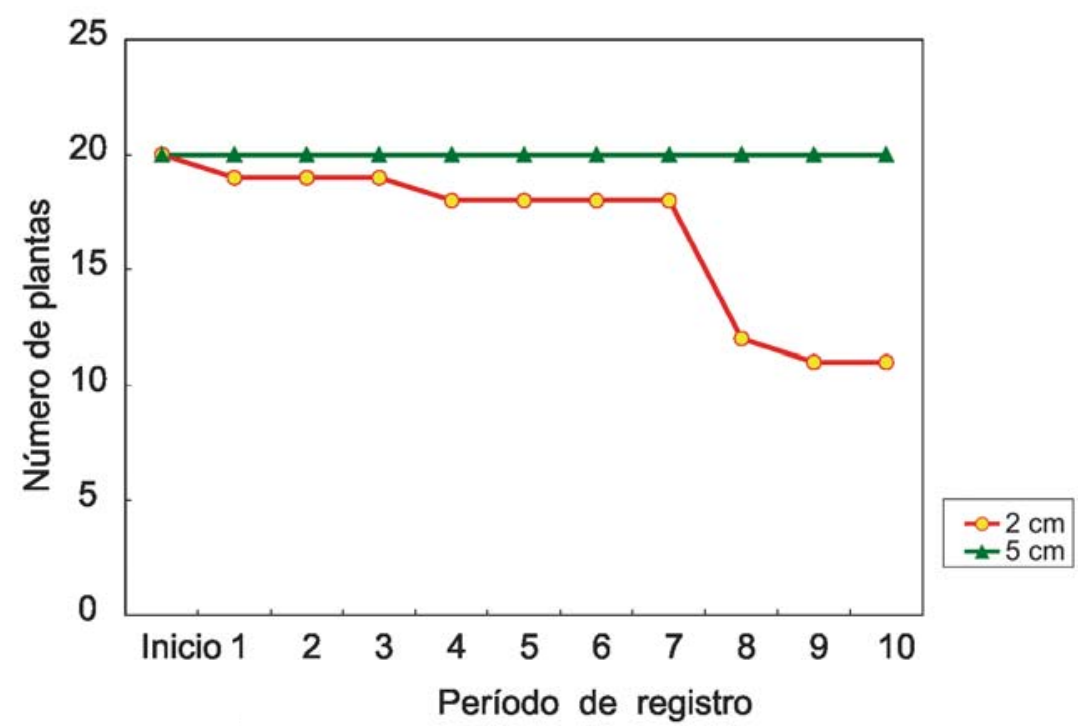

Figura 7. Sobrevivencia de plantas de Bothrichloa laguroides según el tratamiento de corte de forraje cada dos o cuatro semanas en condiciones de invernáculo.

\section{Andropogon lateralis}

\section{Alternativas de Uso de Andropogon lateralis}

En el año 1990 se separó una parte de un potrero sobre un suelo arenoso en la Unidad Experimental La Magnolia, donde predominaba Andropogon lateralis, a los efectos de imprimirle un tratamiento de pastoreo que repitiera las condiciones observadas en pasturas de la región donde el mismo persistía aún bajo altas presiones de pastoreo.

La pastura inicialmente se encontraba con una cantidad de forraje disponible mayor a $3.500 \mathrm{~kg} \mathrm{MS} / \mathrm{ha}$, a los efectos de aumentar la presión de pastoreo se procedió a la inclusión de lanares, fundamentalmente capones, con una carga del orden de 30 animales adultos por hectárea (mayores a $40 \mathrm{~kg}$ de peso vivo) desde el mes de noviembre hasta finalizado el mes de abril (Figura 8).

Inicialmente el pastoreo de los animales fue normal sin problemas a pesar de la alta disponibilidad, luego la pastura fue adoptando una especie de doble perfil donde las plantas erectas de $A$. lateralis se destacaban por sobre las rastreras como Axonopus affinis y Paspalum notatum (Figura 9).
Al mismo tiempo se monitoreó la evolución de la pastura natural luego de la división de un potrero destinado a la cría de ganado vacuno donde se incrementó la presión de pastoreo, en la misma unidad experimental. En la Figura 10 se observa el proceso ocurrido en el potrero de cría donde las plantas erectas de Andropogon lateralis iban paulatinamente reduciendo su tamaño dando lugar a las especies de hábito de crecimiento rastrero.

En una tercera etapa, en la pastura sometida a alta carga con lanares, se comenzó a observar una nueva reducción en el tamaño de las plantas de Andropogon lateralis, incluyendo la apertura en el centro de las mismas, en donde se fue posibilitando la invasión por parte de las especies de hábito rastrero como Axonopus affinis y Paspalum notatum. Finalmente luego de haberse mantenido una alta presión de pastoreo durante seis meses sobre la pastura comenzó a incrementar la presencia de Juncus sp. (Figura 11).

Estas observaciones fueron coincidentes con las obtenidas en los relevamientos regionales (Capítulo II), donde en las zonas de topografía más baja, en las márgenes de rastrojos de cultivos de soja se observaron plan- 


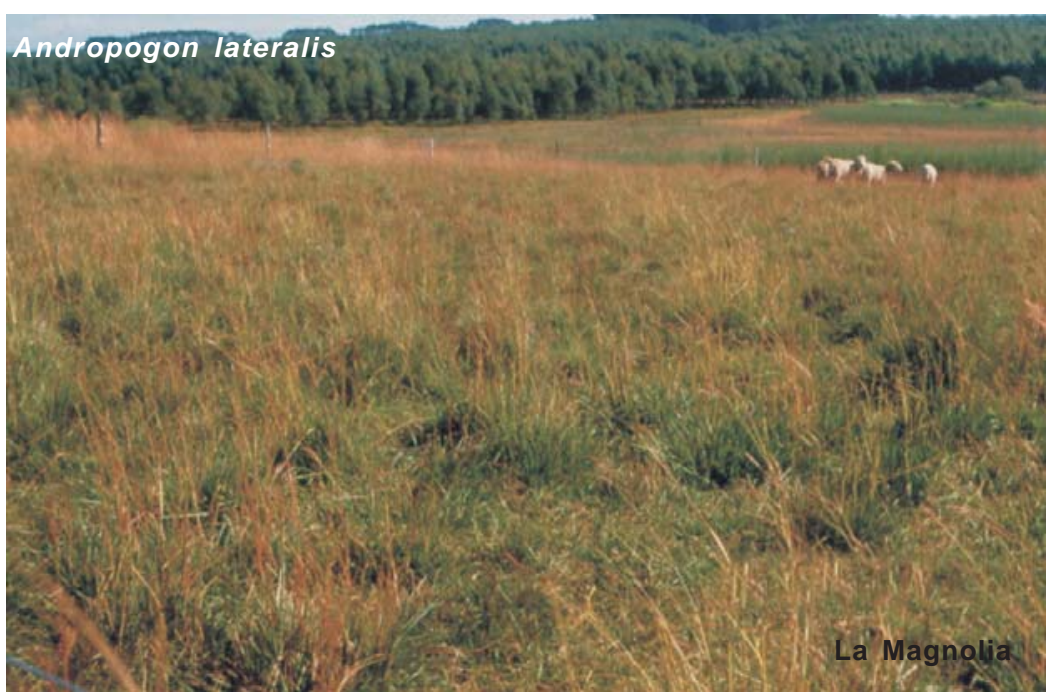

Figura 8. Pastoreo de pastura dominada por Andropogon lateralis en la Unidad Experimental La Magnolia con alta carga de lanares.

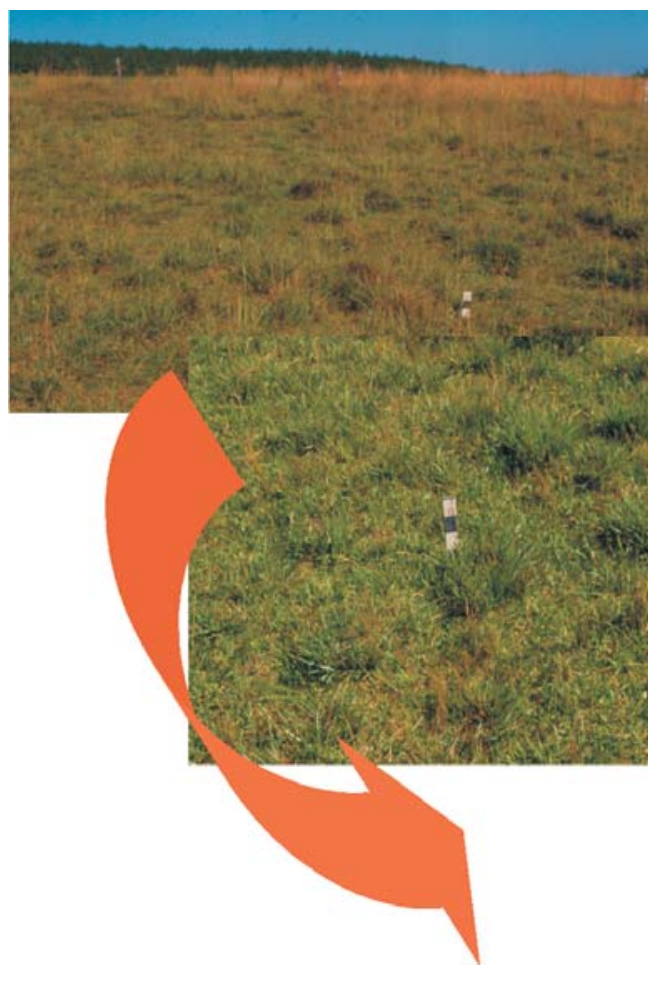

tas de Andropogon lateralis sometidas a muy altas presiones de pastoreo como en la Figura 12. En dicha figura se destaca el porte achaparrado de la especie así como la apertura central en la planta permitiendo la entrada de especies de hábito de crecimiento rastrero al igual que lo registrado en la Unidad Experimental La Magnolia.
Figura 9. Evolución de una pastura dominada por Andropogon lateralis a una situación de doble perfil con incremento de especies de hábito de crecimiento rastrero.

Doble perfil

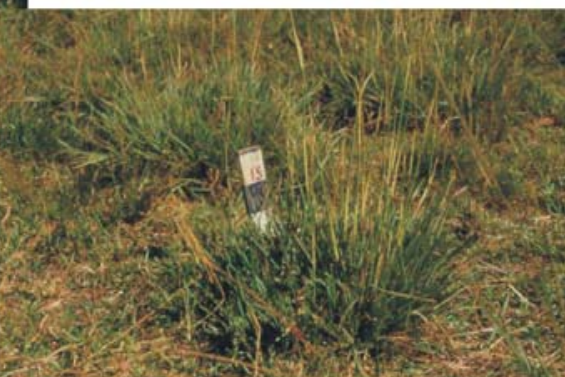

Esta especie no solo tiene una amplia adaptación a diferentes niveles de presión de pastoreo como se vio en los tres casos anteriormente descritos sino que además tiene un alto potencial de acumulación de forraje, el cual estimamos que perfectamente puede adaptarse para su utilización luego de la parición en los sistemas ganaderos de cría 

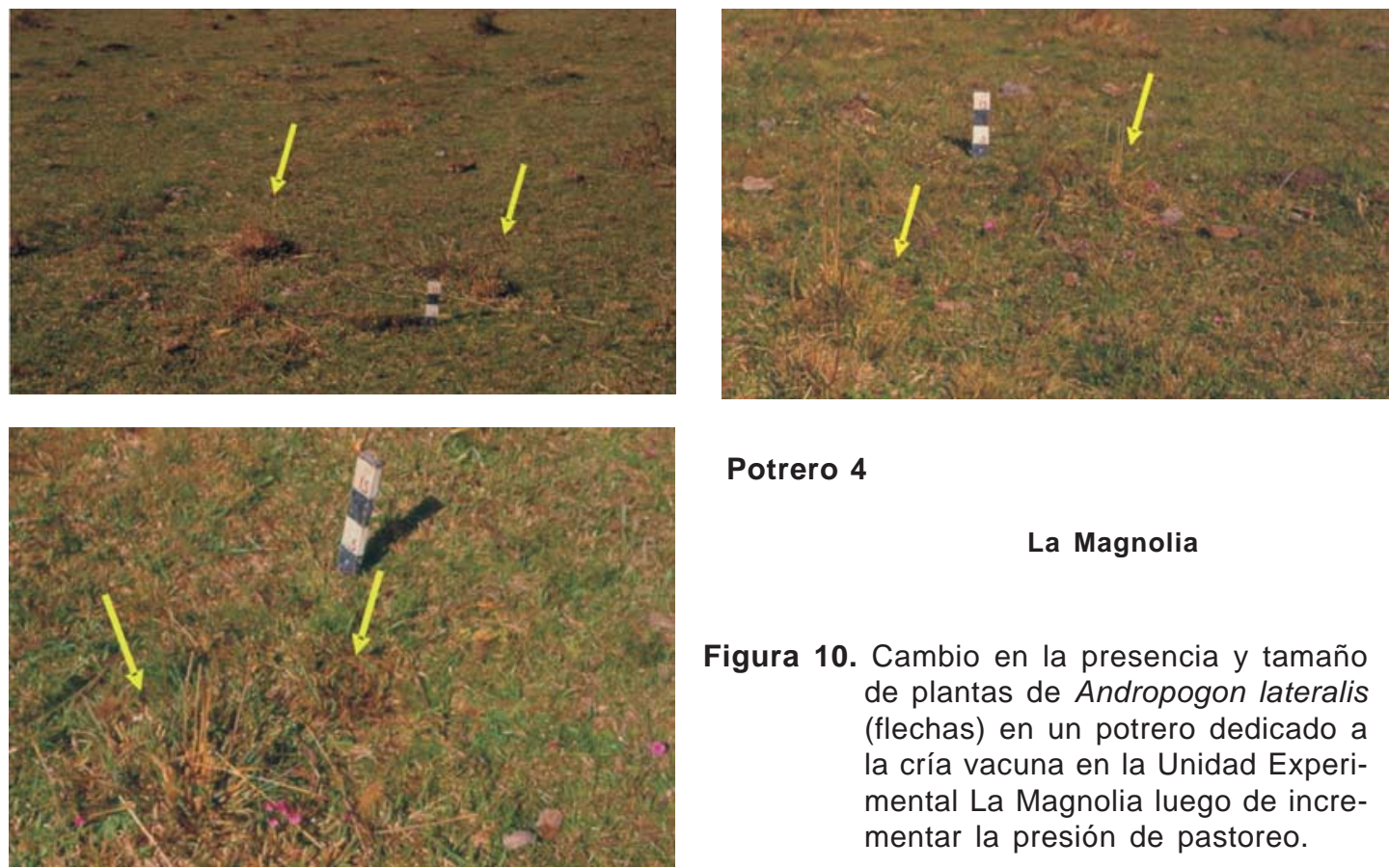

\section{Potrero 4}

La Magnolia

Figura 10. Cambio en la presencia y tamaño de plantas de Andropogon lateralis (flechas) en un potrero dedicado a la cría vacuna en la Unidad Experimental La Magnolia luego de incrementar la presión de pastoreo.

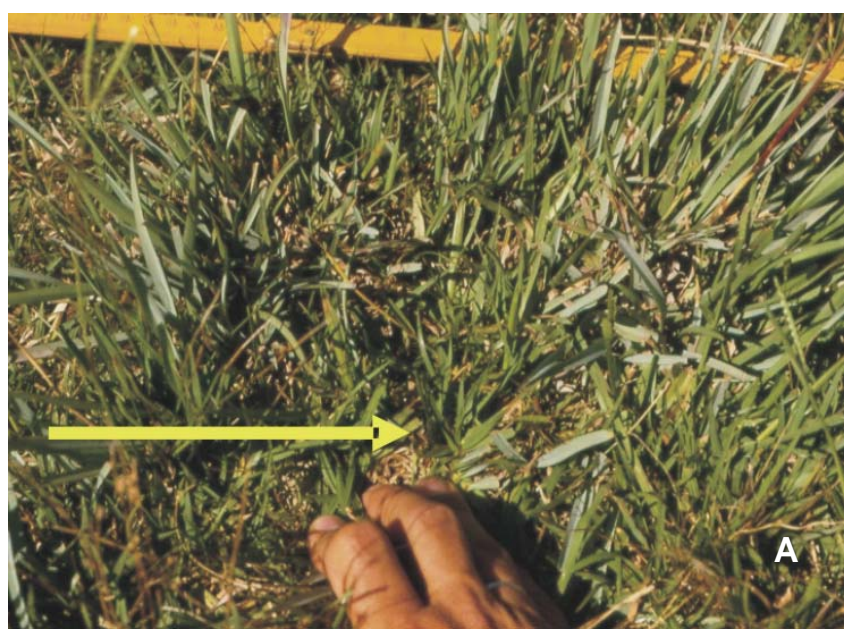

Figura 11. Presencia de especies de hábito de crecimiento rastreo (Paspalum notatum (A)) y resistentes al pastoreo (Juncus sp.(B)) dentro de plantas de Andropogon lateralis en la Unidad Experimental La Magnolia.

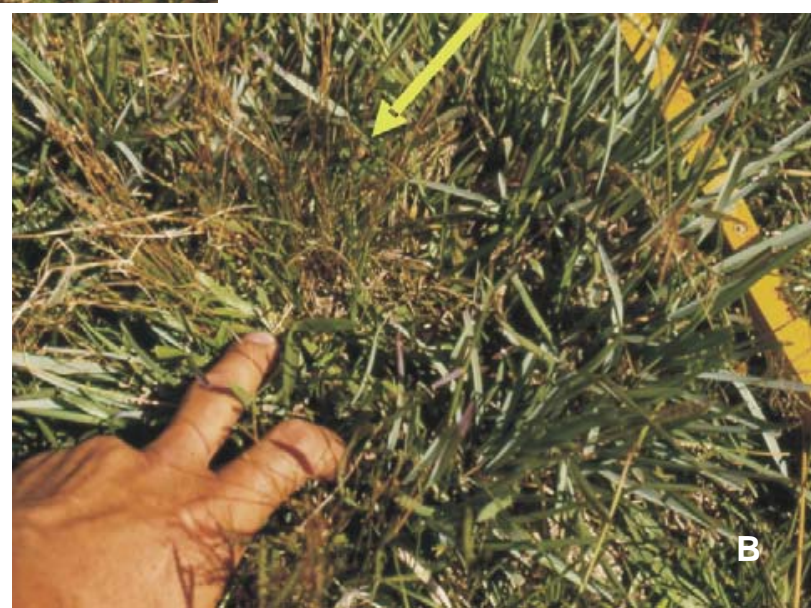




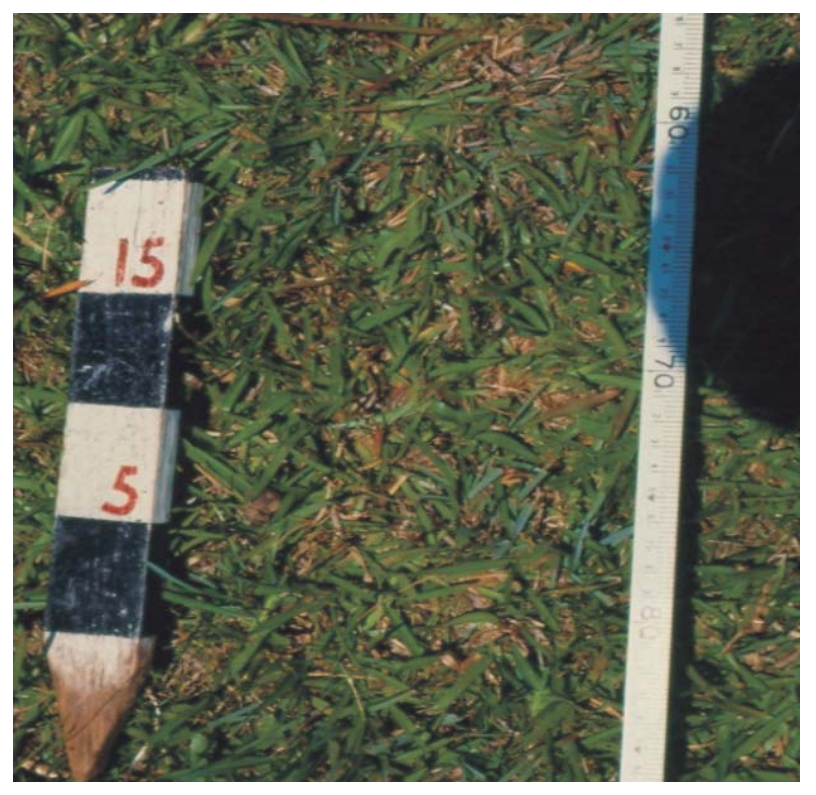

Figura 12. Presencia y forma de plantas de Andropogon lateralis en bordes de chacra de soja (Dpto. de Rivera (1987)) en brunosoles de la región noreste.

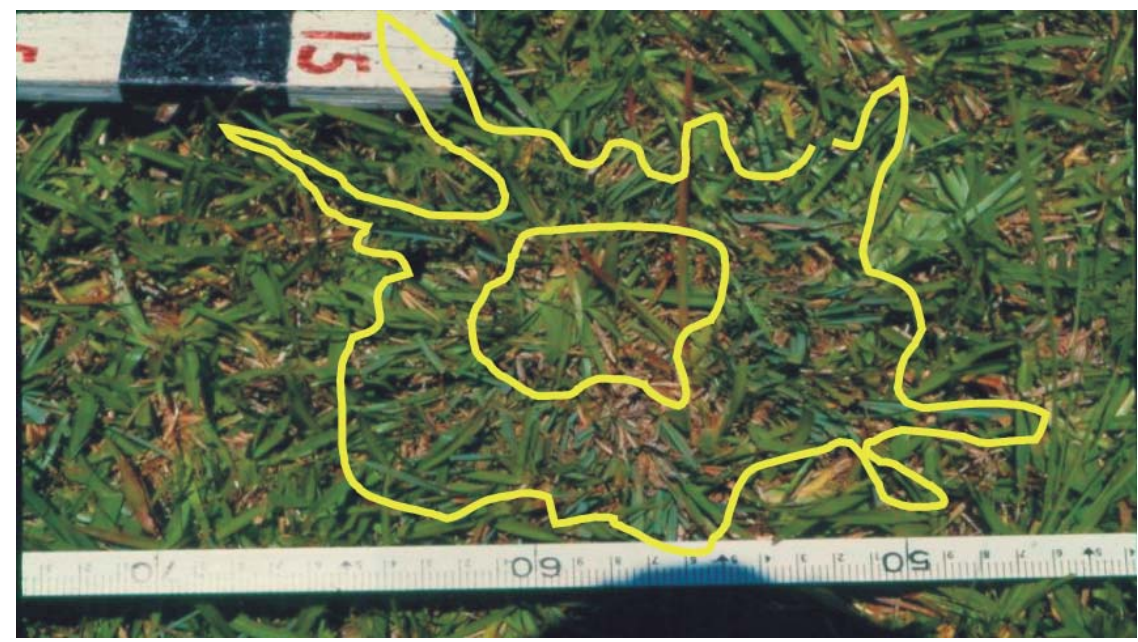

y fundamentalmente como base forrajera para el período de entore a fines de la primavera e inicios del verano. Si bien no dispones de registros que nos indiquen diferentes formas de acumulación de la especies iniciando en diferentes momentos de la primavera, estimamos que los volúmenes pueden ser muy importantes cuando la especie es dominante en la pastura natural. En la Figura 13 se hace una estimación del crecimiento de la pastura y el inicio de su período reproductivo como forma de destacar su mejor aporte al sistema de producción basado en campo natural. Seguramente con mayor información sobre la época de acumulación de forraje y su calidad se podrán implementar medidas de manejo más ajustadas en el rodeo de cría regional.

\section{Coelorachis selloana}

Coelorachis selloana es una especie cespitosa, perenne, de crecimiento estival, con una apetecibilidad prolongada y productividad media, es considerada una especie tierna, de acuerdo a la clasificación de Rosengurtt (1979). El mismo autor (Rosengurtt, 1980) incluye a esta especie en una lista de especies promisorias, conjuntamente con Bromus auleticus, Paspalum dilatatum y Poa lanigera entre 


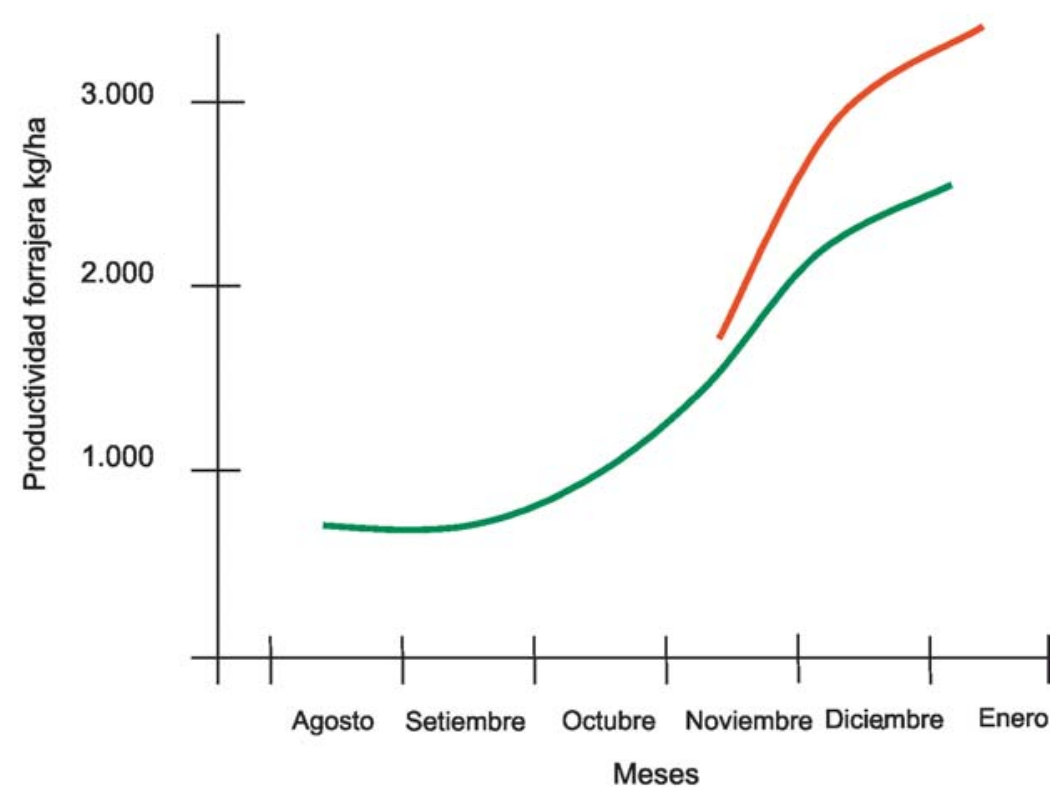

Figura 13. Estimación de la productividad forrajera (línea verde) y el inicio del período reproductivo (línea roja) en Andropogon lateralis en el período primavera-inicio del verano.

otras, dado su potencial para ser utilizadas en los sistemas ganaderos.

En la región se encuentra principalmente en los suelos arcillosos (Capítulo II) con mayor frecuencia, sin embargo también es encontrada en otros tipos de suelo; desde el punto de vista del manejo del pastoreo, fue reportada su presencia tanto en situaciones de extrema presión de pastoreo hasta situaciones donde el pastoreo es relativamente aliviado con ganado vacuno. En condiciones de campo es posible encontrarla debajo de E. trinii, compitiendo con E. nudicaule, debajo $E$. horridum o incluso entremezclada con Cynodon dactylon. Es una importante forrajera que se encuentra en las pasturas naturales de la región noreste.

En un experimento con diferentes ofertas de forraje la especie mostró un incremento significativo con la mayor oferta, es decir una menor presión de pastoreo; esta respuesta se verificó en la temporada de crecimiento primavera - otoño durante tres años en Bañado Medina (Olmos et al., 2011) (Figura 14).

A los efectos de verificar la respuesta de la especie a la presión e intensidad de uso, se analizó su respuesta en productividad con diferentes tratamientos de altura y frecuencia de corte (Figura 15) durante una estación de crecimiento primavera - otoño; los resultados indicaron un menor crecimiento en la situación de corte a $2 \mathrm{~cm}$ de altura cada dos semanas (tratamiento 2) comparada con los otros tratamientos dos semanas corte 5 cm (tratamiento 3), a cuatro semanas corte a $2 \mathrm{~cm}$ (tratamiento 4), a cuatro semanas corte a $5 \mathrm{~cm}$ (tratamiento 5) y ocho semanas (tratamiento 1), respaldando lo observado en el campo en pastoreo donde la pastura usada menos intensamente incrementó la presencia de la especie. En la Figura 16 se aprecia la diferencia entre plantas clonadas que fueron cortadas cada dos semanas y plantas cortadas cada ocho semanas a $2 \mathrm{~cm}$ de altura durante la temporada de crecimiento.

La posibilidad de incrementar la frecuencia de Coelorachis selloana en las pasturas naturales, mediante el manejo del pastoreo, seguramente podría contribuir a mejorar la productividad general de las mismas.

\section{Stipa charruana}

Esta especie es considerada una especie dura (Rosengurtt, 1979) de apetecibilidad 


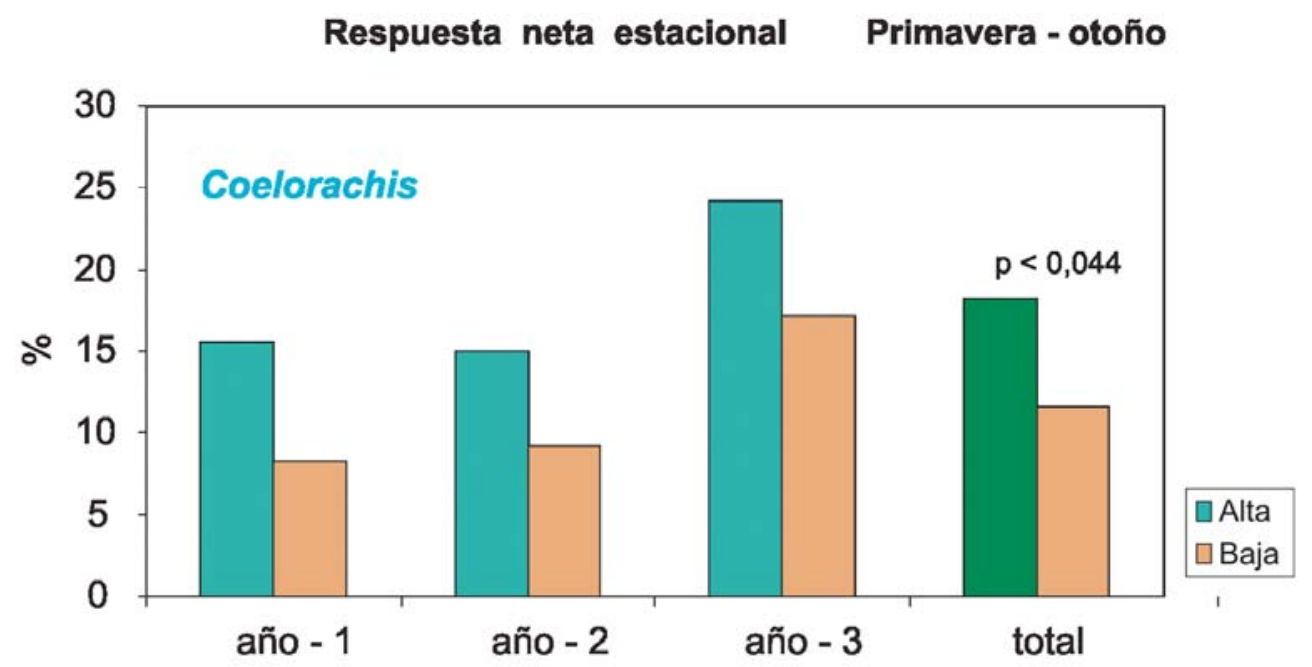

Figura 14. Cambio en la presencia de Coelorachis selloana en pasturas naturales de Bañado Medina según la oferta de forraje en el período primaveraotoño durante tres años consecutivos.

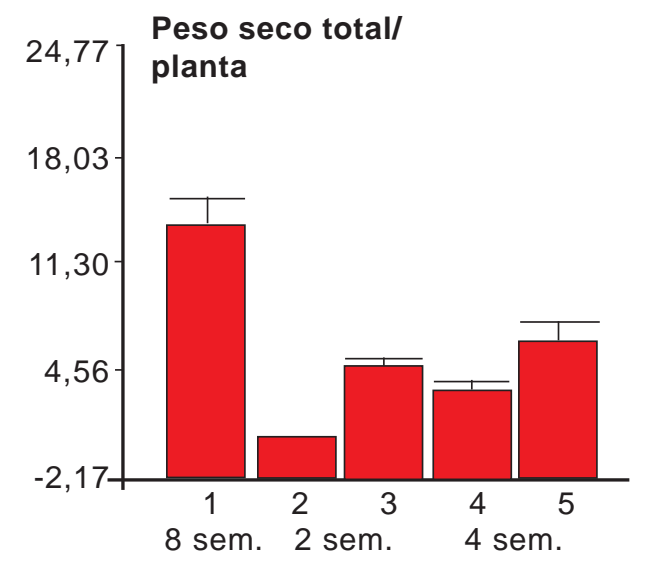

Figura 15. Producción de forraje por plantas de Coelorachis selloana sometidas a tratamientos de intensidad y frecuencia de corte en condiciones de invernáculo.

Figura 16. Comparación de plantas (genotipo no. 108) sometidas a dos tratamientos de intensidad y frecuencia de corte, I corte a $2 \mathrm{~cm} \mathrm{cada}$ ocho semanas y II corte a $2 \mathrm{~cm}$ cada dos semanas.

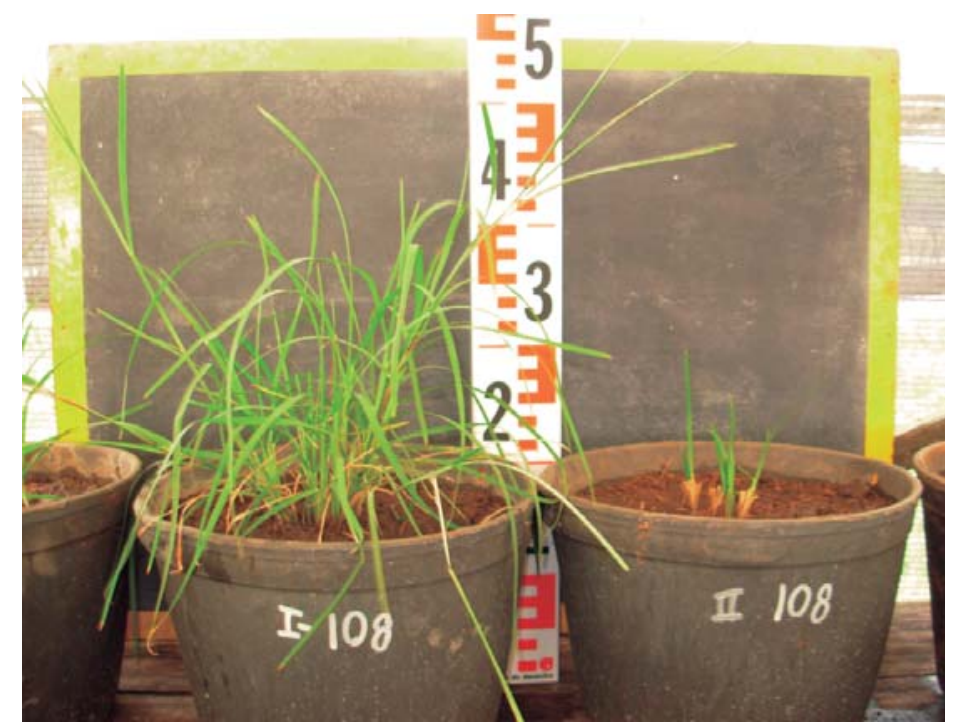




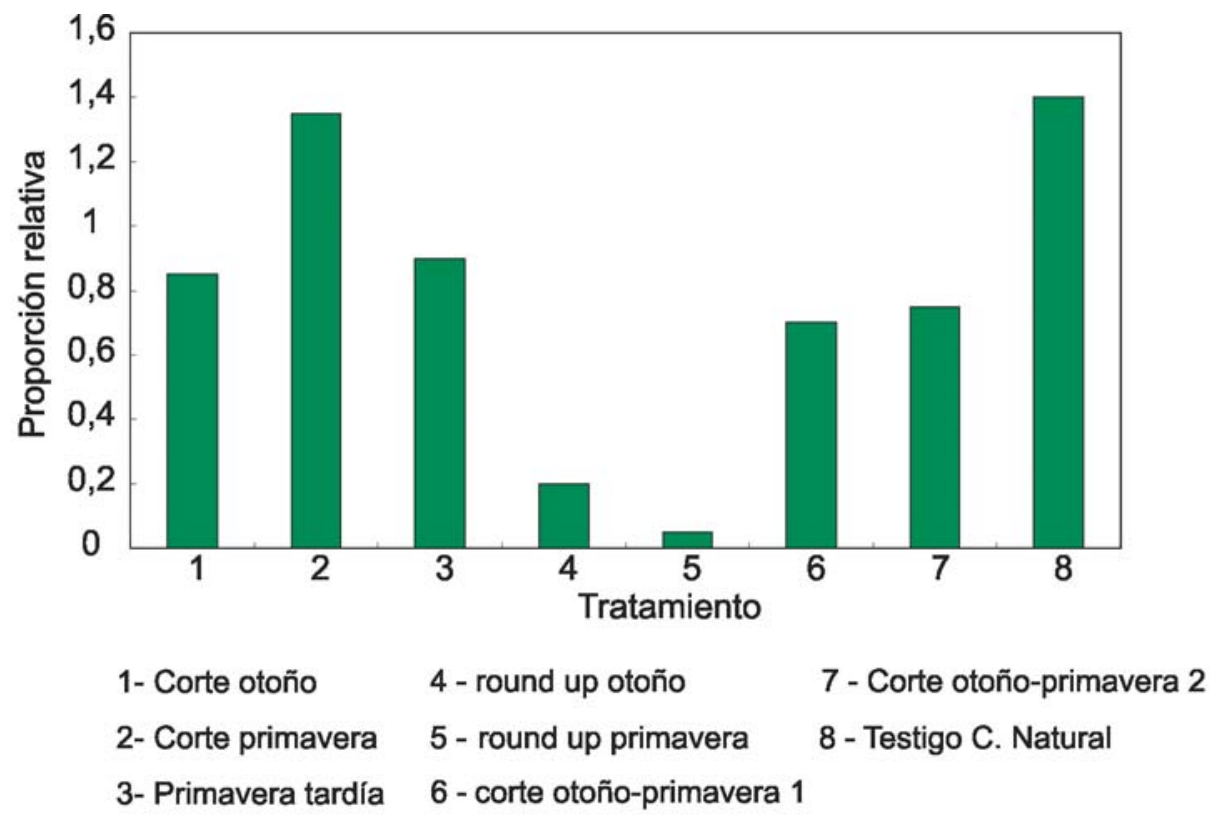

Figura 17. Cambio relativo en la presencia de Stipa charruana en pasturas naturales de la región noreste según la aplicación de ocho tratamientos. Adaptado Beasley E.; Esteves, J., 1994.

solamente cuando muy joven y que presenta además, luego de la floración un fruto muy agresivo. De acuerdo al mismo autor (1943) la misma fue diseminada principalmente a raíz de la introducción conjuntamente con las plantaciones de eucaliptos en la región imperceptiblemente.

Al contrario de lo que ocurre con las especies forrajeras vistas anteriormente, esta especie la debemos considerar como una maleza o por lo menos una especie no deseada en la pastura. En este sentido se planteó un trabajo para conocer la forma de reducir su población en las pasturas naturales, utilizando tratamientos tanto mecánicos como químicos (Beasley y Esteves, 1994).

En la Figura 17 se grafica los resultados de la aplicación de los ocho tratamientos en un campo natural de la Cuchilla del Ombú en el departamento de Tacuarembó con presencia de la especie.

A los efectos de visualizar la tasa de cambio en la presencia en la pastura de Stipa charruana los registros se evaluaron en forma relativa a la presencia previa a los tratamientos; así valores por encima de 1 indican un incremento de la misma respecto a la situación inicial pretratamiento, por el contrario un valor menor que 1 indica una reduc- ción de la presencia de la especie en relación al inicio del período experimental.

En general los cortes realizados solamente en primavera tendieron a mantener o aumentar levemente la presencia de la especie en la pastura, en cambio los corte que involucran al período de otoño incluyendo o no la primavera tendieron a presentar una reducción en la población de Stipa charruana en la pastura. Los tratamientos 4 y 5 donde se aplicó el herbicida Round up disminuyeron drásticamente la presencia de la especie con una tendencia a mayor efecto en la primavera. En la Figura 18 se observa el día de aplicación de algunos tratamientos mecánicos y químicos con una escoba química sobre las plantas individuales.

En la Figura 19 se grafica la evolución de la altura del ápice vegetativo y su período de diferenciación reproductivo, conjuntamente con la fase de alargamiento de los entrenudos luego de la floración. De acuerdo a los registros un impacto sobre las plantas en los primeros veinte días de octubre puede tener un efecto beneficioso sobre la reducción de la floración y producción de semillas, contribuyendo a frenar el aumento de la población en el mediano plazo. El tratamiento testigo - 8 produjo significativamente más semilla que 


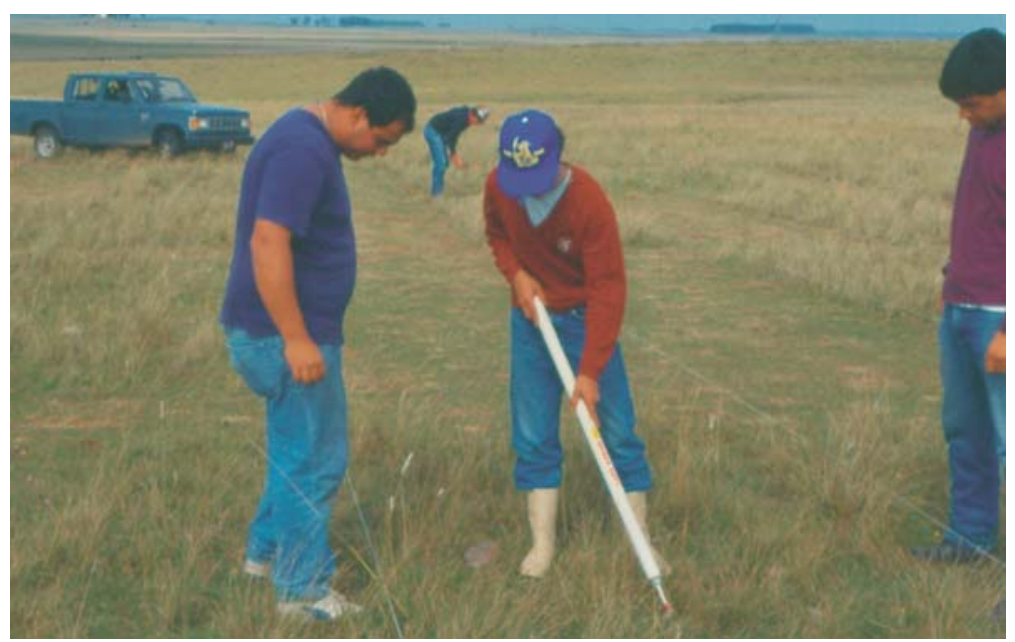

Figura 18. Aplicación de tratamientos mecánicos y químicos para el control de Stipa charruana en pasturas naturales de la región noreste.

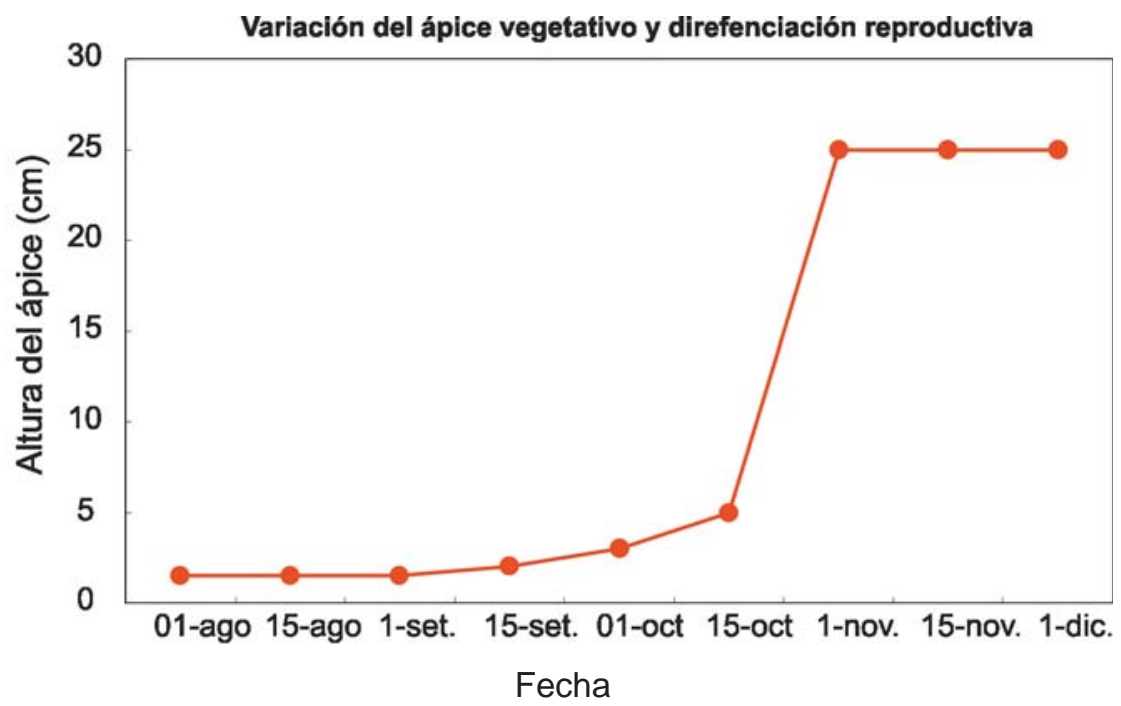

Figura 19. Evolución del ápice vegetativo, período de diferenciación reproductiva y alargamiento de entrenudos en Stipa charruana en la región noreste.

los tratamientos $1,2,3$, y 4 , siendo 346 semillas $/ \mathrm{m}^{2}$ y 116 semillas $/ \mathrm{m}^{2}$ respectivamente; los tratamientos 5, 6 y 7 no produjeron semilla.

Para un control rápido de la población debería aplicarse quizás una combinación de tratamientos de corte en diferentes fechas así como evaluar la posible aplicación de herbicidas de tal forma que no afecten la presencia de otras especies forrajeras con el método de alfombras químicas.
Finalmente se propone un listado mínimo de especies que sería importante profundizar en su conocimiento de ecofisiología y manejo; no solo pensando en la productividad forrajera sino también incluyendo algunas que podrían favorecer la recuperación de áreas degradadas por diferentes causas. Estas serían: Bromus auleticus, Stipa setigera, Hordeum stenostachys, Poa lanigera, Coelorachis selloana, Paspalum dilatatum, Paspalum notatum, Paspalum 
plicatulum, Axonopus affinis, Piptochaetium stipoides, Piptochaetium montevidensis, Adesmia bicolor, Adesmia latifolia, Desmanthus sp.

\section{BIBLIOGRAFÍA}

ALLEGRI M.; FORMOSO, F. 1978. Región noreste. In: Avances en Pasturas IV. Miscelánea No. 18. Centro Investigaciones Agrícolas A. Boerger. pp.: 83-110.

BEASLEY E.; ESTEVES, J. 1994. Evaluación de métodos para el control de Stipa charruana, Arech. Tesis. Universidad Católica del Uruguay. Instituto de Gestión Agropecuaria. Tacuarembó. 30 p.

CASTRILLÓN A.; PÍREZ, C. 1987. Evaluación de la capacidad de instalarse de especies forrajeras en el campo natural con diferentes tratamientos de laboreo. Tesis. Universidad de la República. Facultad de Agronomía. Montevideo. 264 p.

FORMOSO F.; ALLEGRI, M. 1984 a. Estudio comparativo de gramíneas perennes invernales en suelos arenosos, pesados e hidromórficos. In: Gramíneas Perennes en el Noreste. Miscelánea No. 56. Centro Investigaciones Agrícolas A. Boerger. pp.: 1-11.

FORMOSO, F.; ALLEGRI, M. 1984 b. Comportamiento de Bromus auleticus y Holcus lanatus en suelos arenosos. In: Gramíneas Perennes en el Noreste. Miscelánea No. 56. Centro Investigaciones Agrícolas A. Boerger. pp.: 19-23.
OLMOS, F. 1985. Siembra en cobertura de 5 especies forrajeras sobre campo natural arrasado con ovinos en Caraguatá. In: I Seminario de Campo Natural. Bañado Medina. Facultad de Agronomía. Resúmenes. pp.: 25.

OLMOS, F. 1991. Mejoramiento de pasturas naturales: región noreste. In: Pasturas y Producción Animal en Áreas de Ganadería Extensiva. INIA. Serie Técnica No. 13. pp.: 91-102.

OLMOS, F. 1993. Bromus auleticus. Serie Técnica No. 35. INIA Tacuarembó. 30 p.

OLMOS, F. 2001. Tecnologías para la mejora de la producción de forraje en brunosoles del noreste. In: Tecnologías forrajeras para sistemas ganaderos de Uruguay. Boletín de divulgación No. 76. INIA Tacuarembó. pp.: 123-148.

OLMOS, F., SOCA, P.; SOSA, M. DO CARMO, M.; CAL, V.; BENTANCUR, C.; GARCÍA, E. 2011. Cambios en la Composición Botánica de Pasturas Naturales según la Oferta de Forraje. XXII Reunión Latinoamericana de Producción Animal. Montevideo. Uruguay.

ROSENGURTT, B. 1979. Tablas de comportamiento de las especies de plantas de campos naturales en el Uruguay. Facultad de Agronomía. Universidad de la República. Dirección General de Extensión Universitaria. 86 p.

ROSENGURTT, B. 1980. Germoplasma de forrajeras nativas. Universidad de la República. Facultad de Agronomía. 17 p. 



\section{MODELO I SÍNTESIS - PRODUCCIÓN}

De acuerdo al modelo conceptual para la ganadería extensiva (Olmos, 1990) descripto en la Figura 1, se propone integrar la información disponible respecto a las pasturas naturales de la región noreste conjuntamente con un modelo de simulación de utilización de las mismas. En base a datos de productividad de las pasturas naturales de la región (Olmos et al., 2005) y al modelo de-

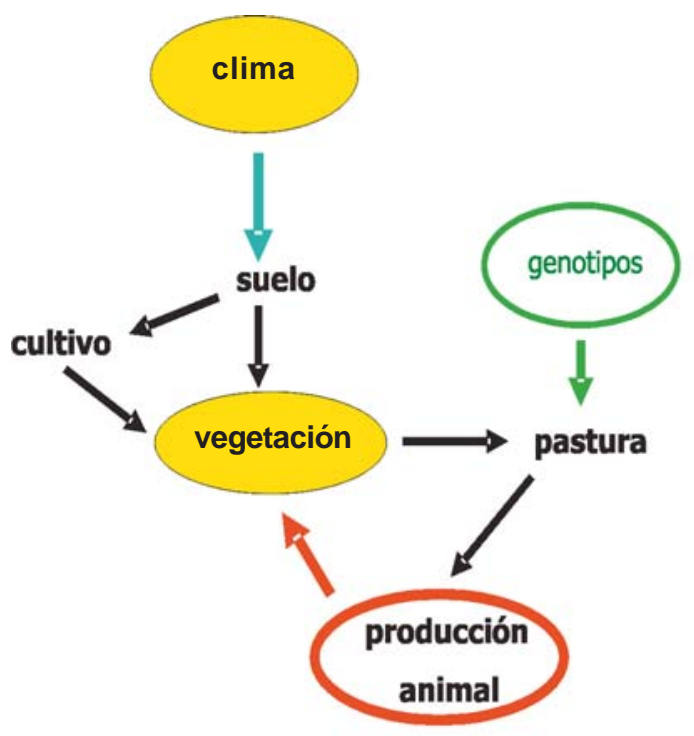

Figura 1. Modelo conceptual de los istemas pastoriles insertados en ecosistemas naturales en la región noreste.
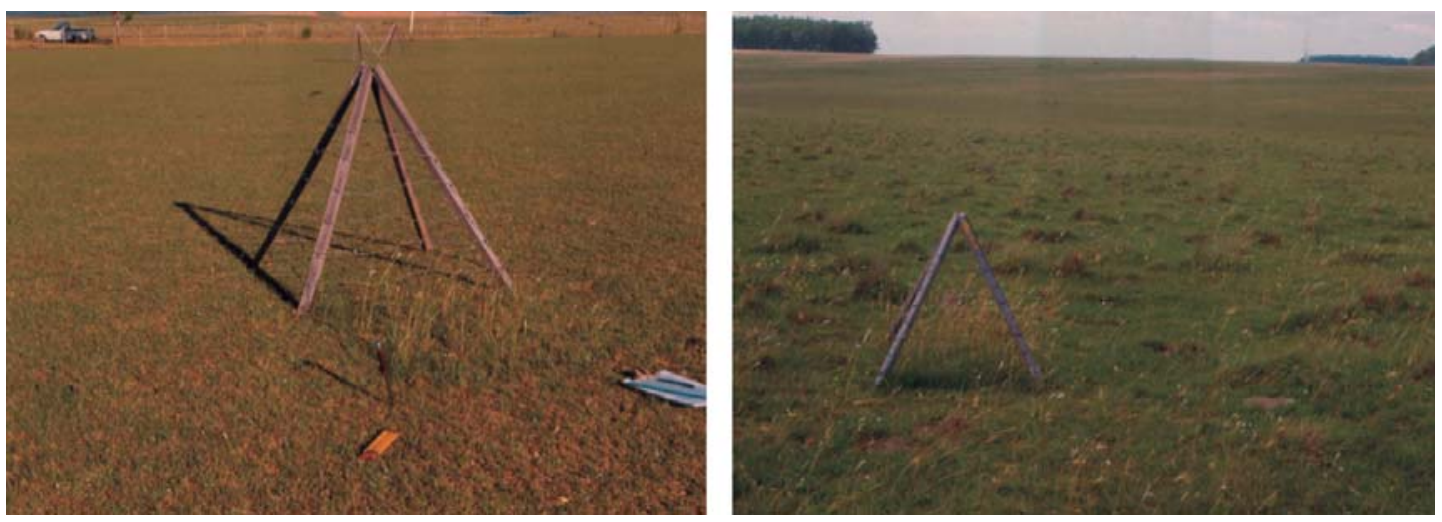

Figura 2. Disponibilidad de forraje en pasturas naturales de la región noreste según la presión de pastoreo. sarrollado para el estudio de la cadena cárnica vacuna en Uruguay (Soares de Lima, 2009), se estudio la implicancia de la variabilidad en la producción de forraje de las pasturas naturales y otras especies complementarias en la productividad animal.

En la Figura 2 se ejemplifica la situación de productividad y disponibilidad de forraje de dos pasturas naturales, sobre un mismo tipo de suelo (brunosol), fuertemente contrastantes de acuerdo al manejo de la presión de pastoreo en cada una. En primavera la pastura aliviada produjo significativamente más forraje por día que la pastura sobrepastoreada, 14 versus $4 \mathrm{~kg} \mathrm{MS/ha/día} \mathrm{respectivamente} \mathrm{en}$ un año relativamente seco. La diferente presión de pastoreo en el mediano plazo genera una estructura y composición botánica diferente en cada pastura, debiéndose por lo tanto, considerar no solo la pastura en si misma sino sus constituyentes o sea los propios genotipos presentes (Figura 1).

El modelo de productividad fue utilizado para una extensión de un predio de 500 hectáreas con pasturas desarrolladas sobre suelos arcillosos, donde se realiza la ganadería de cría y se consideran las principales variables funcionales del modelo: número de vacas totales, unidades ganaderas por hectárea (U.G./ha), edad al primer entore, porcentaje 
Cuadro 1. Productividad de un sistema de producción con ganado de cría, en tres condiciones de manejo del pastoreo en un año favorable (húmedo) otro desfavorable (seco). En base a datos de Soares de Lima (2009) y Olmos et al. (2005).

\begin{tabular}{|l|c|c|c|}
\hline \multirow{2}{*}{ Variable } & \multicolumn{3}{|c|}{ Forraje anual disponible } \\
\cline { 2 - 4 } & $\mathbf{2 8 3 0}$ & $\mathbf{4 5 8 0}$ & $\mathbf{7 5 5 0}$ Año húmedo \\
\cline { 2 - 4 } Vacas & Campo bruto & Sobrepastoreo & Manejo aliviado \\
UG / ha & 225 & 300 & 580 \\
ler. entore & 0,64 & 0,89 & 1,38 \\
\% preñez & 3 & 3 & 2 \\
Pasto remanente & 52 & 52 & 76 \\
Carne equivalente & 359 & 550 & 1265 \\
& 38 & 55 & 134 \\
\cline { 2 - 4 } & $\mathbf{1 0 0 8}$ & $\mathbf{1 5 9 0}$ & $\mathbf{3 3 3 8}$ \\
\cline { 2 - 5 } Variable & Campo bruto & Sobrepastoreo & Manejo aliviado \\
\hline Vacas & 87 & 140 & 280 \\
UG / ha & 0,21 & 0,32 & 0,67 \\
1er. entore & 3 & 3 & 2 \\
\% preñez & 52 & 52 & 76 \\
Pasto remanente & 550 & 540 & $\mathbf{6 8}$ \\
Carne equivalente & $\mathbf{5}$ & $\mathbf{3 0}$ & \\
\hline
\end{tabular}

de preñez y el forraje disponible para consumo y el remanente luego del pastoreo (Soares de Lima, 2009).

En el Cuadro 1 se presenta los valores de las variables descritas para tres situaciones de manejo del pastoreo, campo bruto luego de cultivo, campo sobrepastoreado y campo con manejo aliviado del pastoreo en dos años contrastantes uno relativamente seco y otro relativamente más húmedo, 1989-1990 y 1990-1991 respectivamente.

Los resultados indican que el manejo histórico de cada pastura determina la disponibilidad de forraje anual y por lo tanto la receptividad de la pastura, alcanzándose un mayor número de animales en el predio a medida que se dispone de una mayor cantidad de forraje. El efecto del año se muestra con un gran impacto en términos de receptividad, disminuyendo la receptividad animal al pasar de un año relativamente húmedo a otro relativamente más seco; en el caso de las tres pasturas la reducción llego a valores menores a la mitad: 225 a 87, 300 a 140 y 580 a 280 animales para la pastura de campo bruto, la sobrepastoreada y la manejada con un pastoreo aliviado respectivamente (Cuadro 1).

En la medida que el modelo se ha validado (Soares de Lima, 2009) la productividad por hectárea en carne equivalente, es el reflejo de la variación en los valores de las principales variables del modelo, indicando que con una mayor disponibilidad de forraje la cantidad de carne equivalente por hectárea es mayor, y esto, a su vez depende de las condiciones climáticas de cada año. El manejo aliviado de la pastura produjo, en términos de carne equivalente 3,5 y 2,4 veces más que el caso de la pastura de campo bruto y la sobrepastoreada respectivamente. En un año relativamente seco la productividad sería 13,6 y 2,27 veces mayor en una pastura aliviada que en un campo bruto luego de cultivo o una pastura sobrepastoreada respectivamente. 
Desde el punto de vista del porcentaje de preñez, es importante destacar los resultados posibles que indican que independientemente del efecto del año desde el punto de vista de la productividad de la pastura, cuando la pastura se manejó con un pastoreo aliviado la preñez fue $76 \%$ comparada tanto con el campo bruto o la situación de sobrepastoreo con un valor de $52 \%$ (Cuadro $1)$; al mismo tiempo esta mayor disponibilidad de forraje permitiría adelantar el entore un año.

A través de este análisis, se puede visualizar la dependencia climática de estos sistemas de producción desarrollados sobre ecosistemas naturales de pasturas. En la Figura 3 se indica (barra celeste) el período de registros de las pasturas utilizada en este análisis, en una serie histórica de valores de lluvia y evaporación para la región noreste, destacándose la amplia variabilidad en los registros entre años relativamente secos y años relativamente más húmedos.

Luego de un análisis del balance forrajero alcanzado en las diferentes situaciones vistas anteriormente, se consideran a continuación dos alternativas de intensificación en el uso de las pasturas naturales, por un lado con la utilización de Bromus auleticus, una especie nativa perenne de crecimiento inver- nal muy adaptada a los suelos de la región noreste (Rosengurtt, 1979; Olmos, 1993) y por otro el análisis del uso complementario de Setaria anceps, una especie introducida perenne de crecimiento estival, también muy adaptada a los suelos de la región noreste (Olmos, 2001).

En el Cuadro 2 se reportan los resultados de incluir en el modelo la incorporación de 40 y 75 hectáreas de Bromus auleticus partiendo de dos situaciones contratantes, una de una pastura sobrepastoreada y otra de una pastura con el manejo aliviado del pastoreo. En la situación en que se incluye a Bromus auleticus en la pastura sobrepastoreada los incrementos en productividad son 1,71 y 1,22 veces más alta que en el caso sin la inclusión de Bromus y con la inclusión de 40 y 75 hectáreas de esta especie respectivamente. Al mismo tiempo con la 40 hectáreas el porcentaje de preñez se podría incrementar a 76 \% comparado con el $52 \%$ sin la inclusión de Bromus, y en el caso de las 75 hectáreas se podría incluso, adelantar un año el entore de las vaquillonas.

En la situación donde partimos de una mayor disponibilidad anual de forraje se podría realizar el entore en general a los dos años, con la inclusión de Bromus auleticus se alcanzaría valores de 80-83 \% de preñez,

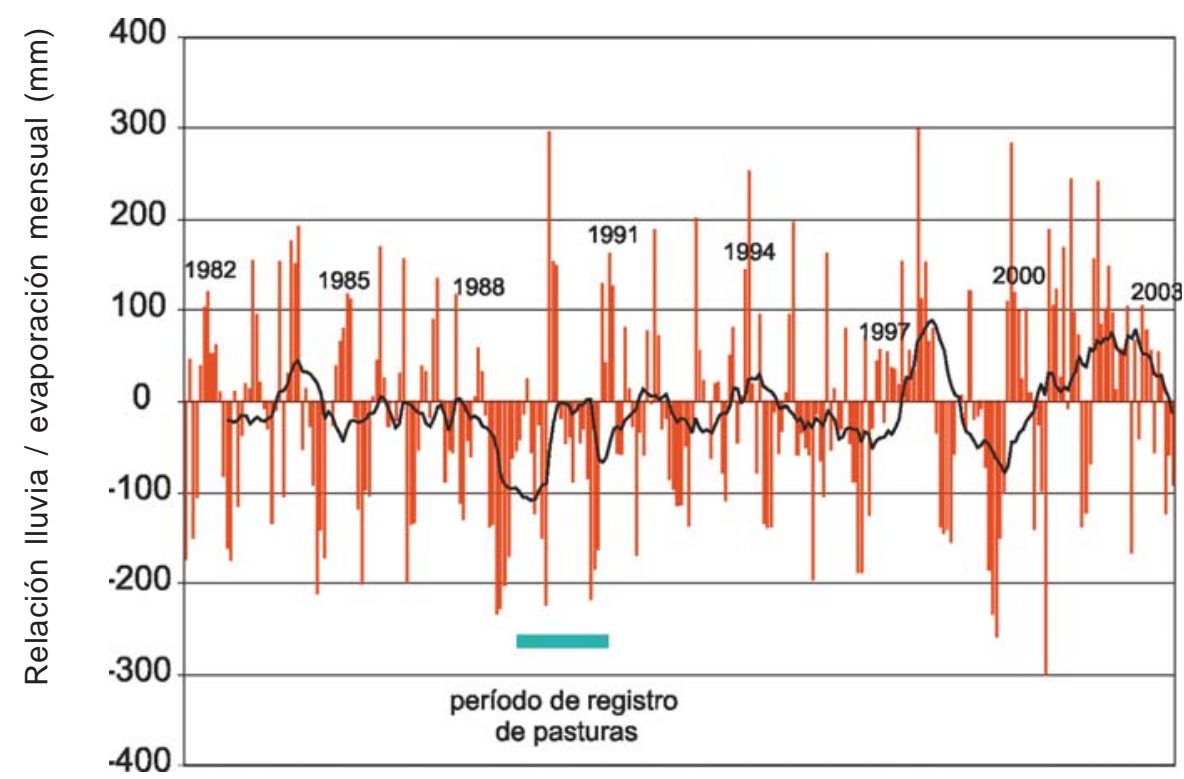

Figura 3. Relación Iluvia / evaporación (barras) y media anual móvil (línea) en base a datos de la Dirección Nacional de Meteorología de Melo. 
Cuadro 2. Productividad de un sistema de producción con ganado de cría, en dos condiciones de manejo del pastoreo, con sobrepastoreo y pastoreo aliviado en un año favorable otro desfavorable; se incluye el complemento de 40 y 75 hectáreas de Bromus auleticus. En base a datos de Soares de Lima (2009) y Olmos et al. (2005).

\begin{tabular}{|c|c|c|c|c|c|}
\hline \multirow[b]{2}{*}{ Variable } & \multicolumn{5}{|c|}{ Forraje anual disponible } \\
\hline & Sobrepastoreo & \multicolumn{2}{|c|}{ Bromus 40 ha } & \multicolumn{2}{|c|}{ Bromus 75 ha } \\
\hline Vacas & 300 & \multicolumn{2}{|l|}{325} & \multicolumn{2}{|c|}{370} \\
\hline UG / ha & 0,89 & \multicolumn{2}{|l|}{0,92} & \multicolumn{2}{|c|}{0,91} \\
\hline 1er. entore & 3 & \multicolumn{2}{|l|}{3} & \multicolumn{2}{|l|}{2} \\
\hline \% preñez & 52 & \multicolumn{2}{|l|}{76} & \multicolumn{2}{|l|}{76} \\
\hline Pasto remanente & 550 & \multicolumn{2}{|l|}{1200} & \multicolumn{2}{|c|}{1050} \\
\hline Bromus & & \multicolumn{2}{|l|}{1280} & \multicolumn{2}{|c|}{1300} \\
\hline Carne equivalente & 55 & \multicolumn{2}{|l|}{77} & \multicolumn{2}{|c|}{94} \\
\hline \multirow[b]{2}{*}{ Variable } & \multicolumn{5}{|c|}{ Forraje anual disponible } \\
\hline & $\begin{array}{c}7550 \\
\text { Manejo } \\
\text { aliviado }\end{array}$ & Bromus 40 ha & \multicolumn{2}{|c|}{ Bromus 75 ha } & $\begin{array}{l}\text { Ciclo } \\
\text { completo }\end{array}$ \\
\hline Vacas & 580 & 580 & & 570 & 360 \\
\hline UG / ha & 1,38 & 1,38 & & 1,38 & 1,33 \\
\hline 1er. entore & 2 & 2 & & 2 & 2 \\
\hline \% preñez & 76 & 80 & & 83 & 83 \\
\hline Pasto remanente & 1265 & 1200 & & 1200 & 1170 \\
\hline Bromus & & 1280 & & 1300 & 1150 \\
\hline Carne equivalente & 134 & 137 & & 134 & 165 \\
\hline
\end{tabular}

pero no se observan cambios en la productividad estimada en carne equivalente siendo los valores estables en las tres situaciones, 137, 134 y 137 kilogramos de carne equivalente para el caso de la pastura sin Bromus y con 40 y 75 hectáreas de Bromus respectivamente. Cuando a este mismo sistema de cría, incluyendo 75 hectáreas de Bromus auleticus, se lo modificó para un sistema de ciclo completo la productividad incrementó sensiblemente en un $23 \%$ alcanzado los $165 \mathrm{~kg}$ de carne equivalente por hectárea, manteniendo el mismo nivel en el porcentaje de preñez de $83 \%$ de las vacas.

Con la inclusión de Setaria anceps al ir incrementando el área complementaria de 40 hectáreas hasta 75 hectáreas la productividad, estimada en carne equivalente, muestra un incremento sostenido a partir de $134 \mathrm{~kg}$ en la situación de $100 \%$ de campo natural y pastoreo aliviado, pasando a $140 \mathrm{~kg}$ y $151 \mathrm{~kg}$ por hectárea (Cuadro 3).

Cuando al sistema de cría se lo transforma en uno de ciclo completo, incluyendo animales para engorde, la productividad del sistema se incrementa aún más, alcanzando el valor de $160 \mathrm{~kg}$ de carne equivalente por hectárea, aún manteniendo el entore a los dos años y un $83 \%$ de preñez.

Esta mejor performance del sistema de cría con la inclusión de Setaria anceps, podría estar correspondida con su ciclo de producción primavero-estival que complementa fuertemente las necesidades de forraje del rodeo durante el período de entore en los meses de diciembre, enero y febrero. En este sentido Olmos (1997 a) ha ejemplificado la 
Cuadro 3. Productividad de un sistema de producción con ganado de cría e invernada, en un año favorable con pastoreo aliviado incluyendo el complemento de 40 y 75 hectáreas de Setaria anceps. En base a datos de Soares de Lima (2009) y Olmos et al. (2005) forraje anual disponible.

\begin{tabular}{|l|c|c|c|c|}
\hline \multirow{2}{*}{ Variable } & \multicolumn{3}{|c|}{ Forraje anual disponible } \\
\cline { 2 - 5 } & $\begin{array}{c}\mathbf{7 5 5 0} \\
\text { Manejo } \\
\text { aliviado }\end{array}$ & Setaria 40 & Setaria 75 & $\begin{array}{c}\text { Ciclo } \\
\text { completo }\end{array}$ \\
\hline Vacas & 580 & 600 & 620 & 370 \\
UG / ha & 1,38 & 1,43 & 1,5 & 1,52 \\
ler. entore & 2 & 2 & 2 & 2 \\
\% preñez & 76 & 80 & 83 & 83 \\
Pasto remanente & 1265 & 1200 & 1050 & 1130 \\
Setaria & 1288 & 1400 & 1130 \\
Carne equivalente & 134 & 140 & 151 & 160 \\
\hline
\end{tabular}

variación en la cantidad de terneros nacidos en un seccional del departamento de Tacuarembó respecto a la variabilidad de las lluvias en dicho período (Figura 4);con mayores precipitaciones en el período agostodiciembre se logra un mayor porcentaje de parición en la primavera siguiente, cuando estos valores no fueron muy altos las lluvias por encima del promedio en el período enero-febrero permitieron alcanzar altos porcentajes de parición a la siguiente primavera. El volumen de lluvias tiene una alta correlación con la productividad de forraje de las pasturas (Olmos, 1997 b). En la Figura 4 se muestra específicamente la relación entre la lluvia, la evaporación y la productividad de las pasturas del período 1989-1991.

En el caso de la utilización de Bromus auleticus solo para el sistema de cría, dado su ciclo de crecimiento principalmente otoño-invernal, mejora claramente la performance del sistema con el registro de valores críticos de crecimiento de pasturas como en el caso de la pastura sobrepastoreada

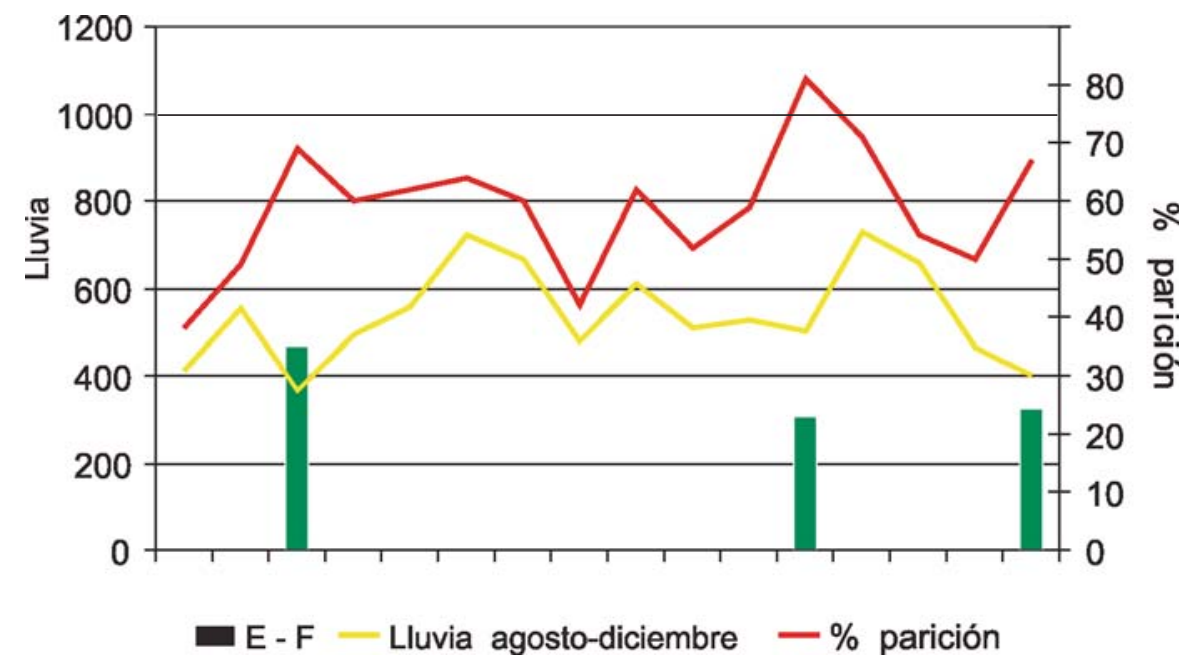

Figura 4. Variación en el número de terneros nacidos (línea roja) durante 16 años en la 8va. Sección de Caraguatá en relación a las lluvias primaverales del año previo (línea amarilla) y las lluvias enero-febrero del mismo año (barras). En base a datos de DICOSE y Dirección Nacional de Meteorología. 
(Cuadro 2). Este comportamiento probablemente se explique en virtud que las pasturas naturales están compuestas en un $70 \%$ por especies de crecimiento estival y al encontrarse sobrepastoreada la productividad invernal es mínima.

La posibilidad de implementar sistemas complementarios de pasturas a las pasturas naturales dependerá de las condiciones locales de suelo y topografía así como de los objetivos de producción del sistema de producción instalado. Concomitantemente a estas características, se debe considerar la disponibilidad de maquinaria y equipos para la realización de los mejoramientos, las habilidades empresariales para el desarrollo de los mismos y la disponibilidad de semilla de calidad.

\section{BIBLIOGRAFÍA}

OLMOS, F. 1990. Utilización de pasturas con animales: avances y propuestas. In: 2 do. Seminario Nacional de Campo Natural. Tacuarembó. pp.: 279-290.

OLMOS, F. 1993. Bromus auleticus. Serie Técnica No. 35. INIA Tacuarembó. 30 p.

OLMOS, F. 1997a. Desarrollo agropecuario y agro-industrial en Tacuarembó. In: Tacuarembó de Puertas Abiertas. Editores: R. Esquivo y R. Zilli. Editorial Prisma. pp.: 79-94.
OLMOS, F. 1997 b. Efectos climáticos sobre la productividad de las pasturas en la región noreste. Boletín de Divulgación No. 64. INIA Tacuarembó. 22 p.

OLMOS, F. 2001. Tecnologías para la mejora de la producción de forraje en brunosoles del noreste. In: Tecnologías forrajeras para sistemas ganaderos de Uruguay. Boletín de divulgación No. 76. INIA Tacuarembó. pp.: 123-148.

OLMOS, F.; FRANCO, J.; SOSA. 2005. Impacto de las prácticas de manejo en la productividad y diversidad de pasturas naturales. In: Seminario de actualización técnica en manejo de campo natural. Serie Técnica No. 151. INIA. pp.: 93-103.

ROSENGURTT, B. 1979. Tablas de comportamiento de las especies de plantas de campos naturales en el Uruguay. Facultad de Agronomía. Universidad de la República. Dirección General de Extensión Universitaria. 86 p.

SOARES DE LIMA LAPETINA J. M. Modelo Bioeconómico para la Evaluación del Impacto de la Genética y Otras Variables sobre la Cadena Cárnica Vacuna en Uruguay. Tesis Doctoral. Universidad Politécnica de Valencia. España. 2009. 240 p. 
Todo sistema posee la capacidad de reaccionar ante una perturbación externa sin sufrir cambios en su estructura y funcionamiento que determinen un cambio significativo en sus principales características; esta capacidad, entre otras características, depende de su estado actual en estructura y funcionalidad, la intensidad y duración de la perturbación así como la escala a la cual se produce la misma. Diversos autores han definido este mecanismo de respuesta o resiliencia, tanto para sistemas físicos, sociales así como para los ecosistemas naturales.

Considerando el caso de las estructuras físicas por ejemplo, Braña et al. (2011) describen en base al diccionario de literatura española que la definición comúnmente aceptada es la de que un material tiene la propiedad (resiliencia) que le permite reasumir su forma o posición original después de ser sometido a una fuerza.

Desde el punto de vista sociológico, la resiliencia representa la capacidad, la flexibilidad, la resistencia, la adaptación y la recuperación del ser humano, que sale transformado por la experiencia y aprendizaje de los errores al sobreponerse a las dificultades y disturbios; adaptándose a la nueva situación y saliendo adelante (www.centropsi copedagogico.cl/index; Chamochumbi, 2005)

En ecología la resiliencia consiste en la capacidad de un ecosistema de absorber perturbaciones sin que su estructura, su funcionalidad y sus procesos, se alteren significativamente, pudiendo regresar a su estado estable alrededor de un punto de equilibrio una vez que la perturbación ha terminado (Calvente, 2007; Wikipedia, 2011). Holling (1973; 1996), a su vez, plantea la integración de las transformaciones lo cual incluye la noción de la capacidad de auto - organizarse, aprender y adaptarse de los ecosistemas.

Krebs (2008), por su parte, se refiere a la resiliencia como la capacidad de una comunidad de absorber disturbios, realizar algunos cambios y mantener aún esencialmente las mismas funciones, estructura e identidad; las comunidades varían en su resiliencia, mientras algunas son frágiles otras son marcadamente robustas. Algunas características permiten distinguirlas, como son: la máxima cantidad de cambio que una comunidad puede experimentar antes de perder su habilidad para recuperarse, la resistencia, que es la facilidad o dificultad para cambiar que tiene una comunidad y la precaución, que es cuán cerca (estado) se encuentra la comunidad de un límite o umbral más allá del cual es difícil retornar.

Tomando como referencia la definición de Arias (2004) citado por Chamochumbi (2005) se refiere a que en ecología la resiliencia es la capacidad, potencial o habilidad de un sujeto (planta), grupo doméstico (familia, población) o sistema social (comunidad) de adaptarse y hacerse superior a la adversidad para continuar su proyecto de vida (dejar descendencia - Darwin); en un sistema natural sería el grado en que se recupera o retorna a su estado anterior ante la acción de un estímulo, agente o factor externo que lo modifica; la capacidad de las comunidades de absorber perturbaciones o soportarlas (Wikipedia, 2011).

Los Ecosistemas Naturales en sí mismos, son conjuntos de factores bióticos y abióticos cuyos componentes interactúan, mediante adaptaciones locales mutuas desarrollados a través del tiempo, estas interacciones varían según el lugar y con el tiempo, los ecosistemas no tienen un estado particular que pueda considerase como óptimo (Sánchez, 2007); son entidades naturales que en función de su propia estructura, composición y funcionamiento tienen algún grado inherente de resistencia a ciertos cambios originados por perturbaciones. Resistencia y resiliencia son propiedades emergentes de los ecosistemas, son únicas del conjunto (Maass, 2003, citado por Sánchez, 2007). Los ecosistemas no tienen un estado particular que pueda considerarse óptimo; en función de su propia estructura, composición y funcionamiento tienen algún grado de resistencia a cambios originados por perturba- 
ciones; los disturbios forman parte de la dinámica normal de los ecosistemas (Pickett y White, 1985; Sánchez, 2007).

Una definición sencilla es la propuesta por Walker y Salt (2006) quienes definen a la resiliencia como la capacidad de un sistema de absorber disturbios y todavía mantener su estructura y función básica.

Hace unas décadas se han desarrollado los estudios de impacto ambiental (EIA) (Espinoza, 2001), los cuales aportan elementos cuantitativos para el discernimiento de los efectos de los impactos de las actividades humanas sobre los ecosistemas, así como aportan metodología para elaborar planes de manejo y mitigación en cada caso. Estos estudios toman en cuenta tanto el componente biológico, el económico como el social en sus evaluaciones.

Actualmente se esta generando una corriente de pensamiento en torno a la resiliencia a diferentes escalas, desde lo que puede ser para nosotros un potrero, un establecimiento agropecuario o una región hasta consideraciones a escala de cuencas, como continentales o planetarias (Walker y Salt, 2006). En este sentido se discute y contrapone la idea actual productivista y eficienticista con la idea de un manejo integrado del ecosistema natural con el propio ser humano inserto en el mismo y tomando decisiones y acciones («social - ecological systems»). Estos autores, citando a Levin (1999), proponen acciones para alcanzar un planeta más resiliente, como el mantenimiento de la diversidad, no por si misma sino como fuentes de futuras opciones, tanto biológica, paisajística, social como económica; la profundización en el conocimiento de variables que se modifican lentamente se transforman en procesos; la habilidad de identificar los umbrales de cambio y la posibilidad de evitarlos; la innovación en todos sus aspectos como aprendizaje local y experimentación frente a los cambios.

Estos aspectos de la interacción entre los seres humanos y el medio ambiente debe ser rápidamente reconocida y analizada en virtud de la fuerte demanda por bienes y servicios pronosticados para los próximos decenios en virtud del importante aumento de la población mundial (Holechek, 2013). El autor sostiene que hay seis recursos naturales básicos que tienden a ser escasos en los próximos 40-50 años, entre los cuales se encuentran el agua, la tierra para la agricultura, el fósforo, el cobre y otros elementos, así como el petróleo.

\section{CUÁL ES LA SITUACIÓN HOY EN LA REGIÓN NORESTE?}

A partir de la colonización, fundamentalmente por europeos, la región ha ido siendo paulatinamente explotada en base al uso más o menos intensivo de sus recursos naturales, primeramente a través del uso de la madera, luego a partir de la introducción y posterior extracción de ganado y finalmente con la introducción de la agricultura propiamente dicha.

En la Figura 1 se grafica la evolución del área de campo natural desde el origen de nuestro país hasta nuestros días (Pérez Castellanos, 1914; D.I.E.A., 2012), conjuntamente con la evolución de las áreas cultivadas por el hombre; al mismo tiempo se realiza una proyección de la superficie correspondiente a cada rubro identificado hacia la década de 2050.

Desde el punto de vista conceptual, se introduce la evolución de la resiliencia general de los sistemas basados en el uso de los recursos naturales así como los niveles de riesgo estimados. En la medida que los impactos sobre el hábitat natural se incrementan, desde el punto de vista de este mismo la resiliencia en general disminuirá y por su parte, basados en una misma estructura clásica de intensificación, el riesgo asociado a estas decisiones se incrementaría (Figura 1).

Tomando más en detalle la estructura productiva de los diferentes sistemas de producción en la Figura 2 se grafica su posición relativa en relación a dos ejes determinantes de su estabilidad propiamente dicha como son la variabilidad climática y la variabilidad en el precio de los productos.

Se destaca claramente que la ganadería extensiva mayor a 1.000 hectáreas de su- 


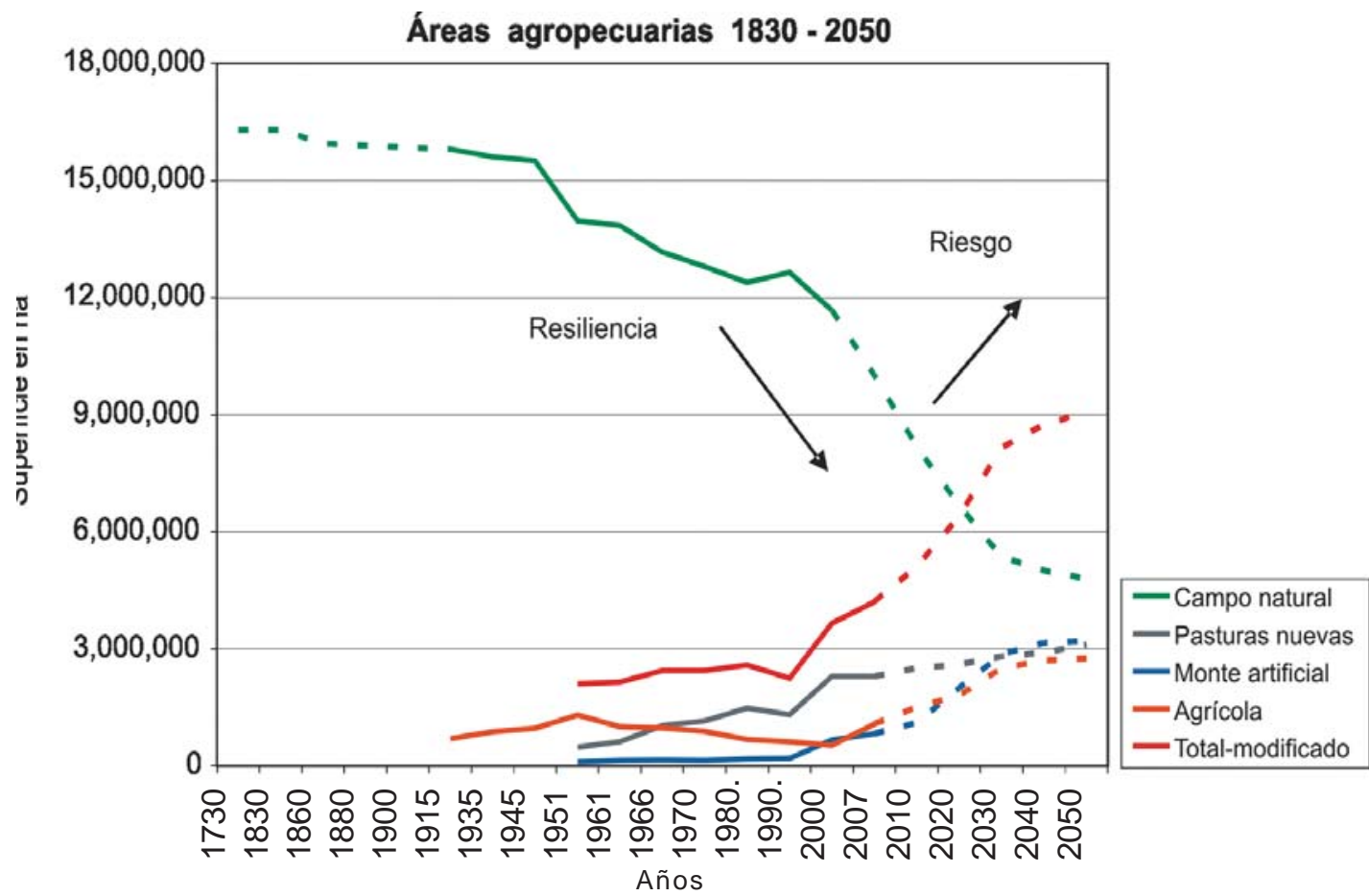

Figura 1. Evolución de la superficie de campo natural y diferentes rubros agrícolas en el período 1730 - 2050 en el Uruguay (líneas llenas) y su estimación (líneas punteadas).

\section{Precios de mercado}

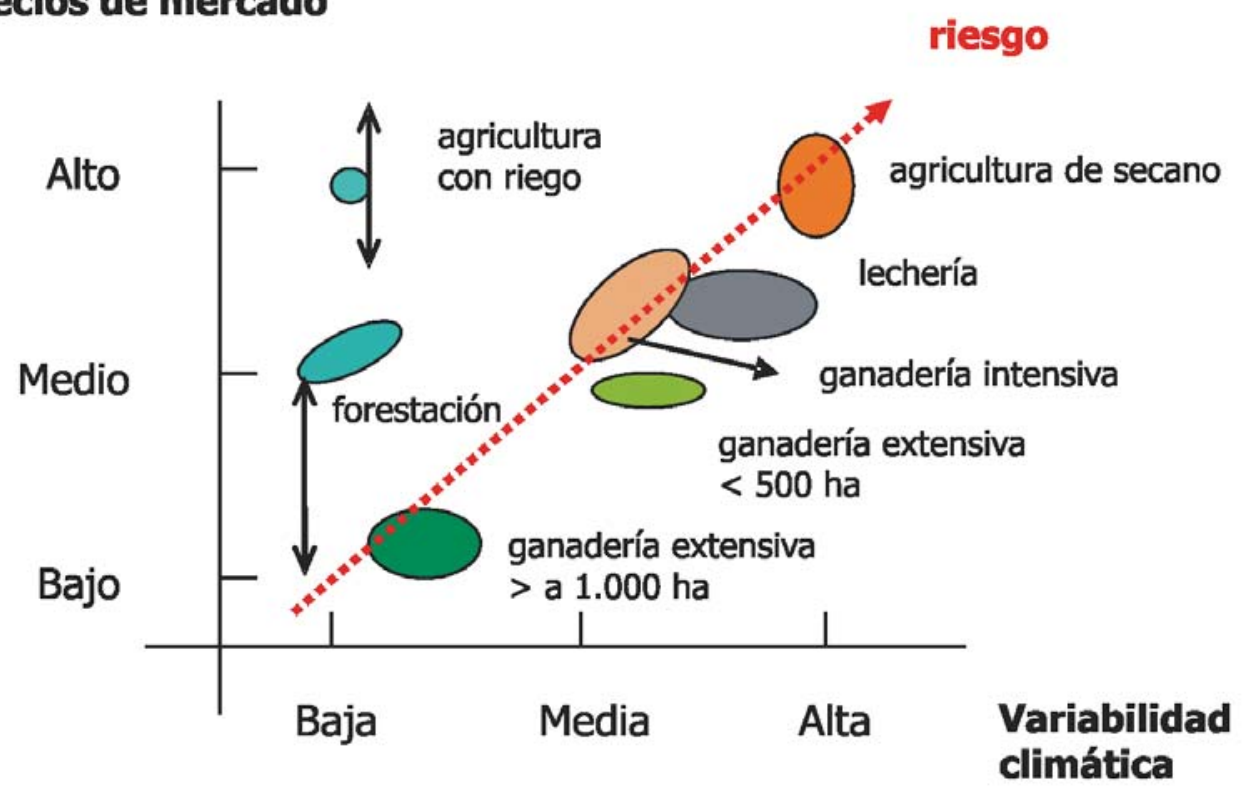

Figura 2. Posición relativa de sistemas de producción regionales en relación a la variabilidad climática y los precios de mercado de los productos. 
perficie predial se encuentra en una situación de alta sostenibilidad basada fuertemente en el componente más resiliente cual es el campo natural y desde el punto de vista de los precios de mercado su variación, si bien afecta los ingresos prediales, dado los eventuales volúmenes tendrían un menor impacto sobre el componente social del ecosistema; paulatinamente al llegar a superficies menores, como es el caso de la ganadería extensiva con predios menores a 500 hectáreas, la mayor necesidad en rela-

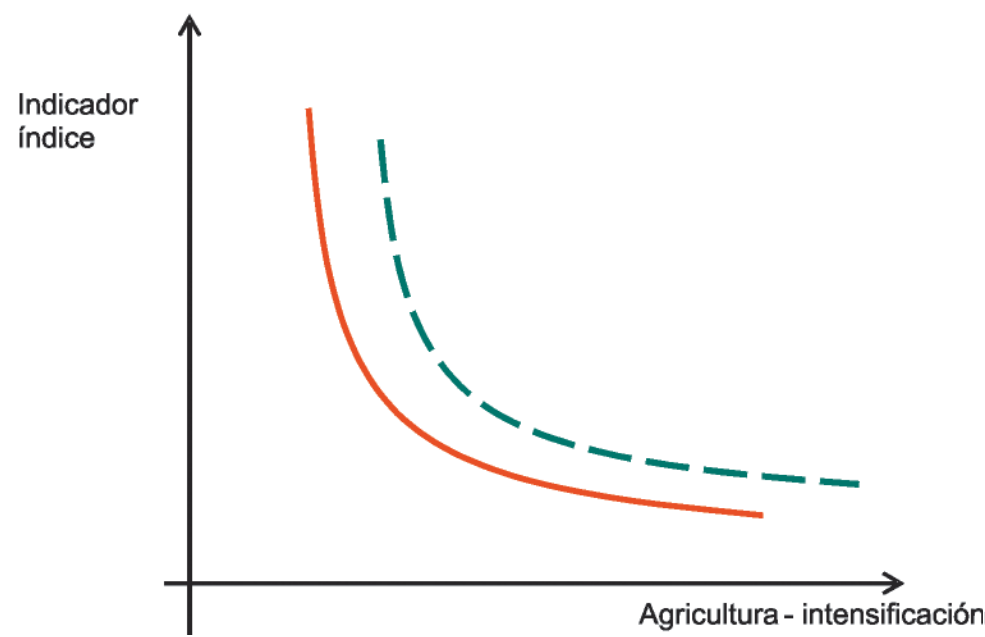

Figura 3. Variación en el indicador de resiliencia o presencia de recursos genéticos relevantes con la intensificación agrícola en la región noreste. ción a la superficie, de mantener adecuados ingresos familiares en el predio determina un mayor impacto la variabilidad de las dos variables consideradas en el gráfico incrementando los niveles de riesgo; en el caso de la ganadería intensiva o lechería, independientemente de la superficie, al disminuir la proporción de campo natural la resiliencia del sistema también se reduciría al mismo tiempo que se incremente la dependencia del sistema de insumos extra prediales, aumentado por lo tanto los niveles de riesgo; en cuanto a la agricultura de secano, dada la gran variabilidad climática ya vista en los capítulos previos en la región se alcanzan los máximos riesgos, en virtud que aún iniciando en años favorables un sistema de producción tarde o temprano el mismo se verá severamente impacto por ciclos de estrés hídrico, lo cual también puede verse potenciado por diferentes ciclo de precio de los productos; con relación a la agricultura con riego, si bien se estarían disminuyendo los riesgos frente a la eventualidad de la variabilidad climática, dada la intensificación del sistema también se vuelven fuertemente dependientes de variables externas como son los precios de los productos y los insumos; por su parte la forestación al ser un cultivo que va más allá de un par de años en el campo, le permite una cierta compensación respecto a la variabilidad climática, estacional e interanual, dependiendo en una forma un poco menor de la variación en los precios ya que el nivel de insumos extra prediales aplicados es también relativamente menor comparado con otros sistemas intensivos.

Si bien la escala general permite visualizar el contexto general, también es importante profundizar en la escala predial, ya que es en ella donde se toman las decisiones de acciones frecuentemente; como fue definido por Caldevilla et al. (2006) citado por Olmos (2006) la UEM o unidad ecológica de manejo es el establecimiento agropecuario. En este sentido en la Figura 3 se describe conceptualmente el impacto que generaría una agricultura de intensificación en un índice o indicador de resiliencia, en la misma se muestra la evolución de la resiliencia a nivel potrero (línea llena roja) así como la pérdida de recursos genéticos (línea punteada azul) si no se tomaran precauciones previa a la intervención en la pastura natural. En el capítulo VIII se propone una metodología de acción ante este tipo de circunstancias.

En dicha figura se aprecia como el continuo incremento en la intensificación a escala predial determina, conjuntamente con la disminución en el área de pasturas naturales, la disminución tanto de la resiliencia como la disponibilidad de recursos genéticos los cuales pueden tener efectos sobre futuras oportunidades tanto locales, regionales como 


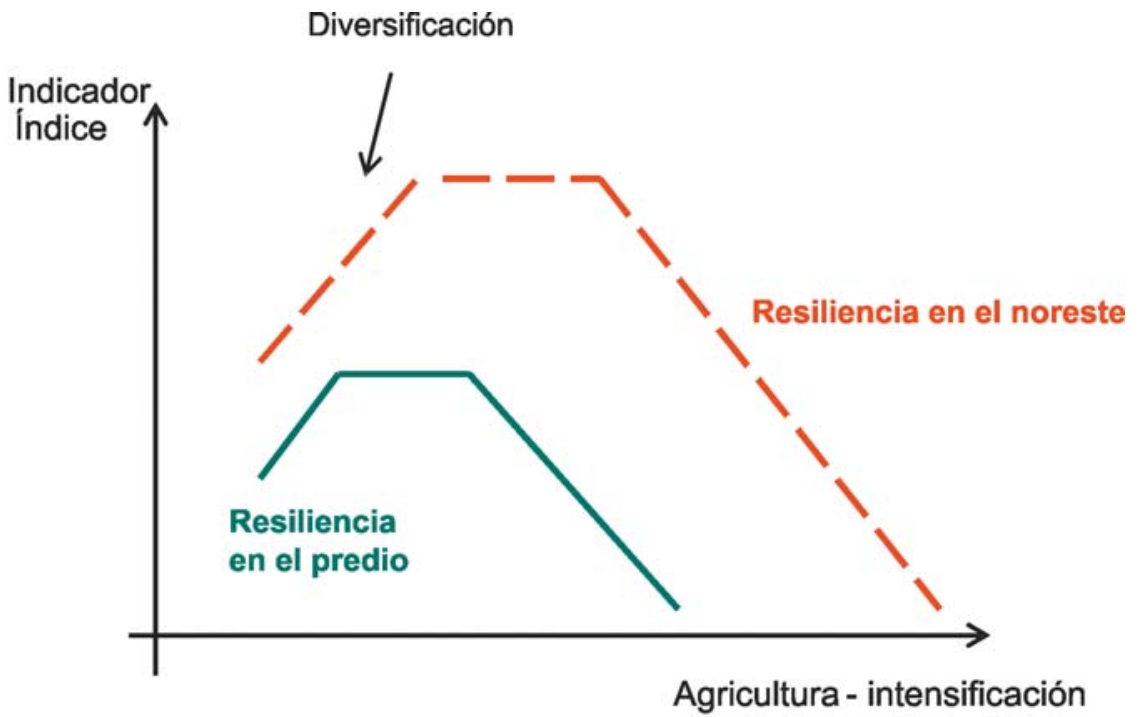

Figura 4. Variación en el indicador o índice de resiliencia a escala predial o regional según la intensificación agrícola en la región noreste.

extra regionales (Olmos y Sosa, 2004), pero partiendo de la célula básica como puede ser el potrero dentro de un establecimiento.

En la medida que se va cambiando de escala la relaciones pueden variar. En la $\mathrm{Fi}$ gura 4 se grafica desde la escala predial hasta la escala regional la interpretación de la relación entre la intensificación basada en la intensificación agrícola y la resiliencia.

Considerando la escala de un predio el incremento en una primera etapa de la intensificación permitiría una suerte de diversificación en rubros, lo que podría interpretarse como contribuyente a la resiliencia social - sistema de producción generando diversas opciones ante las oscilaciones tanto del clima como de los mercados, independientemente de que se comienza paulatinamente un incremento en la dependencia de insumos extra prediales. Así, luego en la medida que la intensificación se va incrementando en superficie y utilización de recursos, los indicadores de ganancia o pérdida de resiliencia se volverían más o menos equivalentes y por encima de un cierto umbral los indicadores comenzarían a descender con la mayor superficie dedicada a la agricultura.

Cuando pasamos a escala de la región la curva de respuesta sería muy similar, sin embargo la misma se encontraría desplazada a la derecha y hacia arriba en el diagrama considerando por lo menos la superficie a intensificar.

En la Figura 5 se pretende ir aún más en detalle a una escala más dentro del manejo 
del establecimiento agropecuaria, en este sentido la intensificación puede visualizarse desde el momento en que se decide con qué presión de pastoreo se va a trabajar a través del año; así pues en la medida que esta sea superior a las posibilidades forrajeras de la pastura la misma podrá comenzar a degradarse a través del cambio en la composición botánica con la disminución en la frecuencia de las especies forrajeras de mayor aporte, llevando paulatinamente a la misma a presentar un menor indicador de resiliencia, en el mismo sentido podría decirse que, asociado a circunstancias puntuales de la variabilidad climática, este manejo puede llevar a afectar la física del suelo por un incremento en la compactación, la aparición de malezas, entre otras posibilidades llevando a una menor productividad del sistema de producción.

El siguiente paso en la intensificación es el caso de desaparición de la vegetación a través de un brusco cambio en el hábitat, sea tanto por el arado mecánico como por el arado química más moderno.

Este cambio a través de los umbrales manejados en la figura ( $a, b, c, d)$ debería servir como mecanismo de alerta en referencia al uso de los recursos naturales y el eventual uso sostenible en el largo plazo. La no consideración del efecto de estos impactos a nivel predial, que pueden ser micro impactos a nivel regional, en la medida que se acumulan terminarán por contribuir a la desaparición, primero de la variabilidad local (por lo menos forrajera), finalmente a escala regional y por lo tanto la resiliencia ambiental.

\section{NUESTRO CASO}

Los resultados presentados en los capítulos previos avalan lo discutido en los párrafos anteriores, para ello tomemos dos ejemplos de manejo de pasturas basados en los criterios locales (UEM) donde en uno se ha aplicado continuamente un sobrepastoreo extremo de la pastura natural y otro donde solamente se realizó una temporada de cultivo y luego se dejó para que la pastura se recuperara naturalmente. En el primer caso que hemos denominado b-3 (Ferráz) es notorio el impacto sobre la productividad de la pastura la cual fue cinco veces menor a la de una pastura manejada con pastoreo aliviado (Sención), la principal diferencia entre ambas pasturas fue la composición botánica. En el segundo caso igualmente la productividad fue significativamente reducida en comparación con situaciones de alivio en sitios linderos aún luego de más de diez años de haberse realizado el cultivo, también la principal diferencia entre ambas pasturas fue la composición botánica.

Podemos afirmar que en ambos casos el impacto en la reducción de la productividad de las pasturas fue severo sin embargo puede admitirse que si los impactos no fueran una proporción importante de los predios (UEM) podrían recuperarse las mismas a través de algunos mecanismos de mitigación; este no sería el caso en la medida que con procesos acumulativos la superficie alcanzada por los impactos sea mayor tanto el predio como en la región.

Deberíamos quizás, como sociedad, preocuparnos más por incrementar nuestro conocimiento sobre nuestros recursos naturales, que hasta ahora han sido la base de la resiliencia de nuestro sistema ecológico social. La aparición de otros rubros como las tecnologías digitales, la industria del software, la pesca y su industria, la minería, entre otros, no hará más que mejorar nuestra performance sobe la cual hemos edificado la sociedad.

La toma de mayores riesgos al apostar por sistemas productivos más intensivos en el uso de insumos, requiere, concomitantemente, un mayor compromiso de gestión y la necesidad imperiosa de un mayor acceso a la información de calidad y en el momento preciso.

La propuesta general de Walker y Salt (2006) es la de encarar el manejo de los recursos naturales teniendo en cuenta los sistemas naturales asociados conjuntamente con los sistemas sociales humanos y considerándolos como sistemas complejos que continuamente se están adaptando a través de ciclo de cambio. Esta propuesta es muy similar a la planteada por Buarque (2002) quien destaca que la planificación es un proceso permanente de reflexión y análisis para 
discernir entre diferentes alternativas que permitan el logro de resultados deseados en el futuro.

De ahí la importancia de crear sistemas de referencia de estado de los ecosistemas, por lo menos de la vegetación, básicamente el manejo de pasturas naturales, lo cual es más del $65 \%$ de la superficie productiva de la región noreste. Ejemplos de este tipo de propuestas tenemos en Rosengurtt (1943 y 1979) quién manejó la idea de pasturas tipo para caracterizar una zona, en Holechek et al. (1988) donde se manejó la idea de pasturas testigo así como zonas testigo dentro de las pasturas para observar cambios en las comunidades en Olmos (2006) y además de esta publicación donde se ha manejado la idea de disponer de pasturas de referencia regionales, básicamente de acuerdo al tipo de suelo, las cuales permitirían realizar un monitoreo y comparación del estado de las pasturas manejadas bajo diferentes circunstancias.

Hay muchas propuestas de mitigación y eficientización de los mismos sistemas o modelos actuales de desarrollo, pero pocos, o por lo menos poca discusión global, sobre uno de los grandes eventos desencadenantes de la presión sobre el uso de los recursos naturales del planeta como es el incremento incesante de la población humana mundial.

El enfoque para afrontar las décadas que se nos avecinan, debería considerar todas las escalas de acción, tanto físicas como sociales e institucionales; es decir desde la UEM (unidad ecológica de manejo) predial, el municipio, el departamento, las regiones agro ecológicas hasta el país en cuanto a los sistemas naturales e institucionales; en cuanto a los niveles sociales ligados fundamentalmente a la educación desde las escuelas urbanas y rurales, los liceos urbanos y rurales y la propia universidad.

En todos los casos es imperioso un enfoque desde la situación actual local y no desde la teoría tendiendo a aplicar una especie de constructivismo real «in situ».

Siguiendo a Walker y Salt (2006) deberíamos reconocer que estamos, quizás, al final de un ciclo de crecimiento donde el modelo no aplica más y estamos entrando en una fase descreimiento y desintegración de las estructuras funcionales del ecosistema socio - ecológico donde deberíamos considerar ampliamente nuevas opciones en todos sentido.

Diferentes ciclos de crecimiento y expansión se han vivido en la región por diversas circunstancias desde la década de 1950, con aceiteras, molinos harineros, el fomento de diversos cultivos a diferentes escalas, llevando lenta pero sostenidamente a la desaparición de pequeños y medianos agricultores, finalizando hasta ahora con el incremento en la concentración de la tierra en manos de menos productores.

\section{TENEMOS LA NECESIDAD DE ...}

\section{La importancia de la biodiversidad}

Una de las amenazas mayores a nuestra sociedad en el estado de desarrollo actual es que no tomemos conciencia de la pérdida de recursos genéticos asociada a la intensificación de los sistemas de producción agropecuaria y pesquera, como consecuencia del incremento de la demanda mundial por alimentos al aumentar sostenidamente la población mundial.

La diversidad de mecanismos de respuestas funcionales a la variación ambiental de diferentes especies en un ecosistema mantiene la resiliencia a los disturbios, por lo tanto los ecosistemas, manejados y no manejados, con bajos niveles de respuesta funcional son particularmente vulnerables a los disturbios y tienen mayor riesgo a cambios de regímenes (Sheffer y Carpenter, 2003).

Diversos autores destacan consistentemente las consecuencias que puede traer para las sociedades humanas los efectos de la pérdida de biodiversidad en los ecosistemas naturales y sus consecuencias sobre la propia resiliencia de los ecosistemas en si mismos así como la suerte de la población o sociedad que los maneja.

En este sentido Walker et al. (1999), indican que probablemente la pérdida acelerada de especies compromete la capacidad de los ecosistemas para mantener la capaci- 
dad biótica para mantener su funcionamiento bajo nuevas circunstancias ambientales y bióticas (Rockström et al., 2009); esta pérdida, a su vez, puede incrementar la vulnerabilidad a los cambios climáticos de los ecosistemas terrestres. Este proceso constituye el 6to. evento de extinción mayor en la historia de la vida de la Tierra (Rockström et al., 2009). El ritmo de desaparición de especies actual es 50 veces superior a la tasa de extinción natural (Vilches et al., 2009).

Cada vez que desaparece una especie estamos perdiendo una oportunidad, una alternativa para el futuro. La apuesta a la biodiversidad es la única opción / dependemos completamente de las plantas, animales, hongos y microorganismos que comparten el planeta con nosotros (Vilches et al., 2009). En este contexto, frente a la explotación intensiva de los recursos naturales Duarte Santos (2013) plantea la necesidad de trazar planes de acción encaminados a proteger los hábitats y las especies de flora y fauna.

La propuesta en algún momento esbozada de incrementar la población humana en Uruguay, sería lo mismo que el incremento en superficie e intensificación desmedido de la agricultura, toda vez que este hecho determinaría un incremento por la demanda de bienes, de uso intensivo del suelo y el agua a la misma escala mundial con las consiguientes cuentas a saldar en las próximas centurias.

\section{Curso de acción}

Independientemente del rumbo e intensidad con que nos embarquemos en una $u$ otra alternativa lo realmente importante es tener meridiana conciencia de las implicancias que tiene esta decisión en el mediano y largo plazo, es decir tomar los recaudos necesarios para capacitarnos, desarrollar los mecanismos que nos ayuden a interpretar y monitorear los impactos que ejerceremos sobre el medio ambiente y como estas acciones repercutirán sobre la propia sociedad. Nada esta prohibido, pero seamos concientes del curso de acción que tomamos. Seamos resilientes con nosotros mismos.
En este sentido deberíamos desarrollar una estrategia, si se incrementa una productividad consumista - insumista, a los efectos de reducir los riesgos de adquisición de los mismos, desarrollar el conocimiento respecto a la variabilidad climática en sus orígenes y consecuencias, entre otras cosas. La conceptualización e identificación clara socialmente que tenemos recursos fijos como el suelo y los recursos genéticos, los cuales deben ser considerados desde la escala predial (Unidad Ecológica de Manejo) hasta la región y país. Esto nos lleva a considerar dos enfoques de resiliencia que será mayoritariamente basada en el buen uso de los recursos naturales y la mayor o menor dependencia de insumos extra prediales y extra país.

Las consecuencias de seguir con un modelo que no contemple mayoritariamente el uso responsable de los recursos naturales nos llevará indefectiblemente al incremento en la:

- desaparición de hábitats

- pérdida de recursos genéticos

- aplicación de plaguicidas

- erosión del suelo

- dependencia de insumos externos

- dependencia de precios externos

- dependencia de la variabilidad climática

al mismo tiempo que a la disminución de:

- la calidad del agua en general

- oportunidades futuras

- el valor de la tierra

Evidentemente esta intensificación no está prohibida, pero deberemos incrementar las precauciones casi que en forma geométrica, si queremos preservar nuestro patrimonio productivo. Para ello necesitamos a su vez, desarrollar mecanismos de respaldo a nivel de sistemas de producción instalados en ecosistemas naturales que afectan el vivir y la convivencia de nuestra sociedad. 
El impacto de los disturbios naturales o inducidos por el hombre en los ecosistemas dependerá de la intensidad, tamaño de la superficie de impacto, frecuencia de eventos, así como la recurrencia de los mismos considerando las escalas de espacio y tiempo (Sánchez, 2007; Rockström et al., 2009).

Seguramente que en los próximos años y decenios asistiremos al incremento de los conflictos sociales por el uso o mal uso de los recursos naturales, deberíamos también prepararnos para estas eventualidades como método de contribución a la mitigación de impactos negativos sobre la sociedad.

\section{Corolario}

... si la Tierra se formó hace unos 4.500 millones de años, el Universo hace unos 13.500 millones de años y el hombre irrumpió en escena hace 5-10.000 años, si Colón «descubrió» América hace 500 años, parafraseando a algún autor, podríamos decir que a esta región nosotros recién llegamos y estamos desempacando (200 años).

Entonces podríamos hacernos algunas preguntas para adelante, hacia el futuro, estas son:

1 - ¿cuánto conocemos nuestro ambiente ?

2 - ¿cómo actuamos en este ambiente?

3 - ¿qué hemos hecho para que nos fuera bien en ciertas circunstancias ?

4- ¿qué hemos hecho para que no nos fuera tan bien en otras circunstancias?

5 - ¿qué ha pasado en nuestra interacción sociedad-ambiente en 200 años ?

6 - ¿qué hacemos / qué no hacemos?

7 - ¿hacia dónde vamos?

\section{Propuesta}

A diferentes escalas la UICN (2010) ha propuesto diversas acciones considerando el ajuste de los sistemas humanos o naturales en respuesta a los estímulos actuales o es- perados; en ese sentido con el método «Ecosystem based Adaptation» propone la intervención en el área de planificación y decisiones políticas construyendo capacidades institucionales conjuntamente con la implementación de acciones sobre los ecosistemas.

A nivel regional se están desarrollando propuestas tendientes a un mejor manejo de los pastizales naturales respecto al actual, como es el caso del propuesto por Marino (2008) en la República Argentina (Bilenca y Miñarro, 2004) o la propuesta para la conservación de Pastizales Templados en América del Sur llevada adelante por UICN (2008).

En el sur de Brasil diversos trabajos enfatizan en la importancia de mantener y mejorar la productividad de los pastizales naturales del Bioma Pampa así como valorizar adecuadamente la biodiversidad no solo desde el punto de vista de la resiliencia del sistema de producción sino también como elemento para incrementar el potencial productivo (Nabinger, 2006; Dall'Agnol et al., 2006; Ávila Jacques et al., 2009).

A escala planetaria la F.A.O. (2002) ha publicado el tratado Internacional sobre los Recursos Fitogenéticos para la Alimentación y la Agricultura del cual nuestro país es firmante, cuyo principal objetivo es la conservación y utilización sostenible de los recursos fitogenéticos para la alimentación y la agricultura y la distribución justa y equitativa de los beneficios derivados de su utilización. En este tratado se plantean acciones concretas de trabajo colectivo.

Deberíamos desarrollar y concretar una estrategia para el país, la cual este articulada por una normativa moderna, aplicada y aplicable, descentralizada y participativa, basada en el conocimiento científico y en el monitoreo de la forma de utilización de los recursos naturales en forma sistemática, dentro de cada sistema de producción (OImos, 2006). Respecto al componente socio económico y las interacciones con el modelo de utilización de los recursos naturales deberíamos actuar en el mismo sentido. 


\section{BIBLIOGRAFÍA}

ÁVILA JACQUES, A. V.; HERINGER, I.; SCHEFFER-BASSO, S. M. 2009. Aspectos do manejo e melhoramento da pastagem nativa. In: Campos Sulinos. Conservacao e uso sustentável da biodiversidade. Ministerio de Meio Ambiente. Secretaria de Biodiversidade e Florestas. Departamento de conservacao de Biodiversidade. Brasilia, D. F. Brasil.

BILENCA, D.; MIÑARRO, F. 2004. Identificación de Áreas Valiosas de Pastizal en las Pampas y Campos de Argentina, Uruguay y Brasil (AVPs). Fundación J. M. Kaplan. Fundación Vida Silvestre Argentina. $323 \mathrm{p}$.

BRAÑA, S.; DÍAZ, C.; NAVARRO, L.; TORRES, M.; VÁZQUEZ, S. 2011. Definiciones Resiliencia. Consulta www 2011.

BUARQUE, S. C. 2002. Construindo o desenvolvimiento local sustentável. Metodologia de planejamento. Editora Garamond Ltda. Universitaria. $177 \mathrm{p}$.

CALVENTE, M. 2007. Resiliencia: un concepto clave para la sustentabilidad. UAIS. Universidad Abierta Interamericana. Centro de altos Estudios Globales. UAIS-CS200-003.

DALL'AGNOL, M.; STEINER, M. G.; BARÉA, K.; SCHEFFER-BASSO, S. M. 2006. Perspectiva deLancamento de Cultivares de Espécies Forrageiras Nativas: o Genero Paspalum. In: Anais do I Simpósio de Forrafeiras e Producao Animal. Departamento de Plantas Forrageiras e Agrometeorología UFRGS. Porto Alegre. Río Grande del Sur. Brasil. pp.: 14160.

CHAMOCHUMBI, W. 2005. La resiliencia en el desarrollo sostenible.Consulta 2011: www.ecoportal.net.

D.I.E.A. 2012. Dirección Investigación y Estadísticas Agropecuarias. Ministerio de Ganadería Agricultura y Pesca. Montevideo, Uruguay. Consulta 2012. www.mgap.gub.uy

DUARTE SANTOS, F. 2013. Década por una Educación para la Sustentabilidad. Consulta 2013: http://www.oei.es/decada/ accion18.htm.

ESPINOZA, G. 2001. Fundamentos de Evaluación de Impacto Ambiental. Centro de
Estudios para el Desarrollo de Chile. BID - CED. Santiago, Chile. 186 p .

F.A.O. 2002. El Tratado Internacional sobre los Recursos Fitogenéticos para la Alimentación y la Agricultura. FAO. Organización de las Naciones Unidas para la Agricultura y la Alimentación. $45 \mathrm{p}$.

HOLECHEK, J. L.; PIEPER, R. D.; HERBEL, C. H. 1988. Range Management. Principles and Practices. Second Edition. Prentice Hall. New Jersey. USA. 526 p.

HOLECHEK, J. L. 2013. Global trends in population, energy use an climate: implications for policy development, rangeland management and rangelad users. The Rangeland Journal, 35: 117-129.

HOLLING, C. S. 1973. Resilience and stability of ecological systems. Annual Review of Ecology and systematics. Volume $4 \mathrm{pp}$.: 1-23.

HOLLING, C. S. 1996. Surprise for science, resilience for ecosystems and incentives for people. Ecological Applications. 6(3): 733-735.

KREBS, CH. 2008. The Ecological World View. University of California Press. Berkeley. Los Angeles. USA. 574 p.

MARINO, G. 2008. Buenas prácticas ganaderas para conservar la vida silvestre de las pampas. Una guía para optimizar la producción y conservar la biodiversidad de los pastizales de la bahía de Samborombón y la Cuenca del Río Salado. Con la coordinación de F. Miñarro y G. Stamatti y la colaboración de M. Beade, E. Jacobo, C. Marull, A. Rodríguez y M. Uhart. Aves Argentinas/Asociación Ornitológica del Plata, B. Aires. Coeditado con la fundación Vida Silvestre Argentina y BirdLife International. 103 p.

NABINGER, C. 2006. Manejo e Productividade das Pastagens Nativas do Subtrópico Brasileiro. In: Anais do I Simpósio de Forrafeiras e Producao Animal. Departamento de Plantas Forrageiras e Agrometeorología UFRGS. Porto Alegre. Río Grande del Sur. Brasil. pp.: 25-75.

OLMOS, F.; SOSA, M. 2004. Climatic Variability in Natural Grasslands Ecosystems in the Northeast Region of Uruguay. In: $1^{\text {st }}$. International CLIVAR Science Conference. 
Understanding and Predicting Our Climate System. June 21-25, Baltimore, Maryland USA.

OLMOS, F. 2006. Estrategias para el Uso, Conservación y Recuperación de los Recursos Naturales Renovables en Uruguay. In: XXI Reunión Grupo Técnico en Forrajeras del Cono Sur. Grupo Campos. 24-26 octubre. Pelotas, Río Grande del Sur, Brasil.

PÉREZ CASTELLANOS, J. M. 1914. Observaciones sobre Agricultura. Editorial Barreiro y Ramos. Montevideo. 608 p.

PICKETT, S. T. A.; WHITE, P. S. 1985. The Ecology of Natural Disturbance and Patch Dynamics. Academic Press, NY, USA.

ROSCKSTRÖM, J.; STEFFEN, W.; NOONE, K.; PERSSON, A.; STUART. F.; CHAPIN, E.; LAMBIN, T.; LENTON, M.; SCHEFFER, M.; FOLKE, C.; SCHELLNHUBER, H. J.; NYKVIST, B.; CYNTHIADE WIT, T.; HUGHES, S.; VAN DER LEEUW, H. RODHE. S.; SÖRLIN, P. K.; SNYDER, R.; COSTANZA, U.; SVEDIN, M.; FALKENMARK, L.; KARLBERG, R. W.; CORELL, V. J.; FABRY, J.; HANSEN, B.; WALKER, D.; LIVERMAN, K.; RICHARDSON, P.; CRUTZEN, P.; FOLEY, J. 2009. Planetary Boundaries: Exploring the Safe Operating Space for Humanity. Ecology and society 14 (2) 32 [on line]URLhttp://www.ecologyandsociety. org/vol14/iss2/art32/.

ROSENGURTT, B. 1943. Estudios sobre praderas naturales del Uruguay. 3ra. Contribución. La estructura y el pastoreo de las praderas en la región de Palleros. Casa Barreiro y Ramos S. A. Montevideo. 281 p.

ROSENGURTT, B. 1979. Tablas de comportamiento de las especies de plantas de campos naturales en el Uruguay. Dirección General de Extensión Universitaria. División Publicaciones y Ediciones. Universidad de la República. Facultad de Agronomía. 86 p.
SÁNCHEZ, O. 2007. Restauración ecológica: algunos conceptos, postulados y debates al iniciar el siglo XXI. Consultor en conservación de vida silvestre. Insurgentes Cuicuilco, C. P. 04530, Delegación Coyoacán, México D. F. Ultima actualización: 15 noviembre, 11-2007.

SHEFFER, M.; CARPENTER, S.R. 2003 - Catastrophic regime shifts in ecosystems: linking theory to observation. TRENDS in Ecology and Evolution. Vol 18. No. 12: 648-656

VILCHES, A. D.; GILN PÉREZ, J.; TOSCANO, C.; MACÍAS, O. 2009. Biodiversidad. Consulta 2011.http://www.oei.es/decada/ accion18.htm.

UICN. Unión Internacional para la Conservación de la Naturaleza 2010 - Building Resilience to Climate Change. Ecosystembased adaptación and lessons from the field. Edited: A. Andrade Pérez, B. Herrera Fernández, R. Cazzolla Gatti. 165 p.

UICN. Unión Internacional para la Conservación de la Naturaleza 2008 - Primer taller sudamericano de la Iniciativa de Conservación de Pastizales Templados. San Clemente del Tuyú. Argentina.

WALKER, B.; KINZIG, A.; LANGRIDGE, J. 1999. Plant attribute diversity, resilience and ecosystem function: the nature and significance of dominant and minor species. Ecosystems, 2: 95-113.

WALKER, B.; SALT, D. 2006. Resilience thinking. Sustaining Ecosystems and People in a Changing World. ISLAND PRESS.174 p.

WIKIPEDIA - http://es.wikipedia.org/wiki/ Resiliencia,consulta 2011.

WWW.cen tropsicopedagogico.cl/index; consulta 2011. 



\section{VALORACIÓN/REANÁLISIS Y PERSPECTIVAS}

En este capítulo se dará énfasis a las principales características de los sistemas de producción insertados en los ecosistemas naturales de la región noreste. Básicamente, de acuerdo al modelo conceptual, se destaca la importancia de los recursos genéticos forrajeros presentes en el ecosistema pastoril y que se encuentran ampliamente adaptados a la variabilidad climática regional descripta en el capítulo III. No deben descartarse otros recursos genéticos, pero los forrajeros son la base de la relación sociedad - ambiente hasta hoy.

Muy probablemente los sistemas de producción basados en el uso de los recursos naturales sean más resilientes frente a los eventuales cambios climáticos, ya que disponen de una mayor diversidad de opciones a la luz de la propia biodiversidad presente. Al mismo tiempo, debemos valorar económicamente mucho más, no solo los tipos de suelos que tenemos en la región en relación a la productividad, sino que también la combinación suelo - recurso forrajero, frente al eventual cambio climático global, lo que nos posiciona como fuente de germoplasma a escala planetaria (Olmos y Sosa, 2004).

Si bien es admisible la posibilidad de mejoras en los valores de los indicadores dentro de los actuales sistemas de producción, es necesario cuantificarlos seguramente dependiendo de la escala del predio, ya que los impactos en los ingresos familiares como los impactos a nivel general de la economía en general son similares. ¿Quién y cómo podríamos actuar sobre los diferentes niveles de decisiones, desde la UEM (unidad ecológica de manejo - predial) hasta las decisiones gubernamentales?

En los siguientes párrafos se plantea una especie de micro análisis conceptual de estos sistemas de producción insertos en los ecosistemas naturales de la región noreste.

\section{MICRO ANÁLISIS CONCEPTUAL}

\section{Fortalezas}

- disponibilidad de recursos genéticos locales y con aptitud internacional

- biodiversidad y resiliencia histórica

- variación en el precio de la tierra

- relación suelo - vegetación

- adaptación de los sistemas de producción al cambio climático

- bajo costo de producción

- bajo costo ambiental de producción

- productos de calidad

\section{Debilidades}

- nivel de los indicadores de producción promedio

- necesidad de monitoreo frente al impacto de las actividades humanas y a eventuales cambios climáticos

- necesidad de mayor conocimiento científico y cultural

- degradación ambiental y productiva (impactos sociales y económicos)

- dependencia externa de fuentes de insumos y petróleo

- estructura y concentración de la tierra

\section{Amenazas}

- expansión de la frontera agrícola

- pérdida de variabilidad genética forrajera (Darwin -fitness)

- inestabilidad de ingresos

- enmalezamiento

- incremento en el uso de plaguicidas

- pérdida de capital: desvalorización del campo

- erosión del suelo 


\section{Oportunidades}

- valoración productiva de la tierra

- recursos genéticos para el mundo

- recuperación de pasturas degradadas

- estabilidad y sustentabilidad productiva completa

- recuperación - estabilidad del ingreso familiar

La composición del ingreso familiar puede actuar como una restricción ya que depende del tamaño de la explotación y eso condiciona el nivel de actividad y productividad, conjuntamente con la capacidad de inversión en tecnología.

\section{RECURSOS GENÉTICOS}

En el marco de la variabilidad climática con la que nos encontramos en la región noreste, se encuentran las especies forrajeras del campo natural que han permanecido en la misma por cientos de años. Estas especies son consideradas recursos genéticos muy valiosos toda vez que tenemos especies adaptadas a diferentes tipos de suelo, niveles de fertilidad con ciclo de crecimiento tanto invernal como estival (Rosengurtt, 1979) y constituyen la base fundamental de la ganadería regional (Olmos y Grodon, 1990).

Una de las características fundamentales que presentan las pasturas naturales es su gran capacidad de tolerancia a las variaciones climáticas estacionales como interanuales determinando una alta capacidad de resiliencia productiva a las mismas. Esto es que las mismas, por ejemplo luego de un período de estrés hídrico, se recuperan prontamente en su productividad contrastando con la pérdida que ocurre generalmente con las pasturas introducidas artificialmente (Olmos, 2004).

En 1980 Rosengurtt, publicó una lista de especies de interés agronómico y con eventual potencial productivo para la región. También en las últimas décadas se han realizado algunos trabajos que indican el potencial que presentan algunas de estas especies para su utilización con criterios productivos (Olmos, 1983), como Bromus auleticus.

En la actualidad en la región los sistemas de producción han tendido a una mayor intensificación dada la alta demanda mundial por bienes primarios dado el crecimiento poblacional mundial. En este sentido tanto la agricultura de secano y bajo riego, como la forestación, la lechería y la propia ganadería extensiva han avanzado sobre los hábitats naturales eliminando importantes áreas de pasturas naturales del territorio nacional (Olmos, 2006). Este avance se ha realizado sin haber tomado por parte de los actores ninguna precaución sobre la variabilidad genética presentes en los distintos establecimientos, salvo raras excepciones. Este es un potencial que disponemos como patrimonio nacional que paulatinamente se reduce, dado el actual modelo de producción, el cual de continuar nos dejaría con un tercio de pasturas naturales en las próximas décadas en el territorio nacional.

Un claro ejemplo de pérdida de diversidad se ilustra a continuación para el caso de Hordeum stenostachys. El mapa inserto en la Figura 1 muestra el área de distribución para la especie (Bothmer et al., 1991) y además hemos estimado el área de pasturas naturales presentes en la región; es en estas zonas en las que en la actualidad se desarrolla el modelo de intensificación sin medidas precautorias. El impacto es fundamentalmente a través de la desaparición de hábitats para las especies adaptadas, en este caso las especies forrajeras.

En el caso de Hordeum stenostachys es interesante disponer de mayor información respecto de la especie tanto en su productividad como en su posible domesticación (Figuras 2 y 3); la especie presenta un importante aporte de forraje en el período invernal complementando la composición de las pasturas naturales que están formadas principalmente por especies estivales (Olmos y Godron, 1990).

Muchas otras especies podrían ser consideradas recursos genéticos importantes como puede ser en este caso la Marcela: 


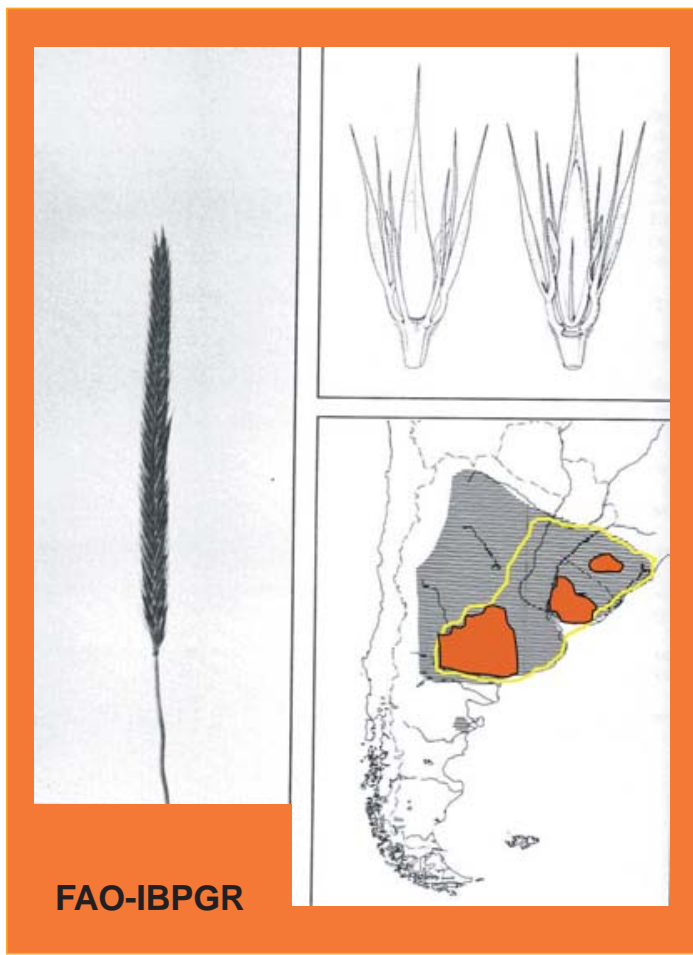

Figura 1. Localización de Hordeum stenostachys en el cono sur de América del Sur (sombreado) el área de pastizales (contorno amarillo) y la expansión agrícola (anaranjado).
Achyrocline satureoides presente en el paisaje regional (Figura 4).

La intensificación de la producción así como la diversificación de rubros nos trae aparejado el impacto sobre los hábitats de estas especies adaptadas, incluyendo su flora y su fauna. En las Figuras 5 y 6 se ejemplifica gráficamente como el continuo avance sobre las pasturas naturales paulatinamente nos puede ir restringiendo las áreas de las especies de interés y finalmente podemos llegar a alcanzar el límite como sería la desaparición no solo de la variabilidad genética presente sino de la propia especie (Figura 7).

La principal dificultad que nos encontramos actualmente no es la necesidad de poner obstáculos a la intensificación sino en por lo menos aplicar el principio de precaución donde estamos destruyendo hábitats y por lo tanto especies que conocemos muy poco no solo en su uso actual sino en un futuro no muy lejano o en otras regiones del planeta.

La propuesta es transformar esta debilidad en una fortaleza reconociendo el alto potencial genético presente en nuestras pas-

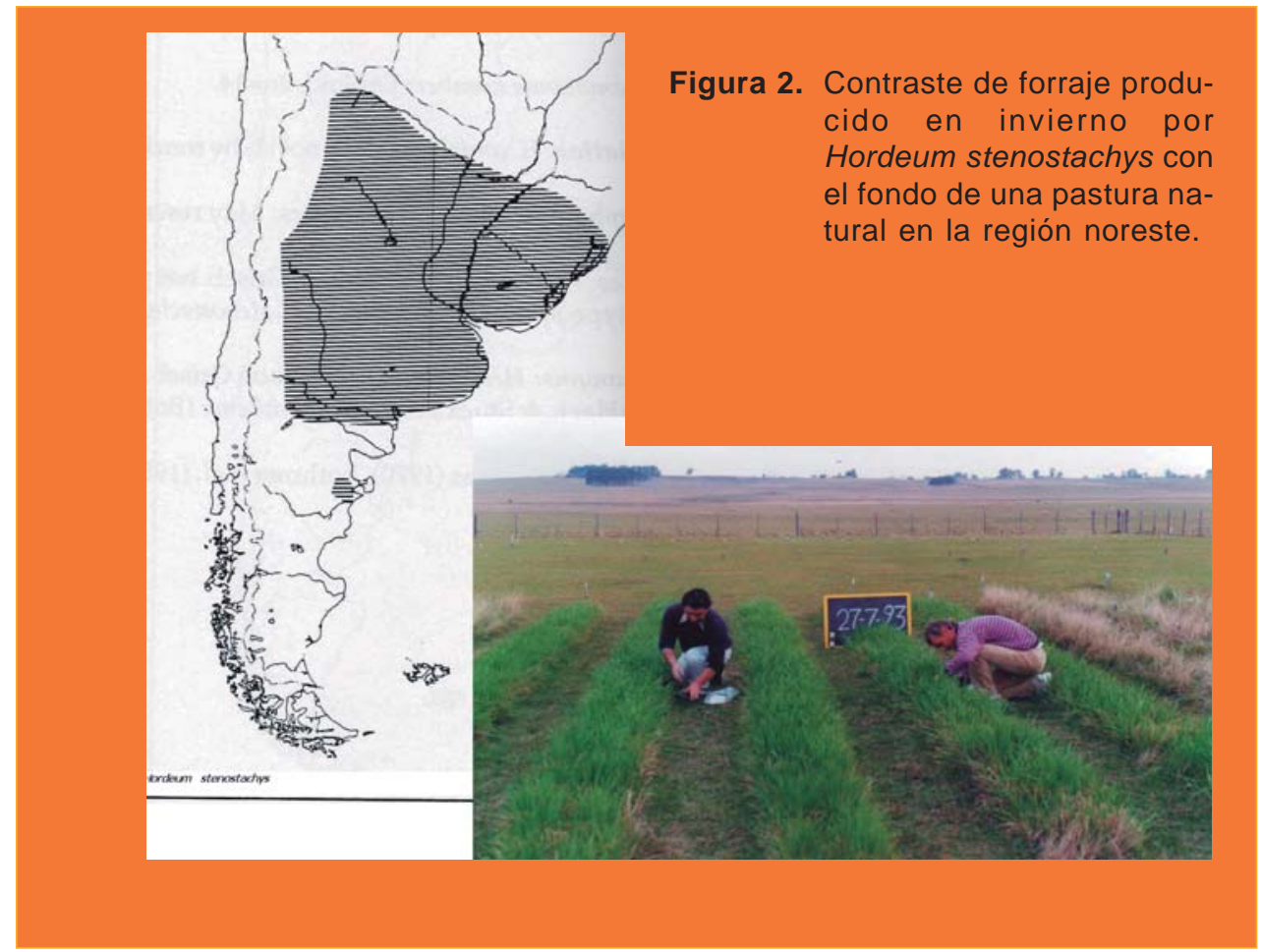


Figura 3. Altura y productividad de líneas de Hordeum stenostachys sobre suelos arcillosos de la región noreste en el período invernal.
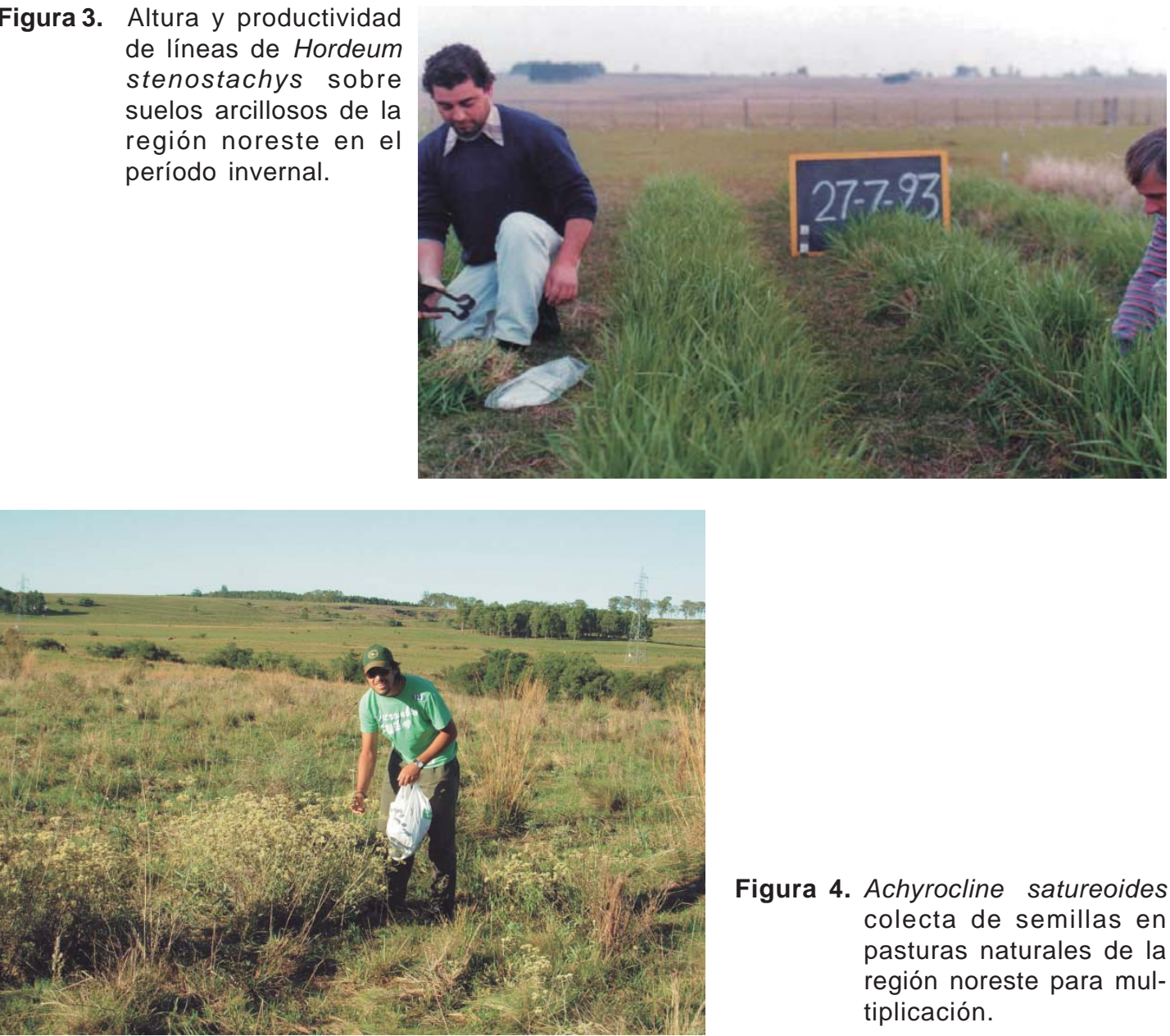

Figura 4. Achyrocline satureoides colecta de semillas en pasturas naturales de la región noreste para multiplicación.

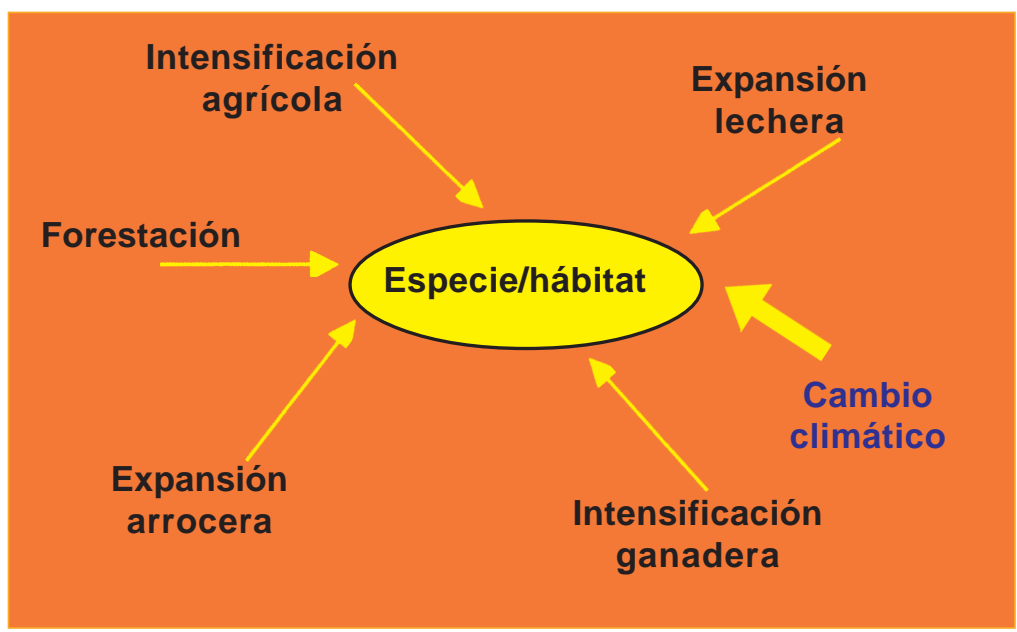

Figura 5. Esquema gráfico de interacción entre la intensificación productiva y los recursos forrajeros nativos. 


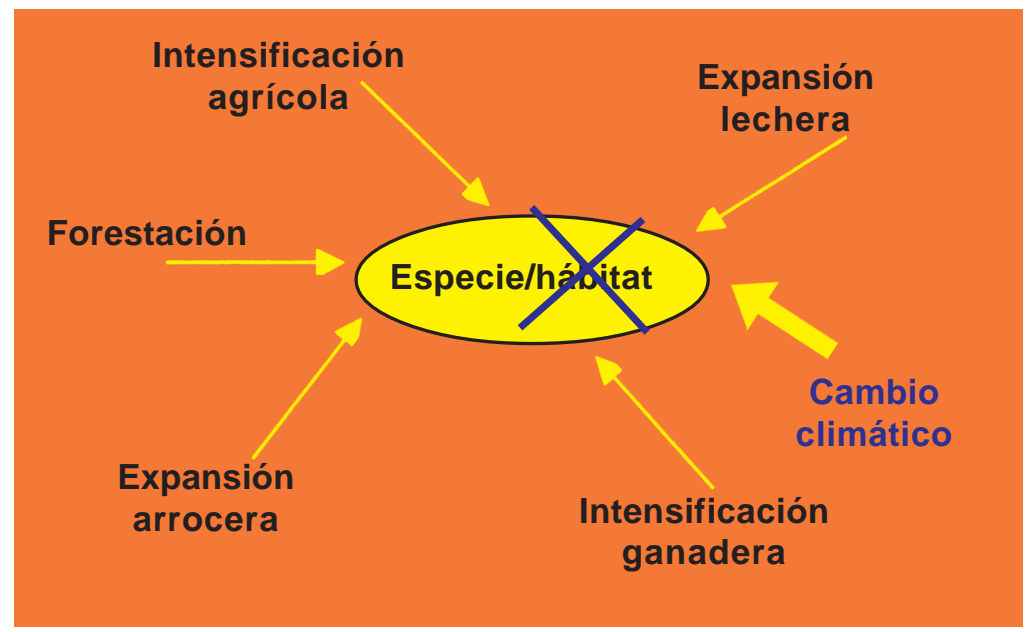

Figura 6. La intensificación propende a la fragmentación y desaparición de hábitats de especies forrajeras adaptadas a la región.

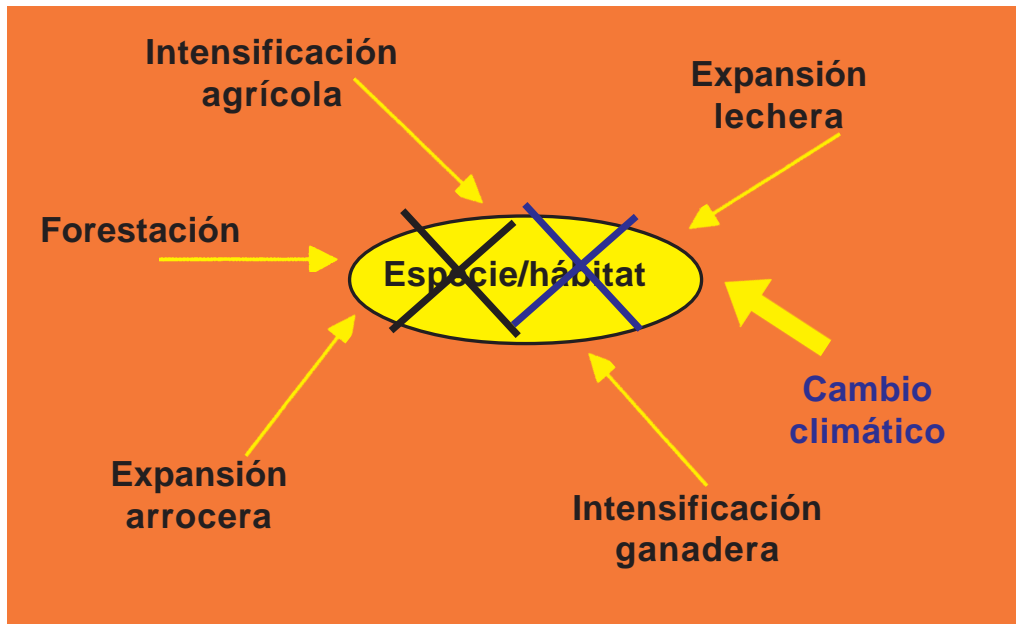

Figura 7. Diagrama consignando el extremo de acumulación de impactos por la intensificación productiva sobre a la desaparición de hábitats y especies.

turas naturales, no solo por su excelente capacidad de resiliencia productiva, sino también por su adaptación a situaciones climáticas y suelo que puede ser explotada como fuente forrajera, fuente de genotipos, fuente de genes en forma estratégica para ser utilizados no solo por nuestros propios productores sino también en otros ecosistemas a nivel global frente a este escenario de cambio.

El campo natural y sus recursos genéticos son los principales instrumentos de resiliencia de nuestros sistemas de producción; es lo que permite la tolerancia ante la severidad de la dependencia climática.
En base a las consideraciones anteriores deberíamos tener presente la necesidad de disponer de un plan de monitoreo de los recursos naturales en general y de las pasturas naturales de la región en particular. Este mecanismo debería poder realizar el seguimiento ambiental con indicadores desde el nivel del predio particular (UEM) hasta la escala regional por lo menos. Para ello es importante la posibilidad de realización de censos de especies, profundizar en su conocimiento ecofisiológico, producción de semilla de especies forrajeras nativas, considerando los diferentes sis- 
temas de producción así como los distintos de suelo y topografías de la región.

Algunos autores han destacado que el modelo actual tiende a maximizar el beneficio económico de corto plazo con un énfasis mínimo en el desarrollo sustentable que considere además de los aspectos económicos los ecológicos y sociales (Goldberg, 1998; Esterlich y Giraudo, 1998); en este sentido y en virtud de los recursos genéticos presentes en las pasturas naturales, es importante enfatizar sobre la necesidad de un marco legal para regular estas acciones propuestas, frente a los cambios experimentados en la vegetación por la expansión de los cultivos agrícolas.

\section{BIBLIOGRAFÍA}

BOTHMER, R.; JACOBSEN, VON, N.; BADEN, C.; JORGENSEN, R. LINDE-LAURSEN, B.L. An ecogeographical study of the genus Hordeum. IBPGR, F.A.O. Rome. 127 p.

ESTERLICH, H. D.; GIRAUDO, C.1998 . Síntesis y conclusiones del taller sobre recuperación y manejo de ecosistemas degradados. In. PROCISUR. Recuperación y manejo de ecosistemas degradados. Montevideo. IICA. PROCISUR. Diálogo 49.

GOLDBERG, A.D. 1998. Síntesis de las ponencias presentadas en la Primer Jornada en el Taller de Recuperación y Manejo de Sistemas Naturales Degradado. In PROCISUR. Recuperación y manejo de ecosistemas degradados. Montevideo. pp. 71-75. IICA-PROCISUR.
OLMOS, F. 1993. Bromus auleticus. Serie Técnica No. 35. INIA Tacuarembó. 30 p.

OLMOS, F. 2004. Factores que afectan la persistencia y productividad de pasturas mejoradas con trébol blanco (Trifolium repens L.) INIA Tacuarembó. Serie Técnica No. 145. 248 p.

OLMOS, F. 2006. Estrategias para el uso, conservación y recuperación de recursos naturales renovables en Uruguay. In: XXI Reuniao do Grupo Técnico em Forrageiras do Cone Sul. Grupo Campos. Documentos 166. EMBRAPA. Pelotas. Río Grande del Sur. Brasil. pp.: 137-150.

OLMOS, F.; GODRON, M.1990. Relevamientos fito-ecológicos en el Noreste uruguayo. In: 2do. Seminario Nacional de Campo Natural. Instituto Nacional de Investigación Agropecuaria. Sociedad Uruguaya de Pasturas Naturales. Facultad de Agronomía. Plan Agropecuario. Ed. Hemisferio Sur. pp.: 35-48.

ROSENGURTT, B. 1979. Tablas de comportamiento de las especies de plantas de campos naturales en el Uruguay. Facultad de Agronomía. Universidad de la República. Dirección General de Extensión Universitaria. 86 p.

ROSENGURTT, B. 1980. Germoplasma de forrajeras nativas. Universidad de la República. Facultad de Agronomía. 17 p. 


\section{PROPUESTA DE USO Y CONSERVACIÓN}

\section{PROPUESTA METODOLÓGICA PARA EL USO Y CONSERVACIÓN DE LAS PASTURAS NATURALES}

\section{Importancia}

La producción ganadera en Uruguay esta basada en la utilización de las pasturas naturales presentes en los ecosistemas naturales y ocupa las $2 / 3$ partes del territorio nacional. Desde el punto de vista económico la pecuaria representa el 63,4\% del valor de la producción bruta agropecuaria, la agricultura representa el $29 \%$ y la silvicultura el 7,6 \% (DIEA, 2007).

La producción pecuaria en su conjunto está determinada por la eficiencia y sustentabilidad productiva en el área de producción sobre campo natural; esta dependencia constituye, a su vez, un importante respaldo al sistema productivo en general, tanto ganadero como agrícola-ganadero, toda vez que sus principales componentes lo hacen resiliente a los frecuentes impactos negativos naturales como son los períodos de estrés hídrico (Olmos, 1997a, b; Olmos y Sosa, 2004; Olmos, 2004; Olmos et al., 2005).

Además de las características propias de sustentabilidad de los sistemas basados en el uso de los recursos naturales, la producción basada en la utilización de pasturas naturales se puede transformar en productos altamente demandados en el mercado internacional, considerando tanto los atributos de calidad así como la procedencia de los mismos (Montossi y Sañudo, 2007).

Una propuesta en el largo plazo, de un uso racional de los recursos naturales, generará un impacto positivo, tanto desde el punto de vista de la productividad física y económica como desde el punto de vista humano.

\section{Problema}

El incremento en superficie de los sistemas de producción más intensivos como la lechería, la agricultura y la forestación así como la intensificación en la propia actividad ganadera, ha determinado en la última década del siglo pasado la desaparición de 1:700.000 hectáreas de campo natural (Olmos, 2006).

La agricultura de secano, liderada por la soja, se ha caracterizado por una fuerte expansión en el área cultivada desplazando a otras actividades en el uso del suelo; por su parte el cultivo de arroz ha incrementado su área en la zona norte del país. Esta expansión de la «frontera agrícola» se ha visto favorecida por la aplicación de la técnica de la siembra directa en suelos nuevos para la producción de granos.

El cambio en el uso del suelo y el patrón de cultivos comienza a alterar el sistema agrícola-ganadero predominante en el pasado, transformándose paulatinamente en uno de agricultura continua. La ganadería vacuna, por su parte, ha exhibido importantes respuestas a las transformaciones del entorno observándose un proceso de intensificación apoyado en los cambios en la alimentación, mostrando un incremento del $50 \%$ en el uso de granos y derivados agroindustriales (Durán et al., 2007) y la forestación ha alcanzando prácticamente la cifra de 800.000 hectáreas plantadas (Dell'Acqua et al. 2006).

La Figura 1 muestra la evolución del uso del suelo a partir de diversas fuentes de información y de estimaciones propias en el período 1830 - 2050 (Pérez Castellanos, 1914; CINAM-CLAEH, 1963; Censo Agropecuario, 1961, 1966, 1970, 1980, 1990, 2000; DIEA, 2006, 2007, 2008). Los tres principales componentes que sustituyen la presencia de las pasturas naturales por otro tipo de uso del suelo son la variación en la su- 


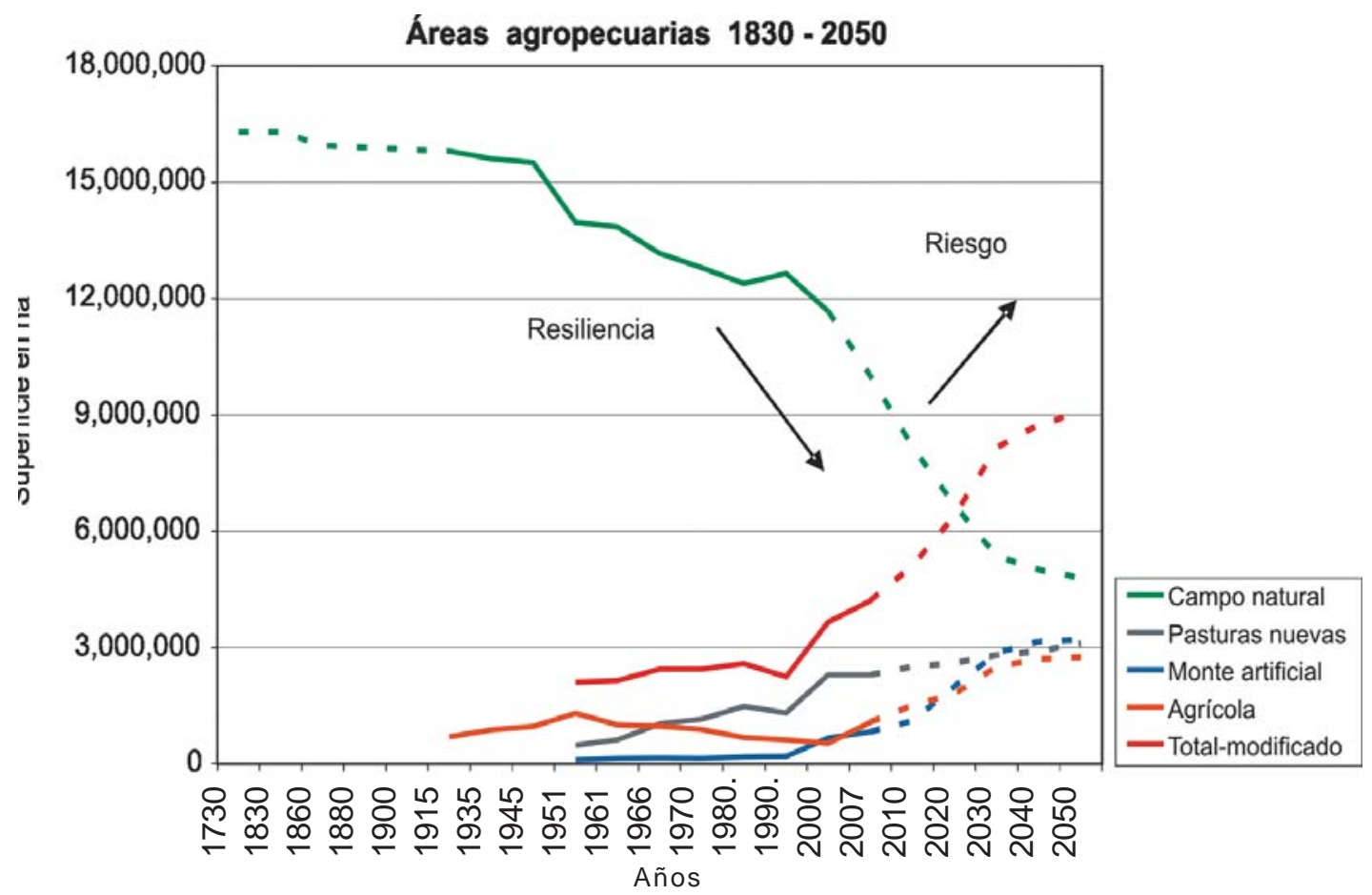

Figura 1. Evolución de la superficie de campo natural y diferentes rubros agrícolas en el período 1730 - 2050 en el Uruguay (líneas Ilenas) y su estimación (líneas punteadas).

perficie agrícola, la cual retoma actualmente, los niveles alcanzados en la década de 1950, la implantación de nuevas pasturas tanto en el área ganadera como en la lechera y el área dedicada a la forestación artificial.

El punteado en las líneas de la Figura 1 corresponde al cambio potencial en el uso del suelo en las próximas décadas, según la posibilidad de utilización del mismo para la agricultura y la forestación (Dell'Acqua et al., 2006; Durán et al., 2007). Estos valores pueden alcanzar el segundo tercio, en superficie, otras 5:000.000 de hectáreas, de explotación intensiva del territorio nacional con la desaparición consecuente de las pasturas naturales.

Debería estar prohibida la expansión productiva? No, sin embargo...

La Figura 2 ilustra el impacto de las actividades humanas en la erosión de los suelos del Uruguay, mostrando que, independientemente de la superficie anual cultivada, la misma se ha incrementado sustantivamente tanto por el uso intensivo de las mismas áreas agrícolas como por la incorporación de nuevas a sistemas de producción más intensivos; tanto la erosión severa como la erosión moderada más que duplicaron su superficie en 30 años pasando de un total de 805.000 hectáreas a principios de la década del 60 a 2:038.000 hectáreas hacia los años 90 , la erosión ligera evolucionó de algo menos de 2:400.000 hectáreas a 3:185.000 hectáreas (De León y López Taborda, CIDE, citados por CINAM-CLAEH, 1963; Sistema Información Geográfica, 2004; MVOTMA MGAP, 2005). La superficie total con algún grado de erosión pasó de 3:205.000 hectáreas a 5:223.000 hectáreas.

Concomitantemente con la erosión, el cambio en el uso del suelo trae aparejado la erosión genética, ya que se procede directamente a la modificación, fragmentación y destrucción de los hábitats donde se encuentran los componentes de las pasturas naturales (Rosengurtt et al., 1939; Southwood, 1977; Rosengurtt, 1979; Begon et al., 1996); la conjunción de estos eventos conlleva la amenaza tanto en la reducción como hasta la eventual desaparición de poblaciones de especies locales de interés potencial. 


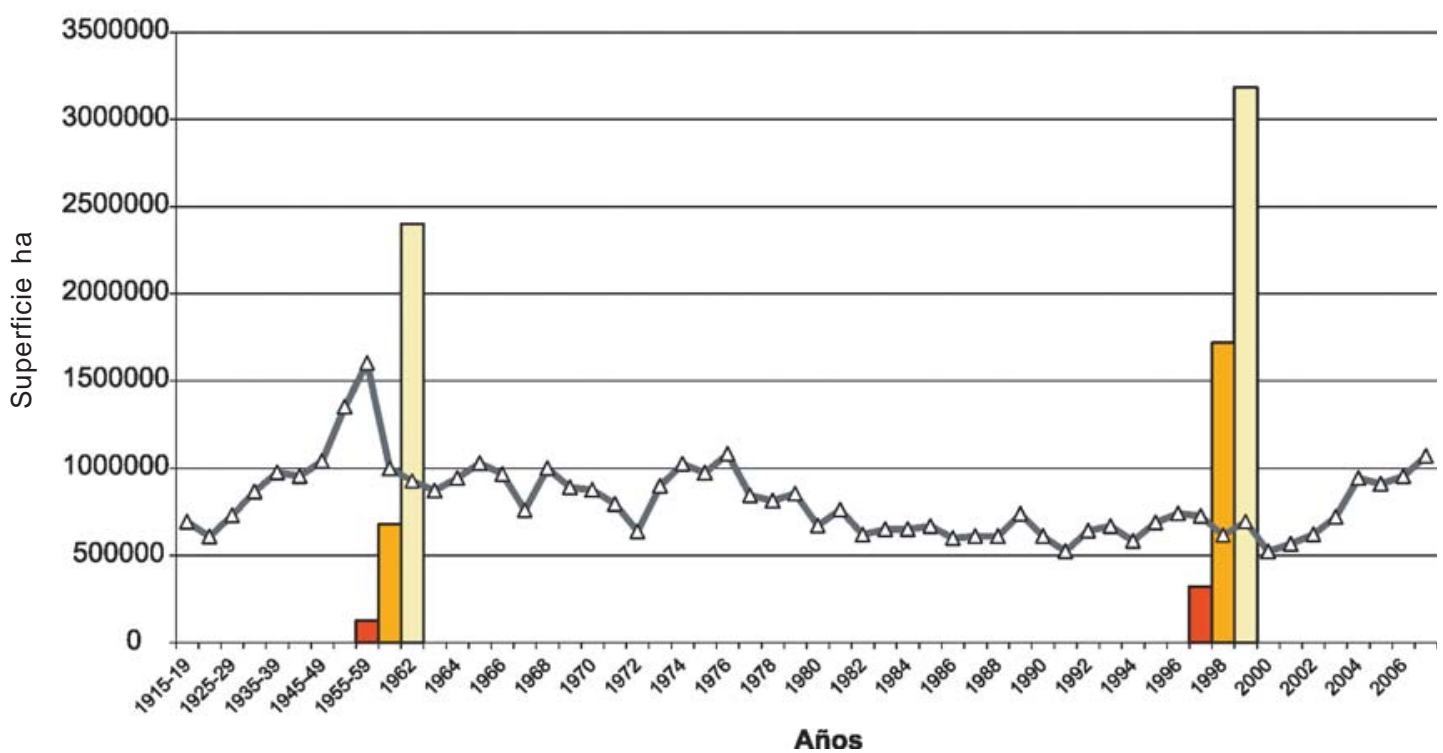

Figura 2. Evolución del área cultivada en el Uruguay (líneas) y estimación de la erosión en los suelos (barras).

Estas poblaciones de interés pueden estar vinculadas a la producción forrajera y el mejoramiento de los campos naturales (Formoso y Allegri, 1984; Boggiano, 1990; Olmos, 1990a, b; von Bothmer, 1991; Olmos, 1993; Izaguirre y Beyhaut, 1997; Olmos, 2000; Olmos, 2001a, b; Izaguirre y Beyhaut, 2003), a la producción de semillas (Millot et al., 1990), a la producción de plantas medicinales, a la producción de aceites esenciales (Davies, 2004; GTZ et al., 2004; Villamil y Bonnecarrère, 2005), a la producción de árboles frutales (Vignale y Bisio, 2005), al uso multipropósito (Lombardo, 1964; Rivas, 2005; Arballo y Cravino, 2005; Brussa y Grela, 2007), o a la conservación de germoplasma (Izaguirre y Grun, 1990; Speranza, 2005; Puigdevall et al., 2007) para intercambio y potencial adaptación a otras regiones (IICA, 1998). No debemos dejar de tener presente que los genotipos, son los motores impulsores de los ecosistemas. Con el incremento o mantenimiento de la variación en el pool genético de las especies, las mismas se encontrarán mejor preparadas para la eventual adaptación al cambio climático (Canter, 1996).

En el Cuadro 1 se ejemplifica la intensidad del impacto de los diferentes sistemas de producción basados en el uso de los recursos naturales.

La ponderación de los impactos (+), fue realizada considerando que vinculado a cada actividad productiva encontramos asociado: la destrucción de las pasturas naturales, ya sea por laboreo clásico o por el laboreo químico, por el incremento en la erosión de los

Cuadro 1. Impacto de diferentes sistemas de producción sobre los recursos naturales.

\begin{tabular}{|l|c|c|c|c|}
\hline \multirow{2}{*}{ Sistema de producción } & \multicolumn{5}{|c|}{ Recurso natural } \\
\cline { 2 - 5 } & Suelo & Flora nativa & Fauna nativa & Agua \\
\hline Agricultura & +++ & +++ & $++/+$ & +++ \\
Forestación & ++ & ++ & $++/+$ & $++/+$ \\
Lechería & ++ & ++ & ++ & $++/+$ \\
Invernada intensiva & ++ & ++ & ++ & ++ \\
Ganadería extensiva & + & + & + & + \\
\hline
\end{tabular}


suelos y la contaminación por el uso de más plaguicidas, por la desaparición de hábitats para la fauna nativa y la presencia de sedimentos y plaguicidas en las cuencas hidrográficas. En paralelo a estos impactos se intensifican otros eventos como la invasión de malezas: Cynodon dactylon, Coleostephum myconis y Eragrostis plana entre otras. Además de estos efectos, otras de las características importantes asociadas al cambio en el uso del suelo, es la velocidad a la cual está ocurriendo el mismo (Durán et al., 2007).

Estas modificaciones importantes que operan sobre los recursos naturales, conjuntamente con la amenazas de severos impactos potenciales en las próximos veinte años por efecto del cambio climático global, determinan la necesidad de elaborar una estrategia para la acción rápida, de forma de alcanzar una mejor adaptación a los cambios que operarían en las próximas décadas de continuar esta tendencia.

Bajo estas circunstancias toda vez que el cambio global impacte y modifique otros ambientes en otras regiones del mundo, el potencial de uso de nuestros recursos genéticos se maximiza.

En virtud que el modelo actual de producción, en base al uso intensivo de los recursos naturales, tiende a maximizar el beneficio económico individual de corto plazo con un mínimo énfasis en el desarrollo sustentable que considere, además de los aspectos económicos, los aspectos ecológicos y sociales, se hace necesaria la implementación de acciones que consoliden un marco legal para regular las actividad productivas a diferentes escalas de intervención como lo son el predio, la región, la cuenca o la seccional policial. Estas acciones, consideradas a través de planes, deberán tener en cuenta tanto medidas de mitigación como de compensación por los impactos negativos establecidos sobre los recursos naturales, la biodiversidad y los hábitats. Debe tenerse presente, además, que estos impactos negativos son generalmente acumulativos, comenzando primero con la reducción de la variabilidad genética y finalmente con la amenaza de desaparición de las especies tanto forrajeras como medicinales, de la fauna, de los microorganismos o la meso fauna.

Un componente no menos importante lo es la estabilidad de los sistemas de producción a nivel predial, o sea la Unidad Ecológica de Manejo (Caldevilla et al., citado por Olmos, 2006). En la medida que un predio ganadero intensifica su producción seguramente significará la implantación de áreas de «pasturas mejoradas» utilizando para ello especies exóticas y destruyendo las pasturas naturales; estas especies exóticas, ante la presencia de eventos de estrés hídrico muy comunes en nuestro ecosistema natural, no solo disminuyen su productividad sino que puede llegar a perderse en el «mejoramiento», por lo tanto en la medida que un predio base su sistema de producción cada vez más en especies exóticas los impactos sobre la productividad serán más extremos ante estas eventualidades, amenazando al mismo tiempo el componente económico de los ingresos prediales.

\section{Necesidad de desarrollar una propuesta legal}

La Ley General de Protección al Medio Ambiente, No. 17.283, define al daño ambiental como toda pérdida o detrimento significativo que se infiera al medio ambiente; en este sentido se incluye la calidad del agua, el suelo y el paisaje, teniendo en cuenta además, la conservación de la diversidad biológica.

Desde el punto de vista de los principios de política ambiental se destacan, entre otros, la efectiva integración de la dimensión ambiental al desarrollo económico y social, tanto de los derechos como deberes de las personas en participar, la transectorialidad entre el sector público y privado, así como la prevención y previsión como criterios prioritarios a tener en cuenta en las acciones.

Frente a los impactos la normativa prevé la necesidad de estructurar medidas y requisitos tendientes a la prevención, eliminación mitigación y compensación de los impactos ambientales negativos. Entre los principales elementos de gestión se consideran las propias normas, reglamentos, programas, 
planes, proyectos, información y educación ambiental, así como el establecimiento de parámetros y estándares y declaraciones juradas. Dentro de las reglamentaciones se prevé la realización de evaluaciones de riesgo y plantea la posibilidad de establecer incentivos económicos y tributarios.

Por su parte la Ley de Impacto Ambiental, No. 16.466, y la Reglamentación del proceso de Evaluación de Impacto Ambiental, decreto No. 349 de 2005, establecen en forma detallada la necesidad de estudios de impacto ambiental cuando las condiciones de los impactos lo ameriten. En este sentido se considera impacto ambiental negativo, toda alteración de las propiedades físicas, químicas o biológicas del medio ambiente causada por cualquier forma de materia o energía resultante de las actividades humanas que afecten:

- la salud, seguridad o calidad de vida de la población

- las condiciones estéticas, culturales, sanitarias del medio

- la configuración, calidad y diversidad de los recursos naturales

Algunas actividades que implican un Estudio de Impacto Ambiental, previo a la aprobación de los proyectos, son:

- áreas mayores a 100 hectáreas en represas

- explotaciones hortícolas, frutícolas o vitícolas de más de 100 hectáreas

- emprendimientos forestales de más de 100 hectáreas

- instalaciones industriales mayores a 1 hectárea

- la realización de caminos, carreteras, puentes y puertos

- la extracción de minerales

En estos estudios de impacto ambiental se debe tener en cuenta los efectos sobre el ambiente biótico (flora y fauna), el ambiente físico (agua, suelo, paisaje) y el ambiente antrópico (población, uso del suelo, aspectos culturales); y al mismo tiempo se deben proponer medidas de mitigación así como presentar un plan de seguimiento y vigilancia.
La Ley de Conservación de Suelos, No. 17.239 , declara de interés nacional promover y regular el uso y conservación de los suelos y de las aguas superficiales destinados a fines agropecuarios; a los efectos de resaltar la importancia del tema establecida por los legisladores la misma establece que: «cuando el productor no puede realizar las prácticas recomendadas y requeridas el Banco de la República Oriental del Uruguay solventará y financiará prioritariamente las actividades de conservación».

La ley permite, a su vez, determinar normas técnicas básicas que deberán aplicarse en el manejo y conservación de suelos y aguas y recuperación de suelos; hasta sería posible prohibir la realización de determinados cultivos o prácticas de manejo de suelos y aguas en las zonas que corresponda. La reglamentación de la ley, plantea la metodología para la evaluación de tierras y permite basar las recomendaciones en los resultados avalados por los institutos de investigación especializados.

La Ley Forestal, No. 15.939 prevé en su artículo 24, la posibilidad de una explotación racional del monte indígena basado en un informe técnico y un plan de acción.

Mediante la Ley No. 17.234 se ha creado el Sistema Nacional de Áreas Protegidas (SNAP) el cual deberá ser el conjunto de áreas naturales representativas de los ecosistemas del país que por su valores ambientales, históricos, culturales o paisajísticos, merezcan ser preservados como patrimonio de la nación, aún cuando los mismos hubieran sido transformados parcialmente por el hombre. Entre los objetivos específicos se encuentran la protección de la diversidad biológica de los ecosistemas, incluyendo el material genético y las especies, con prioridad en la flora y fauna autóctonas amenazadas; asimismo establece la necesidad de proteger los hábitats naturales principalmente vinculados a especies amenazadas.

Desde el punto de vista de las estructuras departamentales existe la posibilidad jurídica de crear comisiones honorarias departamentales para la consideración del uso racional de la flora y fauna nativa, así como del uso del suelo y la calidad del agua. 
En la actualidad, año 2008, existen una serie de propuestas de orden legislativo (en discusión) que apuntan a consolidar las acciones y cometidos del estado y los ciudadanos en general con relación al ambiente; en este sentido se encuentran a consideración la Ley de Ordenamiento Territorial, el Marco Normativo sobre Bioseguridad, la Ley sobre Recursos Genéticos y una nueva Ley de Caza Deportiva.

A pesar de todos estos esfuerzos... hoy por ejemplo, se requiere autorización ambiental para la instalación de una represa mayor a 100 hectáreas, pero no se requiere de la autorización ambiental respecto al impacto que ocasiona el uso de esa agua en la represa como puede ser la destrucción de 900 hectáreas de campo natural; respecto a la Ley de Conservación de Suelos no se aplica en el sentido de la conservación de la vegetación, en la cual aún aplicándola en forma estricta no se plantean medidas para la conservación de las plantas, y tampoco respecto a los demás componentes del hábitat; cuando se plantea la forestación artificial, aún en áreas de prioridades forestal y mediante la presentación de un proyecto, no se determinan mecanismos para la conservación de las pasturas naturales que se destruyen; a través del monitoreo del uso del agua en los cultivos irrigados es posible la verificación de la implementación de medidas de conservación de suelos así como del sistema de rotaciones empleados, sin embargo este mecanismo no se encuentra operacional en el área de cultivos de secano; disponemos de una normativa para el manejo del monte indígena con 800.000 hectáreas, pero no disponemos de un mecanismo para la consideración del uso de más de 10:000.000 de hectáreas de pasturas naturales.

Con base en estos antecedentes, se hace necesario implementar mecanismos que determinen un uso más racional de las pasturas naturales, a través de una normativa adecuada a las condiciones locales y en virtud de su extrema importancia como uno de los principales componente de los sistemas de producción agropecuarios en el país.
La pastura natural constituye un recurso natural insustituible que le da estabilidad a los sistemas de producción en los ecosistemas naturales predominantes en el país; por lo tanto, y de acuerdo a los antecedentes, se vuelve importante compatibilizar la intensificación productiva con el uso racional de los recursos naturales, específicamente las pasturas naturales.

\section{MÉTODO}

La propuesta del método aporta en el sentido de una compatibilización mínima entre la intensificación en el uso de los recursos naturales por parte de particulares en el corto plazo, y la sustentabilidad estratégica del país a mediano y largo plazo. En Uruguay el $95 \%$ de la tierra esta en poder de particulares.

La propuesta consiste en que ante la eventualidad de la destrucción de las pasturas naturales, disponer de una alternativa, a través de un plan de acción, que minimice este impacto negativo en relación al hábitat donde se encuentran, así como establecer acciones de compensación ambientales a diferentes escalas.

El método, por su parte, debe permitir el diagnóstico de una situación (A), la comparación con otras situaciones (B) así como monitorear las variaciones en el tiempo de cada situación diagnosticada (C). Las acciones deben emprenderse tanto a nivel predial, como a nivel regional o de una cuenca.

\section{A - Caracterización de una pastura natural}

Atributos básicos de la pastura a ser considerados:

- curva área especie

- composición botánica / transecta 10 metros - 100 puntos

- composición botánica / tipos productivos - tipos vegetativos

- curva de concentración

- índice de diversidad de Shannon

- banco de semillas en el suelo 
- especies y grado de enmalezamiento

- caracterización del potrero: mapa de la vegetación por tipo de suelo y topografía

- muestro del potrero - básico: 50 x 50 m.

El reconocimiento del estado de la pastura, en base a estos atributos (Olmos, 1990a; Olmos, 1991a, b; Olmos y Godron, 1990; Olmos et al., 2005) contribuirá a una estimación de la productividad potencial de forraje de la misma de acuerdo a la clasificación de Tipos Productivos y Tipos Vegetativos sugeridos por Rosengurtt (1979).

\section{B - Comparación de comunidades}

La caracterización relativa de los potreros dentro del predio: la unidad ecológica de manejo, puede realizarse en base al criterio denominado $1-3-5$, donde 5 significa el mejor estado de la pastura o $80-100 \%$ y 1 significa su peor condición o 0 - $20 \%$ de su estado potencial (Olmos et al., 2005). En el caso de los predios particulares generalmente la mejor condición se encuentra en los potreros denominados «invernadas» asociados, a su vez, a mejores condiciones de suelo. Este mismo criterio se propone para el análisis comparativo regional o en una cuenca, así en una región donde los suelos predominantes son similares, las pasturas «de referencia» serán, por ejemplo, tres invernadas reconocidas por su productividad en la zona.

Para realizar las comparaciones se propone utilizar el coeficiente de similitud propuesto por Czekanowski (1913), citado por Kent y Coker (2000), el cual se basa en la similitud mínima en la composición botánica entre dos comunidades, este criterio permite calcular el grado de similitud o solapamiento entre diferentes situaciones (Figura 3).

A partir de los registros obtenidos en una misma estación del año de las diferentes comunidades, se propone realizar un análisis de similitud utilizando métodos estadísticos multivariados.

Esta metodología podría aplicarse a su vez, para el monitoreo de mejoramientos extensivos, considerando los principales atributos poblacionales (densidad de plantas, estructura de edades, estructura funcional, banco de semillas en el suelo), de las especies de interés (Olmos, 2001; Olmos et al., 2004).

\section{C - Variación entre años}

La comparación de la evolución de las diferentes comunidades naturales en el tiempo puede monitorearse utilizando el mismo método propuesto para su comparación en forma sincrónica. En este sentido, el uso del método permitirá registrar cambios en las pasturas naturales en virtud de cambios en las prácticas de manejo aplicados a las mismas y/o por efectos de cambios en el comportamiento del clima local.

\section{Escalas}

Si bien es el hombre, que con sus actividades impacta mayoritariamente sobre el estado y funcionamiento de los ecosistemas, otros factores como la topografía y el tipo de suelo determinan áreas relativamente homo-

$$
\mathrm{S}_{\mathrm{c}}=2 \Sigma \min \left(\mathrm{X}_{\mathrm{i}}, \mathrm{Y}_{\mathrm{i}}\right) / \Sigma \mathrm{X}_{\mathrm{i}}+\Sigma \mathrm{Y}_{\mathrm{i}} \quad \text { Coeficiente de Czekanowski }
$$

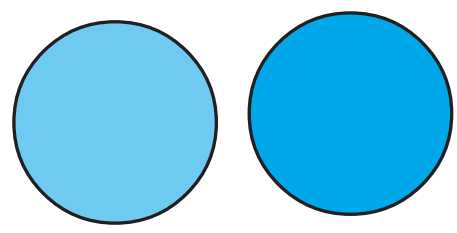

$0 \%$

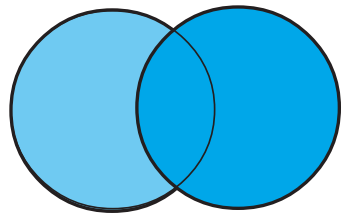

$25 \%$

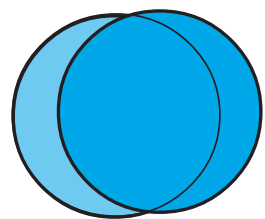

$75 \%$

Figura 3. Ejemplificación, en tres casos, del grado de similitud o solapamiento entre dos comunidades diferentes. 
géneas de parches de vegetación con una marcada similitud en las características de cada hábitat.

En este sentido, si bien se pueden reconocer tres niveles de escala: local, regional y nacional, la interacción del manejo privado de los recursos naturales, básicamente a través de la UEM (unidad ecológica de manejo) (Caldevilla et al., citado por Olmos, 2006), determina un patrón de mosaico de uso del suelo mucho más fragmentado; así deberíamos reconocer como fuertes factores estructuradores de los hábitats naturales no solo la topografía y el tipo de suelo, sino también el nivel de decisión a la escala del potrero y en la escala predial.

La integración a diversas escalas correspondería a una secuencia: potrero/UEM/ micro-cuenca/cuenca-región/país.

A nivel de la toma de decisiones se pueden distinguir dos niveles, por un lado el nivel de decisión individual, y por otro el nivel de decisión gubernamental, tanto departamental como nacional, el cual a su vez, debe coordinar acciones transfronterizas, por ejemplo, cuando es necesario tomar acciones frente a la posible invasión de especies.

La importancia de considerar el monitoreo de las pasturas naturales se basa no solo desde el punto de vista de la escala espacial, sino que además, se necesita incorporar la escala temporal, teniendo en cuenta la intensidad del impacto ejercido sobre las mismas.

En términos de escalas se proponen algunos ítems básicos a ser considerados:

- representatividad del ecosistema

- efecto: local - cuenca - regional

- área de superficie impactada

- impactos acumulados por unidad de superficie/seccional policial

- efectos a escala del paisaje

- suelo - topografía - potrero, en la unidad ecológica de manejo UEM

- efecto en poblaciones endémicas locales

- impacto sobre corredores biológicos

Partiendo desde la escala individual hasta el nivel de decisión gubernamental es ne- cesario la definición de los umbrales de daño para los diferentes ítems a ser considerados en los planes de manejo ambiental, acompañados de un conjunto de indicadores componentes de una estructura de monitoreo general.

En la construcción de estos indicadores de estado de los recursos naturales, el nivel de los impactos negativos acumulados podría tener diferentes umbrales para los diferentes niveles de autorización de acciones antrópicas. Por ejemplo cuando se llega a la destrucción del 10, 25, o el $50 \%$ de las pasturas naturales de una seccional policial en un departamento, las acciones compensatorias deberían ser proporcionales a los niveles de impacto.

A escala regional o de cuenca se deben identificar otros indicadores, además de los propios inherentes al estado de las pasturas, donde se considera el uso del suelo, la implementación de sistemas de rotaciones, la calidad y acumulación de agua tanto superficial como subterránea, los cambios en el secuestro de $C$ por sistema de producción, entre otros. Un buen indicador debería ser lo suficientemente sensible como para mostrar cambios tanto espaciales como temporales; a su vez debe ser predecible y medible, con el que se pueda interactuar (Wani et al., 2005). La principalidad utilidad de un indicador es la de caracterizar el estado actual, realizar el seguimiento y permitir predecir un cambio significativo, de las condiciones biológicas, químicas o físicas en los ecosistemas.

El uso del sensoramiento remoto y la aplicación y uso de los sistemas de información geográfica son herramientas muy útiles para el monitoreo de los cambios espaciales y temporales en el uso de los recursos naturales. En este sentido la tecnología espacial a generado diferentes modos de acceso a información satelital la cual permite obtener información relevante desde la escala sub-métrica hasta la escala regional o nacional (Wani et al., 2005), facilitando no solo el monitoreo sino también la generación de indicadores de estado de los recursos naturales así como una fuerte contribución a la toma de decisiones. 
Un ejemplo claro, respecto al monitoreo de superficies importantes de pastizales naturales, por su metodología y sus objetivos, es el presentado por Watson et al. (2007) en Australia. La importancia de este trabajo radica en que se registra información básica fundamental respecto a la vegetación y el paisaje en forma sistemática y coordinada por diferentes organismos, permitiendo su análisis independientemente de los modelos utilizados para el análisis de la información.

\section{Medidas de mitigación}

La propuesta de trabajo no constituye una elaboración exhaustiva en si misma, si pretende, ser un aporte para la construcción de una guía metodológica que conduzca a la elaboración de un plan de manejo ambiental, para las condiciones de las pasturas naturales en Uruguay.

Dado el carácter casi irreversible del daño luego de la destrucción de la pastura natural se enfatiza en la necesidad de establecer algunas acciones y criterios técnicos, respecto tanto al alcance de los planes de mitigación, como los de compensación, insertos en los planes de manejo ambiental.

En este sentido la mitigación comprende el diseño y ejecución de actividades orientadas a reducir los impactos ambientales negativos significativos; la compensación por su parte constituye el reemplazo o sustitución de recursos o ecosistemas deteriorados por otros de similar condición e importancia (Espinoza, 2006).

De acuerdo a Espinoza (2006) un plan de manejo ambiental se define: «como el conjunto detallado de actividades, que producto de una evaluación, están orientadas a prevenir, mitigar, corregir o compensar los impactos ambientales que son causados por el desarrollo de un proyecto, obra o actividad. El mismo incluye los planes de seguimiento, monitoreo, contingencia y abandono según la naturaleza del proyecto, obra o actividad». El mismo autor propone a su vez los contenidos básicos necesarios para la implementación del plan:

\section{a - un programa de mitigación}

b - un programa de medidas compensatorias

c - un programa de prevención de riesgos

d - un programa de contingencia

e - un programa de seguimiento

f - un programa de participación ciudadana

g-un programa de capacitación

Si bien dentro del plan de manejo se contempla la escala de los impactos, no debe de dejarse de tener presente la importancia de las escalas de acción como se identificaron en los párrafos anteriores, así siempre debe estar presente en todo plan la consideración desde la escala más detallada como el potrero dentro del establecimiento, el predio en si mismo, la región, la cuenca y la escala nacional.

Otros dos elementos esenciales para el establecimiento del plan de manejo son la construcción de la línea de base así como la consideración que a nivel de ecosistemas los trabajos son esencialmente interdisciplinarios.

Particularmente incluimos a continuación una serie de ítems que deberían considerarse para la implementación de planes de manejo de pasturas naturales frente a impactos negativos significativos:

- tipo de suelo

- topografía

- Iocalización en la cuenca

- representatividad del área afectada respecto a la superficie total del ecosistema

- caracterización de la pastura

- sistema de pastoreo: especie única mixto

- presión de pastoreo

- cambio en el sistema de empotreramiento

- disponibilidad y distribución de la sombra/uso de especies nativas

- disponibilidad y distribución de las aguadas

- recuperación de pasturas por manejo de la pastura

- semillazón anual - bianual - plurianual de las pasturas 
- recuperación de pasturas por re-siembra de especies nativas

- establecimiento de semilleros prediales de especies nativas

- establecimiento de potreros como banco de semillas de comunidades nativas

- establecimiento de potreros de referencia para monitoreo del estado de las pasturas

- control de enmalezamiento por especies nativas

- control de invasión de especies exóticas I control preventivo - control de erradicación

- pertenencia del sitio en su integridad a hábitats de corredores biológicos

- efecto del impacto en la pastura sobre la fragmentación de hábitats

\section{Medidas de compensación}

De acuerdo a lo establecido en los párrafos referentes a las acciones de mitigación, en el caso de las acciones de compensación es sumamente importante establecer la moneda de cambio que se va a utilizar. En este sentido es imprescindible contar con la mejor descripción posible del hábitat impactado para poder establecer las acciones a desarrollar sobre un mismo ecosistema que contemple las relaciones especie hábitat afectadas negativamente, incluyendo tanto la flora como la fauna.

A continuación se enumeran una serie de ítems a ser considerados en acciones de compensación de impactos negativos sobre las pasturas naturales:

- delimitar áreas de no intervención dentro del área a intervenir / por ejemplo 10-15 \% como parches o en áreas homogéneas

- delimitación de áreas de no intervención a nivel de cuenca y a nivel de seccional policial

- realización de semilleros prediales o regionales de especies forrajeras nativas

- determinación de áreas de pasturas de referencias para monitoreo del progreso en la compensación / por ejemplo áreas de invernada
- banco de reserva «in-situ» similar a área de no intervención de especies forrajeras re-instalación de plantas en potreros contiguos de referencia con características de suelo y topografía similares a los de su origen para efectos de conservación de la variabilidad y posibilidades de reinstalación

- envío de semilla a banco de germoplasma «ex-situ»/ regional - nacional - internacional

- participación en micro - corredores biológicos dentro del predio, o a nivel regional

- compensación por sitio: extra predial según la intensidad del impacto negativo, por ejemplo si se destruyen 100 hectáreas de campo natural compenso con la recuperación de pasturas degradadas dentro de un ecosistema similar (suelo, topografía) en el predios, dentro de una cuenca o en una región, a través de los métodos considerados anteriormente tanto en mitigación como en compensación

Ante la creciente presión de intensificación de la producción y consiguiente amenaza sobre las pasturas naturales, ante la posibilidad de impactos negativos sobre su productividad y persistencia, no solo habría que considerar la superficie de impacto, sino también el grado de vulnerabilidad en que se encuentra cada pastura en cada situación en particular en relación a su región, así como su efecto sobre la acumulación de impactos sobre una misma región. En este sentido sería necesario la definición de umbrales de riesgos por seccional policial, por ejemplo.

\section{CONSIDERACIONES GENERALES}

Los sistemas de producción en Uruguay están basados en las posibilidades y potencialidades de los ecosistemas naturales. La estructura de estos ecosistemas puede simplificarse en algunos componentes básicos con sus particularidades asociadas a cada región, caracterizada por los valores que toman cada uno de los parámetros para su caracterización. 
Los principales sistemas de producción no solo dependen de las restricciones ambientales (suelo - clima - vegetación) a la producción, sino que también son extremadamente dependientes de factores externos extra prediales como es la variación de los precio de los insumos y los productos; en este sentido entre los principales insumos asociados a los sistemas tenemos: combustible, maquinaria, fertilizantes, fitosanitarios, plaguicidas, semillas y donde desde el punto de vista del productor, prácticamente lo que puede decidir es la época de siembra y el uso del suelo.

Como corolario de esta información: la intensificación incrementa la dependencia de de los sistemas de producción de factores externos extra prediales. La adopción de tecnología no es un proceso tecnológico, la misma depende de los precios internacionales, de la adaptación del sistema de producción a los ecosistemas naturales y de la variabilidad climática.

Para ejemplificar conceptualmente el impacto de las variaciones en los extremos del modelo propuesto por Olmos (1990c), se grafica en la Figura 4 la localización relativa de los principales sistemas de producción en Uruguay en relación a la variación de precios y la variabilidad climática.

Las consideraciones necesarias para enfrentar los desafíos de incrementar la productividad y al mismo tiempo considerar la sustentabilidad de los sistemas de producción agropecuaria, deberán ser exhaustivas, cuantificadas científicamente y específicas para cada sistema propuesto (OImos, 2007). Por lo tanto surge la necesidad de identificar limitantes productivas respecto a la severidad de la dependencia climática de acuerdo al sistema de producción y la interacción con otras variables con un enfoque en el problema a resolver en forma multidisciplinaria.

En este contexto, la viabilidad y necesidad de un uso y manejo sustentable de las pasturas naturales se vuelve cada vez más relevante.

Probablemente debamos como sociedad, pensar, más en sistemas complejos en lugar de aproximaciones lineales, que operan en condiciones dinámicas, haciéndolo en forma constructivista y donde participen no solo los expertos en agricultura y los economistas, sino toda la sociedad en su conjunto.

\section{Precios de mercado}

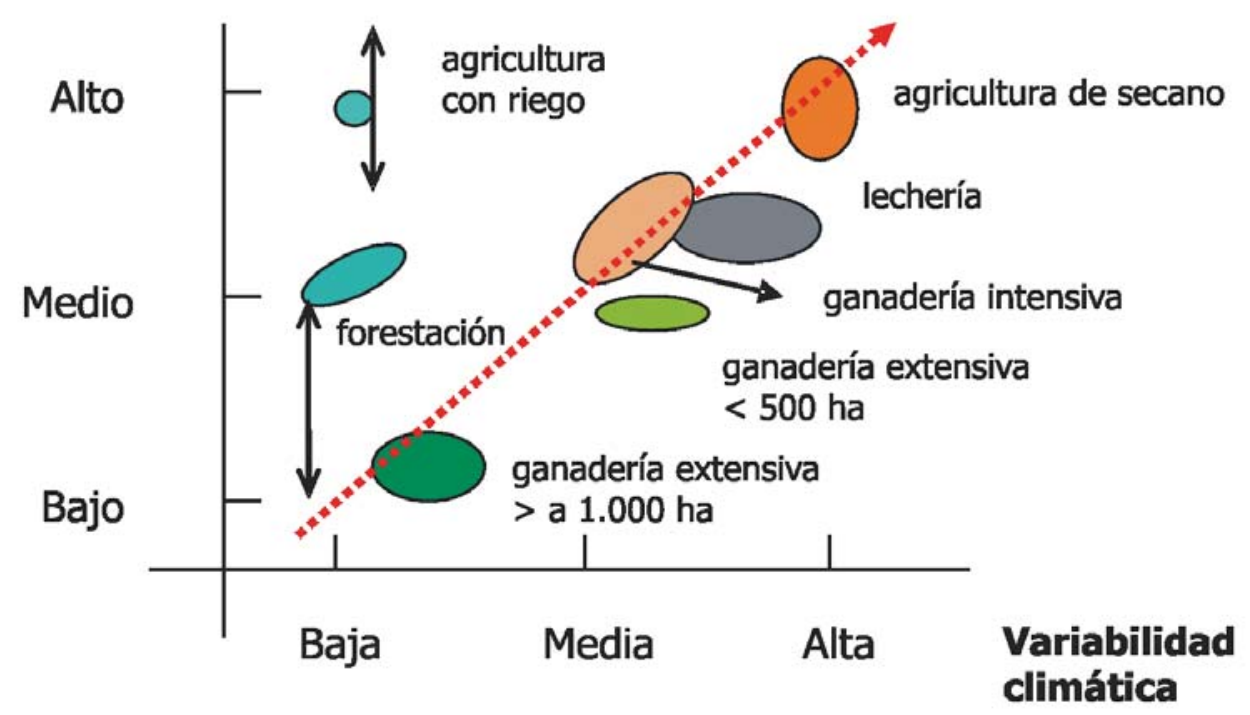

Figura 4. Vulnerabilidad de los principales sistemas de producciónfrente a la variación de factores externos. 


\section{BIBLIOGRAFÍA}

ARBALLO, E.; CRAVINO, J. 2005. Aves del Uruguay. Manual Ornitológico. Vol I. Ed. Hemisferio Sur.

BEGON, M.; HARPER, J. L.; TOWNSEND, C. R. 1996. Ecolgy. Individuals, populations and communities. 3rd. Editions Blackwell Science.

BOGGIANO, O. 1990. Evaluación de 14 gramíneas perennes bajo pastoreo. In: II eminario Nacional de Campo Natural. Tacuarembó. Uruguay. Ed. Hem. Sur. pp. : 185-195.

BRUSSA, C.; I. GRELA, I. 2007. Flora arbórea del Uruguay. Con énfasis en las especies de Rivera y Tacuarembó. COFUSA.

CANTER, L. W.1996. Environmental impact assessment - McGraw-Hill International Editions. 2nd. Edition. 660 p.

CENSO AGROPECUARIO. 1961-1966-19701980-1990-2000. Ministerio Ganadería, Agricultura y Pesca. Montevideo.

CINAM-CLAEH.1963. Situación económica y social del Uruguay Rural. Ministerio de Ganadería y Agricultura. Comisión Honoraria del Plan de Desarrollo Agropecuario. $520 \mathrm{p}$.

DAVIES, P. 2004. Estudios en domesticación y cultivos de especies medicinales y aromáticas nativas. INIA. Serie FPTA-INIA No. 11.

DIEA. 2007. Anuario Estadístico Agropecuario. Dirección Estadísticas Agropecuarias. Ministerio de Ganadería, Agricultura y Pesca. Montevideo.

DELL'ACQUA; PETRAGLIA, C.; SAN ROMÁN, D. 2006. Resultados de la interpretación de imágenes satelitales para forestación y el uso de los suelos de prioridad forestal. www.mgap.gub.uy/DGF.

DURÁN, V.; SÁDER, M; SOUTO, G. 2007. Tendencias de los mercados internacionales y su impacto en el sector agropecuario uruguayo. Anuario OPYPA 2007. pp.: 307-322.

ESPINOZA, G. 2006. Gestión y fundamentos de evaluación de impacto ambiental. Banco Interamericano de Desarrollo - Centro de Estudios para el Desarrollo. Santiago, Chile. 287 p.
FORMOSO, F.; M. ALLEGRI.1984. estudio comparativo de gramíneas perennes invernales en suelos arenosos, pesados e hidromórficos. In: Gramíneas perennes en el noreste. Centro investigaciones Agrícolas A. Boerger. Estación Experimental Agropecuaria del Norte pp. 1-11.

GTZ, FUNDASOL, FUNDAQUIM, URU.TEC, RED PROPYMES. 2004. Aportes para el desarrollo del sector de plantas medicinales y aromáticas en el Uruguay. 134 p.

IICA. 1998. Recuperación y manejo de ecosistemas degradados. Diálogo XLIV. PROCISUR - Instituto Interamericano de Cooperación para la Agricultura. 111p.

IZAGUIRRE, P.; GRUN, S. 1990. Novedades agrostológicas para el Uruguay. In: II Seminario Nacional de Campo Natural. Tacuarembó. Uruguay. Ed. Hem. Sur. pp.:179-181.

IZAGUIRRE, P.; BEYHAUT, R.1997. Las leguminosas en Uruguay y regiones vecinas. Parte I. Ed. Hem. Sur. 549 p.

IZAGUIRRE, P.; BEYHAUT, R. 2003. Las leguminosas en Uruguay y regiones vecinas. Parte 2: Caesalpinioideae. Parte 3: Mimosoideae. Ed. Hem. Sur. 302 p.

KENT, M.; COKER, P. 2000. Vegetation description and analysis. A Practical Approach. John Wiley \& Sons.

LOMBARDO, A. 1964. Flora arbórea y arborescente del Uruguay. Concejo Departamental de Montevideo. Dirección de Paseos Públicos.

MILLOT, J. C.; MAJÓ, G; CARRIQUIRY, E; ACQUISTAPACE, M.1990. Diversidad genética en la producción de semilla de Bromus auleticus. In: II Seminario Nacional de Campo Natural. Tacuarembó. Uruguay. Ed. Hem. Sur. pp. : 95-104.

MONTOSSI, F.; SAÑUDO, C. 2007. Evaluación y promoción de la calidad de la carne bovina y ovina del Uruguay en el mercado europeo. INIA serie Técnica No. 166.

MVOTMA-MGAP. 2005. Plan de acción nacional de lucha contra la desertificación y la sequía. Dirección Nacional de Medio Ambiente, MVOTMA. Dirección General de Recursos Naturales Renovables, MGAP. República Oriental del Uruguay. CCD, PNUMA. 
OLMOS, F. 1990a. Relevamientos fito ecológicos en la región noreste. In: II Seminario Nacional de Campo Natural. Tacuarembó. Ed. Hem. Sur. pp.: 3-9.

OLMOS, F. 1990b. Ecosistema templado cálido. In. Introducción, conservación y evaluación de germoplasma forrajero en el Cono Sur. Diálogo XXVIII. IICA- PROCISUR. pp. : $287-$ 298.

OLMOS, F. 1990c. Utilización de pasturas con animales: avances y propuestas. In: II Seminario Nacional de Campo Natural. Tacuarembó. Ed. Hemisferio Sur. pp.: 279-290.

OLMOS, F. 1991a. Productividad primaria en 10 comunidades de la región noreste. INIA Tacuarembó. Hoja de divulgación No. 4.

OLMOS, F. 1991b. Principales especies dominantes en comunidades herbáceas naturales de la región noreste. INIA Tacuarembó. Hoja de divulgación No. 5.

OLMOS, F. 1993. Bromus auleticus. INIA Tacuarembó. Serie Técnica No. 35. Olmos, F. 1997a. La productividad de las pasturas en relación a los principales parámetros del clima. In: Efectos climáticos sobre la productividad de pasturas en la región noreste. INIA Tacuarembó. Bol. Div. No. 64 pp. 1-12.

OLMOS, F. 1997a. La productividad de las pasturas en relación a los principales parámetros del clima. In: Efectos climáticos sobre la productividad de pasturas en la región noreste. INIA Tacuarembó. Bol. Div. No. 64 pp. 1-12.

OLMOS, F. 1997b. Efecto del estrés hídrico estival en la composición botánica de pasturas convencionales. In: Efectos climáticos sobre la productividad de pasturas en la región noreste. INIA Tacuarembó. Bol. Div. No. 64 pp. 13-20.

OLMOS, F. 2000. Variation and adaptation in Trifolium repens from pastures in Uruguay, with a preliminary assessment of a natvie clover, Trifolium poly mor phum. PhD Thesis. The University of Wales Aberystwyth.

OLMOS, F. 2001a. Mejoramiento de pasturas con lotus en la región noreste. INIA Tacuarembó Serie Técnica No. 124.

OLMOS, F. 2001b. Tecnologías para la mejora de la producción de forraje en brunosoles del noreste. In: Tecnologías forrajeras para siste- mas ganaderos de Uruguay. Bol. Div. No. 76 . INIA Tacuarembó. pp. 123-148.

OLMOS, F. 2004. Ecofisiología teórica y práctica. In: Factores que afectan la persistencia y productividad de pasturas mejoradas con trébol blanco (Trifolium repens L.) INIA Tacuarembó. Ser. Técnica No. 145. pp.: 243-248.

OLMOS, F. 2006. Estrategias para el uso, conservación y recuperación de recursos naturales renovables en Uruguay. In: XXI Reunião do Grupo Técnico em Forrageiras do Come Sul. Grupo Campos. EMBRAPA. Pelotas. pp. 137-150.

OLMOS, F. 2007. Sistemas de producción sensibles a la variabilidad climática. Cosecha y uso del agua. In: Importancia del agua en el actual escenario agrícola. Posibilidades de aplicación de riego suplementario. Seminario de Discusión Técnica. EEMAC - Facultad de Agronomía. Paysandú. pp.: 1-15.

OLMOS, F.; GODRON, M.1990. Relevamientos fitoecológicos en el noreste uruguayo. In: 2do. Seminario Nacional de Campo Natural. Ed. Hem. Sur. Tacuarembó. pp.: 35-48.

OLMOS, F.; SOSA, M. 2004.Climatic variability in Natural Grasslands Ecosystems in the Northeast Region Of Uruguay. In:CLIVAR 2004. 1st. International CLIVAR Science Conference. Abstracts. Baltimore, Maryland. USA. pp.: 281.

OLMOS, F.; FRANCO, J; SOSA, M. 2004. Variación estacional en la estructura de plantas de trébol blanco en pasturas de la región noreste. In: Factores que afectan la persistencia y productividad de pasturas mejoradas con trébol blanco (Trifolium repens L.). INIA Tacuarembó. Serie Técnica No. 145. Capítulo 10. pp.: 219-241.

OLMOS, F.; FRANCO, J; SOSA, M. 2005. Impacto de las prácticas de manejo en la productividad y diversidad de pasturas naturales. In: Seminario de actualización técnica en manejo de campo natural. INIA Serie Técnica No. 151. pp. 93-103.

PÉREZ CASTELLANO J. M. 1914. Observaciones sobre agricultura. 1ra. Edición Completa. A. Barreiro y Ramos. Librería Nacional. Montevideo. $608 \mathrm{p}$.

PUIGDEVALL, J.; RIVERO, E.; BALZO, M. 2007. Educación sustentable. Plan de Soberanía Alimentaria. Intendencia Municipal de Treinta y Tres.

ROSENGURTT, B.; GALLINAL, J. P.; BERGALLI, L. ARAGONE, L; CAMPAL, E. F.1939. La variabilidad de la composición de las praderas. Talleres Gráficos Urta y Curbelo. Montevideo. 
ROSENGURTT, B.1979. Tabla de comportamiento de especies de campo natural. Facultad de Agronomía. Universidad de la República. Montevideo.

RIVAS, M. 2005. Desafíos y alternativas para la conservación in situ de los palmares de Butia capitata (Marte.) Becc.pp.: 161-168.

SISTEMA INFORMACIÓN GEOGRÁFICA. 2004. División Suelos y Aguas. Dirección General de Recursos Naturales Renovables. MGAP. www.mgap.gub.uy

SOUTHWOOD, T. R. E. 1977. Habitat, the template for ecological strategies. Journal of Animal Ecology. 46: 337-365.

SPERANZA, P. 2005. Los desafíos de la exploración de los recursos genéticos en plantas apomícticas: lecciones del caso de Paspalum dilatatum. In: V Simposio de Recursos Genéticos para América Latina y el Caribe. Montevideo, Uruguay. pp.: 73-76.
VIGNALE, B.; BISIO, L. 2005. Selección de frutales nativos en Uruguay. In: $V$ Simposio de Recursos Genéticos para América Latina y el Caribe. Montevideo, Uruguay. pp.: 35-39.

VILLAMIL, J.; BONNECARRÈRE, V. 2005. Nuevos enfoques en el campo de las plantas aromáticas y medicinales: producción de fitoterápicos. In: Revista INIA. No. 5. Uruguay. pp.: 4346.

VON BOTHMER, R.; JACOBSEN, N; BADEN, C; JORGENSEN, R.B.; LINDE-LAURSEN, L. 199. An ecogeographical study of the genus Hordeum. IBPGR. International Board for Plant Genetic Resources. Rome. 126 p.

WANI, S. P.; PIARA SINGH; DWIVEDI, R. S.; NAVALGUND, R. R.; RAMAKRISHNA A. 2005. Biophysical indicators of agro-ecosystem services and methods for monitoring the impacts of NRM technologies at different scales. In: Natural Resources Management in Agriculture. Ed. By B. Shiferaw, H. A. Freeman and S.M. Swinton. CABI International. 


\section{APÉNDICE}

\section{DECLARACIÓN DE HOHHOT}

\section{International Grasslands Congress / VIII International Rangeland Congress Junio 2008 - Hohhot, Inner Mongolia, China}

\section{Los participantes de la Iniciativa para la Conservación de las Pasturas Templadas del Mundo reconocemos que:}

WATSON, I. W.; NOVELLY, P. E.; THOMAS, W. E. 2007. Monitoring changes in pastoral rangelands - the Western Australian Rangeland Monitoring System (WARMS). The Rangeland Journal, 2007: 191-205

- Considerando que las pasturas naturales templadas proveen servicios ambientales esenciales para la vida en la tierra como fuente de alimentos, fibra, sustento y bienestar humano, la diversidad biológica y cultural, la recarga de los acuíferos y el secuestro de carbono, particularmente frente al cambio climático global.

- Acordando que las pasturas naturales templadas son ecosistemas terrestres dominados por vegetación herbácea y arbustiva, mantenida por el pastoreo, el fuego, las sequías y/o las bajas temperaturas y que todos estos procesos son dinámicos y manifiestan una gran variabilidad en el tiempo, espacio, así como en su intensidad.

- Reconociendo las oportunidades que las pasturas naturales templadas proveen para la alimentación de los pueblos, es imperativo mantener la diversidad genética de los ecosistemas de pasturas.

- Teniendo en cuenta la importancia de las pasturas naturales templadas para la vida y la sobrevivencia cultural de los pueblos indígenas nómades y el valor del conocimiento indígena así como la experiencia acumulada por parte de los que tradicionalmente utilizan las pasturas templadas naturales.

- Reconociendo que las pasturas naturales templadas están comúnmente consideradas entre los ecosistemas más amenazados en el planta, habiendo sido modificados por la actividad humana hasta tal grado que la mayoría de las pasturas han sido transformadas y muy poco de ellas se mantienen en su estado natural.

- Reconociendo que las restantes áreas de pasturas naturales continúan siendo amenazadas por políticas inapropiadas que conducen a la pérdida de las mismas, así como prácticas de manejo y uso de la tierra no sustentables.

- Reconociendo que el éxito en la conservación requerirá aproximaciones de manejo participativo y en conjunto entre todos los sectores para asegurar que la integración de la producción y la conservación de la biodiversidad tenga como consecuencia la continua provisión de bienes y servicios ambientales por parte de las pasturas.

- Reconociendo la importancia del fortalecimiento de los territorios indígenas, las áreas comunitarias conservadas y el establecimiento de nuevas áreas protegidas.

- Reconociendo que una de las más importantes oportunidades para la colaboración es asegurando el reconocimiento social mundial del valor permanente de las pasturas naturales.

- Desarrollando e implementando incentivos para la buena administración de la tierra, la restauración y el manejo sustentable de las pasturas naturales templadas es esencial para garantir su uso sostenido como ambientes de trabajo saludables.

- Por lo tanto, los participantes en el Taller Iniciativa de Conservación de las Pasturas Templadas del Mundo desarrollado en Hohhot, China, provenientes de cinco continentes y catorce países, declaramos que las pasturas indígenas templadas están críticamente amenazadas y se requiere una 
acción urgente para proteger y mantener los servicios que proveen para sostener la vida humana. Hacemos un llamado a todos los sectores de la sociedad a colaborar hacia este objetivo.

\section{FIRMANTES}

\section{Li Bo, China}

John MacKinnon, China

Dr. Wu Ning, China

Dr. Luo Peng, China

Gendensengee Enkhtaivan, Mongolia

Enebish Tumurbaatar, Mongolia

Eugene Simonov, Rusia

Ilya Smelaynsky, Rusia

Dr. Tatiana Tkachuk, Rusia

Dr. Clinton Carbutt, South Africa

Anthea Stephens, South Africa

Mahlodi Tau, South Africa

Dr. Alan Mark, Nueva Zelanda

Dr. Katherine Dickinson, Nueva Zelanda
Dr. Louise Gilfedder, Australia

Dr. Bronwyn Myers, Australia

Dr. Dick Williams, Australia

Dr. Ian Lunt, Australia

Dr. Taghi Farver, Irán

Jalil Noroozi, Irán

Karsten Wesche, Alemania

Jeff Hardesty, USA

Susan Antenen, USA

Bill Henwood, Canadá

Bruno Delesalle, Canadá

Bob Peart, Canadá

Ed Wiken, Canadá

Robert Hofstede, Ecuador

Andrea Michelson, Ecuador

Jurgen Hoth, México

Elizabeth Juliana Jacobo, Argentina

Ulises Martinez, Argentina

Fernando Olmos, Uruguay

The HOHHOT DECLARATION

The World Temperate Grasslands Conservation Initiative Workshop XXI International Grasslands Congress/VIII International Rangeland Congress

June 28-29, 2008

Hohhot, Inner Mongolia, China 


\section{PROPUESTA DE LEY}

Dada la importancia económica, biológica y social que constituyen las pasturas naturales en el país, la capacidad de resiliencia que presentan las mismas ante fenómenos climáticos y económicos adversos, así como el potencial que disponen en cuanto a los recursos genéticos presentes en las mismas, planteamos en este capítulo la necesidad de implementar una reglamentación de su uso más adecuado a sus propias características productivas así como en virtud de la expansión e intensificación agrícola que propende a sus sustitución sin considerar el principio de precaución y los riesgos asociados a la intensificación.

En este sentido, sin perjuicio de otras consideraciones, planteamos el desarrollo de una Ley de Uso, Conservación y Recuperación del Campo Natural, cuyo principal cometido sería, ante la sustitución del campo natural por el desarrollo de otra actividad, la realización de un informe técnico detallado por un Ingeniero Agrónomo dentro del marco de las evaluaciones de impacto ambiental.

En este informe debería incluirse al menos:

a - una descripción del campo natural a sustituir considerando sus componentes: las especies de la flora, la frecuencia de las especies y su estado de conservación

b - un plan de mitigación y compensación del impacto ambiental negativo ocasionado

c - un plan de uso y manejo del suelo alternativo

Asimismo deberían considerarse otros aspectos generales regionales como los impactos acumulativos teniendo en cuenta que lo que se esta sustituyendo lo constituyen recursos genéticos adaptados a las condiciones locales del ecosistema.

Otros componentes como la fauna y la calidad del agua también deberían considerarse. 



\section{REFLEXIONES GENERALES}

En el proceso de investigación y adquisición de conocimiento se pueden distinguir dos vías básicas o procesos complementarios, son aquellos períodos donde por un lado se profundiza y analizan los componentes de los sistemas y el otro donde luego de consolidar nuevos conocimientos se vuelven a aplicar en el sistema general.

En este sentido podemos afirmar, en base a la información técnica disponible, que hemos pasado por un período de profundización y análisis de los principales componentes del ecosistema pastoril y se han propuesto soluciones tecnológicas para básicamente levantar las principales limitantes ambientales a la productividad agropecuaria, desde hace más de treinta años en la región. Finalmente en esta última década se han construido modelos donde se pueden plasmar estos resultados y visualizar los nuevos componentes del ecosistema y los sistemas de producción a ser analizados en más detalle. Muchos de estos resultados deberían ser validados y aplicados en condiciones de campo (Figura 1) en la próxima década.

En el momento actual, entonces, deberíamos reposicionarnos en la región noreste y visualizar en grandes líneas algunos aspectos a ser considerados respecto a las pasturas naturales para su mejor comprensión funcional y productiva a mediano y largo plazo; el ecosistema de pastizales naturales es un elemento central en la economía social regional.
En este sentido Olmos (1990) realizó una propuesta que apunta en el sentido de propender a un mejor conocimiento funcional de uno de los principales componentes del ecosistema, la propia pastura, la propia composición botánica y su dinámica. En base a estos antecedentes se propone algunas ideas básicas para la generación de hipótesis y nuevas líneas de trabajo:

- determinación de las principales especies «base» desde el punto de vista forrajero e indicadoras de estado de la pastura

- estudiar su biología y estrategias de colonización

- determinar el manejo (tiempo, carga, intensidad de pastoreo) necesario para pasar de uno a otro tipo de pastura dentro de cada tipo de suelo / recuperación e incremento de la productividad

- iniciar estos estudios sobre las principales especies consideradas malezas

- trabajar a diferentes escalas: potreros - establecimientos - regiones

- establecimiento de pasturas de referencia regionales según el tipo de suelo

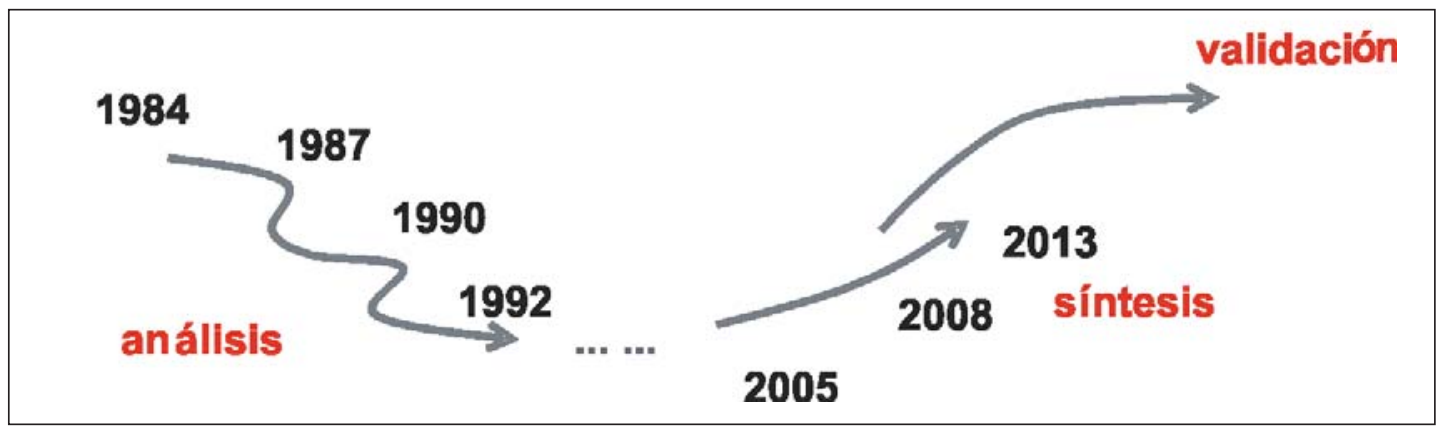

Figura 1. Secuencia histórica sobre la investigación regional en sistemas de producción dentro del ecosistema natural de pastizales. 
A escala de décadas en términos de investigación, pensamos que estamos actualmente en un proceso de consolidación, validación y aplicación de nuevas prácticas que nos conduzcan como sociedad a una mayor productividad, con sostenibilidad, en los sistemas de producción basados en los ecosistemas naturales de la región (Figura 2), sin embargo nuevos procesos deberán ser encarados y seguramente volver a profundizar en los elementos que nos permitan una mejor comprensión de la dinámica del sistema, sobretodo basados en que habrá una mayor demanda por la intensificación en el uso de los recursos.

Desde el punto de vista de las especies forrajeras componentes de las pasturas na- turales de la región noreste deberíamos propender a la consolidación de un mayor conocimiento de los mecanismos que operan en su dinámica y alcanzar un nuevo orden respecto al uso y manejo en la siguiente década.

\section{BIBLIOGRAFÍA}

OLMOS F. 1990 . Caracterización de Comunidades Naturales en la Región Noreste. In: II Seminario Nacional de Campo Natural. Instituto Nacional Investigación Agropecuaria. Sociedad Uruguaya de Pasturas Naturales. Facultad de Agronomía. Instituto Plan Agropecuario. Tacuarembó. Uruguay. Ed. Hemisferio Sur. pp.: 3-10. 